JOINT TRANSPORTATION RESEARCH PROGRAM

FHWA/IN/JTRP-2007/13

Final Report

DERIVING THE COST IMPACTS OF INDIANA'S STORM WATER RULE 13 ON INDOT MAINTENANCE FACILITY OPERATIONS

Lynn A. Corson

October 2007 
Final Report

FHWA/IN/JTRP-2007/13

\title{
DERIVING THE COST IMPACTS OF INDIANA'S STORM WATER RULE 13 ON INDOT MAINTENANCE FACILITY OPERATIONS
}

\author{
By \\ Lynn A. Corson, Ph.D. \\ Indiana Clean Manufacturing Technology and Safe Materials Institute \\ School of Civil Engineering \\ Purdue University \\ Joint Transportation Research Program \\ Project No. C-36-78W \\ File No. 04-07-23 \\ SPR-2854 \\ Conducted in Cooperation with the \\ Indiana Department of Transportation \\ And the U.S. Department of Transportation \\ Federal Highway Administration
}

The contents of this report reflect the views of the authors who are responsible for the facts and accuracy of the date presented herein. The contents do not necessarily reflect the official views or policies of the Indiana Department of Transportation and the Federal Highway Administration. This report does not constitute a standard, specification or regulation.

Purdue University

West Lafayette, Indiana

October 2007 
TECHNICAL REPORT STANDARD TITLE PAGE

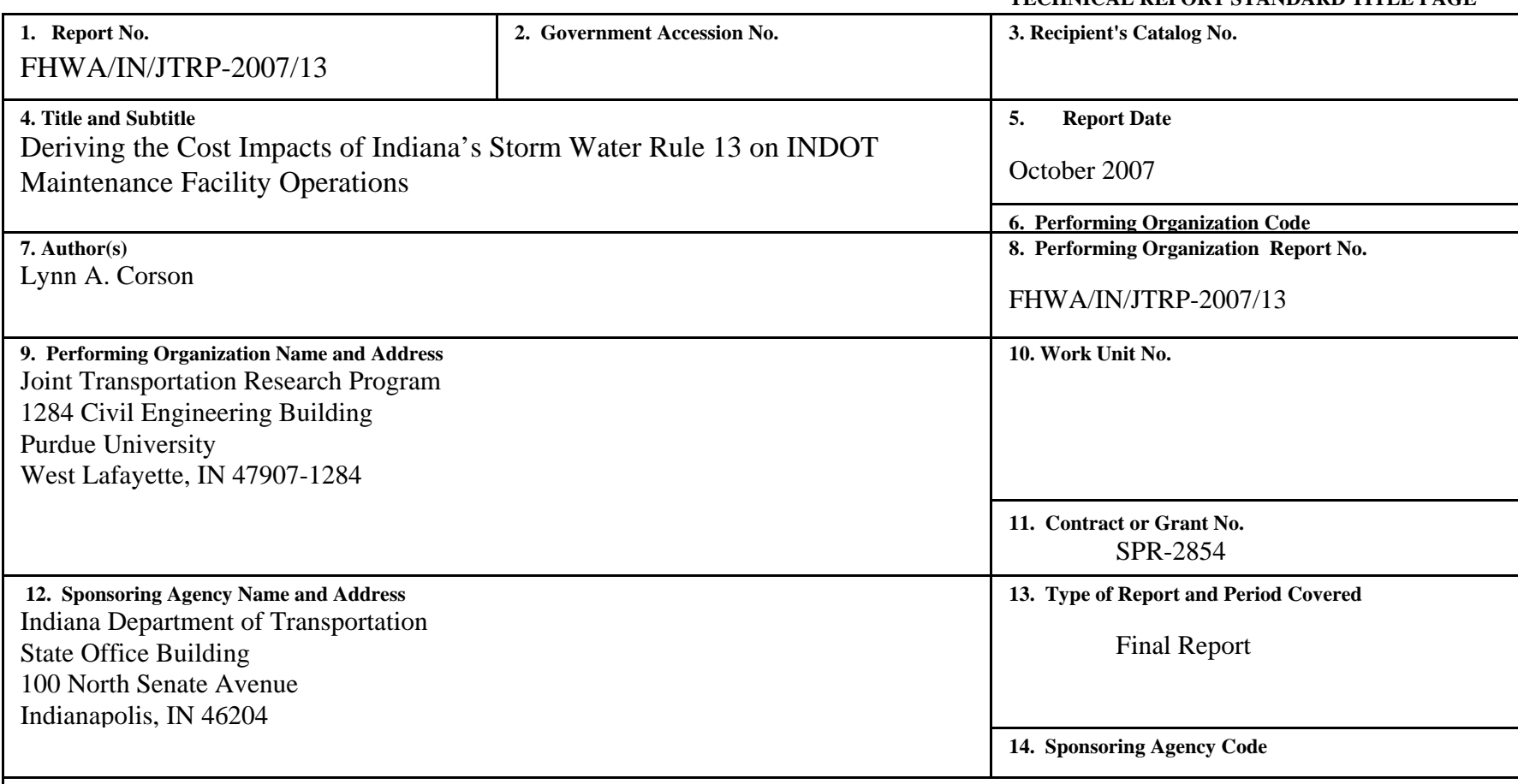

15. Supplementary Notes

Prepared in cooperation with the Indiana Department of Transportation and Federal Highway Administration.

\section{Abstract}

The objectives of this research were:

1. To classify maintenance facilities by ten or fewer "typologies" (categories) to analyze storm water collection and drainage from the sites and to estimate the cost of installing or implementing Best Management Practices (BMPs), identified by INDOT, to prevent or reduce contamination of the drainage that migrates to waters of the state;

2. To prepare an Environmental Management System (EMS) modeled on the ISO 14001 Standard and "pilot" the EMS in an INDOT District; conduct EMS Awareness training for affected employees.

The research included the conduct of on-site operations and environmental assessments at 50 INDOT maintenance facilities and the subsequent grouping of these facilities into 5 scoring categories to facilitate estimating the cost of upgrading each facility to the next higher category and to the highest scoring category. Costs for facilities in each category and for all categories are provided and a cost per funding cycle is estimated.

An Environmental Management System Manual, conforming to the ISO 14001:2004 Standard was prepared with the INDOT EMS Committee. The EMS is intended to apply to all employees and all contractors statewide. Employee training and full implementation of the EMS will be completed in late 2007. INDOT intends to seek third-party certification of its EMS.

The 50 Facility Site Assessment Reports and the EMS Manual are included in this report.

17. Key Words

Storm water controls, Best Management Practices, BMPs, BMP

costs, ISO 14001, Environmental Management System, EMS

\section{Distribution Statement}

No restrictions. This document is available to the public through the National Technical Information Service, Springfield, VA 22161
19. Security Classif. (of this report)

Unclassified

Form DOT F 1700.7 (8-69)
20. Security Classif. (of this page) Unclassified
21. No. of Pages

22. Price 


\section{TABLE OF CONTENTS}

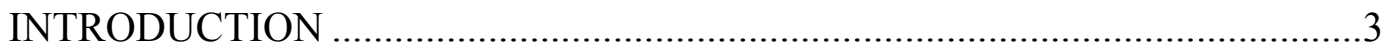

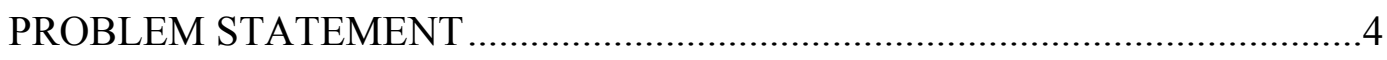

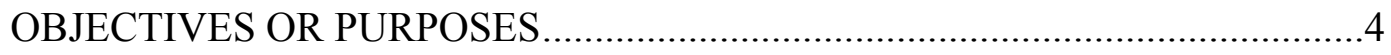

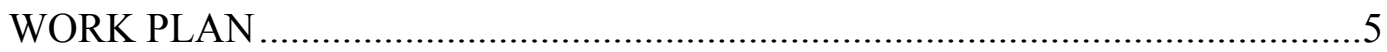

ANALYSIS OF THE DATA, CONCLUSIONS AND RECOMMENDATIONS, INCLUDING STRATEGIES FOR IMPLEMENTATION ...................................10

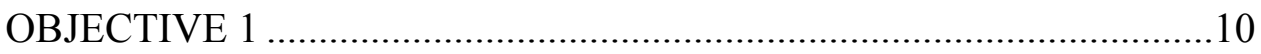

MODIFICATION OF THE WORK PLAN.....................................10

FACILITY SITE ASSESSMENTS ……………………...........13

THE COST OF IMPLEMENTING VARIOUS BMPs ..................20

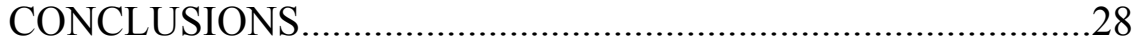

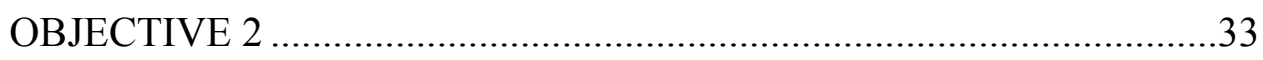

MODIFICATION OF THE WORK PLAN.....................................33

DESCRIPTION OF THE DEVELOPMENT PROCESS, RECOMMENDATIONS AND STRATEGIES FOR IMPLEMENTATION.................................................................

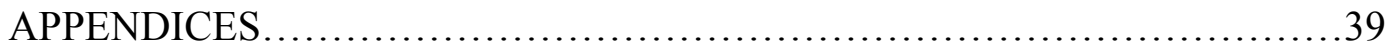




\section{Introduction}

U.S. Environmental Protection Agency (EPA) regulations promulgated December 8, 1999 require small, municipal, separate, storm sewer systems (MS4s) to obtain National Pollutant Discharge Elimination System (NPDES) permits for storm water discharges. State transportation agencies are regulated by the EPA rule as MS4s. To avoid being a co-permittee with an estimated 138 municipalities, the Indiana Department of Environmental Management (IDEM) proposed that INDOT apply for a NPDES permit in accordance with 327 IAC 5-4-6. INDOT's permit will regulate the discharge of storm water runoff from state-maintained highways and maintenance facilities within MS4s and their contiguous urbanized areas. Approximately 1,900 (17\%) of the 11,300 center line miles of highway for which INDOT is responsible and 59 (42\%) of its 142 maintenance facility locations will be covered by the permit. ${ }^{1}$

The storm water rules require maintenance facilities to reduce contaminant loading of storm water runoff from the site surface and reduce contaminants in shop floor drain and washbay effluent discharged to waters of the state. As of February 2003, $23(39 \%)$ of the 59 facility locations within MS4s were not connected to a municipal waste water treatment facility for discharge of shop floor drain and washbay effluent and 59 (71\%) of the 83 facility locations outside MS4 areas were not connected.

IDEM has proposed that facilities outside of MS4 areas be separately permitted to regulate contaminant discharge to waters of the state. Regardless of this proposal, INDOT officials are committed to making the necessary changes to all maintenance

\footnotetext{
${ }^{1}$ Includes the Toll Road District, which was removed from the INDOT organization during the course of this study.
} 
facilities and are incorporating these changes into new, prototype facilities being constructed at any location.

\section{PROBLEM STATEMENT}

INDOT maintenance facilities are located in a variety of environmental settings. The structural and non-structural Best Management Practices (BMPs) implemented by INDOT to comply with the storm water rules need to match the facility location and its operation within the environmental setting. The cost of implementing these Best Management Practices (BMPs) at maintenance facilities required for compliance with storm water discharge permits can only be roughly estimated. A better analysis is needed so the department can make accurate projections for budgeting purposes.

\section{OBJECTIVES OR PURPOSE}

The structural BMPs required are generally known: connection to a municipal wastewater treatment plant for discharge of effluent; installation of in-ground tanks for collection of salt-contaminated runoff from the salt-sand mixing/loading area; construction of extended roofs from salt domes to cover the salt-sand mixing/loading area; installation of oil/water separators; converting to brinemaking and brine application equipment; installation of structures to contain and filter site runoff. There has been no analysis, to date, however, to match the appropriate structural BMPs to each existing facility based on its operational and environmental characteristics. 
There are also many non-structural BMPs (performance-based tasks or activities) that can be implemented at maintenance facilities to facilitate compliance with the storm water rule. Operational procedures pertaining to Stockpiling Winter Material, Equipment Servicing, Scraping and Painting of Equipment, Building and Grounds Maintenance, and other operations need to be performed by facility personnel in a uniform manner across all districts to provide the best possible protection of the waters of the state. This study also examined the need for modifying the operational procedures for those facilities located in a sensitive environmental setting and estimated the costs associated with any modifications.

\section{WORK PLAN}

The final draft of INDOT's storm water discharge permit application was submitted to IDEM September 30, 2003. Section VI. of the application, "Pollution Prevention at INDOT Operation and Maintenance Facilities," included a proposal to "form a Field Maintenance and Operations Team" with one of its objectives to "review all existing field maintenance and operations procedures and evaluate these procedures for compliance with storm water regulations and pollution reduction..." The task force was to be comprised of personnel from throughout the state, including the central office.

It was envisioned that this Team would operate similar to the Winter Operations Team and that "an Environmental Management System (EMS) would [be developed by] this group, and even ISO 14001 compliance [may be pursued]." [9/29/03 e-mail from T. Duncan]. 
The maintenance/operations component -- to focus on non-structural BMPs -needed to be integrated with the selection of appropriate structural BMPs at facilities so accurate costs of both could be determined.

This study intended to work with the task force for the stated purpose as well as to identify the operational and environmental characteristics of each facility and to categorize each facility by one of approximately ten typologies to be used for estimating the costs of implementing the structural and non-structural BMPs statewide. The analysis would have been conducted according to this procedure:

1. gather/review facility information from INDOT Environmental Services Section files, previous JTRP studies and other sources;

2. develop descriptive criteria from the information gathered to define the operational characteristics of approximately 10 typologies as precisely as possible;

3. review aerial photos, topographic maps, environmental reports, and other relevant information about the facilities;

4. develop descriptive criteria from the information gathered to define the environmental characteristics of the typologies as precisely as possible;

5. conduct site visits to a sample of facilities in each typology to confirm the operational and environmental characteristics;

6. assign one or more structural and /or non-structural BMPs to each typology (the same BMP can be assigned to more than one typology);

7. assign each facility to one (and only one) typology on a "best fit" basis; 
8. prepare cost estimates of the installation (including purchase or construction), maintenance, and other life-cycle costs of each structural BMP and the personnel and related costs associated with each non-structural BMP;

9. calculate costs for each typology based on the individual costs of the structural and non-structural BMPs assigned and the number of facilities assigned to each;

10. extrapolate costs to a statewide estimate, by budget cycle, accounting for, then, in-place allocations to Operations/Maintenance, Building \& Grounds, and District Environmental accounts.

This procedure (1-10, above) would have been incorporated with the development of the EMS to focus on the operations at maintenance facilities. The development of an EMS was included in INDOT's application for the storm water permit as a goal pertaining to the minimum control measure for "pollution prevention and good housekeeping." Study staff to be assigned this task are certified EMS Lead Auditors. The following activities were envisioned as components of INDOT's EMS development:

EMS awareness training for the Maintenance/Operations Team and others, as desired;

an analysis of the various "aspects" of maintenance facility operations and their actual and potential "impacts" on the environment; a review of existing INDOT policies and procedures governing facility operations, the identification of areas for improvement and the preparation of revised or new policies/procedures to address these areas; the review would include:

- the legal, regulatory, AASHTO and other requirements; 
- the organization, administration and implementation of such policies and procedures;

- the documents required to report activities conducted pursuant to these policies and procedures;

- the monitoring of these activities and the implementation of corrective action, when required;

- the responsibility of department management for review and continued improvement of the EMS program.

preparation of a proposed EMS for implementation as a "pilot" in an INDOT District. [The Seymour District Manager "volunteered" his district for the pilot].

The EMS "aspects" and "impacts" analysis, together with review of policies and procedures governing facility operations, was to facilitate the implementation of, especially, non-structural BMPs intended to assist compliance with the storm water rules and better protect the environment.

The review would also include the requirements of INDOT's NPDES storm water permit and the findings of past JTRP-sponsored research. The cost-benefit analysis would contrast the implementation of operational procedures (non-structural BMPs) with the installation/construction of structural BMPs. A critical aspect of the structural BMP analysis would be the cost of maintenance, given the complex construction of some structures and the reduction of maintenance workers available to perform this work.

The implementation of project findings would prioritize facilities located in Municipal Separate Storm Sewer System (MS4) areas and, within those areas, facilities 
that are not currently connected to a local wastewater treatment plant for the discharge of truck wash and shop floor drain effluent.

Guidance with study and periodic review of the findings would be sought from the Study Advisory Committee whose members are staff of most of the critical decisionmaking offices within INDOT concerning these matters. 


\author{
Analysis of the Data \\ Conclusions and Recommendations \\ Including Strategies for Implementation
}

These two sections of the report are organized by Objective:

\begin{abstract}
Objective 1: To classify maintenance facilities by ten or fewer "typologies" (categories) to analyze storm water collection and drainage from the sites, and to estimate the cost of installing or implementing BMPs to prevent or reduce contamination of the drainage that migrates to waters of the state.
\end{abstract}

\title{
MODIFICATION OF THE WORK PLAN
}

The objective of the SPR-2854 research project was to identify the structural and non-structural best management practices (BMPs) that need to be implemented by INDOT maintenance facilities to comply with the federal and state storm water regulations, based on a facility's location and its operation within the surrounding environment. It was assumed that all facilities could be categorized by ten or fewer typologies or groups of facilities resembling one another in location and operation characteristics, as regards actual and potential environmental impacts resulting from improper control of storm water and discharge from other operations to storm water and/or waters of the state. INDOT was to have organized a Maintenance and Operations 
Team (MOT) of staff from headquarters, districts, sub-districts and units to assist with the categorizing of facilities, by similar characteristics.

Once the BMPs were identified and the facilities categorized, known cost factors would be applied to both structural BMPs ("Technologies") and non-structural BMPs ("Good Housekeeping Practices"), so the department could make accurate projections for budgeting purposes.

The above procedures were to have been incorporated in the development of an ISO 14001-type Environmental Management System (EMS) as a "pilot" in the Seymour District.

The reorganization of the department (“TOPDOT") with the resulting personnel and structure/function changes prevented the MOT from being organized and delayed, until August, 2006, a decision to proceed with the development of an EMS, but with a different scope. In December, 2005, INDOT formally adopted the Ohio Department of Transportation (ODOT) Facility Assessment System; however, the criteria for assessing the environmental setting in which facilities are located were deficient. With ODOT representatives concurring, INDOT staff asked this Study's Principal Investigator to develop criteria that could be integrated with the ODOT software and be used as a facility environmental assessment tool by INDOT staff assigned this function.

At the March 20, 2006, SPR-2854 Study Advisory Committee attended, primarily, by the directors and staff of Facilities and Equipment Management Division, the discussion focused on the tasks performed by employees that, in part, affect the condition of facilities and equipment and their conformance to the assessment criteria. The discussion was followed by recognition of the need to seek adoption of the criteria 
by the Highway Operations Division, especially the Maintenance Administration unit, which is responsible for employee task performance pertaining to facilities and equipment.

At the same meeting it was proposed to seek concurrence from the Highway Operations Division regarding the preparation of an EMS, statewide, for both it and the Facilities and Equipment Management Division.

Subsequently, on April 21, 2006, the heads of the aforementioned divisions, their management staff and the Deputy Commissioner of Operations met and decided that the SPR-2854 study should include: (1) a review of environmental-related Operating Procedures and other policies and change; (2) the preparation of an EMS boilerplate for the two divisions, statewide; and (3) the preparation of a PowerPoint presentation to explain what an EMS is, why INDOT needs one and what is in INDOT's EMS.

Following the April meeting (on May 12), the PI completed and submitted to the Facilities and Equipment Management Division, an update of the Facility Environmental Assessment Criteria used to assess the conditions and environmental aspects of the maintenance facilities. (See Appendix I) These criteria were used to "score" maintenance facilities visited by the PI's graduate assistant and to estimate the cost of upgrades to those facilities required to reduce any actual or potential environmental impact recorded during the site assessments.

The Facilities and Equipment Management Division began the first "round" of facilities assessment in May and it continued throughout the summer. The PI assumed, based on previous discussions and earlier email correspondence (March 31, 2006) from 
the Facilities Management Division, that the 15 environmental assessment criteria developed during the study were the ones used during the first round of assessments.

At the September 6, 2006 SAC meeting - in a side conversation - the PI was given a copy of the environmental assessment criteria (dated May 15, 2006) used during the first round of assessments. (See Appendix II) A review of the document the following day revealed that of the 15 criteria submitted by the PI, 12 had been used as submitted, two were not used, one had been divided into five separate criteria and five additional criteria had been added. Consequently, the relevance of the assessment scoring and upgrade cost estimating performed during the study has been significantly affected and should be repeated using the May 15 criteria.

At the same September 6 SAC meeting, the PI was informed that the cost of one of the "technology" BMPs - the New Cover-All Style Building for salt and equipment storage - used in the Cost of Facility Upgrades calculations had increased from $\$ 800,000$ to $\$ 900,000$. Any subsequent upgrade cost estimating should include this and any other BMP cost adjustments in the calculations.

\section{FACILITY SITE ASSESSMENTS}

The Principal Investigator's graduate assistant visited 50 INDOT maintenance facilities, spending one-half to a full day on-site, using the INDOT Facility Stormwater and Washwater Effluent Drainage Assessment form (Appendix III). Subsequently, each facility was scored using the original environmental assessment criteria proposed by the Principal Investigator (Appendix I) and the costs of implementing various structural and 
"good housekeeping" BMPs were estimated using the original cost data provided by INDOT.

The original 15 environmental assessment criteria (subsequently, only 13 were used for scoring because 2 were considered similar to others) address maintenance shop and site discharge, mixing/loading areas, brine production, secondary containment, salt bed washing, salt bed rack area cleaning and cold patch, scrap, trash and scalp storage. Each criteria was scored on a scale of 1 through 6 , or a variant of this range. The scores for each of the 50 facilities visited and scored are listed by district in Appendix IV. The average score for the district and for all districts, combined, is also provided.

For purpose of comparison, the 50 facilities are listed in Appendix V in rank order, by assessment score, and in Appendix VI, in alpha order, for each of the criteria used in the assessment. The compilation of the facility scores and ranks, by district, are shown in Table 1, below.

Table 1

\begin{tabular}{|c|c|c|c|c|c|c|c|c|}
\hline District & $\begin{array}{l}\text { Mean } \\
\text { Score }\end{array}$ & $\begin{array}{c}\text { No. } \\
\text { Facilities } \\
\text { Scored }\end{array}$ & $\begin{array}{c}\text { Total } \\
\text { Facilities } \\
\text { in Dist. } \\
(10 / 02)\end{array}$ & $\begin{array}{l}\text { Percent } \\
\text { Dist. } \\
\text { Facilities } \\
\text { Scored }\end{array}$ & $\begin{array}{c}\text { No. } \\
\text { Scored } \\
\text { Facilities } \\
\text { Above } \\
\text { Dist. Mean }\end{array}$ & Percent & $\begin{array}{c}\text { No. } \\
\text { Scored } \\
\text { Facilities } \\
\text { Above } \\
\text { Total } \\
\text { Mean }\end{array}$ & Percent \\
\hline LaPorte & 3.50 & 9 & 24 & 38 & 4 & 44 & 4 & 44 \\
\hline Ft. Wayne & 2.78 & 7 & 22 & 32 & 2 & 29 & 2 & 29 \\
\hline Crawfordsville & 3.64 & 6 & 18 & 33 & 4 & 67 & 4 & 67 \\
\hline Seymour & 3.82 & 12 & 23 & 52 & 4 & 33 & 7 & 58 \\
\hline Greenfield & 3.89 & 8 & 26 & 31 & 5 & 63 & 6 & 75 \\
\hline Vincennes & 3.86 & 8 & 22 & 36 & 3 & 38 & 4 & 50 \\
\hline TOTAL & 3.62 & 50 & $135^{*}$ & 37 & 22 & 44 & 27 & 54 \\
\hline
\end{tabular}

* The total number of facilities in this table does not include the Toll Road District because it was removed from INDOT during the course of this study. 
Table 1 reveals the range of mean scores of all districts to be from 2.78 to 3.89 with the mean total of all districts at 3.62. There were 27 facilities that scored above the total mean and 23 that scored below. The number of facilities scored in each district ranged from 3 (33 percent of the total) in the Crawfordsville District to 12 (52 percent of the total) in the Seymour District. The number of facilities in each district scoring above the mean for that district ranged from 2 (29 percent) in the Ft. Wayne District to 5 (63 percent) in the Greenfield District. The four facilities in the Crawfordsville District scoring above the district mean comprise 67 percent of the total number of facilities scored. Seymour had the highest number of facilities (7) of any district scoring above the total department mean; Ft. Wayne had the lowest number (2). The six facilities in the Greenfield District represent 75 percent of its scored facilities that were above the total department mean.

The data for the facilities scored can be considered reasonably representative of all facilities in the district: the selection was not entirely random, however, as scheduling with facility managers was sometimes conditioned by their availability and agreement and the time allocated by the staff conducting the assessments.

The individual facility scores presented in Appendix IV need to be reviewed to better understand the district mean scores, as there are usually one or more facilities considerably above or below the district mean. For example, in the LaPorte District (mean of 3.50), the two facilities with the highest scores - Wanatah Unit (4.92) and New Gary Subdistrict/Miller Unit (5.77) are relatively new or newly renovated facilities. Flora Unit (2.00) is an older facility with many improvements needed. The New Gary Subdistrict scored the highest of the 50 facilities assessed. 
The Ft. Wayne District's Angola Subdistrict (4.75) and the Gas City Unit (3.92) are the only facilities that scored above the district's mean.

The Lafayette Unit (1.54) in the Crawfordsville District scored the lowest of all 50 facilities assessed. Its location, condition and management oversight could all be improved. Four of Crawfordsville other five facilities scored above the district mean.

Most of the Seymour District facilities scored well; only Brownstown Unit (3.17), Old Amity Unit (3.33) and Corydon Unit (3.13) were significantly below the district mean (3.82) compared to other facilities.

Only the Kokomo Unit (3.00) and the New Castle Unit (3.17) were significantly below the Greenfield District mean score (3.89). Five of its 8 facilities scored above the district mean.

The eight Vincennes District (mean 3.86) facilities all scored 3.17 or more with the Bedford Unit (5.00) scoring the highest in the district and second highest among the 50 facilities assessed. The Bedford Unit stormwater drainage system has been upgraded in recent years, an improvement which, undoubtedly, contributed to its high score.

A review of Table 2 on the following page, reveals that criteria $D$ and $G$ appear to most influence the facility and district scores [Note: criteria E, pertaining to brine production, is not included in this analysis as only 9 of the 50 facilities had installed the equipment at the time of the assessment.] 
Table 2

Mean Criteria Scores, by District

District

\begin{tabular}{|c|c|c|c|c|c|c|c|}
\hline Criteria & 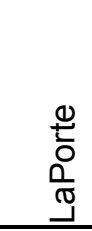 & 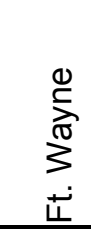 & 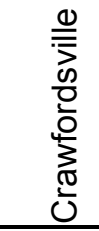 & ¿ & 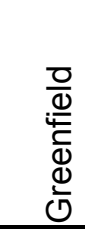 & 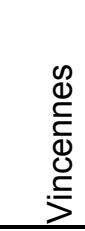 & $\begin{array}{l}\frac{0}{0} \\
\frac{0}{ \pm} \\
.00 \\
0 \\
\overline{0}\end{array}$ \\
\hline$A$ & 3.2 & 2.7 & 3.5 & 3.2 & 4.6 & 4.4 & 3.6 \\
\hline B & 3.4 & 2.4 & 4.0 & 3.0 & 3.9 & 3.8 & 3.4 \\
\hline C & 2.9 & 3.3 & 3.2 & 3.0 & 3.8 & 4.5 & 3.4 \\
\hline D & 2.3 & 1.1 & 2.0 & 1.3 & 1.1 & 1.0 & 1.5 \\
\hline E & 6.0 & - & 3.5 & 6.0 & 6.0 & - & 5.4 \\
\hline $\mathrm{F}$ & 4.3 & 2.4 & 3.5 & 4.8 & 5.4 & 4.1 & 4.2 \\
\hline$G$ & 2.1 & 5.3 & 4.3 & 5.5 & 6.0 & 6.0 & 4.8 \\
\hline $\mathrm{H}$ & 3.9 & 2.2 & 2.7 & 4.4 & 3.8 & 4.0 & 3.6 \\
\hline I & 4.3 & 2.3 & 5.0 & 5.0 & 3.8 & 3.4 & 4.0 \\
\hline $\mathrm{J}$ & 3.8 & 2.0 & 4.7 & 4.6 & 3.5 & 3.3 & 3.7 \\
\hline $\mathrm{K}$ & 4.3 & 3.3 & 3.7 & 3.8 & 3.9 & 4.0 & 3.9 \\
\hline $\mathrm{L}$ & 2.9 & 2.6 & 3.0 & 2.8 & 2.8 & 3.5 & 2.9 \\
\hline $\mathrm{N}$ & 4.3 & 3.7 & 4.0 & 4.8 & 3.6 & 4.5 & 4.2 \\
\hline Mean Score & 3.50 & 2.78 & 3.64 & 3.82 & 3.89 & 3.86 & 3.62 \\
\hline
\end{tabular}

[Note: the criteria and district means in this table are summarized from Appendix IV; they cannot be derived by mathematical computation from data in this table because of the variability of the number of facilities scored in each district and the criteria used in each assessment.]

Criteria D (from Appendix I) assesses the design of the Salt/Sand Mixing/Loading area:

\section{Which of the following best describes the design of the Salt/Sand Mixing/Loading area(s)?}

$>\square$ (1) Outside with no covered enclosure, no berm, and no retention/detention pond

(2) Outside with no covered enclosure but within a bermed area and/or water from the area enters a retention/detention pond

(5) Mixing/Loading is performed inside a covered enclosure (e.g. Load-Out Building) but larger salt delivery trucks offload outside

(6) Full operations are performed inside a covered enclosure (e.g. Cover-All style building) including salt delivery and 
off-loading

Among the 50 facilities assessed, only the New Gary Subdistrict (LaPorte District) received a score of 6; Wanatah Unit (LaPorte District), New Plainfield Unit (Crawfordsville District) and Falls City Subdistrict/Sellersburg Unit (Seymour District) received a score of 5 and the other 46 assessed received a score of 2 or 1, meaning that the mixing/loading area has no covered enclosure and is, usually, not bermed nor does it have a retention/detention pond for stormwater drainage.

This is a surprising finding because covering the mixing/loading area to prevent salt and sand migration from the storage building and the surrounding area has been discussed by INDOT maintenance and operations staff for years as a structural BMP. Apparently this BMP needs to be prioritized in all districts.

It should be noted, however, that LaPorte, Crawfordsville and Seymour Districts had a mean of 4.3, 5.0 and 5.0, respectively, for criteria I:

\section{Which of the following best describes the condition of the Salt/Sand Mixing/Loading area(s)?}

$>\square$ (1) Excessive amounts of salt outside the designated area, very little to no sweeping is performed

(3) Moderate amount of salt outside the designated area, some sweeping is performed

(6) Little-to-no salt outside the designated area, regular sweeping is performed

Apparently, facility employees perform occasional or regular sweeping of the mixing/loading area to prevent salt /sand migration outside the area. This is a necessary procedure that needs to be enforced by facility management at those sites where the mixing/loading area is not enclosed. 
Criteria G, pertaining to secondary containment of outside tanks of brine, magnesium chloride, waste oil and other liquids is another BMP that INDOT staff have discussed for years and followed through by constructing or purchasing the BMPs:

\section{G. Does the facility have secondary containment (including double-walled tanks) for outside tanks containing Brine, Magnesium Chloride, Waste Oil, and other liquids?}

$>\square$ (1) NOT All tanks and pipes are secondarily contained

$>\square$ (2) Tanks are contained but pipes are not contained(e.g. double walled tank with no containment for pipes)

$>\square$ (6) All tanks and pipes are secondarily contained

A few districts built forms for pouring concrete containment structures and shared the forms with their facilities and the construction was done by facility employees. Apparently only in the LaPorte District was this procedure not implemented because only the New Gary Subdistrict (a relatively new facility) and Mishawaka Unit scored 6; the other seven facilities scored 1. Of particular interest is that, despite low scores for practically every facility in the Ft. Wayne District, six of its seven facilities received the highest score of 6; only one, the Warsaw Subdistrict, received a score of 1. Among the other Districts, four of six Crawfordsville facilities scored 6, seven of the twelve Seymour facilities scored 6, all eight Greenfield facilities scored 6, as did the eight facilities in the Vincennes District.

The total group of 50 facilities scored 4.8 for criteria $\mathrm{G}$ (see above) and also scored 4.2 for both criteria $\mathrm{F}$ and $\mathrm{N}$.

Criteria F could only be scored using the extremes of the range: a score of 1 if NOT all drums of paint, vehicle fluids and other liquids stored inside the facility have 
secondary containment (pallets, overpack drums, secondary containment structures, etc.) and a score of 6 if all drums did have secondary containment. Thirty-two of the fifty facilities assessed had implemented some type of secondary containment for drums. This BMP is another of those that has been discussed for years within INDOT, so it is surprising that more facilities did not receive a score of 6.

Criteria $\mathrm{N}$, pertaining to the storage of scrap tires, scrap metal, $\mathrm{R} / \mathrm{W}$ trash, street sweepings and scalp, was assessed as a BMP criteria - to prevent leaching of containments from scrap and waste piles found, usually, at various locations on the facility property. Twenty facilities scored 6 , meaning that these materials were stored in dumpsters or roll-offs that are emptied regularly or that the material was not stored onsite. Twenty-seven facilities scored 1 or 3 because they had excessive (1) to moderate (3) amounts of these materials being stored with no cover or berm for a long period of time (1) or a short period of time (3) before being hauled away or used (the scalp).

\section{THE COST OF IMPLEMENTING VARIOUS BMPS}

Appendix VII lists the costs associated with eight structural ("Technology") and five non-structural ("Housekeeping Practices") BMPs. These are the costs of facility upgrades and for "prototype" facilities identified by Steve McAvoy, Manager, Office of Facilities Management. As noted previously, after the completion of the cost estimates the Principal Investigator was informed that the cost of the new Cover-All building (to cover all salt operations) had increased from $\$ 800,000$ to $\$ 900,000$. The increased cost is not used in the following calculations. 
Tom Vanderpool, Division Director, Facilities and Equipment, and others have stated a preference for "incremental" improvements in implementing BMPs and related facility upgrades. This approach is understandable given the financial resources in the department that can be allocated for this purpose.

This incremental approach is depicted in Appendix VIII, Example of Upgrade Costs: Lafayette Unit. The Lafayette Unit was selected because, as noted previously, it scored the lowest of the 50 facilities assessed. The explanation of the incremental approach is provided in the Appendix. The cost factors used to increase the facility score are based on implementing the "least costly" structural or housekeeping BMP appropriate for the deficiencies observed in the assessment.

The Lafayette Unit's assessed score of 1.54 can be raised to 2.23 for an expenditure of $\$ 800$, including the cost of (1) covering the cold patch with a tarp (\$100), (2) cleaning the scrap area and storing $\mathrm{R} / \mathrm{W}$ trash and scrap in dumpsters (\$300), and (3) purchasing two secondary containment pallets for drums of liquids stored inside the facility (\$400). To raise the score to 3.00 requires an expenditure of an additional $\$ 1,350$, including the cost of (1) sweeping the salt/sand/loading area regularly (\$450 annually) and (2) cleaning salt beds more thoroughly ( $\$ 900$ annually). Therefore, to improve the facility's score from 1.54 to 3.00 would cost $\$ 800+\$ 1,350$ or $\$ 2,150$. Incremental improvements beyond this are considerably more expensive, as shown in the Appendix, even when employing the least costly alternatives: to improve the score from 3.00 to 4.08 would require an additional cost of $\$ 25,580$ and to improve the score, further, to 5.00 would require an additional expenditure of $\$ 155,000$. This incremental approach would result in an expenditure of $\$ 182,730$ for the Lafayette Unit. 
The availability of funds to upgrade each facility will influence the decision regarding whether the incremental approach is the most economical approach. If $\$ 800,000$ (now $\$ 900,000$ ) was available for each facility to have a Cover-All building constructed, it would eliminate the need for the incremental approach, but this is unrealistic. There may be, however, less costly upgrades that can incorporate other technology and housekeeping practice BMPs and, thus, result in overall cost savings.

The Study Advisory Committee asked for the Principal Investigator to prepare two examples of facility upgrades for each scoring category. These are found in Appendix IX and summarized below.

\section{Category 1 (1.00 to 2.00$)$}

Lafayette Unit

$$
\begin{aligned}
& 1.00 \text { to } \geq 2.00 \\
& 2.00 \text { to } \geq 3.00 \\
& 3.00 \text { to } \geq 4.00 \\
& 4.00 \text { to } \geq 5.00
\end{aligned}
$$

U.S. 27 S. Unit
1.00 to $\geq 2.00$

2.00 to $\geq 3.00$

3.00 to $\geq 4.00$

4.00 to $\geq 5.00$

Mean 1.00 to $\geq 2.00$

$$
\begin{array}{r}
\$ 800 \\
1,350 \\
25,580 \\
155,000
\end{array}
$$

$$
\begin{array}{r}
\$ 100 \\
1,150 \\
31,680 \\
385,000 *
\end{array}
$$

$\$ 450$

*includes a Salt-Load-out Building at a cost of $\$ 250,000$, one of three BMPs remaining for this facility to increase the scoring category from 4.00 to $\geq 5.00$.

Category 2 (2.00 to 3.00$)$

$\begin{array}{llr}\text { Crown Point Unit } & 2.00 \text { to } \geq 3.00 & \$ 950 \\ & 3.00 \text { to } \geq 4.00 & 18,180 \\ & 4.00 \text { to } \geq 5.00 & 155,000 \\ \text { Michigan City Unit } & 2.00 \text { to } \geq 3.00 & \$ 400 \\ & 3.00 \text { to } \geq 4.00 & 18,630 \\ & 4.00 \text { to } \geq 5.00 & 155,000\end{array}$




$$
\text { Mean } 2.00 \text { to } \geq 3.00 \quad \$ 675
$$

\begin{tabular}{|c|c|c|}
\hline Fortville Unit & $\begin{array}{l}3.00 \text { to } \geq 4.00 \\
4.00 \text { to } \geq 5.00\end{array}$ & $\begin{array}{r}\$ 1,000 \\
45,450\end{array}$ \\
\hline \multirow[t]{3}{*}{ Brownstown Unit } & $\begin{array}{l}3.00 \text { to } \geq 4.00 \\
4.00 \text { to } \geq 5.00\end{array}$ & $\begin{array}{r}\$ 800 \\
155,000\end{array}$ \\
\hline & Mean 3.00 to $\geq 4.00$ & $\$ 900$ \\
\hline & \multicolumn{2}{|c|}{ Category 4 (4.00 to 5.00$)$} \\
\hline Jasper Unit & 4.00 to $\geq 5.00$ & $\$ 65,450$ \\
\hline Columbus Subdistrict & 4.00 to $\geq 5.00$ & $\$ 45,000$ \\
\hline & Mean 4.00 to $\geq 5.00$ & $\$ 55,225$ \\
\hline
\end{tabular}

The scoring category mean costs, above, can be used to extrapolate the cost of incremental BMP upgrades - from one scoring category to the next higher category - and to estimate the cost of upgrades to raise the score of all facilities to the highest category. The simple calculations used here are not a substitute for the process the Maintenance and Operations Team would have used (see pages 8 and 9), assigning each facility to a particular "typology" based on similar operational and locational (environmental setting) characteristics. Underlying the cost projections is the assumption that the percentage of facilities in each category of the 50 facilities assessed will be approximately the same in the total population of INDOT facilities; this assumption will need to be verified. 
Table 3

Estimated Cost to Upgrade Facilities in Each Scoring Category to the Next Higher Category

$\begin{array}{lccccc}\text { No. of Facilities } & \begin{array}{l}\text { Percent of } \\ \text { Facilities } \\ \text { Assessed }\end{array} & \begin{array}{l}\text { No. of Total } \\ \text { Facilities }\end{array} & \begin{array}{l}\text { Mean } \\ \text { Upgrade } \\ \text { Cost }^{2}\end{array} & \text { Total Cost } \\ 1.00-\geq 2.00 & 2 & 4 & 5 & \$ 450 & \$ 2,250 \\ 2.00-\geq 3.00 & 8 & 16 & 22 & \$ 675 & \$ 14,850 \\ 3.00-\geq 4.00 & 21 & 42 & 57 & \$ 900 & \$ 51,300 \\ 4.00-\geq 5.00 & 17 & 34 & 46 & \$ 55,225 & \$ 2,540,350 \\ 5.00-6.00^{1} & 2 & 4 & 5 & - & - \\ \text { Total } & 50 & 100 & 135 & & \$ 2,608,750 \\ \text { Mean } & & & (130) & & (\$ 20,067) \\ (\text { Total } 1.00-\geq 4.00) & (31) & & (84) & & (\$ 68,400)\end{array}$

${ }^{1}$ The $5.00-6.00$ category is the highest and ,therefore, the desired scoring category to which all facilities should be upgraded.

${ }^{2}$ The "mean upgrade cost" is based on the upgrade costs of the two facilities scored in each category as shown in Appendix IX, and pp. 20-21.

As Table 3 reveals, the mean upgrade cost for each facility is $\$ 20,067$ and the total cost for facilities in the first three scoring categories is minimal - $\$ 68,400$ for 84 facilities ( $\$ 814$ each). The actual cost per facility is undoubtedly higher, but the "incremental approach" that some INDOT officials prefer appears appropriate for facilities that need the most improvement. The total cost of the one-category upgrade is $\$ 2.61$ million. Most of the upgrades to the 46 facilities in the $4.00-\geq 5.00$ scoring category require the construction of a salt bed rack, therefore the mean upgrade cost $(\$ 55,225)$ is considerably greater than that of other categories.

The estimated cost to upgrade INDOT's 135 maintenance facilities to the highest scoring category is $\$ 7.28$ million, as shown in Table 4 on the following page. With the exception of the U.S. 27 S. Unit, which would require the installation of a salt load-out building, at a cost of $\$ 250,000$, to increase its score from 4.00 to $\geq 5.00$, facility upgrades 
to the highest scoring category can be accomplished without the installation of the most expensive structural BMPs (e.g., salt load-out building or Cover-All Style building).

Table 4

Estimated Cost to Upgrade Facilities in Each Scoring Category to the Highest Category

$\begin{array}{ccc}\text { Scoring Category } & \text { No. of Total Facilities } & \text { Total Upgrade Cost }^{3} \\ 1.00-\geq 2.00 & 5 & \\ 2.00-\geq 3.00 & 22 & \$ 286,250 \\ 3.00-\geq 4.00 & 57 & \$ 1,249,600 \\ 4.00-\geq 5.00 & 46 & \$ 3,199,125 \\ 5.00-6.00^{1} & 5 & \$ 2,540,350 \\ \text { Total } & 135 & - \\ \text { Total Mean }^{2} & (130) & \$ 7,275,325 \\ & & (\$ 55,964)\end{array}$

${ }^{1}$ The $5.00-6.00$ category is the highest and ,therefore, the desired scoring category to which all facilities should be upgraded.

${ }^{2}$ The number of facilities scoring in the highest (5) category are substracted from the total to estimate the mean cost using the total cost.

${ }^{3}$ The Total Upgrade Cost for, e.g., the $2.00-\geq 3.00$ scoring category is derived multiplying the number of facilities in that category (22) time each category mean $(\$ 675, \$ 900$ and $(\$ 55,225)$ and adding the products $(\$ 1,249,600)$.

The total upgrade cost of facilities in each category is more dependent on the number of facilities in the category than the cost of the upgrade, from one scoring category to the next.

The increase in the mean upgrade cost from the lower to the higher scoring categories reflects (1) the decision as to what housekeeping BMPs are selected to promote the upgrade, for the lower categories, and (2) the relatively restricted choice of more costly structural (building) BMPs, for the higher categories. The greater number of facilities in the higher scoring categories, then, results in the greater total upgrade cost. 
Table 5 on the following page depicts a possible distribution of the total cost of raising all facilities to the highest scoring category - $\$ 7.28$ million - maintaining a "cycle" (fiscal year, fiscal biennium, other time or funding period) cost of less than $\$ 1.0$ million. To project these costs over eight cycles requires distributing facilities within the three highest scoring categories $(22,57,46)$ approximately equally to each cycle. Obviously, the number of cycles can be reduced or expanded dependent upon the availability of funds. 
Table 5

Distribution of BMP Upgrade Costs to Increase All Facilities in Each Scoring Category to the Highest Category

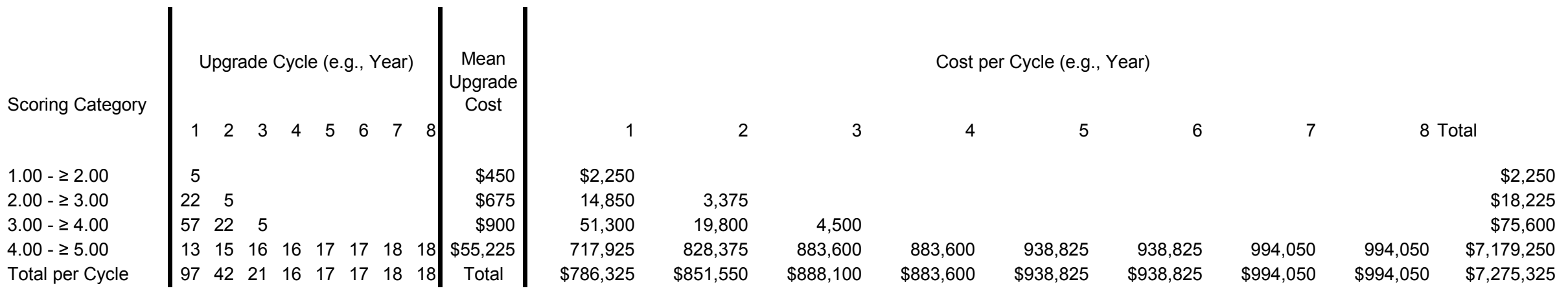




\section{Conclusions}

Incremental upgrades to INDOT's 135 maintenance facilities - - from their current scoring category to the next highest - - are estimated to cost $\$ 2.61$ million with \$2.54 million of the total required to upgrade the 46 facilities in the next to highest scoring category $(4.00 \geq 5.00)$ because the number and variety of structural and housekeeping BMPs will be limited and more costly.

The estimated cost to upgrade all facilities to the highest scoring category (5.00 6.00 ) is $\$ 7.28$ million and, using the calculations employed here, the upgrades can be accomplished (with the exception of the U.S. 27 S. Unit) without the installation of the most expensive structural BMPs (salt load-out building or Cover-All Style building).

Using a "cycle" cost projection approach applied to the total $\$ 7.28$ million reveals that the upgrade to all facilities can be accomplished in eight cycles for an expenditure of less than $\$ 1$ million per cycle.

The availability of funds, both in department and district accounts, and the willingness of management to allocate such funds, will determine the priority with which facility upgrades are accomplished. As Table 3 shows, the 84 facilities in the first three scoring categories can be upgraded to the next higher scoring category for only $\$ 68,400$. The upgrading program will have been implemented by the time this study is published, but a review of upgrades, to date, using current cost and facility data will reveal whether this cost estimate is realistic.

Tables 1 and 2 are useful for identifying the districts that should be the focus of the upgrades and the criteria associated with those upgrades. The Ft. Wayne District, 
with the lowest mean assessment score, scored lower than any other district on eight of 13 assessment criteria. LaPorte, the second lowest scoring district, scored lowest on two criteria and tied with Seymour District as the lowest on a third.

The responsibility assumed by Unit and Sub-district managers for implementation and oversight of "housekeeping" BMPs can influence, considerably, the assessment and score of a facility and, ultimately, the district. Criteria I, J, K, L and N (Appendix I) assess the performance of INDOT operating procedures that address "housekeeping":

I - sweeping salt/sand in the mixing/loading area

$\mathrm{J}$ - keeping salt from accumulating on the active surface

$\mathrm{K}$ - cleaning around salt bed racks

$\mathrm{L}$ - covering cold patch and storing on an impervious surface

$\mathrm{N}$ - properly storing scrap tires, scrap metal, $\mathrm{R} / \mathrm{W}$ trash, street sweepings and scalp

The table below compares the mean district score of the five housekeeping criteria to the district's overall mean score and its non-housekeeping criteria mean score:

$\begin{array}{lccc}\text { District } & \begin{array}{c}\text { Overall } \\ \text { Mean } \\ \text { Score }\end{array} & \begin{array}{c}\text { Housekeeping } \\ \text { Criteria Mean } \\ \text { Score }\end{array} & \begin{array}{c}\text { Non- } \\ \text { Housekeeping } \\ \text { Criteria Mean } \\ \text { Score }\end{array} \\ \text { LaPorte } & 3.50 & 3.92 & 3.51 \\ \text { Ft. Wayne } & 2.78 & 2.78 & 2.77 \\ \text { Crawfordsville } & 3.64 & 4.08 & 3.34 \\ \text { Seymour } & 3.82 & 4.20 & 3.90 \\ \text { Greenfield } & 3.89 & 3.52 & 4.33 \\ \text { Vincennes } & 3.86 & 3.74 & 3.97 \\ \quad \text { All Districts } & 3.62 & 3.74 & 3.74\end{array}$


The mean score of the housekeeping criteria in the LaPorte, Crawfordsville and Seymour districts was higher than the district's overall mean score and its "nonhousekeeping" criteria mean score. The housekeeping mean scores were lower than the non-housekeeping mean scores and the overall mean scores in the Greenfield and Vincennes district. In the Ft. Wayne District, the three mean scores were essentially the same.

The assessment score and potential upgrade of a facility depends on a number of factors. Perhaps, some facility managers have the funds and available crew hours to build, install or purchase structural BMPs, where others do not and so, implementing non-structural (housekeeping) BMPs by managing employee performance of operating procedures is the only or most economical alternative. From the table data, it is evident that, overall, districts generally balance the two approaches, as the mean of each (3.74) for all districts represents. 


\section{Recommendations, Including Strategies for Implementation}

First, the facility assessments completed to date using INDOT's criteria (Appendix II) need to be scored and grouped by scoring category within districts and throughout the department so priority facilities can be identified. And first priority should be given to facilities in each district that are within Municipal Separate Storm Sewer System (MS4) areas and among the MS4 facilities, those that are not connected to a local wastewater treatment plant for the discharge of truck wash and shop floor drain effluent. (See page 9, preceding)

A previous JTRP study authored by this study's Principal Investigator (FHWA/IN/JTRP-2002/24 [February 2003], table page 43) showed the following MS4 totals and the number then [October 2002] not connected to a wastewater treatment plant:

\begin{tabular}{lcc} 
District & MS4 & $\begin{array}{c}\text { Total } \\
\text { Total }\end{array}$ \\
\cline { 2 - 2 } Crawfordsville & 8 & 3 \\
Fort Wayne & 8 & 1 \\
Greenfield & 14 & 4 \\
LaPorte & 12 & 10 \\
Seymour & 7 & 2 \\
Vincennes & 6 & 0 \\
$\quad$ Total & 55 & 20
\end{tabular}

The above table needs to be updated by a current survey of the facilities located in MS4 areas and, among those, which are still not connected to a wastewater treatment plant. The LaPorte district was the obvious priority in October 2002; perhaps it should remain a priority because of these criteria and those used for this study's environmental assessments. 
Second, current costs of housekeeping and structural BMPs need to be applied to the scoring categories to allow estimates of the cost of facility upgrades to the next highest category and the highest category.

Third, the availability of funds at the district and department levels for facility upgrades need to be determined.

This straightforward procedure ignores the original premise of this study: that all INDOT maintenance facilities can be categorized by approximately ten typologies based on operational and locational (environmental) characteristics. The facility assessments have proceeded over the course of this study and may, now, be nearing completion. The scoring categories, as defined and used in this report become, de facto, the "typologies" and characteristics of each are, undoubtedly, better defined through the on-site assessment process than using the Maintenance and Operations Team approach originally intended.

Facility upgrades are needed to ensure that necessary operations can be performed without posing a threat to the environment, namely, the waters of the state. The upgrades can be implemented and the environment can be protected only when facility managers recognize the need for adherence to the operating procedures and require their implementation and when INDOT administrators allocate sufficient funds to support the facility managers' efforts. 


\section{Objective 2: Prepare an Environmental Management System (EMS) modeled on the ISO 14001 Standard and "pilot" the EMS in an INDOT District; conduct EMS Awareness training for affected employees.}

\section{MODIFICATION OF THE WORK PLAN}

The development of an Environmental Management System (EMS) was intended to focus on the operations at INDOT maintenance facilities. The development of an EMS was specified in INDOT's application for a NPDES Phase II stormwater permit to the Indiana Department of Environmental Management. The EMS was originally to have been piloted in INDOT's Seymour District and a gap analysis [a review of existing operations, policies and procedures against the EMS Standard] was conducted at the Madison Subdistrict in December, 2004.

The subsequent personnel and organization changes in INDOT delayed further implementation of this objective. At the March 20, 2006 Study Advisory Committee meeting attended primarily by the staff of the Facilities and Equipment Management Division, the discussion focused on the tasks performed by employees of other divisions that affect the condition of facilities and equipment and, ultimately, the rating of the facilities using the new environmental assessment criteria. The SAC members present at that meeting agreed to seek adoption of the assessment criteria by the Highway Operations Division, especially the Maintenance Administration Unit, which is responsible for employee task performance pertaining to facilities and equipment. The 
Committee members also agreed to seek the involvement of the Highway Operations Division in the preparation and implementation of the EMS.

At the April 21 meeting with the Principal Investigator, the heads of the two aforementioned divisions, their management staff and the Deputy Commissioner for Operations agreed that among other tasks to be completed, the SPR-2854 study should include: (1) a review of environmental-related Operating Procedures and other policies and recommend changes; (2) the preparation of an EMS "boilerplate" for the two divisions, statewide, and (3) the preparation of a PowerPoint presentation to explain what an EMS is, why INDOT needs one and (after development) what the components are of INDOT's EMS. To this point, the discussion about INDOT developing an EMS focused only on a "boilerplate" for internal use and, perhaps, self-certification [approval of its own EMS rather than so-called "third party" certification].

At the September 6, 2006 SAC meeting, Matt Frazer, of the Facilities and Equipment Management Division staff, was appointed by Tom Vanderpool, Facilities and Equipment Management Division Director, as the Environmental Management Representative responsible for organizing and leading the Environmental Management Committee. It was apparent from the discussion at this meeting that INDOT officials were considering third-party certification of their EMS, rather than develop only an EMS boilerplate or rely on self-certification.

Shayla Barrett, an EMS Lead Auditor on the staff of the Principal Investigator's Clean Manufacturing Technology Institute (CMTI), conducted EMS Awareness training for the INDOT EMS Committee on October 4, 2006. At the second meeting, October 11, the Committee was queried about the scope of the department's EMS. The response was 
that the scope of the EMS was being discussed and that the Director of the Facilities and Equipment Management Division said the scope should be expanded to include "[all] environmental activities of INDOT employees and INDOT contractors." The broadening of the scope was discussed, again, at the EMS Committee meeting November 1 and, finally, was documented and approved by the Committee at its meeting December 7.

The broadened scope of the EMS from an EMS "boilerplate" for two divisions to a third-party certified EMS for all INDOT employees and contractors demands significantly more time and resources by INDOT and CMTI. To date, CMTI has assisted the EMS Committee with the development of a proposed EMS Manual and Procedures that conform to ISO 14001 and facilitated bi-weekly meetings.

The need for implementation of the EMS is critical to both the pending NPDES stormwater permit and the facilities environmental assessment program. A third-party certified EMS will also aid the department's administration of operations (e.g., facilities management) and contracts (e.g., highway maintenance and construction) that will or could have environmental impacts.

For these reasons the Principal Investigator, on January 4, 2007, submitted a JTRP Implementation Proposal to assist INDOT with the Implementation of an Environmental Management System Conforming to the ISO 14001 Environmental Management System Standard. The proposal was approved and CMTI staff have continued to meet regularly with the INDOT EMS Committee and will assist INDOT's implementation of the EMS through December 2007. 


\section{Description of the Development Process, Recommendations and Strategies for Implementation}

Prior to the first development meeting in October 2006, representatives from INDOT and CMTI reviewed other state transportation departments' EMSs, including the Florida, Texas, Maine, New Hampshire, New York, Pennsylvania and Washington Departments of Transportation, the Massachusetts Highway Department and the Maryland State Highway Administration. The American Association of State Highway and Transportation Officials (AASHTO) EMS Implementation guide was also reviewed at the same time. All reviewed EMSs and guides focused on compliance with environmental regulations. EMS Committee members felt that they had achieved this goal and wanted an EMS that would focus on improving the environmental performance of the organization. Based on this objective, a decision was made not to use the AASHTO guide or any of the existing DOT EMSs as templates for INDOT's EMS.

The next step was to review other existing templates and boilerplates for creating and implementing an EMS. The United States Environmental Protection Agency (U.S. EPA) EMS website provided links to many templates. One that had been successfully used by CMTI for both manufacturing facilities and local governments was the New York State Department of Environmental Conservation Pollution Prevention Unit's "Understanding and Implementing an Environmental Management System - A Step-by-Step Guide for Small and Medium-sized Organizations.” Based upon a review of the Guide a decision was made to use this template. 
Following the appointment of an INDOT EMS team and the EMS Champion (Matt Frazier), the team began to work on the development of the INDOT EMS by reviewing the "Step-by-Step" template. Through subsequent bi-weekly meetings, the team amended and massaged the template until it fulfilled INDOT's EMS requirements. Once this was accomplished, the team began to identify INDOT's environmental aspects. During this one-month process, the team discovered that the procedure to identify environmental aspects adopted from the "Step-by-Step" model was not the one they preferred to follow. Consequently, the team amended the procedure to reflect the INDOT process for identifying environmental aspects and determining which ones were to be considered significant by the organization. This resulted in fewer forms required to accomplish the task and, also, in a revised aspects procedure. The team employed this revision process with each subsequent procedure as each was implemented.

The change in the scope of the EMS to include all INDOT employees and contractors reflects the changes in the ISO 14001:2004 version of the Environmental Management System Standard, which emphasizes that everyone working for or on behalf of the organization shall be included in the EMS scope. The modification of the EMS scope and amending the procedures to reflect what was actually occurring within INDOT is objective evidence that the EMS is already working. The ISO 14001 standard requires that the EMS be kept up-to-date, and the EMS team already has this mindset.

After identifying environmental aspects and determining those considered significant, the team set up objectives and targets. These were based on current INDOT environmental goals and the previously identified significant aspects. The team established an objective and target - some short range and some long range - for each 
significant aspect,. Since these objectives and targets were identified, one has been accomplished. This reflects, again, that the EMS is a "living document" and that the EMS team is aware of the need to review and update the procedures accordingly. The remaining objectives and targets have programs that identify staff responsibility and methods for achieving the objectives and targets. This also helps to establish EMS training needs for INDOT employees. A review of current training practices indicates that the most pressing EMS training need is to communicate the environmental policy to everyone and train all INDOT employees and contractors on their specific roles for the EMS. This EMS Awareness training is being conducted during the summer and fall of 2007.

The EMS team must perform an internal audit and implement the nonconformity and corrective and preventive action procedure. Once this has been accomplished, a management review of the system must take place. The team is evaluating compliance to environmental regulations through its current audits and is monitoring and measuring the key characteristics of the operation that could create a significant aspect through permit monitoring requirements. It is also monitoring its progress towards achieving the objectives and targets. It is anticipated that INDOT will have an EMS that is ISO 14001 compatible by December, 2007. At that time, the organization can seek third party certification, if it so desires.

[NOTE: A copy of the $7^{\text {th }}$ Draft of INDOT's Environmental Management System Manual is provided on a CD-ROM in a sleeve affixed to the back cover.] 


\section{APPENDICES \\ TABLE OF CONTENTS}

Appendix I

Appendix II

Appendix III

Appendix IV

Appendix V

Appendix VI

Appendix VII

Appendix VIII

Appendix IX

Appendix X

Appendix XI
Original INDOT Facility Environmental Assessment Criteria Proposed by Purdue

INDOT Facility Environmental Assessment Criteria Prepared by INDOT (Incorporating Purdue-proposed Criteria) May 15, 2006

INDOT Facility Stormwater and Washwater Effluent Drainage Assessment Form

Site Assessment Scores for Selected Facilities, by District (Including Overall Average Score for All Facilities Visited)

Facility Assessment Scores, by District (Rank Order)

Comparative Criteria and Average Score for Facilities Assessed (Alpha Order)

Implementation Cost of Various BMPs

Example of Upgrade Costs: Lafayette Unit

Cost of Facility Upgrades (Two Examples per Scoring Category)

Facility Site Assessment Reports

INDOT's Environmental Management System Manual $7^{\text {th }}$ Draft 


\section{Appendix I}

\section{Original INDOT Facility Environmental Assessment Criteria Proposed by Purdue}


Name of Facility

District/Subdistrict

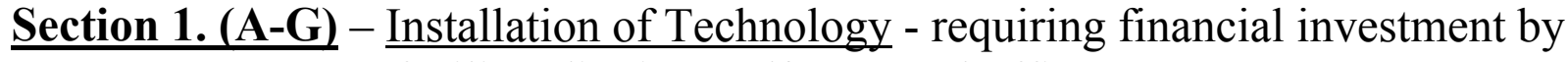
facility, district, and/or central office

\section{A. Which of the following best describes the discharge of the} shop floor drain contents?

$>\square$ (1) Discharged directly to Waters of the State

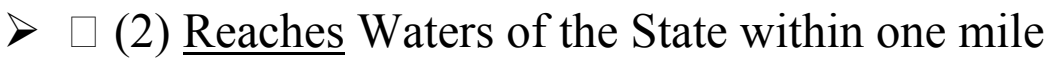

$>\square$ (3) Discharged off site to a roadside ditch, county ditch, field etc. that does not reach waters of the State within one mile

$>\square$ (4) Remains on site (retention/detention pond)

$>\square$ (5) Discharged to a Municipal Sewer System

$>\square$ (6) Remains on site(e.g. underground tanks) and is reused for brine

\section{B. Which of the following best describes the discharge of the Stormwater from the active surface of the site?}

$>\square$ (1) Discharged into a karst sinkhole

$>\square$ (2) Discharged directly to Waters of the State

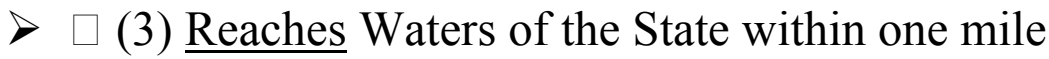

$>\square$ (4) Discharged off site to a roadside ditch, county ditch, field etc. that does not reach waters of the State within one mile

$>\square$ (5) Remains on site (retention/detention pond)

$>\square$ (6) Discharged to a Municipal Sewer System(if approved)

\section{Which of the following best describes the treatment of the facility wastewater?}

$>\square$ (1) Not connected to a Municipal Sewer System and is NOT equipped with a functioning oil/water separator

$>\square$ (3) Not connected to a Municipal Sewer System and is equipped with a functioning oil/water separator

$>\square$ (5) Connected to a Municipal Sewer system without a functioning oil/water separator

(6) Connected to a Municipal Sewer system with a functioning oil/water separator 
D. Which of the following best describes the design of the Salt/Sand Mixing/Loading area(s)?

$>\square$ (1) Outside with no covered enclosure, no berm, and no retention/detention pond

$>\square$ (2) Outside with no covered enclosure but within a bermed area and/or water from the area enters a retention/detention pond

$>\square$ (5) Mixing/Loading is performed inside a covered enclosure (e.g. Load-Out Building) but larger salt delivery trucks offload outside

(6) Full operations are performed inside a covered enclosure (e.g. Cover-All style building) including salt delivery and off-loading

E. If the facility has Brine Production equipment, is it secondarily contained?

$>\square$ (1) $\underline{\text { NOT }}$ All equipment is secondarily contained

$>\square$ (6) All equipment is secondarily contained

$>\quad(0) \underline{\text { No }}$ Brine Production at facility

F. Which of the following best describes the secondary containment (including pallets and over pack drums) for drums and other containers of paint, vehicle fluids, etc. stored Inside?

$>\square$ (1) NOT All is secondarily contained

$>\square$ (6) All is secondarily contained

G. Does the facility have secondary containment (including doublewalled tanks) for outside tanks containing Brine, Magnesium Chloride, Waste Oil, and other liquids?

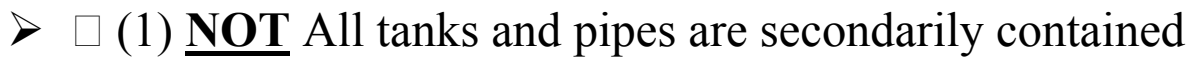

$>\square$ (2) Tanks are contained but pipes are not contained(e.g. double walled tank with no containment for pipes)

$>\square$ (6) All tanks and pipes are secondarily contained 
$\underline{\text { Section 2. (H-N) }}$ - Good House Keeping Practices - requiring, usually, only initiative of local facility management and little investment

\section{$H$. Which of the following best describes the salt bed washing} practices at the facility?

$>\square$ (1) All washing performed on site with no connection to a Municipal Sewer System and wash water drains off site

$>\square$ (2) All washing is performed on site with no connection to a Municipal Sewer System but the wash water is held in a retention/detention pond

$>\square$ (3) Light washing is performed on site but the majority is performed at a nearby facility that is connected to a Municipal Sewer System or brine system

$>\square$ (3.5) All washing is performed in a wash bay and the wash water does NOT pass through a fully functioning oil/water separator before being discharged to a Municipal Sewer System

$>\square$ (4) All washing is performed in a wash bay and the wash water passes through a fully functioning oil/water separator and then is discharged to a Municipal Sewer System

$>\square$ (5) No washing is performed on site. All truck washing is performed at a nearby facility with a wash bay

(6) All washing is performed in a wash bay and the wash water passes through a fully functioning oil/water separator and is retained onsite(e.g. underground tanks) for reuse in brine production

\section{Which of the following best describes the condition of the Salt/Sand Mixing/Loading area(s)?}

$>\square$ (1) Excessive amounts of salt outside the designated area, very little to no sweeping is performed

$>\square$ (3) Moderate amount of salt outside the designated area, some sweeping is performed

$>\square$ (6) Little-to-no salt outside the designated area, regular sweeping is performed 


\section{J. Which of the following best describes the amount of salt on the active surface at the site?}

$>\square$ (1) Excessive amount throughout the site and/or signs of vegetation kills and/or evidence of salt migrating off site in storm water

$>\square$ (3) Moderate amount around storage and loading areas with no signs of vegetation kills or salt migrating off site in storm water

$>\square$ (6) No salt on the active surface. The conditions indicate that the facility operators are fully implementing cleaning practices

\section{$K$. Which of the following best describes the condition of the area around the Salt Bed Racks?}

$>\square$ (1) Excessive amount of salt and/or paint chips and/or stains from hydraulic fluid/chain grease leakage, and the area is NOT bermed

$>\square$ (2) Excessive amount of salt and/or paint chips and/or stains from hydraulic fluid/chain grease leakage, and the area is bermed

$>\square$ (3) Moderate amount of salt and/or paint chips and/or stains from hydraulic fluid/chain grease leakage with or without a berm

$>\square$ (4) Little-to-no salt and/or paint chips and/or stains from hydraulic fluid/chain grease leakage, and the area is NOT bermed

$>\square$ (5) Little-to-no salt and/or paint chips and/or stains from hydraulic fluid/chain grease leakage, and the area is bermed

(6) Salt Bed Racks are located in a covered enclosure with no contact with stormwater

\section{Which of the following best describes the storage of Cold Patch?}

$>\square$ (1) Stored outside on a pervious surface with no cover(e.g. tarp) and/or no berm

$>\square$ (2) Stored outside on an impervious surface with no cover(e.g. tarp) and/or no berm

$>\square$ (3) Stored outside on a pervious surface with cover(e.g. tarp) and berm

$>\square$ (4) Stored outside on an impervious surface with cover(e.g. tarp) and berm

$>\square$ (5) Stored inside a building with a pervious floor

$>\square$ (6) Stored inside a building with an impervious floor 
M. Which of the following best describes the on site organization of materials such as Scrap Metal, Scrap Tires, Cold Patch, Signs, etc.?

$>\square$ (1) All storage areas are NOT clearly designated with signs

$>\quad$ (3) All storage areas are clearly designated with signs but All material is NOT kept within the designated areas

$>\square$ (6) All storage areas are clearly designated with signs and All material is kept within the designated areas

N. Which of the following best describes the storage of Scrap Tires, Scrap Metal, ROW Trash, Street Sweepings, and Scalp?

$>\square$ (1) Excessive amount(s) being stored with $\underline{\text { NO }}$ cover or berm for long periods of time before being hauled away or used(e.g. scalp)

$>\square$ (3) Moderate amount(s) being stored with $\underline{\mathrm{NO}}$ cover or berm but for only a short period of time before being hauled away or used(e.g. scalp)

$>\square$ (5) Moderate amount(s) being stored in a bermed or covered area but for only a short period of time before being hauled away or used(e.g. scalp)

(6) Stored in dumpsters or roll-offs that are emptied regularly (if appropriate) or not stored on-site

O. Which of the following best describes the Mixing, Loading, or Cleaning of equipment containing environmentally harmful chemicals (such as Herbicides, Liquid Asphalt, Paints, etc.)?

$>\square$ (1) Mixing, Loading, and/or Cleaning of equipment is NOT performed in an area that will contain spilled materials

$>\square$ (6) All Mixing, Loading, or Cleaning of equipment is performed in an area that will contain spilled materials

$\square(0)$ N/A 


\section{Appendix II}

\section{INDOT Facility Environmental}

Assessment Criteria

Prepared by INDOT (Incorporating Purdueproposed criteria)

May 15, 2006 


\section{ENVIRONMENTAL GENERAL CONDITION ASSESSMENT for INDOT FACILITIES \\ May 15, 2006}

GENERAL NOTE: $6=$ Absence of Deficiencies (81\%-100\%)

$5=$ Minor Deficiencies (61\%-80\%)

$4=\quad$ Significant Deficiencies (41\%-60\%)

$3=\quad$ Major Deficiencies (21\%-40\%)

$2=\quad$ Extreme Deficiencies (1\%-20\%)

$1=\quad$ Non Functional $(0 \%)$

0 $=$ Does Not Apply

SHOP:

Trip Hazards

6= No trip hazards; can walk throughout the shop area without having to

step over anything; hoes, creeper, tools, etc. and there are no open

holes and all grating are in place.

$5=$ One (1) trip hazard; can walk throughout the shop area and have to

step over only one item; hoes, creeper, tool, etc. and there are no open

holes and all grating are in place.

4= Two (2) trip hazards; can walk throughout the shop area and have to

step over two (2) items; hoes, creeper, tools, etc. and there are no open

holes and all grating are in place.

3= More than Two (2) trip hazards; can walk throughout the shop area and

have to step over more than two (2) items; hoes, creeper, tools, etc. and there are no open holes and all grating are in place.

$2=$ More than Two (2) trip hazards; can walk throughout the shop area and

have to step over more than two (2) items; hoes, creeper, tools, etc. and with

open holes or grates are missing or not in their intended place.

1= More than Two (2) trip hazards; can walk throughout the shop area and

have to step over more than two (2) items; hoes, creeper, tools, etc. and with

open holes or grates are missing or not in their intended place and 

floor.

there is an oil or other slick substance(s) or spill(s) on the

Isle Space

6= All isles are three (3) or more feet wide and there is a painted stripe on both sides designating the isle.

$5=$ All isles are three (3) or more feet wide; however, not painted or marked as an isle.

4= Isle less than three (3) feet wide, but painted or marked as an isle.

$3=$ Isle less than three (3) feet wide and not painted or marked as an isle.

$2=$ Isle less than three (3) feet wide, with one (1) protruding object that makes the isle less than 2 feet wide.

$1=$ Isle less than three (3) feet wide, with multiple protruding objects that makes the isle less than $\mathbf{2}$ feet wide in some places.

NOTE: Some Eye Wash and Emergency Showers are connected, assess them separately. Eye Wash

6= Eye wash is operational, clean, unobstructed, and labeled so it is visible

from ten (10) feet away. Inspection tag indicating that it has been inspected monthly.

5= Eye wash is operational, clean, unobstructed, but not labeled so it is visible from ten (10) feet away.

4= Eye wash is operational, clean, but obstructed, and labeled so it is visible

from ten (10) feet away. Inspection tag indicating that it has been inspected monthly.

3= Eye wash is operational, clean, but obstructed and/or not labeled so it is

visible from ten (10) feet away. OR Does NOT have an inspection tag

indicating that it has been inspected monthly, or the tag does not indicate a

current inspection.

$2=$ Eye wash is operational, not clean, unobstructed, and labeled so it is visible

from ten (10) feet away. AND Does NOT have an inspection tag 
indicating that it has been inspected monthly, or the tag does not indicate a current inspection.

$1=$ Eye wash is not operational, OR not clean, and is obstructed, and labeled so it is visible from ten (10) feet away. No current inspection.

\section{Emergency Shower}

6= Emergency shower is operational, clean, unobstructed, and labeled so it is visible from ten (10) feet away. Inspection tag indicating that it has been inspected monthly.

$5=$ Emergency shower is operational, clean, unobstructed, but not labeled so it

is visible from ten (10) feet away. Inspection tag indicating that it has been inspected monthly.

4= Emergency shower is operational, clean, but obstructed, and labeled so it is visible from ten (10) feet away. Inspection tag indicating that it has been inspected monthly.

3= Emergency shower is operational, clean, but obstructed and/or not labeled

so it is visible from ten (10) feet away. OR Does NOT have an inspection

tag indicating that it has been inspected monthly, or the tag does not indicate

a current inspection.

$2=$ Emergency shower is operational, not clean, unobstructed, and labeled so it

is visible from ten (10) feet away. AND Does NOT have an inspection tag indicating that it has been inspected monthly, or the tag does not indicate a current inspection.

$1=$ Emergency shower is not operational, OR not clean, and is obstructed, and labeled so it is visible from ten (10) feet away.

\section{Oil/Water Separator}

6= Functioning separator with "Y" strainers at the pump inlet and outlet, with proper venting and an up-to-date maintenance log. $5=$ Functioning separator with proper venting and an up-to-date 
maintenance log, but without "Y" strainers.

4= Functioning separator with proper venting, but without " $\mathbf{Y}$ "

strainers

and maintenance log not up-to-date.

3= Functioning separator without proper venting, without "Y" strainers, maintenance log not up-to-date, and with pumps shorting out.

$2=$ Non-functioning separator without proper venting, without "Y"

strainers, and maintenance log not up-to-date.

$1=$ Non-functioning separator without proper venting, without "Y"

strainers, and maintenance log not up-to-date, and excessive sludge

build-up visible.

Pipe Identification
(Signage or Color Code)

Universal Color Code: Electric $=$ RED

Gas or Oil $=$ YELLOW

Telephone $=$ WHITE

Water $=$ BLUE

Sewer $\quad$ GREEN

$6=81 \%-100 \%$ of the pipes area labeled or color coded.

$5=61 \%-80 \%$ of the pipes are labeled or color coded.

$4=41 \%-60 \%$ of the pipes are labeled or color coded.

$3=21 \%-40 \%$ of the pipes are labeled or color coded.

$2=1 \%-20 \%$ of the pipes are labeled or color coded.

$1=$ None $(0 \%)$ of the pipes are labeled or color coded.

Trashcan Lids

$6=$ All trashcans have lids and are on the trashcans (81\%-100\%).

$5=$ All trashcans have lids, but (61\%-80\%) of the lids are not being used or

are not on the can(s).

$4=(41 \%-60 \%)$ of the trashcans do not have lids on them.

$3=(21 \%-40 \%)$ of the trashcans do not have lids on them.

$2=(1 \%-20 \%)$ of the trashcans do not have lids on them.

$1=$ None of the trashcans have lids.

Trashcan Labels

6= All trashcans have neatly stenciled labels that are readable from at

least ten (10) feet away.

$5=$ All trashcans have neatly stenciled labels but are not readily readable

from at least ten (10) feet away or are otherwise obscured. OR (61\%-80\%) 
of trashcans do not have labels identifying them as trashcans.

$4=$ All trashcans have hand written labels that are readable from at

least ten (10) feet away. OR (41\%-60\%) of trashcans do not have labels identifying them as trashcans.

$3=$ All trashcans have hand written labels but are not readily readable

from at least ten (10) feet away or are otherwise obscured. OR (21\%-40\%) of trashcans do not have labels identifying them as trashcans.

$2=(1 \%-20 \%)$ of trashcans do not have labels identifying them as trashcans.

$1=$ None of the trashcans have labels identifying them as trashcans $(0 \%)$.

\section{Dumpster Storage}

$6=81 \%-100 \%$ of the refuse is in the dumpster.

$5=61 \%-80 \%$ of the refuse is in the dumpster.

$4=41 \%-60 \%$ of the refuse is in the dumpster.

$3=21 \%-40 \%$ of the refuse is in the dumpster.

$2=1 \%-20 \%$ of the refuse is in the dumpster.

$1=$ None $(0 \%)$ of the refuse is in the dumpster or a dumpster is not provided.

NOTE: Used shop rags may be discarded into the used oil dry drum and disposed of together.

\section{Used Shop Rags Storage}

$6=81 \%-100 \%$ of used shop rags are stored in a designated

container (metal

drum that is not rusted or in a plastic drum in good condition).

Only used

shop rags and no trash is stored in the drum.

$5=61 \%-80 \%$ of used shop rags are stored in a designated

container (metal

drum that is not rusted or in a plastic drum in good condition).

Only used

shop rags and no trash is stored in the drum.

$4=41 \%-60 \%$ of used shop rags are stored in a designated container (metal drum

that is not rusted or in a plastic drum in good condition). Only used shop

rags and no trash is stored in the drum.

$3=21 \%-40 \%$ of used shop rags are stored in a designated container (metal drum 
that is not rusted or in a plastic drum in good condition). Only used shop rags and no trash is stored in the drum.

$2=1 \%-20 \%$ of used shop rags are stored in a designated container (metal drum

that is not rusted or in a plastic drum in good condition). Some

\section{trash or}

materials other than used shop rags are found in the drum.

$1=$ Used rags are laying about the shop, none are stored properly (0\%). Some

trash or materials other than used shop rags are found in the drum.

\section{Used Shop Rags Containers’ Labels}

$6=81 \%-100 \%$ of designated used shop rags containers are neatly stenciled with labels readable from at least ten (10) feet away.

$5=61 \%-80 \%$ of designated used shop rags containers are neatly stenciled with

labels readable from at least ten (10) feet away. OR containers are labeled

with a hand written label that is readable from at least ten (10) feet away.

$4=41 \%-60 \%$ of designated used shop rags containers are neatly stenciled

with labels readable from at least ten (10) feet away. OR 41\%60 of the

containers are labeled with a hand written label that is not readable from at

least ten (10) feet away.

$3=21 \%-40 \%$ of designated used shop rags containers are neatly stenciled

with labels readable from at least ten (10) feet away. OR 21\%$40 \%$ of the

containers are labeled with a hand written label that is not readable from at

least ten (10) feet away.

$2=1 \%-20 \%$ of designated used shop rags containers are neatly stenciled

with labels readable from at least ten (10) feet away. OR 1\%$20 \%$ of the

containers are labeled with a hand written label that is not readable from at

least ten (10) feet away.

$1=$ None $(0 \%)$ of designated used shop rags containers are labeled with labels 
readable from at least ten (10) feet away.

\section{Used Shop Rags Containers' Lids}

$6=81 \%-100 \%$ of designated used shop rags containers have lids and those lids are being used properly.

$5=61 \%-80 \%$ of designated used shop rags containers have lids and those lids are being used properly.

$4=41 \%-60 \%$ of designated used shop rags containers have lids and those lids are being used properly.

$3=21 \%-40 \%$ of designated used shop rags containers have lids and those lids are being used properly.

$2=1 \%-20 \%$ of designated used shop rags containers have lids and those lids are being used properly.

$1=$ None $(0 \%)$ of designated used shop rags containers have lids or none of the containers' lids are being used properly.

NOTE: Each facility must have a safety plan that shows all the fire extinguisher locations, reference it first and then you will not have to count the fire extinguishers, the plan will tell you how many there are and where they are located.

\section{Fire Extinguishers}

6= Readily accessible/visible, labeled properly with a neatly stenciled label readable from at least twenty (20) feet away, and has an inspection tag that indicates that it has been inspected in the last month, plus annual inspection tag. $81 \%-100 \%$ meet these criteria.

$5=$ Readily accessible/visible, labeled properly with a neatly stenciled label readable from at least twenty (20) feet away, and has an inspection tag that indicates that it has NOT been inspected in the last month, plus annual inspection tag. OR Only (61\%-80\%) of Fire Extinguishers meet the criteria in 6.

4= Readily accessible/visible, labeled properly with a neatly stenciled label 
readable from at least twenty (20) feet away, but no indication (NO TAGS)

that it has been inspected in the last month nor an annual inspection tag.

OR Only (41\%-60\%) of Fire Extinguishers meet the criteria in 6.

3= Not readily accessible/visible, but labeled properly with a neatly stenciled

label readable from at least twenty (20) feet away, and may or may not

have an inspection tag that indicates that it has been inspected in the last

month, plus annual inspection tag. OR Only (21\%-40\%) of

Fire Extinguishers meet the criteria in 6.

$2=$ Not readily accessible/visible, not labeled properly, and does

not have an

inspection tag that indicates that it has been inspected in the last month, plus

annual inspection tag. OR Only (1\%-20\%) of Fire

Extinguishers meet the criteria in 6.

$1=$ No fire extinguishers visible.

\section{Spill Response Kit}

6= Spill response kit is readily available, labeled, and has enough absorbent pigs

to contain a moderate spill, usually a kit is a labeled 55 gallon

drum filled

with absorbent pigs.

$5=$ Spill response kit is readily available, labeled, but does not have enough

absorbent pigs to contain a moderate spill, a kit consisting of a labeled 55

gallon drum less than $1 / 2$ full of absorbent pigs.

$4=$ Do not use this score.

$3=$ Do not use this score.

$2=$ Do not use this score.

$1=$ NO spill response kit available in the shop area.

\section{Chemicals}

6= All chemicals are stored in a properly labeled (HAZCOM) cabinet manufactured for and used solely for chemical storage. All chemicals have lids secured and have readable labels. The cabinet is securely closed. The Material Safety Data Sheets (MSDSs) are on file in a readily accessible location. OR (81\%$100 \%$ ) of chemicals are stored properly. 
$5=$ All chemicals are stored in a cabinet manufactured for and used solely for

chemical storage. All chemicals have lids secured and have readable it

labels. But the cabinet is not properly labeled (HAZCOM) and

is securely closed. The MSDSs are on file in a readily accessible location.

OR Only (61\%-80\%) of chemicals are stored properly.

$4=$ At least one chemical is setting somewhere in the shop and is not properly

stored in the chemical storage cabinet. At least one chemical does not have a

secured lid or illegible label. The cabinet is labeled properly

(HAZCOM) and is securely closed. The MSDSs are on file in a readily

accessible location. OR Only (41\%-60\%) of chemicals are stored properly.

$3=$ Two (2) or more chemicals are setting about and are not properly stored in

the chemical storage cabinet, and the cabinet may or may not be securely

closed. No Hazcom. Two (2) or more chemicals do not have secured lids or

there labels are illegible.The MSDSs are on file in a readily accessible

location, but not all the chemical's MSDSs are on file.

OR Only (21\%-40\%) of chemicals are stored properly.

$2=$ The chemical cabinet is not functioning as it should; the doors do not secure

properly, there is no more room in it, there is signs of leaking chemicals, not

properly labeled (HAZCOM), and/or there are dangerous situations present

for human exposure to harmful chemicals. The MSDSs are not on file in a

readily accessible location. OR Only (1\%-20\%) of chemicals are stored

properly.

$1=$ There is no chemical storage cabinet; however, there are chemicals that

require a cabinet. No Hazcom. OR None $(0 \%)$ of the chemicals are stored

properly.

\section{Waste Oil}


$5=$

properly labeled ( no

$4=$

$6=$ All waste oil is properly stored in well labeled (neatly stenciled label) (HAZCOM) and non-leaking containers that has secondary containment. 81\%-100\% meet these criteria.

$61 \%-80 \%$ waste oil is properly stored in well labeled (neatly stenciled label)

(HAZCOM) and non-leaking containers that has secondary containment.

The bung is open, and/or the drums or tank are/is not

HAZCOM). OR Only (61\%-80\%) of Waste Oil containers meet the criteria

in 6 .

$41 \%-60 \%$ waste oil is properly stored in well labeled (neatly stenciled label)

(HAZCOM) and non-leaking containers that has secondary containment. The bung is open, and/or there are signs of excess spillage about the drums,

and/or the drums are not properly labeled (no HAZCOM).

OR Only (41\%-60\%) of Waste Oil containers meet the criteria in 6 .

$3=21 \%-40 \%$ waste oil is properly stored in well labeled (neatly stenciled label)

(HAZCOM) and non-leaking containers that do not have secondary

containment. There is used floor-dry on the floor, signs of excess spillage.

OR Only (21\%-40\%) of Waste Oil containers meet the criteria in 6.

$2=1 \%-20 \%$ waste oil is properly stored in drums designated for used oil storage

that do not have secondary containment and a floor drain is nearby. The

bung is open and/or there are signs of excess spillage about the drums.

OR

All waste oil is properly stored in a dedicated waste oil tank (below

ground).

OR

Only (1\%-20\%) of Waste Oil containers meet the criteria in 6.

$1=$ All waste oil is not stored in containers designated for used oil

storage that are not located on/in secondary containment and there

are signs of oil flowing into the floor drains, and/or the bung is open 
and/or there are signs of excess spillage about the drums. There is oil

on the floor and no sign of floor-dry being used to keep the area clean.

$$
\text { OR }
$$

All waste oil is properly stored in a dedicated waste oil tank (below

ground) and there are signs of spillage about the piping or tank

opening.

Basically $0 \%$ meets the criteria in 6.

Waste Filters

6= All waste filters (oil, hydraulic, diesel and gas) have been properly drained

for 24 hours into the proper waste storage container, crushed if possible and placed into a DOT approved storage drum supplied by current shop waste disposal vendor. Drum is properly labeled for filters or has signage posted above the drum to identify as proper disposal container. $81 \%-100 \%$ of waste

filters meet these criteria.

$5=$ All waste filters (oil, hydraulic, diesel and gas) have been properly drained

for 24 hours into the proper waste storage container, crushed if possible and placed into a DOT approved storage drum supplied by current shop waste disposal vendor. Drum is not properly labeled for filters or has no signage posted above the drum to identify as proper disposal container. $\quad$ OR Only (61\%-80\%) of Waste Filters meet the criteria in 6 .

4= All waste filters (oil, hydraulic, diesel and gas) have been properly drained

for 24 hours into the proper waste storage container, crushed if possible. Crushed filters have been placed in unapproved storage container not provided by shop waste vendor. Storage container is not properly labeled for filters or has no signage posted above the container to identify as proper

disposal container.

OR Only (41\%-60\%) of Waste Filters meet the criteria in 6.

$3=$ All waste filters (oil, hydraulic, diesel and gas) have been properly drained

for 24 hours into the proper waste storage container. Uncrushed filters have been placed in unapproved storage container not provided by shop waste vendor. Storage container is not properly labeled for filters or has no signage posted above the container to identify as proper disposal container.

OR Only (21\%-40\%) of Waste Filters meet the criteria in 6. 
2= Partial amount of waste filters (oil, hydraulic, diesel and gas) have been properly drained for 24 hours into the proper waste storage container. Uncrushed filters have been placed in unapproved storage container not provided by shop waste vendor and the container is leaking various materials on the shop floor. Storage container is not properly labeled for filters or has no signage posted above the container to identify as proper disposal container. OR Only (1\%-20\%) of Waste Filters meet the criteria in 6 .

1 = None of the waste filters (oil, hydraulic, diesel and gas) have been properly drained for 24 hours into the proper waste storage container. Uncrushed filters have been placed in unapproved storage container not provided by shop waste vendor and the container is leaking various materials on the shop floor. Storage container is not properly labeled for filters or has no signage posted above the container to identify as proper disposal container. OR (0\%) of Waste Filters meet the criteria in 6.

Waste Antifreeze

6= All waste antifreeze is properly stored in well labeled (neatly stenciled label

or sign) and non-leaking container that has secondary containment.

81\%-100\% meet these criteria.

$5=$ All waste antifreeze is properly stored in well labeled (neatly stenciled label

or sign) and non-leaking containers that has secondary containment. The

bung is open, and/or the drums or tank are/is not properly labeled.

OR Only (61\%-80\%) of Waste Antifreeze meet the criteria in 6.

4= All waste antifreeze is properly stored in well labeled (neatly stenciled label

or sign) and non-leaking containers that has secondary containment.

The bung is open, and/or there are signs of excess spillage about the drums, and/or the drums are not properly labeled. 6.

OR Only (41\%-60\%) of Waste Antifreeze meet the criteria in

3= All waste antifreeze is properly stored in well labeled (neatly stenciled label

or sign) and non-leaking containers that do not have secondary 
containment. There is used floor-dry on the floor, signs of excess spillage.

6.

OR Only (21\%-40\%) of Waste Antifreeze meet the criteria in

$2=$ All waste antifreeze is properly stored in drums designated for waste

antifreeze storage that do not have secondary containment and a floor

drain is nearby. The bung is open and/or there are signs of excess spillage

about the drums.

OR Only (1\%-20\%) of Waste Antifreeze meet the criteria in 6 .

$1=$ All waste antifreeze is not stored in containers designated for waste

antifreeze storage that are not located on/in secondary containment and

there are signs of antifreeze flowing into the floor drains, and/or the bung is open and/or there are signs of excess spillage about the drums. There is antifreeze on the floor and no sign of floor-dry being used to keep the area clean. OR (0\%) of Waste Antifreeze meet the criteria in 6 .

\section{Waste Oil Absorbents}

6= Stored in a DOT approved storage drum supplied by current shop waste disposal vendor. (metal drum that is not rusted or does not leak) with a neatly stenciled label or sign readable from at least ten (10) feet away, and a secured lid. 81\%-100\% meet these criteria.

$5=$ Stored in a designated container (metal or plastic drum that is not

rusted or does not leak) with a hand written label or sign readable from at

least ten (10) feet away, and a secured lid.

OR Only (61\%-80\%) of Waste Oil Absorbents meet the criteria in 6 .

$4=$ Stored in a designated container (metal or plastic drum that may have

some rust or may leak) with a hand written label or sign that is not readable

from at least ten (10) feet away, and a secured lid.

OR Only (41\%-60\%) of Waste Oil Absorbents meet the criteria in 6 .

$3=$ Stored in a designated container (not metal or not plastic drum) with a at least

neatly stenciled or hand written label that is not readable from 
ten (10) feet away, and an unsecured lid or no lid.

OR Only (21\%-40\%) of Waste Oil Absorbents meet the criteria in 6.

$2=$ Stored in a designated container (not metal or not plastic drum) with a

hand written label or sign not readable from at least ten (10) feet away, and

an unsecured lid or no lid. Used rags are lying about.

OR Only (1\%-20\%) of Waste Oil Absorbents meet the criteria in 6 .

$1=$ Stored in a designated container with an unreadable label or sign or no label

and no lid. Used rags are lying about.

OR (0\%) of Waste Oil Absorbents meet the criteria in 6 .

\section{Waste Household Batteries}

6= All waste household batteries have been properly placed into a vendor

provided 5-gallon plastic bucket. Bucket is properly labeled for waste batteries or has signage posted above the bucket to identify as proper disposal container. $81 \%-100 \%$ meet these criteria.

5= All waste household batteries have been properly placed into a vendor provided 5-gallon plastic bucket. Bucket is improperly labeled for household batteries or has no signage posted above the bucket to identify as proper disposal container.

OR Only (61\%-80\%) of Waste Household Batteries meet the criteria in 6.

4= All waste household batteries have been improperly placed into a metal bucket not provided by the current battery/ballast/light bulb or MCD vendor. Bucket is improperly labeled for household batteries or has no signage posted above the bucket to identify as proper disposal container.

OR Only (41\%-60\%) of Waste Household Batteries meet the criteria in 6 .

$3=$ All waste household batteries have been improperly placed into a metal

bucket with small holes or rusted areas not provided by the current battery/ballast/light bulb or MCD vendor. Bucket is improperly labeled for household batteries or has no signage posted above the bucket to identify as proper disposal container.

OR Only (21\%-40\%) of Waste Household Batteries meet the criteria in 6 . 
2= All waste household batteries have been improperly placed into a cardboard

box. The box is improperly labeled for household batteries or has no signage posted above the box to identify as proper disposal container.

OR Only (1\%-20\%) of Waste Household Batteries meet the criteria in 6.

1= All waste household batteries have been improperly placed into a cardboard

box. The box is improperly labeled for household batteries or has no signage posted above the box to identify as proper disposal container. A sign of leaking from the batteries is visible from the stains on the box and floor. OR $(0 \%)$ of Waste Household Batteries meet the criteria in 6.

Waste Light Bulbs

6= All waste light bulbs have been properly placed into the specific vendor

provided cardboard box or fiber drum. The box or fiber drum is properly labeled for waste light bulbs or has signage posted above the box or drum to identify as proper disposal container. 81\%-100\% meet these criteria.

$5=$ All waste light bulbs have been properly placed into the specific vendor

provided cardboard box or fiber drum. The box or fiber drum is improperly labeled for light bulbs or has no signage posted above the box or fiber drum to identify as proper disposal container.

OR Only (61\%-80\%) of Waste Light Bulbs meet the criteria in 6.

4= All waste light bulbs have been improperly placed into a nonvendor

provided cardboard box or fiber drum of insufficient size for proper transport. The box or fiber drum is improperly labeled for light bulbs or has no signage posted above the box or fiber drum to identify as proper disposal container.

OR Only (41\%-60\%) of Waste Light Bulbs meet the criteria in 6.

$3=$ All waste light bulbs have been improperly placed into a nonvendor

provided cardboard box or fiber drum of insufficient size for proper transport. The box or fiber drum is improperly labeled for light bulbs or has no signage posted above the box or fiber drum to identify as proper disposal container. Visible signs of broken bulbs are mixed in with intact bulbs.

OR Only (21\%-40\%) of Waste Light Bulbs meet the criteria in 6. 
$2=$ Waste light bulbs have been improperly placed onto the floor with no containment to prevent damage. The location has no signage posted above the bulbs as proper disposal location. OR Only (1\%-20\%) of Waste Light Bulbs meet the criteria in 6.

$1=$ Waste light bulbs have been improperly placed onto the floor with no containment to prevent damage. The location has no signage posted above the bulbs as proper disposal location. Visible signs of broken bulbs are mixed in with intact bulbs. OR (0\%) of Waste Light Bulbs meet the criteria in 6 .

Waste Ballasts

6= All waste ballasts have been properly placed into a vendor provided 5-gallon

plastic bucket. The bucket is properly labeled for waste ballasts or has signage posted above the bucket to identify as proper disposal container.

81\%-100\% meet these criteria.

$5=$ All waste ballasts have been properly placed into a vendor provided 5-gallon plastic bucket. The bucket is improperly labeled for waste ballasts or has no signage posted above the bucket to identify as proper disposal container.

OR Only (61\%-80\%) of Waste Ballasts meet the criteria in 6 .

$4=$ All waste ballasts have been improperly placed into a metal bucket not provided by the current battery/ballast/light bulb or MCD vendor. The bucket is improperly labeled for waste ballasts or has no signage posted above the bucket to identify as proper disposal container.

OR Only (41\%-60\%) of Waste Ballasts meet the criteria in 6 .

$3=$ All waste ballasts have been improperly placed into a metal bucket with

small holes or rusted areas not provided by the current battery/ballast/light bulb or MCD vendor. The bucket is improperly labeled for waste ballasts or has no signage posted above the bucket to identify as proper disposal container.

OR Only (21\%-40\%) of Waste Ballasts meet the criteria in 6.

$2=$ All waste ballasts have been improperly placed into a cardboard box. The box is improperly labeled for waste ballasts or has no signage posted above the box to identify as proper disposal container.

OR Only (1\%-20\%) of Waste Ballasts meet the criteria in 6.

$1=$ All waste ballasts have been improperly placed into a cardboard box. The box is improperly labeled for waste ballasts or has no signage posted above the box to identify as proper disposal container. A sign of leaking from the ballasts is visible from the stains on the box and floor. 
OR (0\%) of Waste Ballasts meet the criteria in 6.

Waste Mercury Containing Devices (MCD)

6= All MCD’s have been properly placed into a vendor provided 5-gallon

plastic bucket. The bucket is properly labeled for waste MCD's or has signage posted above the bucket to identify as proper disposal container.

81\%-100\% meet these criteria.

$5=$ All MCD's have been properly placed into a vendor provided 5-gallon plastic bucket. The bucket is improperly labeled for waste MCD's or has no signage posted above the bucket to identify as proper disposal container.

OR Only (61\%-80\%) of Waste Mercury Containing Devices meet the criteria in 6 .

4= All MCD's have been improperly placed into a metal bucket not provided by the current battery/ballast/light bulb or MCD vendor. The bucket is improperly labeled for MCD's or has no signage posted above the bucket to identify as proper disposal container. OR Only (41\%-60\%) of Waste Mercury Containing Devices meet the criteria in 6.

3= All MCD's have been improperly placed into a metal bucket with small holes or rusted areas not provided by the current battery/ballast/light bulb or MCD vendor. The bucket is improperly labeled for MCD's or has no signage posted above the bucket to identify as proper disposal container. OR Only (21\%-40\%) of Waste Mercury Containing Devices meet the criteria in 6 .

2= All MCD’s have been improperly placed into a cardboard box. The box is improperly labeled for MCD's or has no signage posted above the box to identify as proper disposal container. OR Only (1\%-20\%) of Waste Mercury Containing Devices meet the criteria in 6.

$1=$ All MCD's have been improperly placed into a cardboard box. The box is improperly labeled for MCD's or has no signage posted above the box to identify as proper disposal container. A sign of leaking from the MCD's is visible from the stains on the box and floor. OR ( $0 \%)$ of Waste Mercury Containing Devices meet the criteria in 6.

New Auto Batteries

6= All new auto batteries are stored inside on secondary

containment, and are not stacked.

$5=$ Do not use this score. 
$4=$ Do not use this score.

$3=$ Do not use this score.

$2=$ Do not use this score.

$1=$ NOT all new auto batteries are stored inside on secondary

containment, and/or they are stack.

\section{Old Auto Batteries}

$6=$ All old auto batteries are stored inside on secondary

containment, and are not stacked.

$5=$ Do not use this score.

$4=$ Do not use this score.

$3=$ Do not use this score.

$2=$ Do not use this score.

$1=$ NOT all old auto batteries are stored inside on secondary containment, and/or they are stack.

\section{Recycles - Collection}

6= All recycles (cans, bottles, newspaper, office paper) are deposited in

designated container(s), with a neatly stenciled label, and a secured lid.

81\%-100\% meet these criteria.

$5=61 \%-80 \%$ of recycles (cans, bottles, newspaper, office paper) are deposited

in designated container(s), with a neatly stenciled label, and a secured lid.

$4=41 \%-60 \%$ of recycles (cans, bottles, newspaper, office paper) are deposited

in designated container(s), with a neatly stenciled label, and a secured lid.

$3=21 \%-40 \%$ of recycles (cans, bottles, newspaper, office paper) are deposited

in designated container(s), with a neatly stenciled label, and a secured lid.

$2=1 \%-20 \%$ of recycles (cans, bottles, newspaper, office paper) are deposited

in designated container(s), with a neatly stenciled label, and a secured lid.

OR there is cross contamination or trash mixed in with the recycle bins.

$1=0 \%$ of recycles (cans, bottles, newspaper, office paper) are deposited 
in designated container(s), with a neatly stenciled label, and a secured lid.

\section{Basically $0 \%$ meets the criteria in 6.}

Recycles - Stored

6= All recycles (cans, bottles, newspaper, office paper) are stored in designated

area (out-of-the-way), labeled, and the bag(s) are closed tightly

or the

storage container(s) have a secured lid, to deter insects and rodents.

81\%-100\% stored recycles meet these criteria.

5= All recycles (cans, bottles, newspaper, office paper) are stored in a

designated area (out-of-the-way), but are either not labeled, or the bag(s) are

not closed tightly or the storage containers do not have secured lids, to deter

insects and rodents. OR Only (61\%-80\%) of recycles storage meet the criteria in 6.

4= All recycles (cans, bottles, newspaper, office paper) are stored in a

designated area (out-of-the-way), labeled, and the bag(s) are tied tightly or

the storage container(s) must have a secured lid, to deter insects and rodents.

But there are four (4) or more bags stored. OR Only (41\%$60 \%)$ of recycles storage meet the criteria in 6 .

$3=$ Only $21 \%-40 \%$ of recycles storage meet the criteria in 6 .

$2=$ Only $1 \%-20 \%$ of recycles storage meet the criteria in 6 .

$1=$ Basically $0 \%$ meets the criteria in 6.

Empty Drums

6= All empty drums are stored in a designated, marked (neatly stenciled

sign) area, located inside or outside, laid on their sides and stacked no 
more than three (3) high and secured from rolling. 81\%-100\%

Empty Drums are stored properly and meet these criteria.

$5=$ All empty drums are stored in a designated area, not marked, located

inside or outside, laid on their sides and stacked no more than three (3)

high and secured from rolling. OR Only (61\%-80\%) of empty drums are stored properly in accordance with 6.

$4=$ Not all empty drums are stored in a designated, marked area, located

inside or outside, laid on their sides and stacked no more than three (3)

high and secured from rolling. OR Only (41\%-60\%) of empty drums are stored properly in accordance with 6.

$3=$ Not all empty drums are stored in a designated area, area is not marked, located inside or outside, or the drums are stacked more than three

(3) high. OR Only (21\%-40\%) of empty drums are stored properly in accordance with 6 .

$2=$ Not all empty drums are stored in a designated area, area is not marked,

located inside or outside. OR Only (1\%-20\%) of empty drums are stored properly in accordance with 6 .

1= Empty drums are strewn about the shop or yard, or no designated and

marked area provided. OR None $(0 \%)$ of the empty drums are stored

properly.

Flammables

6= All flammable materials are stored in a cabinet manufactured for and used

solely for flammable materials storage and labeled with a neatly stenciled

label readable from at least ten (10) feet away (HAZCOM).

The cabinet is

securely closed. 81\%-100\% of Flammables meet these criteria.

$5=$ All flammable materials are stored in a cabinet manufactured

for and used

solely for flammable materials storage. But the cabinet is not

properly

labeled with a neatly stenciled label readable from at least ten (10) feet away 
(HAZCOM) and it is securely closed. OR Only (61\%-80\%) of flammables

are stored properly in accordance with the criteria in 6 .

$4=$ At least one flammable material is setting somewhere in the shop and is not

properly stored in the flammable materials storage cabinet. The cabinet is

labeled properly with a neatly stenciled label readable from at least ten (10)

feet away(HAZCOM) and is securely closed. OR Only (41\%$60 \%)$ of

flammables are stored properly in accordance with the criteria in 6 .

$3=$ Two (2) to four (4) flammable materials are setting about and are not

properly stored in the flammable materials storage cabinet, and the cabinet

may or may not be securely closed. The cabinet is labeled properly with a

neatly stenciled label readable from at least ten (10) feet away(HAZCOM).

OR Only (21\%-40\%) of flammables are stored properly in accordance with

the criteria in 6.

$2=$ More than four (4) flammable materials are setting about and are not

properly stored in the flammable materials storage cabinet, and/or the

cabinet is not securely closed, and/or there are signs that a flammable

liquid has leaked from the cabinet, or the cabinet is not properly labeled

(HAZCOM). OR Only (1\%-20\%) of flammables are stored properly in accordance with the criteria in 6 .

$1=$ The flammable materials cabinet is not functioning as it should; the doors do not secure properly, there is no more room in it, there is signs

of leaking flammable liquid, not properly labeled (HAZCOM), and/or there

are dangerous situations present for human exposure flammable materials. OR None $(0 \%)$ of the flammables are stored properly in accordance with the criteria in 6 . 
NOTE: $\quad$ Compressed Gas Cylinders, Acetylene Cylinders, Argon Cylinders, and Oxygen Cylinders; each type of cylinder must be separated by at least twenty-five (25) feet or they must be separated by a fire-proof or fire-rated wall higher than the tallest cylinder. All of these types of gas cylinders are to be assessed using the following Compressed Gas Cylinders criteria.

\section{Compressed Gas Cylinders, Acetylene Cylinders, Argon Cylinders, and Oxygen Cylinders}

6= All compressed gas cylinders are stored in a designated area, outdoors, under-roof, area clearly marked with a neatly stenciled sign readable from at least twenty (20) feet away and the cylinders are secured

from falling over with a chain located at $1 / 2$ to $3 / 4$ the height of the

cylinders from the floor. "No Smoking" and "Flammable" signs are posted

and readable from at least twenty (20) feet away. All caps are

on. $81 \%-100 \%$

of the Compressed Gas Cylinders are stored properly.

$5=$ All compressed gas cylinders are stored in a designated area, indoors,

or outside with no roof, area clearly marked with a neatly stenciled

sign readable from at least twenty (20) feet away and the cylinders are

secured from falling over with a chain located at $1 / 2$ to $3 / 4$ the height of

the cylinders from the floor. "No Smoking" and "Flammable"

signs are

posted and readable from at least twenty (20) feet away. Some have caps

missing, or not on. OR Only (61\%-80\%) of the Compressed

Gas Cylinders

are stored properly in accordance with the criteria in 6 .

$4=$ All compressed gas cylinders are stored in a designated area either

inside or outside; however, the area is not marked clearly with a sign

readable from at least twenty (20) feet away but the cylinders are secured

from falling over with a chain properly located at $1 / 2$ to $3 / 4$ the height of

the cylinders from the floor. "No Smoking" and "Flammable" signs are

posted and readable from at least twenty (20) feet away. 
OR Only (41\%-60\%) of the Compressed Gas Cylinders are stored properly

in accordance with the criteria in 6 .

$3=$ All compressed gas cylinders are stored in a designated area, marked clearly

with a sign readable from at least twenty (20) feet away but at least one

cylinder is not secured from falling over with a chain properly located at $1 / 2$

to $3 / 4$ the height of the cylinders from the floor. "No Smoking" and

"Flammable" signs are posted and readable from at least

twenty (20) feet

away. OR Only (21\%-40\%) of the Compressed Gas Cylinders are stored

properly in accordance with the criteria in 6 .

$2=$ At least one (1) compressed gas cylinder is not stored in a designated

area, and the area is marked clearly with a sign readable from at least twenty

(20) feet away and the cylinders that are in the designated area are secured

from falling over with a chain properly located at $1 / 2$ to $3 / 4$ the height of the

cylinders from the floor. OR NO "No Smoking” and

"Flammable" signs are

posted and readable from at least twenty (20) feet away. OR Only (1\%-20\%)

of the Compressed Gas Cylinders are stored properly in accordance with the

criteria in 6.

$1=$ One (1) or more compressed gas cylinders are not stored in a designated

area, and the area is not marked clearly with a sign readable from at least

twenty (20) feet away and the cylinders that are in the designated area are

secured from falling over with a chain properly located at $1 / 2$ to $3 / 4$ the height

of the cylinders from the floor. OR NO "No Smoking" and "Flammable"

signs are posted and readable from at least twenty (20) feet away. OR None

(0\%) of the Compressed Gas Cylinders are stored properly in accordance

with the criteria in 6. 
Shop Floor Drains $\quad 6=$ Drain discharge remains on site (e.g. underground tanks) and is reused for

brine.

$5=$ Drains discharge to a Municipal Sewer System.

4= Drain discharge remains on site (retention/detention pond).

3= Drains discharge off site to a roadside ditch, county ditch, field etc. that does not reach waters of the State within one mile.

$2=$ Drain discharge reaches waters of the State within one mile.

$1=$ Drain discharges directly to waters of the State or discharges

into a karst sinkhole.

Pumps, Sump Pumps, and Liquid Transfer Pumps

6= Pump is operational, wired with proper switch with emergency off. Liquid transfer pump is in secondary containment.

$5=$ Do not use this score.

$4=$ Do not use this score.

$3=$ Do not use this score.

$2=$ Do not use this score.

$1=$ Pump not operational. Liquid transfer pump is not in secondary containment.

YARD ACTIVITIES, including SALT STORAGE AND HANDLING:

Stormwater Runoff from the active surface of the site (yard)

6= Stormwater runoff discharges to a Municipal Sewer System (if approved).

$5=$ Stormwater runoff remains on site (retention/detention pond).

$4=$ Stormwater runoff discharges off site to a roadside ditch, county ditch, field

etc. that does not reach waters of the State within one mile.

$3=$ Stormwater runoff discharge reaches waters of the State

within one mile.

$2=$ Stormwater runoff discharges directly to waters of the State.

$1=$ Stormwater runoff discharges into a karst sinkhole.

\section{Facility Wastewater Treatment}

6= Connected to a Municipal Sewer system with a functioning oil/water separator.

$5=$ Connected to a Municipal Sewer system without a functioning oil/water separator.

$4=$ Do not use this score.

$3=$ Do not use this score.

$2=$ Not connected to a Municipal Sewer System and is equipped with a 
functioning oil/water separator.

$1=$ Not connected to a Municipal Sewer System and is NOT

equipped with a

functioning oil/water separator.

\section{Catch Basins/Manholes}

6= Catch Basins/Manholes are clean and water discharges with out obstruction.

$5=$ Do not use this score.

$4=$ Do not use this score.

$3=$ Do not use this score.

$2=$ Do not use this score.

1= Catch Basins/Manholes are not clean, sediments have built-up, and water

discharge is obstructed.

Pesticides

6= All pesticides are stored in a properly labeled (neatly stenciled sign readable

from at least twenty (20) feet away) and secured structure with automatic

fire suppression and secondary containment. The labels on the chemicals are

intact and readable. The chemicals are mixed in a contained area. The

MSDSs are on file in a readily accessible location.

$5=$ All pesticides are stored in a properly labeled (neatly stenciled sign readable

from at least twenty (20) feet away) and secured structure without automatic

fire suppression and secondary containment. The labels on the chemicals are

intact and readable. The chemicals are mixed in a contained area. The

MSDSs are on file in a readily accessible location.

4= All pesticides are stored in a properly labeled (neatly stenciled sign readable

from at least twenty (20) feet away) and secured structure without automatic

fire suppression and without secondary containment. The labels on the

chemicals are intact and readable. The chemicals are mixed in a contained

area. The MSDSs are on file in a readily accessible location.

$3=$ Pesticides are stored in a non-secured structure without automatic 
fire suppression and without secondary containment. The labels on the

chemicals are not intact or not readable. The chemicals are mixed in a

uncontained area. The MSDSs are on file in a readily accessible location,

but not all the herbicides' MSDSs are on file.

$2=$ Pesticides are stored outside in the open. The MSDSs are not

on file and are

not readily available.

$1=$ Herbicides are stored outside in the open and there are signs of spilling.

\section{Salt/Sand Mixing/Loading Area(s)}

$6=$ Full operations are performed inside a covered enclosure (e.g.

Cover-All

style building) including salt delivery and off-loading.

$5=$ Mixing/Loading is performed inside a covered enclosure (e.g. Load-

Out

Building) but larger salt delivery trucks offload outside.

$4=$ Do not use this score.

$3=$ Do not use this score.

$2=$ Outside with no covered enclosure but within a bermed area

and/or

water from the area enters a retention/detention pond

$1=$ Outside with no covered enclosure, no berm, and no

retention/detention

pond.

Salt/Sand Mixing/Loading Area(s) HOUSEKEEPING

$6=$ Little-to-no salt outside the designated area, regular sweeping is performed.

$5=$ Do not use this score.

$4=$ Do not use this score.

3= Moderate amount of salt outside the designated area, some

sweeping is

performed. Less than a front-end loader bucket.

$2=$ Do not use this score.

$1=$ Excessive amounts of salt outside the designated area, very little to no

sweeping is performed. More than a front-end loader bucket.

Amount of Salt on the Active Surface at the Site (Throughout the Yard and Beyond)

$6=$ No salt on the active surface. The conditions indicate that the

facility

operators are fully implementing cleaning practices.

$5=$ Do not use this score.

$4=$ Do not use this score. 
$3=$ Moderate amount around storage and loading areas with no signs of

vegetation kills or salt migrating off site in storm water runoff. Less than a front-end loader bucket.

$2=$ Do not use this score.

$1=$ Excessive amount throughout the site and/or signs of vegetation kills and/or

evidence of salt migrating off site in storm water runoff. More than a front- end loader bucket.

\section{Brine Production Equipment and Secondary Containment}

$6=$ All equipment has secondary containment, including piping.

$5=$ Do not use this score.

$4=$ Do not use this score.

$3=$ Do not use this score.

$2=$ Do not use this score.

$1=$ NOT All equipment has secondary containment, including

piping.

$0=$ No Brine Production at facility.

Outside Tanks containing Brine, Magnesium Chloride, Waste Oil, and Other Liquids

$6=$ All tanks and pipes have secondary containment.

$5=$ Do not use this score.

$4=$ Do not use this score.

$3=$ Do not use this score.

$2=$ Tanks are contained but pipes are not contained (e.g. double

walled tanks with no secondary containment for pipes).

$1=$ NOT All tanks and pipes have secondary containment.

\section{Salt Bed Truck Washing}

6= All washing is performed in a wash bay and the wash water passes through a

fully functioning oil/water separator and is retained onsite (e.g. underground tanks) for reuse in brine production.

$5=$ No washing is performed on site. All truck washing is performed at a nearby facility equipped with a wash bay.

4= All washing is performed in a wash bay and the wash water passes through a

fully functioning oil/water separator and then is discharged to a Municipal

Sewer System.

$3=$ Light washing is performed on site but the majority is performed at a nearby 
facility that is connected to a Municipal Sewer System or brine system.

$2=$ All washing is performed on site with no connection to a

Municipal Sewer

System but the wash water is held in a retention/detention pond.

$1=$ All washing performed on site with no connection to a

Municipal Sewer

System and wash water drains off site.

\section{Salt Bed Racks}

6= Salt Bed Racks are located in a covered enclosure with no

contact with

stormwater.

5= Little-to-no salt and/or paint chips and/or stains from hydraulic fluid/chain grease leakage, and the area is bermed.

4= Little-to-no salt and/or paint chips and/or stains from hydraulic fluid/chain grease leakage, and the area is NOT bermed.

$3=$ Do not use this score.

2= Excessive amount of salt and/or paint chips and/or stains from hydraulic

fluid/chain grease leakage, and the area is bermed.

1= Excessive amount of salt and/or paint chips and/or stains from hydraulic

fluid/chain grease leakage, and the area is NOT bermed.

\section{Storage of Cold Patch}

6= Stored inside a building with an impervious floor.

$5=$ Stored inside a building with a pervious floor.

4= Stored outside on an impervious surface with cover (e.g. tarp) and berm.

$3=$ Stored outside on a pervious surface with cover (e.g. tarp) and berm.

$2=$ Stored outside on an impervious surface with no cover (e.g. tarp) and/or no

berm.

$1=$ Stored outside on a pervious surface with no cover (e.g. tarp) and/or no berm.

\section{Storage of Scrap Tires}

6= Stored in dumpsters or roll-offs that are emptied regularly (if appropriate).

$5=$ Moderate amount(s) being stored in a bermed or covered area but for only a short period of time before being hauled away. $4=$ Do not use this score. 
3= Moderate amount(s) being stored with NO cover or berm but for only a short

period of time before being hauled away.

$2=$ Do not use this score.

$1=$ Excessive amount(s) being stored with NO cover or berm for long periods of

Storage of Scrap Metal time before being hauled away.

$6=$ Stored in dumpsters or roll-offs that are emptied regularly (if appropriate).

$5=$ Moderate amount(s) being stored in a bermed or covered area but for only a short period of time before being hauled away.

$4=$ Do not use this score.

3= Moderate amount(s) being stored with NO cover or berm but for only a short period of time before being hauled away.

$2=$ Do not use this score.

1= Excessive amount(s) being stored with NO cover or berm for long periods of time before being hauled away.

\section{Storage of Right-Of-Way Trash}

$6=$ Stored in dumpsters or roll-offs that are emptied regularly (if appropriate).

$5=$ Moderate amount(s) being stored in a bermed or covered area but for only a short period of time before being hauled away.

$4=$ Do not use this score.

3= Moderate amount(s) being stored with NO cover or berm but for only a short period of time before being hauled away.

$2=$ Do not use this score.

$1=$ Excessive amount(s) being stored with NO cover or berm for long periods of

Storage of Street Sweepings time before being hauled away.

$6=$ Stored in dumpsters or roll-offs that are emptied regularly (if appropriate).

$5=$ Moderate amount(s) being stored in a bermed or covered area but for only a short period of time before being hauled away.

$4=$ Do not use this score.

3= Moderate amount(s) being stored with NO cover or berm but for only a short

period of time before being hauled away.

$2=$ Do not use this score. 
1= Excessive amount(s) being stored with NO cover or berm for long periods of time before being hauled away.

Mixing, Loading, or Cleaning of Equipment Containing Environmentally (also

Human) Harmful Chemicals (such as Pesticides, Liquid Asphalt, Paints, etc.)

6= All Mixing, Loading, or Cleaning of equipment is performed in

an area that

contains the material.

$5=$ Do not use this score.

$4=$ Do not use this score.

$3=$ Do not use this score.

$2=$ Do not use this score.

$1=$ Mixing, Loading, and/or Cleaning of equipment is NOT performed in an area that contains the material.

$0=$ Not Applicable.

Storage of Scalp, see stockpile storage below.

\section{Stockpile Storage}

6= Stockpiles of material (sand, dirt, spoil, and aggregates) are covered with tarps or located inside a storage shed so no stormwater runoff washes material away from site.

$5=$ Stockpiles of material (sand, dirt, spoil, and aggregates) are not covered but are located in a bermed area so no stormwater runoff washes material away from site.

4= Stockpiles of material (sand, dirt, spoil, and aggregates) are not covered and not bermed and stormwater runoff discharges off site to a roadside ditch, county ditch, field etc. that does not reach waters of the State within one mile.

$3=$ Stockpiles of material (sand, dirt, spoil, and aggregates) are not covered and not bermed and stormwater runoff discharge reaches waters of the State within one mile.

$2=$ Stockpiles of material (sand, dirt, spoil, and aggregates) are not covered and not bermed and stormwater runoff discharges directly to waters of the State. 
$1=$ Stockpiles of material (sand, dirt, spoil, and aggregates) are not covered and not bermed and stormwater runoff discharges into a karst sinkhole.

\section{Incinerator}

6= Incinerator is located at least fifty (50) feet from any burnable structure, is operational, and the area around the incinerator is clean and neat. There are signs that give instructions on its operation and what is to be burned in the incinerator and what is not to be burned in it.

$5=$ Incinerator is located at least fifty (50) feet from any burnable structure, is operational, and the area around the incinerator is clean and neat. There are NO signs that give instructions on its operation and what is to be burned in the incinerator and what is not to be burned in it.

$4=$ Incinerator is located at least fifty (50) feet from any burnable structure, is operational, but the area around the incinerator is NOT clean and neat. There are signs that give instructions on its operation and what is to be burned in the incinerator and what is not to be burned in it.

$3=$ Incinerator is located at least fifty (50) feet from any burnable structure, is operational, but the area around the incinerator is NOT clean and neat. There are NO signs that give instructions on its operation and what is to be burned in the incinerator and what is not to be burned in it.

$2=$ Incinerator is located at least fifty (50) feet from any burnable structure, is

NOT operational, and the area around the incinerator is clean and neat.

There are signs that give instructions on its operation and what is to be burned in the incinerator and what is not to be burned in it. $1=$ Incinerator is located WITHIN fifty (50) feet of a burnable structure,

OR is NOT operational, and the area around the incinerator is clean and neat. The incinerator is no longer used.

\section{Compost}


6= Road kill is composted in a facility with at least three (3) compost bins.

Carcasses are completely covered with sawdust or manure and there is little

to no odor. The bins are turned and rotated on a two (2) week schedule.

81\%-100\% of the road kill composting meet these criteria.

$5=61 \%-80 \%$ of the road kill composting meet the criteria in 6 .

$4=41 \%-60 \%$ of the road kill composting meet the criteria in 6 .

$3=21 \%-40 \%$ of the road kill composting meet the criteria in 6 .

$2=1 \%-20 \%$ of the road kill composting meet the criteria in 6 .

$1=$ None $(0 \%)$ of the road kill composting meet the criteria in 6 .

\section{Hazardous Waste Storage}

6= All hazardous waste is properly stored in well labeled (neatly stenciled label)

and non-leaking containers (DOT approved 55 gallon drum, 5 gallon bucket or 1 gallon can). Furthermore, the waste containers are stored in a hazardous materials storage building that has secondary containment. The building is labeled (placard) with the appropriate hazard communication information.

$5=$ All hazardous waste is properly stored in well labeled (neatly stenciled label) and non-leaking containers (DOT approved 55 gallon drum, 5 gallon bucket or 1 gallon can). Furthermore, the waste containers are stored in a hazardous materials storage building that has secondary containment. The building is not appropriately labeled (placard) with the appropriate hazard communication information.

4= All hazardous waste is properly stored in well labeled (neatly stenciled label)

and non-leaking containers (DOT approved 55 gallon drum, 5 gallon bucket or 1 gallon can). Furthermore, the waste containers are stored in structure other than a hazardous materials storage building. The building lacks secondary containment but is labeled (placard) with the appropriate hazard communication information.

$3=$ All hazardous waste is properly stored in well labeled (neatly stenciled label)

and non-leaking containers (DOT approved 55 gallon drum, 5 gallon bucket or 1 gallon can). Furthermore, the waste containers are stored in structure other than a hazardous materials storage building. The building lacks secondary containment and lacks appropriate labeling (placard) with the appropriate hazard communication information. 
2= A quantity of hazardous waste is improperly stored in unlabeled labeled

and non-leaking containers while the remaining quantity is properly containerized in DOT approved containers (55 gal., 5 gal., and 1 gal.) Furthermore, the waste containers are stored in structure other than a hazardous materials storage building. The building lacks secondary containment and lacks appropriate labeling (placard) with the appropriate hazard communication information.

$1=$ All hazardous wastes are improperly stored in unlabeled labeled containers and some leaking of waste is noticed from the containers. Furthermore, the waste containers are stored in structure other than a hazardous materials storage building. The building lacks secondary containment and lacks appropriate labeling (placard) with the appropriate hazard communication information. 


\section{Appendix III}

\section{INDOT Facility Stormwater and Washwater Effluent Drainage Assessment Form}


Date

INDOT Facility Stormwater and Washwater Effluent Drainage Assessment

Name of Facility

\section{$\underline{\text { Surface Water }}$}

\section{District/Subdistrict}

1. Does any area of the active surface collect storm water or facility-generated wash water (such as from washing trucks outdoors)?

2. Is there any movement of surface water from one area to another on-site by ditch, drain tile or natural channel?

3. Is there any movement of surface water off-site (e.g., beneath the perimeter fence) via sheet flow, ditch, pipe or channel to adjacent property?

4. Is the surface water discharged directly to (check all that apply) -

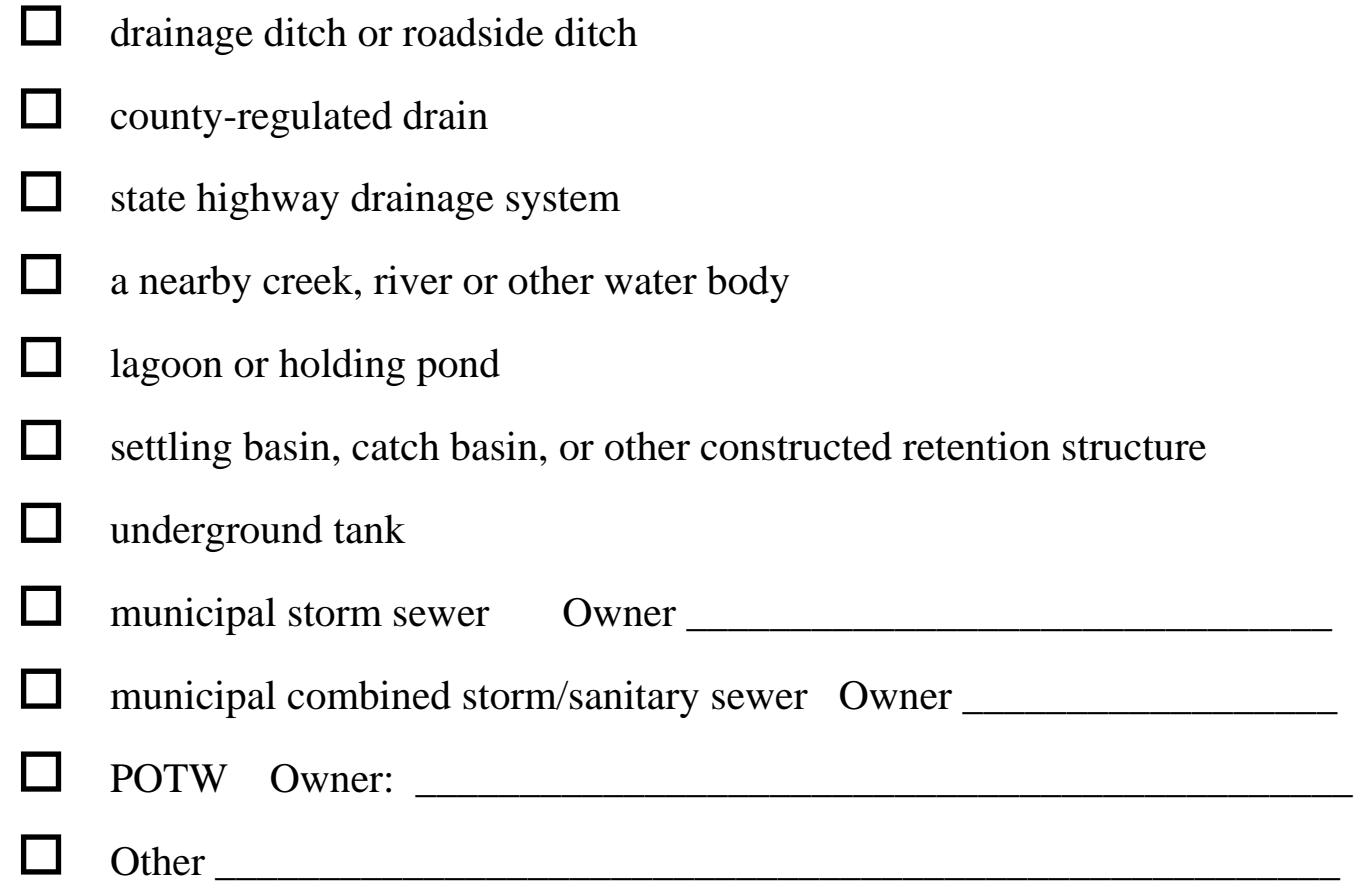

5. If surface water is discharged, other than to a municipal storm, sanitary or combined sewer, does it ultimately reach "waters of the state” (e.g., farm ditch, creek, stream, river, lake or pond)? If yes, name of that water body.

6. What is the estimated distance of this water body from the facility? 


\section{Shop Floor Drain \& Wash Bay Effluent}

1. Are there drains in shop floors and wash bays that remove liquids and wash water effluent from the building(s)?

2. Does the effluent flow to -

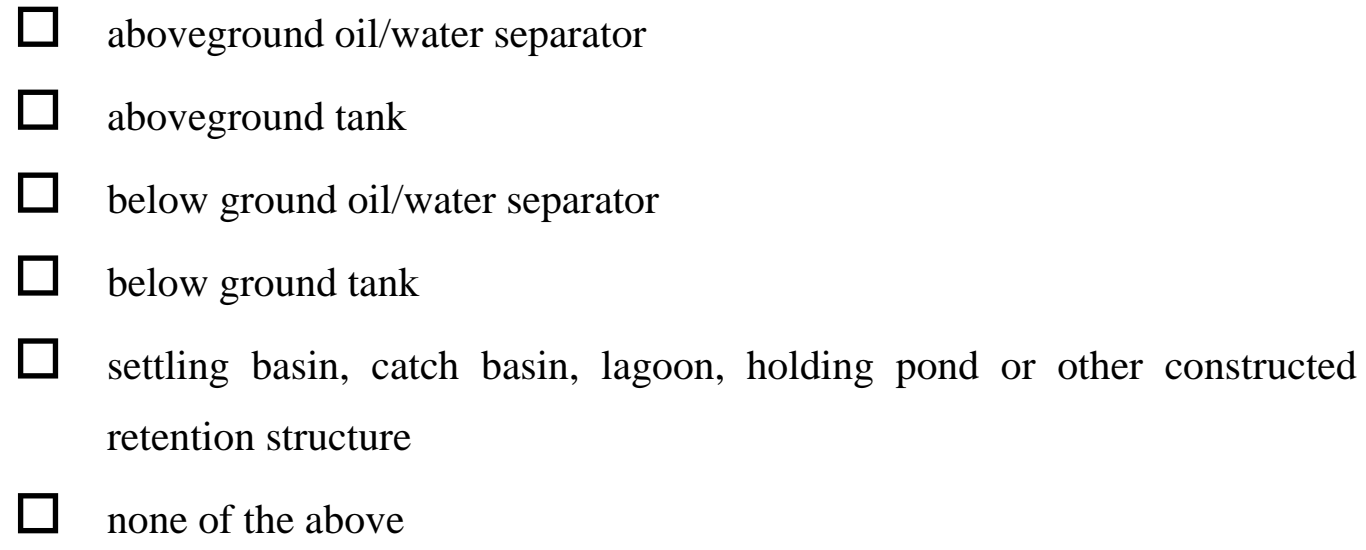

3. If the effluent is captured by the devices in 2., above, is it contained until pumped and hauled to a POTW or until it evaporates, or does it overflow to a drainage system?

4. If the effluent overflows to a drainage system, is the system above or below ground?

5. If the effluent overflows to a drainage system, does it mix with storm water?

6. If the effluent $\underline{\text { does }}$ mix with storm water, see "Surface Water" section (preceding page, \#4 and \#5) for discharge.

7. If the effluent doesn't mix with storm water, is it discharged to -

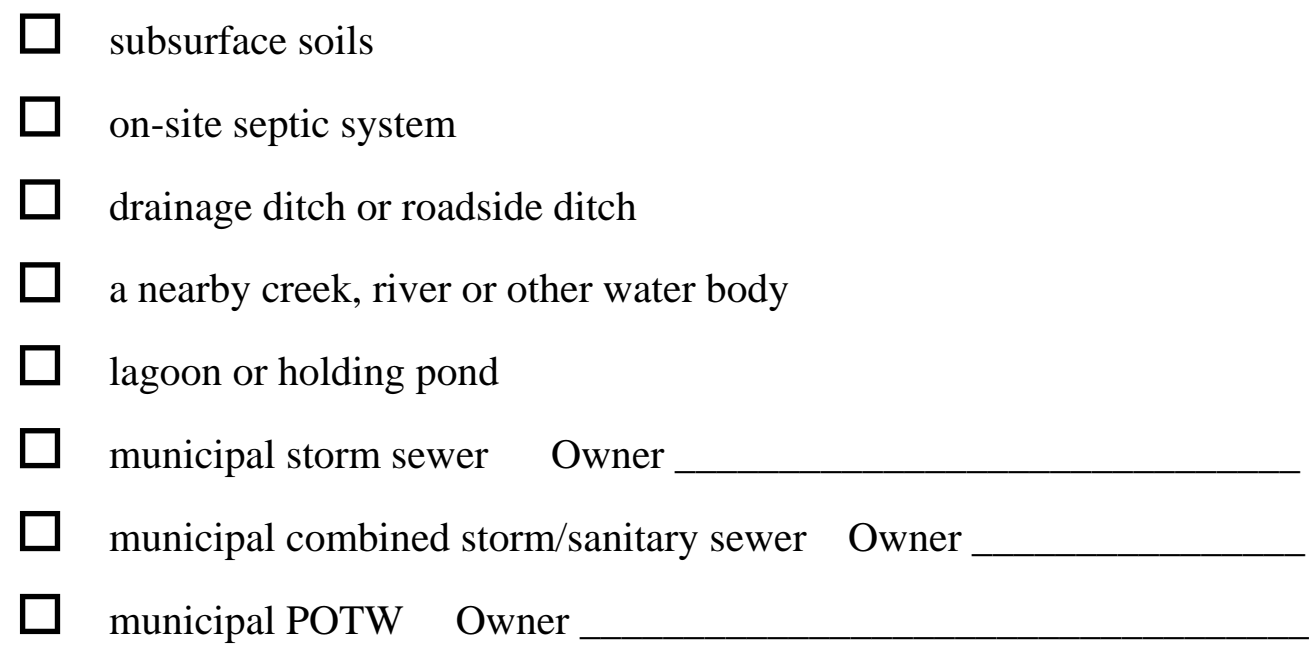


8. If shop floor drain and washbay effluent is discharged, other than to a municipal storm, sanitary or combined sewer, does it ultimately reach "waters of the state?" If yes, name of that water body:

Activity Areas (check those that apply and describe (1) whether they are bermed to prevent storm water runoff or (2) if there are drains and their locations in the activity areas)

$\square$ salt storage (pads or domes)

$\square$ salt/sand mixing

$\square$ salt bed loading/wetting

$\square \quad$ salt bed washout

$\square$ salt bed storage

$\square \quad$ vehicle and equipment washing (inside)

$\square \quad$ vehicle and equipment washing (outside)

$\square$ asphalt equipment clean-out

$\square \quad$ herbicide mixing and tank rinsing

$\square \quad$ traffic paint mixing and transfer

$\square$ bulk tank off-loading and storage

$\square$ waste piles (e.g., ROW trash, street sweeping debris)

$\square \quad$ truck/equipment parking

$\square$ truck/equipment fueling

$\square$ materials storage (210 lot, fencing, etc.)

$\square$ aggregate storage

$\square$ hot/cold patch storage

$\square$ storage of “scalp” and dirt from R/W maintenance 


\section{Appendix IV}

\section{Site Assessment Scores for Selected Facilities, by District (Including Overall Average Score for All Facilities Visited)}




\section{Site Assessment Scores}

\begin{tabular}{|c|c|c|c|c|c|c|c|c|c|c|c|c|c|c|c|}
\hline LaPorte District & A & B & C & D & $F$ & G & $\mathbf{H}$ & $\mathbf{I}$ & $\mathbf{J}$ & $\mathrm{K}$ & $\mathbf{L}$ & $M$ & $\mathbf{N}$ & 0 & Score \\
\hline Chesterton Unit & 2 & 3 & 3 & 2 & 6 & 1 & 5 & 6 & 6 & 5 & 2 & & 3 & & 3.67 \\
\hline Wanatah Unit & 5 & 6 & 6 & 5 & 6 & 1 & 4 & 6 & 6 & 6 & 2 & & 5 & & 4.83 \\
\hline Flora Unit & 1 & 2 & 1 & 1 & 1 & 1 & 5 & 3 & 1 & 3 & 2 & & 3 & & 2.00 \\
\hline Winamac Sub/Unit & 5 & 2 & 6 & 1 & 6 & 1 & 4 & 3 & 3 & 4 & 2 & & 3 & & 3.33 \\
\hline New Gary Sub / Miller Unit & 6 & 4 & 6 & 6 & 6 & 6 & 6 & 6 & 6 & 5 & 6 & & 6 & & 5.75 \\
\hline Logansport Unit & 1 & 2 & 1 & 2 & 1 & 1 & 5 & 3 & 3 & 4 & 6 & & 6 & & 2.92 \\
\hline \multicolumn{16}{|l|}{ S. Bend Unit (not manned) ${ }^{1}$} \\
\hline Mishawaka Unit & 4 & 5 & 1 & 2 & 6 & 6 & 2 & 6 & 3 & 4 & 2 & & 6 & & 3.92 \\
\hline Crown Point Unit & 2 & 3 & 1 & 1 & 1 & 1 & 1 & 3 & 3 & 4 & 2 & & 6 & & 2.33 \\
\hline Michigan City Unit & 3 & 4 & 1 & 1 & 6 & 1 & 3 & 3 & 3 & 4 & 2 & & 1 & & 2.67 \\
\hline Average Score for District & 3.2 & 3.4 & 2.9 & 2.3 & $\overline{4.3}$ & 2.1 & 3.9 & 4.3 & 3.8 & 4.3 & 2.9 & & 4.3 & & 3.49 \\
\hline
\end{tabular}

1 The South Bend Unit scores are not included because it is an unmanned Unit and will skew the averages

2 Blank boxes indicate a score of "zero" or no score due to a lack of data or the criteria not being applicable to the site

These zeros are not factored into the average score for the site or district. 


\begin{tabular}{|l|c|c|c|c|c|c|c|c|c|c|c|c|c|c|c|c|c|}
\hline Fort Wayne District & A & B & C & D & F & G & H & & & I & J & K & L & M & N & O & Score \\
\hline Angola Sub & 5 & 5 & 6 & 2 & 6 & 6 & 4 & & & 6 & 6 & 4 & 2 & & 5 & & $\mathbf{4 . 7 5}$ \\
\hline Orland Unit (not manned) ${ }^{3}$ & & & & & & & & & & & & & & & & & \\
\hline Waterloo Unit & 1 & 2 & 1 & 1 & 1 & 6 & 1 & & & 1 & 1 & 3 & 2 & & 3 & & $\mathbf{1 . 9 2}$ \\
\hline Monroe Unit & 1 & 2 & 1 & 1 & 1 & 6 & 1 & & & 3 & 3 & 5 & 2 & & 3 & & $\mathbf{2 . 4 2}$ \\
\hline New Haven Unit & 5 & 2 & 5 & 1 & 1 & 6 & 3.5 & & & 1 & 1 & 1 & 2 & & 3 & & $\mathbf{2 . 6 3}$ \\
\hline US 27 S. Unit & 1 & 2 & 1 & 1 & 1 & 6 & 1 & & & 1 & 1 & 3 & 2 & & 3 & & $\mathbf{1 . 9 2}$ \\
\hline Gas City Unit & 5 & 2 & 6 & 1 & 6 & 6 & 4 & & & 3 & 1 & 4 & 6 & & 3 & & $\mathbf{3 . 9 2}$ \\
\hline Warsaw Sub & 1 & 2 & 3 & 1 & 1 & 1 & 1 & & & 1 & 1 & 3 & 2 & & 6 & & $\mathbf{1 . 9 2}$ \\
\hline Average Score for District & 2.7 & 2.4 & 3.3 & $\mathbf{1 . 1}$ & $\mathbf{2 . 4}$ & $\mathbf{5 . 3}$ & $\mathbf{2 . 2}$ & & & $\mathbf{2 . 3}$ & $\mathbf{2 . 0}$ & $\mathbf{3 . 3}$ & $\mathbf{2 . 6}$ & & 3.7 & & $\mathbf{2 . 7 8}$ \\
\hline
\end{tabular}

${ }^{3}$ The Orland Unit scores are not included because it is an unmanned Unit and will skew the averages

\begin{tabular}{|l|c|c|c|c|c|c|c|c|c|c|c|c|c|c|c|c|c|}
\hline Crawfordsville District & A & B & C & D & F & G & H & & & I & J & K & L & M & N & O & Score \\
\hline New Plainfield Unit & 6 & 2 & 6 & 5 & 6 & 1 & 6 & & & 6 & 6 & 4 & 4 & & 3 & & $\mathbf{4 . 5 8}$ \\
\hline Lafayette Unit & 1 & 2 & 1 & 1 & 1 & 1 & 1 & & & 3 & 1 & 2 & 2 & & 3 & & $\mathbf{1 . 5 8}$ \\
\hline Lebanon Unit & 2 & 3 & 1 & 1 & 6 & 6 & 1 & & & 6 & 6 & 4 & 6 & & 3 & & $\mathbf{3 . 7 5}$ \\
\hline Ft. Harrison Unit & 5 & 6 & 5 & 1 & 6 & 6 & 3.5 & & & 6 & 6 & 4 & 2 & & 6 & & $\mathbf{4 . 7 1}$ \\
\hline Crawfordsville District/Sub & 5 & 6 & 5 & 2 & 1 & 6 & 3.5 & & & 6 & 6 & 4 & 2 & & 3 & & $\mathbf{4 . 1 3}$ \\
\hline Carbondale Unit & 2 & 5 & 1 & 2 & 1 & 6 & 1 & & & 3 & 3 & 4 & 2 & & 6 & & $\mathbf{3 . 0 0}$ \\
\hline Average Score for District & 3.5 & $\mathbf{4 . 0}$ & $\mathbf{3 . 2}$ & $\mathbf{2 . 0}$ & $\mathbf{3 . 5}$ & $\mathbf{4 . 3}$ & $\mathbf{2 . 7}$ & & & $\mathbf{5 . 0}$ & $\mathbf{4 . 7}$ & $\mathbf{3 . 7}$ & $\mathbf{3 . 0}$ & & $\mathbf{4 . 0}$ & & 3.63 \\
\hline
\end{tabular}




\begin{tabular}{|l|c|c|c|c|c|c|c|c|c|c|c|c|c|c|c|c|c|}
\hline Seymour District & A & B & C & D & F & G & H & & & I & J & K & L & M & N & O & Score \\
\hline Beanblossom Unit & 1 & 2 & 1 & 1 & 6 & 6 & 5 & & & 6 & 6 & 4 & 2 & & 3 & & $\mathbf{3 . 5 8}$ \\
\hline Brownstown Unit & 1 & 2 & 1 & 1 & 1 & 6 & 5 & & & 6 & 6 & 4 & 2 & & 3 & & $\mathbf{3 . 1 7}$ \\
\hline Columbus Sub & 5 & 2 & 6 & 1 & 6 & 6 & 4 & & & 6 & 6 & 3 & 2 & & 6 & & $\mathbf{4 . 4 2}$ \\
\hline Falls City Sub/Sellersburg Unit & 5 & 3 & 6 & 5 & 6 & 2 & 4 & & & 6 & 3 & 4 & 2 & & 6 & & $\mathbf{4 . 3 3}$ \\
\hline Greensburg & 2 & 3 & 1 & 1 & 6 & 6 & 5 & & & 3 & 3 & 4 & 2 & & 3 & & 3.25 \\
\hline Brookville Unit & 5 & 6 & 6 & 1 & 6 & 6 & 4 & & & 6 & 6 & 4 & 4 & & 3 & & $\mathbf{4 . 7 5}$ \\
\hline Salem Unit & 2 & 3 & 1 & 1 & 1 & & 5 & & & 6 & 6 & 4 & 6 & & 6 & & $\mathbf{3 . 7 3}$ \\
\hline Versailles Unit & 2 & 3 & 1 & 1 & 6 & & 5 & & & 6 & 6 & 4 & 4 & & 6 & & $\mathbf{4 . 0 0}$ \\
\hline Old Amity Unit & 2 & 3 & 1 & 1 & 6 & 6 & 3 & & & 3 & 3 & 4 & 2 & & 6 & & $\mathbf{3 . 3 3}$ \\
\hline Corydon Unit & 5 & 1 & 5 & 1 & 1 & 6 & 3.5 & & & 3 & 3 & 4 & 2 & & 3 & & $\mathbf{3 . 1 3}$ \\
\hline Spencer Unit & 3 & 4 & 1 & 1 & 6 & & 5 & & & 6 & 6 & 4 & 4 & & 6 & & $\mathbf{4 . 1 8}$ \\
\hline North Vernon Unit & 5 & 4 & 6 & 1 & 6 & & 4 & & & 3 & 1 & 3 & 2 & & 6 & & $\mathbf{3 . 7 3}$ \\
\hline Average Score for District & 3.2 & $\mathbf{3 . 0}$ & $\mathbf{3 . 0}$ & $\mathbf{1 . 3}$ & $\mathbf{4 . 8}$ & 5.5 & $\mathbf{4 . 4}$ & & & 5.0 & 4.6 & 3.8 & 2.8 & & 4.8 & 3.80 \\
\hline
\end{tabular}

\begin{tabular}{|l|c|c|c|c|c|c|c|c|c|c|c|c|c|c|c|c|c|}
\hline Greenfield District & A & B & C & D & F & G & H & & & I & J & K & L & M & N & O & Score \\
\hline Anderson Unit & 5 & 5 & 6 & 1 & 6 & 6 & 4 & & & 3 & 3 & 6 & 2 & & 1 & & $\mathbf{4 . 0 0}$ \\
\hline Fortville Unit & 5 & 3 & 6 & 1 & 6 & 6 & 4 & & & 3 & 1 & 1 & 2 & & 6 & & 3.67 \\
\hline Kokomo Unit & 3 & 4 & 1 & 1 & 1 & 6 & 3 & & & 3 & 3 & 4 & 4 & & 3 & & $\mathbf{3 . 0 0}$ \\
\hline Westfield Unit & 4 & 5 & 1 & 2 & 6 & 6 & 3 & & & 6 & 6 & 4 & 2 & & 3 & & 4.00 \\
\hline Shelbyville Unit & 5 & 3 & 6 & 1 & 6 & 6 & 4 & & & 6 & 6 & 4 & 6 & & 6 & & 4.92 \\
\hline New Castle Unit & 4 & 5 & 1 & 1 & 6 & 6 & 2 & & & 3 & 3 & 4 & 2 & & 1 & & 3.17 \\
\hline Winchester Unit & 5 & 3 & 6 & 1 & 6 & 6 & 4 & & & 3 & 3 & 4 & 2 & & 6 & & $\mathbf{4 . 0 8}$ \\
\hline 71st Unit & 6 & 3 & 3 & 1 & 6 & 6 & 6 & & & 3 & 3 & 4 & 2 & & 3 & & 3.83 \\
\hline Average Score for District & 4.6 & 3.9 & 3.8 & 1.1 & 5.4 & 6.0 & 3.8 & & & 3.8 & 3.5 & 3.9 & 2.8 & & 3.6 & & 3.83 \\
\hline
\end{tabular}

\begin{tabular}{|l|c|c|c|c|c|c|c|c|c|c|c|c|c|c|c|c|c|}
\hline Vincennes District & A & B & C & D & F & G & H & & & I & J & K & L & M & N & O & Score \\
\hline Chrisney Unit & 5 & 3 & 6 & 1 & 1 & 6 & 4 & & & 1 & 1 & 4 & 4 & & 3 & & 3.25 \\
\hline Jasper Unit & 5 & 3 & 5 & 1 & 6 & 6 & 3.5 & & & 6 & 3 & 4 & 2 & & 6 & & $\mathbf{4 . 2 1}$ \\
\hline
\end{tabular}




\begin{tabular}{|l|c|c|c|c|c|c|c|c|c|c|c|c|c|c|c|c|c|}
\hline Bloomfield Unit & 5 & 3 & 5 & 1 & 6 & 6 & 3.5 & & & 1 & 3 & 4 & 2 & & 3 & & $\mathbf{3 . 5 4}$ \\
\hline Shoals Unit & 2 & 3 & 1 & 1 & 6 & 6 & 5 & & & 3 & 3 & 4 & 1 & & 3 & & 3.17 \\
\hline Grantsburg Unit & 3 & 4 & 3 & 1 & 1 & 6 & 5 & & & 3 & 3 & 4 & 1 & & 6 & & 3.33 \\
\hline Petersburg Unit & 5 & 6 & 5 & 1 & 1 & 6 & 3.5 & & & 6 & 6 & 4 & 6 & & 6 & & $\mathbf{4 . 6 3}$ \\
\hline \hline Poseyville Unit & 5 & 4 & 5 & 1 & 6 & 6 & 3.5 & & & 1 & 1 & 4 & 6 & & 3 & & 3.79 \\
\hline Bedford Unit & 5 & 4 & 6 & 1 & 6 & 6 & 4 & & & 6 & 6 & 4 & 6 & & 6 & & 5.00 \\
\hline Average Score for District & 4.4 & 3.8 & 4.5 & 1 & 4.1 & 6 & 4 & & & 3.4 & 3.3 & 4 & 3.5 & & 4.5 & & 3.86 \\
\hline
\end{tabular}

\begin{tabular}{|c|c|c|c|c|c|c|c|c|c|c|c|c|c|c|c|r|r|}
\hline Criteria & A & B & C & D & F & G & H & & & I & J & K & L & M & N & O & Score \\
\hline Overall Average & 3.6 & 3.4 & 3.4 & 1.5 & 4.2 & 4.8 & 3.6 & & & 4.0 & 3.7 & 3.9 & 2.9 & & 4.2 & & 3.62 \\
\hline
\end{tabular}




\section{Appendix V}

\section{Facility Assessment Scores, by District (Rank Order)}




\section{Facility Assessment Scores, by District (Rank Order)}

Facility

New Gary Sub/Miller Unit

Bedford Unit

Shelbyville Unit

Wanatah Unit

Angola Sub

Brookville Unit

Fort Harrison Unit

New Plainfield Unit

Petersburg Unit

Columbus Sub

Falls City Sub/Sellersburg Unit

Jasper Unit

Spencer Unit

Anderson Unit

Westfield Unit

Crawfordsville District/Sub

Winchester Unit

71st Street Unit

Versailles Unit

Gas City Unit

Mishawaka Unit

Poseyville Unit

Lebanon Unit

North Vernon Unit

Salem Unit

Chesterton Unit

MEAN OF SCORED FACILITIES

Fortville Unit

Beanblossom Unit

Bloomfield Unit

Grantsburg Unit

Old Amity Unit

Winamac Sub/Unit

Chrisney Unit

Greensburg

Brownstown Unit

New Castle Unit

Shoals Unit

Corydon Unit

Carbondale Unit

Kokomo Unit

Logansport Unit

Michigan City Unit

New Haven Unit

Monroe Unit

Crown Point Unit

Flora Unit

US 27 South Unit

Waterloo Unit

Warsaw Sub

Lafayette Unit

\section{District}

LaPorte

Vincennes

Greenfield

LaPorte

Fort Wayne

Seymour

Crawfordsville

Crawfordsville

Vincennes

Seymour

Seymour

Vincennes

Seymour

Greenfield

Greenfield

Crawfordsville

Greenfield

Greenfield

Seymour

Fort Wayne

LaPorte

Vincennes

Crawfordsville

Seymour

Seymour

LaPorte

Greenfield

Seymour

Vincennes

Vincennes

Seymour

LaPorte

Vincennes

Seymour

Seymour

Greenfield

Vincennes

Seymour

Crawfordsville

Greenfield

LaPorte

LaPorte

Fort Wayne

Fort Wayne

LaPorte

LaPorte

Fort Wayne

Fort Wayne

Fort Wayne

Crawfordsville
Score

5.77

5.00

4.92

4.92

4.75

4.75

4.71

4.69

4.63

4.54

4.46

4.21

4.18

4.15

4.15

4.13

4.08

4.00

4.00

3.92

3.92

3.79

3.75

3.73

3.73

3.67

3.62

3.67

3.58

3.54

3.33

3.33

3.33

3.25

3.25

3.17

3.17

3.17

3.13

3.00

3.00

2.92

2.67

2.63

2.42

2.33

2.08

2.00

2.00

1.92

1.54 


\section{Site Assessment Scores}

\section{for Selected Facilities, by District}

(Including Overall Average Score for All Facilities Visited) 


\section{Site Assessment Scores}

\begin{tabular}{|l|c|c|c|c|c|c|c|c|c|c|c|c|c|c|c|c|}
\hline LaPorte District & A & B & C & D & E & F & G & H & I & J & K & L & M & N & O & Score \\
\hline Chesterton Unit & 2 & 3 & 3 & 2 & & 6 & 1 & 5 & 6 & 6 & 5 & 2 & & 3 & & $\mathbf{3 . 6 7}$ \\
\hline Wanatah Unit & 5 & 6 & 6 & 5 & 6 & 6 & 1 & 4 & 6 & 6 & 6 & 2 & & 5 & & $\mathbf{4 . 9 2}$ \\
\hline Flora Unit & 1 & 2 & 1 & 1 & & 1 & 1 & 5 & 3 & 1 & 3 & 2 & & 3 & & $\mathbf{2 . 0 0}$ \\
\hline Winamac Sub/Unit & 5 & 2 & 6 & 1 & & 6 & 1 & 4 & 3 & 3 & 4 & 2 & & 3 & & $\mathbf{3 . 3 3}$ \\
\hline New Gary Sub / Miller Unit & 6 & 4 & 6 & 6 & 6 & 6 & 6 & 6 & 6 & 6 & 5 & 6 & & 6 & & 5.77 \\
\hline Logansport Unit $^{1}$ & 1 & 2 & 1 & 2 & & 1 & 1 & 5 & 3 & 3 & 4 & 6 & & 6 & & $\mathbf{2 . 9 2}$ \\
\hline S. Bend Unit (not manned) ${ }^{1}$ & & & & & & & & & & & & & & & & \\
\hline Mishawaka Unit & 4 & 5 & 1 & 2 & & 6 & 6 & 2 & 6 & 3 & 4 & 2 & & 6 & & $\mathbf{3 . 9 2}$ \\
\hline Crown Point Unit & 2 & 3 & 1 & 1 & & 1 & 1 & 1 & 3 & 3 & 4 & 2 & & 6 & & $\mathbf{2 . 3 3}$ \\
\hline Michigan City Unit & 3 & 4 & 1 & 1 & & 6 & 1 & 3 & 3 & 3 & 4 & 2 & & 1 & & $\mathbf{2 . 6 7}$ \\
\hline \multicolumn{1}{|c|}{ Average Score for District } & 3.2 & 3.4 & $\mathbf{2 . 9}$ & $\mathbf{2 . 3}$ & $\mathbf{6 . 0}$ & $\mathbf{4 . 3}$ & $\mathbf{2 . 1}$ & $\mathbf{3 . 9}$ & $\mathbf{4 . 3}$ & $\mathbf{3 . 8}$ & $\mathbf{4 . 3}$ & $\mathbf{2 . 9}$ & & $\mathbf{4 . 3}$ & & 3.50 \\
\hline
\end{tabular}

1 The South Bend Unit scores are not included because it is an unmanned Unit and will skew the averages

2 Blank boxes indicate a score of "zero" or no score due to a lack of data or the criteria not being applicable to the site

These zeros are not factored into the average score for the site or district. 


\begin{tabular}{|l|c|c|c|c|c|c|c|c|c|c|c|c|c|c|c|c|}
\hline Fort Wayne District & A & B & C & D & E & F & G & H & I & J & K & L & M & N & O & Score \\
\hline Angola Sub & 5 & 5 & 6 & 2 & & 6 & 6 & 4 & 6 & 6 & 4 & 2 & & 5 & & $\mathbf{4 . 7 5}$ \\
\hline Orland Unit (not manned) ${ }^{3}$ & & & & & & & & & & & & & & & & \\
\hline Waterloo Unit & 1 & 2 & 1 & 1 & & 1 & 6 & 1 & 1 & 1 & 3 & 2 & & 3 & & $\mathbf{1 . 9 2}$ \\
\hline Monroe Unit & 1 & 2 & 1 & 1 & & 1 & 6 & 1 & 3 & 3 & 5 & 2 & & 3 & & $\mathbf{2 . 4 2}$ \\
\hline New Haven Unit & 5 & 2 & 5 & 1 & & 1 & 6 & 3.5 & 1 & 1 & 1 & 2 & & 3 & & $\mathbf{2 . 6 3}$ \\
\hline US 27 S. Unit & 1 & 2 & 1 & 1 & & 1 & 6 & 1 & 1 & 1 & 3 & 2 & & 3 & & 1.92 \\
\hline Gas City Unit & 5 & 2 & 6 & 1 & & 6 & 6 & 4 & 3 & 1 & 4 & 6 & & 3 & & 3.92 \\
\hline Warsaw Sub & 1 & 2 & 3 & 1 & & 1 & 1 & 1 & 1 & 1 & 3 & 2 & & 6 & & $\mathbf{1 . 9 2}$ \\
\hline Average Score for District & 2.7 & 2.4 & 3.3 & 1.1 & & 2.4 & 5.3 & 2.2 & 2.3 & 2.0 & 3.3 & 2.6 & & 3.7 & & 2.78 \\
\hline
\end{tabular}

${ }^{3}$ The Orland Unit scores are not included because it is an unmanned Unit and will skew the averages

\begin{tabular}{|l|c|c|c|c|c|c|c|c|c|c|c|c|c|c|c|c|}
\hline Crawfordsville District & A & B & C & D & E & F & G & H & I & J & K & L & M & N & O & Score \\
\hline New Plainfield Unit & 6 & 2 & 6 & 5 & 6 & 6 & 1 & 6 & 6 & 6 & 4 & 4 & & 3 & & $\mathbf{4 . 6 9}$ \\
\hline Lafayette Unit & 1 & 2 & 1 & 1 & 1 & 1 & 1 & 1 & 3 & 1 & 2 & 2 & & 3 & & $\mathbf{1 . 5 4}$ \\
\hline Lebanon Unit & 2 & 3 & 1 & 1 & & 6 & 6 & 1 & 6 & 6 & 4 & 6 & & 3 & & $\mathbf{3 . 7 5}$ \\
\hline Ft. Harrison Unit & 5 & 6 & 5 & 1 & & 6 & 6 & 3.5 & 6 & 6 & 4 & 2 & & 6 & & $\mathbf{4 . 7 1}$ \\
\hline Crawfordsville District/Sub & 5 & 6 & 5 & 2 & & 1 & 6 & 3.5 & 6 & 6 & 4 & 2 & & 3 & & $\mathbf{4 . 1 3}$ \\
\hline Carbondale Unit & 2 & 5 & 1 & 2 & & 1 & 6 & 1 & 3 & 3 & 4 & 2 & & 6 & & $\mathbf{3 . 0 0}$ \\
\hline Average Score for District & $\mathbf{3 . 5}$ & $\mathbf{4 . 0}$ & $\mathbf{3 . 2}$ & $\mathbf{2 . 0}$ & $\mathbf{3 . 5}$ & $\mathbf{3 . 5}$ & $\mathbf{4 . 3}$ & $\mathbf{2 . 7}$ & $\mathbf{5 . 0}$ & $\mathbf{4 . 7}$ & $\mathbf{3 . 7}$ & $\mathbf{3 . 0}$ & & $\mathbf{4 . 0}$ & & 3.64 \\
\hline
\end{tabular}




\begin{tabular}{|l|c|c|c|c|c|c|c|c|c|c|c|c|c|c|c|c|}
\hline Seymour District & A & B & C & D & E & F & G & H & I & J & K & L & M & N & O & Score \\
\hline Beanblossom Unit & 1 & 2 & 1 & 1 & & 6 & 6 & 5 & 6 & 6 & 4 & 2 & & 3 & & $\mathbf{3 . 5 8}$ \\
\hline Brownstown Unit & 1 & 2 & 1 & 1 & & 1 & 6 & 5 & 6 & 6 & 4 & 2 & & 3 & & $\mathbf{3 . 1 7}$ \\
\hline Columbus Sub & 5 & 2 & 6 & 1 & 6 & 6 & 6 & 4 & 6 & 6 & 3 & 2 & & 6 & & $\mathbf{4 . 5 4}$ \\
\hline Falls City Sub/Sellersburg Unit & 5 & 3 & 6 & 5 & 6 & 6 & 2 & 4 & 6 & 3 & 4 & 2 & & 6 & & $\mathbf{4 . 4 6}$ \\
\hline Greensburg & 2 & 3 & 1 & 1 & & 6 & 6 & 5 & 3 & 3 & 4 & 2 & & 3 & & $\mathbf{3 . 2 5}$ \\
\hline Brookville Unit & 5 & 6 & 6 & 1 & & 6 & 6 & 4 & 6 & 6 & 4 & 4 & & 3 & & $\mathbf{4 . 7 5}$ \\
\hline Salem Unit & 2 & 3 & 1 & 1 & & 1 & & 5 & 6 & 6 & 4 & 6 & & 6 & & $\mathbf{3 . 7 3}$ \\
\hline Versailles Unit & 2 & 3 & 1 & 1 & & 6 & & 5 & 6 & 6 & 4 & 4 & & 6 & & $\mathbf{4 . 0 0}$ \\
\hline Old Amity Unit & 2 & 3 & 1 & 1 & & 6 & 6 & 3 & 3 & 3 & 4 & 2 & & 6 & & $\mathbf{3 . 3 3}$ \\
\hline Corydon Unit & 5 & 1 & 5 & 1 & & 1 & 6 & 3.5 & 3 & 3 & 4 & 2 & & 3 & & $\mathbf{3 . 1 3}$ \\
\hline Spencer Unit & 3 & 4 & 1 & 1 & & 6 & & 5 & 6 & 6 & 4 & 4 & & 6 & & $\mathbf{4 . 1 8}$ \\
\hline North Vernon Unit & 5 & 4 & 6 & 1 & & 6 & & 4 & 3 & 1 & 3 & 2 & & 6 & & $\mathbf{3 . 7 3}$ \\
\hline \multicolumn{1}{|c|}{ Average Score for District } & 3.2 & 3.0 & 3.0 & 1.3 & $\mathbf{6 . 0}$ & $\mathbf{4 . 8}$ & 5.5 & $\mathbf{4 . 4}$ & $\mathbf{5 . 0}$ & $\mathbf{4 . 6}$ & $\mathbf{3 . 8}$ & $\mathbf{2 . 8}$ & & $\mathbf{4 . 8}$ & & $\mathbf{3 . 8 2}$ \\
\hline
\end{tabular}

\begin{tabular}{|l|c|c|c|c|c|c|c|c|c|c|c|c|c|c|c|c|}
\hline Greenfield District & A & B & C & D & E & F & G & H & I & J & K & L & M & N & O & Score \\
\hline Anderson Unit & 5 & 5 & 6 & 1 & 6 & 6 & 6 & 4 & 3 & 3 & 6 & 2 & & 1 & & $\mathbf{4 . 1 5}$ \\
\hline Fortville Unit & 5 & 3 & 6 & 1 & & 6 & 6 & 4 & 3 & 1 & 1 & 2 & & 6 & & 3.67 \\
\hline Kokomo Unit & 3 & 4 & 1 & 1 & & 1 & 6 & 3 & 3 & 3 & 4 & 4 & & 3 & & 3.00 \\
\hline Westfield Unit & 4 & 5 & 1 & 2 & 6 & 6 & 6 & 3 & 6 & 6 & 4 & 2 & & 3 & & $\mathbf{4 . 1 5}$ \\
\hline Shelbyville Unit & 5 & 3 & 6 & 1 & & 6 & 6 & 4 & 6 & 6 & 4 & 6 & & 6 & & $\mathbf{4 . 9 2}$ \\
\hline New Castle Unit & 4 & 5 & 1 & 1 & & 6 & 6 & 2 & 3 & 3 & 4 & 2 & & 1 & & 3.17 \\
\hline Winchester Unit & 5 & 3 & 6 & 1 & & 6 & 6 & 4 & 3 & 3 & 4 & 2 & & 6 & & $\mathbf{4 . 0 8}$ \\
\hline 71st Unit & 6 & 3 & 3 & 1 & 6 & 6 & 6 & 6 & 3 & 3 & 4 & 2 & & 3 & & $\mathbf{4 . 0 0}$ \\
\hline Average Score for District & 4.6 & 3.9 & 3.8 & 1.1 & 6.0 & 5.4 & 6.0 & 3.8 & 3.8 & 3.5 & 3.9 & 2.8 & & 3.6 & & 3.89 \\
\hline
\end{tabular}




\begin{tabular}{|l|c|c|c|c|c|c|c|c|c|c|c|c|c|c|c|c|}
\hline Vincennes District & A & B & C & D & E & F & G & H & I & J & K & L & M & N & O & Score \\
\hline Chrisney Unit & 5 & 3 & 6 & 1 & & 1 & 6 & 4 & 1 & 1 & 4 & 4 & & 3 & & $\mathbf{3 . 2 5}$ \\
\hline Jasper Unit & 5 & 3 & 5 & 1 & & 6 & 6 & 3.5 & 6 & 3 & 4 & 2 & & 6 & & $\mathbf{4 . 2 1}$ \\
\hline Bloomfield Unit & 5 & 3 & 5 & 1 & & 6 & 6 & 3.5 & 1 & 3 & 4 & 2 & & 3 & & $\mathbf{3 . 5 4}$ \\
\hline Shoals Unit & 2 & 3 & 1 & 1 & & 6 & 6 & 5 & 3 & 3 & 4 & 1 & & 3 & & $\mathbf{3 . 1 7}$ \\
\hline Grantsburg Unit & 3 & 4 & 3 & 1 & & 1 & 6 & 5 & 3 & 3 & 4 & 1 & & 6 & & $\mathbf{3 . 3 3}$ \\
\hline Petersburg Unit & 5 & 6 & 5 & 1 & & 1 & 6 & 3.5 & 6 & 6 & 4 & 6 & & 6 & & $\mathbf{4 . 6 3}$ \\
\hline \hline Poseyville Unit & 5 & 4 & 5 & 1 & & 6 & 6 & 3.5 & 1 & 1 & 4 & 6 & & 3 & & $\mathbf{3 . 7 9}$ \\
\hline Bedford Unit & 5 & 4 & 6 & 1 & & 6 & 6 & 4 & 6 & 6 & 4 & 6 & & 6 & & $\mathbf{5 . 0 0}$ \\
\hline Average Score for District & 4.4 & 3.8 & 4.5 & 1 & & 4.1 & $\mathbf{6}$ & 4 & 3.4 & 3.3 & 4 & 3.5 & & 4.5 & & 3.86 \\
\hline
\end{tabular}

\begin{tabular}{|c|c|c|c|c|c|c|c|c|c|c|c|c|c|c|c|r|}
\hline Criteria & A & B & C & D & E & F & G & H & I & J & K & L & M & N & O & Score \\
\hline Overall Average & 3.6 & 3.4 & 3.4 & 1.5 & 5.4 & 4.2 & 4.8 & 3.6 & 4.0 & 3.7 & 3.9 & 2.9 & & 4.2 & & 3.62 \\
\hline
\end{tabular}


Appendix VI

\section{Comparative Criteria and Average Score for Facilities Assessed (Alpha Order)}




\begin{tabular}{|c|c|c|c|c|c|c|c|c|c|c|c|c|c|c|c|c|}
\hline Facility (alpha order) & A & B & C & $\mathbf{D}$ & $E$ & $\mathbf{F}$ & G & $\mathbf{H}$ & $\mathbf{I}$ & $\mathbf{J}$ & $\mathrm{K}$ & $\mathbf{L}$ & $\mathbf{M}$ & $\mathbf{N}$ & 0 & Score \\
\hline 71st Unit & 6 & 3 & 3 & 1 & 6 & 6 & 6 & 6 & 3 & 3 & 4 & 2 & & 3 & & 4.00 \\
\hline Anderson Unit & 5 & 5 & 6 & 1 & 6 & 6 & 6 & 4 & 3 & 3 & 6 & 2 & & 1 & & 4.15 \\
\hline Angola Sub & 5 & 5 & 6 & 2 & & 6 & 6 & 4 & 6 & 6 & 4 & 2 & & 5 & & 4.75 \\
\hline Beanblossom Unit & 1 & 2 & 1 & 1 & & 6 & 6 & 5 & 6 & 6 & 4 & 2 & & 3 & & 3.58 \\
\hline Bedford Unit & 5 & 4 & 6 & 1 & & 6 & 6 & 4 & 6 & 6 & 4 & 6 & & 6 & & 5.00 \\
\hline Bloomfield Unit & 5 & 3 & 5 & 1 & & 6 & 6 & 3.5 & 1 & 3 & 4 & 2 & & 3 & & 3.54 \\
\hline Brookville Unit & 5 & 6 & 6 & 1 & & 6 & 6 & 4 & 6 & 6 & 4 & 4 & & 3 & & 4.75 \\
\hline Brownstown Unit & 1 & 2 & 1 & 1 & & 1 & 6 & 5 & 6 & 6 & 4 & 2 & & 3 & & 3.17 \\
\hline Carbondale Unit & 2 & 5 & 1 & 2 & & 1 & 6 & 1 & 3 & 3 & 4 & 2 & & 6 & & 3.00 \\
\hline Chesterton Unit & 2 & 3 & 3 & 2 & & 6 & 1 & 5 & 6 & 6 & 5 & 2 & & 3 & & 3.67 \\
\hline \begin{tabular}{|l} 
Chrisney Unit \\
\end{tabular} & 5 & 3 & 6 & 1 & & 1 & 6 & 4 & 1 & 1 & 4 & 4 & & 3 & & 3.25 \\
\hline Columbus Sub & 5 & 2 & 6 & 1 & 6 & 6 & 6 & 4 & 6 & 6 & 3 & 2 & & 6 & & 4.54 \\
\hline Corydon Unit & 5 & 1 & 5 & 1 & & 1 & 6 & 3.5 & 3 & 3 & 4 & 2 & & 3 & & 3.13 \\
\hline Crawfordsville District/Sub & 5 & 6 & 5 & 2 & & 1 & 6 & 3.5 & 6 & 6 & 4 & 2 & & 3 & & 4.13 \\
\hline Crown Point Unit & 2 & 3 & 1 & 1 & & 1 & 1 & 1 & 3 & 3 & 4 & 2 & & 6 & & 2.33 \\
\hline Falls City Sub/Sellersburg Unit & 5 & 3 & 6 & 5 & 6 & 6 & 2 & 4 & 6 & 3 & 4 & 2 & & 6 & & 4.46 \\
\hline Flora Unit & 1 & 2 & 1 & 1 & & 1 & 1 & 5 & 3 & 1 & 4 & 2 & & 3 & & 2.08 \\
\hline Fortville Unit & 5 & 3 & 6 & 1 & & 6 & 6 & 4 & 3 & 1 & 1 & 2 & & 6 & & 3.67 \\
\hline Ft. Harrison Unit & 5 & 6 & 5 & 1 & & 6 & 6 & 3.5 & 6 & 6 & 4 & 2 & & 6 & & 4.71 \\
\hline Gas City Unit & 5 & 2 & 6 & 1 & & 6 & 6 & 4 & 3 & 1 & 4 & 6 & & 3 & & 3.92 \\
\hline Grantsburg Unit & 3 & 4 & 3 & 1 & & 1 & 6 & 5 & 3 & 3 & 4 & 1 & & 6 & & 3.33 \\
\hline Greensburg & 2 & 3 & 1 & 1 & & 6 & 6 & 5 & 3 & 3 & 4 & 2 & & 3 & & 3.25 \\
\hline Jasper Unit & 5 & 3 & 5 & 1 & & 6 & 6 & 3.5 & 6 & 3 & 4 & 2 & & 6 & & 4.21 \\
\hline
\end{tabular}


Comparative Criteria and Average Score for Facilities Assessed

\begin{tabular}{|l|c|c|c|c|c|c|c|c|c|c|c|c|c|c|c|c|}
\hline Facility (alpha order) & A & B & C & D & E & F & G & H & I & J & K & L & M & N & O Score \\
\hline Kokomo Unit & 3 & 4 & 1 & 1 & & 1 & 6 & 3 & 3 & 3 & 4 & 4 & & 3 & $\mathbf{3 . 0 0}$ \\
\hline Lafayette Unit & 1 & 2 & 1 & 1 & 1 & 1 & 1 & 1 & 3 & 1 & 2 & 2 & & 3 & 1.54 \\
\hline Lebanon Unit & 2 & 3 & 1 & 1 & & 6 & 6 & 1 & 6 & 6 & 4 & 6 & & 3 & $\mathbf{3 . 7 5}$ \\
\hline Logansport Unit & 1 & 2 & 1 & 2 & & 1 & 1 & 5 & 3 & 3 & 4 & 6 & & 6 & $\mathbf{2 . 9 2}$ \\
\hline Michigan City Unit & 3 & 4 & 1 & 1 & & 6 & 1 & 3 & 3 & 3 & 4 & 2 & & 1 & & $\mathbf{2 . 6 7}$ \\
\hline Mishawaka Unit & 4 & 5 & 1 & 2 & & 6 & 6 & 2 & 6 & 3 & 4 & 2 & & 6 & 3.92 \\
\hline Monroe Unit & 1 & 2 & 1 & 1 & & 1 & 6 & 1 & 3 & 3 & 5 & 2 & & 3 & $\mathbf{2 . 4 2}$ \\
\hline New Castle Unit & 4 & 5 & 1 & 1 & & 6 & 6 & 2 & 3 & 3 & 4 & 2 & & 1 & 3.17 \\
\hline New Gary Sub / Miller Unit & 6 & 4 & 6 & 6 & 6 & 6 & 6 & 6 & 6 & 6 & 5 & 6 & & 6 & $\mathbf{5 . 7 7}$ \\
\hline New Haven Unit & 5 & 2 & 5 & 1 & & 1 & 6 & 3.5 & 1 & 1 & 1 & 2 & & 3 & $\mathbf{2 . 6 3}$ \\
\hline New Plainfield Unit & 6 & 2 & 6 & 5 & 6 & 6 & 1 & 6 & 6 & 6 & 4 & 4 & & 3 & 4.69 \\
\hline North Vernon Unit & 5 & 4 & 6 & 1 & & 6 & & 4 & 3 & 1 & 3 & 2 & & 6 & $\mathbf{3 . 7 3}$ \\
\hline Old Amity Unit & 2 & 3 & 1 & 1 & & 6 & 6 & 3 & 3 & 3 & 4 & 2 & & 6 & $\mathbf{3 . 3 3}$ \\
\hline Petersburg Unit & 5 & 6 & 5 & 1 & & 1 & 6 & 3.5 & 6 & 6 & 4 & 6 & & 6 & $\mathbf{4 . 6 3}$ \\
\hline Poseyville Unit & 5 & 4 & 5 & 1 & & 6 & 6 & 3.5 & 1 & 1 & 4 & 6 & & 3 & $\mathbf{3 . 7 9}$ \\
\hline Salem Unit & 2 & 3 & 1 & 1 & & 1 & & 5 & 6 & 6 & 4 & 6 & & 6 & $\mathbf{3 . 7 3}$ \\
\hline Shelbyville Unit & 5 & 3 & 6 & 1 & & 6 & 6 & 4 & 6 & 6 & 4 & 6 & & 6 & $\mathbf{4 . 9 2}$ \\
\hline Shoals Unit & 2 & 3 & 1 & 1 & & 6 & 6 & 5 & 3 & 3 & 4 & 1 & & 3 & $\mathbf{3 . 1 7}$ \\
\hline Spencer Unit & 3 & 4 & 1 & 1 & & 6 & & 5 & 6 & 6 & 4 & 4 & & 6 & $\mathbf{4 . 1 8}$ \\
\hline US 27 S. Unit & 1 & 2 & 1 & 1 & & 1 & 6 & 1 & 1 & 1 & 4 & 2 & & 3 & $\mathbf{2 . 0 0}$ \\
\hline Versailles Unit & 2 & 3 & 1 & 1 & & 6 & & 5 & 6 & 6 & 4 & 4 & & 6 & $\mathbf{4 . 0 0}$ \\
\hline Wanatah Unit & 5 & 6 & 6 & 5 & 6 & 6 & 1 & 4 & 6 & 6 & 6 & 2 & & 5 & $\mathbf{4 . 9 2}$ \\
\hline Warsaw Sub & 1 & 2 & 3 & 1 & & 1 & 1 & 1 & 1 & 1 & 3 & 2 & & 6 & $\mathbf{1 . 9 2}$ \\
\hline Waterloo Unit & 1 & 2 & 1 & 1 & & 1 & 6 & 1 & 1 & 1 & 4 & 2 & & 3 & $\mathbf{2 . 0 0}$ \\
\hline
\end{tabular}


Comparative Criteria and Average Score for Facilities Assessed

\begin{tabular}{|l|c|c|c|c|c|c|c|c|c|c|c|c|c|c|c|c|}
\hline Facility (alpha order) & A & B & C & D & E & F & G & H & I & J & K & L & M & N & O & Score \\
\hline Westfield Unit & 4 & 5 & 1 & 2 & 6 & 6 & 6 & 3 & 6 & 6 & 4 & 2 & & 3 & & 4.15 \\
\hline Winamac Sub/Unit & 5 & 2 & 6 & 1 & & 6 & 1 & 4 & 3 & 3 & 4 & 2 & & 3 & & 3.33 \\
\hline Winchester Unit & 5 & 3 & 6 & 1 & & 6 & 6 & 4 & 3 & 3 & 4 & 2 & & 6 & 4.08 \\
\hline & & & & & & & & & & & & & & & & \\
\hline Overall Average & 3.6 & 3.4 & 3.4 & 1.5 & 5.4 & 4.2 & 4.8 & 3.6 & 4.0 & 3.7 & 3.9 & 2.9 & & 4.2 & & 3.62 \\
\hline
\end{tabular}


Appendix VII

\section{Implementation Cost \\ Of Various BMPs}


Technology

Cost

Secondary Containment Pallets(\$200 each)

Construction of concrete containment(in house)

Oil/Water Separator(contracted out)

Construction of concrete pole for Salt Bed Racks(contracted out)

Wash water reuse for brine(incl. tanks, brine system, pumps, sec.

containment, building)(contacted out)

Salt Loadout Building on an Existing Dome(contracted out)

New Cover-All Style Building(covers all salt operations, salt bed racks,

cold patch, brine prod/tanks)(contracted out)

Connection to Municipal Sewer System(contracted out)

\begin{tabular}{|l|c|c|c|}
\multicolumn{1}{c|}{ Materials } & In house Labor & Total Cost \\
\cline { 2 - 4 } & $\$ 400.00$ & 0 & $\$ 400.00$ \\
\cline { 2 - 4 } & $\$ 4,400.00$ & 3000 & $\$ 7,400.00$ \\
\hline & $\$ 20,000.00$ & 0 & $\$ 20,000.00$ \\
\hline ted out) & $\$ 45,000.00$ & 0 & $\$ 45,000.00$ \\
\hline ut) & $\$ 90,000.00$ & 0 & $\$ 90,000.00$ \\
\hline alt bed racks, & $\$ 250,000.00$ & 0 & $\$ 250,000.00$ \\
& $\$ 800,000.00$ & 0 & $\$ 800,000.00$ \\
\hline & $\$ 1,143,000.00$ & 0 & $\$ 1,143,000.00$ \\
\hline
\end{tabular}

Housekeeping Practices

Cost

Placing a tarp over the cold patch pile

Clean scrap area and begin storing ROW trash and scrap in dumpsters ${ }^{2}$

Sweeping salt/sand mixing and loading area

Cleaning salt beds thoroughly

Driving to the nearest Unit to wash salt beds if not connected to a Municipal Sewer ${ }^{4}$

${ }^{1}$ Cost is based on a concrete containment pad measuring 36'x20'x8' and a wall of 33'x18'x3'. The concrete itself costs $\$ 2,400$.

The construction forms for installation cost $\$ 10,000$. However, the forms can be reused and therefore it is conservatively estimated

that the forms will be shared among 5 Units, meaning each Unit will be resposible for $1 / 5$ of the total cost, or $\$ 2,000$.

It is also estimated that it will take 5 men working 5 days to complete the construction or 200 hours labor.

${ }^{2}$ It is estimated that the average labor cost is $\$ 15.00$ per hour

${ }^{3}$ Assumptions for Sewer Cost: Average distance to connection $=2.3$ miles, 12 " pipe cost $=\$ 80.00 / \mathrm{ft}$ Pump Station cost $=\$ 30,000.00$, Manhole cost $=\$ 3,500.00 / 300 \mathrm{ft}$

Therefore, average total sewer connection cost $=(2.3 \times 5280 \times \$ 80.00)+(\$ 30,000.00)+(2.3 \mathrm{miles} / 300 \mathrm{ft} \times 3,500.00)=\$ 1,143,000.00$

${ }^{4}$ Assumptions for driving cost: Average distance to neighboring facility $=20$ miles each way

Average number of trucks per Unit $=7$ trucks

Cost of driving $=\$ 2.75 / \mathrm{mile}$

Average number of trips per truck per season $=14$ trips

Average cost $=\$ 2.75 \times 40 \times 14 \times 7=\$ 10,780.00$ 
Appendix VIII

\section{Example of Upgrade Costs: Lafayette Unit}




\section{Example of Upgrade Costs: Lafayette Unit}

\begin{tabular}{|c|c|c|c|c|c|c|c|c|c|c|c|c|c|c|c|c|}
\hline Criteria & A & B & C & D & $\mathbf{E}$ & $\mathbf{F}$ & $\mathbf{G}$ & $\mathrm{H}$ & I & $J$ & $\mathbf{K}$ & $\mathbf{L}$ & $\mathbf{M}$ & $\mathbf{N}$ & 0 & \\
\hline Lafayette Unit & 1 & 2 & 1 & 1 & 1 & 1 & 1 & 1 & 3 & 1 & 2 & 2 & & 3 & & 1.54 \\
\hline${ }^{*}$ There are five scor & evels & ossit & $\mathrm{n}$ thi & tem & $-3,3$ & & & & & & & & & & & \\
\hline & $\geq 1$ & $\geq 2$ & $\geq 3$ & $\geq 4$ & $\geq 5$ & \multirow{2}{*}{\multicolumn{10}{|c|}{$\begin{array}{l}\text { The "X" indicates the facility's current ranking and the subsequent } \\
\text { boxes show the possible scores if improvements are made. }\end{array}$}} & \\
\hline Lafayette Unit & $\mathbf{x}$ & & & & & & & & & & & & & & & \\
\hline
\end{tabular}

In this first box is the list of the least costly

\section{$2.23 \geq 2 \quad$ Cost $=\$ 800.00$}

$\mathrm{L}=4 \longleftarrow$ Cover cold patch with tarp

$\mathrm{N}=5 \quad$ Clean scrap area and store ROW Trash and scrap in dumpsters

$\mathrm{F}=6$ purchase sec. containment pallets for inside

\section{$3 \geq 3 \quad$ Additional Cost $=\$ 1,350.00$}

$\mathrm{I}=6$

Sweep salt/sand mixing and loading area regularly $\mathrm{K}=4, \mathrm{~J}=6 \quad$ Clean salt beds more thoroughly*

* by performing this single practice both criteria "K" and "J" are improved

* costs for housekeeping procedures(such as sweeping) are based on a yearly estimate

\section{$4.08 \geq 4 \quad$ Additional Cost $=\$ 25,580.00$}

$\begin{array}{ll}G=6 & \text { Construct concrete containment for outside tanks } \\ E=6 & \text { Construct concrete containment for brine production system } \\ H=5 & \text { drive to nearest Unit or Sub for salt bed washing }\end{array}$

\section{$5.00 \geq 5 \quad$ Additional Cost $=\$ 155,000.00$}

$\mathrm{C}=3$

$\mathrm{K}=6, \mathrm{~L}=6$

install an oil/water separator

$A=6, H=6$ construct concrete pole barn for Salt Bed Racks and Cold Patch Wash water reuse for brine methods of increasing the facility score to the next scoring level. First, if the cold patch

pile at the facility is covered with a tarp the score for criteria "L" will increase from a current score of 2 to a score of 4 . However, this practice alone will not increase the/facility score to the next level of $\geq 2$ so the next least costly method of raising the score is cleaning the scrap area and storing trash in dumpsters instead of on the ground. This will increase Criteria " $\mathrm{N}$ " from a score of 3 to a score of 5 . However, this is still not enough to raise the overall score to a 2 or greater so the next/least costly improvement is purchasing sec. containment pallets for inside drums. This increases Criteria " $F$ " from a current score of 1 to a \$core of 6 . These three improvements/together xaise the overall score of the facility to 2.23 . This score is $\geq 2$ and therefore puts the facility into the next level. These three improvements will cost $\$ 800$. Next the goal is to improve the score to $\geq 3$. The improvements listed in the second box accomplish this and raise the score to 3 . The cost to/improve from a 2.23 to a 3 is $\$ 1,350$. Therefore, to improve the facility's current score of 1.54 to a score 3 it will cost $\$ 800+\$ 1,350$ $=\$ 2,150$. The next goal is to increase to $\geq 4 \ldots$. 


\section{Appendix IX}

\section{Cost of Facility Upgrades}

\section{(Two Examples per Scoring Category)}




\section{Cost of Upgrading the Lafayette Unit}

\begin{tabular}{|l|c|c|c|c|c|c|c|c|c|c|c|c|c|c|c|}
\hline Criteria & A & B & C & E & F & G & H & I & J & K & L & M & N & O & \\
\hline Lafayette Unit & 1 & 2 & 1 & 1 & 1 & 1 & 1 & 3 & 1 & 2 & 2 & & 3 & & 1.58 \\
\hline
\end{tabular}

\begin{tabular}{|c|c|}
\hline & $\geq 1 \quad \geq 2 \quad \geq 3$ \\
\hline Lafayette Unit & $\mathbf{x}$ \\
\hline
\end{tabular}

\section{$2.23 \geq 2 \quad$ Cost $=$}

\begin{tabular}{|ll|}
\hline $\mathrm{L}=4$ & Cover cold patch with tarp \\
$\mathrm{N}=5$ & Clean scrap area and store ROW Trash and scrap in dumpsters \\
$\mathrm{F}=6$ & purchase sec. containment pallets for inside \\
\hline
\end{tabular}

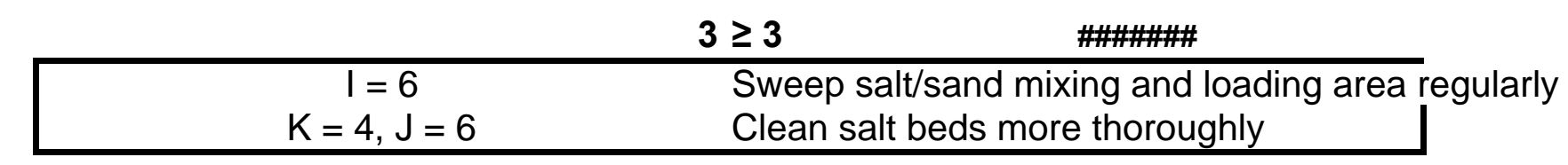

\section{$4.08 \geq 4$}

\section{\#\#\#\#\#}

\begin{tabular}{|cc|}
\hline$G=6$ & $\begin{array}{l}\text { Construct concrete containment for outside tanks } \\
\text { Construct concrete containment for brine production system } \\
\text { drive to nearest Unit or Sub for salt bed washing } \\
H=5\end{array}$ \\
\hline $\mathrm{S}=3$ & $\mathbf{5 . 0 0}$ \\
$\mathrm{K}=6, \mathrm{5}=6$ & install an oil/water separator \\
$\mathrm{A}=6, \mathrm{H}=6$ & construct concrete pole barn for Salt Bed Racks and Cold Patch \\
\hline
\end{tabular}


Cost of Upgrading the U.S. 27 South Unit

\begin{tabular}{|l|c|c|c|c|c|c|c|c|c|c|c|c|c|c|c|c|}
\hline Criteria & A & B & C & D & E & F & G & H & I & J & K & L & M & N & O & \\
\hline US 27 S. Unit & 1 & 2 & 1 & 1 & & 1 & 6 & 1 & 1 & 1 & 3 & 2 & & 3 & & $\mathbf{1 . 9 2}$ \\
\hline
\end{tabular}

\begin{tabular}{|l|c|c|c|c|c|}
\hline Score Ranges & $\geq 1$ & $\geq 2$ & $\geq 3$ & $\geq 4$ & $\geq 5$ \\
\hline US 27 S. Unit & $\mathrm{x}$ & & & & \\
\hline
\end{tabular}

$2.08 \geq 2 \quad$ Cost $=\$ 100.00$

$\mathrm{L}=4 \quad$ Cover cold patch with tarp

$3.08 \geq 3 \quad$ Additional Cost $=\$ 1,150.00$

\begin{tabular}{|ll|}
\hline $\mathrm{N}=5$ & Clean scrap area and store ROW Trash and scrap in dumpsters \\
$\mathrm{F}=6$ & purchase sec. containment pallets for inside \\
$\mathrm{I}=6$ & Sweep salt/sand mixing and loading area regularly \\
\hline
\end{tabular}

$4.08 \geq 4 \quad$ Additional Cost $=\$ 31,680.00$

$\begin{array}{cl}\mathrm{K}=4, \mathrm{~J}=6 & \text { Clean salt beds more thoroughly } \\ \mathrm{H}=5 & \text { drive to nearest Unit or Sub for salt bed washing } \\ \mathrm{C}=3 & \text { install an oil/water separator }\end{array}$

$5.00 \geq 5 \quad$ Additional Cost $=\$ 385,000.00$

$\mathrm{K}=6, \mathrm{~L}=6 \quad$ construct concrete pole barn for Salt Bed Racks and Cold Patch

$A=6, H=6 \quad$ Wash water reuse for brine

$\mathrm{D}=5 \quad$ Salt Loadout Building 
Cost of Upgrading the Crown Point Unit

\begin{tabular}{|l|c|c|c|c|c|c|c|c|c|c|c|c|c|c|c|c|}
\hline Criteria & A & B & C & D & E & F & G & H & I & J & K & L & M & N & O & \\
\hline Crown Point Unit & 2 & 3 & 1 & 1 & & 1 & 1 & 1 & 3 & 3 & 4 & 2 & & 6 & & 2.33 \\
\hline
\end{tabular}

\begin{tabular}{|l|c|c|c|c|c|}
\hline Score Ranges & $\geq 1$ & $\geq 2$ & $\geq 3$ & $\geq 4$ & $\geq 5$ \\
\hline Crown Point Unit & & $x$ & & & \\
\hline
\end{tabular}

$3.42 \geq 3$

Cost $=\$ 950.00$

\begin{tabular}{|cl|}
\hline$L=4$ & Cover cold patch with tarp \\
$\mathrm{F}=6$ & purchase sec. containment pallets for inside \\
$\mathrm{I}=6, \mathrm{~J}=6$ & Sweep salt/sand mixing and loading area regularly \\
\hline
\end{tabular}

\section{$4.17 \geq 4 \quad$ Additional Cost $=\$ 18,180.00$}

$\mathrm{H}=5 \quad$ drive to nearest Unit or Sub for salt bed washing

$\mathrm{G}=6 \quad$ Construct concrete containment for outside tanks

$5.08 \geq 5 \quad$ Additional Cost $=\$ 155,000.00$

$\mathrm{C}=3 \quad$ install an oil/water separator

$K=6, L=6 \quad$ construct concrete pole barn for Salt Bed Racks and Cold Patch

$A=6, H=6 \quad$ Wash water reuse for brine 
Cost of Upgrading the Michigan City Unit

\begin{tabular}{|l|c|c|c|c|c|c|c|c|c|c|c|c|c|c|c|c|}
\hline Criteria & A & B & C & D & E & F & G & H & I & J & K & L & M & N & O & \\
\hline Michigan City Unit & 3 & 4 & 1 & 1 & & 6 & 1 & 3 & 3 & 3 & 4 & 2 & & 1 & & 2.67 \\
\hline
\end{tabular}

\begin{tabular}{|l|c|c|c|c|c|}
\hline Score Ranges & $\geq 1$ & $\geq 2$ & $\geq 3$ & $\geq 4$ & $\geq 5$ \\
\hline Michigan City Unit & & $x$ & & & \\
\hline
\end{tabular}

$3.17 \geq 3$

Cost $=\$ 400.00$

$\mathrm{L}=4 \quad$ Cover cold patch with tarp

$4.25 \geq 4 \quad$ Additional Cost $=\$ 18,630.00$

$\mathrm{I}=6, \mathrm{~J}=6 \quad$ Sweep salt/sand mixing and loading area regularly

$\mathrm{H}=5 \quad$ drive to nearest Unit or Sub for salt bed washing

$\mathrm{G}=6 \quad$ Construct concrete containment for outside tanks

$5.08 \geq 5 \quad$ Additional Cost $=\$ 155,000.00$

$\mathrm{C}=3 \quad$ install an oil/water separator

$K=6, L=6 \quad$ construct concrete pole barn for Salt Bed Racks and Cold Patch

$A=6, H=6 \quad$ Wash water reuse for brine 
Cost of Upgrading the Fortville Unit

\begin{tabular}{|l|c|c|c|c|c|c|c|c|c|c|c|c|c|c|c|c|}
\hline Criteria & A & B & C & D & E & F & G & H & I & J & K & L & M & N & O & \\
\hline Fortville Unit & 5 & 3 & 6 & 1 & & 6 & 6 & 4 & 3 & 1 & 1 & 2 & & 6 & & 3.67 \\
\hline
\end{tabular}

\begin{tabular}{|l|c|c|c|c|c|}
\hline Score Ranges & $\geq 1$ & $\geq 2$ & $\geq 3$ & $\geq 4$ & $\geq 5$ \\
\hline Fortville Unit & & & $x$ & & \\
\hline
\end{tabular}

$4.08 \geq 4 \quad$ Cost $=\$ 1,000.00$

\begin{tabular}{ll|}
$\mathrm{L}=4$ & Cover cold patch with tarp \\
$\mathrm{K}=4$ & Clean salt beds more thoroughly \\
\hline
\end{tabular}

$5.08 \geq 5 \quad$ Additional Cost $=\$ 45,450.00$

$\mathrm{I}=6, \mathrm{~J}=6 \quad$ Sweep salt/sand mixing and loading area regularly

$K=6, L=6 \quad$ construct concrete pole barn for Salt Bed Racks and Cold Patch 
Cost of Upgrading the Brownstown Unit

\begin{tabular}{|l|c|c|c|c|c|c|c|c|c|c|c|c|c|c|c|c|}
\hline Criteria & A & B & C & D & E & F & G & H & I & J & K & L & M & N & O & \\
\hline Brownstown Unit & 1 & 2 & 1 & 1 & & 1 & 6 & 5 & 6 & 6 & 4 & 2 & & 3 & & 3.17 \\
\hline
\end{tabular}

\begin{tabular}{|l|c|c|c|c|c|}
\hline Score Ranges & $\geq 1$ & $\geq 2$ & $\geq 3$ & $\geq 4$ & $\geq 5$ \\
\hline Brownstown Unit & & & $\mathrm{x}$ & & \\
\hline
\end{tabular}

\begin{tabular}{|ll|}
\multicolumn{1}{c}{$\mathbf{4 . 0 0} \geq \mathbf{4} \quad$ Cost $=\$ \mathbf{8 0 0 . 0 0}$} \\
\hline $\mathrm{L}=4$ & Cover cold patch with tarp \\
$\mathrm{N}=6$ & Store ROW Trash and scrap in dumpsters \\
$\mathrm{F}=6$ & purchase sec. containment pallets for inside \\
\hline
\end{tabular}

\begin{tabular}{|cl|}
\multicolumn{5}{c}{$\mathbf{5 . 0 0} \geq \mathbf{5} \quad$ Additional Cost $=\$ \mathbf{\$ 1 5 5 , 0 0 0 . 0 0}$} \\
\hline $\mathrm{C}=3$ & install an oil/water separator \\
$\mathrm{K}=6, \mathrm{~L}=6$ & construct concrete pole barn for Salt Bed Racks and Cold Patch \\
$\mathrm{A}=6, \mathrm{H}=6$ & Wash water reuse for brine \\
\hline
\end{tabular}


Cost of Upgrading the Jasper Unit

\begin{tabular}{|l|c|c|c|c|c|c|c|c|c|c|c|c|c|c|c|c|}
\hline Criteria & A & B & C & D & E & F & G & H & I & J & K & L & M & N & O & \\
\hline Jasper Unit & 5 & 3 & 5 & 1 & & 6 & 6 & 3.5 & 6 & 3 & 4 & 2 & & 6 & & 4.21 \\
\hline
\end{tabular}

\begin{tabular}{|l|c|c|c|c|c|}
\hline Score Ranges & $\geq 1$ & $\geq 2$ & $\geq 3$ & $\geq 4$ & $\geq 5$ \\
\hline Jasper Unit & & & & & \\
\hline
\end{tabular}

$5.08 \geq 5 \quad$ Cost $=\$ 65,450.00$

\begin{tabular}{|cl|}
\hline $\mathrm{J}=6$ & sweep regularly \\
$\mathrm{C}=6, \mathrm{H}=4$ & install an oil/water separator \\
$\mathrm{K}=6, \mathrm{~L}=6$ & construct concrete pole barn for Salt Bed Racks and Cold Patch
\end{tabular}


Cost of Upgrading the Columbus Sub

\begin{tabular}{|l|c|c|c|c|c|c|c|c|c|c|c|c|c|c|c|c|}
\hline Criteria & A & B & C & D & E & F & G & H & I & J & K & L & M & N & O & \\
\hline Columbus Sub & 5 & 2 & 6 & 1 & 6 & 6 & 6 & 4 & 6 & 6 & 3 & 2 & & 6 & & 4.54 \\
\hline
\end{tabular}

\begin{tabular}{|l|l|l|l|c|c|}
\hline Score Ranges & $\geq 1$ & $\geq 2$ & $\geq 3$ & $\geq 4$ & $\geq 5$ \\
\hline Columbus Sub & & & & $x$ & \\
\hline
\end{tabular}

\section{$5.08 \geq 5 \quad$ Cost $=\$ 45,000.00$}

$\mathrm{K}=6, \mathrm{~L}=6 \quad$ construct concrete pole barn for Salt Bed Racks and Cold Patch 
APPENDIX X

FACILITY SITE ASSESSMENT REPORTS 
FACILITY SITE ASSESSMENT REPORTS CRAWFORDSVILLE DISTRICT 
Date_ $7 / 26 / 2005$

\section{INDOT Facility Stormwater and Washwater Effluent Drainage Assessment}

Name of Facility _Cabondale Unit
District/Subdistrict__Crawfordsville___

\section{Surface Water}




\section{Shop Floor Drain \& Wash Bay Effluent}

1. Are there drains in shop floors and wash bays that remove liquids and wash water effluent from the building(s)? _

2. Does the effluent flow to -

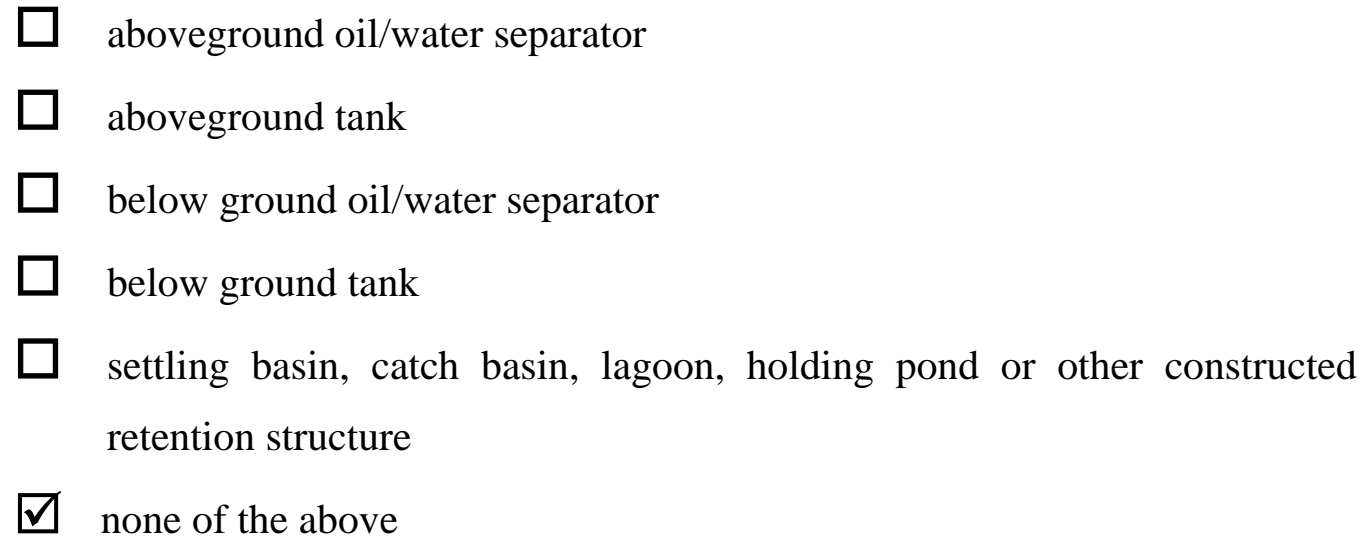

3. If the effluent is captured by the devices in 2., above, is it contained until pumped and hauled to a POTW or until it evaporates, or does it overflow to a drainage system?

4. If the effluent overflows to a drainage system, is the system above or below ground? _ Below ground drainage pipe

5. If the effluent overflows to a drainage system, does it mix with storm water?__No

6. If the effluent $\underline{\text { does }}$ mix with storm water, see "Surface Water" section (preceding page, \#4 and \#5) for discharge.

7. If the effluent doesn't mix with storm water, is it discharged to -

$\square \quad$ subsurface soils

$\square \quad$ on-site septic system

$\square$ drainage ditch or roadside ditch

$\square$ a nearby creek, river or other water body

$\square \quad$ lagoon or holding pond

$\square \quad$ municipal storm sewer Owner

$\square$ municipal combined storm/sanitary sewer Owner

$\square$ municipal POTW Owner 
8. If shop floor drain and washbay effluent is discharged, other than to a municipal storm, sanitary or combined sewer, does it ultimately reach "waters of the state?" If yes, name of that water body: __ Yes,

Activity Areas (check those that apply and describe (1) whether they are bermed to prevent storm water runoff or (2) if there are drains and their locations in the activity areas)

$\square$ salt storage (pads or domes) _ There are no berms or drains in the area but most of the stormwater from the area enters a detention pond

$\square$ salt/sand mixing __ Area drains into detention pond

$\square$ salt bed loading/wetting _ There is a drainage pipe located in the wetting area _that drains into the roadside ditch along the east property line

$\square$ salt bed washout_There is a catch basin in the washing area that drains into the roadside ditch along the west property line

$\square$ salt bed storage _ _drains into the roadside ditch along the west property line

$\square$ vehicle and equipment washing (inside) __All Unit Building floor drains empty into the roadside ditch along the west property line

$\square$ vehicle and equipment washing (outside) _ The outside washing area contains _ a catch basin that drains into the roadside ditch along the west property line asphalt equipment clean-out

$\square \quad$ herbicide mixing and tank rinsing

$\square \quad$ traffic paint mixing and transfer

$\square$ bulk tank off-loading and storage __Stormwater from this area enters the _detention pond

$\square$ waste piles (e.g., ROW trash, street sweeping debris)

$\square$ truck/equipment parking_Stormwater from the area enters a drainage pipe that _empties into the roadside ditch along the east side of the property

$\square$ truck/equipment fueling

$\square$ materials storage (210 lot, fencing, etc.)

$\square$ aggregate storage _ No berms or drains

$\square$ hot/cold patch storage __No berm or drain. Majority of storwater from this area _enters the detention pond

$\square$ storage of “scalp” and dirt from R/W maintenance 
Date_7/26/2005

\section{INDOT Facility Stormwater and Washwater Effluent Drainage Assessment}

Name of Facility __Crawfordsville Subdistrict
District/Subdistrict__Crawfordsville__

\section{Surface Water}

1. Does any area of the active surface collect storm water or facility-generated wash water (such as from washing trucks outdoors)? _ Yes

2. Is there any movement of surface water from one area to another on-site by ditch, drain tile or natural channel? __ Yes

3. Is there any movement of surface water off-site (e.g., beneath the perimeter fence) via sheet flow, ditch, pipe or channel to adjacent property? _

4. Is the surface water discharged directly to (check all that apply) -

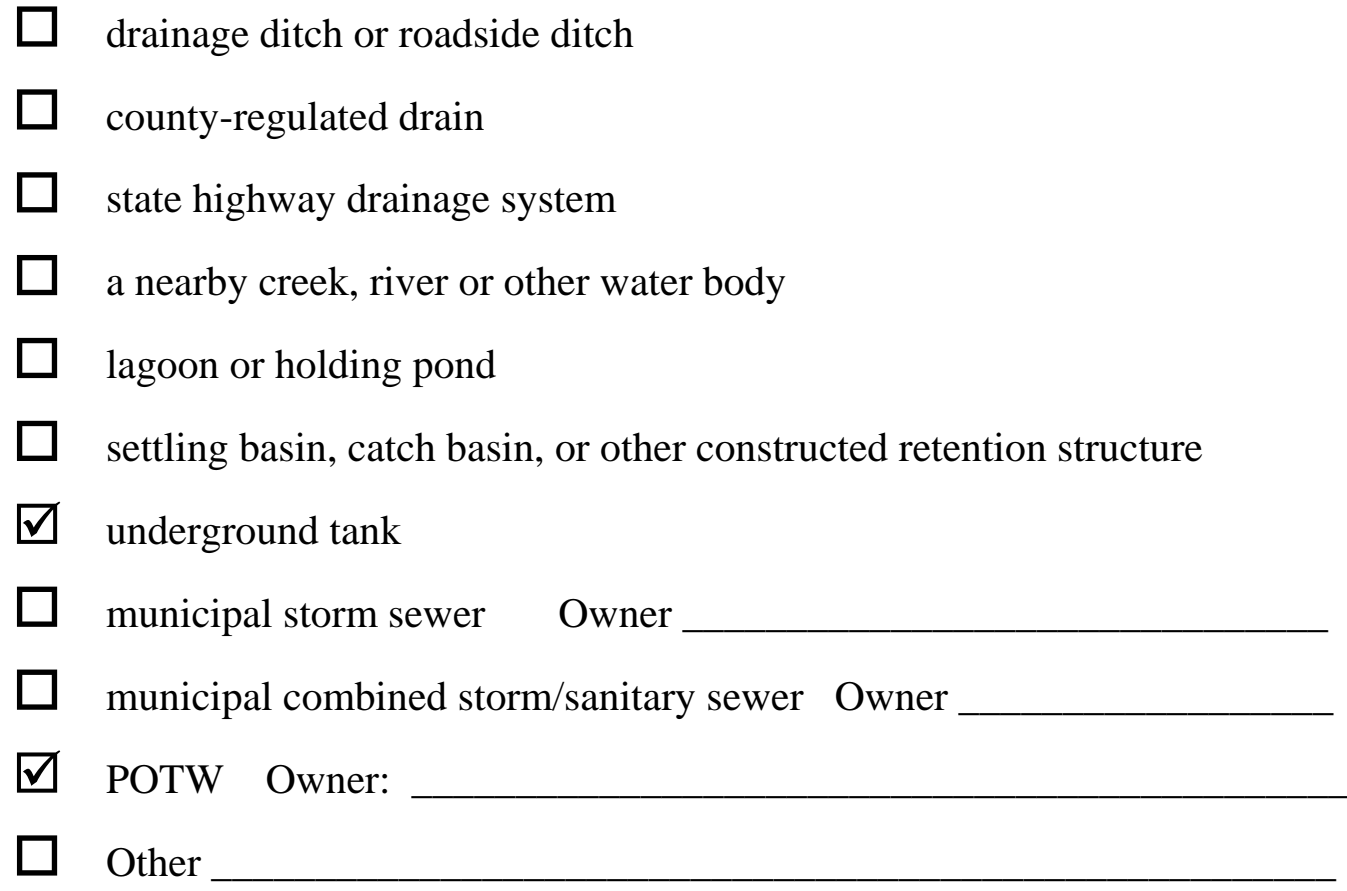

5. If surface water is discharged, other than to a municipal storm, sanitary or combined sewer, does it ultimately reach "waters of the state" (e.g., farm ditch, creek, stream, river, lake or pond)? If yes, name of that water body. _Some surface water is discharged to Black Creek

6. What is the estimated distance of this water body from the facility? 0.25 miles NW of the facility 


\section{Shop Floor Drain \& Wash Bay Effluent}

1. Are there drains in shop floors and wash bays that remove liquids and wash water effluent from the building(s)? _ Y Yes

2. Does the effluent flow to -

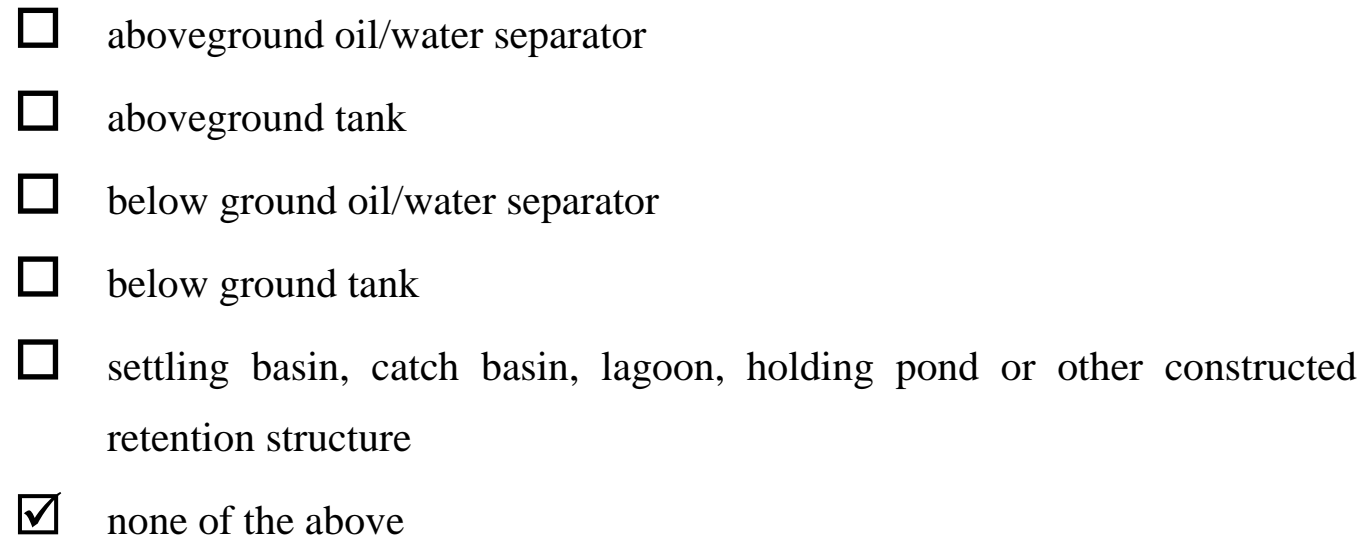

3. If the effluent is captured by the devices in 2., above, is it contained until pumped and hauled to a POTW or until it evaporates, or does it overflow to a drainage system?

4. If the effluent overflows to a drainage system, is the system above or below ground? _ Below ground holding tanks

5. If the effluent overflows to a drainage system, does it mix with storm water?__ Yes

6. If the effluent $\underline{\text { does }}$ mix with storm water, see "Surface Water" section (preceding page, \#4 and \#5) for discharge.

7. If the effluent doesn't mix with storm water, is it discharged to -

$\square \quad$ subsurface soils

$\square \quad$ on-site septic system

$\square$ drainage ditch or roadside ditch

$\square$ a nearby creek, river or other water body

$\square \quad$ lagoon or holding pond

$\square \quad$ municipal storm sewer Owner

$\square$ municipal combined storm/sanitary sewer Owner

$\square$ municipal POTW Owner 
8. If shop floor drain and washbay effluent is discharged, other than to a municipal storm, sanitary or combined sewer, does it ultimately reach "waters of the state?" If yes, name of that water body:

Activity Areas (check those that apply and describe (1) whether they are bermed to prevent storm water runoff or (2) if there are drains and their locations in the activity areas)

$\square$ salt storage (pads or domes) __ Area is not bermed but there is a catch basin that catches stormwater and conveys it to underground storage tanks

$\square$ salt/sand mixing_see "salt storage"

$\square$ salt bed loading/wetting _ see "salt storage"

$\square$ salt bed washout _ Bed washing is performed outside over a catch basin that - drains into underground storage tanks that are metered into the sewer system

$\square$ salt bed storage __ see "salt storage"

$\square \quad$ vehicle and equipment washing (inside)

$\square$ vehicle and equipment washing (outside) _ performed over a catch basin that - drains into underground tanks that are metered into the sewer system

$\square$ asphalt equipment clean-out___erformed on job site by burning with a torch

$\square$ herbicide mixing and tank rinsing _ Tanks are rinsed over catch basin that _drains to underground storage tanks that are metered into the sewer system

$\square$ traffic paint mixing and transfer _ Performed outside over catch basin that _drains directly into a surface water ditch that empties into Black Creek

$\square$ bulk tank off-loading and storage

$\square$ waste piles (e.g., ROW trash, street sweeping debris) __ Stored in dumpsters

$\square$ truck/equipment parking _ Storm water enters catch basin that drains into _ un derground storage tanks that are metered into the sewer system

$\square$ truck/equipment fueling

$\square$ materials storage (210 lot, fencing, etc.)

$\square$ aggregate storage __ No berms or drains

$\square$ hot/cold patch storage _ _ No berms or drains

$\square$ storage of "scalp" and dirt from R/W maintenance __ No berms or drains 
Date_ $7 / 26 / 2005$

\section{INDOT Facility Stormwater and Washwater Effluent Drainage Assessment}

Name of Facility __Fort Harrison Unit
District/Subdistrict__Crawfordsville___

\section{Surface Water}




\section{Shop Floor Drain \& Wash Bay Effluent}

1. Are there drains in shop floors and wash bays that remove liquids and wash water effluent from the building(s)? _ Y Yes

2. Does the effluent flow to -

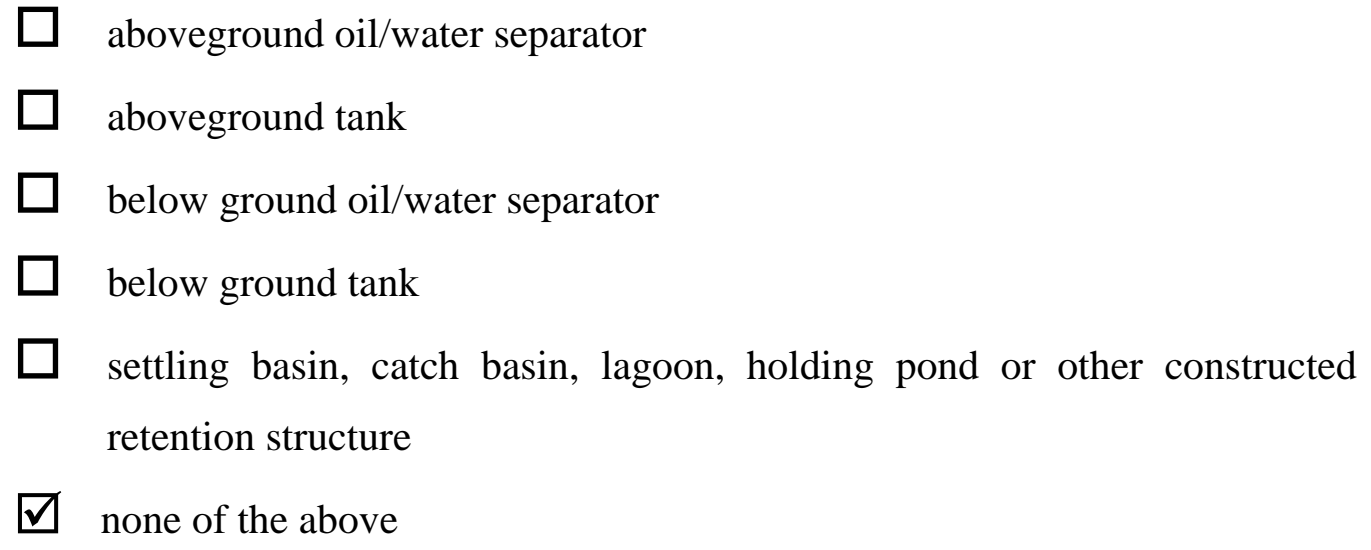

3. If the effluent is captured by the devices in 2., above, is it contained until pumped and hauled to a POTW or until it evaporates, or does it overflow to a drainage system?

4. If the effluent overflows to a drainage system, is the system above or below ground?

5. If the effluent overflows to a drainage system, does it mix with storm water?

6. If the effluent $\underline{\text { does }}$ mix with storm water, see "Surface Water" section (preceding page, \#4 and \#5) for discharge.

7. If the effluent doesn't mix with storm water, is it discharged to -

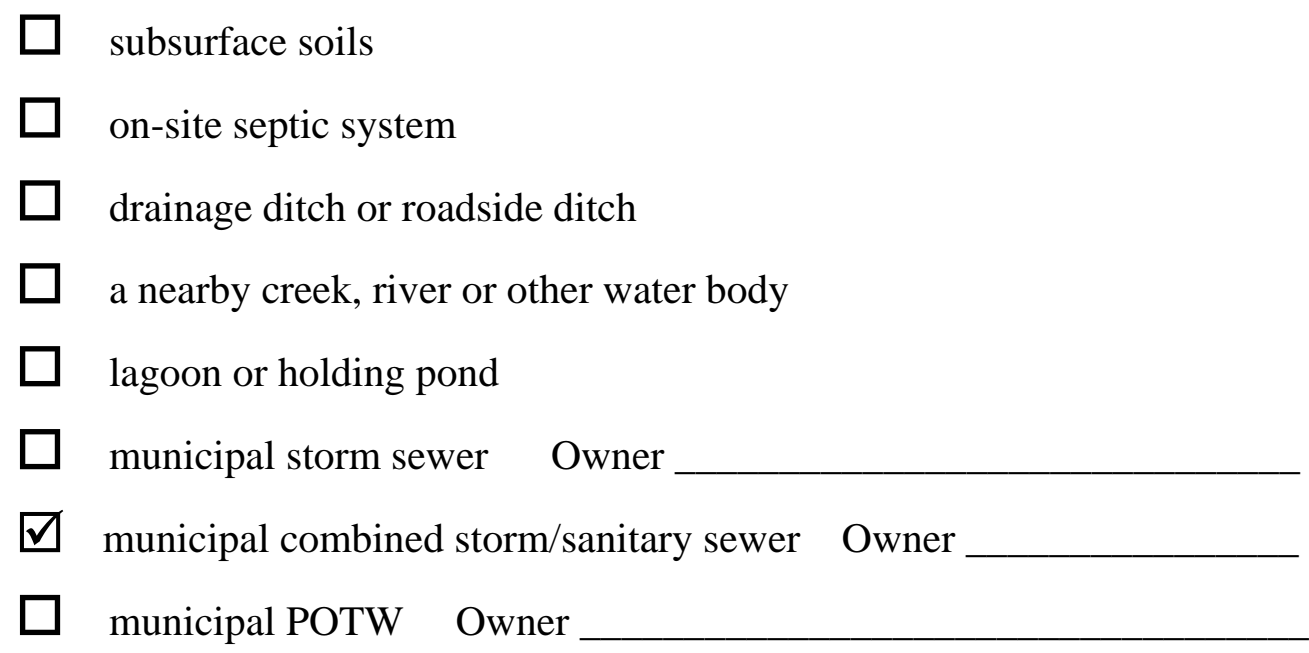


8. If shop floor drain and washbay effluent is discharged, other than to a municipal storm, sanitary or combined sewer, does it ultimately reach "waters of the state?" If yes, name of that water body: __ No

Activity Areas (check those that apply and describe (1) whether they are bermed to prevent storm water runoff or (2) if there are drains and their locations in the activity areas)

$\square \quad$ salt storage (pads or domes) _ _ No berms or drains in the area

$\square$ salt/sand mixing _ _ No berms or drains in the area

$\square$ salt bed loading/wetting _ _ No berms or drains in the area

$\square$ salt bed washout __ All washwater enters a catch basin that is connected to a _combined sewer system

$\square$ salt bed storage __ All stormwater from this area enters catch basins connected - to a combined sewer system

$\square \quad$ vehicle and equipment washing (inside)

$\square$ vehicle and equipment washing (outside) __ same as "salt bed washout"

$\square$ asphalt equipment clean-out __ Performed on job site

$\square \quad$ herbicide mixing and tank rinsing

$\square \quad$ traffic paint mixing and transfer

$\square \quad$ bulk tank off-loading and storage

$\square$ waste piles (e.g., ROW trash, street sweeping debris)

$\square$ truck/equipment parking _ Stormwater from the area enters catch basins that _connected to a combined sewer system

$\square$ truck/equipment fueling

$\square$ materials storage (210 lot, fencing, etc.)

$\square$ aggregate storage __ No berms or drains in the area

$\square$ hot/cold patch storage __ Same as "Salt Bed Storage"

$\square$ storage of “scalp” and dirt from R/W maintenance 
Date_2/9/2005

\title{
INDOT Facility Stormwater and Washwater Effluent Drainage Assessment
}

\author{
Name of Facility __Lebanon Unit \\ District/Subdistrict _ C Crawfordsville
}

\section{Surface Water}

1. Does any area of the active surface collect storm water or facility-generated wash water (such as from washing trucks outdoors)? _

2. Is there any movement of surface water from one area to another on-site by ditch, drain tile or natural channel? _ Yes, by ditch

3. Is there any movement of surface water off-site (e.g., beneath the perimeter fence) via sheet flow, ditch, pipe or channel to adjacent property? _. A ditch surrounds the property, which empties into Prairie Creek. This prevents run-off to adjacent property.

4. Is the surface water discharged directly to (check all that apply) -

$\square$ drainage ditch or roadside ditch

$\square$ county-regulated drain

$\square$ state highway drainage system

$\square \quad$ a nearby creek, river or other water body

$\square \quad$ lagoon or holding pond

$\square$ settling basin, catch basin, or other constructed retention structure

$\square$ underground tank

$\square$ municipal storm sewer Owner_

$\square$ municipal combined storm/sanitary sewer Owner

$\square$ POTW Owner:

$\square$ Other

5. If surface water is discharged, other than to a municipal storm, sanitary or combined sewer, does it ultimately reach "waters of the state” (e.g., farm ditch, creek, stream, river, lake or pond)? If yes, name of that water body. _ Y Yes, Prairie Creek

6. What is the estimated distance of this water body from the facility? 


\section{$\underline{\text { Shop Floor Drain \& Wash Bay Effluent }}$}

1. Are there drains in shop floors and wash bays that remove liquids and wash water effluent from the building(s)? _ Y Yes

2. Does the effluent flow to -

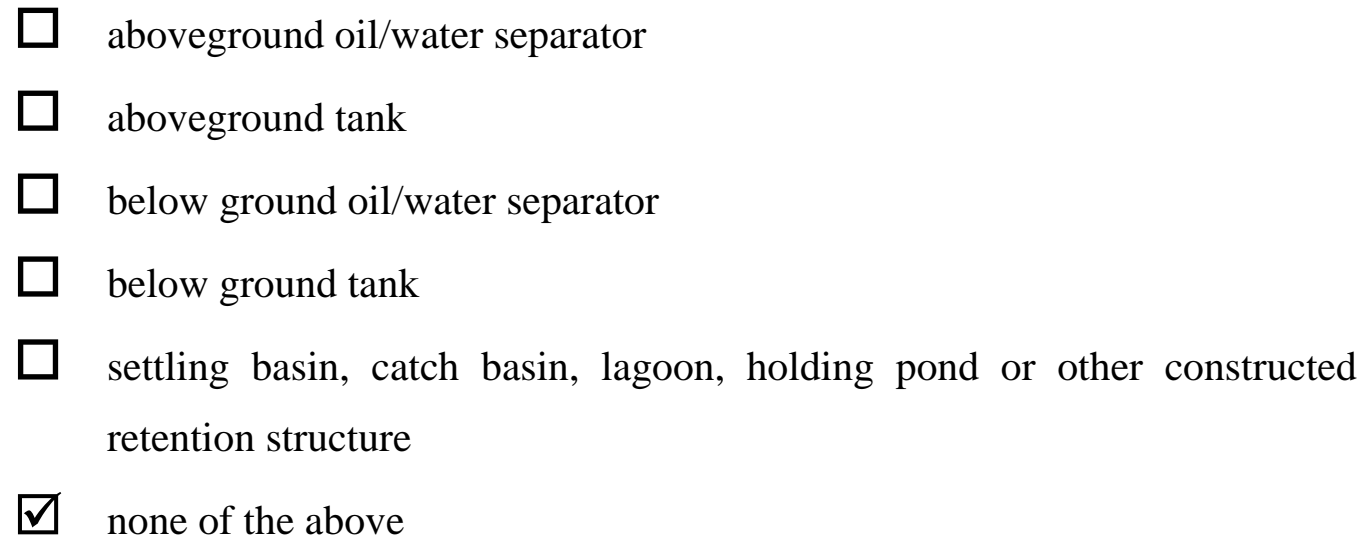

3. If the effluent is captured by the devices in 2., above, is it contained until pumped and hauled to a POTW or until it evaporates, or does it overflow to a drainage system?

4. If the effluent overflows to a drainage system, is the system above or below ground?

5. If the effluent overflows to a drainage system, does it mix with storm water?_Y Yes

6. If the effluent does mix with storm water, see "Surface Water" section (preceding page, \#4 and \#5) for discharge.

7. If the effluent doesn't mix with storm water, is it discharged to -

$\square$ subsurface soils

$\square$ on-site septic system

$\square$ drainage ditch or roadside ditch

$\square$ a nearby creek, river or other water body

$\square \quad$ lagoon or holding pond

$\square$ municipal storm sewer Owner

$\square$ municipal combined storm/sanitary sewer Owner

$\square$ municipal POTW Owner 
8. If shop floor drain and wash bay effluent is discharged, other than to a municipal storm, sanitary or combined sewer, does it ultimately reach "waters of the state?" If yes, name of that water body: _ Prairie Creek

Activity Areas (check those that apply and describe (1) whether they are bermed to prevent $\underline{\text { storm water runoff or (2) if there are drains and their locations in the activity areas) }}$

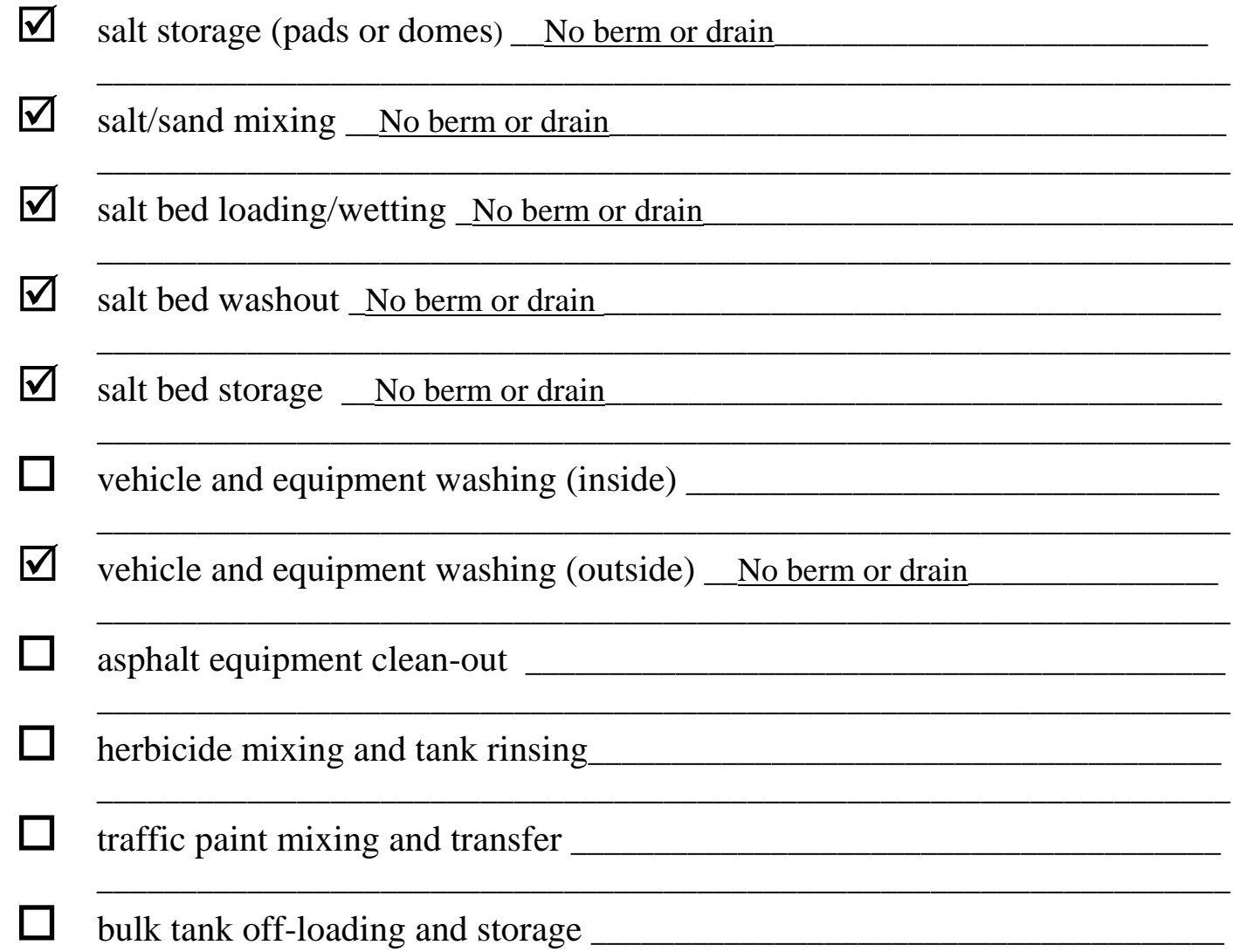

$\square$ waste piles (e.g., ROW trash, street sweeping debris)__Contained in_dumpster

$\square$ truck/equipment parking __ No berm or drain

$\square \quad$ truck/equipment fueling

$\square$ materials storage (210 lot, fencing, etc.)

$\square$ aggregate storage __ No berm or drain

$\square$ hot/cold patch storage _ _ Stored inside a covered building

$\square$ storage of “scalp” and dirt from R/W maintenance __ No berm or drain 
Date_6/21/2005

\section{INDOT Facility Stormwater and Washwater Effluent Drainage Assessment}

Name of Facility __Lafayette Unit
District/Subdistrict__rawfordsville___

\section{$\underline{\text { Surface Water }}$}

1. Does any area of the active surface collect storm water or facility-generated wash water (such as from washing trucks outdoors)? _ _ Yes

2. Is there any movement of surface water from one area to another on-site by ditch, drain tile or natural channel? _ Yes

3. Is there any movement of surface water off-site (e.g., beneath the perimeter fence) via sheet flow, ditch, pipe or channel to adjacent property? __ $\underline{\text { Yes }}$

4. Is the surface water discharged directly to (check all that apply) -

$\square$ drainage ditch or roadside ditch

$\square$ county-regulated drain

$\square$ state highway drainage system

$\square$ a nearby creek, river or other water body

$\square \quad$ lagoon or holding pond

$\square$ settling basin, catch basin, or other constructed retention structure

$\square$ underground tank

$\square$ municipal storm sewer Owner

$\square$ municipal combined storm/sanitary sewer Owner

$\square$ POTW Owner:

$\square$ Other

5. If surface water is discharged, other than to a municipal storm, sanitary or combined sewer, does it ultimately reach "waters of the state” (e.g., farm ditch, creek, stream, river, lake or pond)? If yes, name of that water body. _ Y Yes, Burnett Creek

6. What is the estimated distance of this water body from the facility?

Approx. 75 yards SE of the site

(Rev 2/7/05) 


\section{Shop Floor Drain \& Wash Bay Effluent}

1. Are there drains in shop floors and wash bays that remove liquids and wash water effluent from the building(s)? _ _ Yes

2. Does the effluent flow to -

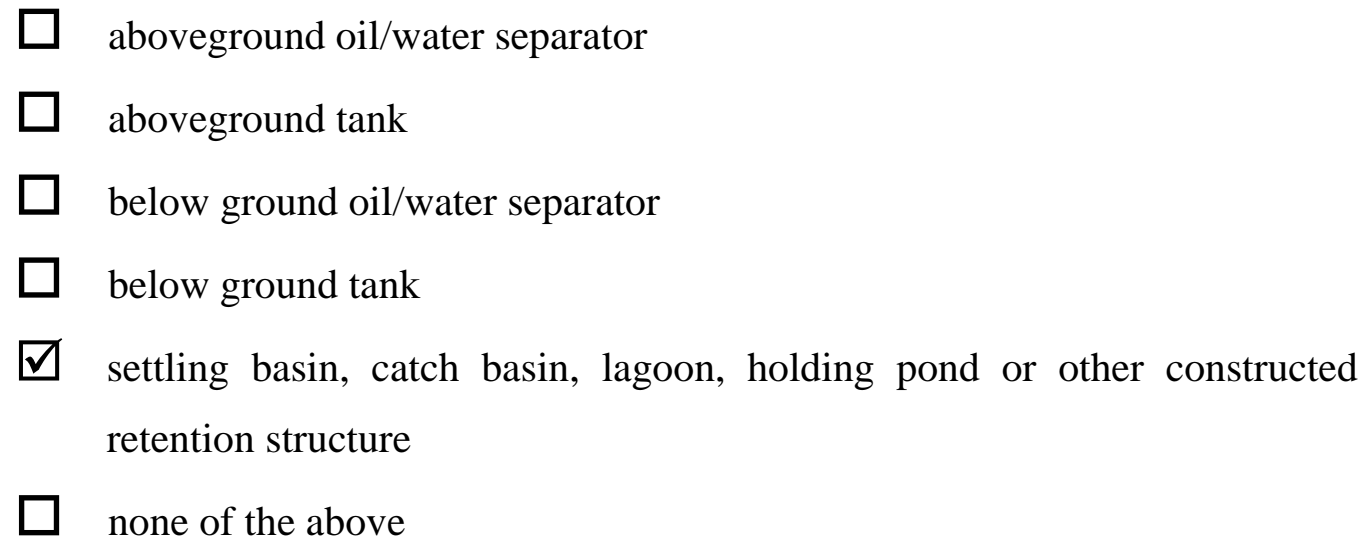

3. If the effluent is captured by the devices in 2., above, is it contained until pumped and hauled to a POTW or until it evaporates, or does it overflow to a drainage system? _ It overflows to a drainage system

4. If the effluent overflows to a drainage system, is the system above or below ground? __Below ground

5. If the effluent overflows to a drainage system, does it mix with storm water?_Yes

6. If the effluent does mix with storm water, see "Surface Water" section (preceding page, \#4 and \#5) for discharge.

7. If the effluent doesn't mix with storm water, is it discharged to -

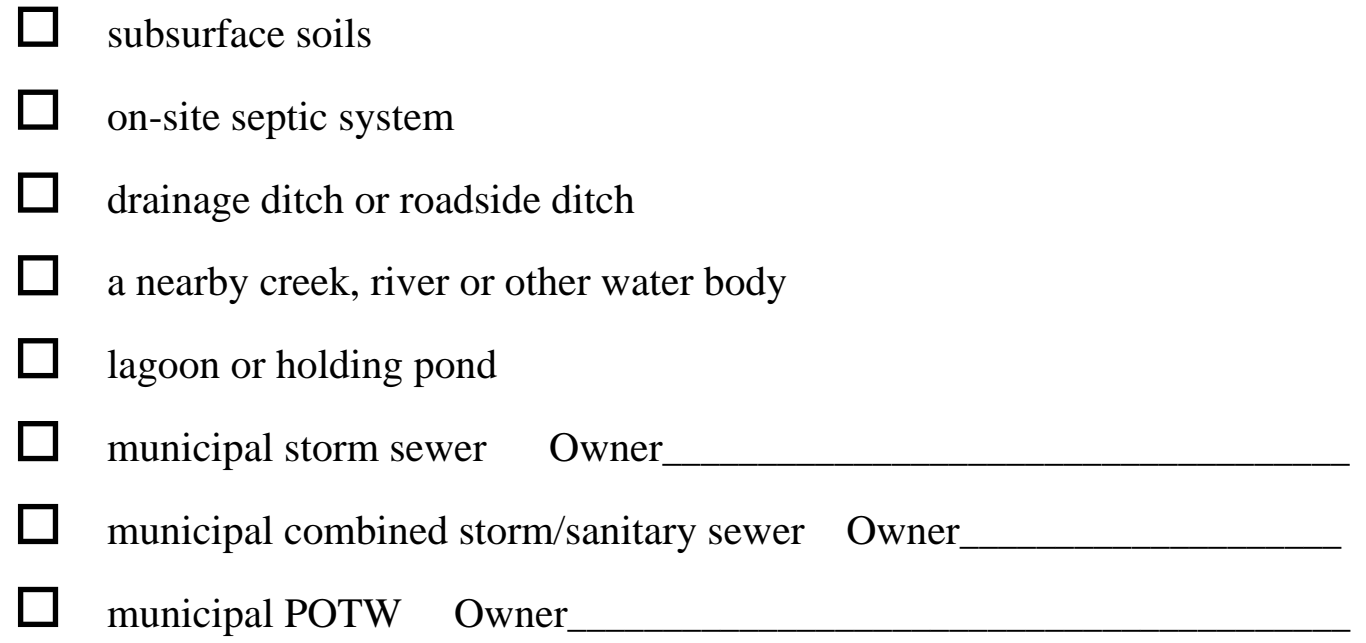


8. If shop floor drain and wash bay effluent is discharged, other than to a municipal storm, sanitary or combined sewer, does it ultimately reach "waters of the state?" If yes, name of that water body: __ Yes, Burnett Creek

Activity Areas (check those that apply and describe (1) whether they are bermed to prevent storm water runoff or (2) if there are drains and their locations in the activity areas)

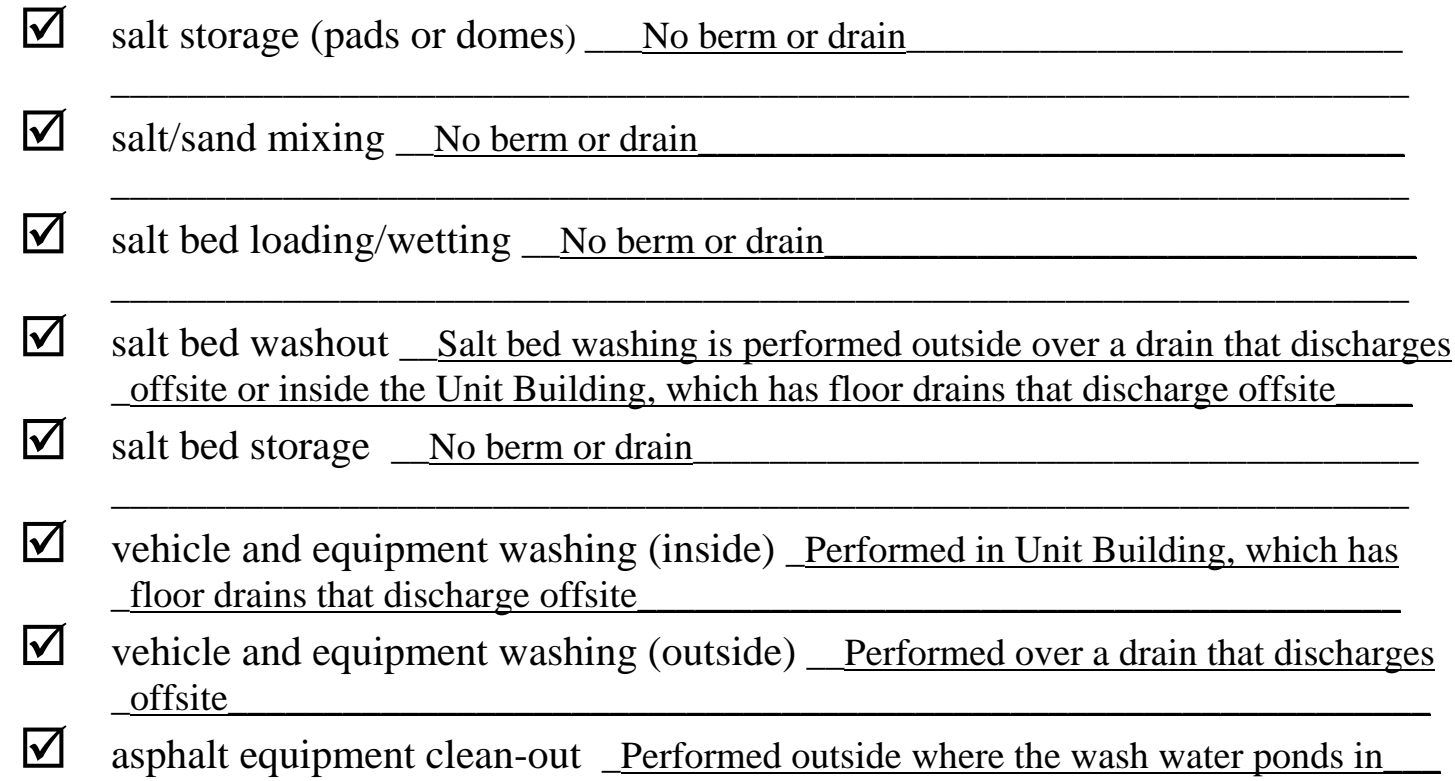
- a low area

$\square$ herbicide mixing and tank rinsing

$\square \quad$ traffic paint mixing and transfer

$\square$ bulk tank off-loading and storage

$\square \quad$ waste piles (e.g., ROW trash, street sweeping debris) _ _ No berm or drain

$\square$ truck/equipment parking __ No berm or drain

$\square \quad$ truck/equipment fueling

$\square$ materials storage (210 lot, fencing, etc.) __ No berm or drain

$\square$ aggregate storage __ No berm or drain

$\square$ hot/cold patch storage _ _ No berm or drain

$\square$ storage of “scalp” and dirt from R/W maintenance __ No berm or drain 
Date_2/9/2005

\section{INDOT Facility Stormwater and Washwater Effluent Drainage Assessment}

Name of Facility ___ New Plainfield Unit
District/Subdistrict__ Crawfordsville___

\section{$\underline{\text { Surface Water }}$}

1. Does any area of the active surface collect storm water or facility-generated wash water (such as from washing trucks outdoors)? _ _ There are a few areas where a small amount of storm water ponds

2. Is there any movement of surface water from one area to another on-site by ditch, drain tile or natural channel? _ Yes, by ditch

3. Is there any movement of surface water off-site (e.g., beneath the perimeter fence) via sheet flow, ditch, pipe or channel to adjacent property? _ Y Yes, by pipe and by sheet flow.

4. Is the surface water discharged directly to (check all that apply) -

$\square$ drainage ditch or roadside ditch

$\square$ county-regulated drain

$\square \quad$ state highway drainage system

$\square$ a nearby creek, river or other water body

$\square \quad$ lagoon or holding pond

$\square$ settling basin, catch basin, or other constructed retention structure

$\square$ underground tank

$\square$ municipal storm sewer Owner

$\square$ municipal combined storm/sanitary sewer Owner

$\square$ POTW Owner:

$\square$ Other

5. If surface water is discharged, other than to a municipal storm, sanitary or combined sewer, does it ultimately reach "waters of the state” (e.g., farm ditch, creek, stream, river, lake or pond)? If yes, name of that water body. _ Y Yes, White Lick Creek

6. What is the estimated distance of this water body from the facility? _ 150 yards 


\section{Shop Floor Drain \& Wash Bay Effluent}

1. Are there drains in shop floors and wash bays that remove liquids and wash water effluent from the building(s)? _ _ Yes

2. Does the effluent flow to -

$\square \quad$ aboveground oil/water separator

$\square$ aboveground tank

$\square$ below ground oil/water separator

$\square$ below ground tank

$\square$ settling basin, catch basin, lagoon, holding pond or other constructed retention structure

$\square$ none of the above

3. If the effluent is captured by the devices in 2., above, is it contained until pumped and hauled to a POTW or until it evaporates, or does it overflow to a drainage system?__ It overflows to a sanitary sewer system

NOTE: This Unit is set up to reuse wash water for brine production. However, at the time of the visit this operation was still under construction, and all water was going to the sanitary sewer.

4. If the effluent overflows to a drainage system, is the system above or below ground? __Below ground

5. If the effluent overflows to a drainage system, does it mix with storm water?__No

6. If the effluent does mix with storm water, see "Surface Water" section (preceding page, \#4 and \#5) for discharge. 
7. If the effluent doesn't mix with storm water, is it discharged to -

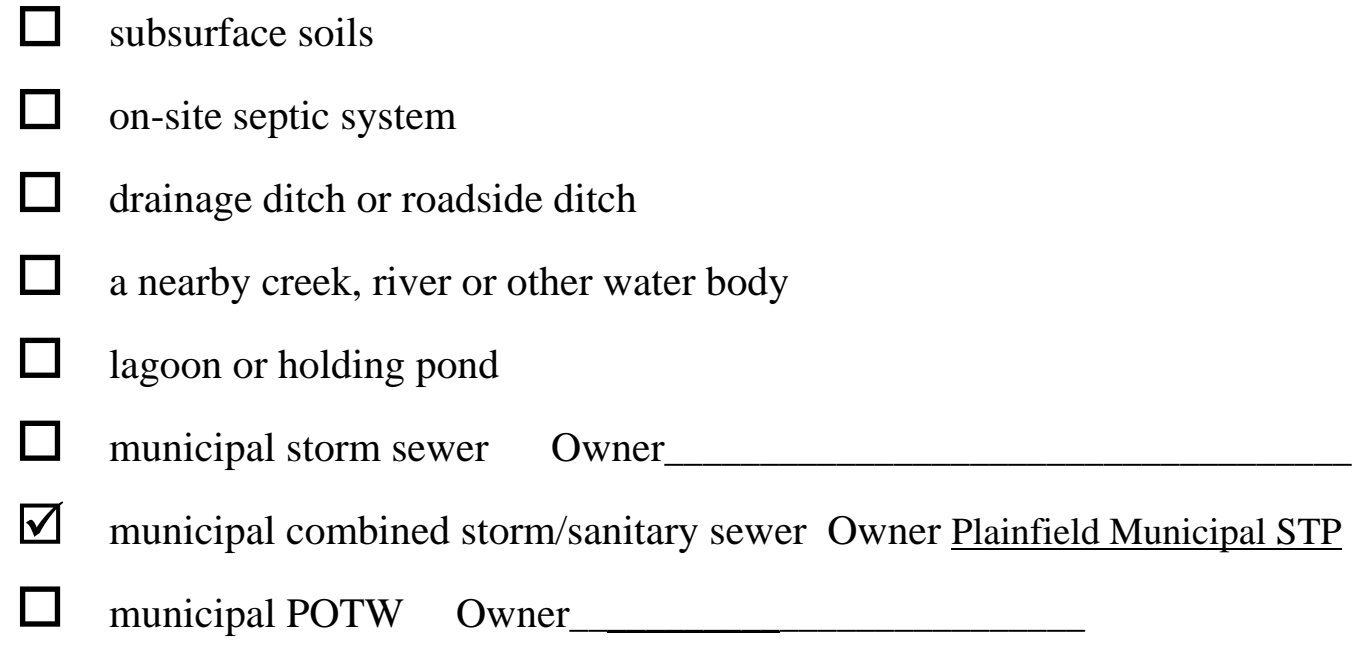

8. If shop floor drain and wash bay effluent is discharged, other than to a municipal storm, sanitary or combined sewer, does it ultimately reach "waters of the state?" If yes, name of that water body:

Activity Areas (check those that apply and describe (1) whether they are bermed to prevent storm water runoff or (2) if there are drains and their locations in the activity areas)

$\square$ salt storage (pads or domes) _ The entrance of the dome was covered by a building -

$\square$ salt/sand mixing_ The mixing area was also inside the building but there was no berm -to prevent storm water from flowing into the building or out of the building.

$\square$ salt bed loading/wetting_This area is the same as the mixing area. Again there was _was no berm in this area

$\square$ salt bed washout__All done inside building with drains

$\square$ salt bed storage _ No berm or drain, The beds are hung above an asphalt paved area approx. $5 \mathrm{ft}$ from the perimeter ditch

$\square \quad$ vehicle and equipment washing (inside) _ Done inside building with drains

$\square$ vehicle and equipment washing (outside)

$\square$ asphalt equipment clean-out

$\square$ herbicide mixing and tank rinsing

$\square \quad$ traffic paint mixing and transfer

$\square$ bulk tank off-loading and storage

$\square$ waste piles (e.g., ROW trash, street sweeping debris) _No berm or drains 
$\square$ truck/equipment parking_There was a small earth berm between this area and the _perimeter ditch that held some storm water

$\square$ truck/equipment fueling

$\square$ materials storage (210 lot, fencing, etc.)

$\square$ aggregate storage_No berm or drain

$\square \overline{\text { hot/cold patch storage _ _ Stored outside covered with a tarp with no berm or drain }}$

$\square$ storage of “scalp” and dirt from R/W maintenance 


\section{INDOT Site Assessment Report Observations and Comments}

\section{$\underline{\text { Surface Area }}$}

General

$>$ This site is not connected to POTW and is not equipped with an oil/water separator. All salt bed washing and truck washing is performed onsite. However, all vehicle maintenance is performed at the Fowler Subdistrict, which is approximately 28 miles from the facility.

$>$ There is a detention pond located in the SW corner of the property that collects the stormwater that drains from the salt dome and salt bed loading areas.

$>$ The floor drains located in the Unit Building are piped to the HWY 63 roadside ditch that runs along the NW property line. This roadside ditch drains into Fall Creek approximately 0.5 miles southwest of the site.

$>$ There were a large number of 1-5 gallon chemical bottles and 2 55-gallon oil drums inside the Unit Building that were not secondarily contained.
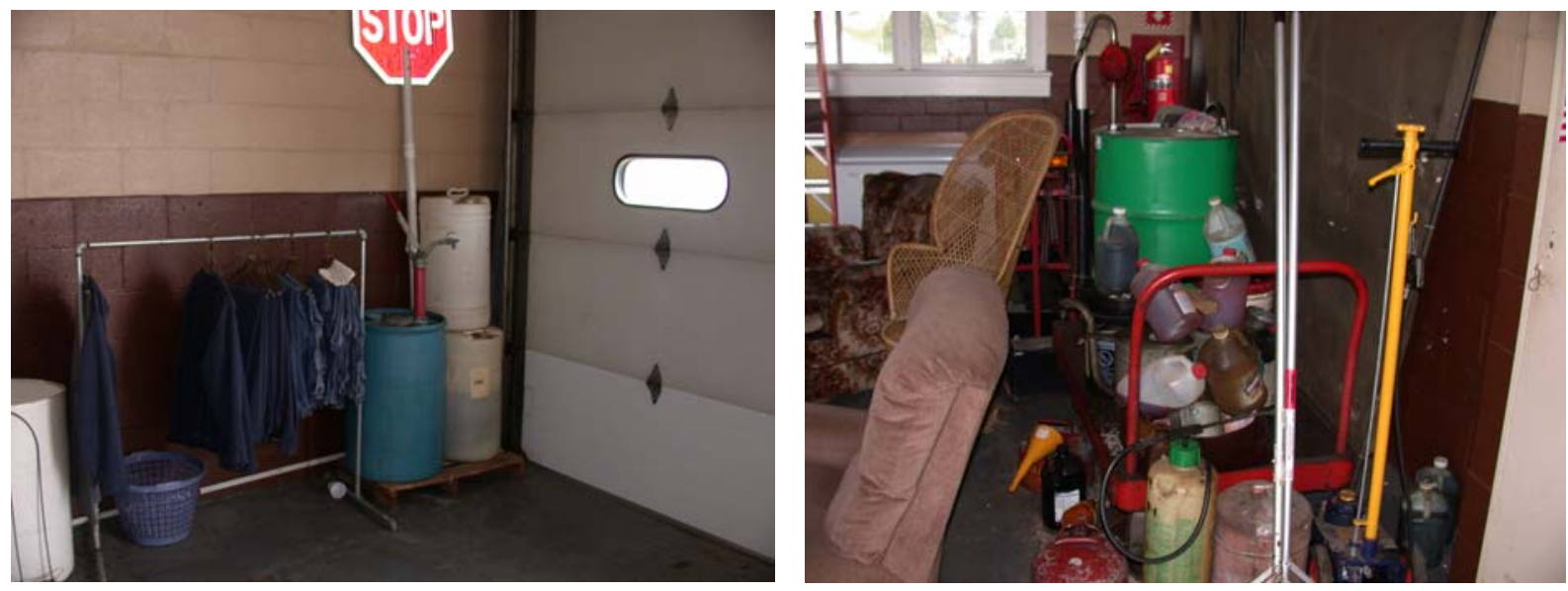
North East portion of Property

$>$ The Entrance to the site is in the NE corner of the property. Old salt bed racks(no longer used) are located in this corner. A small cold storage building and an even smaller tool shed are located NW of the old salt bed racks.

An approximately one acre pond is located outside of the fence, NE of the property line. Some stormwater from the NE portion of the property may enter this pond. The pond was likely formed from a borrow pit used to build an overpass.

$>$ There is a large pile of scrap metal just inside the NE fence line. There is no cover or berm around this pile of metal.

A large cold storage building is located in the NW corner of the site. This building contains no drains and is used to store tractors and other tools. There is a tar kettle parked outside on the south side of this building with no cover or berm. There are also several large stormwater pipe segments located in this area.

The Unit Building is located in the center of the NE half of the property. The truck parking area is on the south side of the Unit Building.
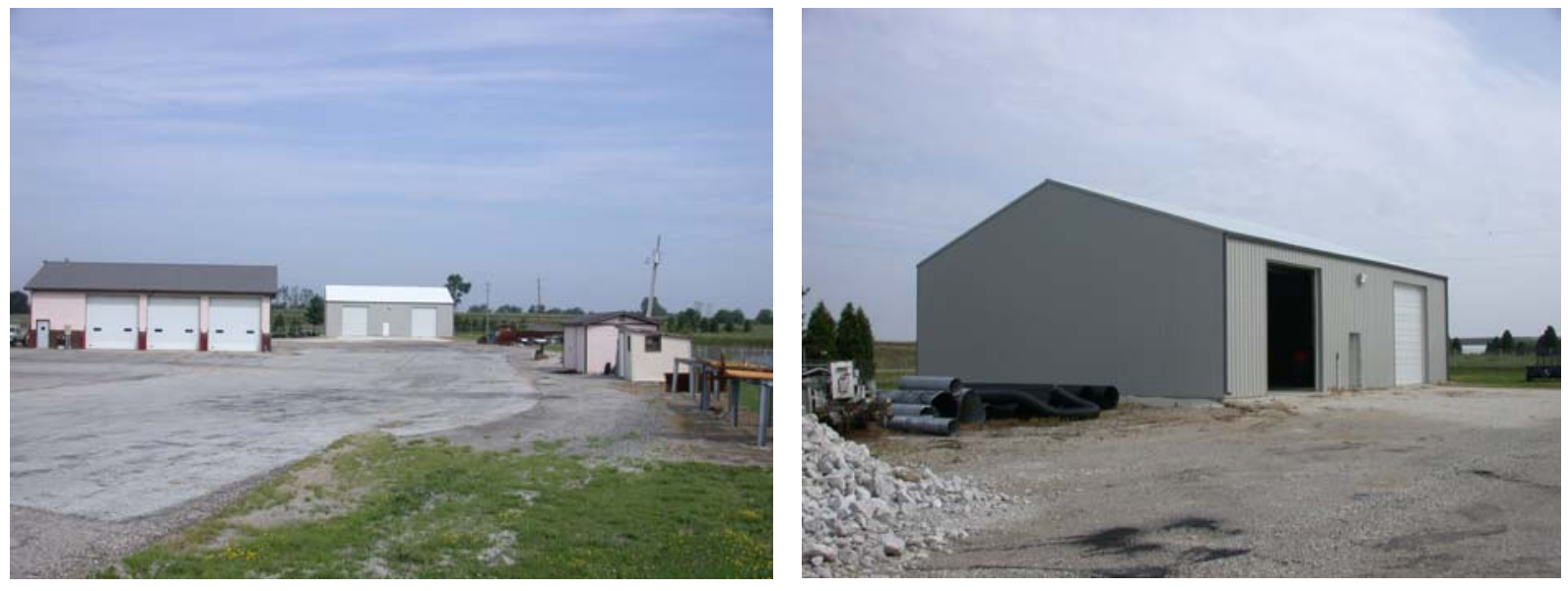

* South West Portion of Property

A secondarily contained $\mathrm{MgCl}$ tank is located approx. $100 \mathrm{ft}$ east of the truck parking area.

A ditch, running NW to SE, spans the entire width of the property. Essentially all stormwater or washwater from the NE half of the property will enter this ditch, which drains into the US 41 roadside ditch. This roadside ditch also drains into Fall Creek approximately 0.5 miles SE of the site. 
Salt bed racks are located SE of the ditch. There is a small building located on the west side of the salt bed racks. The building is used to store road signs and other odds-and-ends.
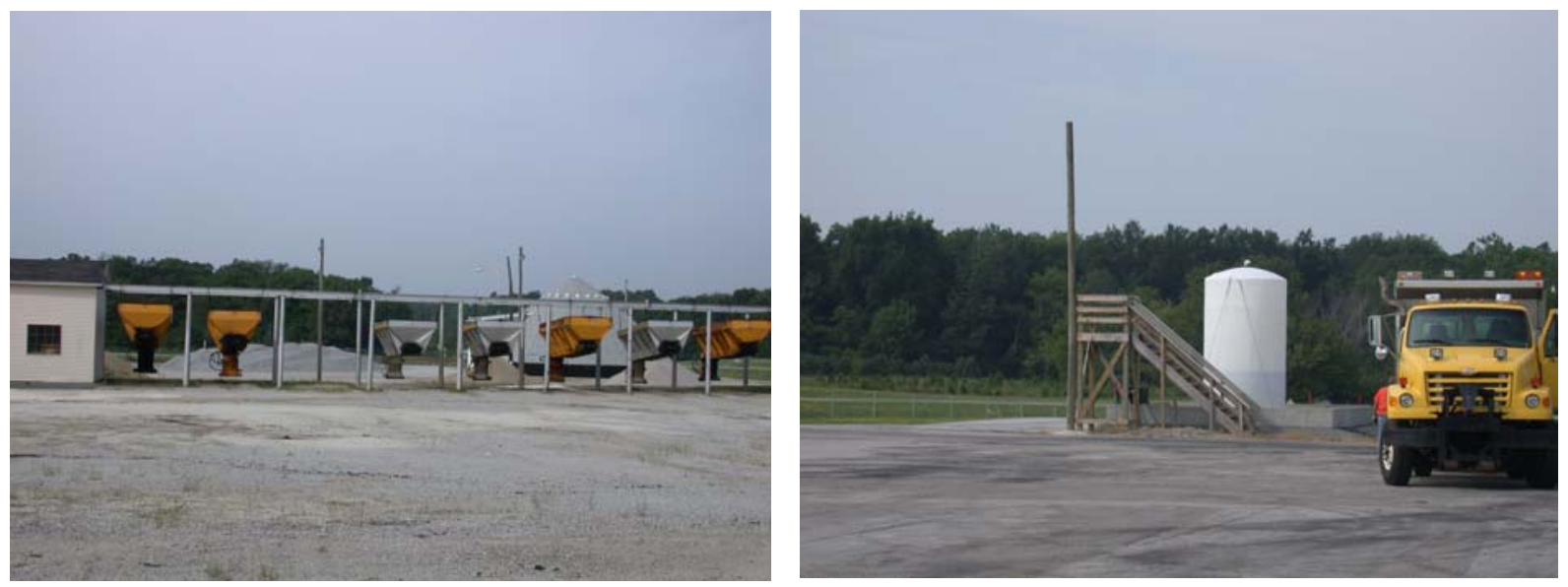

Several large aggregate piles are stored SE of the salt bed racks. There is also two large piles of cold patch located in this area that are not covered or bermed.

There is a small ditch that runs from east to west and drains into the HWY 63 roadside ditch. This ditch collects stormwater from the areas around the salt bed racks, aggregate piles, and part of the Salt Dome.

The Salt Dome is located in the SE corner of the property. There is a detention pond next to the Salt Dome. This pond collects some of the stormwater falls around the entrance of the Salt Dome.
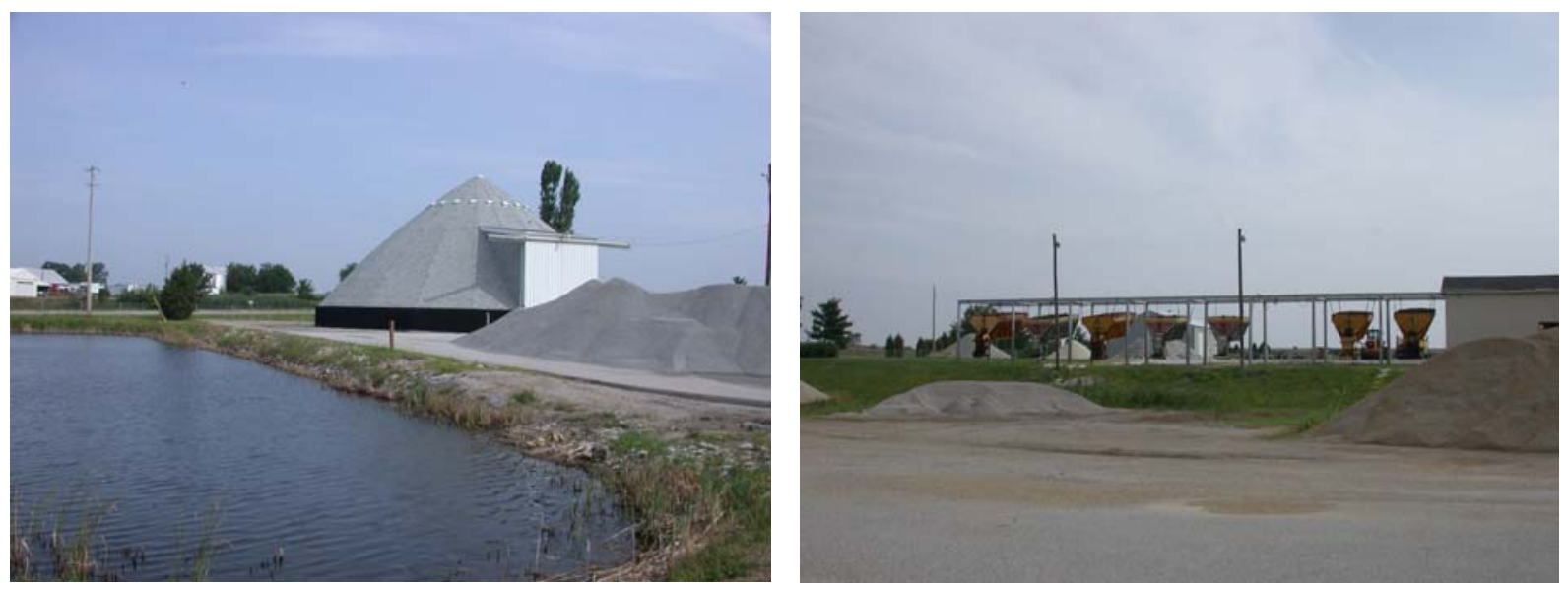

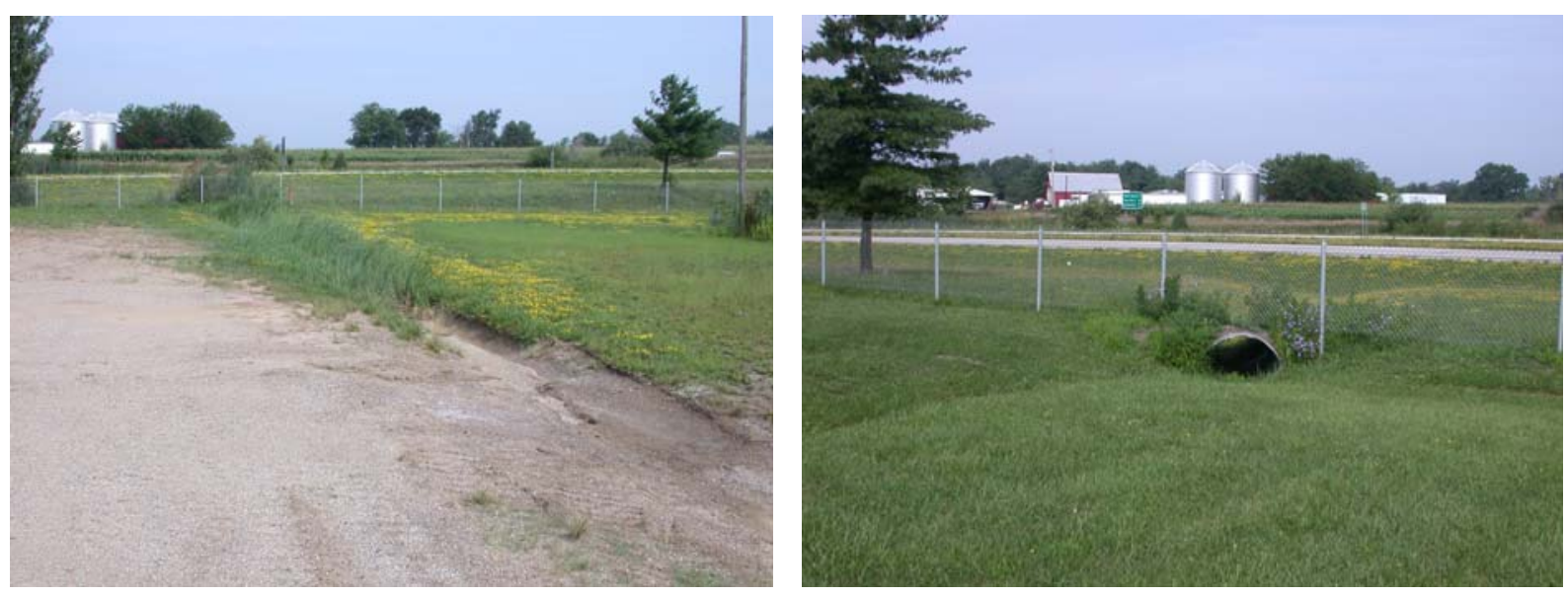

\section{Buildings}

Unit Building

There is no oil/water separator in the Unit Building. All vehicle and salt bed washing is performed inside the unit building or right outside of the unit building. In both cases the washwater drains into the HWY 63 roadside ditch.

Most of the chemicals stored in the Unit Building are not secondarily contained.

\section{Salt Dome}

There was a small amount of salt on the ground around the entrance of the Salt Dome. It was evident that some salt was being transported via stormwater runoff into the roadside ditch.

Other Buildings

There is one large cold storage building and three small tool sheds on site. None of these buildings have floor drains or have liquids stored within them. 


\section{INDOT Site Assessment Report Observations and Comments}

\section{$\underline{\text { Surface Area }}$}

General

$>$ This facility is connected to a POTW but is not equipped with an oil/water separator.

There are four, 10,000 gallon underground storage tanks that receive stormwater from the site and all liquids captured by the indoor floor drains. Water from the tanks is slowly metered into the sewer at a desirable rate.

All outdoor catch basins that collect stormwater and washwater drain into the underground storage tanks.

There is a traffic paint mixing area and a 210 lot at this facility. The paint is mixed and loaded outside over a catch basin that drains into a grassed ditch, which eventually empties into Black Creek approximately 0.25 miles from the facility. The ditch was full of yellow paint and when asked if this was an acceptable practice the environmental coordinator said that the paint is water soluble and therefore is not harmful to the environment.
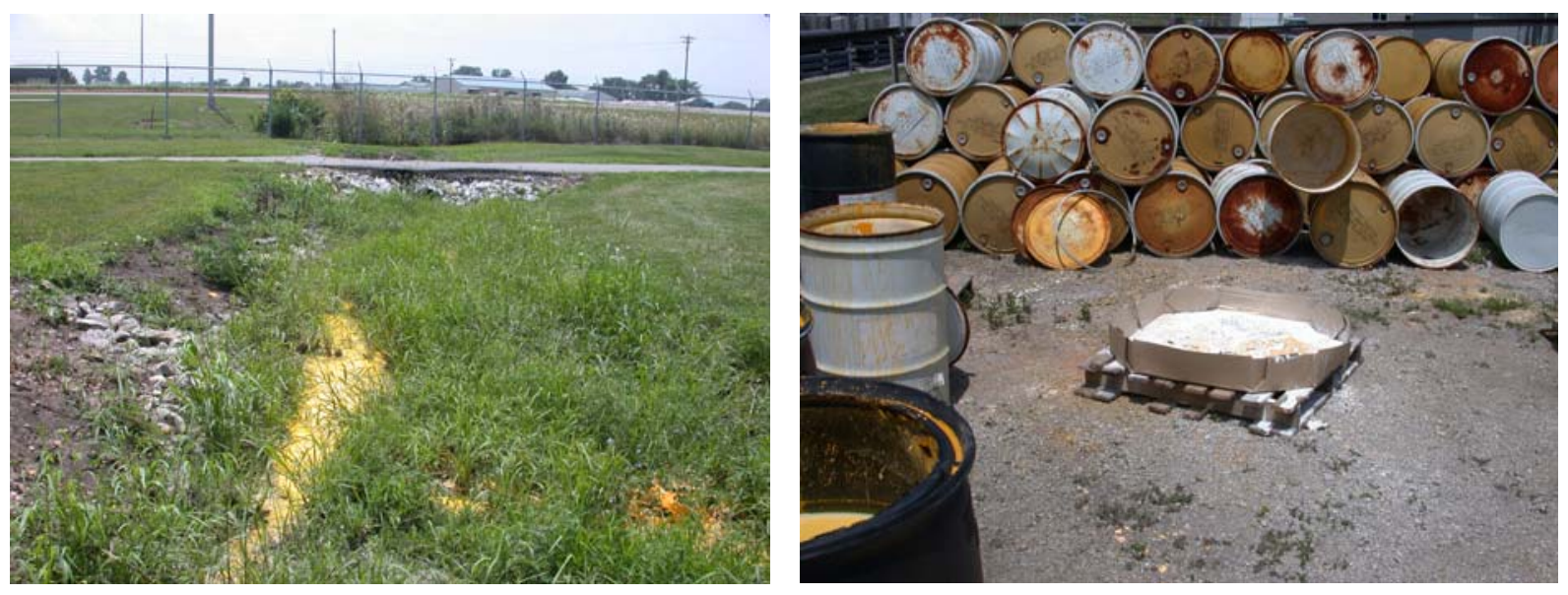


\section{East Portion of Property}

There are two small piles of sand, a small pile of plastic and metal scrap, and several snow plows stored in the NE corner of the facility fence line.

An old rectangular salt storage building, which is currently used to store sand, and a secondarily contained $\mathrm{MgCl}$ tank are located along the north fence line. All stormwater from this area is collected in a catch basin near the center of the site and conveyed to the underground storage tanks on the south side of the property.

The new Salt Dome is located west of the old salt storage building. The area around the new Salt Dome is graded to allow runoff to be collected in a concrete ditch on the west side of the dome. This concrete ditch drains into a catch basin, which conveys all stormwater to the underground storage tanks. A pile of cold patch is stored on the north side of the Salt Dome with no cover or berm.

$>$ The Salt Bed Racks are located approx. 20 feet south of the Salt Dome. The salt beds are stored outside over a concrete pad. All stormwater from this area enters the same catch basin as the stormwater from the Salt Dome area.
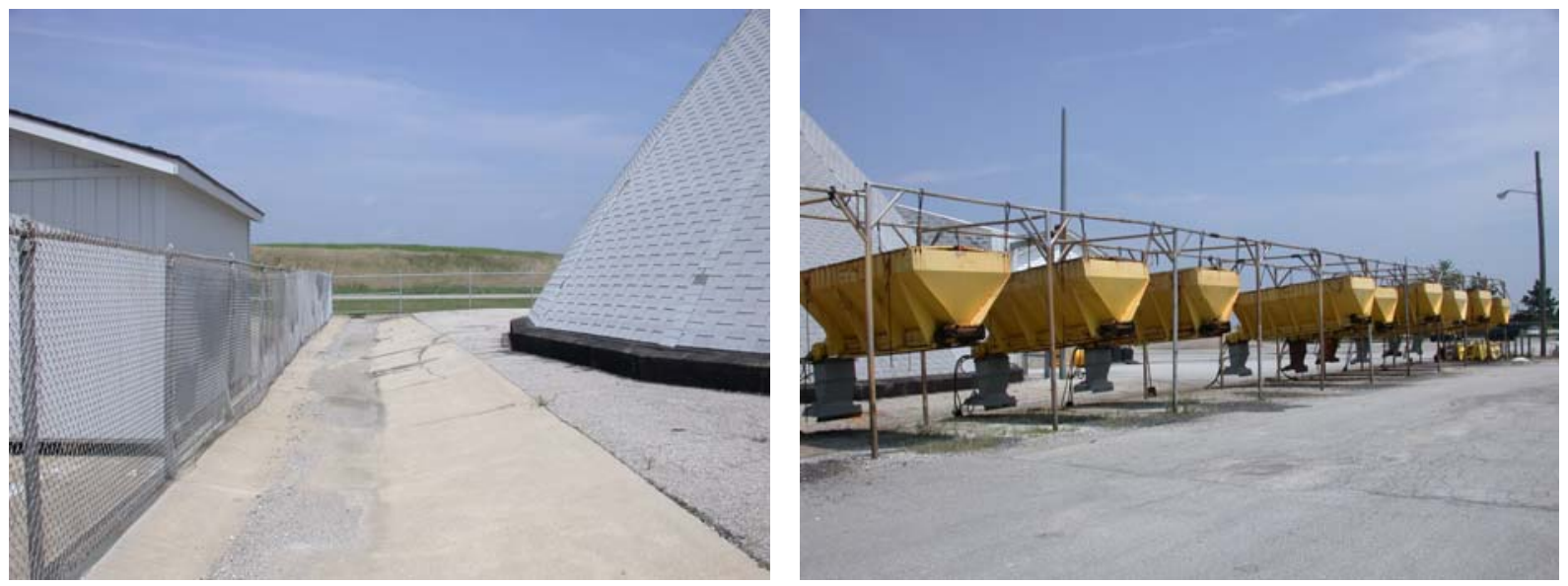

There is a large cold storage building located west of the Salt Dome. This building is used to store tools, tractors, and road signs.

The Sub Building is located in the SE corner of the fence line. This building contains a maintenance area with floor drains and an office area. All liquids captured in the floor drains are conveyed to the underground storage tanks.

There is an outside salt bed and vehicle washing area located on the west side of the sub building. A large catch basin collects all washwater and all stormwater from the area and drains into the underground storage tanks. 
There is another cold storage building located approx. 50 feet west of the washing area. This building is also used to store tools but contains some offices as well.

The 4, 10,000 gallon underground storage tanks are located south of the cold storage building along the south fence line. There are metal access doors and vents located on top of the ground for each tank. There are also several metal pipe segments, several tractors, and a large dumpster in the area.
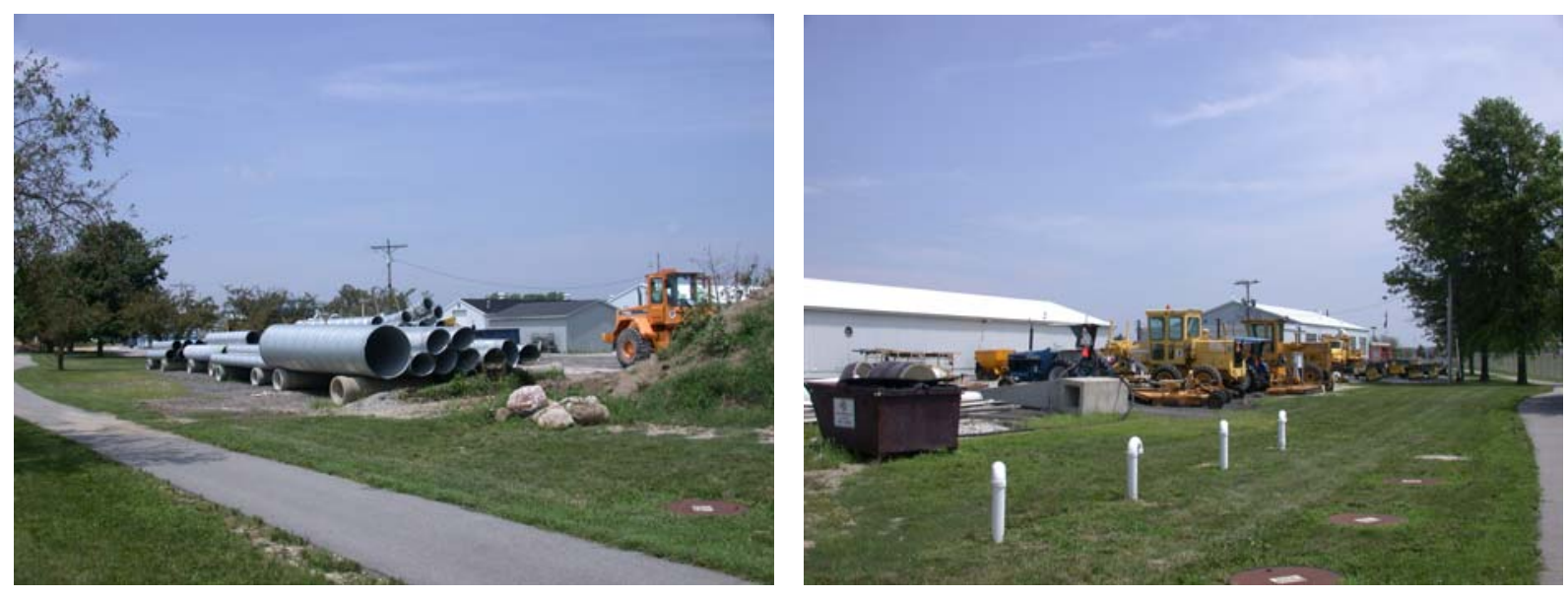

West Portion of Property

There is a Paint Mixing Area and a 210 lot located on the west portion of the property.

The paint area is not kept clean. There were numerous 55-gallon drums of both white and yellow paint turned on there sides and leaking paint onto the ground. There were also several 55-gallon drums of paint standing up-right, with no lids, collecting rain and overflowing onto the ground. All stormwater and spilled paint from the area drains into a grass ditch that empties into Black Creek approx. 0.25 miles from the facility.

All paint mixing and loading is performed outside over a catch basin that also empties into the grass ditch. No precautions are taken to reduce the amount of paint entering the environment. Paint is purposefully washed into the catch basin.

The grass ditch located on the east side of the paint mixing area is filled with dark yellow water.

The Environmental Coordinator said that the paint has no negative effects on the environment because it is water-based paint not oil-based. He also admitted that there has been complaints from the public about the yellow water in the ditch. 

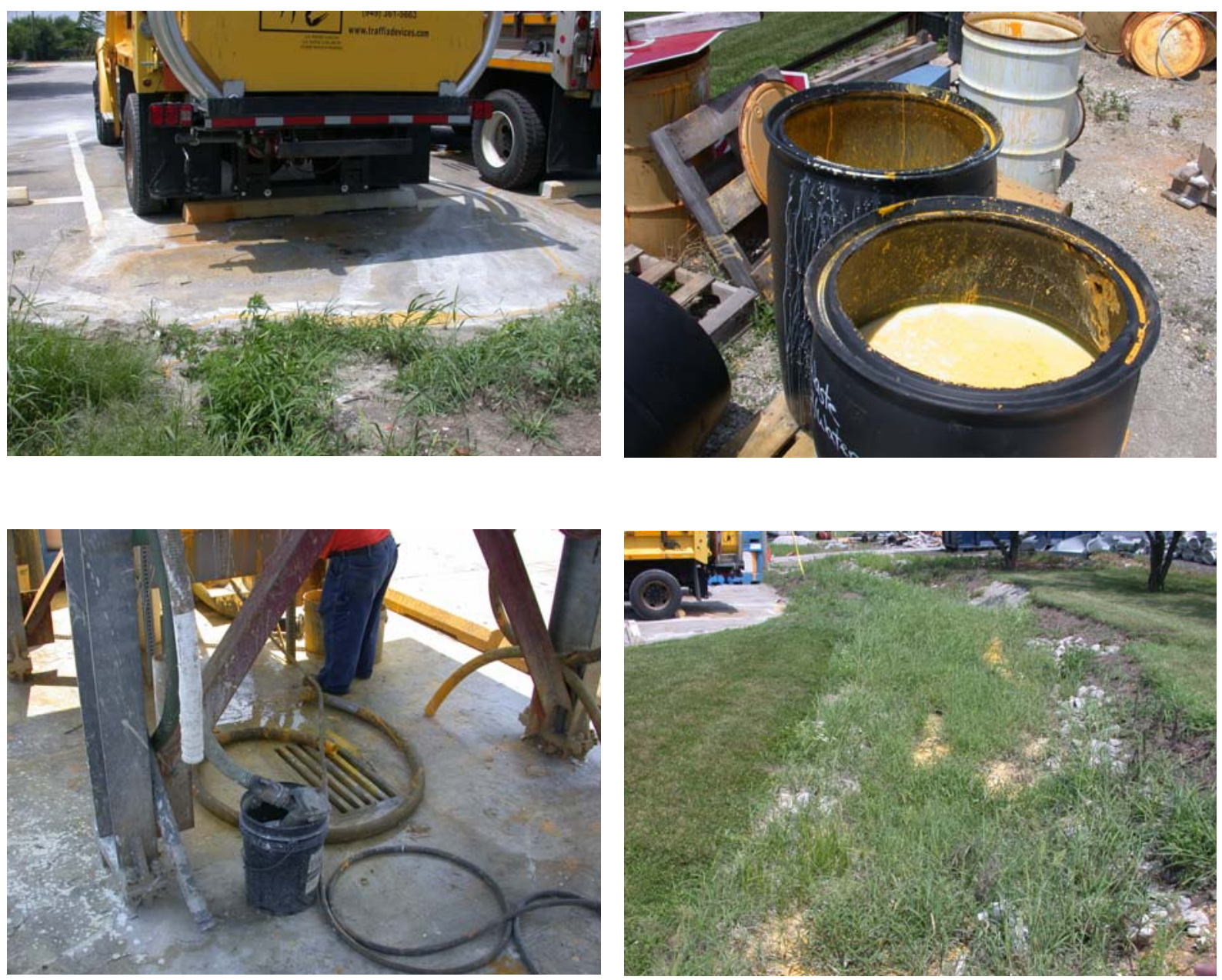

$>$ The 210 lot is located west of the paint mixing and loading area. All stormwater from the 210 lot enters a roadside ditch that eventually empties into Black Creek.
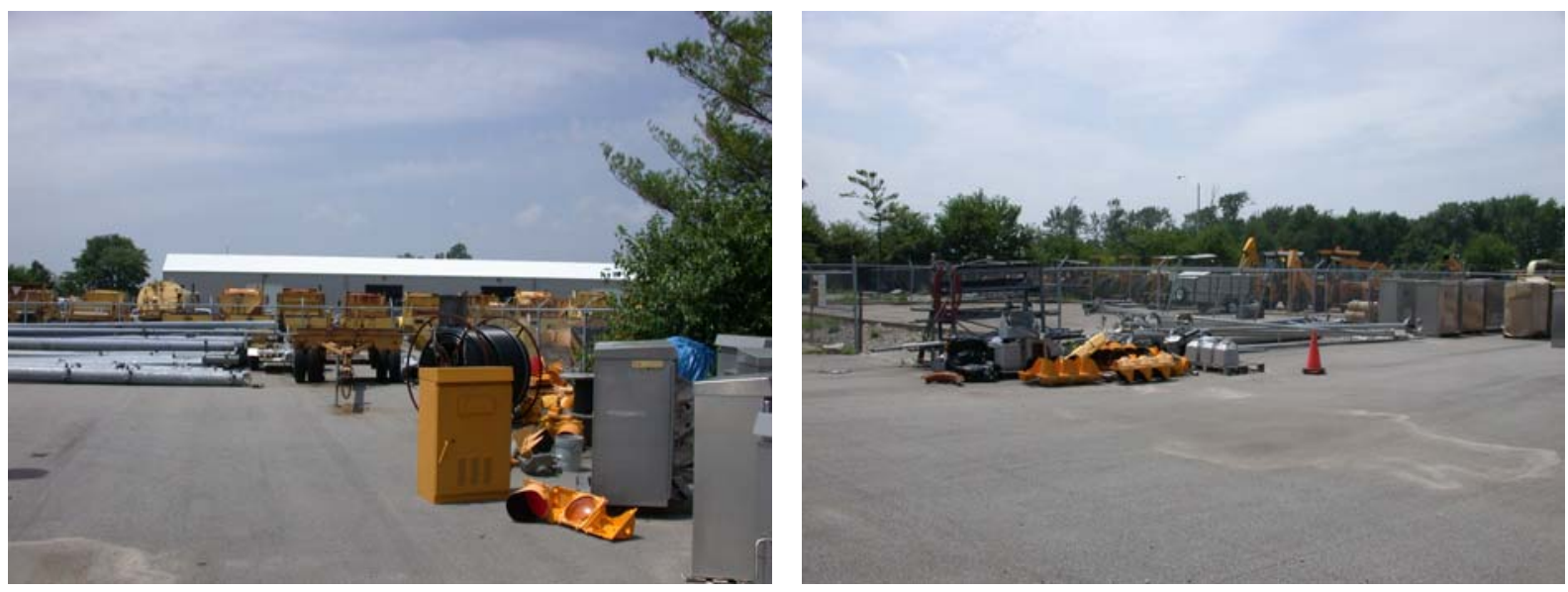


\section{Buildings}

* Sub Building

$>$ There is no oil/water separator in the Sub Building. There were 55-gallon oil drums inside the Sub Building that were not secondarily contained.

* Salt Dome

$>$ The stormwater from around the Salt Dome enters a catch basin that drains into the underground storage tanks.

* Traffic Paint Building

$>$ There are several offices and a break room in the paint building. There is also a large room were road signs are painted that has floor drains that empty into the sewer.

* Other Buildings

There were several cold storage buildings onsite and the district central office building is located east of the sub district area. 


\section{INDOT Site Assessment Report Observations and Comments}

\section{Surface Area}

General

Most of the stormwater from this facility enters a municipal combined sewer system.

$>$ All vehicle and salt bed washing is performed outside. The washwater flows into a catch basin that is connected to a municipal combined sewer system.

$>$ This facility is not equipped with an oil/water separator. Very little vehicle maintenance is performed at this facility.

\section{West Property Line}

The Unit Building is located on the SW corner of the property. There are offices and a maintenance area inside the Unit Building. All floor drains inside the Unit Building drain directly into the municipal combined sewer system.

$>$ An outside vehicle and salt bed washing area is located on the east side of the Unit Building. All washwater from this area flows into a stormwater curb drain near the entrance of the facility. This drain also catches stormwater from the road that runs along the south property line.
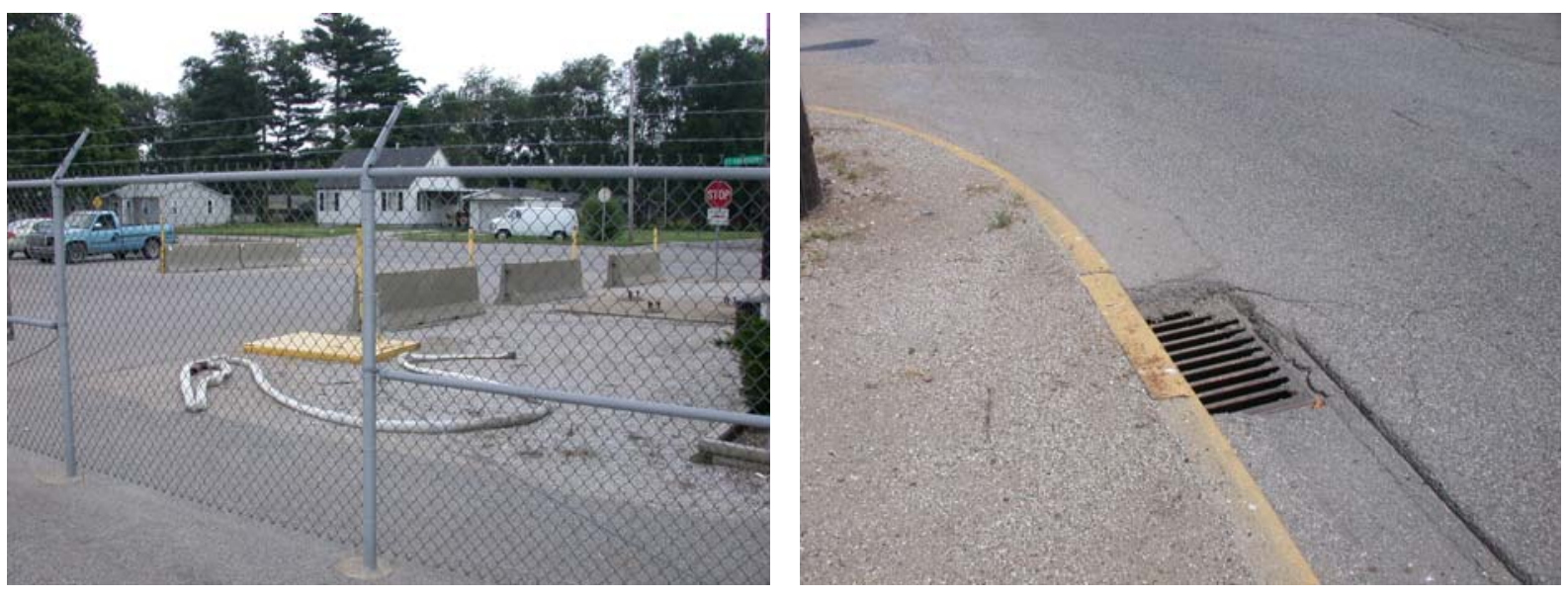
> There are two cold storage buildings located north of the Unit Building. These cold storage buildings are used to store tools, tractors, road signs, and other miscellanea.

There is also a truck parking area on the north side of the Unit Building. The stormwater from this area enters a catch basin that drains into the combined sewer system. There is also a tar kettle parked in this area that is not bermed.

$>$ On the north side of one of the cold storage buildings there is a secondarily contained Magnesium Chloride tank.
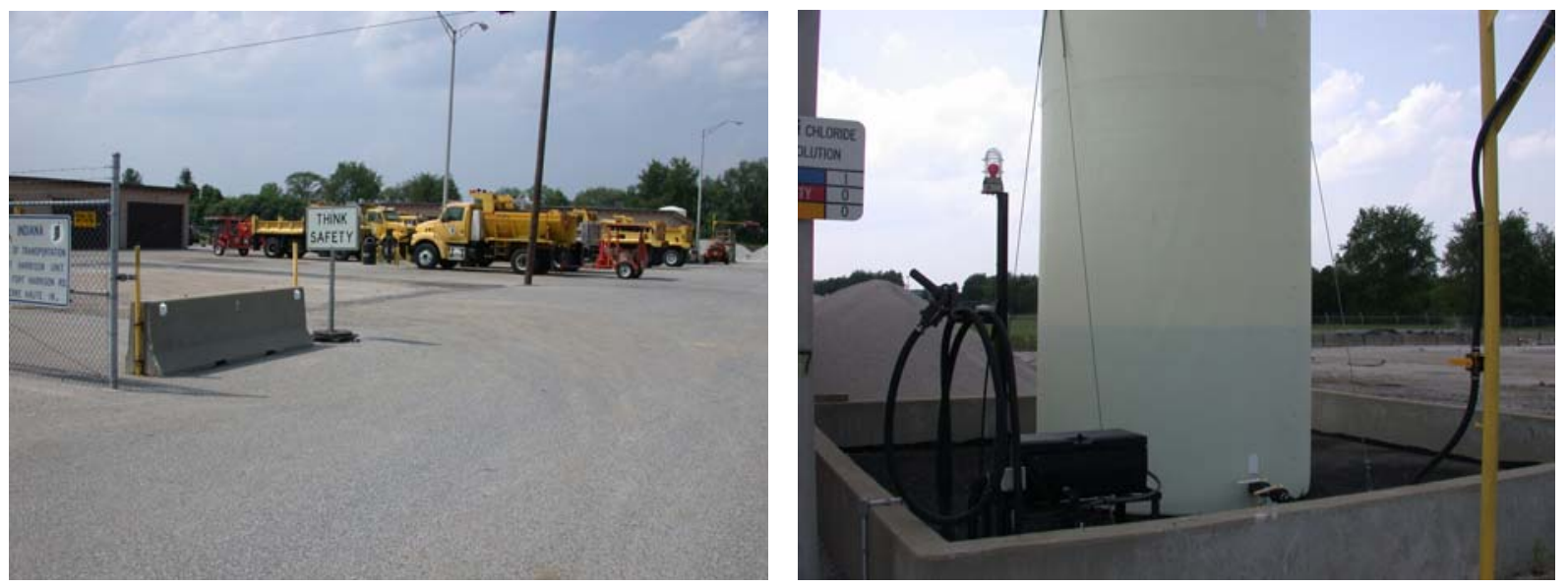

There are several piles of aggregate stored in the NW corner of the property.

\section{East Property Line}

The SE corner of the property is used to store snow plows and a large pile of cold patch. The pile of cold patch is not properly bermed and or covered with a tarp.

$>$ The salt bed racks are located approximately 10 feet north of the cold patch pile.

The stormwater from the SE corner of the facility flows into either catch basins inside the facility boundaries or under the south fence line into the street curb catch basins.

There is a large pile of plastic pipe segments being stored on the north side of the salt bed racks

The Salt Dome is located in the NE corner of the facility. There was very little salt residue on the ground around the Salt Dome and salt bed loading area. Stormwater from this area flows offsite, under the NE corner perimeter fence. 
There were no signs of salt being transported offsite in stormwater runoff.
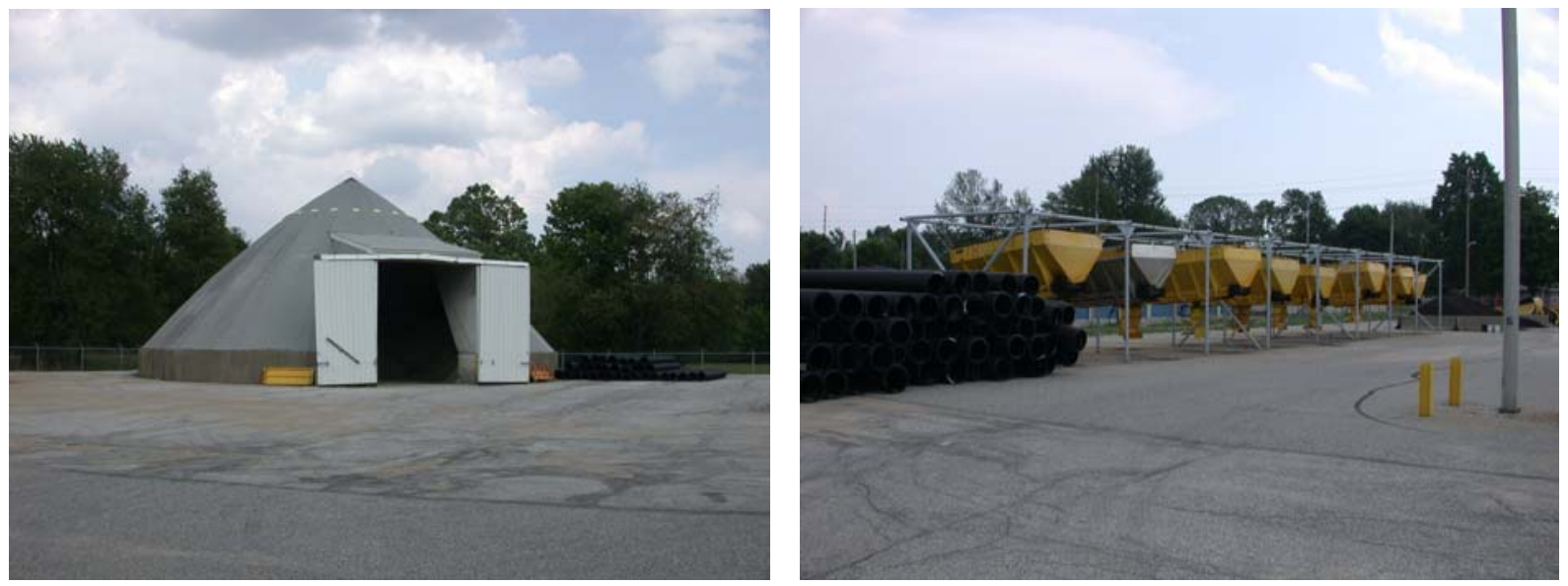

\section{Buildings}

Unit Building

> There is no Oil/Water separator in the Unit Building. There are several floor drains inside the Unit Building that prevent liquids from exiting the building. All floor drains drain into the municipal combined sewer system.

Because oil changes are not performed at this facility, there is very little oil stored on site.

Salt Dome

The are around the salt dome is kept clean of salt. There are no drains or catch basins near the Salt Dome.

All stormwater from the area flows offsite under the NE corner perimeter fence line.

Other Buildings

Both cold storage buildings are used to store tools and tractors. All floor drains inside these buildings are connected to the combined sewer system. 


\title{
INDOT Site Assessment Report Observations and Comments
}

Facility: Lebanon Unit

February 9, 2005

\author{
Surface Area
}

General

$>$ This facility is not connected to a sewer system. There is a septic system and drinking water well on site.

All storm water is collected in ditches that encompass the site and drain into Prairie Creek, approx. $100 \mathrm{ft}$ from the edge of the property.

The shop floor drain is not connected to an oil/water separator. It is piped to the roadside ditch on US-52, which empties into Prairie Creek.

$>$ The Sub District Building is located in Frankfort, approx. 16 miles away. Due to the lengthy commute, most truck and salt bed washing occurs at the Lebanon site along with minor maintenance jobs. Wash water flows into the roadside ditch, which empties into Prairie Creek.

The site is located on US-52, which runs along the North property line.

\section{West Property Line}

$>$ The salt racks are located in the Northwest corner of the property, approx 5-10 feet from the West ditch. The soil under the racks is a mixture of sand and gravel, and the land slopes toward the ditch. Don Arnold suggested building a small berm between the salt racks and ditch.

$>$ The Unit Building is southeast of the salt racks and faces North, toward SR-52.

On the south side of the building, there is a waste oil tank, which has no secondary containment. On the ground around the waste oil tank there was evidence of some oil spillage. Next to this waste oil tank were three 5-gallon buckets: one lying on its side and two that were upright and overflowing a mixture of oil and rainwater. These buckets were either used to transport waste oil from inside the Unit Building to the waste oil tank or used on asphalt jobs. This area sloped toward the West ditch. 
> The Magnesium Chloride tank is south of the Unit Building and secondarily contained with a concrete enclosure. No overhead salt bed spraying occurs at this site.

The truck and salt bed washing area is to the southeast of the Magnesium Chloride tank. This area is not bermed, and all wash water flows approx. 30 yards into the West ditch.

$>$ The herbicide and pesticide storage building is located south of the wash area. On the west side of this building, there were 10-15 unmarked 55-gallon drums. Many of the drums had a significant amount of exterior rust. This area also slopes toward the West ditch.

The salt dome is located to the south of the herbicide and pesticide storage building. This area is not bermed and it slopes toward the West ditch. There is also a ditch behind the Salt Dome, which divides the property. This ditch conveys water from the West ditch to the East ditch. There are several large aggregate piles south of the salt dome

\section{East Property Line}

The Northeast quadrant of the property is mainly used for truck and equipment parking. It is a gravel area and slopes toward the East ditch.

$>$ The Mix Shed is located south of the parking area. This building is used for sand and cold patch storage.

A loading ramp is positioned in front of the Mix Shed. The area around the loading ramp was free of salt.

There is a large Cold Storage Building located in the Southeast corner of the site, south of the ditch, which divides the property.

\section{Buildings}

Unit Building

In the center of the Unit Building there is a lateral floor drain that spans the entire width of the building. This drain is not connected to an oil/water separator. It is piped directly to the SR-52 roadside ditch, which empties into Prairie Creek. 
There were three 55-gallon drums on containment pallets, which stored hydraulic fluid and possibly oil. However, all oil changes were said to be done at the Sub District.

$>$ A tar kettle was parked in the building along with tools. All chemicals and paints were properly stored in fireproof lockers that also provide secondary containment.

* Herbicide and Pesticide Storage Building

This is a small, wooden building that is used to store herbicide, pesticide, and tools. All chemicals were stored in fireproof lockers with built-in secondary containment. There was no evidence of any leaks or spills.

\section{* Salt Dome}

All salt/sand mixing takes place outside at this site. The area around the Salt Dome was clean, and there was no sign of salt spillage.

$>$ There are no berms or drains around the Salt Dome. All storm water from this area drains approx. 30 yards to the West ditch

Mix Shed

$>$ This three-sided, covered building is used to store sand and cold patch. The morning of the site visit the roads were being salted due to a small snowstorm the previous night. Even so, the areas around the Mix Shed, Loading Ramp, and Salt Dome were clean with very little salt or sand. The cleanup job after the storm was very good.

\section{* Cold Storage Building}

$>$ This building contained several tractors and some grass cutting equipment. There were no drains in the building, and there was no sign of any fluid leaks from equipment getting outside the building. 


\section{INDOT Site Assessment Report Observations and Comments}

\section{$\underline{\text { Surface Area }}$}

General

$>$ This site is not connected to POTW and is not equipped with an oil/water separator. All salt bed washing and truck washing is performed onsite.

There is an outdoor washing area, north of the Unit Building. A catch basin in the center of the washing area captures wash water and storm water. This catch basin is actually a small settling tank that is outfitted with a J-tube outlet pipe. The Unit Building floor drains also discharge into this small settling tank. The water that exits the settling tank is piped to the east property line and eventually enters Burnett Creek, which is located 75 yards SE of the site.
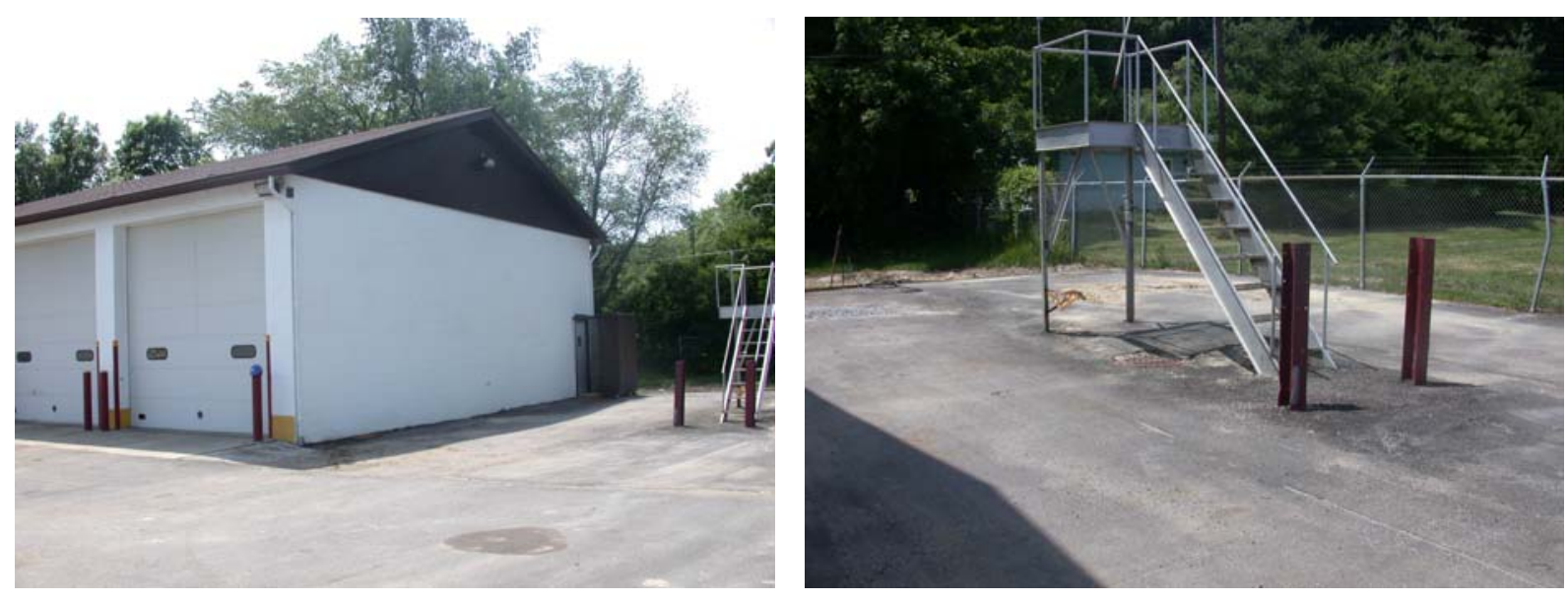
There is a, recently installed, brine production system at this Unit. There is no secondary containment around the equipment or the holding tanks. The Building that houses the brine equipment has drainage holes along the east side of the building, which allow any spills or water used to wash the equipment to drain outside.
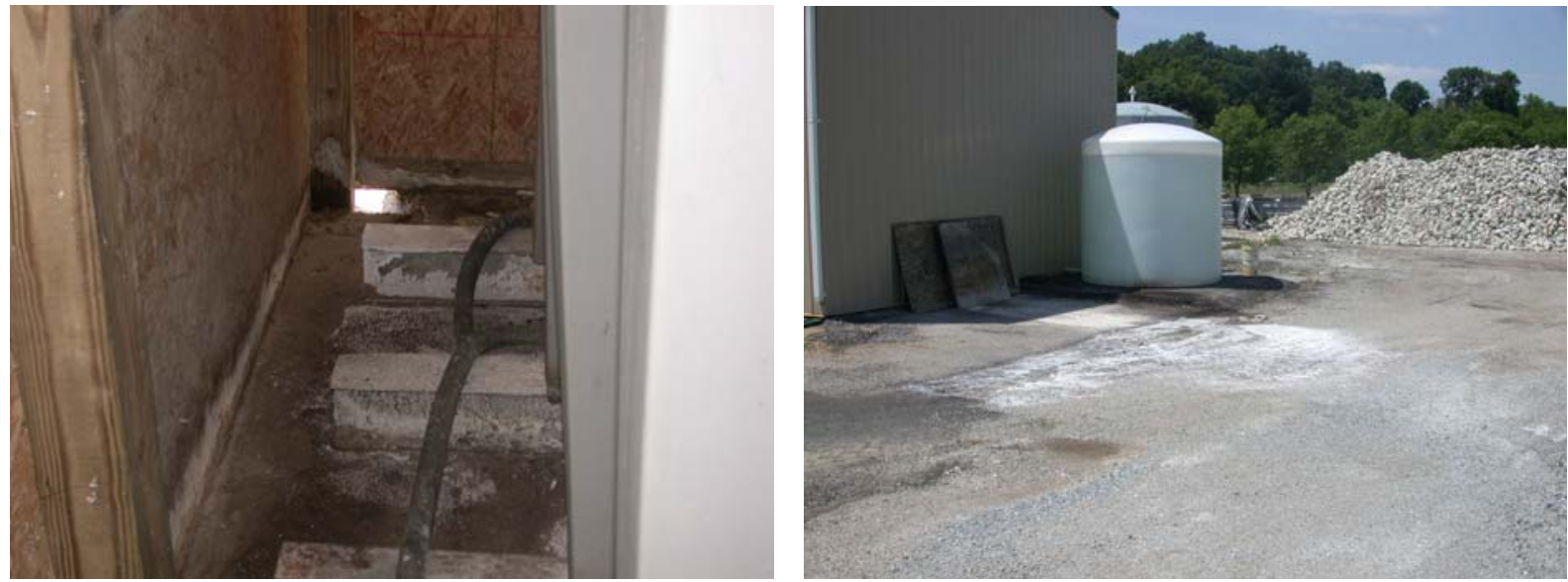

There is a large area of dead vegetation (including trees) on the east side of the property. This area is near the brine production and storage area. It is apparent that this vegetation kill was caused by salt runoff. This dead area is located outside the east property fence line and is approx. 15 feet by 60 feet.
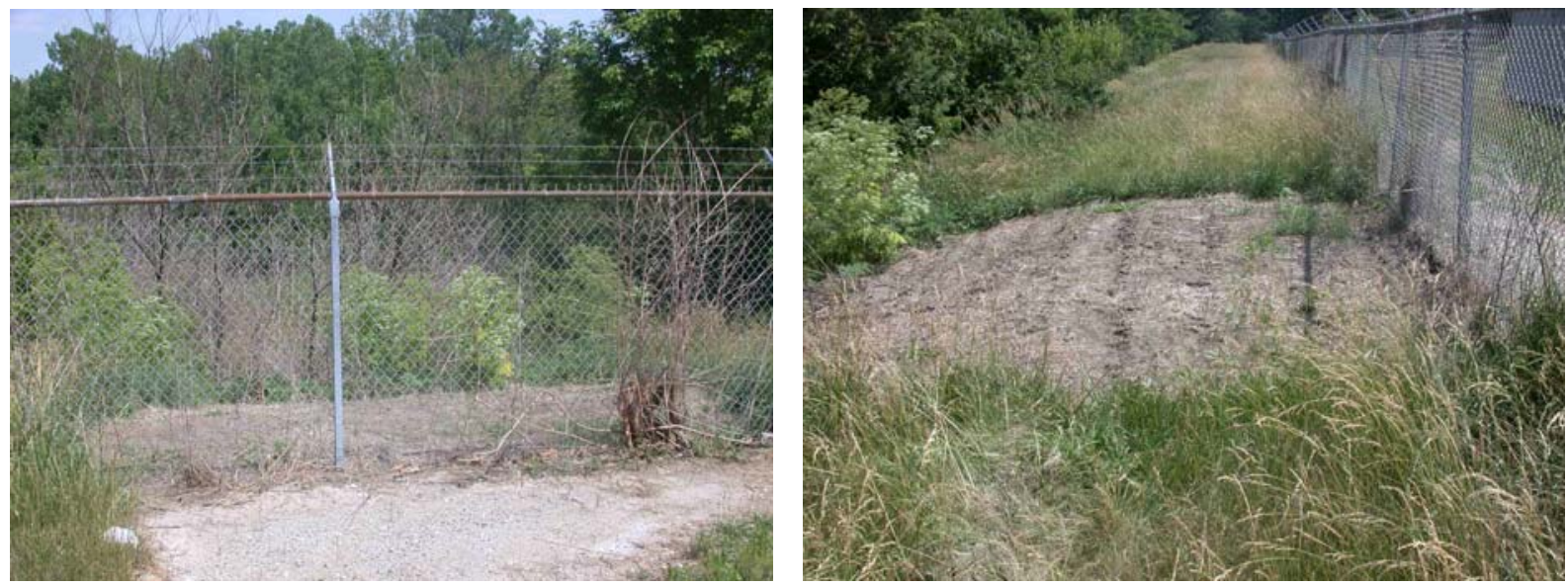

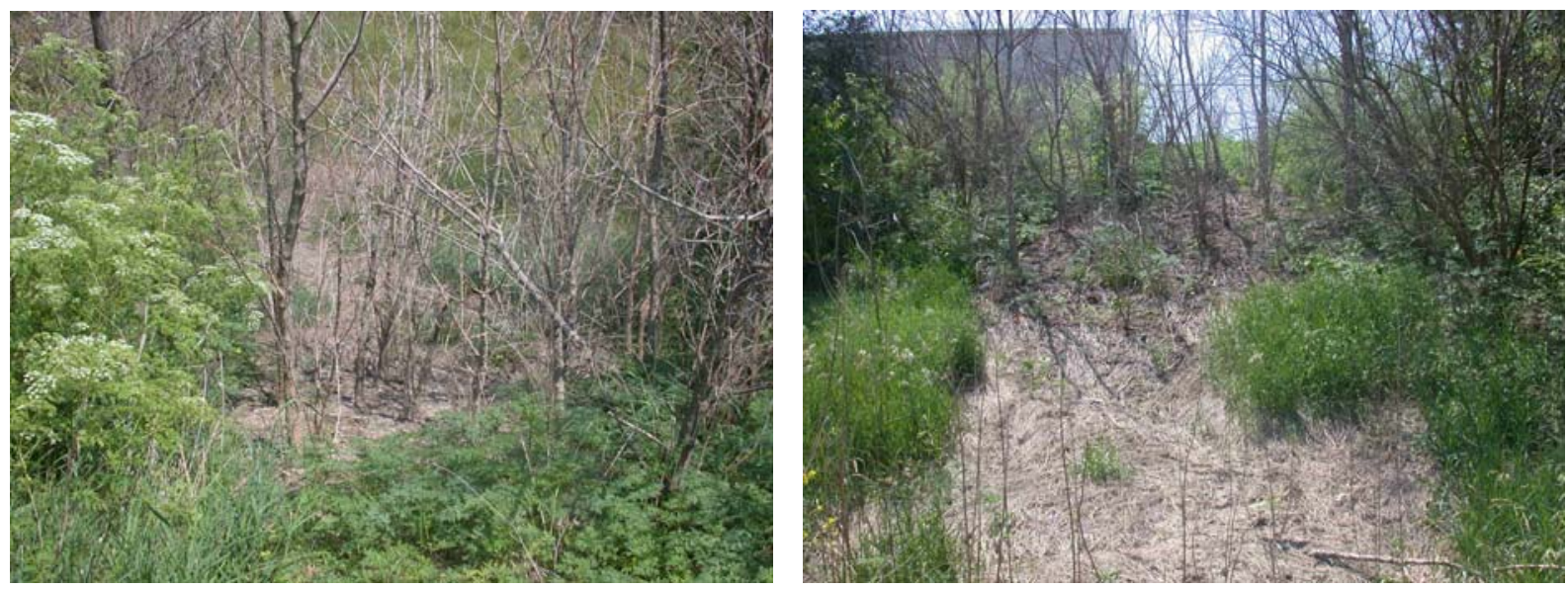

The amount of salt on the active surface and in the drainage ditches at this site is excessive. The drainage ditch behind the salt bed racks and the area behind the brine production system were coated with a layer of salt. The salt loading area, which is located at the entrance of the Salt Dome, was also covered with salt. It is evident that salt is being transported off site by storm water.
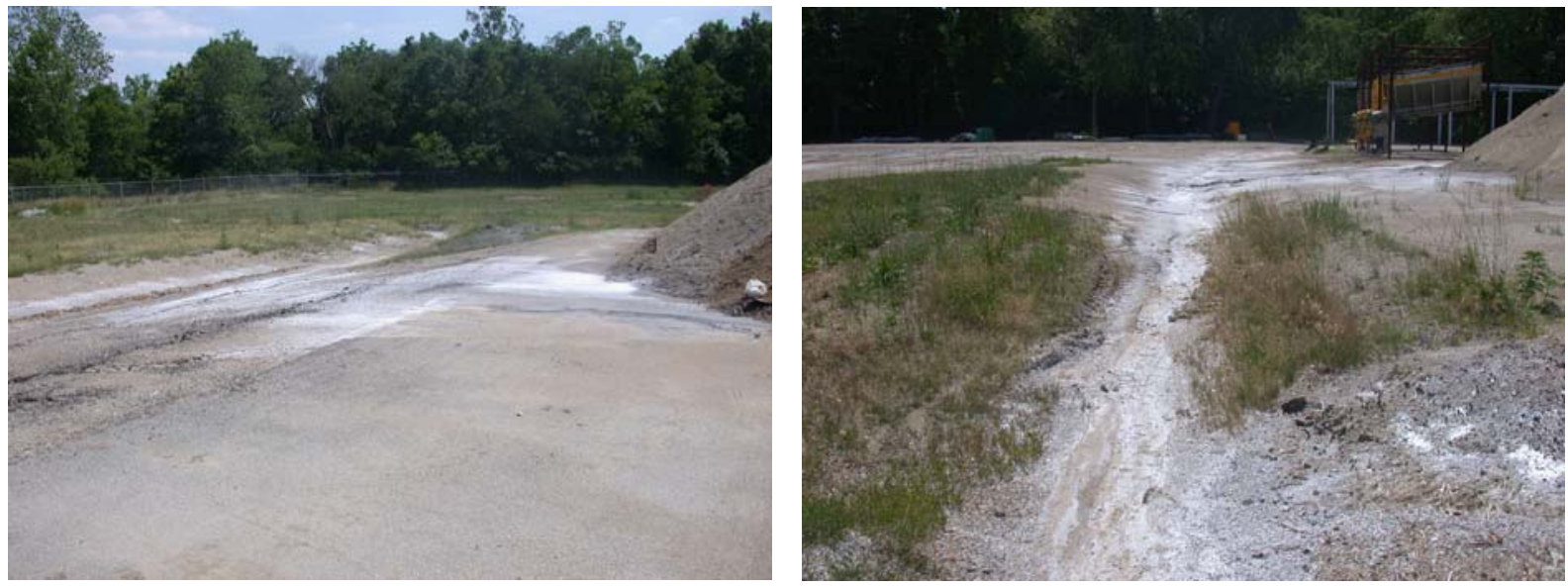

* West Property Line

$>$ This facility is located on the south side of State HWY 43. A parking area for personal vehicles is located outside the North fence line.

$>$ In the NE corner of the property, there is a truck and salt bed washing area. There is a catch basin located in this paved area that collects wash water and storm water. The water captured in the basin is then conveyed east by pipe and discharged off INDOT property. There is a low, unpaved area on the east side of this washing area that also collects some wash water and storm water. The water 
ponds in this area until it overflows to a ditch that drains to the east property line. At the time of the site visit a truck bed, which previously contained cold patch, was being washed out over this unpaved area.
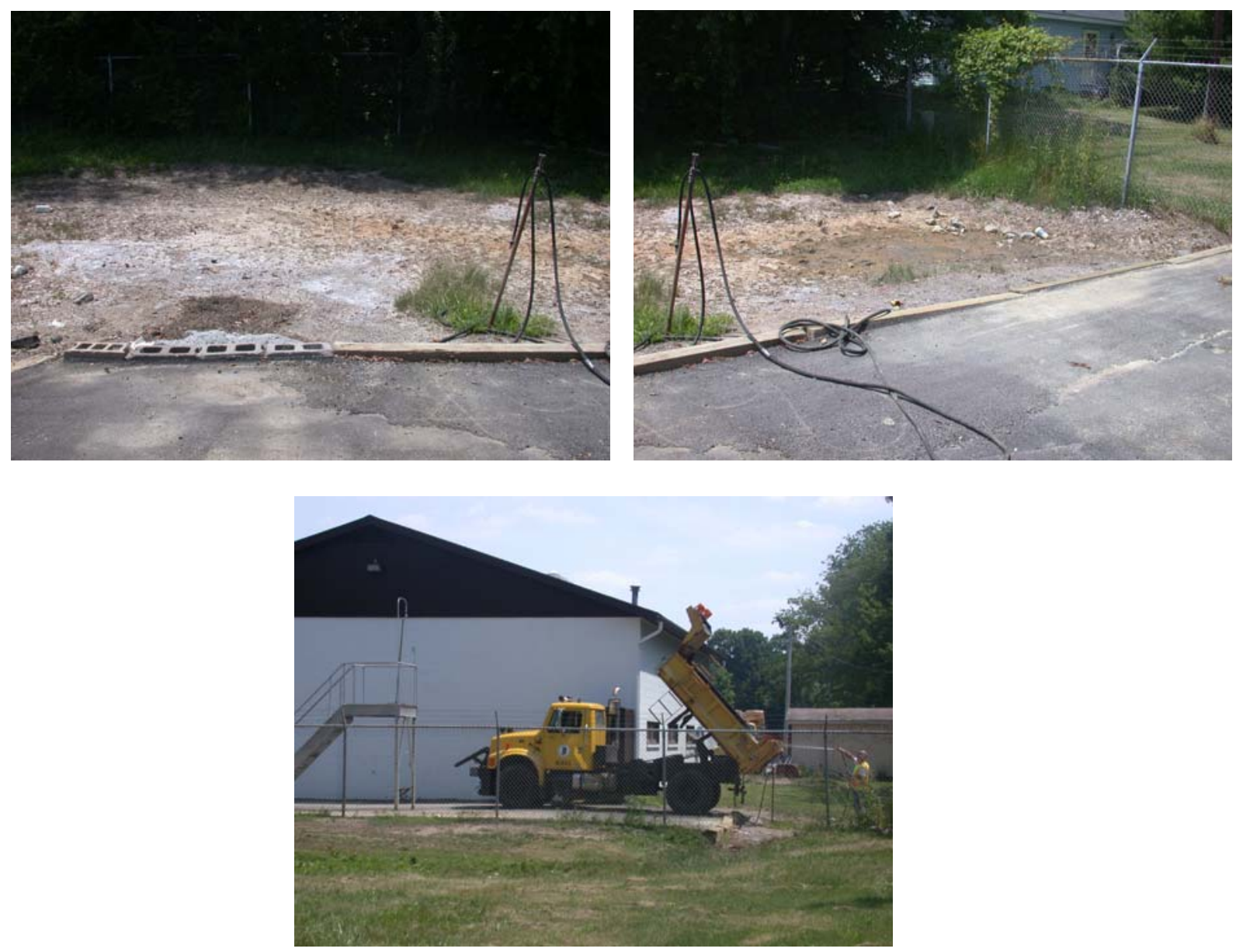

The Unit Building is located south of the washing area. The oil and hydraulic fluid drums inside the Unit Building were not secondarily contained. The floor drains tie into the outside catch basin located in the washing area. This catch basin acts as a small settling tank, from which overflow water is piped off site.

There is a small tool shed located approx. 15 yards SE of the Unit Building.

There is a truck and tractor parking area located approx. 15 yards SW of the Unit Building.

The Salt Dome is approx. 20 yards south of the truck and tractor parking area. The entrance of the Salt Dome faces SE and is not equipped with a covered 
structure for salt mixing/loading. There was a considerable amount of salt residue on the active surface in this area.

There are two sets of salt bed racks at this facility. One is located east of the Salt Dome and the other is south of the Salt Dome. The active surface around the salt bed racks and the ditches around them are covered with salt.

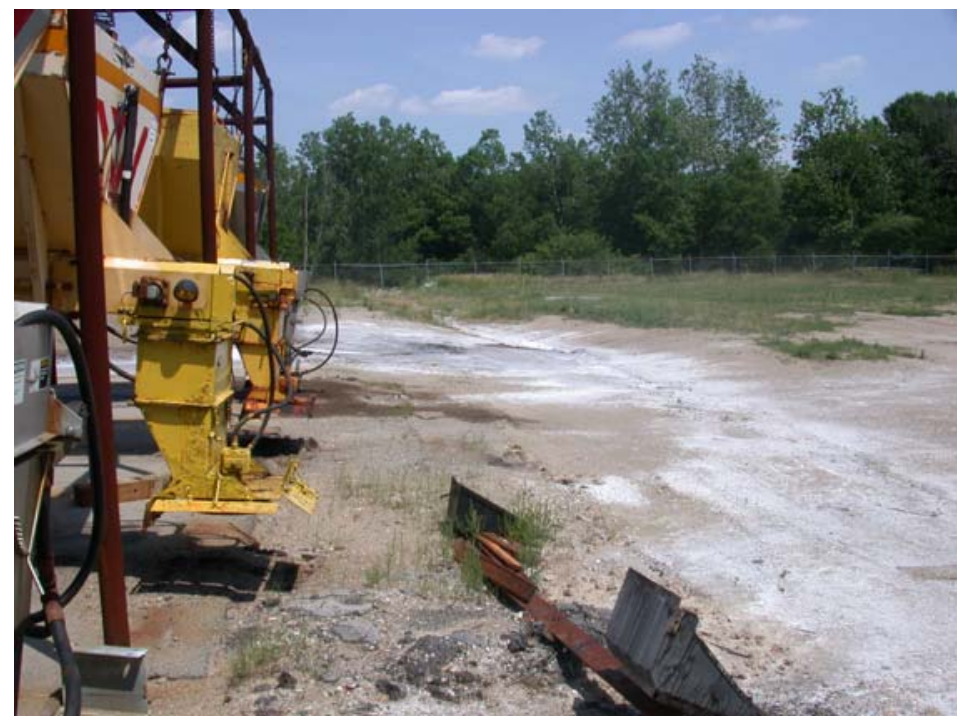

The area south of the salt racks is used to store metal miscellany, dirt piles, and three empty 55-gallon drums. The area is not organized.
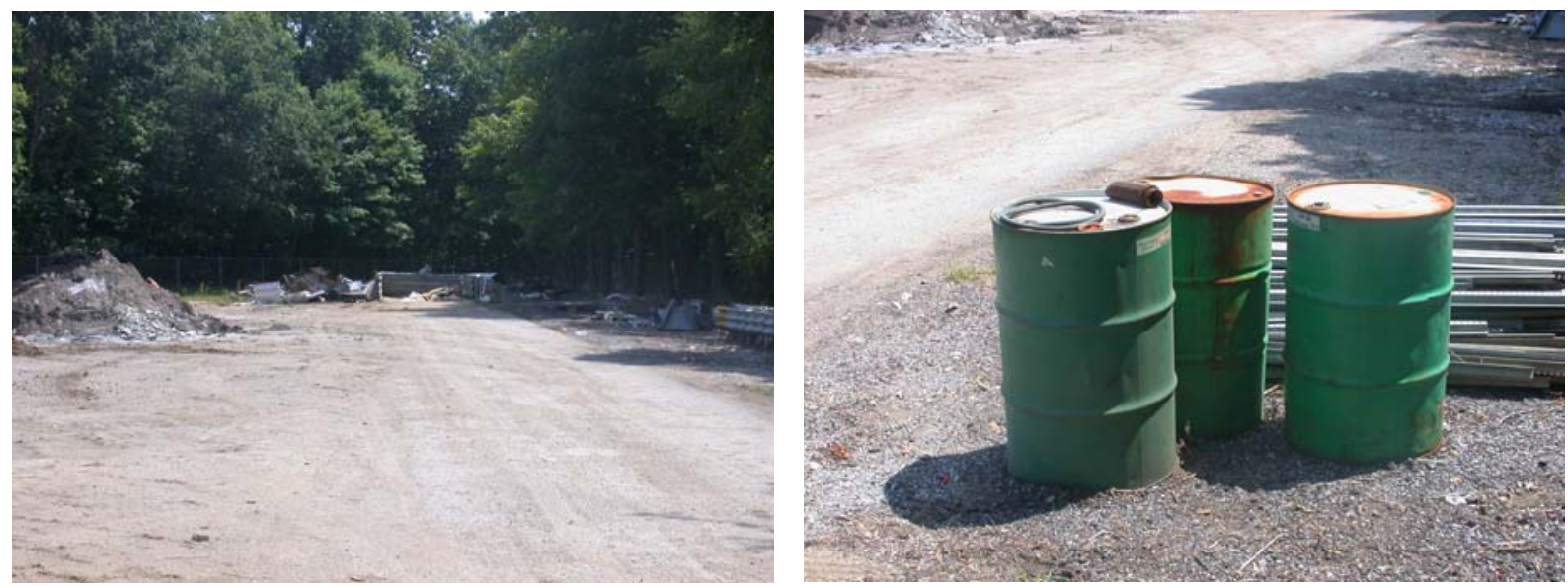
East Property Line

$>$ The entrance to the site is located in the NE corner of the property. Snowplows line the inside of the fence in this area. South of the entrance, there are several aggregate bins. One of these bins holds cold patch that is not covered with a tarp or bermed.

A brine production building and brine storage tanks are located south of the aggregate area. There is no secondary containment of the equipment or tanks. There was a large amount of salt on the surface around this building.
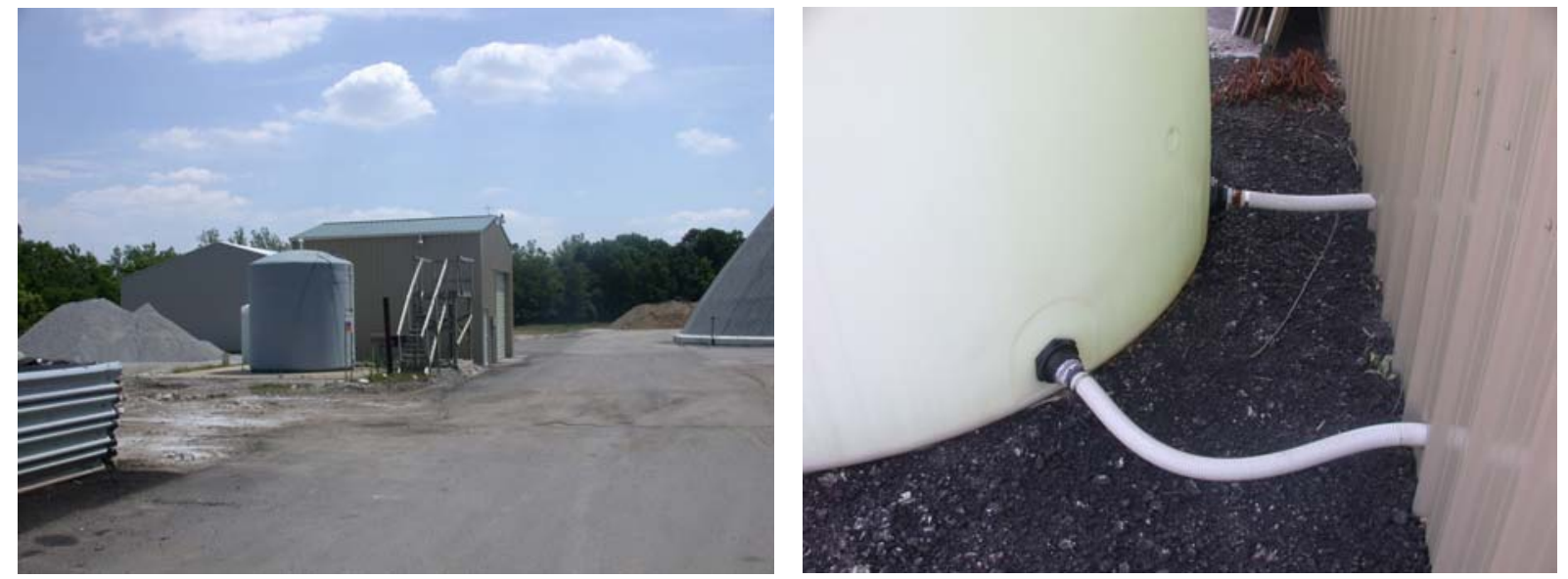

There is a cold storage building located south of the brine production building. This building stores mainly tools and signs.

The SE corner of the site is empty except for a few small aggregate piles and a drainage ditch that runs west to east across the property.

\section{Buildings}

Unit Building

The Unit Building is not equipped with an oil/water separator and is not connected to a POTW. All liquid that enters the floor drains is conveyed off site.

There is no secondary containment of oil or hydraulic fluid drums.

Salt bed washing is performed inside and outside the Unit Building. 


\section{* Salt Dome}

$>$ All salt loading and mixing is performed outside the entrance of the Salt Dome. There was a substantial amount of salt residue in this area and in the drainage ditches around this area.

* Brine Production Building

$>$ There was no secondary containment in or outside of this building. It is evident from a large vegetation kill that brine has been draining out of the building and off the property.

$>$ The Foreman stated that the brine equipment is periodically washed and the wash water is allowed to drain out of the building and off site.

* Cold Storage Building

This building stores signs and tools. There are no drains in this building. 


\section{INDOT Site Assessment Report Observations and Comments}

\section{$\underline{\text { Surface Area }}$}

General

$>$ This facility is new and had been operating for 2 months at the time of the visit. The old facility was demolished, and the new facility was built on the same property.

$>$ The runoff from the active surface collects at an inlet on the West boundary line and is piped underground to White Lick River, approximately 150 yards away. There is a Waste Water Treatment facility between the creek and the INDOT site, but the storm water is not treated.

$>$ This INDOT facility is connected to a sanitary sewer, which is owned by the City of Plainfield.

$>$ The facility is set up to reuse wash water collected from salt bed washing and truck washing to produce brine. However, at the time of the visit, this operation was still under construction, and all wash water was being sent to the sanitary sewer.

The facility is located on Center Street, which runs along the North property line.

West Property Line (faces the WW treatment plant)

The Unit Building is located in the Northwest corner of the property. Drainage from the roof and surrounding area runs off of the paved surface, into a rip-rapped ditch (which eventually becomes dirt), and down the West edge of the property to the main inlet, which is piped 150 yards to White Lick River.

On the West side of the building, there is a covered waste oil tank sitting on a steel grate, above a secondary containment basin. 
On the South side of the Unit Building, there are two, approximately 9000 gallon, brine tanks that are not secondarily contained or properly protected from a possible truck collision. Don Arnold suggested eventually pouring a concrete enclosure around the tanks that would serve both purposes.

Approximately 20 yards south of the unit building, there is a Magnesium Chloride tank that is secondarily contained with a concrete enclosure. No salt load spraying occurs at this site. The Magnesium Chloride is pumped into a storage tank on the salt trucks and then sprayed onto the salt at the spreader.

Just to the south is the Salt Dome. There is no berm around the dome, which is about 40 yards from the storm water inlet that drains to White Lick Creek. However, all the salt loading and mixing is done in an enclosure, which is explained in more detail later in this report.

The salt bed storage racks are located in the Southwest corner of the property. This area is paved and approx. 10 feet from the drainage ditch, which runs parallel with the West boundary line. There was one noticeable pile of salt under the racks that evidently came from a salt bed.

\section{East property line}

The truck and equipment parking is located in the Northeast corner of the property. A dirt berm, between the parking area and drainage ditch, holds a significant amount of storm water and prevents it from getting into the ditch. This causes noticeable ponding at the edge of this parking area.

$>$ Two small wooden storage bins that hold tools are located south of the parking area. Cold patch is stored next to these bins in an outdoor pile covered by a tarp.

In the Southeast corner of the property, there is a large Cold Storage Building that contains no drains.

$>$ The Southeast corner of the property is very low and holds much of the water that drains down the West and South ditches. The water ponds outside the fence on what looked to be WW treatment plant property.

On the Southern property line, there are several large aggregate piles. 


\section{Buildings}

* Unit Building

$>$ The Unit Building has a lateral floor drain that runs the entire length of the maintenance area. The water, which collects in this drain, is piped under the floor to the wash bay catch basin. From this basin, the water is periodically pumped to the oil/water separator, which is connected to the sanitary sewer.

$>$ All oil drums in the unit building are stored on steel grates above a secondary containment basin.

$>$ The brine mixing equipment is located in the wash bay but was not running at the time of the visit.

\section{* Salt Dome}

$>$ The Salt Dome is outfitted with a roofed structure on the front that is approx. 60'x60' and 40' tall. All salt loading and sand mixing occurs in this covered structure. This structure is designed to prevent storm water from coming in contact with salt. However, due to the manner in which the site was paved, the runoff from this entire area collects in a trough that runs in the front door of the structure, through the building(coming in contact with salt), and out the back side. The storm water then runs approx. 40 yards on the paved surface into the main inlet, which is piped directly to White Lick Creek. Some sort of berm should be installed in order to redirect the storm water around the structure. 
FACILITY SITE ASSESSMENT REPORTS

FORT WAYNE DISTRICT 
Date_5/25/05

\title{
INDOT Facility Stormwater and Washwater Effluent Drainage Assessment
}

\author{
Name of Facility _ _ Gas City Unit
}

District/Subdistrict__Fort Wayne

\section{$\underline{\text { Surface Water }}$}

1. Does any area of the active surface collect storm water or facility-generated wash water (such as from washing trucks outdoors)? _

2. Is there any movement of surface water from one area to another on-site by ditch, drain tile or natural channel? _ Yes

3. Is there any movement of surface water off-site (e.g., beneath the perimeter fence) via sheet flow, ditch, pipe or channel to adjacent property? __ $\underline{\text { Yes }}$

4. Is the surface water discharged directly to (check all that apply) -

$\square$ drainage ditch or roadside ditch

$\square$ county-regulated drain

$\square$ state highway drainage system

$\square$ a nearby creek, river or other water body

$\square \quad$ lagoon or holding pond

$\square$ settling basin, catch basin, or other constructed retention structure

$\square$ underground tank

$\square$ municipal storm sewer Owner

$\square$ municipal combined storm/sanitary sewer Owner

$\square$ POTW Owner:

$\square$ Other

5. If surface water is discharged, other than to a municipal storm, sanitary or combined sewer, does it ultimately reach "waters of the state” (e.g., farm ditch, creek, stream, river, lake or pond)? If yes, name of that water body. _ _ Yes, Long Branch Creek, _ _which drains into Walnut Creek 1.7 miles NW of the site

6. What is the estimated distance of this water body from the facility?

It borders the West property line 


\section{$\underline{\text { Shop Floor Drain \& Wash Bay Effluent }}$}

1. Are there drains in shop floors and wash bays that remove liquids and wash water effluent from the building(s)? _ Y Yes

2. Does the effluent flow to -

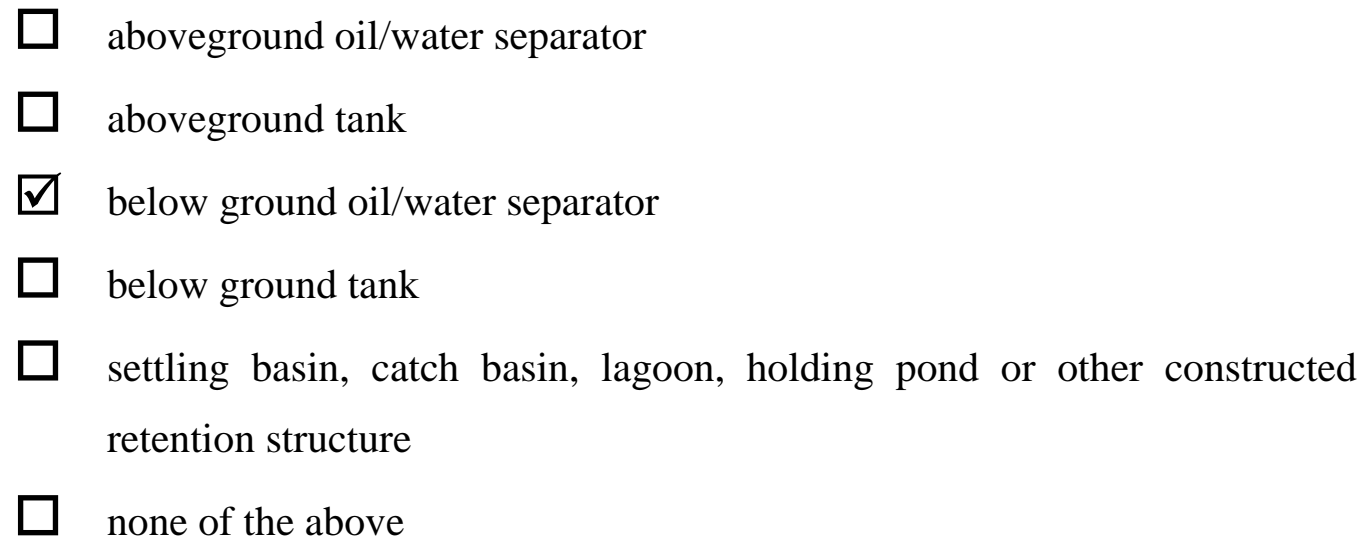

3. If the effluent is captured by the devices in 2., above, is it contained until pumped and hauled to a POTW or until it evaporates, or does it overflow to a drainage system?___ Sewer_system

4. If the effluent overflows to a drainage system, is the system above or below ground? __Below ground

5. If the effluent overflows to a drainage system, does it mix with storm water?_ No

6. If the effluent does mix with storm water, see "Surface Water" section (preceding page, \#4 and \#5) for discharge.

7. If the effluent doesn't mix with storm water, is it discharged to -

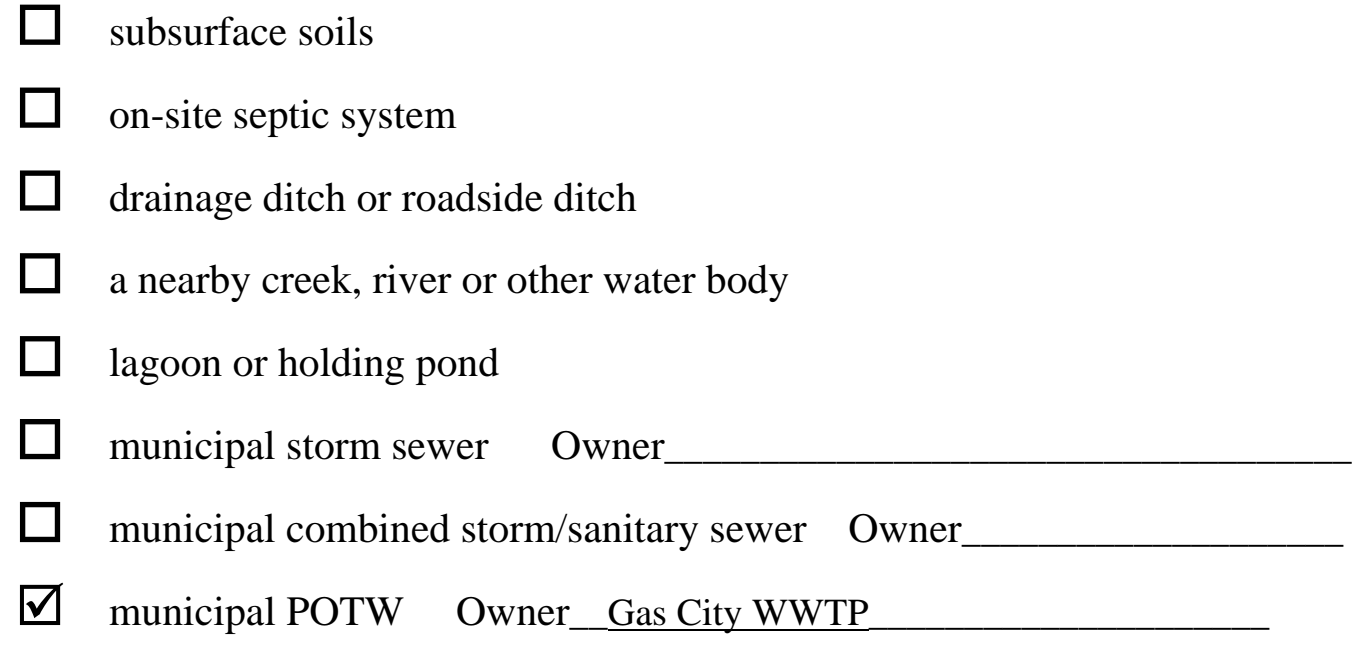


8. If shop floor drain and wash bay effluent is discharged, other than to a municipal storm, sanitary or combined sewer, does it ultimately reach "waters of the state?" If yes, name of that water body:

Activity Areas (check those that apply and describe (1) whether they are bermed to prevent storm water runoff or (2) if there are drains and their locations in the activity areas)

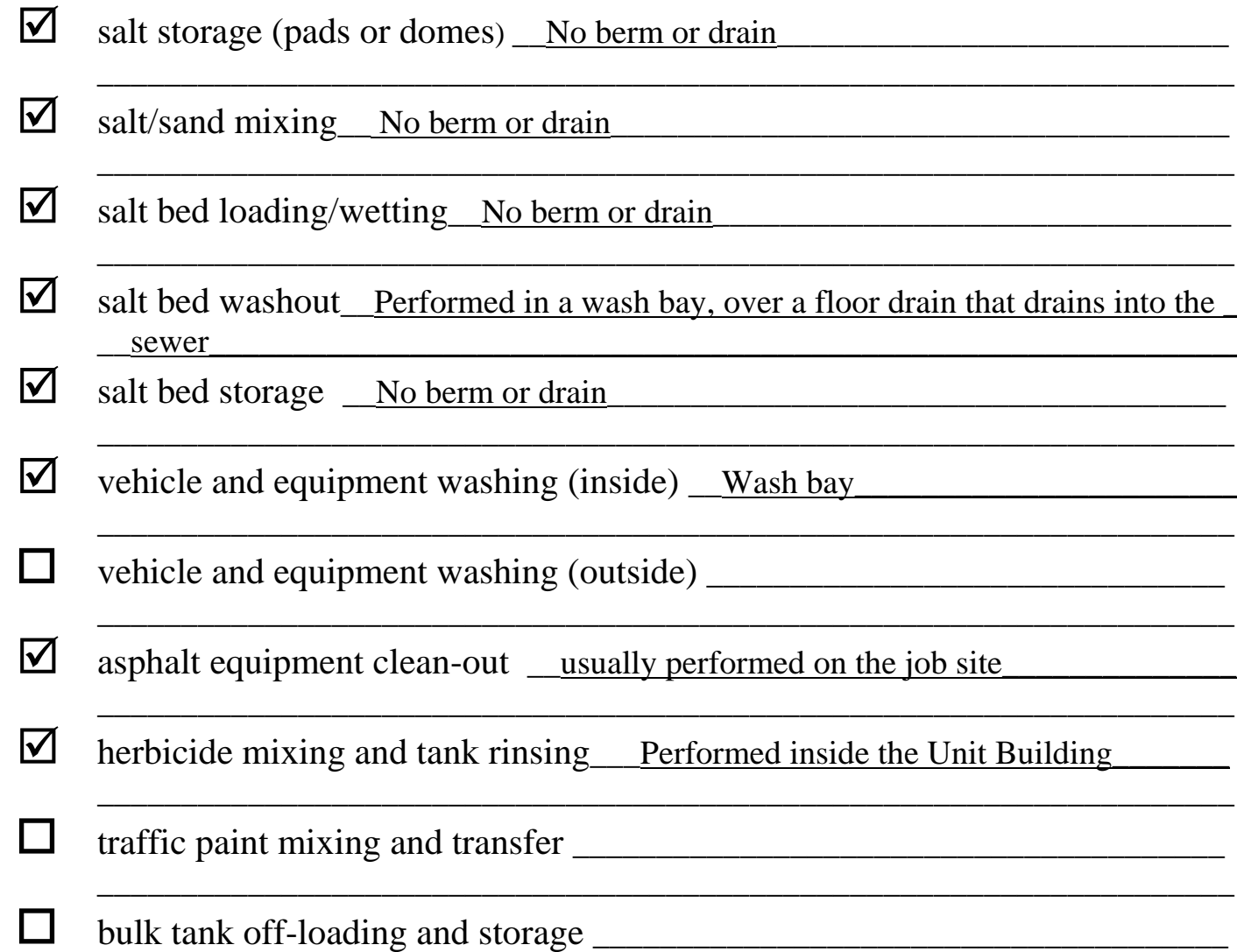

$\square$ waste piles (e.g., ROW trash, street sweeping debris) __ No berm or drain

$\square$ truck/equipment parking__ During the winter the salt trucks are parked under roof

$\square \quad$ truck/equipment fueling

$\square$ materials storage (210 lot, fencing, etc.)

$\square$ aggregate storage__ No berm or drain

$\square$ hot/cold patch storage __stored under roof

$\square$ storage of “scalp” and dirt from R/W maintenance__ No berm or drain 
Date__3/23/05

\section{INDOT Facility Stormwater and Washwater Effluent Drainage Assessment}

Name of Facility __New Haven_Unit
District/Subdistrict__ Fort Wayne__

\section{$\underline{\text { Surface Water }}$}

1. Does any area of the active surface collect storm water or facility-generated wash water (such as from washing trucks outdoors)? _ _ Y Yes

2. Is there any movement of surface water from one area to another on-site by ditch, drain tile or natural channel? _ Yes

3. Is there any movement of surface water off-site (e.g., beneath the perimeter fence) via sheet flow, ditch, pipe or channel to adjacent property? __ $\underline{\text { Yes }}$

4. Is the surface water discharged directly to (check all that apply) -

$\square$ drainage ditch or roadside ditch

$\square$ county-regulated drain

$\square$ state highway drainage system

$\square$ a nearby creek, river or other water body

$\square \quad$ lagoon or holding pond

$\square \quad$ settling basin, catch basin, or other constructed retention structure

$\square$ underground tank

$\square$ municipal storm sewer Owner

$\square$ municipal combined storm/sanitary sewer Owner

$\square$ POTW Owner:

$\square$ Other

5. If surface water is discharged, other than to a municipal storm, sanitary or combined sewer, does it ultimately reach "waters of the state” (e.g., farm ditch, creek, stream, river, lake or pond)? If yes, name of that water body. _ Y Yes, Henry Bandellier Drain, _which empties into Martin Ditch approx. 50 feet from the site. Martin Ditch eventually empties into Maumee River.

6. What is the estimated distance of this water body from the facility?

_Henry Bandellier drain borders the South property line. 
Shop Floor Drain \& Wash Bay Effluent

1. Are there drains in shop floors and wash bays that remove liquids and wash water effluent from the building(s)? _

2. Does the effluent flow to -

$\square$ aboveground oil/water separator

$\square$ aboveground tank

$\square$ below ground oil/water separator

$\square$ below ground tank

$\square$ settling basin, catch basin, lagoon, holding pond or other constructed retention structure

$\square$ none of the above

3. If the effluent is captured by the devices in 2., above, is it contained until pumped and hauled to a POTW or until it evaporates, or does it overflow to a drainage system?_It overflows to a drainage system

4. If the effluent overflows to a drainage system, is the system above or below ground? __Below ground

5. If the effluent overflows to a drainage system, does it mix with storm water?__No

6. If the effluent $\underline{\text { does }}$ mix with storm water, see "Surface Water" section (preceding page, \#4 and \#5) for discharge.

7. If the effluent doesn't mix with storm water, is it discharged to -

$\square$ subsurface soils

$\square \quad$ on-site septic system

$\square \quad$ drainage ditch or roadside ditch

$\square$ a nearby creek, river or other water body

$\square \quad$ lagoon or holding pond

$\square$ municipal storm sewer Owner

$\square$ municipal combined storm/sanitary sewer Owner_New Haven

$\square \quad$ municipal POTW Owner

(Rev 2/7/05) 
8. If shop floor drain and wash bay effluent is discharged, other than to a municipal storm, sanitary or combined sewer, does it ultimately reach "waters of the state?" If yes, name of that water body:

Activity Areas (check those that apply and describe (1) whether they are bermed to prevent storm water runoff or (2) if there are drains and their locations in the activity areas)

$\square$ salt storage (pads or domes) __ No berm or drain

$\square$ salt/sand mixing__ No berm or drain

$\square$ salt bed loading/wetting__No berm or drain

$\square$ salt bed washout_Some washing is performed inside the Unit Building over a drain. Some washing is performed outside were there is no berm or drain.

$\square$ salt bed storage $\_$No berm or drain

$\square \quad$ vehicle and equipment washing (inside) __ Floor drain

$\square \quad$ vehicle and equipment washing (outside) __ No berm or drain

$\square \quad$ asphalt equipment clean-out

$\square$ herbicide mixing and tank rinsing__ Performed inside near floor drain

$\square \quad$ traffic paint mixing and transfer

$\square$ bulk tank off-loading and storage

$\square$ waste piles (e.g., ROW trash, street sweeping debris)

$\square \quad$ truck/equipment parking__No berm or drain

$\square \quad$ truck/equipment fueling

$\square$ materials storage (210 lot, fencing, etc.)

$\square$ aggregate storage__ No berm or drain

$\square$ hot/cold patch storage __ No berm or drain

$\square$ storage of “scalp” and dirt from R/W maintenance 
Date_ 5/26/2005

\section{INDOT Facility Stormwater and Washwater Effluent Drainage Assessment}

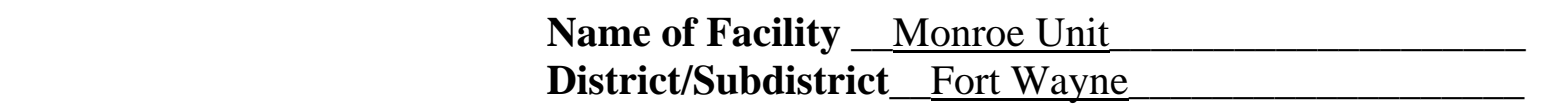

\section{$\underline{\text { Surface Water }}$}

1. Does any area of the active surface collect storm water or facility-generated wash water (such as from washing trucks outdoors)? _ _ Y Yes

2. Is there any movement of surface water from one area to another on-site by ditch, drain tile or natural channel? _ Yes

3. Is there any movement of surface water off-site (e.g., beneath the perimeter fence) via sheet flow, ditch, pipe or channel to adjacent property? __ $\underline{\text { Yes }}$

4. Is the surface water discharged directly to (check all that apply) -

$\square$ drainage ditch or roadside ditch

$\square$ county-regulated drain

$\square$ state highway drainage system

$\square$ a nearby creek, river or other water body

$\square \quad$ lagoon or holding pond

$\square \quad$ settling basin, catch basin, or other constructed retention structure

$\square$ underground tank

$\square$ municipal storm sewer Owner

$\square$ municipal combined storm/sanitary sewer Owner

$\square$ POTW Owner:

$\square$ Other

5. If surface water is discharged, other than to a municipal storm, sanitary or combined sewer, does it ultimately reach "waters of the state” (e.g., farm ditch, creek, stream, river, lake or pond)? If yes, name of that water body. __ Yes, Smith Ditch, which _empties into Yellow Creek approx. 500 yards SE of the facility

6. What is the estimated distance of this water body from the facility?

Smith Ditch borders the Northern property line

(Rev 2/7/05) 


\section{Shop Floor Drain \& Wash Bay Effluent}

1. Are there drains in shop floors and wash bays that remove liquids and wash water effluent from the building(s)? _ _ Yes

2. Does the effluent flow to -

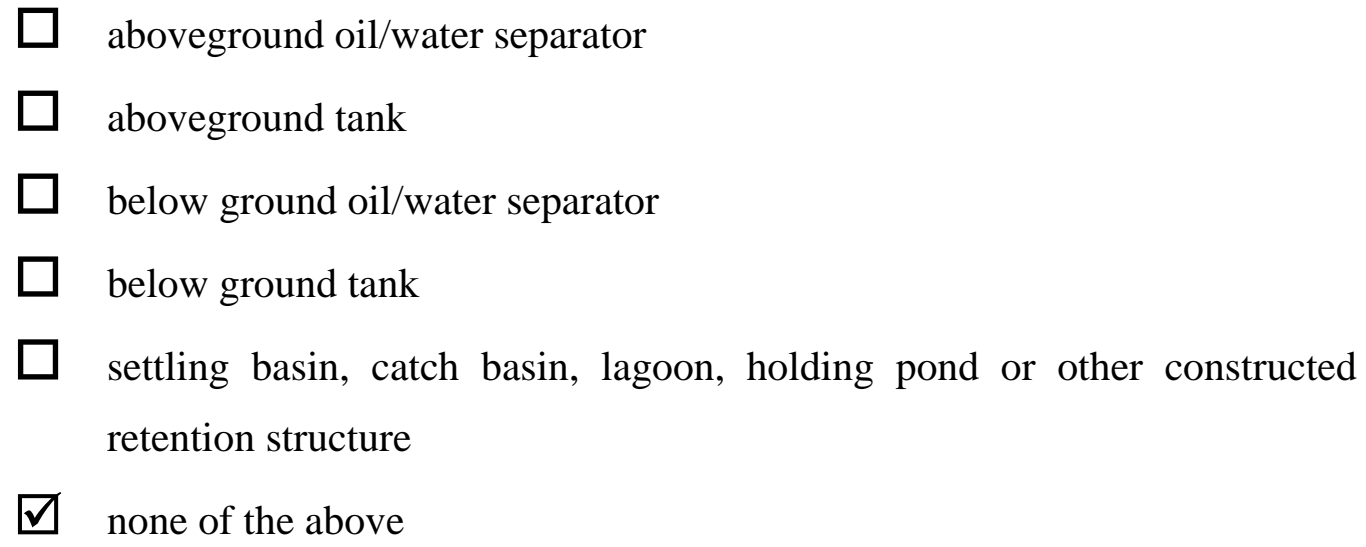

3. If the effluent is captured by the devices in 2., above, is it contained until pumped and hauled to a POTW or until it evaporates, or does it overflow to a drainage system?

4. If the effluent overflows to a drainage system, is the system above or below ground?

5. If the effluent overflows to a drainage system, does it mix with storm water?

6. If the effluent does mix with storm water, see "Surface Water" section (preceding page, \#4 and \#5) for discharge.

7. If the effluent doesn't mix with storm water, is it discharged to -

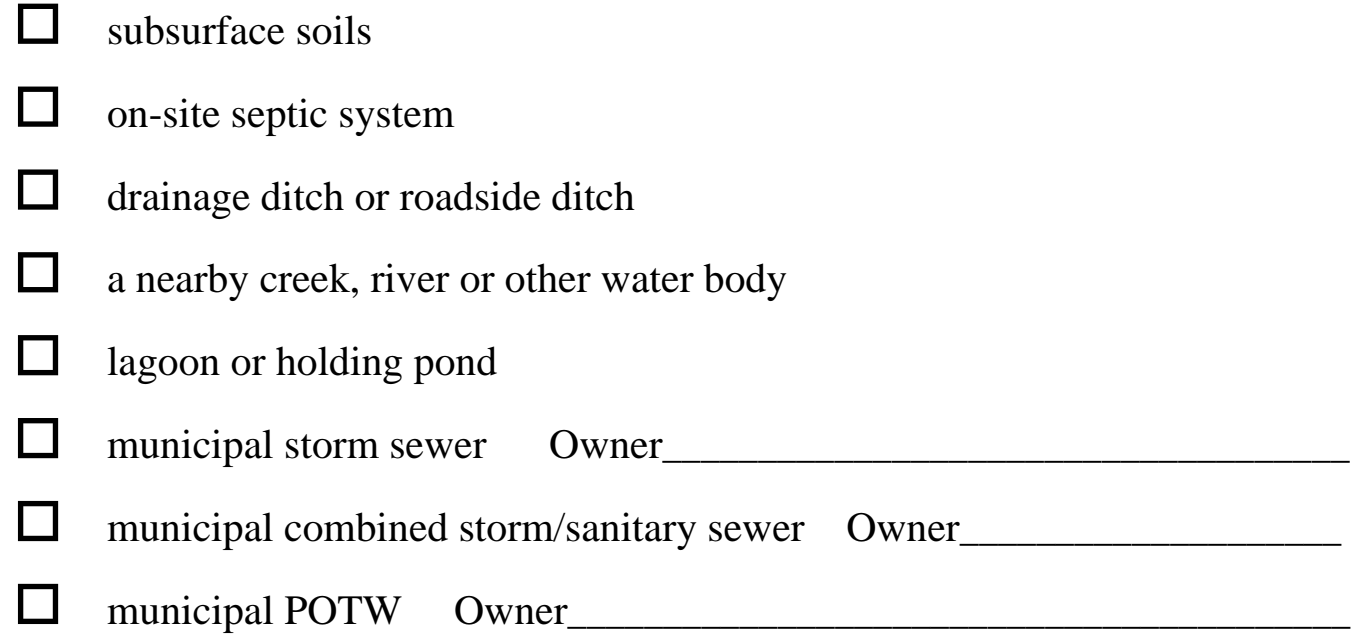


8. If shop floor drain and wash bay effluent is discharged, other than to a municipal storm, sanitary or combined sewer, does it ultimately reach "waters of the state?" If yes, name of that water body: _ Yes, Smith Ditch

Activity Areas (check those that apply and describe (1) whether they are bermed to prevent storm water runoff or (2) if there are drains and their locations in the activity areas)

$\square$ salt storage (pads or domes) _ There is no berm but there is a drain approx 10 yards NE of the Salt Dome and loading pad that catches all the runoff from these areas. The water is piped directly to Smith Ditch

$\square$ salt/sand mixing__Performed inside Salt Building

$\square$ salt bed loading/wetting__No berm but there is a drain

$\square$ salt bed washout__ Performed inside the Unit Building, which has a floor drain that is piped to Smith Ditch

$\square$ salt bed storage _ There is a small berm behind the salt bed racks. No drain

$\square$ vehicle and equipment washing (inside) _ Performed inside the Unit Building

$\square \quad$ vehicle and equipment washing (outside)

$\square$ asphalt equipment clean-out __ No berm or drain

$\square$ herbicide mixing and tank rinsing__small amount mixed inside the Unit Building

$\square \quad$ traffic paint mixing and transfer

$\square$ bulk tank off-loading and storage

$\square \quad$ waste piles (e.g., ROW trash, street sweeping debris)

$\square$ truck/equipment parking_ There is no berm. The runoff from this area enters a drain, - which is piped to Smith Ditch

$\square$ truck/equipment fueling

$\square$ materials storage (210 lot, fencing, etc.)

$\square$ aggregate storage__ No berm or drain

$\square$ hot/cold patch storage __ No berm or drain

$\square$ storage of “scalp” and dirt from R/W maintenance 
Date_2/16/2005

INDOT Facility Stormwater and Washwater Effluent Drainage Assessment

Name of Facility ___ Orland Unit

\section{$\underline{\text { Surface Water }}$}

\section{District/Subdistrict__Fort Wayne}

1. Does any area of the active surface collect storm water or facility-generated wash water (such as from washing trucks outdoors)? _ _ Some ponding in parking area

2. Is there any movement of surface water from one area to another on-site by ditch, drain tile or natural channel? _ _ No, there is a roadside ditch only

3. Is there any movement of surface water off-site (e.g., beneath the perimeter fence) via sheet flow, ditch, pipe or channel to adjacent property? _ Y Yes, sheet flow to the _ river and to the roadside ditch

4. Is the surface water discharged directly to (check all that apply) -

$\square$ drainage ditch or roadside ditch

$\square$ county-regulated drain

$\square$ state highway drainage system

$\square$ a nearby creek, river or other water body

$\square \quad$ lagoon or holding pond

$\square \quad$ settling basin, catch basin, or other constructed retention structure

$\square$ underground tank

$\square$ municipal storm sewer Owner

$\square$ municipal combined storm/sanitary sewer Owner

$\square$ POTW Owner:

$\square$ Other

5. If surface water is discharged, other than to a municipal storm, sanitary or combined sewer, does it ultimately reach "waters of the state” (e.g., farm ditch, creek, stream, river, lake or pond)? If yes, name of that water body. _ _ Yes, Pigeon River

6. What is the estimated distance of this water body from the facility? It is on the North boundary line 


\section{$\underline{\text { Shop Floor Drain \& Wash Bay Effluent }}$}

1. Are there drains in shop floors and wash bays that remove liquids and wash water effluent from the building(s)? __ No

2. Does the effluent flow to -

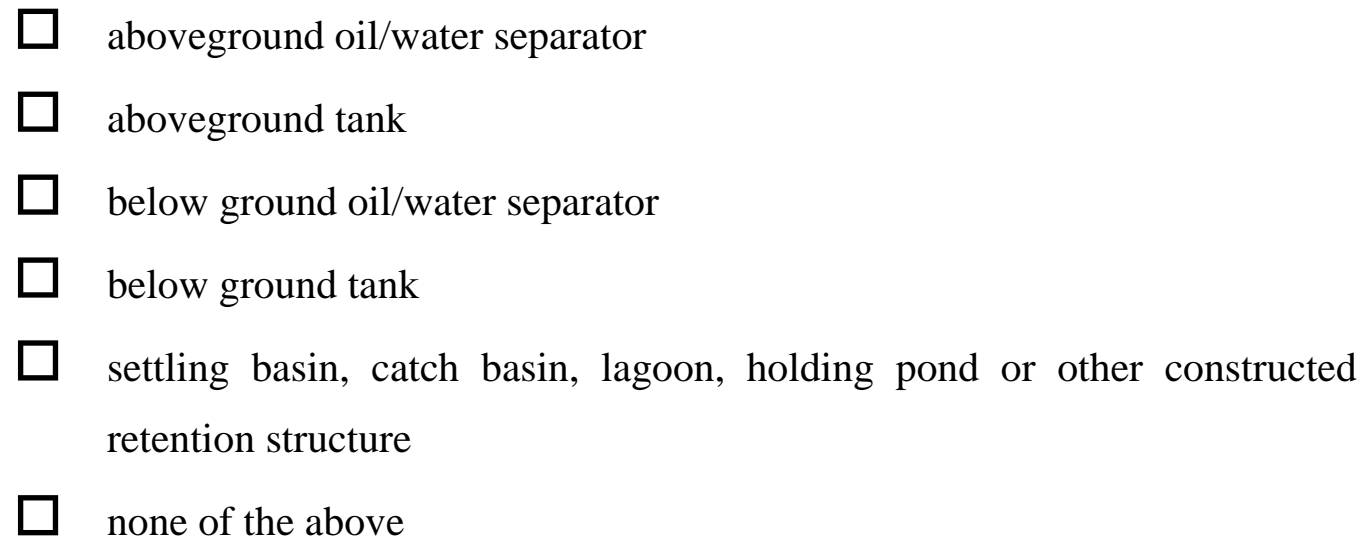

3. If the effluent is captured by the devices in 2., above, is it contained until pumped and hauled to a POTW or until it evaporates, or does it overflow to a drainage system?

4. If the effluent overflows to a drainage system, is the system above or below ground?

5. If the effluent overflows to a drainage system, does it mix with storm water?

6. If the effluent does mix with storm water, see "Surface Water" section (preceding page, \#4 and \#5) for discharge.

7. If the effluent doesn't mix with storm water, is it discharged to -

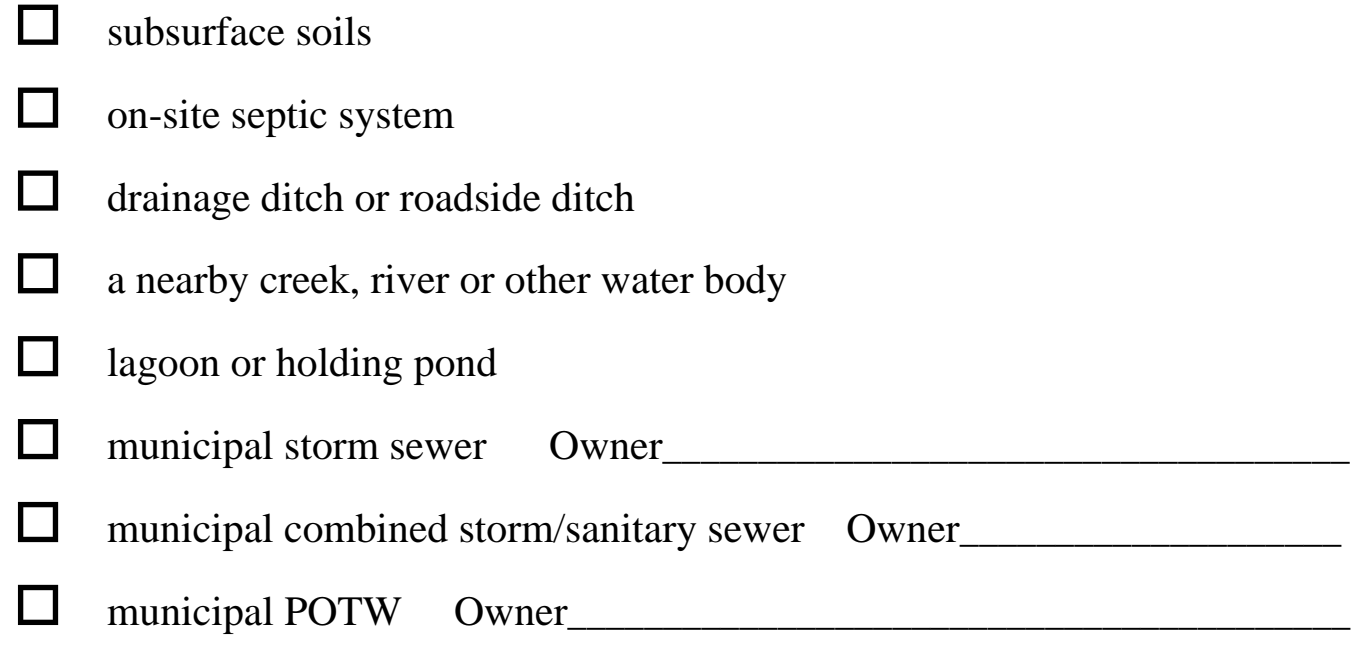


8. If shop floor drain and wash bay effluent is discharged, other than to a municipal storm, sanitary or combined sewer, does it ultimately reach "waters of the state?" If yes, name of that water body:

Activity Areas (check those that apply and describe (1) whether they are bermed to prevent storm water runoff or (2) if there are drains and their locations in the activity areas)

$\square$ salt storage (pads or domes) __ No berm or drain

$\square$ salt/sand mixing__ No berm or drain

$\square \quad$ salt bed loading/wetting

$\square \quad$ salt bed washout

$\square \quad$ salt bed storage

$\square \quad$ vehicle and equipment washing (inside)

$\square \quad$ vehicle and equipment washing (outside)

$\square \quad$ asphalt equipment clean-out

$\square$ herbicide mixing and tank rinsing

$\square \quad$ traffic paint mixing and transfer

$\square \quad$ bulk tank off-loading and storage

$\square$ waste piles (e.g., ROW trash, street sweeping debris)

$\square$ truck/equipment parking

$\square \quad$ truck/equipment fueling

$\square$ materials storage (210 lot, fencing, etc.)

$\square$ aggregate storage__ No berm or drain

$\square$ hot/cold patch storage

$\square$ storage of “scalp” and dirt from R/W maintenance__ No berm or drain 
Date_6/22/2005

\section{INDOT Facility Stormwater and Washwater Effluent Drainage Assessment}

Name of Facility __Warsaw Unit and Sub
District/Subdistrict __ Fort Wayne $\_$_

\section{$\underline{\text { Surface Water }}$}

1. Does any area of the active surface collect storm water or facility-generated wash water (such as from washing trucks outdoors)? _ Yes

2. Is there any movement of surface water from one area to another on-site by ditch, drain tile or natural channel? ___ Yes

3. Is there any movement of surface water off-site (e.g., beneath the perimeter fence) via sheet flow, ditch, pipe or channel to adjacent property? __ Yes

4. Is the surface water discharged directly to (check all that apply) -

$\square$ drainage ditch or roadside ditch

$\square$ county-regulated drain

$\square \quad$ state highway drainage system

$\square$ a nearby creek, river or other water body

$\square \quad$ lagoon or holding pond

$\square$ settling basin, catch basin, or other constructed retention structure

$\square$ underground tank

$\square$ municipal storm sewer Owner

$\square$ municipal combined storm/sanitary sewer Owner

$\square$ POTW Owner:

$\square$ Other

5. If surface water is discharged, other than to a municipal storm, sanitary or combined sewer, does it ultimately reach "waters of the state” (e.g., farm ditch, creek, stream, river, lake or pond)? If yes, name of that water body. ___ Yes, The name of the ditch is unknown

6. What is the estimated distance of this water body from the facility? It borders the east property line 


\section{Shop Floor Drain \& Wash Bay Effluent}

1. Are there drains in shop floors and wash bays that remove liquids and wash water effluent from the building(s)? _ Y Yes

2. Does the effluent flow to -

$\square$ aboveground oil/water separator

$\square$ aboveground tank

$\square$ below ground oil/water separator

$\square$ below ground tank

$\square$ settling basin, catch basin, lagoon, holding pond or other constructed retention structure

$\square$ none of the above

3. If the effluent is captured by the devices in 2., above, is it contained until pumped and hauled to a POTW or until it evaporates, or does it overflow to a drainage system?__ drainage system

4. If the effluent overflows to a drainage system, is the system above or below ground? _ Below ground

5. If the effluent overflows to a drainage system, does it mix with storm water?__ No

6. If the effluent $\underline{\text { does }}$ mix with storm water, see "Surface Water" section (preceding page, \#4 and \#5) for discharge.

7. If the effluent doesn't mix with storm water, is it discharged to -

$\square \quad$ subsurface soils

$\square$ on-site septic system

$\square$ drainage ditch or roadside ditch

$\square$ a nearby creek, river or other water body

$\square \quad$ lagoon or holding pond

$\square \quad$ municipal storm sewer Owner

$\square$ municipal combined storm/sanitary sewer Owner

$\square \quad$ municipal POTw Owner 
8. If shop floor drain and washbay effluent is discharged, other than to a municipal storm, sanitary or combined sewer, does it ultimately reach "waters of the state?" If yes, name of that water body: __ No

Activity Areas (check those that apply and describe (1) whether they are bermed to prevent storm water runoff or (2) if there are drains and their locations in the activity areas)

$\square$ salt storage (pads or domes) _ There is a berm and drain in this area

$\square$ salt/sand mixing _Berm and drain

$\square$ salt bed loading/wetting _ loading is performed in a bermed area but wetting is -not.

$\square$ salt bed washout_Performed inside a washbay

$\square$ salt bed storage _ No berm but there is a drain

$\square$ vehicle and equipment washing (inside) __ Inside washbay

$\square \quad$ vehicle and equipment washing (outside)

$\square$ asphalt equipment clean-out

$\square$ herbicide mixing and tank rinsing _ There is a small amount stored in secondary _containment lockers_in the Unit Building

$\square \quad$ traffic paint mixing and transfer

$\square$ bulk tank off-loading and storage

$\square \quad$ waste piles (e.g., ROW trash, street sweeping debris)

$\square \quad$ truck/equipment parking

$\square$ truck/equipment fueling

$\square$ materials storage (210 lot, fencing, etc.)

$\square$ aggregate storage __ No berm or drain

$\square$ hot/cold patch storage __ No berm or drain

$\square$ storage of "scalp” and dirt from R/W maintenance __ No berm or drain 
Date_3/23/2005

\title{
INDOT Facility Stormwater and Washwater Effluent Drainage Assessment
}

\author{
Name of Facility __US 27 S_Unit
}

District/Subdistrict_Fort Wayne

\section{$\underline{\text { Surface Water }}$}

1. Does any area of the active surface collect storm water or facility-generated wash water (such as from washing trucks outdoors)? _

2. Is there any movement of surface water from one area to another on-site by ditch, drain tile or natural channel? _ Yes

3. Is there any movement of surface water off-site (e.g., beneath the perimeter fence) via sheet flow, ditch, pipe or channel to adjacent property? __ $\underline{\text { Yes }}$

4. Is the surface water discharged directly to (check all that apply) -

$\square$ drainage ditch or roadside ditch

$\square$ county-regulated drain

$\square$ state highway drainage system

$\square$ a nearby creek, river or other water body

$\square \quad$ lagoon or holding pond

$\square$ settling basin, catch basin, or other constructed retention structure

$\square$ underground tank

$\square$ municipal storm sewer Owner

$\square$ municipal combined storm/sanitary sewer Owner

$\square$ POTW Owner:

$\square$ Other

5. If surface water is discharged, other than to a municipal storm, sanitary or combined sewer, does it ultimately reach "waters of the state” (e.g., farm ditch, creek, stream, river, lake or pond)? If yes, name of that water body. _ _Yes, Houk Ditch, which _drains into St. Mary’s River approx $1 / 2$ miles from the site

6. What is the estimated distance of this water body from the facility?

_ It borders the NW property line 


\section{Shop Floor Drain \& Wash Bay Effluent}

1. Are there drains in shop floors and wash bays that remove liquids and wash water effluent from the building(s)? _ Y Yes

2. Does the effluent flow to -

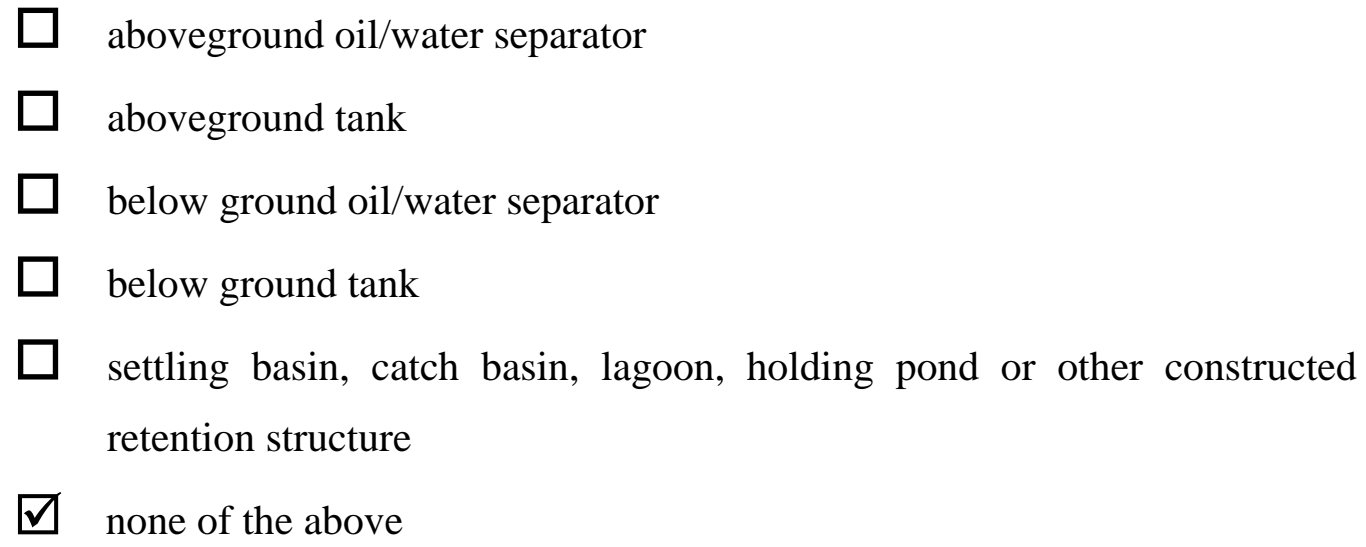

3. If the effluent is captured by the devices in 2., above, is it contained until pumped and hauled to a POTW or until it evaporates, or does it overflow to a drainage system?

4. If the effluent overflows to a drainage system, is the system above or below ground?

5. If the effluent overflows to a drainage system, does it mix with storm water?

6. If the effluent does mix with storm water, see "Surface Water" section (preceding page, \#4 and \#5) for discharge.

7. If the effluent doesn't mix with storm water, is it discharged to -

$\square$ subsurface soils

$\square$ on-site septic system

$\square$ drainage ditch or roadside ditch

$\square$ a nearby creek, river or other water body

$\square \quad$ lagoon or holding pond

$\square \quad$ municipal storm sewer Owner

$\square$ municipal combined storm/sanitary sewer Owner

$\square$ municipal POTW Owner 
8. If shop floor drain and wash bay effluent is discharged, other than to a municipal storm, sanitary or combined sewer, does it ultimately reach "waters of the state?" If yes, name of that water body: _ Yes, Houk Ditch

Activity Areas (check those that apply and describe (1) whether they are bermed to prevent $\underline{\text { storm water runoff or (2) if there are drains and their locations in the activity areas) }}$

$\square$ salt storage (pads or domes) __ No berm or drain

$\square$ salt/sand mixing

$\square$ salt bed loading/wetting_No berm or drain

$\square$ salt bed washout__ Performed inside over a drain that empties into an outside ditch. This ditch drains directly into Houk Ditch

$\square$ salt bed storage $\_$No berm or drain

$\square$ vehicle and equipment washing (inside) __ same as "salt bed washout"

$\square \quad$ vehicle and equipment washing (outside)

$\square$ asphalt equipment clean-out _

$\square$ herbicide mixing and tank rinsing__same as "salt bed washout"

$\square \quad$ traffic paint mixing and transfer

$\square$ bulk tank off-loading and storage

$\square \quad$ waste piles (e.g., ROW trash, street sweeping debris) _ _ No berm or drains

$\square$ truck/equipment parking__ No berm or drains

$\square \quad$ truck/equipment fueling

$\square$ materials storage (210 lot, fencing, etc.)

$\square$ aggregate storage__ No berm or drains

$\square$ hot/cold patch storage _ Covered with tarp

$\square$ storage of “scalp” and dirt from R/W maintenance 
Date_2/16/2005

\section{INDOT Facility Stormwater and Washwater Effluent Drainage Assessment}

Name of Facility __ Waterloo Unit
District/Subdistrict__ Fort Wayne___

\section{$\underline{\text { Surface Water }}$}

1. Does any area of the active surface collect storm water or facility-generated wash water (such as from washing trucks outdoors)? __ Yes

2. Is there any movement of surface water from one area to another on-site by ditch, drain tile or natural channel? ___ Yes

3. Is there any movement of surface water off-site (e.g., beneath the perimeter fence) via sheet flow, ditch, pipe or channel to adjacent property? __ Yes, sheet flow and _

4. Is the surface water discharged directly to (check all that apply) -

$\square$ drainage ditch or roadside ditch

$\square$ county-regulated drain

$\square \quad$ state highway drainage system

$\square$ a nearby creek, river or other water body

$\square \quad$ lagoon or holding pond

$\square$ settling basin, catch basin, or other constructed retention structure

$\square$ underground tank

$\square$ municipal storm sewer Owner

$\square$ municipal combined storm/sanitary sewer Owner

$\square$ POTW Owner:

$\square$ Other

5. If surface water is discharged, other than to a municipal storm, sanitary or combined sewer, does it ultimately reach "waters of the state” (e.g., farm ditch, creek, stream, river, lake or pond)? If yes, name of that water body. _ Y Yes, Cedar Creek

6. What is the estimated distance of this water body from the facility? 25 feet from _the North property line 


\section{$\underline{\text { Shop Floor Drain \& Wash Bay Effluent }}$}

1. Are there drains in shop floors and wash bays that remove liquids and wash water effluent from the building(s)? _ Y Yes

2. Does the effluent flow to -

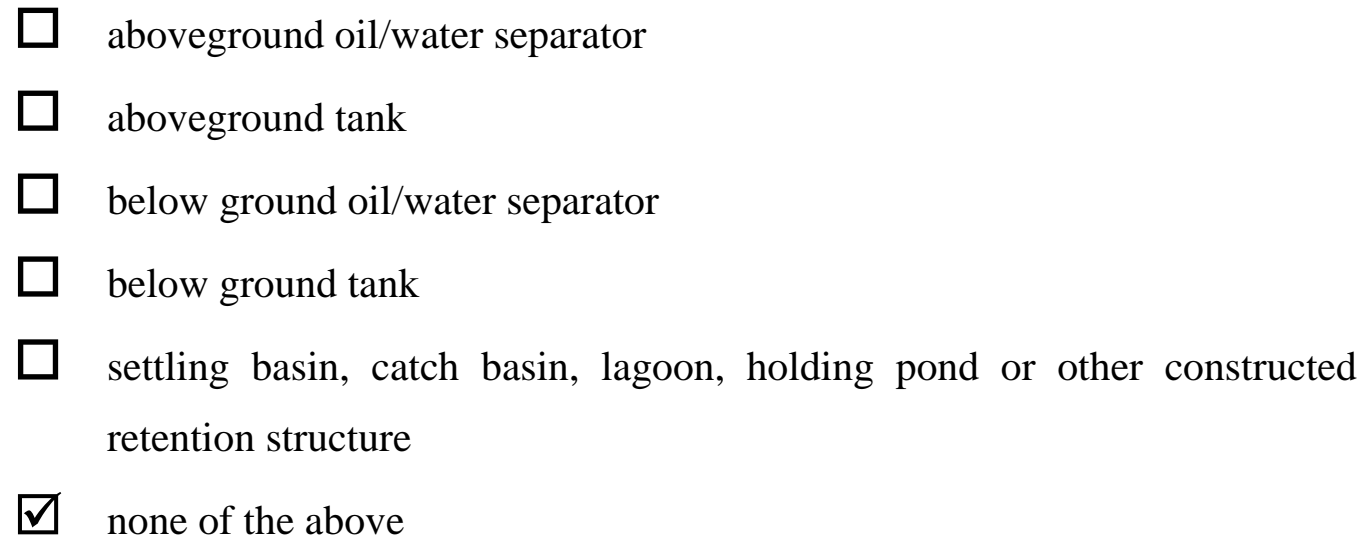

3. If the effluent is captured by the devices in 2., above, is it contained until pumped and hauled to a POTW or until it evaporates, or does it overflow to a drainage system?

4. If the effluent overflows to a drainage system, is the system above or below ground? _ The effluent flows directly into Cedar Creek

5. If the effluent overflows to a drainage system, does it mix with storm water?_Y Yes

6. If the effluent does mix with storm water, see "Surface Water" section (preceding page, \#4 and \#5) for discharge.

7. If the effluent doesn't mix with storm water, is it discharged to -

$\square$ subsurface soils

$\square$ on-site septic system

$\square$ drainage ditch or roadside ditch

$\square$ a nearby creek, river or other water body

$\square \quad$ lagoon or holding pond

$\square$ municipal storm sewer Owner

$\square$ municipal combined storm/sanitary sewer Owner

$\square$ municipal POTW Owner 
8. If shop floor drain and wash bay effluent is discharged, other than to a municipal storm, sanitary or combined sewer, does it ultimately reach "waters of the state?" If yes, name of that water body: _ Yes, Cedar Creek

Activity Areas (check those that apply and describe (1) whether they are bermed to prevent storm water runoff or (2) if there are drains and their locations in the activity areas)

$\square$ salt storage (pads or domes) ___ No berm, there is a catch basin that receives some _storm water from the Salt Dome area_(piped directly into Cedar Creek)

$\square$ salt/sand mixing

$\square$ salt bed loading/wetting__No berm, the drain previously described receives storm water from this area as well

$\square$ salt bed washout_ No berm, the drain previously described receives _storm water from this area

$\square$ salt bed storage _ No berm, or drain

$\square \quad$ vehicle and equipment washing (inside) _Floor drain empties into Cedar Creek

$\square \quad$ vehicle and equipment washing (outside) _ _ No berm, wash water enters the _catch basin previously described

$\square$ asphalt equipment clean-out

$\square \quad$ herbicide mixing and tank rinsing

$\square \quad$ traffic paint mixing and transfer

$\square$ bulk tank off-loading and storage

$\square$ waste piles (e.g., ROW trash, street sweeping debris) _ _ No berm, storm water from this area also enters the catch basin previously described

$\square$ truck/equipment parking_No berm, No drain

$\square \quad$ truck/equipment fueling

materials storage (210 lot, fencing, etc.)

$\square$ aggregate storage__ No berm, some storm water_from this area also enters the catch basin previously described

$\square$ hot/cold patch storage __ No berm, storm water from this area also enters the catch basin previously described

$\square$ storage of “scalp” and dirt from R/W maintenance__No berm, some storm water from this area also enters the catch basin previously described 


\section{INDOT Site Assessment Report Observations and Comments}

\section{Surface Area}

General

$>$ This facility is connected to a municipal POTW and is equipped with an oil/water separator.

Salt bed and vehicle washing is performed in a wash bay that is located in the Unit Building.

This facility is bordered to the SW by Long Branch Creek, which drains into Walnut Creek approx. 1.7 miles NW of the site. All the storm water from the facility enters Long Branch Creek.

* South Property Line

The Salt Dome is located in the SW corner of the site. As the storm water from this area flows under the perimeter fence it enters a riprap ditch that extends approx. 30 yards to Long Branch Creek. Were the runoff flows off the paved surface there is a large area with no vegetation. The salt in the runoff has most likely caused this dead zone.
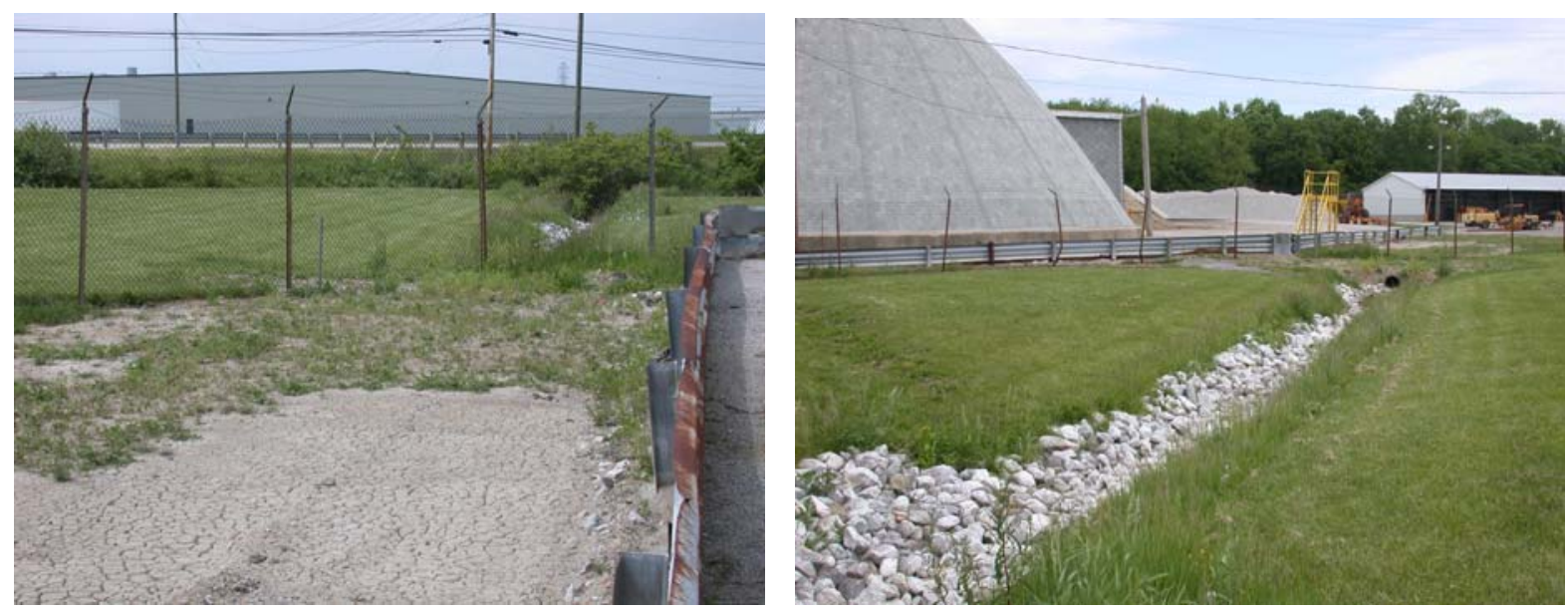
$>$ The Unit Building is located east of the Salt Dome. At the time of the site visit, the trucks were parked along the north side of the Unit Building. However, the Unit Foreman explained that during the winter the salt trucks are parked in covered buildings, which are onsite. The runoff from around the Unit Building and parking area flows to Long Branch Creek by ditch.

$>$ There is a herbicide storage building NE of the Unit Building. All herbicide containers are stored on secondary containment pallets.

East of the herbicide building, there is a Calcium Chloride tank and a Brine tank that are both secondarily contained. The runoff from this area and from around the herbicide building flows into a grassed ditch that runs to a roadside ditch. The roadside ditch drains into Long Branch Creek.
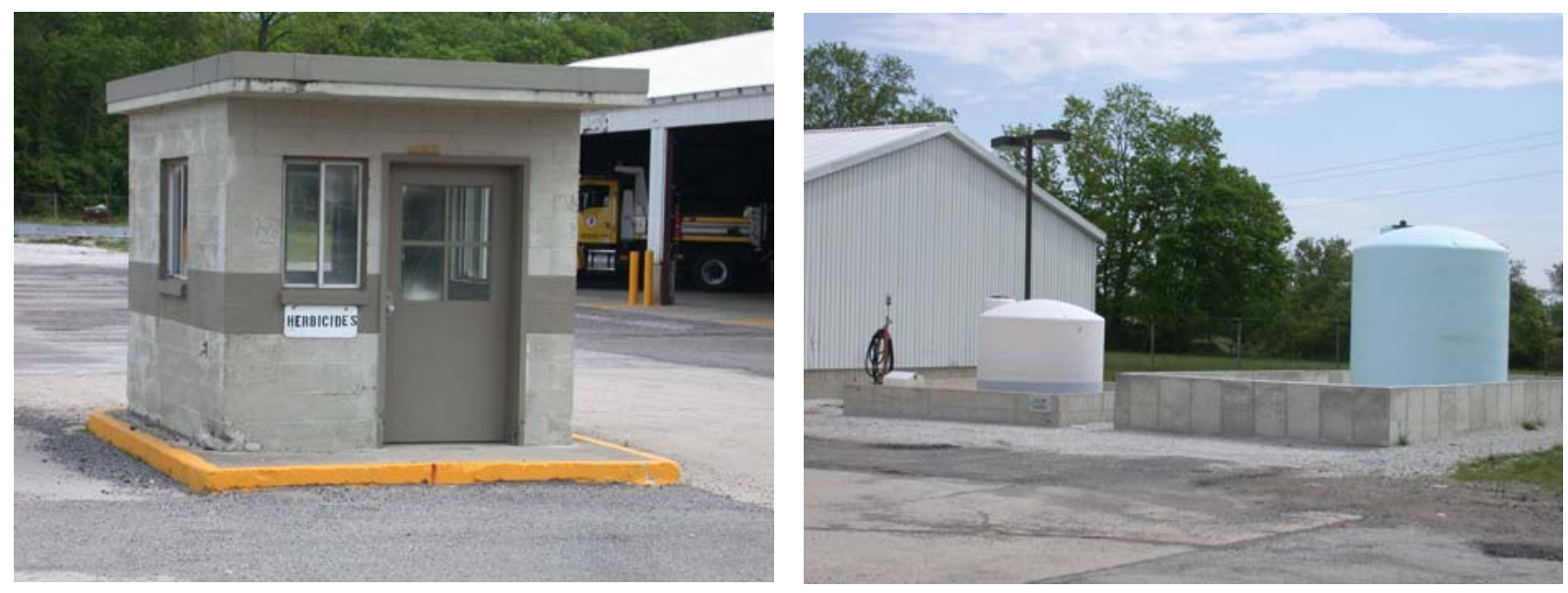

North of the Calcium Chloride tank there is a building that is used for storage and parking trucks. There are two of these buildings onsite. The other is located approx. 30 yards NW of this building.
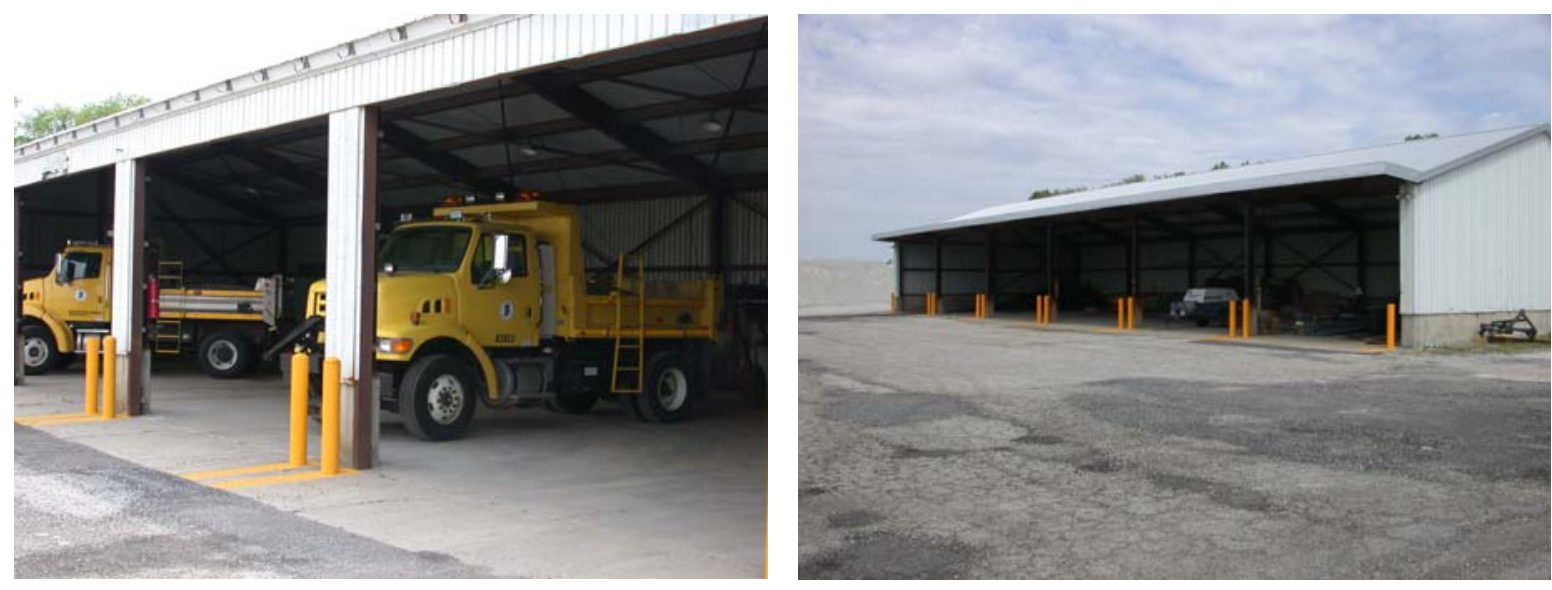


\section{* North Property Line}

In the NE corner of the site there are several piles of various metal objects and piles of trash. Behind one of the storage buildings in this area there were three 55gallon drums sitting outside in the weather. Two of these drums were lying on their sides. One drum had a sticker that said "Used Oil Only". These drums should be properly managed.
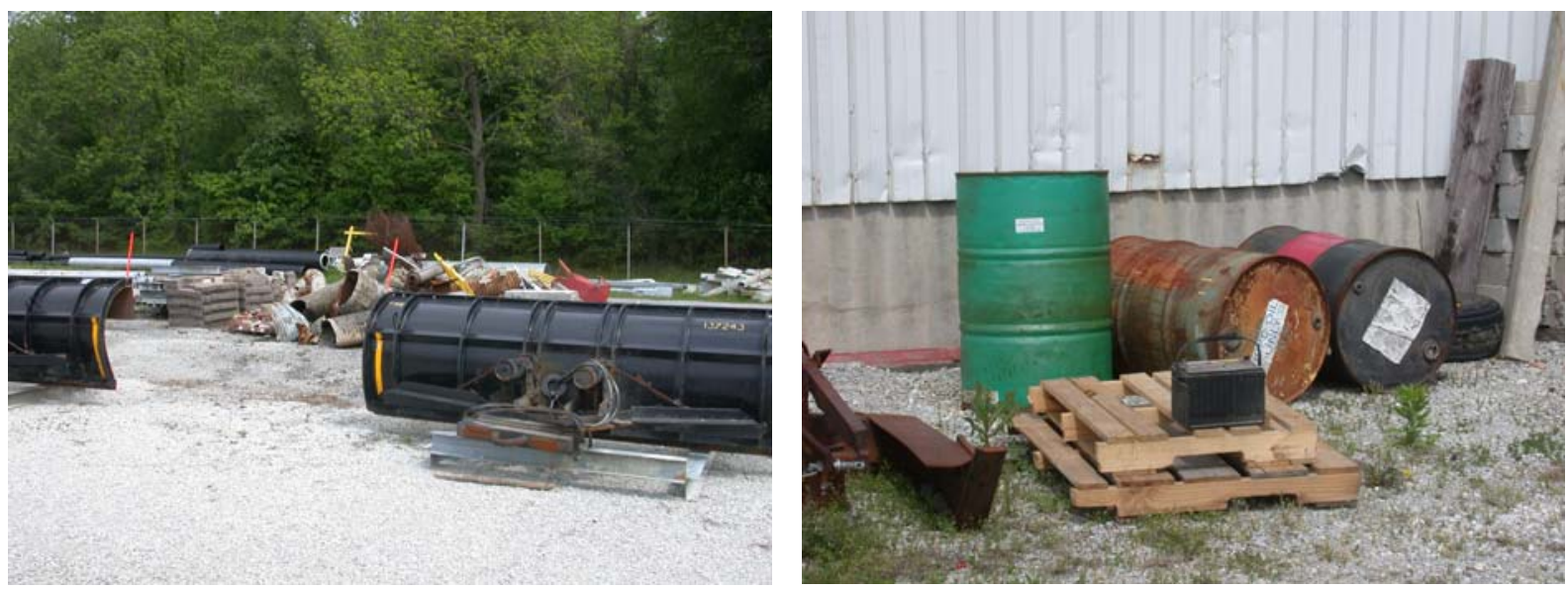

The salt bed racks are located SW of the trash area. All the runoff from this area is collected in a ditch, which runs through the center of the property, into an underground pipe that runs past the Salt Dome, and then into a ditch that empties into Long Branch Creek.
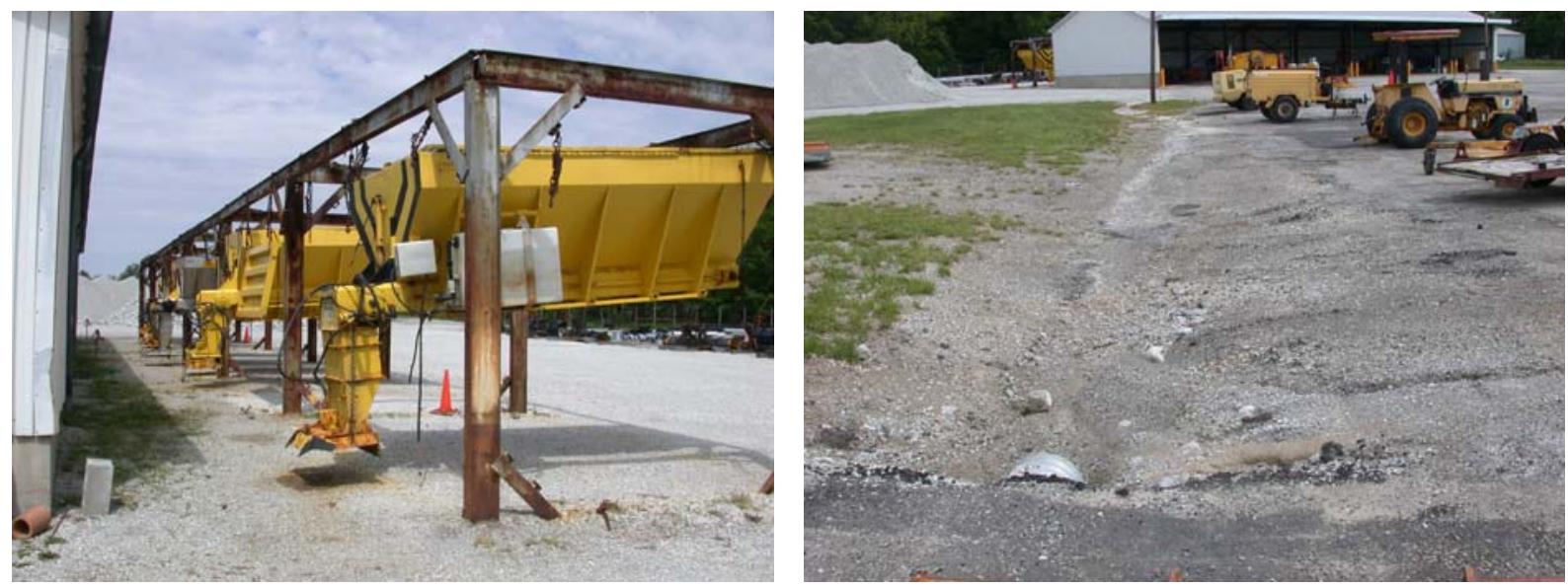
The entire NW corner of the site is used to store aggregate piles. The runoff from this area is also collected in the ditch that runs down the center of the property and sent to Long Branch Creek.

\section{Buildings}

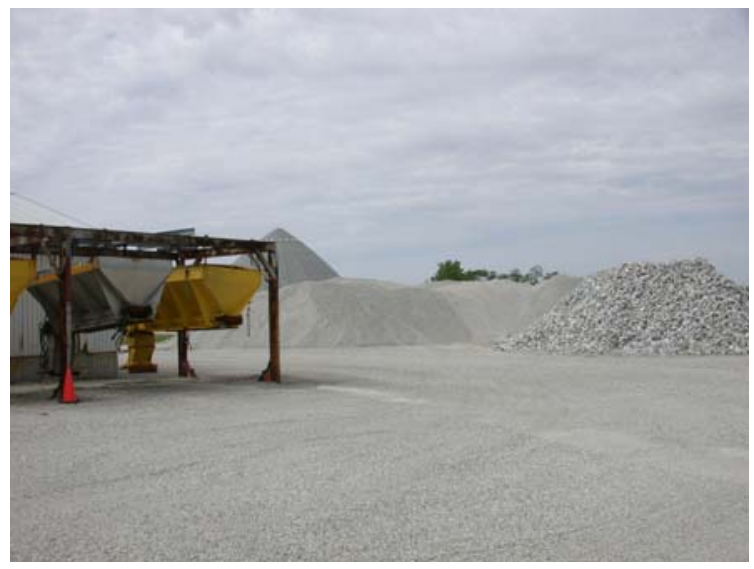

\section{Unit Building}

The Unit Building is connected to the sewer and is equipped with an oil/water separator. All drums inside the Unit Building were on secondary containment pallets.

All vehicle and salt bed washing is performed in the wash bay, which is inside the Unit Building.

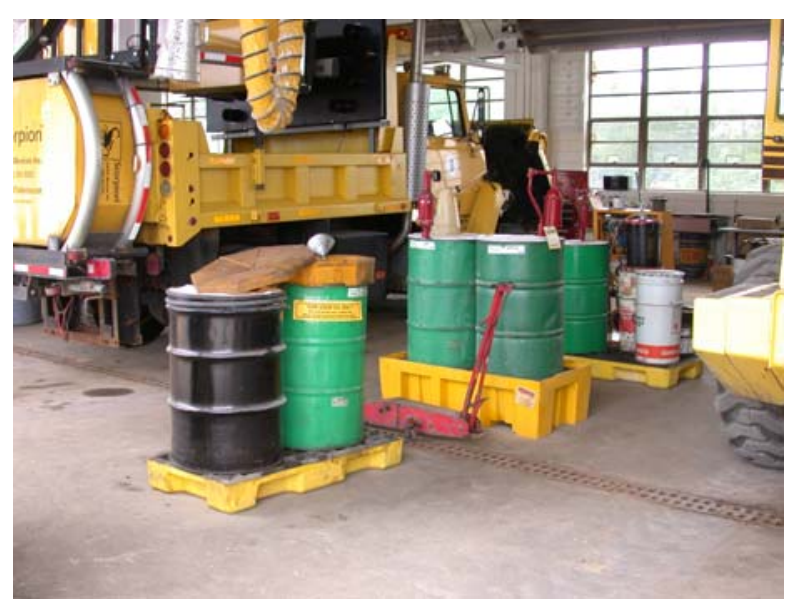




\section{* Salt Dome}

$>$ There was a significant amount of salt on the ground around the entrance of the Salt Dome.

The runoff from around the salt dome flows over the ground and then into a ditch that empties into Long Branch Creek.
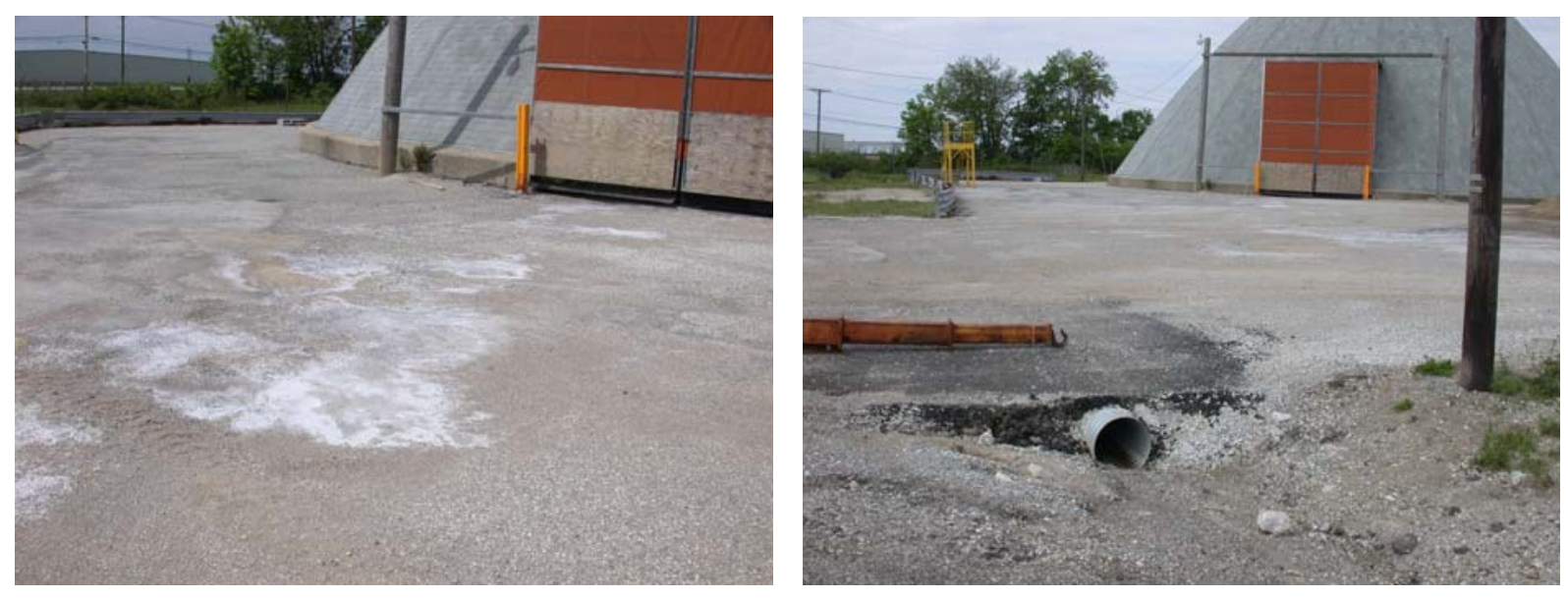

* Other Buildings

There are two storage/parking buildings on site. Each building can house 5 salt trucks at one time if necessary. 


\title{
INDOT Site Assessment Report Observations and Comments
}

Facility: Angola Subdistrict

February 16, 2005

\author{
Surface Area
}

General

$>$ An on-site retention pond collects much of the storm water that falls on the active surface. When this pond overflows (the Foreman said it very rarely overflows) the water is conveyed south, via a 300 yard grassed ditch, to Fox Lake.

$>$ The Salt Dome, sand storage, and cold patch storage areas are encompassed by a concrete berm. A catch basin collects the storm water inside this area and pipes it to two 20,000-gallon underground storage tanks. From these tanks, the storm water is slowly metered into the sanitary sewer system.

$>$ An outdoor, uncovered washbay area drains into a catch basin that is also connected to the underground storage tanks. This area is not bermed, which allows storm water to enter the catch basin.

$>$ In addition, a catch basin collects storm water in the vehicle parking area, which is piped to a ditch, west of the site. This ditch runs approx. 1.5 miles north, to Buck Lake.

Site Layout

$>$ The Sub Building is located at the entrance of the property off U.S. 20 (US 20 borders the West property line). North of the Sub Building two 20,000-gallon tanks are buried along with an underground oil/water separator.

$>$ South of the Sub Building is a parking area for trucks. The storm water from this area enters a catch basin and eventually reaches Buck Lake.

$>$ In the Southwest corner of the property, there is a large storage garage, which contains no drains.

The Salt Dome is located in the center of the site, along with a covered shed that houses cold patch and a sand pile used for mixing. This area is encompassed by a 
concrete curb that diverts all storm water to a catch basin connected to the underground storage tanks.

Salt beds are stored on concrete barricades, just outside the bermed area, east of the Salt Dome. All storm water from this area flows north into the retention pond.

$>$ South of the salt bed storage area is a secondarily contained calcium chloride tank. Storm water that falls in this area also flows into the retention pond.

$>$ A wash bay area is located northwest of the salt dome. All water used for washing, as well as any storm water that falls in this area, is collected by a large catch basin that empties into the underground storage tanks.

In the back, northeast, corner of the property, there are several piles of aggregate as well as a pile of scalp material. All storm water that falls in this area drains directly into the retention pond.

\section{$\underline{\text { Buildings }}$}

Sub Building

This building contains a lateral floor drain that runs the entire length of the maintenance area. All liquid collected in this drain enters an oil/water separator, which is connected to a sanitary sewer system.

$>$ On the east side of this building, an 800 gallon, double walled tank is used to store used oil. The area around this tank was very clean with no sign of any leaks.

\section{* Large Storage Garage}

$>$ This building was not open on the day of the visit, but the Foreman said the building is used for storage and vehicle maintenance jobs such as headlight changes. He stated that there were no drains in this building.

\section{* Salt Dome}

As previously stated, a concrete curb encompasses the salt dome and loading area. This prevents any storm water that is exposed to salt spillage from migrating off the concrete pad. 


\section{INDOT Site Assessment Report Observations and Comments}

\section{$\underline{\text { Surface Area }}$}

General

$>$ This facility is not connected to a sewer system or equipped with an oil/water separator. All salt bed washing and vehicle washing is done inside the Unit Building. Liquids captured in the Unit Building floor drain are piped directly to Smith Ditch, which borders the Northern property line. Smith Ditch drains into Yellow Creek approximately 500 yards SE of the facility.
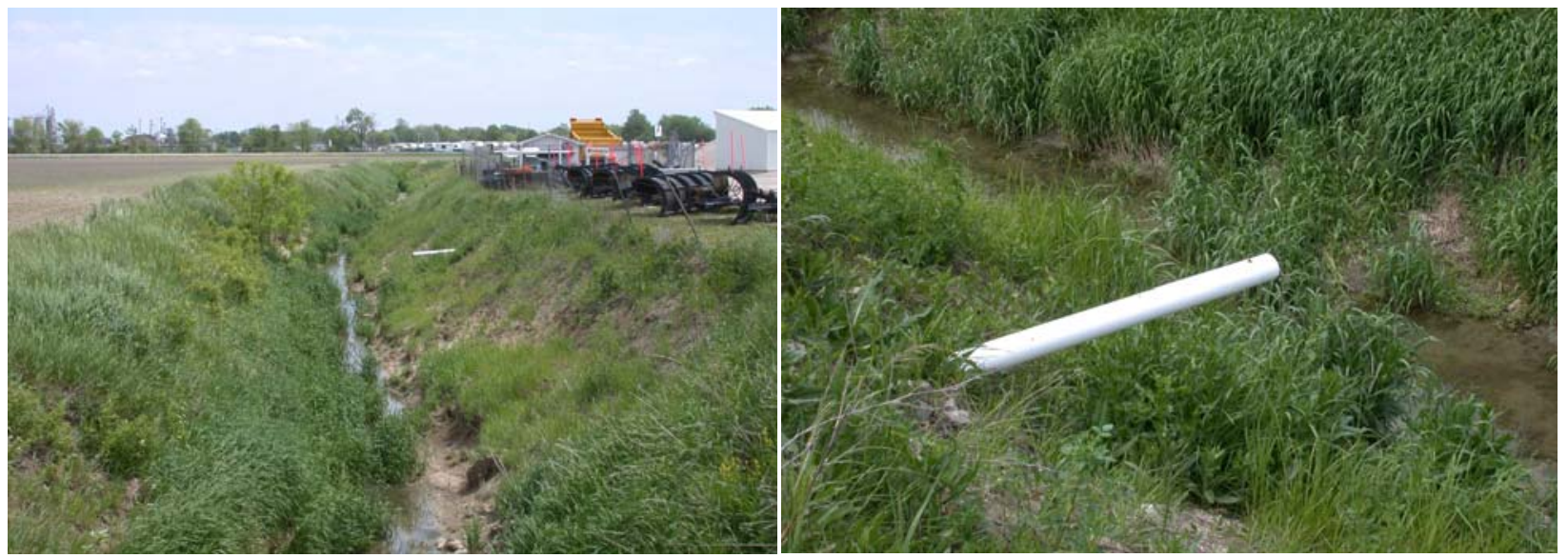

The Subdistrict Building is located in Bluffton approx. 15-18 miles away.

The Unit Foreman stated that the closest possible sewer connection is approx. 300 yards south of the facility. This sewer line runs along State HWY 124. 
> There was a noticeable amount of salt on the active surface around the Salt Building and Salt Loading Pad. There were several salt trails leading from this area to a catch basin placed approx. 20 feet away. The runoff captured by this catch basin is piped directly to Smith Ditch.
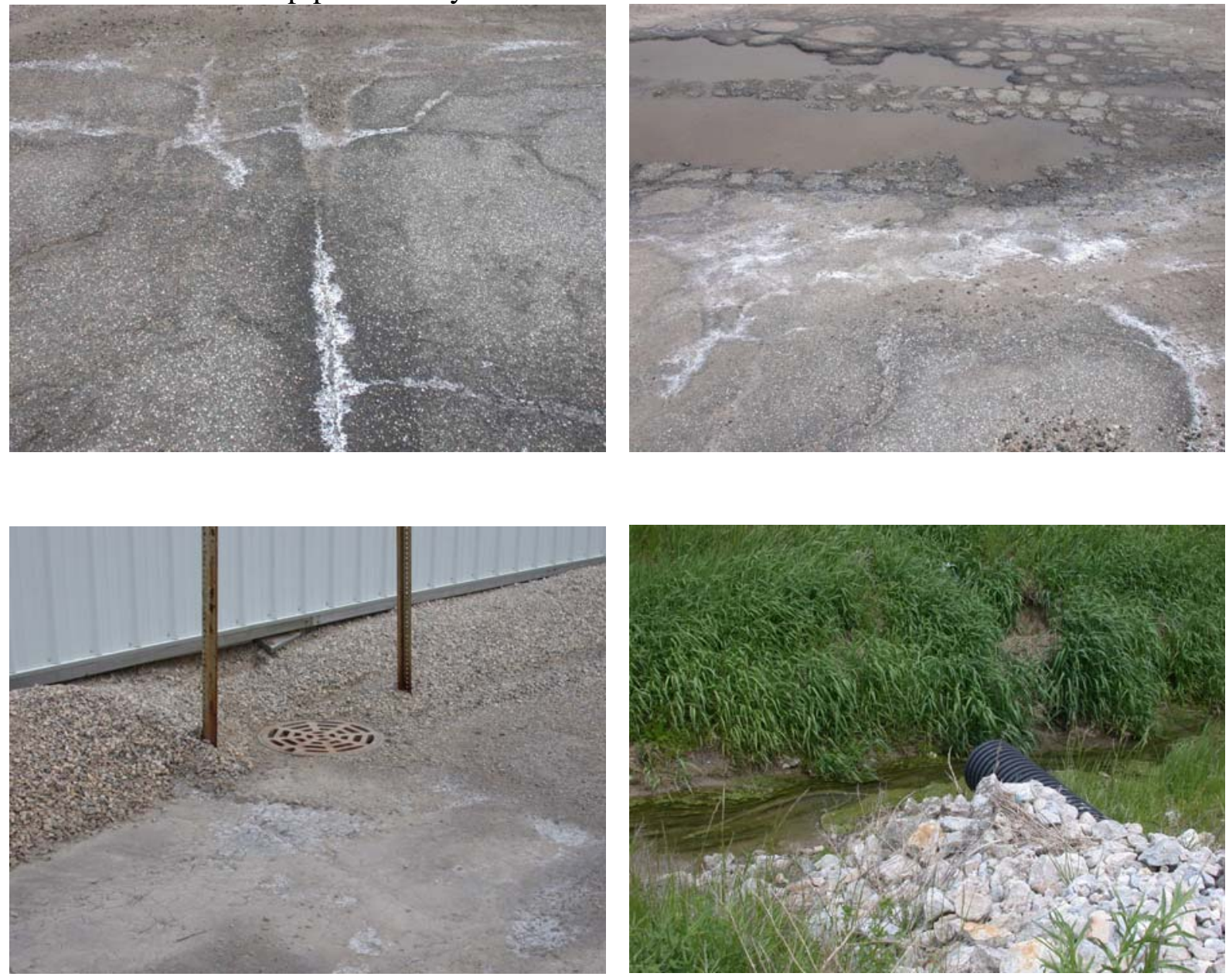

* North Property Line

$>$ The Unit Building is located in the NW corner of the site, approx. 35 feet from Smith Ditch.

> There are several snowplows and a fenced in area, which stores various metal objects, orange traffic cones, and pressurized tanks, located on the edge of Smith Ditch.

There is a three-sided cold storage building located south of the Unit Building. At the time of the visit, the only things being stored in this building were road signs, traffic cones, tires, and a small trailer. 
South Property Line

The Salt Storage Building is located in the SW corner of the site. On the south side of the building, there are three secondarily contained Calcium Chloride tanks. On the NE corner of the Salt Storage Building there is a salt loading ramp and pad. There is a catch basin located approx. 20 feet from this area that catches runoff and conveys it to Smith Ditch.

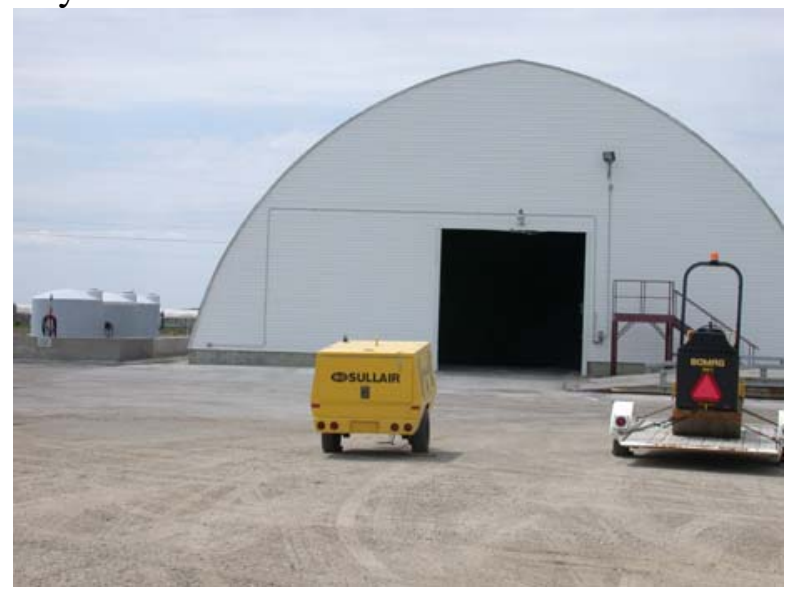

The Salt Bed Racks are located east of the Salt Storage Building. The runoff from this area is conveyed to Smith Ditch, via a grassed ditch.
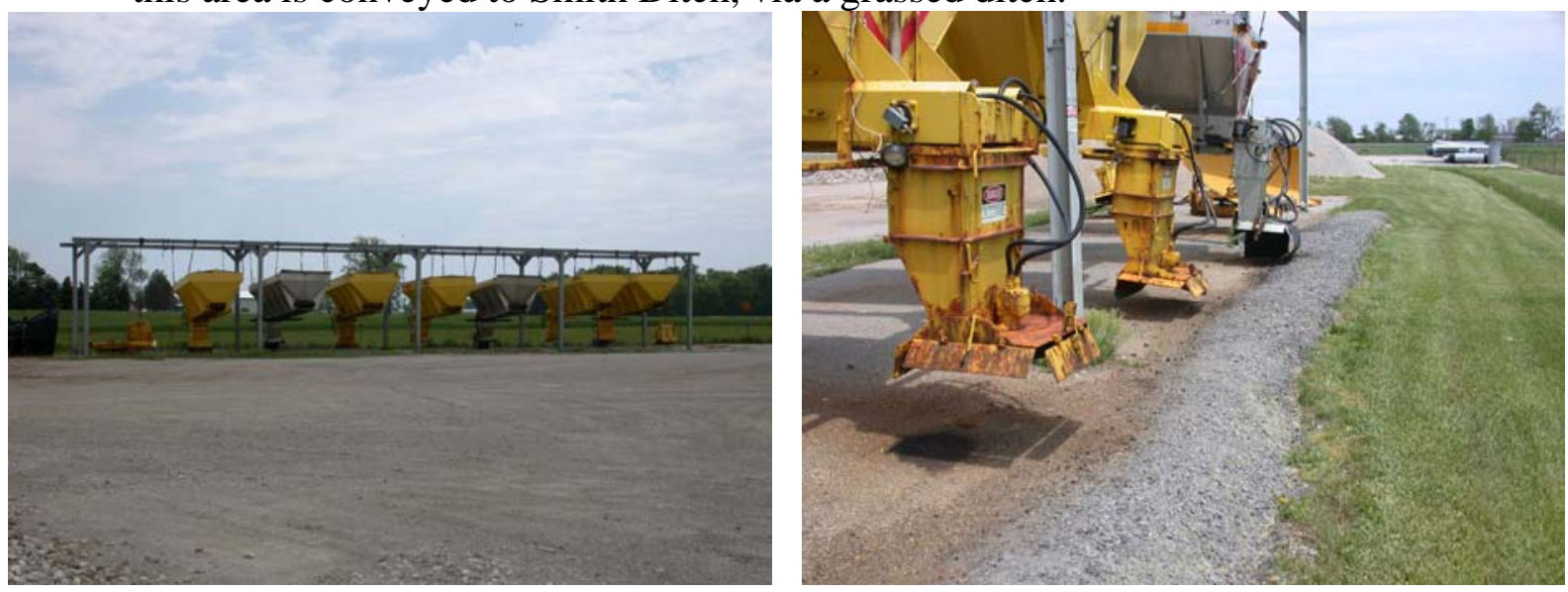

The SE corner of the site is used to store aggregate piles and metal pipe segments. 


\section{Buildings}

\section{Unit Building}

All salt bed washing is done inside the Unit Building. The wash water is captured by the floor drain and it is piped to Smith Ditch. This facility is not equipped with an oil/water separator.

There was a 55-gallon drum of oil in the Unit Building that was not secondarily contained. Any leak or spill will be piped directly to Smith Ditch.

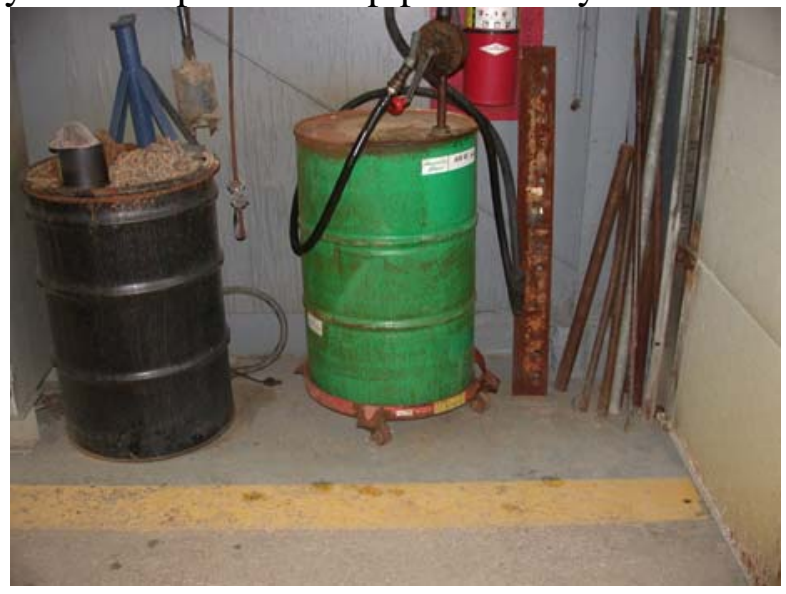

\section{Salt Dome}

There was a significant amount of salt on the ground around the entrance of the Salt Dome. It was evident that this salt was being transported by storm water to a nearby catch basin, which is piped to Smith Ditch.

There was also salt on the ground around the salt loading pad. This salt was also being transported to the catch basin by storm water.

\section{Other Buildings}

The Cold Storage Building housed road signs, traffic cones, a small trailer, and some tires. This building was not very large. 


\title{
INDOT Site Assessment Report Observations and Comments
}

\author{
$\underline{\text { Surface Area }}$
}

General

> There is an Asphalt-Testing Lab on this site along with a Salt Dome and Unit Building. However, the Unit Building is no longer in operation and is used for equipment storage only.

$>$ No salt bed storage, salt truck parking, equipment washing or vehicle maintenance takes place on site. All of these operations take place at the Angola Sub.

This site is bordered to the North by Pigeon River, which the Lab Foreman stated is stocked with trout every year and is one of Indiana's most pristine rivers.

Site Layout

$>$ S.R. 327 borders the East property line. The Asphalt Lab is in the Southeast corner of the site. The area around this building slopes slightly toward the roadside ditch, which drains directly into Pigeon River.

$>$ The Salt Dome is on the West property line, approx. 50 yards from Pigeon River. The area surrounding the Salt Dome also slopes slightly toward the roadside ditch.

North of the salt dome, in the Northwest corner of the property, there are several piles of aggregate, the remnants of a salt bed storage structure, and an old lawn mower along with some rusty metal scraps that need to be disposed of. This area slopes toward Pigeon River.

The Old Unit Building is located on the North property line, approx. 10 yards from Pigeon River. The area surrounding this building also slopes toward Pigeon River. 


\section{Buildings}

* Unit Building

$>$ The Unit Building is no longer in operation. The floor drain, which at one time ran to Pigeon River, has been filled in with dirt. There are no other drains in the building

$>$ The Unit Building is used to store a front end loader, a small tractor, and some grass cutting equipment.

* Asphalt Laboratory

> The Asphalt Laboratory Building is connected to a septic system, which handles all the floor drains, sinks, and toilet effluent. All chemicals used for testing are stored in a small secondarily contained storage room.

\section{* Salt Dome}

The area around the Salt Dome was clean with very little salt residue. There were no berms around the entrance of the dome or the loading area. 


\title{
INDOT Site Assessment Report Observations and Comments
}

\author{
$\underline{\text { Surface Area }}$
}

General

> This Unit Building floor drain is connected to a sewer system. All liquids collected by the Unit Building floor drain go through an underground tank that is used as a makeshift oil/water separator. It is actually a small tank with a J-tube on the outlet. The idea is that the oil will rise to the top of the tank and be captured while the water flows out of the J-tube. However, in order to be efficient the tank would need to be larger. The Unit Foreman said that he has many problems with the underground tank due to clogging and backups. He said that it is insufficient and he has requested an oil/water separator several times.

$>$ All vehicle and salt bed washing is performed on-site, either inside or outside the Unit Building. All outside wash water drains into Henry Bandellier Drain.

* North Property Line

$>$ The Unit Building is located near the center of the North property line. There was a small lean-to on the north side of the Unit Building used to store equipment and tools.

$>$ The makeshift oil/water separator is buried on the NW side of the Unit Building. The floor drain effluent flows through this device and then to the sewer system. 
The INDOT vehicle parking area is located on the south side of the Unit Building. This area is a gravel/dirt mixture. At the time of the visit, there were several small piles of salt in this area along with puddles of storm water with an oily sheen.

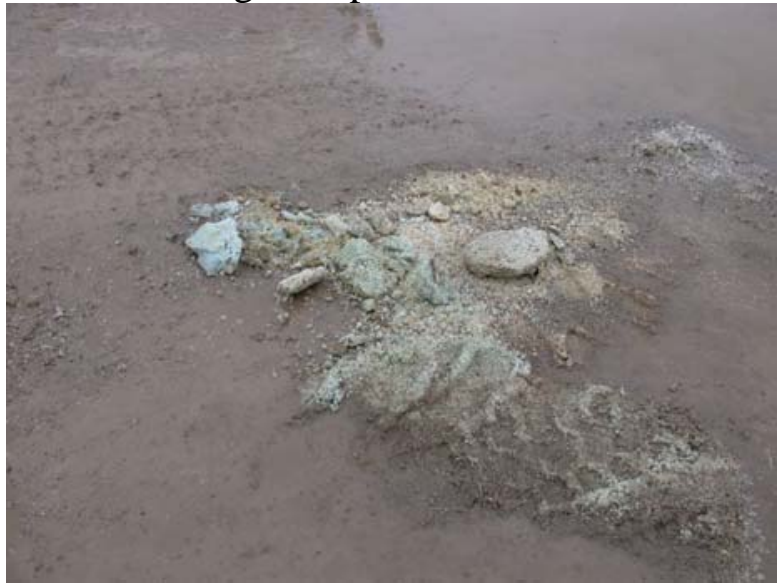

On the east side of the Unit Building, a small dump truck had recently been washed. As a result, there was a pile of salt and yellow paint chips on the ground behind the truck. It was apparent that washing vehicles and salt beds in this area is a common practice. This area is paved and all runoff from this area will eventually enter Hendry Bandellier Drain.
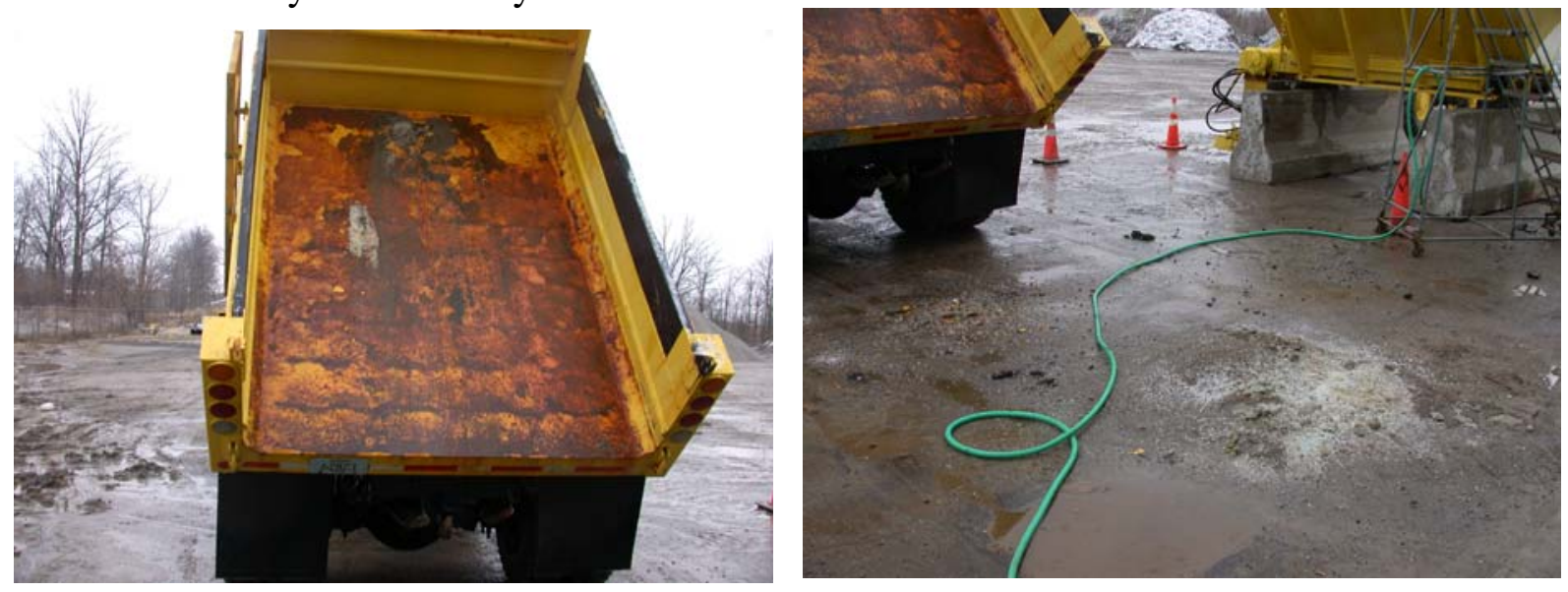

* West Property Line

$>$ There is a parking area for personal cars in the NW corner of the property. There is a catch basin in this parking area used to catch storm water and convey it south to Henry Bandellier Drain.

The Salt Dome and Calcium Chloride tank is located south of the parking area. The Calcium Chloride tank is secondarily contained with a concrete enclosure. There was a noticeable amount of salt on the ground around the entrance of the Salt Dome. 
South of the Salt Dome, a three-sided storage building stores tools and a pile of cold patch.

$>$ The salt/sand loading pad is located east of the storage building. This entire area was loaded with salt. There were several large piles of salt around the base of the pad. The storm water from this area flows south to the perimeter ditch, which drains into Henry Bandellier Drain.
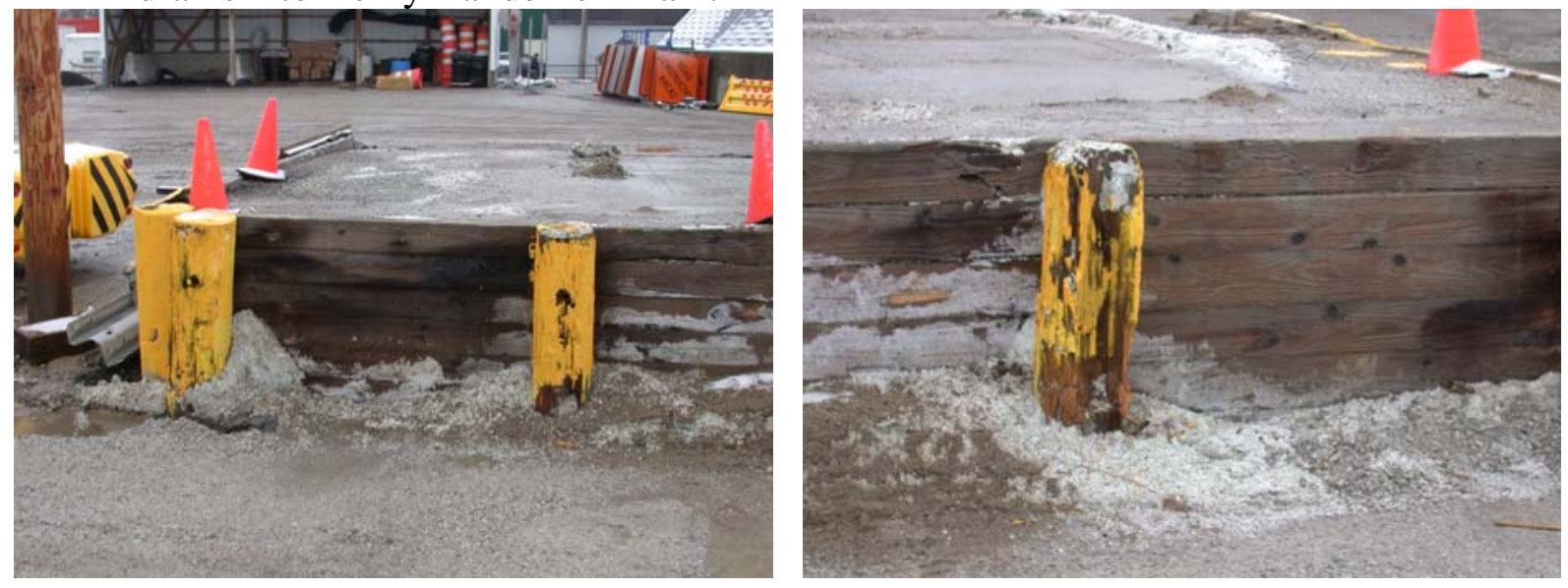

The drainage pipe, which carries the storm water from the parking area, empties into a ditch that conveys the water down the west property line into the SW corner. The water is then piped under the perimeter fence and into Henry Bandellier Drain.
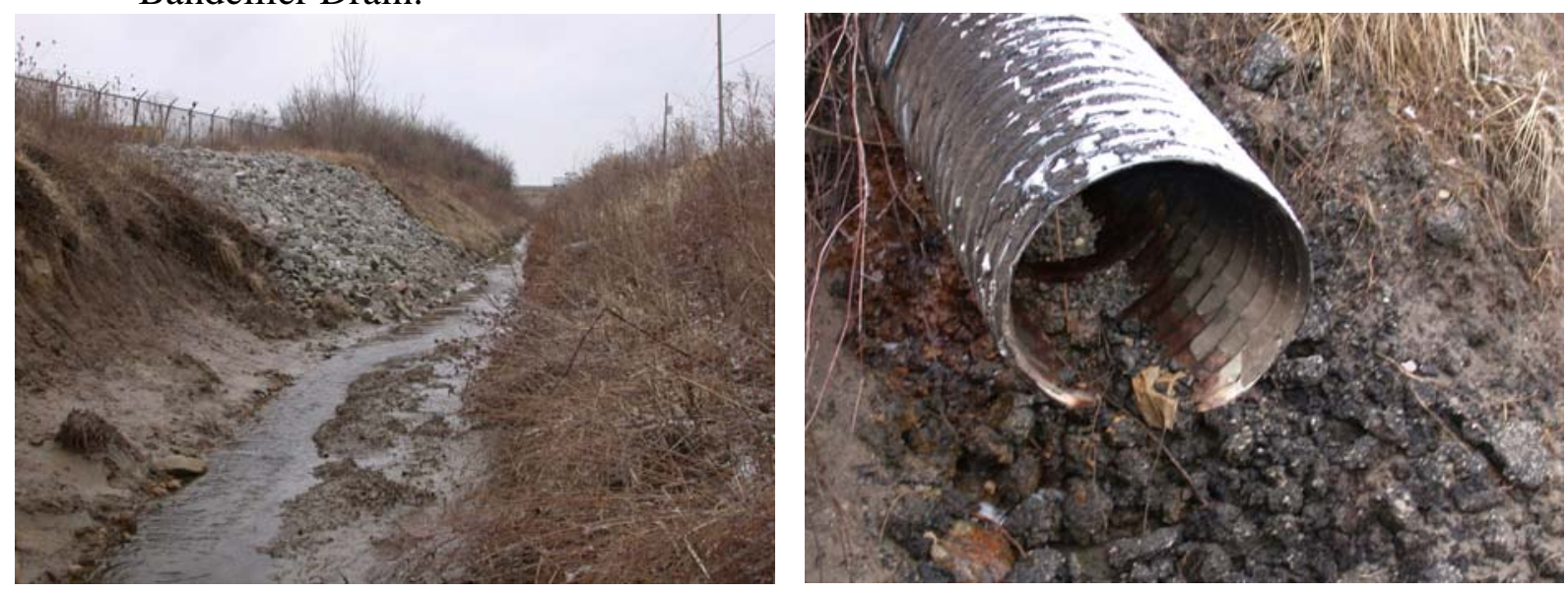
South Property Line (bordered by Henry Bandellier Drain)

> The salt bed racks are located on the south property line, just east of the SW corner of the property. This area is gravel and slopes toward the south property line. There was a substantial amount of salt and paint chips under the racks.
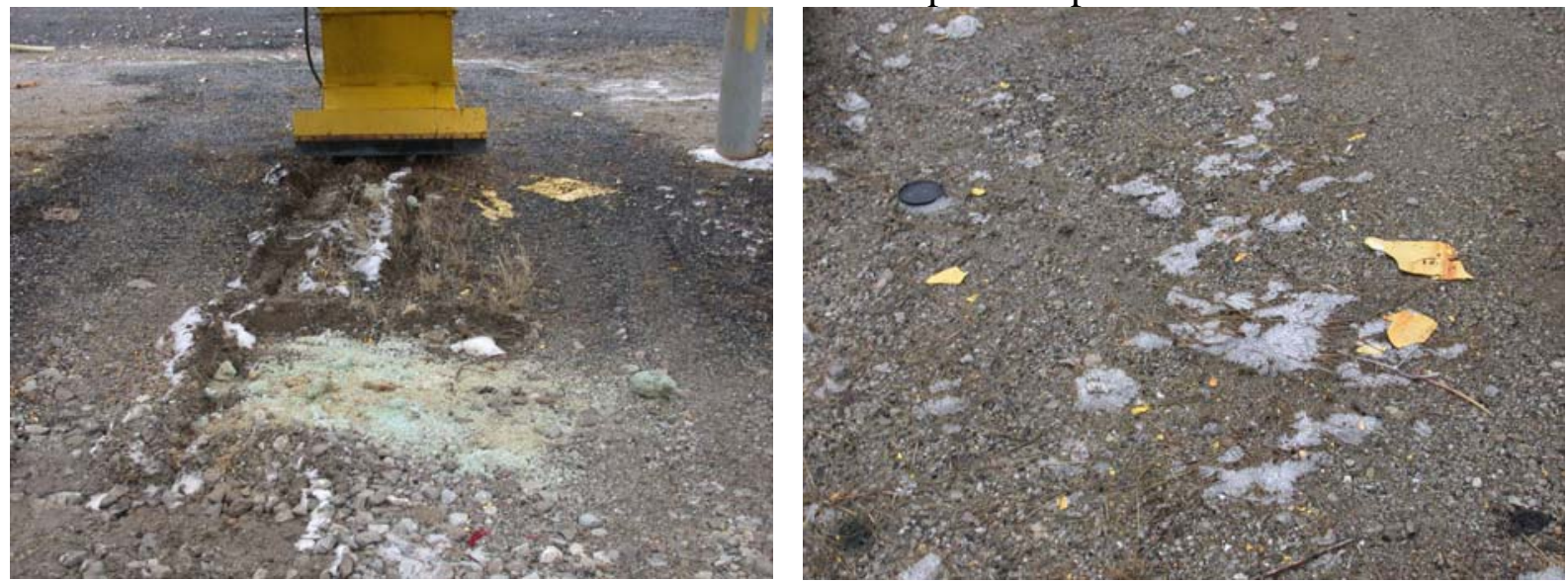

The entire SE quadrant of the property is used to store aggregate piles.

\section{Buildings}

Unit Building

There were several piles of salt on the active surface around the Unit Building. The runoff from this area enters Henry Bandellier Drain.

Because the floor drains in the Unit Building are connected to the sewer system, all salt bed and vehicle washing should be done inside. However, it was evident that some salt bed washing is performed outside.

\section{Salt Dome}

There was a substantial amount of salt on the active surface around the Salt Dome. 


\section{INDOT Site Assessment Report Observations and Comments}

\section{$\underline{\text { Surface Area }}$}

General

This site is bordered to the NW by Houk Ditch, which drains into St. Mary’s River approx. $1 / 2$ miles from the site.

All storm water and contacted water from this site enters Houk Ditch.

This facility is not connected to a sewer system and is not equipped with an oil/water separator.

All vehicle and salt bed washing is performed in the Unit Building. The water from the Unit Building is piped approx. 10 feet to an on-site ditch, which drains directly into Houk Ditch.
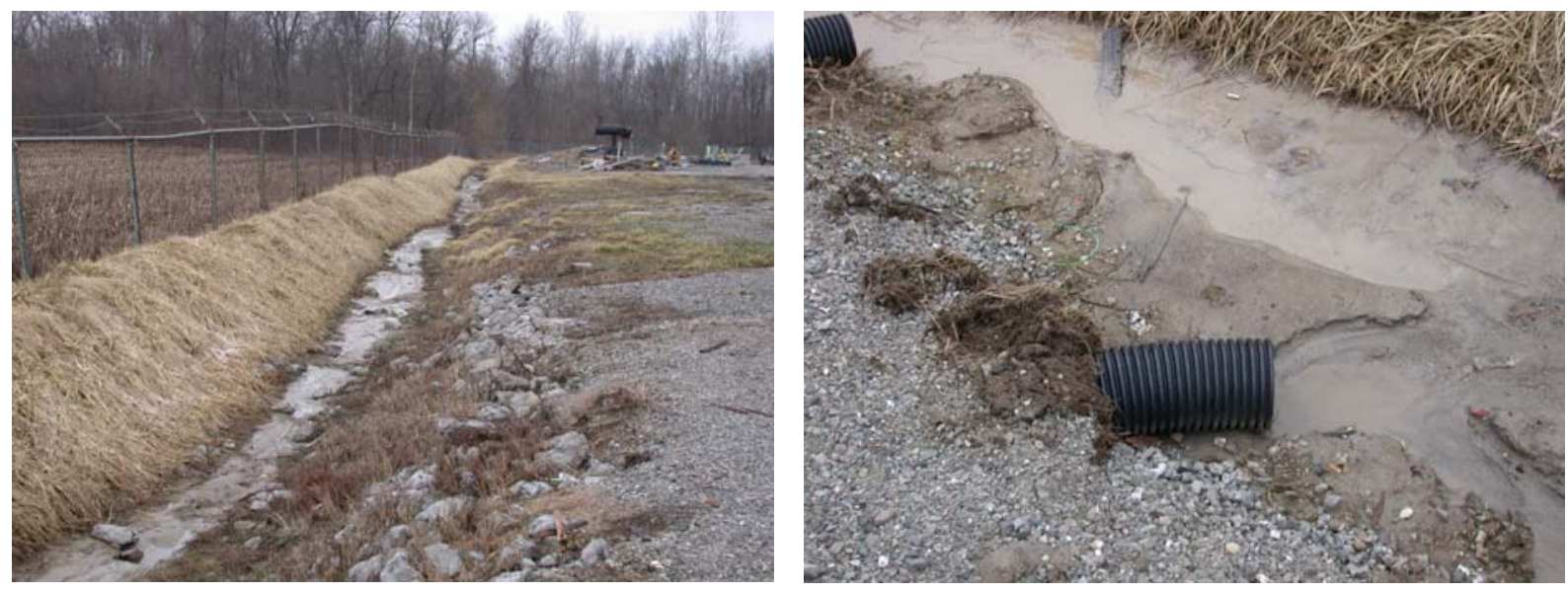

At high levels the water of Houk Ditch is said to reach the Salt Dome. 
There is a substantial amount of erosion on the bank of the ditch, which is being caused by the high volume of runoff coming from INDOT property.

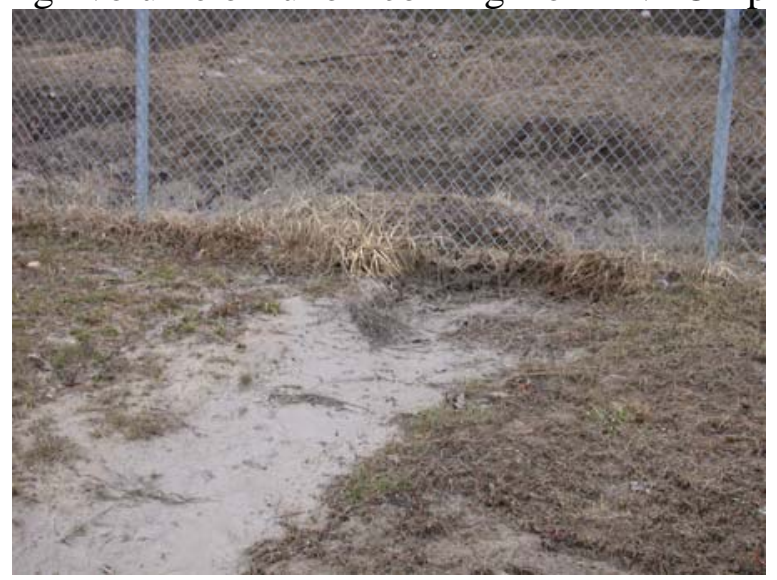

At the time of the site visit, there was an excessive amount of salt on the ground around the Salt Dome and the salt loading area. All storm water that comes in contact with these areas flows directly into Houk Ditch.
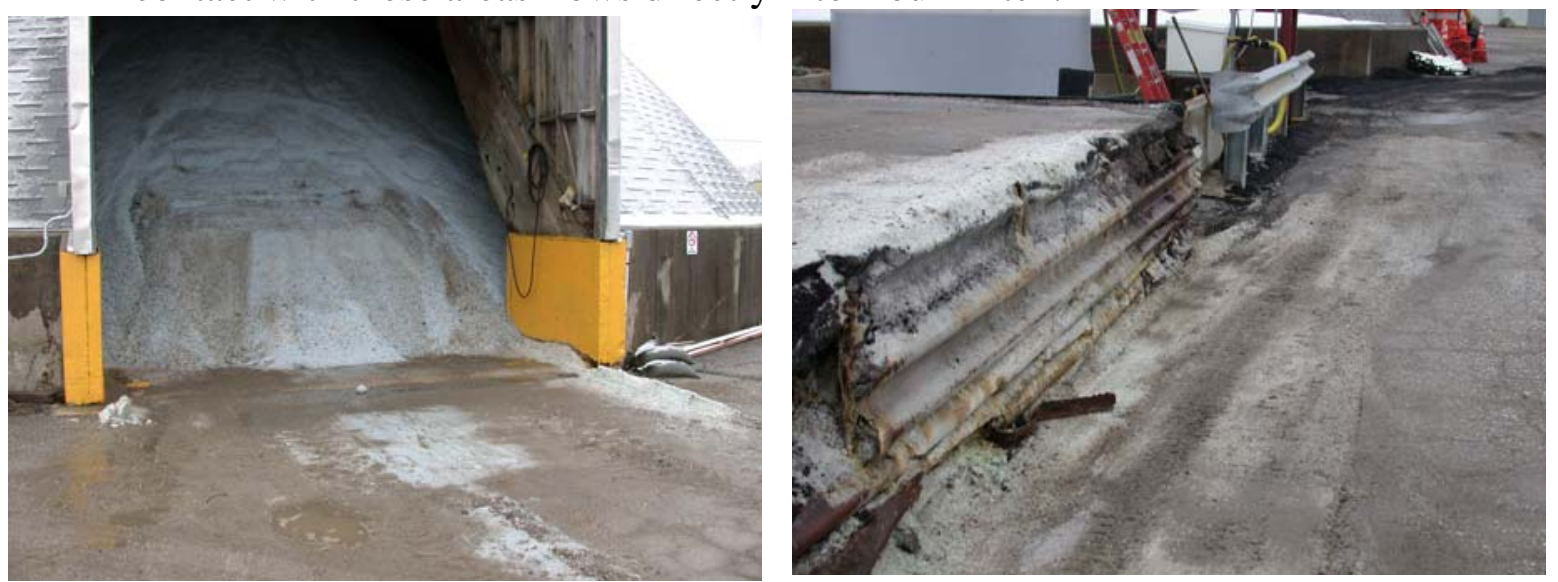

There were several piles of salt throughout the active surface. The storm water that comes in contract with these piles of salt drains into Houk Ditch.
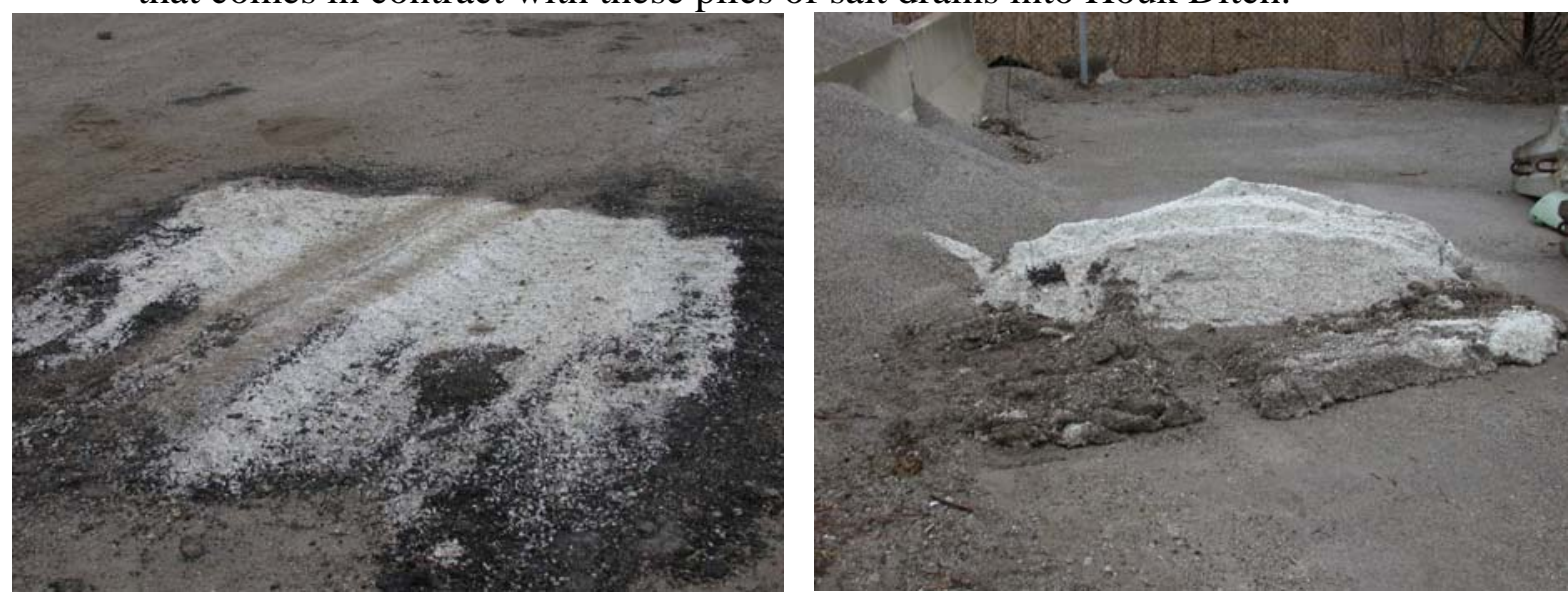
South West Property Line

The Unit Building is located in the southern most corner of the property, approx. 200 yards from Houk Ditch. The floor drain effluent from the Unit Building is piped to an on-site ditch, which runs the entire length of the SW property line, eventually emptying into Houk Ditch.

An incinerator is located NW of the Unit Building.

The Salt Dome and salt loading area is located NE of the incinerator, in the center of the property. The salt loading area is uncovered and the active surface was loaded with salt that was obviously lost during loading. There was also a large amount of salt just outside the entrance of the Salt Dome.

$>$ An aggregate storage area is located south of the Salt Dome. The rest of the SW property line is used for storing various metal objects such as pipe segments and fencing.

North East property line ( bordered by U.S. HWY 27 )

$>$ The salt bed storage racks are located in the northern most corner of the property, approx. 75 feet from Houk Ditch. This area drains directly into Houk ditch in the form of sheet flow.
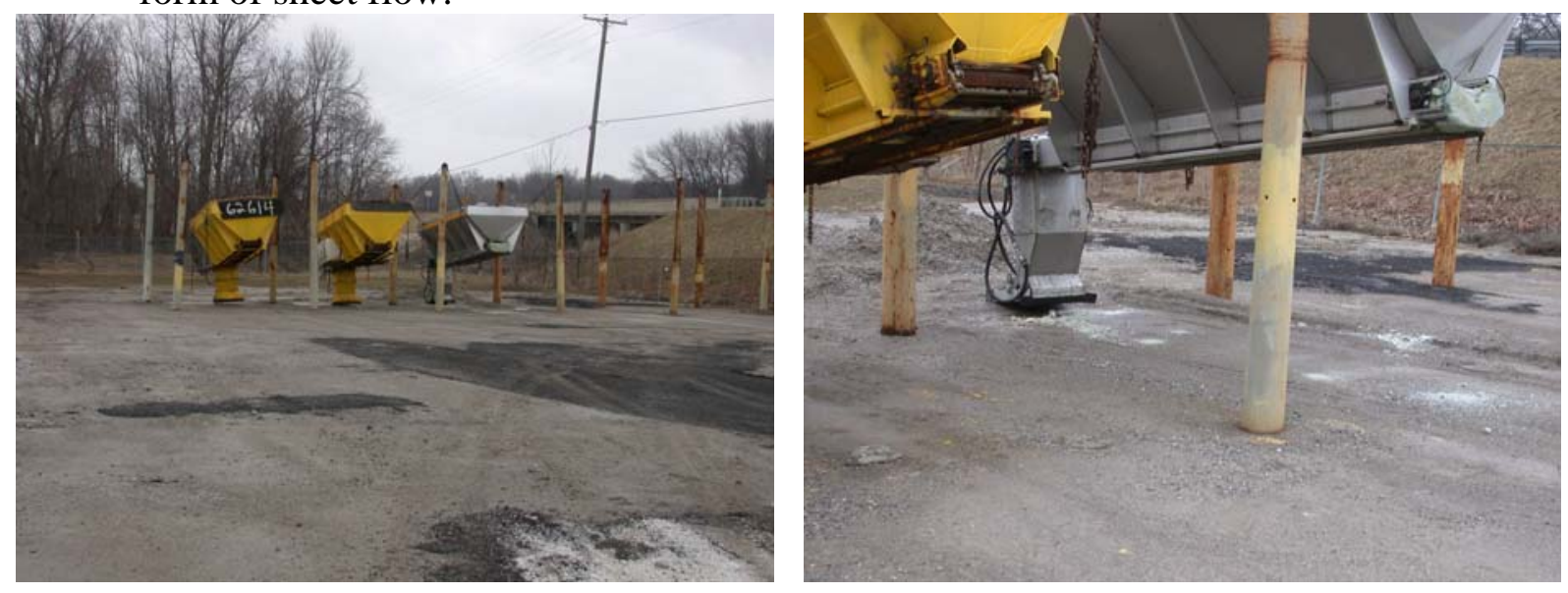

Sand and cold patch is stored SE of the salt bed storage area. The cold patch is not bermed and was not covered at the time of the visit.

The truck parking area is located SE of the sand and cold patch. This area was not bermed.

At the time of the visit there was a small building being constructed in the SE corner of the property. 


\section{Buildings}

* Unit Building

A All vehicle and salt bed washing is performed inside the Unit Building.

$>$ A lateral floor drain in the center of the Unit Building empties into an on-site ditch. This drain catches all washwater and spills.

$>$ A tar buggy, from which there was some evidence of asphalt leakage onto the floor, is kept in the Unit Building. The tar buggy is kept approx. 10 feet from the floor drain.

$>$ There were 55-gallon drums of oil and transmission fluid kept in the Unit Building as well.

\section{* Salt Dome}

There was a significant amount of salt around the Salt Dome entrance and the salt loading pad on the day of the visit. 


\section{INDOT Site Assessment Report \\ Observations and Comments}

\section{$\underline{\text { Surface Area }}$}

General

This facility is equipped with an oil/water separator but is not connected to a POTW. The Unit Foreman said that the floor drains in all the buildings, including the washbay, drain into a large septic system. Several people in the central office were asked to confirm this but no one had this information. If there is no septic system the floor drains must drain into the ditch that runs along the east property line.

There was a substantial amount of salt on the active surface at this facility. Stormwater from the site is collected in catch basins or flows over ground to the drainage ditch that runs along the east property line. There is evidence that salt is being transported into the ditch via contaminated stormwater.

There is a waste oil tank outside the Sub Building that is not secondarily contained. There are also several 55-gallon drums with unknown contents outside the Sub Building that should be properly disposed of.
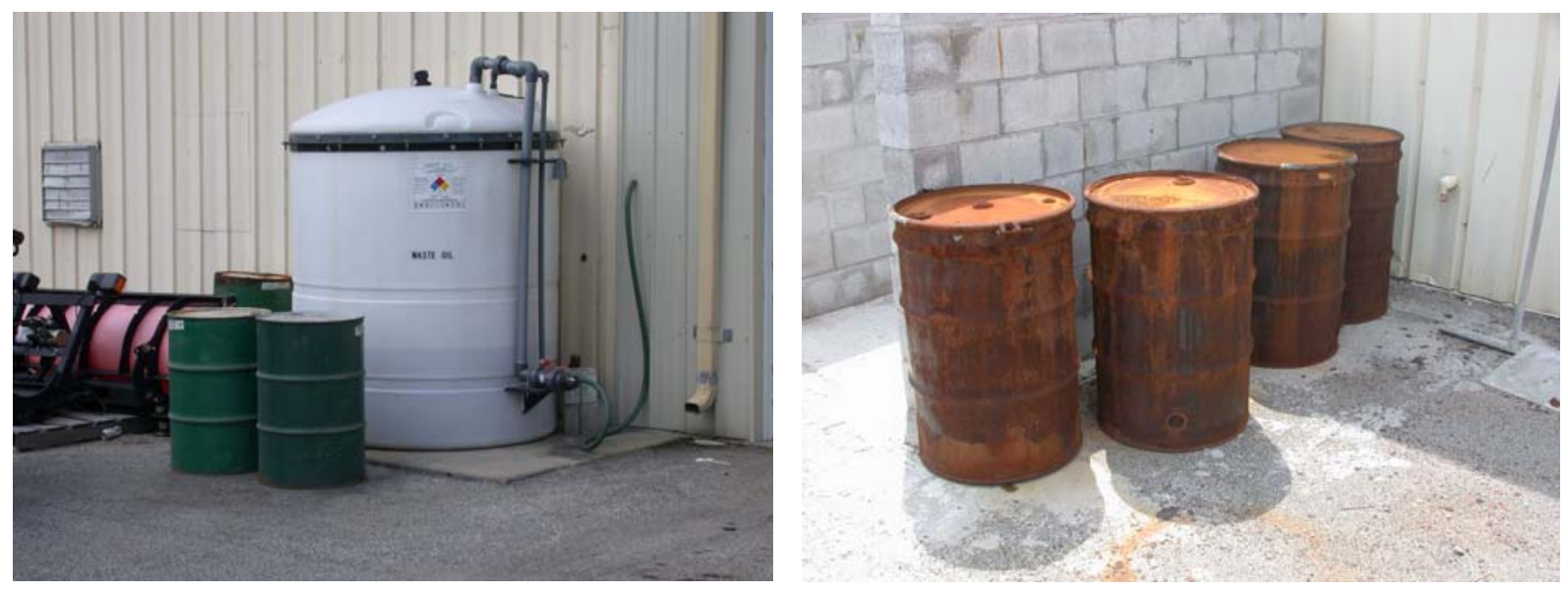


\section{West Portion of Property}

$>$ There is a testing office building in the NW corner of the site. This building was not open on the day of the site visit. There are two catch basins around the perimeter of the building that collect stormwater and convey it the drainage ditch.

$>$ The Sub Building is located in the SW corner of the site. This Building consists of offices and a large maintenance area with floor drains.

The waste oil tank is located on the east side of the Sub Building. This tank is not secondarily contained.

The Unit Building is located SE of the Sub Building. The oil/water separator and washbay is located in this building. There is a truck parking area on the east side of the Unit Building.

\section{East Portion of Property}

The Salt Dome is located NE of the Sub Building. There is a berm around the salt mixing/loading area and there is a catch basin within the bermed area that collects water and conveys it to the ditch that runs along the east property line.

The salt bed racks are located on the west side of the Salt Dome. There is a substantial amount of salt and paint chips under the racks
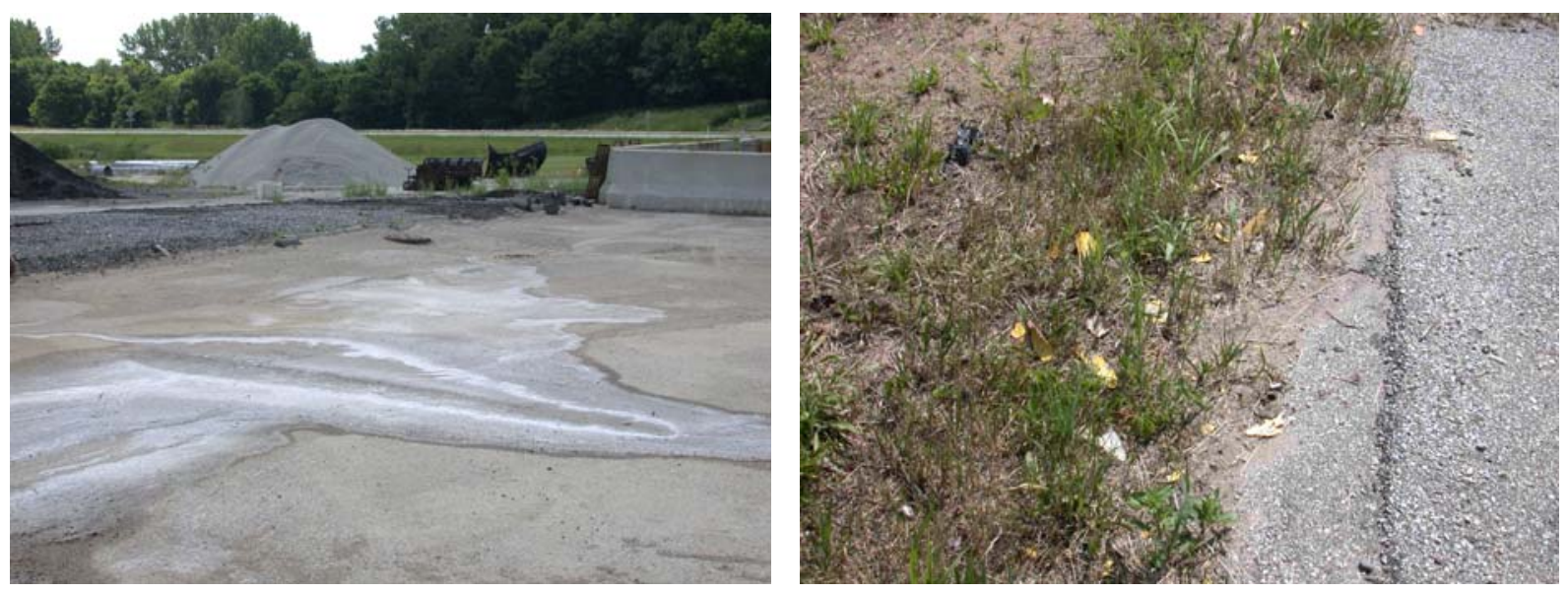

There is a pile of cold patch located SE of the Salt Dome that is not bermed or covered.

There is also a small pole barn located south of the Salt Dome that is used to store tractors and a tar kettle.

The entire NE corner of the site is used to store aggregate piles 
There is a large vegetation kill in the SE corner of the property. Sheet flow from the truck parking area and Salt Dome area flow through this corner and into the drainage ditch.
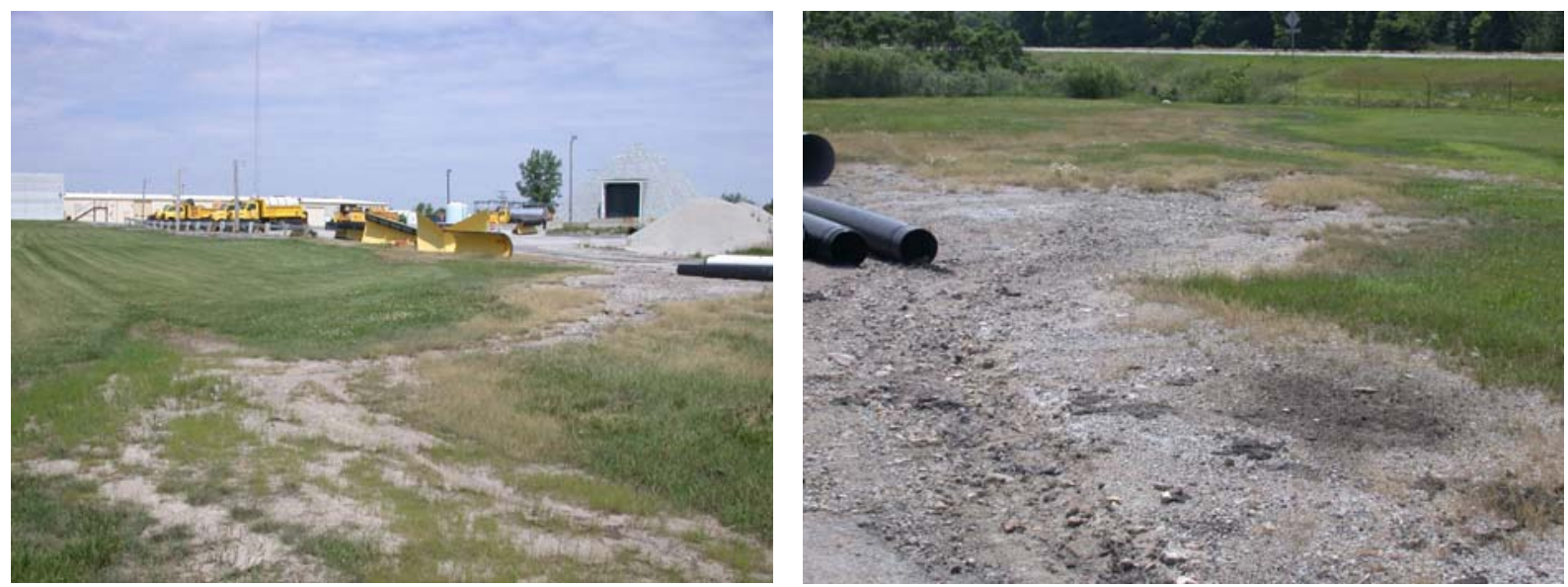

\section{Buildings}

* Sub and Unit Buildings

There is an oil/water separator in the Unit Building that receives water from the floor drains in the Unit Building as well as the Sub Building.

There oil and hydraulic fluid drums in the Sub Building were not secondarily contained.

Empty 55-gallon drums and old batteries are stored on the ground outside of the Sub Building.
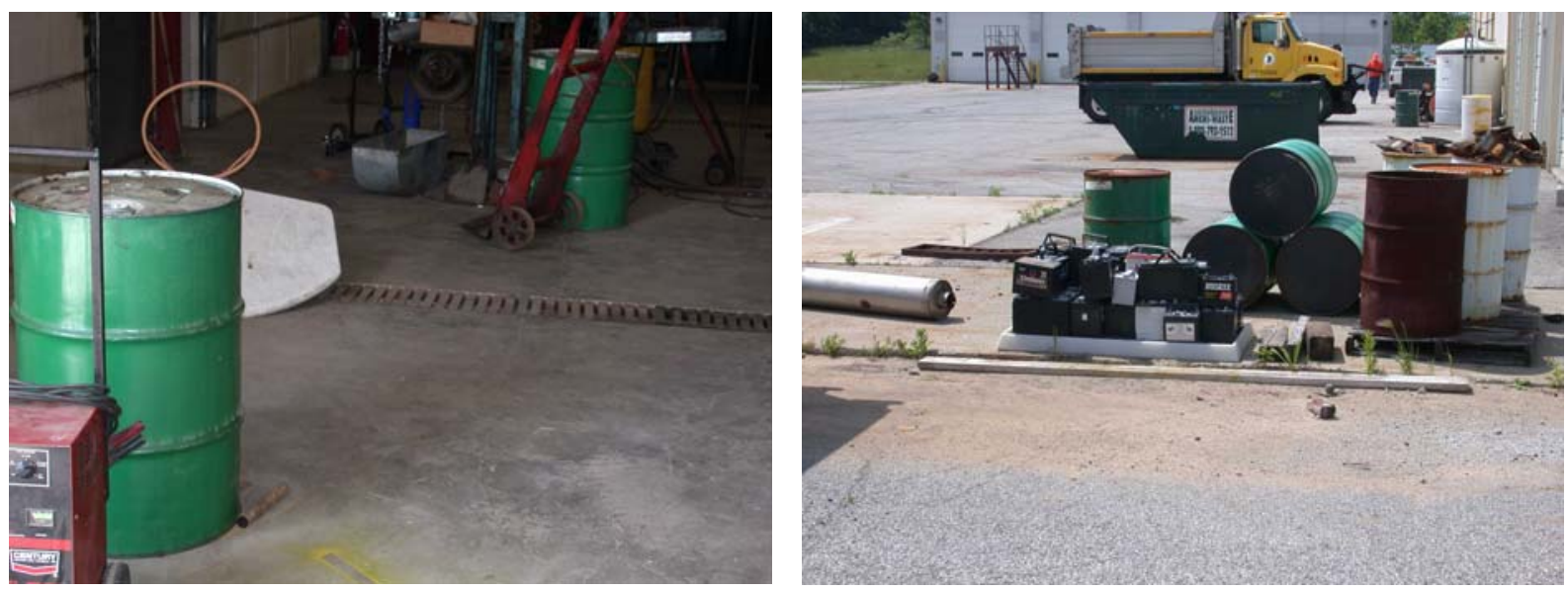
Salt Dome

$>$ The area around the Salt Dome is not kept clean. There is a significant amount of salt on the ground around the dome. Stormwater is mixing with the salt and being discharged into a drainage ditch.

A tarp is put over the entrance of the Salt Dome during the off-season.

\section{* Other Buildings}

There is a Testing Office Building and a small pole barn on-site. The Testing Office was not open during the visit.
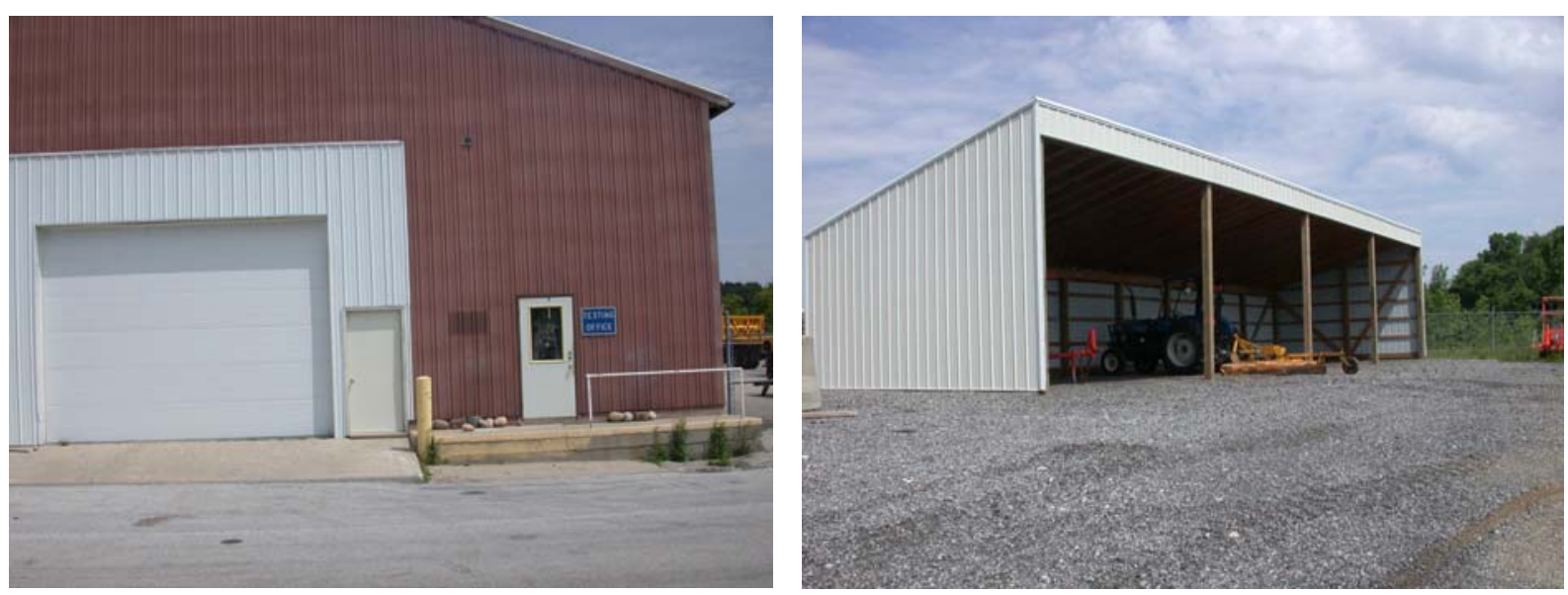


\title{
INDOT Site Assessment Report Observations and Comments
}

\author{
Surface Area
}

General

> All storm water, wash water, and liquids captured in the Unit Building floor drain enter Cedar Creek, which runs parallel to the Northern property line. This facility does not have an oil/water separator.

$>$ In 2002-2003, a catch basin was placed in the center of the active surface to collect storm water. This catch basin was tied into a previously existing pipeline, which runs from the US HWY 6 roadside ditch to Cedar Creek. The pipeline runs through the center of the property.

$>$ All vehicle and salt bed washing is performed onsite. However, all vehicle maintenance, such as oil changes, are said to be performed at the Subdistrict facility.

$>$ This facility has a perimeter fence but is missing a section that borders Cedar Creek due to the recent installation of the catch basin. The bank of the creek slopes steeply in some areas and is wooded. Upon inspection of the section of Cedar Creek bank that borders the Waterloo facility, the following discoveries were made: 5 discarded 55-gallon drums (looked to be old oil or hydraulic fluid drums), an old plastic drum with the word "trash" painted on the side, several large sections of rusty corrugated pipe, 2 bails of rusty wire fencing, several old tires, Styrofoam pieces, and various types of plastic fragments (i.e. five gallon buckets, yellow plastic debris). All this was located 10-20 feet off INDOT property, outside the perimeter fence.

$>$ The 55-gallon drums that were found on the creek bank were lying on their sides. It could not be determined if all the drums were empty or currently harboring chemicals that could be toxic to the environment. One drum had nearly rusted away but others were intact with lids. 
The Unit Building is in the Southeast corner of the property.

Approximately 40 yards west of the Unit Building, there is a small building that houses two offices and a break room. Next to this building is a shed used to store tools.

$>$ A vehicle and salt bed washing station is located approx. 10 yards south of the Office Building. There are no berms or drains in this area. The wash water travels approx. 30 yards south, to the catch basin in the middle of the property. There were noticeable salt piles and salt residue in this area and a salt trail leading to the catch basin was clearly visible.

$>$ The catch basin is located at the middle and lowest point on the property. The water is piped from the catch basin approx. 50 yards north into Cedar Creek. The water standing around the iron grate at the entrance of the catch basin had a white discoloration. The effluent end of the pipe projects out, approx. 2 feet, over the creek allowing for no infiltration before the water enters the creek.

$>$ The Salt Dome is located approx. 50 yards west of the catch basin. There were piles of salt on the active surface at the entrance of the salt dome. This salt loss had obviously occurred during salt bed loading. The storm water that is exposed to this salt area drains in two directions: North, down the creek bank or East, to the catch basin. Either way the salt/water mixture drains into Cedar Creek.

West of the Salt Dome is a secondarily contained Calcium Chloride tank. No salt bed spraying is performed at this site.

$>$ West of the Chloride tank, there is another small storage building.

West of the small storage building, there is an extremely large pile of grindings/scalp (ground up asphalt). This pile was, at least, 20 feet tall and the area around this pile drains in the same manner as the area around the Salt Dome (down the creek bank or to the catch basin).

* North Property Line (bordered by Cedar Creek)

$>$ The Salt Dome and large pile of grindings/scalp are located on the West side of the property. Much of the storm water that falls in this area, migrates north under the perimeter fence and into Cedar Creek. A small hand-dug trench was visible, which directed this storm water to Cedar Creek. The storm water flowed north through the trench, down a steeply sloped bank, and into Cedar Creek. There is a deep channel being eroded into the bank of the creek causing sediment, as well as 
salt, to be transported into Cedar Creek. This erosion is due to the high volume and high velocity of storm water coming from INDOT property.

Moving east along the perimeter fence approx. 50 yards, there is an area used for material storage. Metal scraps, plastic pieces, and old tires were all stored on the ground in this area, which has no berm and drains into Cedar Creek.

D Approx. 20 yards east, the salt beds are stored along the fence line on concrete highway dividers. They are stored on a paved surface, which drains under the fence and into Cedar Creek. The salt beds are stored approx. 25 yards from Cedar Creek.

$>$ The vehicle parking area is east of the salt beds, also along the fence line. Storm water in this area also flows down the creek bank and into Cedar Creek. There was salt on the ground in this area.

$>$ The Unit Building is located east of the vehicle parking area.

\section{Buildings}

\section{Unit Building}

> Some vehicle and salt bed washing takes place in the Unit Building and some takes place outside. The floor drain is not connected to an oil/water separator and it is piped directly to Cedar Creek. The drain is connected to a long, flexible pipe that emerges halfway down the sloping creek bank and drains onto the ground.

There was a drum of hydraulic fluid, which was not secondarily contained, in the building but there were no oil drums.

$>$ On the north side of the building, there were a few shovels along with a fivegallon bucket that had been used on an asphalt job. The bucket had filled with storm water and begun spilling an oily/water mixture onto the ground. The ground in this area was stained with a black/brown color. The bucket probably contained diesel fuel used to clean the shovels and other tools. This seems to be a common practice among many INDOT facilities.

* Office/break building

$>$ This building contains two office areas, a kitchen area (refrigerator, stove, sink), and an area with lounge chairs and a couch. 
* 2 Small Storage Buildings

$>$ One small storage building is used to store tools and road signs. The other is used to store bags of Dow Flake and tools.

* Salt Dome

The Salt Dome had no berm at the entrance or around the loading/mixing area. There was a substantial amount of salt on the active surface at the entrance of the Salt Dome. 
FACILITY SITE ASSESSMENT REPORTS

\section{GREENFIELD DISTRICT}


Date_3/9/2005

\section{INDOT Facility Stormwater and Washwater Effluent Drainage Assessment}

Name of Facility___Anderson Unit_______reenfield
District/Subdistrict__

\section{$\underline{\text { Surface Water }}$}

1. Does any area of the active surface collect storm water or facility-generated wash water (such as from washing trucks outdoors)? _ There is a detention pond on the East _ portion of the property

2. Is there any movement of surface water from one area to another on-site by ditch, drain tile or natural channel? __ Yes

3. Is there any movement of surface water off-site (e.g., beneath the perimeter fence) via sheet flow, ditch, pipe or channel to adjacent property? _Y Yes, when the detention _pond rises to a certain level it overflows into a railroad side ditch

4. Is the surface water discharged directly to (check all that apply) -

$\square$ drainage ditch or roadside ditch

$\square$ county-regulated drain

$\square \quad$ state highway drainage system

$\square$ a nearby creek, river or other water body

$\square \quad$ lagoon or holding pond

$\square$ settling basin, catch basin, or other constructed retention structure

$\square$ underground tank

$\square$ municipal storm sewer Owner

$\square$ municipal combined storm/sanitary sewer Owner

$\square$ POTW Owner:

$\square$ Other

5. If surface water is discharged, other than to a municipal storm, sanitary or combined sewer, does it ultimately reach "waters of the state” (e.g., farm ditch, creek, stream, river, lake or pond)? If yes, name of that water body. _ _Yes, from the detention pond the storm water overflows to a railroad side ditch, which ultimately drains into Fall Creek.

6. What is the estimated distance of this water body from the facility? _ The railroad side ditch is 50 feet from the property line and Fall Creek is approx. 2 miles from the property

$(\operatorname{Rev} 2 / 7 / 05)$ 
Shop Floor Drain \& Wash Bay Effluent

1. Are there drains in shop floors and wash bays that remove liquids and wash water effluent from the building(s)? _

2. Does the effluent flow to -

$\square$ aboveground oil/water separator

$\square$ aboveground tank

$\square$ below ground oil/water separator

$\square$ below ground tank

$\square$ settling basin, catch basin, lagoon, holding pond or other constructed retention structure

$\square$ none of the above

3. If the effluent is captured by the devices in 2., above, is it contained until pumped and hauled to a POTW or until it evaporates, or does it overflow to a drainage system?_It enters the sanitary sewer system

4. If the effluent overflows to a drainage system, is the system above or below ground? __Below ground

5. If the effluent overflows to a drainage system, does it mix with storm water? No

6. If the effluent does mix with storm water, see "Surface Water" section (preceding page, \#4 and \#5) for discharge.

7. If the effluent doesn't mix with storm water, is it discharged to -

$\square \quad$ subsurface soils

$\square \quad$ on-site septic system

$\square$ drainage ditch or roadside ditch

$\square \quad$ a nearby creek, river or other water body

$\square \quad$ lagoon or holding pond

$\square$ municipal storm sewer Owner

$\square$ municipal combined storm/sanitary sewer Owner_Anderson STP

$\square \quad$ municipal POTW Owner

(Rev 2/7/05) 
8. If shop floor drain and wash bay effluent is discharged, other than to a municipal storm, sanitary or combined sewer, does it ultimately reach "waters of the state?" If yes, name of that water body:

Activity Areas (check those that apply and describe (1) whether they are bermed to prevent storm water runoff or (2) if there are drains and their locations in the activity areas)

$\square$ salt storage (pads or domes) __ No berm or drain

$\square$ salt/sand mixing__ No berm or drain

$\square$ salt bed loading/wetting__No berm or drain

$\square$ salt bed washout__ There is a drain in this area

$\square$ salt bed storage Storage area is under a roofed enclosure,which prevents storm water from coming in contact with the salt beds

$\square$ vehicle and equipment washing (inside) __Done over a catch basin that captures all wash water

$\square$ vehicle and equipment washing (outside)

$\square$ asphalt equipment clean-out __ Done inside

$\square$ herbicide mixing and tank rinsing__ Mixing is performed inside

$\square \quad$ traffic paint mixing and transfer

$\square$ bulk tank off-loading and storage

$\square$ waste piles (e.g., ROW trash, street sweeping debris)

$\square$ truck/equipment parking__ Trucks park under a roofed enclosure

$\square \quad$ truck/equipment fueling

$\square$ materials storage (210 lot, fencing, etc.) __ No berm or drain

$\square$ aggregate storage__ No berm or drain

$\square$ hot/cold patch storage __ No berm or drain

$\square$ storage of “scalp” and dirt from R/W maintenance__ No berm or drain 
Date_4/11/2006

\section{INDOT Facility Stormwater and Washwater Effluent Drainage Assessment}

Name of Facility $\_71^{\text {st }}$ Unit
District/Subdistrict __ Greenfield

\section{$\underline{\text { Surface Water }}$}

1. Does any area of the active surface collect storm water or facility-generated wash water (such as from washing trucks outdoors)? _ Y Yes

2. Is there any movement of surface water from one area to another on-site by ditch, drain tile or natural channel? ___ Yes

3. Is there any movement of surface water off-site (e.g., beneath the perimeter fence) via sheet flow, ditch, pipe or channel to adjacent property? _

4. Is the surface water discharged directly to (check all that apply) -

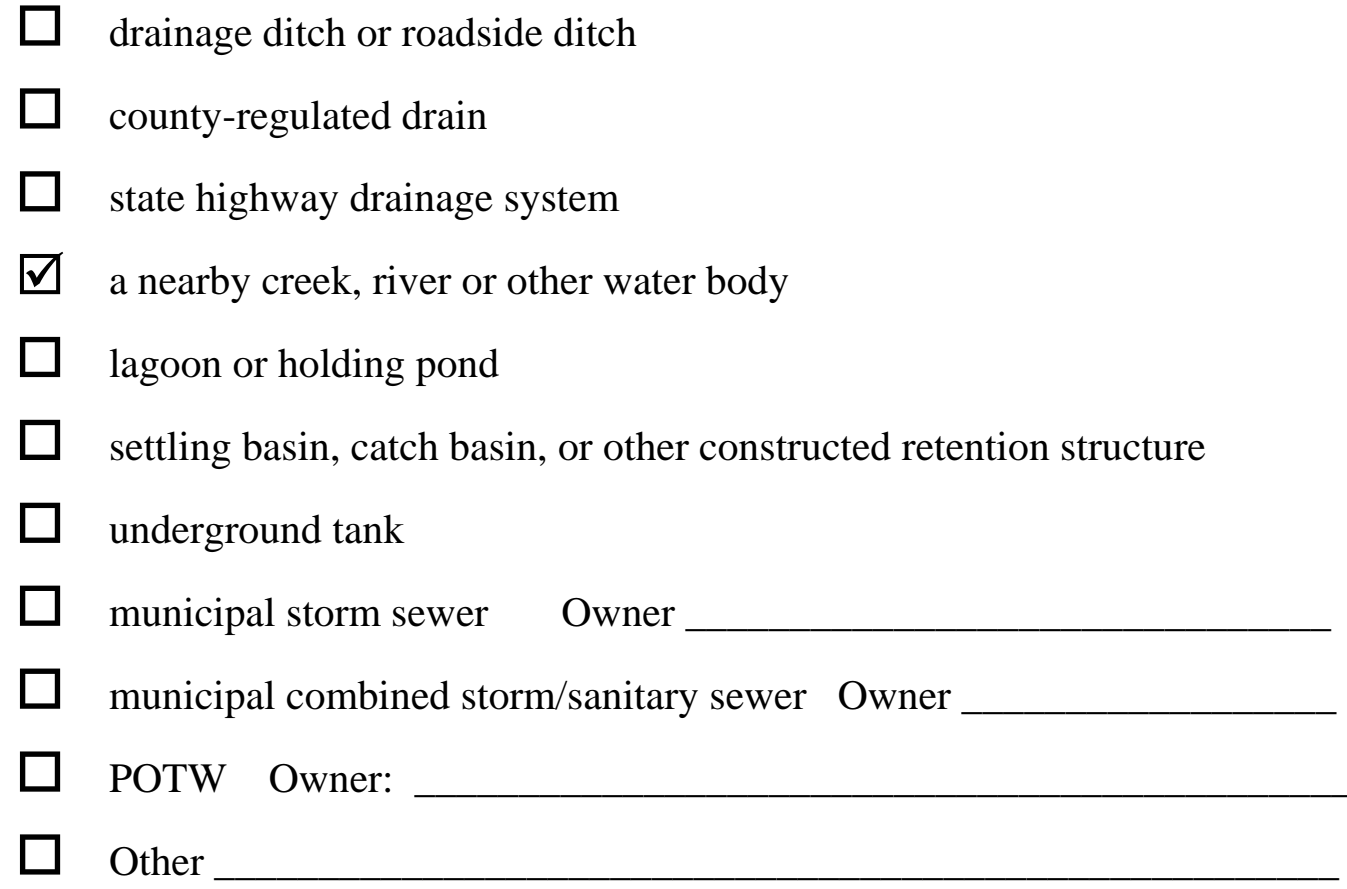

5. If surface water is discharged, other than to a municipal storm, sanitary or combined sewer, does it ultimately reach "waters of the state” (e.g., farm ditch, creek, stream, river, lake or pond)? If yes, name of that water body. ___Eagle Creek

6. What is the estimated distance of this water body from the facility? 1 mile 


\section{Shop Floor Drain \& Wash Bay Effluent}

1. Are there drains in shop floors and wash bays that remove liquids and wash water effluent from the building(s)? _ Yes

2. Does the effluent flow to -

$\square$ aboveground oil/water separator

$\square$ aboveground tank

$\square$ below ground oil/water separator

$\square$ below ground tank

$\square$ settling basin, catch basin, lagoon, holding pond or other constructed retention structure

$\square$ none of the above

3. If the effluent is captured by the devices in 2., above, is it contained until pumped and hauled to a POTW or until it evaporates, or does it overflow to a drainage system?_Contained in a storage tank and reused as brine

4. If the effluent overflows to a drainage system, is the system above or below ground? _. Above ground storage tank

5. If the effluent overflows to a drainage system, does it mix with storm water?__No

6. If the effluent $\underline{\text { does }}$ mix with storm water, see "Surface Water" section (preceding page, \#4 and \#5) for discharge.

7. If the effluent doesn't mix with storm water, is it discharged to -

$\square \quad$ subsurface soils

$\square$ on-site septic system

$\square$ drainage ditch or roadside ditch

$\square$ a nearby creek, river or other water body

lagoon or holding pond

municipal storm sewer Owner

municipal combined storm/sanitary sewer

Owner
Effluent is pumped into a storage tank and reused for brine. If the tank fills, the effluent is released into a ditch that eventually drains into Eagle Creek.

municipal POTW Owner 
8. If shop floor drain and washbay effluent is discharged, other than to a municipal storm, sanitary or combined sewer, does it ultimately reach “waters of the state?” If yes, name of that water body: _If the storage tank fills it is released into a ditch that drains into Eagle Creek Activity Areas (check those that apply and describe (1) whether they are bermed to prevent storm water runoff or (2) if there are drains and their locations in the activity areas)

$\square$ salt storage (pads or domes)_ There is a sand berm at the entrance of the Salt _Dome. There are no drains in the area

$\square$ salt/sand mixing _ _ No berm or drains

$\square$ salt bed loading/wetting __ No berm or drains

$\square \quad$ salt bed washout __ Performed in the Unit Building

$\square$ salt bed storage _ No berm or drains

$\square \quad$ vehicle and equipment washing (inside) __Performed in the Unit Building

$\square \quad$ vehicle and equipment washing (outside)

$\square \quad$ asphalt equipment clean-out

$\square$ herbicide mixing and tank rinsing

$\square \quad$ traffic paint mixing and transfer

$\square$ bulk tank off-loading and storage

$\square \quad$ waste piles (e.g., ROW trash, street sweeping debris) _ No berm or drains

$\square$ truck/equipment parking _ There is a catch basin in this area that conveys _ surface water to the roadside ditch.

$\square$ truck/equipment fueling

$\square$ materials storage (210 lot, fencing, etc.)

$\square$ aggregate storage __ No berm or drain

$\square$ hot/cold patch storage _ No berm or drain

$\square$ storage of “scalp” and dirt from R/W maintenance 
Date_3/9/2005

\section{INDOT Facility Stormwater and Washwater Effluent Drainage Assessment}

Name of Facility __Fortville Unit
District/Subdistrict___reenfield___

\section{$\underline{\text { Surface Water }}$}

1. Does any area of the active surface collect storm water or facility-generated wash water (such as from washing trucks outdoors)? _- No

2. Is there any movement of surface water from one area to another on-site by ditch, drain tile or natural channel? _ No

3. Is there any movement of surface water off-site (e.g., beneath the perimeter fence) via sheet flow, ditch, pipe or channel to adjacent property? _ _ Yes, there is sheet flow _ directly to Thorpe Creek and there is a ditch that conveys storm water to the I-69 roadside ditch, which eventually drains into Thorpe Creek.

4. Is the surface water discharged directly to (check all that apply) -

$\square$ drainage ditch or roadside ditch

$\square$ county-regulated drain

$\square$ state highway drainage system

$\square$ a nearby creek, river or other water body

$\square \quad$ lagoon or holding pond

$\square$ settling basin, catch basin, or other constructed retention structure

$\square$ underground tank

$\square$ municipal storm sewer Owner

$\square$ municipal combined storm/sanitary sewer Owner

$\square$ POTW Owner: _ Fortville City

$\square$ Other

5. If surface water is discharged, other than to a municipal storm, sanitary or combined sewer, does it ultimately reach "waters of the state” (e.g., farm ditch, creek, stream, river, lake or pond)? If yes, name of that water body. _ Y Yes, Thorpe Creek

6. What is the estimated distance of this water body from the facility? _ 20 feet 
Shop Floor Drain \& Wash Bay Effluent

1. Are there drains in shop floors and wash bays that remove liquids and wash water effluent from the building(s)? _ _ Yes

2. Does the effluent flow to -

$\square$ aboveground oil/water separator

$\square$ aboveground tank

$\square$ below ground oil/water separator

$\square$ below ground tank

$\square$ settling basin, catch basin, lagoon, holding pond or other constructed retention structure

$\square$ none of the above

3. If the effluent is captured by the devices in 2., above, is it contained until pumped and hauled to a POTW or until it evaporates, or does it overflow to a drainage system?_It enters the sanitary sewer system

4. If the effluent overflows to a drainage system, is the system above or below ground? __Below ground

5. If the effluent overflows to a drainage system, does it mix with storm water?__No

6. If the effluent does mix with storm water, see "Surface Water" section (preceding page, \#4 and \#5) for discharge.

7. If the effluent doesn't mix with storm water, is it discharged to -

$\square$ subsurface soils

on-site septic system

$\square$ drainage ditch or roadside ditch

$\square$ a nearby creek, river or other water body

NOTE: There is a catch basin near the truck parking area that captures storm water. The Unit Foreman said that this catch basin drains into the sanitary sewer system.

$\square \quad$ lagoon or holding pond

$\square$ municipal storm sewer Owner

$\square$ municipal combined storm/sanitary sewer Owner_Fortville Municipal WWTP

$\square$ municipal POTW Owner

$(\operatorname{Rev} 2 / 7 / 05)$ 
8. If shop floor drain and wash bay effluent is discharged, other than to a municipal storm, sanitary or combined sewer, does it ultimately reach "waters of the state?" If yes, name of that water body:

Activity Areas (check those that apply and describe (1) whether they are bermed to prevent storm water runoff or (2) if there are drains and their locations in the activity areas)

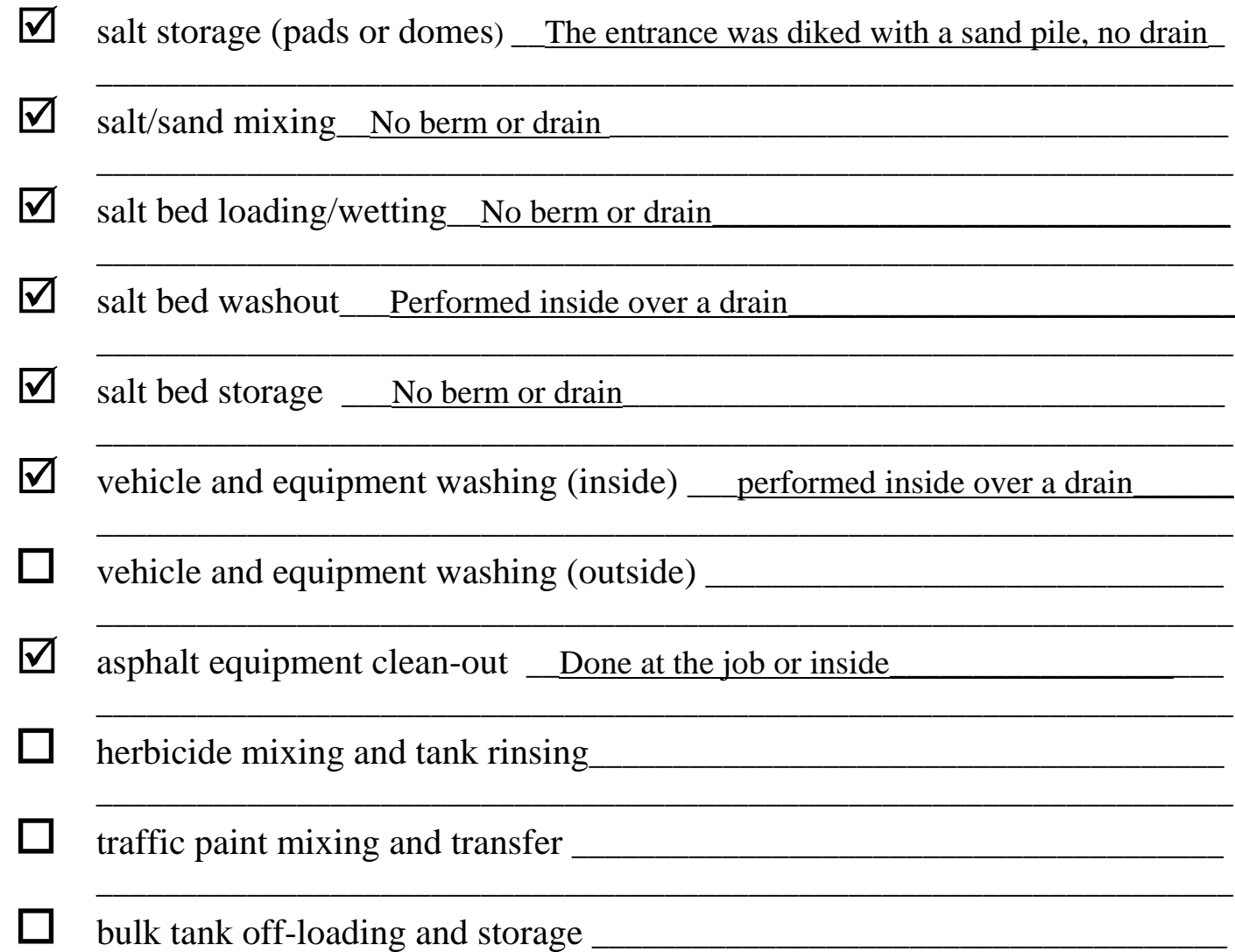

$\square$ waste piles (e.g., ROW trash, street sweeping debris) __ No berm or drain

$\square$ truck/equipment parking_ There is a drain in this area that is connected to the _ sanitary sewer

$\square \quad$ truck/equipment fueling

$\square$ materials storage (210 lot, fencing, etc.) __ No berm or drain

$\square$ aggregate storage__ No berm or drain

$\square$ hot/cold patch storage _

$\square$ storage of “scalp” and dirt from R/W maintenance__ No berm or drain 
Date_8/18/2005

\section{INDOT Facility Stormwater and Washwater Effluent Drainage Assessment}

Name of Facility __New Castle Unit
District/Subdistrict __ Greenfield

\section{$\underline{\text { Surface Water }}$}

1. Does any area of the active surface collect storm water or facility-generated wash water (such as from washing trucks outdoors)? _

2. Is there any movement of surface water from one area to another on-site by ditch, drain tile or natural channel? ___ Yes

3. Is there any movement of surface water off-site (e.g., beneath the perimeter fence) via sheet flow, ditch, pipe or channel to adjacent property? _

4. Is the surface water discharged directly to (check all that apply) -

$\square$ drainage ditch or roadside ditch

$\square$ county-regulated drain

$\square \quad$ state highway drainage system

$\square$ a nearby creek, river or other water body

$\square$ lagoon or holding pond

$\square$ settling basin, catch basin, or other constructed retention structure

$\square$ underground tank

$\square$ municipal storm sewer Owner

$\square$ municipal combined storm/sanitary sewer Owner

$\square$ POTW Owner:

$\square$ Other

5. If surface water is discharged, other than to a municipal storm, sanitary or combined sewer, does it ultimately reach "waters of the state” (e.g., farm ditch, creek, stream, river, lake or pond)? If yes, name of that water body. No

6. What is the estimated distance of this water body from the facility? 


\section{Shop Floor Drain \& Wash Bay Effluent}

1. Are there drains in shop floors and wash bays that remove liquids and wash water effluent from the building(s)? _ Yes

2. Does the effluent flow to -

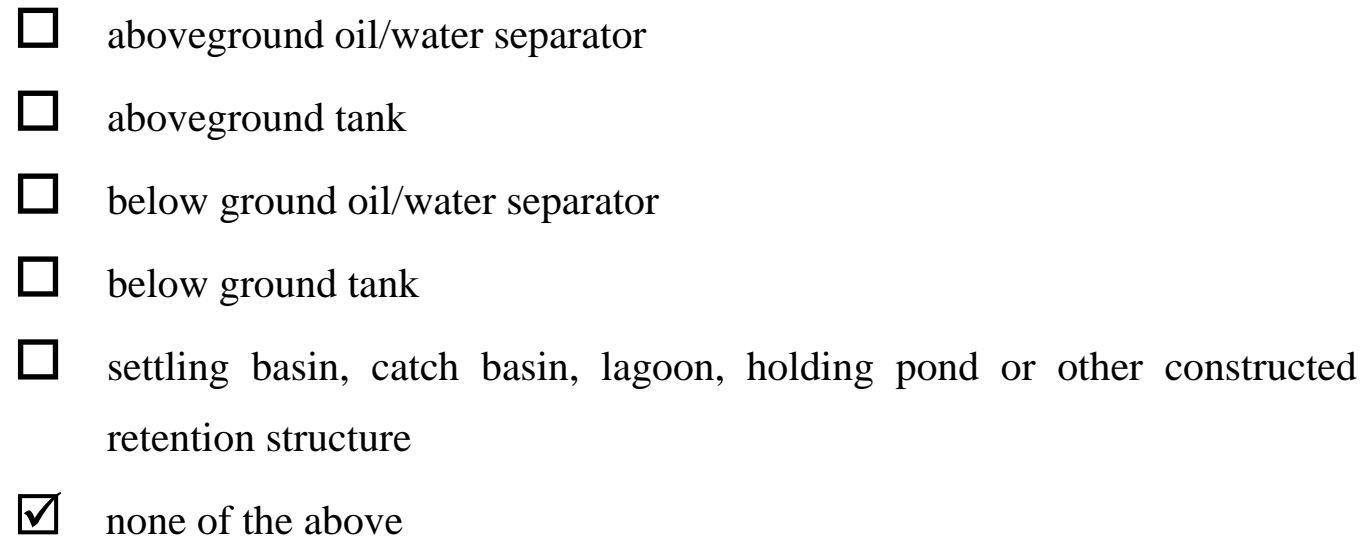

3. If the effluent is captured by the devices in 2., above, is it contained until pumped and hauled to a POTW or until it evaporates, or does it overflow to a drainage system?

4. If the effluent overflows to a drainage system, is the system above or below ground?

5. If the effluent overflows to a drainage system, does it mix with storm water?

6. If the effluent $\underline{\text { does }}$ mix with storm water, see "Surface Water" section (preceding page, \#4 and \#5) for discharge.

7. If the effluent doesn't mix with storm water, is it discharged to -

$\square \quad$ subsurface soils

$\square \quad$ on-site septic system

$\square$ drainage ditch or roadside ditch

$\square$ a nearby creek, river or other water body

$\square$ lagoon or holding pond

$\square \quad$ municipal storm sewer Owner

$\square$ municipal combined storm/sanitary sewer Owner

$\square$ municipal POTW Owner 
8. If shop floor drain and washbay effluent is discharged, other than to a municipal storm, sanitary or combined sewer, does it ultimately reach "waters of the state?" If yes, name of that water body: __ No

Activity Areas (check those that apply and describe (1) whether they are bermed to prevent storm water runoff or (2) if there are drains and their locations in the activity areas)

$\square$ salt storage (pads or domes) _ N No berms but there is a catch basin near the _entrance of the Salt Dome that drains into an on-site detention pond

$\square$ salt/sand mixing _ Same as "Salt Storage"

$\square$ salt bed loading/wetting _ _ There is a catch basin near the wetting area that _ drains into the detention pond

$\square$ salt bed washout _ Performed inside and outside the Unit Building. All drains lead to the detention pond

$\square$ salt bed storage _ Catch basin near by that drains into the detention pond

$\square$ vehicle and equipment washing (inside) __ Same as "Salt Bed Washout"

$\square$ vehicle and equipment washing (outside) _ Same as "Salt Bed Washout"

asphalt equipment clean-out

$\square$ herbicide mixing and tank rinsing _ A small amount is storaed outside in a secondary containment locker. Mixing is performed inside the Unit Building. traffic paint mixing and transfer

$\square$ bulk tank off-loading and storage

$\square$ waste piles (e.g., ROW trash, street sweeping debris) _ There are dumpsters for _debris but street sweepings are piled on the ground and not bermed

$\square$ truck/equipment parking _ Inside Unit Building

$\square$ truck/equipment fueling

$\square$ materials storage (210 lot, fencing, etc.)

$\square$ aggregate storage _ No berm but a catch basin is located nearby

$\square$ hot/cold patch storage __ Same as "Aggregate Storage”

$\square$ storage of "scalp" and dirt from R/W maintenance ___Piled on ground with no berm or cover 
Date_7/11/2005

\title{
INDOT Facility Stormwater and Washwater Effluent Drainage Assessment
}

\author{
Name of Facility __Kokomo Unit \\ District/Subdistrict _ _ Greenfield
}

\section{$\underline{\text { Surface Water }}$}

1. Does any area of the active surface collect storm water or facility-generated wash water (such as from washing trucks outdoors)? _

2. Is there any movement of surface water from one area to another on-site by ditch, drain tile or natural channel? ___ Yes

3. Is there any movement of surface water off-site (e.g., beneath the perimeter fence) via sheet flow, ditch, pipe or channel to adjacent property? __ $\underline{\text { Yes }}$

4. Is the surface water discharged directly to (check all that apply) -

$\square$ drainage ditch or roadside ditch

$\square$ county-regulated drain

$\square$ state highway drainage system

$\square$ a nearby creek, river or other water body

$\square \quad$ lagoon or holding pond

$\square$ settling basin, catch basin, or other constructed retention structure

$\square$ underground tank

$\square$ municipal storm sewer Owner

$\square$ municipal combined storm/sanitary sewer Owner

$\square$ POTW Owner:

$\square$ Other

5. If surface water is discharged, other than to a municipal storm, sanitary or combined sewer, does it ultimately reach "waters of the state” (e.g., farm ditch, creek, stream, river, lake or pond)? If yes, name of that water body. __Yes, wetland/bog area that _overflows into a ditch, which eventually flows into a roadside ditch

6. What is the estimated distance of this water body from the facility? _ The wetland/bog area is located approx. 20 feet from the east fence line 


\section{$\underline{\text { Shop Floor Drain \& Wash Bay Effluent }}$}

1. Are there drains in shop floors and wash bays that remove liquids and wash water effluent from the building(s)? _ Y Yes

2. Does the effluent flow to -

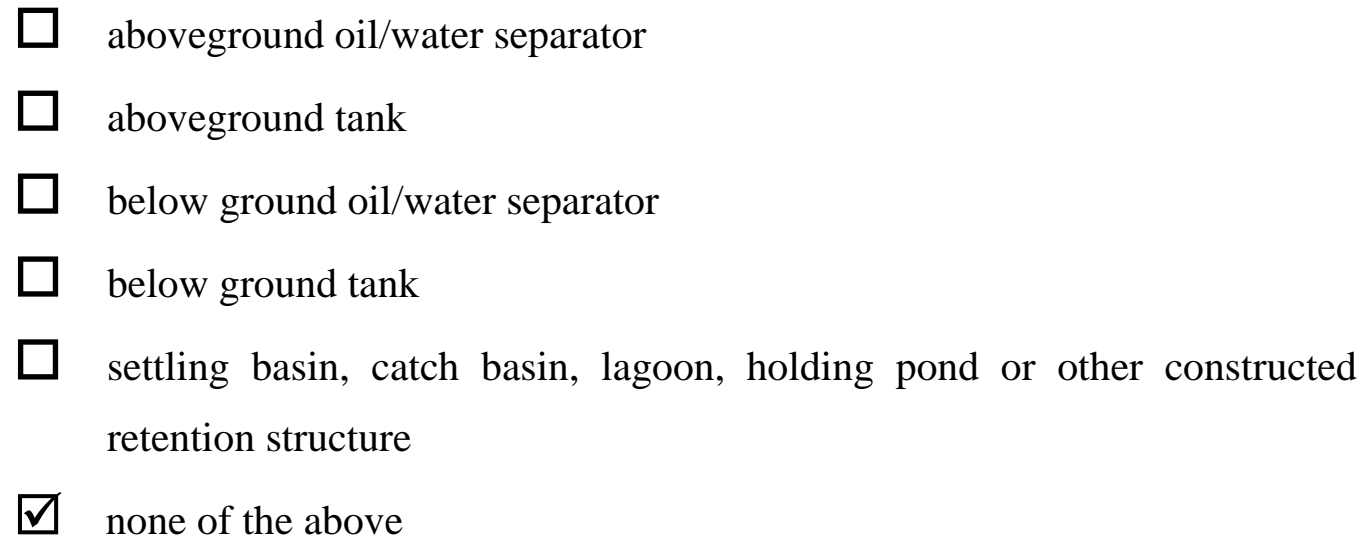

3. If the effluent is captured by the devices in 2., above, is it contained until pumped and hauled to a POTW or until it evaporates, or does it overflow to a drainage system?

4. If the effluent overflows to a drainage system, is the system above or below ground?

5. If the effluent overflows to a drainage system, does it mix with storm water? Yes

6. If the effluent $\underline{\text { does }}$ mix with storm water, see "Surface Water" section (preceding page, \#4 and \#5) for discharge.

7. If the effluent doesn't mix with storm water, is it discharged to -

$\square$ subsurface soils

$\square \quad$ on-site septic system

$\square$ drainage ditch or roadside ditch

$\square$ a nearby creek, river or other water body

$\square \quad$ lagoon or holding pond

$\square$ municipal storm sewer Owner

$\square$ municipal combined storm/sanitary sewer Owner

$\square$ municipal POTW Owner 
8. If shop floor drain and wash bay effluent is discharged, other than to a municipal storm, sanitary or combined sewer, does it ultimately reach "waters of the state?" If yes, name of that water body: __ Yes, wetland/bog area

Activity Areas (check those that apply and describe (1) whether they are bermed to prevent storm water runoff or (2) if there are drains and their locations in the activity areas)

$\square$ salt storage (pads or domes) __ No berm or drain

$\square$ salt/sand mixing _ _ No berm or drain

$\square$ salt bed loading/wetting _ _ No berm or drain

$\square$ salt bed washout _ There is a drain under the salt bed rack that drains offsite

$\square$ salt bed storage _ No berm or drain

$\square$ vehicle and equipment washing (inside) _ Performed inside Unit Building over a -floor drain

$\square$ vehicle and equipment washing (outside)

$\square$ asphalt equipment clean-out__Performed on job site

$\square \quad$ herbicide mixing and tank rinsing

$\square \quad$ traffic paint mixing and transfer

$\square \quad$ bulk tank off-loading and storage

$\square$ waste piles (e.g., ROW trash, street sweeping debris)_Stored in dumpsters

$\square$ truck/equipment parking _ There is a drain in this area that drains offsite

$\square$ truck/equipment fueling _ There is a secondarily contained 1,000 gallon above _ground fuel tank outside the Unit Building.

$\square$ materials storage (210 lot, fencing, etc.)

$\square$ aggregate storage _

$\square$ hot/cold patch storage _ The cold patch is stored outside under a tarp

$\square$ storage of “scalp” and dirt from R/W maintenance _ No berm or drain 
Date__8/18/05

\section{INDOT Facility Stormwater and Washwater Effluent Drainage Assessment}

Name of Facility __Shelbyville Unit___
District/Subdistrict___reenfield

\section{$\underline{\text { Surface Water }}$}

1. Does any area of the active surface collect storm water or facility-generated wash water (such as from washing trucks outdoors)? _ Y Yes

2. Is there any movement of surface water from one area to another on-site by ditch, drain tile or natural channel? ___ Yes

3. Is there any movement of surface water off-site (e.g., beneath the perimeter fence) via sheet flow, ditch, pipe or channel to adjacent property? _

4. Is the surface water discharged directly to (check all that apply) -

$\square$ drainage ditch or roadside ditch

$\square$ county-regulated drain

$\square \quad$ state highway drainage system

$\square$ a nearby creek, river or other water body

$\square \quad$ lagoon or holding pond

$\square$ settling basin, catch basin, or other constructed retention structure

$\square$ underground tank

$\square \quad$ municipal storm sewer Owner

$\square$ municipal combined storm/sanitary sewer Owner

$\square$ POTW Owner:

$\square$ Other

5. If surface water is discharged, other than to a municipal storm, sanitary or combined sewer, does it ultimately reach "waters of the state” (e.g., farm ditch, creek, stream, river, lake or pond)? If yes, name of that water body. Yes, Big Blue Creek

6. What is the estimated distance of this water body from the facility? 0.5 miles to the SE 


\section{$\underline{\text { Shop Floor Drain \& Wash Bay Effluent }}$}

1. Are there drains in shop floors and wash bays that remove liquids and wash water effluent from the building(s)? _ Y Yes

2. Does the effluent flow to -

$\square$ aboveground oil/water separator

$\square$ aboveground tank

$\square$ below ground oil/water separator

$\square$ below ground tank

$\square$ settling basin, catch basin, lagoon, holding pond or other constructed retention structure

$\square$ none of the above

3. If the effluent is captured by the devices in 2., above, is it contained until pumped and hauled to a POTW or until it evaporates, or does it overflow to a drainage system?_overflows to a drainage system

4. If the effluent overflows to a drainage system, is the system above or below ground? _ Below ground

5. If the effluent overflows to a drainage system, does it mix with storm water?__ No

6. If the effluent $\underline{\text { does }}$ mix with storm water, see "Surface Water" section (preceding page, \#4 and \#5) for discharge.

7. If the effluent doesn't mix with storm water, is it discharged to -

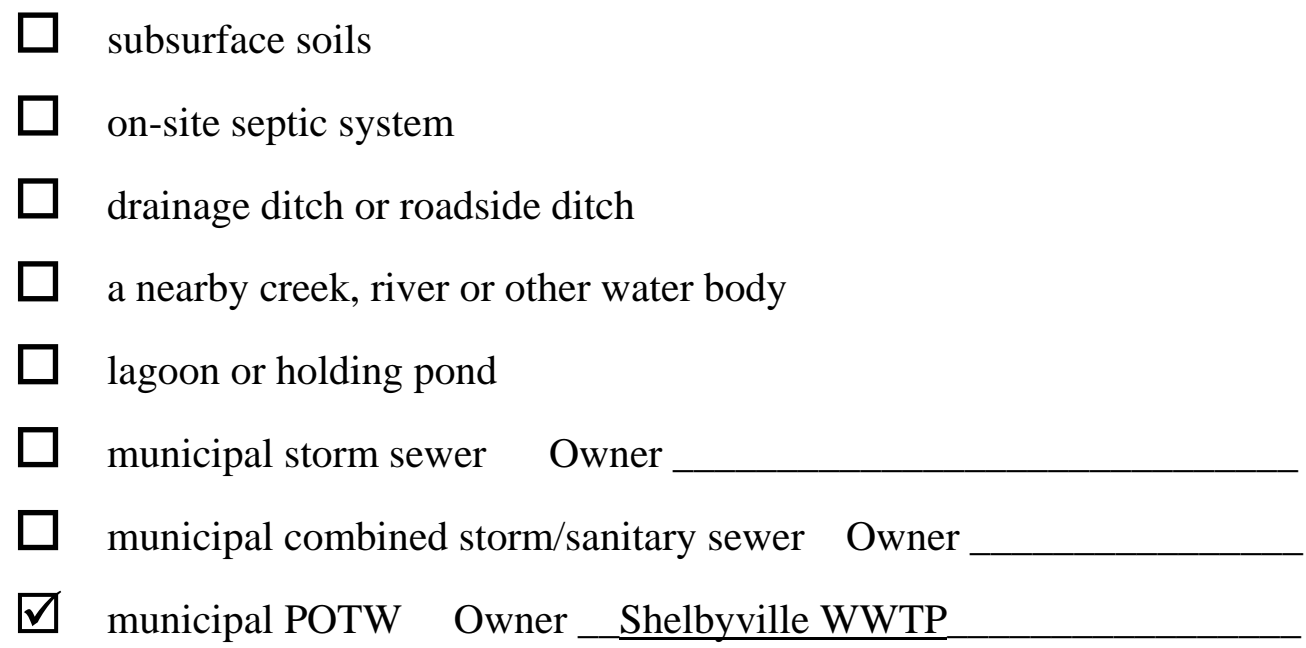


8. If shop floor drain and washbay effluent is discharged, other than to a municipal storm, sanitary or combined sewer, does it ultimately reach "waters of the state?" If yes, name of that water body:

Activity Areas (check those that apply and describe (1) whether they are bermed to prevent storm water runoff or (2) if there are drains and their locations in the activity areas)

$\square$ salt storage (pads or domes) _ _ Sand berm at entrance

$\square$ salt/sand mixing

$\square$ salt bed loading/wetting __ No berm or drains

$\square$ salt bed washout __ Performed inside Unit Building

$\square$ salt bed storage __ No berms or drains

$\square \quad$ vehicle and equipment washing (inside) __ Inside Unit Building

$\square \quad$ vehicle and equipment washing (outside)

$\square$ asphalt equipment clean-out __ Performed on job site

$\square \quad$ herbicide mixing and tank rinsing

$\square \quad$ traffic paint mixing and transfer

$\square$ bulk tank off-loading and storage

$\square$ waste piles (e.g., ROW trash, street sweeping debris)

$\square$ truck/equipment parking __ Inside pole barn

$\square \quad$ truck/equipment fueling

$\square$ materials storage (210 lot, fencing, etc.)

$\square$ aggregate storage __ No berm or drain

$\square$ hot/cold patch storage _ Inside pole barn

$\square$ storage of “scalp” and dirt from R/W maintenance _ No berm or drain 
Date_7/11/2005

\title{
INDOT Facility Stormwater and Washwater Effluent Drainage Assessment
}

\author{
Name of Facility _ Westfield Unit
}

District/Subdistrict _ _ Greenfield

\section{$\underline{\text { Surface Water }}$}

1. Does any area of the active surface collect storm water or facility-generated wash water (such as from washing trucks outdoors)? _

2. Is there any movement of surface water from one area to another on-site by ditch, drain tile or natural channel? __ Yes

3. Is there any movement of surface water off-site (e.g., beneath the perimeter fence) via sheet flow, ditch, pipe or channel to adjacent property? _

4. Is the surface water discharged directly to (check all that apply) -

$\square$ drainage ditch or roadside ditch

$\square$ county-regulated drain

$\square$ state highway drainage system

$\square$ a nearby creek, river or other water body

$\square$ lagoon or holding pond

$\square$ settling basin, catch basin, or other constructed retention structure

$\square$ underground tank

$\square$ municipal storm sewer Owner

$\square$ municipal combined storm/sanitary sewer Owner

$\square$ POTW Owner:

$\square$ Other

5. If surface water is discharged, other than to a municipal storm, sanitary or combined sewer, does it ultimately reach "waters of the state” (e.g., farm ditch, creek, stream, river, lake or pond)? If yes, name of that water body.

No

6. What is the estimated distance of this water body from the facility? _ No 


\section{Shop Floor Drain \& Wash Bay Effluent}

1. Are there drains in shop floors and wash bays that remove liquids and wash water effluent from the building(s)? _ Y Yes

2. Does the effluent flow to -

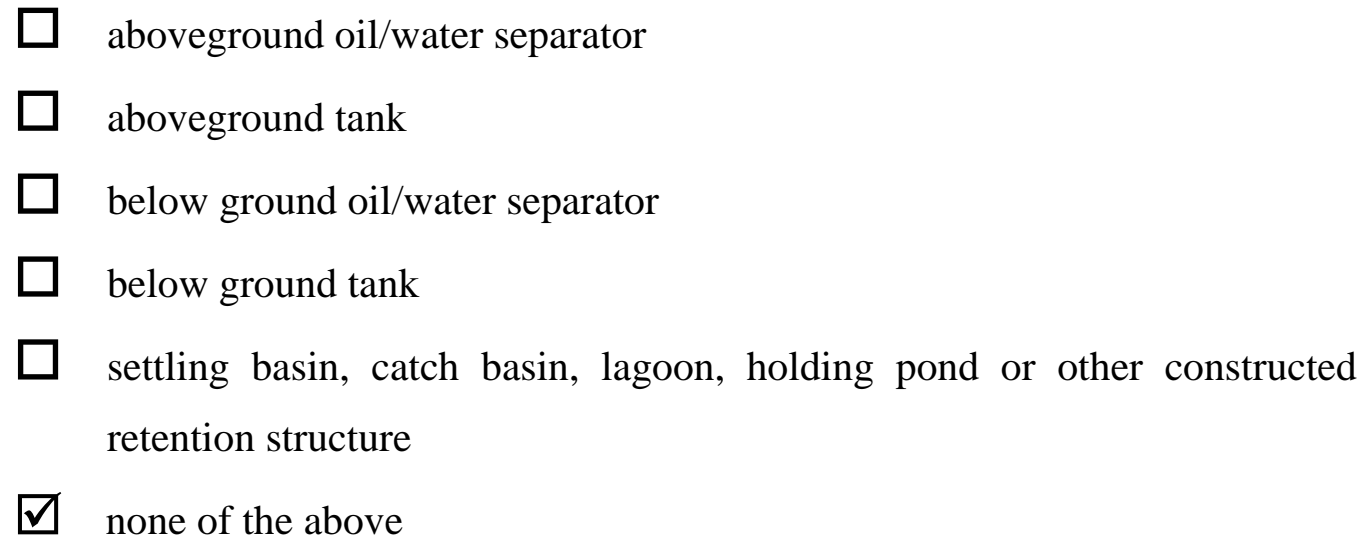

3. If the effluent is captured by the devices in 2., above, is it contained until pumped and hauled to a POTW or until it evaporates, or does it overflow to a drainage system?

4. If the effluent overflows to a drainage system, is the system above or below ground? __Below ground

5. If the effluent overflows to a drainage system, does it mix with storm water? Y Yes

6. If the effluent $\underline{\text { does }}$ mix with storm water, see "Surface Water" section (preceding page, \#4 and \#5) for discharge.

7. If the effluent doesn't mix with storm water, is it discharged to -

$\square$ subsurface soils

$\square$ on-site septic system

$\square$ drainage ditch or roadside ditch

$\square$ a nearby creek, river or other water body

$\square \quad$ lagoon or holding pond

$\square$ municipal storm sewer Owner

$\square$ municipal combined storm/sanitary sewer Owner

$\square$ municipal POTW Owner 
8. If shop floor drain and wash bay effluent is discharged, other than to a municipal storm, sanitary or combined sewer, does it ultimately reach "waters of the state?" If yes, name of that water body: __ No

Activity Areas (check those that apply and describe (1) whether they are bermed to prevent storm water runoff or (2) if there are drains and their locations in the activity areas)

$\square$ salt storage (pads or domes) __ There is a drain near the entrance of the salt dome - that drains into an onsite retention pond

$\square$ salt/sand mixing _ No berm but all water from the area drains into the retention pond

$\square$ salt bed loading/wetting _ _ No berm but all water from the area drains into the retention pond

$\square$ salt bed washout

$\square$ salt bed storage _ All water from the area drains into a wetland/bog area onsite

$\square \quad$ vehicle and equipment washing (inside)

$\square \quad$ vehicle and equipment washing (outside)

$\square$ asphalt equipment clean-out _ _ performed on the job site(offsite)

$\square$ herbicide mixing and tank rinsing _ Small amount mixed inside the Unit Building

$\square \quad$ traffic paint mixing and transfer

$\square$ bulk tank off-loading and storage

$\square$ waste piles (e.g., ROW trash, street sweeping debris)__ Stored in_dumpsters

$\square$ truck/equipment parking _ All water from the area enters the wetland/bog

$\square \quad$ truck/equipment fueling

$\square$ materials storage (210 lot, fencing, etc.)

$\square$ aggregate storage __ All water from the area enters the retention pond

$\square$ hot/cold patch storage _ All water from the area enters the retention pond

$\square$ storage of “scalp” and dirt from R/W maintenance 
Date_8/18/2005

\title{
INDOT Facility Stormwater and Washwater Effluent Drainage Assessment
}

\author{
Name of Facility _ Winchester Unit \\ District/Subdistrict _ _ Greenfield
}

\section{$\underline{\text { Surface Water }}$}

1. Does any area of the active surface collect storm water or facility-generated wash water (such as from washing trucks outdoors)? _ Y Yes

2. Is there any movement of surface water from one area to another on-site by ditch, drain tile or natural channel?

3. Is there any movement of surface water off-site (e.g., beneath the perimeter fence) via sheet flow, ditch, pipe or channel to adjacent property? _

4. Is the surface water discharged directly to (check all that apply) -

$\square$ drainage ditch or roadside ditch

$\square$ county-regulated drain

$\square \quad$ state highway drainage system

$\square$ a nearby creek, river or other water body

$\square \quad$ lagoon or holding pond

$\square$ settling basin, catch basin, or other constructed retention structure

$\square$ underground tank

$\square \quad$ municipal storm sewer Owner

$\square$ municipal combined storm/sanitary sewer Owner

$\square$ POTW Owner:

$\square$ Other

5. If surface water is discharged, other than to a municipal storm, sanitary or combined sewer, does it ultimately reach "waters of the state” (e.g., farm ditch, creek, stream, river, lake or pond)? If yes, name of that water body. _Y Yes, Sugar Creek

6. What is the estimated distance of this water body from the facility? 0.25 miles 


\section{Shop Floor Drain \& Wash Bay Effluent}

1. Are there drains in shop floors and wash bays that remove liquids and wash water effluent from the building(s)? _ Y Yes

2. Does the effluent flow to -

$\square$ aboveground oil/water separator

$\square$ aboveground tank

$\square$ below ground oil/water separator

$\square$ below ground tank

$\square$ settling basin, catch basin, lagoon, holding pond or other constructed retention structure

$\square$ none of the above

3. If the effluent is captured by the devices in 2., above, is it contained until pumped and hauled to a POTW or until it evaporates, or does it overflow to a drainage system?___ Overflows to a drainage system

4. If the effluent overflows to a drainage system, is the system above or below ground? _ _ Below

5. If the effluent overflows to a drainage system, does it mix with storm water? _ No

6. If the effluent $\underline{\text { does }}$ mix with storm water, see "Surface Water" section (preceding page, \#4 and \#5) for discharge.

7. If the effluent doesn't mix with storm water, is it discharged to -

$\square \quad$ subsurface soils

$\square$ on-site septic system

$\square$ drainage ditch or roadside ditch

$\square \quad$ a nearby creek, river or other water body

$\square \quad$ lagoon or holding pond

$\square$ municipal storm sewer Owner

$\square$ municipal combined storm/sanitary sewer Owner

$\square$ municipal POTW Owner _ Winchester WWTP 
8. If shop floor drain and washbay effluent is discharged, other than to a municipal storm, sanitary or combined sewer, does it ultimately reach "waters of the state?" If yes, name of that water body:

Activity Areas (check those that apply and describe (1) whether they are bermed to prevent storm water runoff or (2) if there are drains and their locations in the activity areas)

$\square$ salt storage (pads or domes) _ There is a catch basin near the Salt Dome that collects stormwater and conveys it to the roadside ditch

$\square$ salt/sand mixing_Same as "Salt Storage"

$\square$ salt bed loading/wetting __ Same as "Salt Storage"

$\square$ salt bed washout _ _ Performed inside the washbay

$\square$ salt bed storage __ No berms or drains

$\square \quad$ vehicle and equipment washing (inside) __ Inside Unit Building

$\square \quad$ vehicle and equipment washing (outside)

$\square$ asphalt equipment clean-out _ Performed on the job site

$\square \quad$ herbicide mixing and tank rinsing

$\square \quad$ traffic paint mixing and transfer

$\square$ bulk tank off-loading and storage

$\square \quad$ waste piles (e.g., ROW trash, street sweeping debris) __ Dumpsters

$\square$ truck/equipment parking _

$\square \quad$ truck/equipment fueling

$\square$ materials storage (210 lot, fencing, etc.)

$\square$ aggregate storage _ There is a catch basin near this area

$\square$ hot/cold patch storage __ No berm or drain

$\square$ storage of “scalp” and dirt from R/W maintenance 


\title{
INDOT Site Assessment Report Observations and Comments
}

\author{
$\underline{\text { Surface Area }}$
}

General

$>$ There is a detention pond at the facility that collects all storm water. At a certain level, the detention pond overflows into a railroad side ditch that drains into Fall Creek, approx. 2 miles from the site.

$>$ There were numerous rusty metal scraps and piles of old corrugated pipe sitting along the edge of the detention pond. There was also a large pile of scrap tires on site.

This facility contains brine-mixing equipment. All the equipment is secondarily contained and is inside a roofed building.

South Property Line

$>$ The Unit Building is located in the southwest corner of the property. The Unit Building consists of the wash bay, maintenance area, and two offices.

> The building north of the Unit Building is called the "Pole Barn". The southern end of this building is used to store salt beds and trucks, and the northern end houses the brine producing and storage equipment.

> There is a small shed, north of the Pole Barn, that contains an incinerator for road kill and a secondarily contained diesel full tank used to fuel the incinerator.

$>$ In the southeast corner of the active surface, there are several large piles of aggregate and a pile of grindings/scalp.

A ditch runs along the south boundary line that collects storm water and conveys it to the detention pond. 
The detention pond is located on the East property line. The pond is connected to the railroad drainage ditch by a pipe located on the east side of the pond.

$>$ The West bank of the pond is covered with rusty metal piles of random objects. There are some pieces of equipment present in the piles that once contained lubricants such as oil and grease. These objects should be removed from the site.

> A steady stream of water flows into the pond, which has an unknown source. There was no water being used onsite at the time of the visit but water was flowing into the pond at a constant rate. This flow of water was coming from underground on the north side of the pond. The Unit Foreman had no idea were the water was coming from. The company that borders the Anderson site to the North deals with dumpsters for garbage collection. This could be the possible source of the water.

$>$ The salt dome is located approx. 15 yards west of the detention pond. The entrance of the Salt Dome is not bermed.

> Southwest of the Salt Dome, is a Calcium Chloride tank that is used to spray salt bed loads. The Calcium Chloride tank was secondarily contained but the spraying area was not. The storm water from this area flows into the detention pond.

North Property Line

North of the Salt Dome, there is a large pile a scrap tires. This pile is not covered with a tarp, and the storm water from this area flows into the detention pond.

$>$ Several aggregate bins are located west of the pile of tires. These bins contain sand and cold patch. A trench has been dug down the center of the bins to assist in drainage of storm water to the North property line ditch. This drainage ditch empties into the detention pond.

\section{Buildings}

\section{Unit Building}

$>$ The drains in the maintenance area and wash bay are connected to an oil/water separator. All the water from the Unit Building enters the sanitary sewer system

The drums of oil and hydraulic fluid in the Unit Building were all secondarily contained. 


\section{* Pole Barn}

$>$ The west side of the pole barn is used to store salt beds and trucks. The east side houses the brine production equipment and storage tanks.

$>$ There are floor drains in the pole barn that are connected to the sanitary sewer. There was a large amount of salt on the floor of the pole barn.

$>$ All the brine equipment is secondarily contained. However, on the ground outside the door of the brine room there was a large pile of salt that was most likely spilled while adding salt to the brine mixer. The storm water that contacts this salt flows into the detention pond.

\section{* Salt Dome}

The area around the Salt Dome entrance was covered with salt. The storm water in this area drains into the detention pond. There were no berms around the loading or mixing areas.

* Other Buildings

The shed that housed the incinerator had no drains. The diesel fuel tank, which fueled the incinerator, was secondarily contained with a thick plastic tub. 


\section{INDOT Site Assessment Report Observations and Comments}

\section{Surface Area}

General

The water that is collected in the Unit Building floor drains passes through an oil/water separator and then is pumped into one of three, 5000-gallon above ground storage tanks. The water is then pumped out of the storage tanks and reused for brine production. If the storage tanks become full the water collected in the floor drains will pass through the oil/water separator and then be released into a grassed ditch that drains into Eagle Creek approx. 1 mile from the facility. The Unit Foreman said that water is rarely released into the ditch because the large storage tanks rarely fill to capacity.

$>$ There is a roadside ditch that runs along the east side of the facility that receives surface water from the site. The ditch is mostly grass but a section of concrete was added in a steep sloped area to reduce erosion. East of the facility, this ditch takes a turn to the south and flows into the I-65 roadside ditch. The I-65 roadside ditch then drains into Eagle Creek.
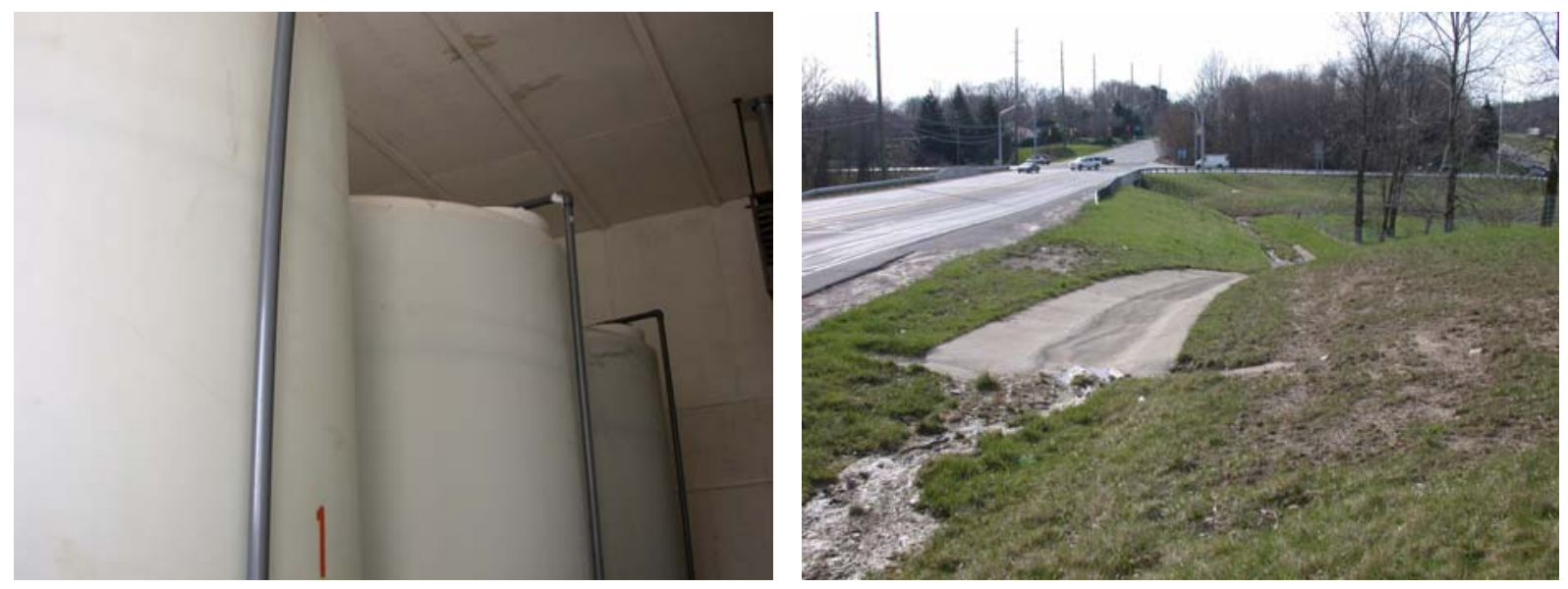

There is a large pile of street sweepings and trash on the property that the Unit Foreman said was left there by a contractor. This pile should be properly disposed of. 

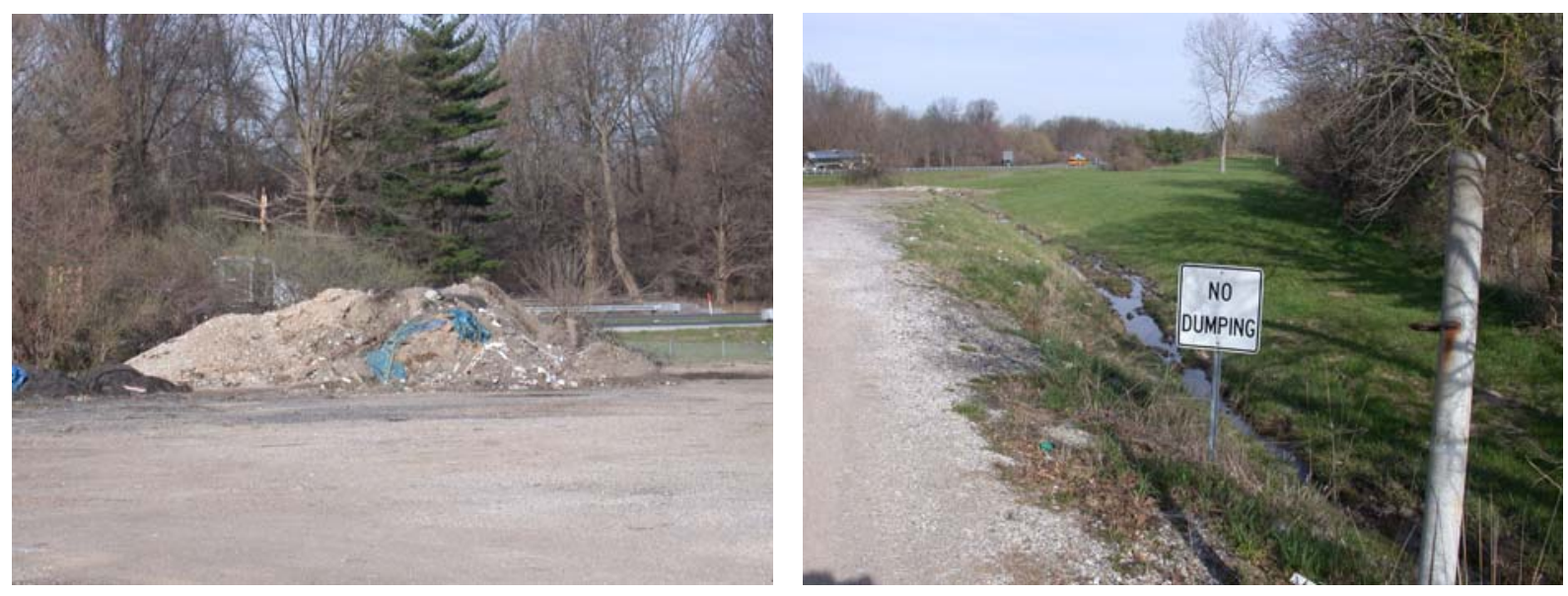

North Portion of Property

The Unit Building is located near the center of the property. A brine production building is located on the SE side of the Unit Building. The brine production building houses three secondarily contained 5000-gallon storage tanks and a brine production system.

The truck parking area is on the NE side of the Unit Building. There is a catch basin in this area that drains into the roadside ditch on the east side of the property.

The salt bed racks are located along the north fence line. The stormwater from this area flows into the roadside ditch. There is no berm in this area.

$>$ Snow plows line the NE corner fence line.

There is a large open field north of the fenced area. A ditch runs through this field and drains into the I-65 roadside ditch. There is a large pile of street sweepings and trash in this area.

South Portion of Property

The Salt Dome is located in the SW corner of the site. There is a sand berm at the entrance of the Dome. The area around the Slat Dome is kept clean.

There are several aggregate piles south of the Salt Dome. This area is not bermed.

A cold patch pile is located east of the Salt Dome, This cold patch pile is not bermed or covered with a tarp. 
A secondarily contained $\mathrm{CaCl}$ tank is located north of the cold patch pile. There is a bed spraying bar connected to this tank. This are is not bermed.
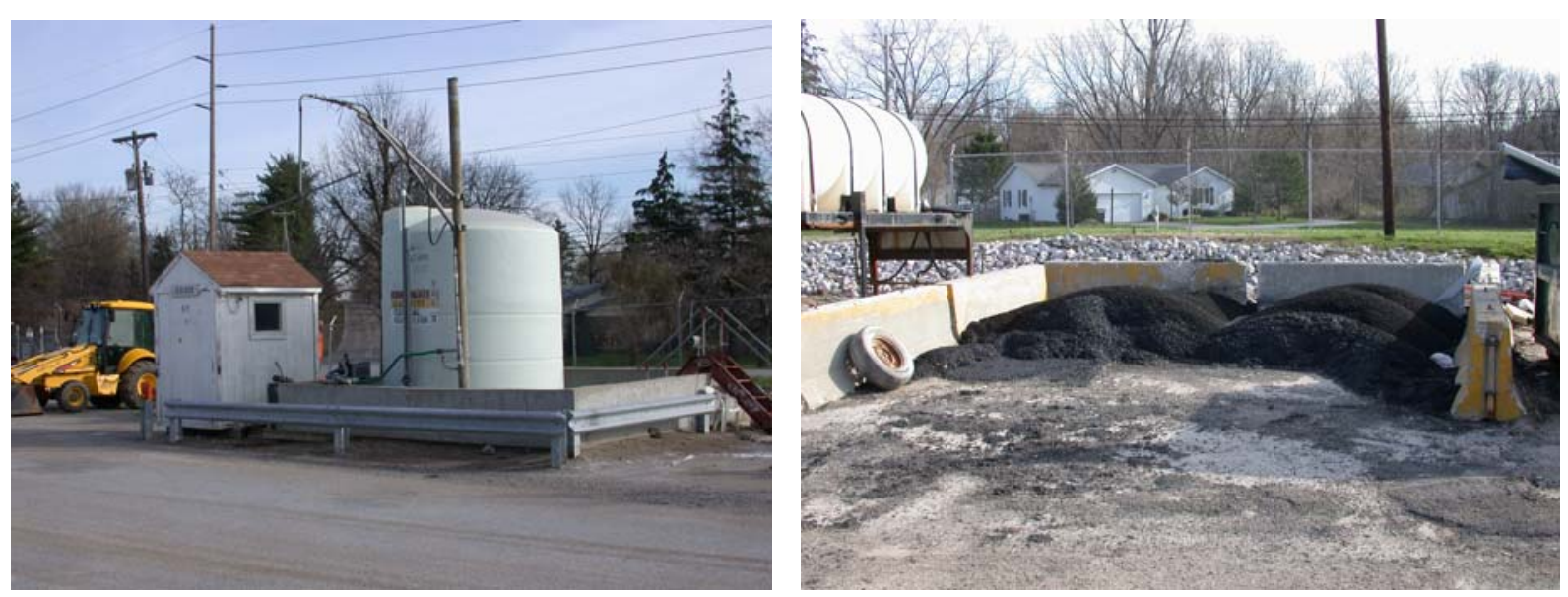

\section{Buildings}

* Unit Building

$>$ All salt bed and vehicle washing is performed in the Unit Building.

All oil and hydraulic fluid drums are secondarily contained.

\section{* Salt Dome}

$>$ The area around the Salt Dome is kept free of salt. There are no vegetation kills at this site.

\section{* Other Buildings}

$>$ There is a brine production building on-site that houses three 5000-gallon storage tanks and brine production equipment. This building is secondarily contained.
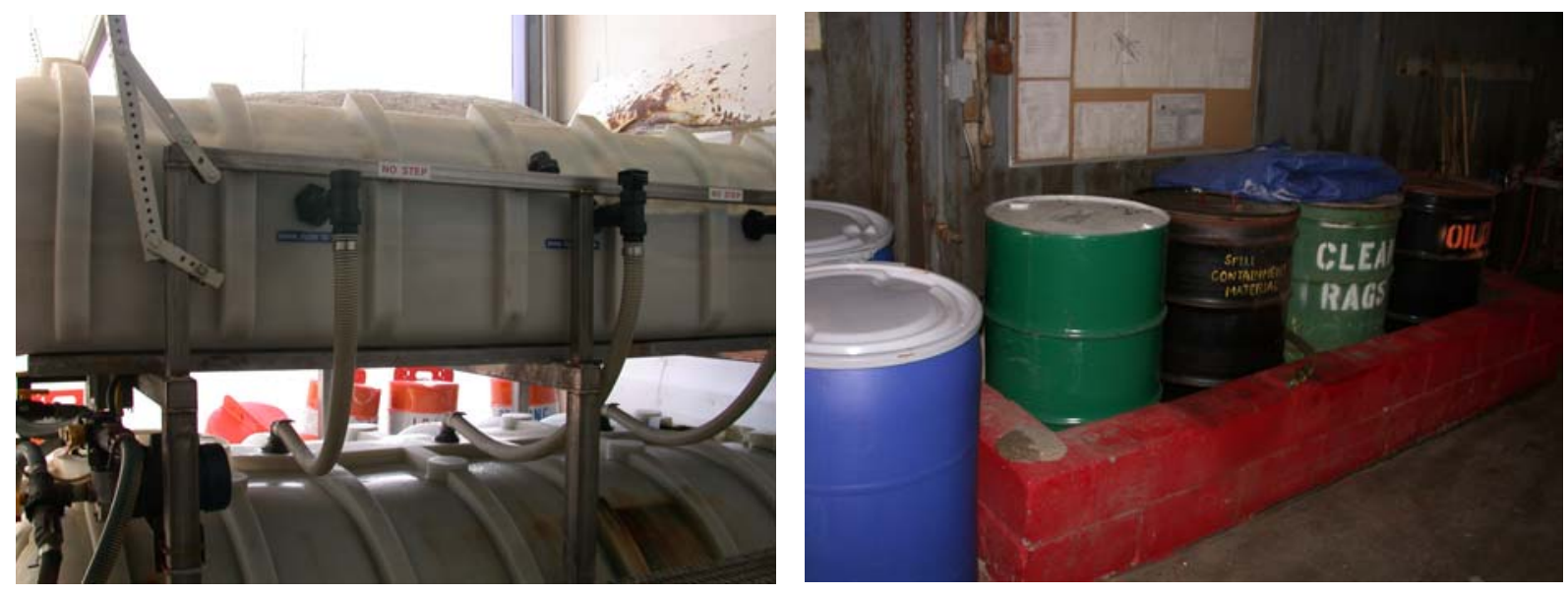


\title{
INDOT Site Assessment Report Observations and Comments
}

\author{
$\underline{\text { Surface Area }}$
}

General

$>$ The Northern portion of the active surface drains directly into Thorpe Creek. The Southern portion of the active surface drains into the I-69 drainage ditch, which enters Thorpe Creek approx. 100 yards west of the facility.

$>$ There is a catch basin in the truck parking area that catches all the storm water in the area. The Unit Foreman said that this catch basin is connected to the sanitary sewer system.

\section{West Property Line}

The entrance for this facility is in the northwest corner of the property. This entrance is off SR 13, just north of I-69. There was evidence of some brine spillage on the ground at the entrance gate.

$>$ The first building located south of the entrance houses the oil/water separator. This building is approx. 10 feet from the West fence line.

$>$ The Unit Building is located south of the oil/water separator, also on the West fence line.

$>$ The truck parking area is south of the Unit Building and contains a catch basin, which captures all the water that collects in this area. The catch basin is located in the grass near the paved surface. Where the water flows off the pavement and into the catch basin, the grass has died and the soil is covered with salt residue. The catch basin is connected to the sanitary sewer system.

South of the truck parking area are a Calcium Chloride tank and a Brine tank used to spray salt bed loads. A concrete containment wall secondarily contains both tanks, but the spraying area is not bermed. 
$>$ The Salt Dome is located west of these tanks, in the southwest corner of the property. The area in front of the Salt Dome is covered with salt residue. A salt trail that leads to the East ditch line is clearly visible. This runoff flows to the East ditch line and then to the I-69 roadside drainage ditch.

* East Property Line

Aggregate bins are located in the southeast corner of the property. These bins included grindings/scalp and cold patch. The cold patch was covered with a tarp to prevent storm water contact. This area drains to the East property line ditch.

$>$ The salt bed storage racks are located north of the aggregate bins on a concrete slab. This slab was covered in some areas by salt piles left from salt beds. It was obvious that the salt beds were not thoroughly cleaned before being hung. The storm water from this area flows, approx 10 feet, to the East property line ditch.

North of the salt bed storage racks is a fenced area, approx. 60' by 60', that contains metal pipe segments and fittings. There were several types of metal objects being stored in this area.

$>$ A small building north of the metal storage area holds pressurized tanks.

\section{Buildings}

\section{Unit Building}

The liquids captured in Unit Building floor drains are piped through an oil/water separator and then into the sanitary sewer system.

$>$ The oil and hydraulic fluid drums were secondarily contained to prevent spills.

\section{* Salt Dome}

$>$ The Salt Dome entrance was bermed with sand but the area outside the dome was covered with salt that had been lost during the process of loading salt beds. The storm water that comes in contact with this area flows to the East property line ditch, which empties into the I-69 drainage ditch.

\section{* Other Buildings}

The building that housed the oil/water separator was not open on the day of the site visit. 


\section{INDOT Site Assessment Report Observations and Comments}

\section{Surface Area}

\section{General}

$>$ There is an asphalt detention pond at this facility that receives all stormwater and floor drain water from inside the Unit Building. There is an overflow pipe in the pond that drains to a county ditch. All salt bed washing is performed at this facility.

$>$ This facility is not equipped with an oil/water separator and is not connected to a POTW. However, the Unit Foreman said that the Unit was going to be connected to the city sewer in the near future. A pump station is required to connect this facility to the sewer system.

$>$ There are catch basins throughout the surface of the facility that drain into the detention pond.

$>$ There is a grassed area on the NE side of the property that is used to store piles of street sweepings, scrap, and road debris.
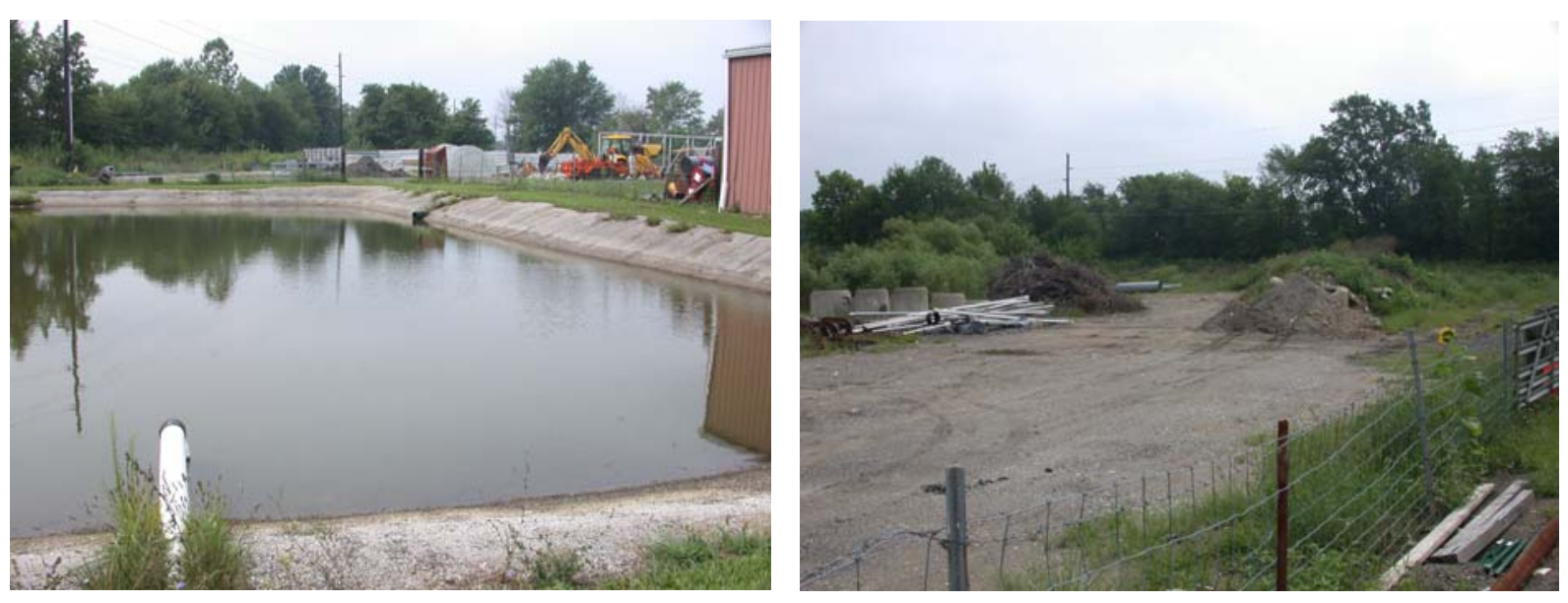
North Portion of Property

$>$ The Unit Building is located in the NW corner of the property. The floor drains in this building drain into a detention pond located in the NE corner of the facility.

There is a grassed area north of the facility fence that is used to store scrap, street sweepings, and junk. The area is not organized and is an eye sore.

$>$ There is an outdoor washing area on the east side of the Unit Building. There are catch basins in the area that drain into the detention pond.

$>$ There is a large cold storage building located approx. 20 yards east of the Unit Building. This building is used for truck parking and storage of road signs and tools. There are floor drains in this building that drain into the detention pond.

> There are several empty 55-gallon drums being stored on the south side of the cold storage building. These drums should be properly disposed of.

$>$ An asphalt detention pond is located east of the cold storage building, in the NE corner of the site. There is an overflow pipe in the north side of the pond that leads to a county ditch located to north.
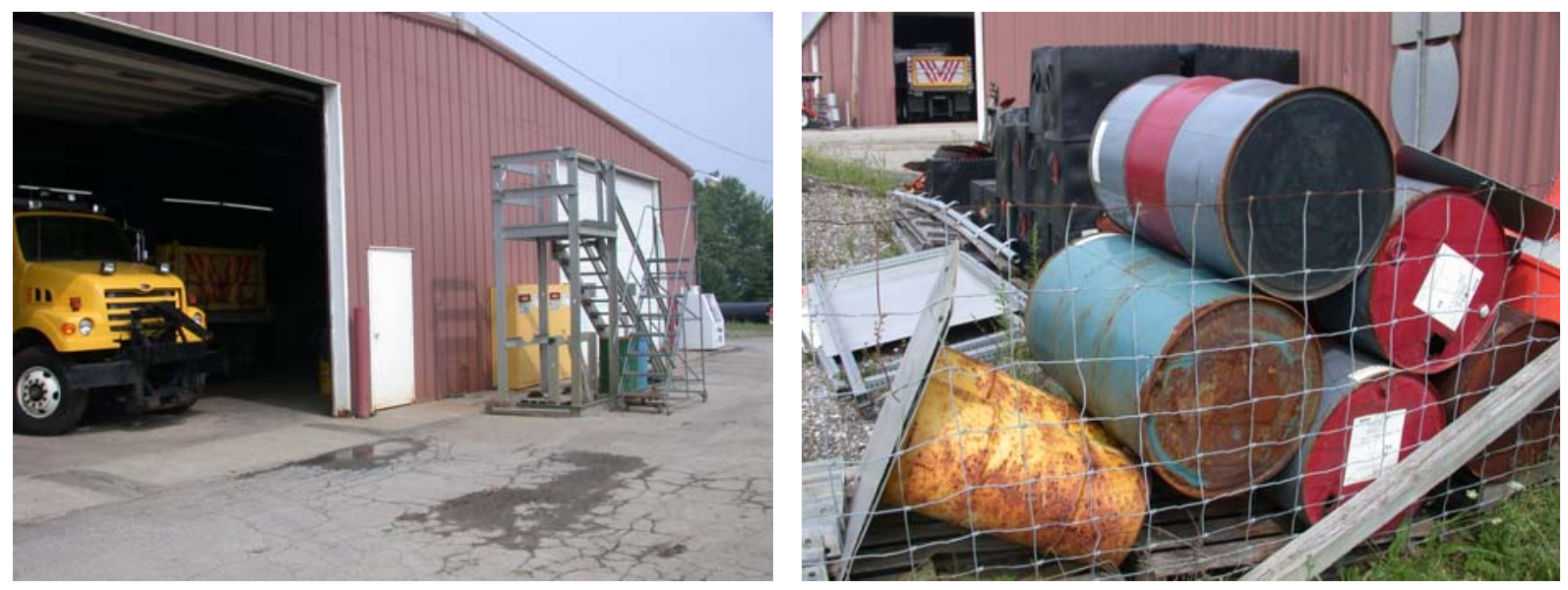

\section{* South Portion of Property}

The Salt Dome is located in the SW corner of the site. There is a sand berm located at the entrance of the Dome.

There are two secondarily contained Calcium Chloride tanks located on the North side of the Salt Dome. There is a bed spraying bar connected to these tanks. There is a catch basin approx. 5 feet from this area that leads to the detention pond. 
There are aggregate bins located approx. 15 yards east of the $\mathrm{CaCl}$ tanks. There is a catch basin also located near these aggregate bins.

$>$ The salt bed racks are located on the east side of the Salt Dome. This area is not bermed and stormwater from the area is captured in a catch basin and conveyed to the detention pond.

$>$ There is a large pile of cold patch east of the salt bed racks that is not bermed or covered. The entire SE corner of the property is used to store aggregate. There is also a tractor and a tar kettle parked in the SE corner.
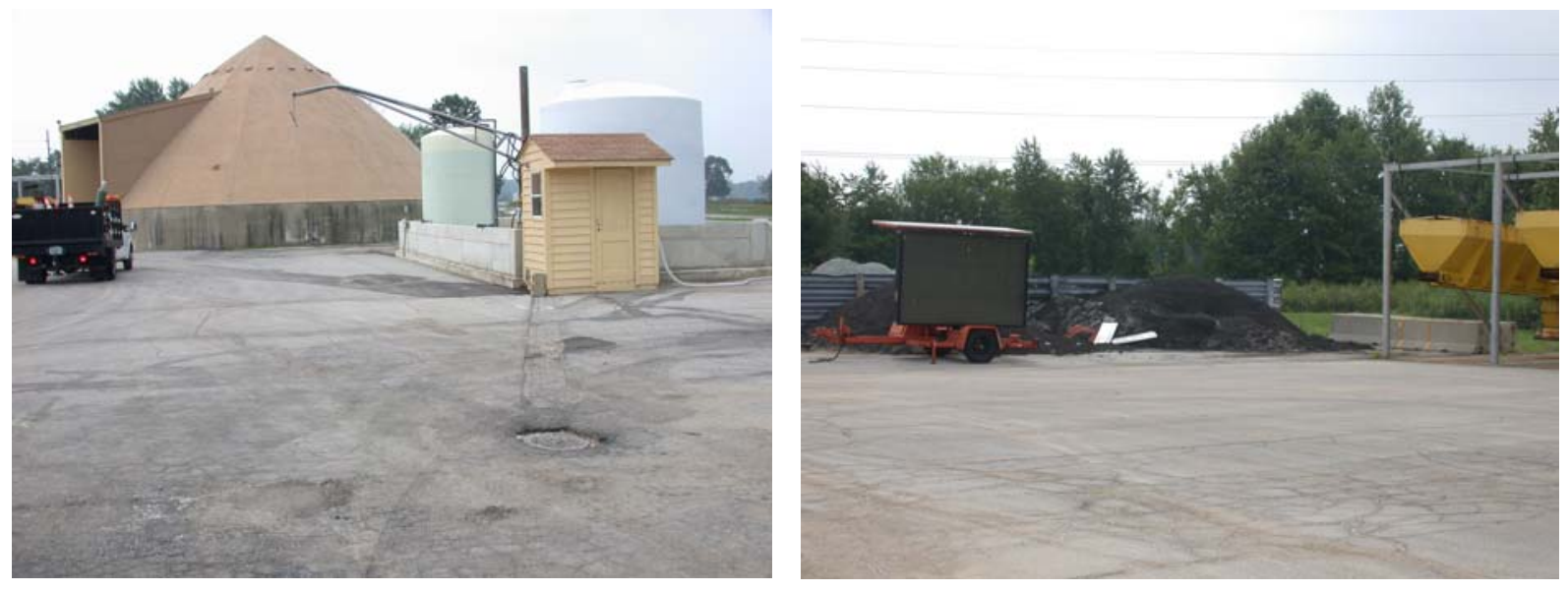

\section{Buildings}

* Unit Building

The Unit Foreman said that the Unit Building would be connected to the city sewer system in the near future. Currently, all floor drains in the Unit Building drain into the detention pond.

All oil and hydraulic fluid drums inside the Unit Building are secondarily contained.
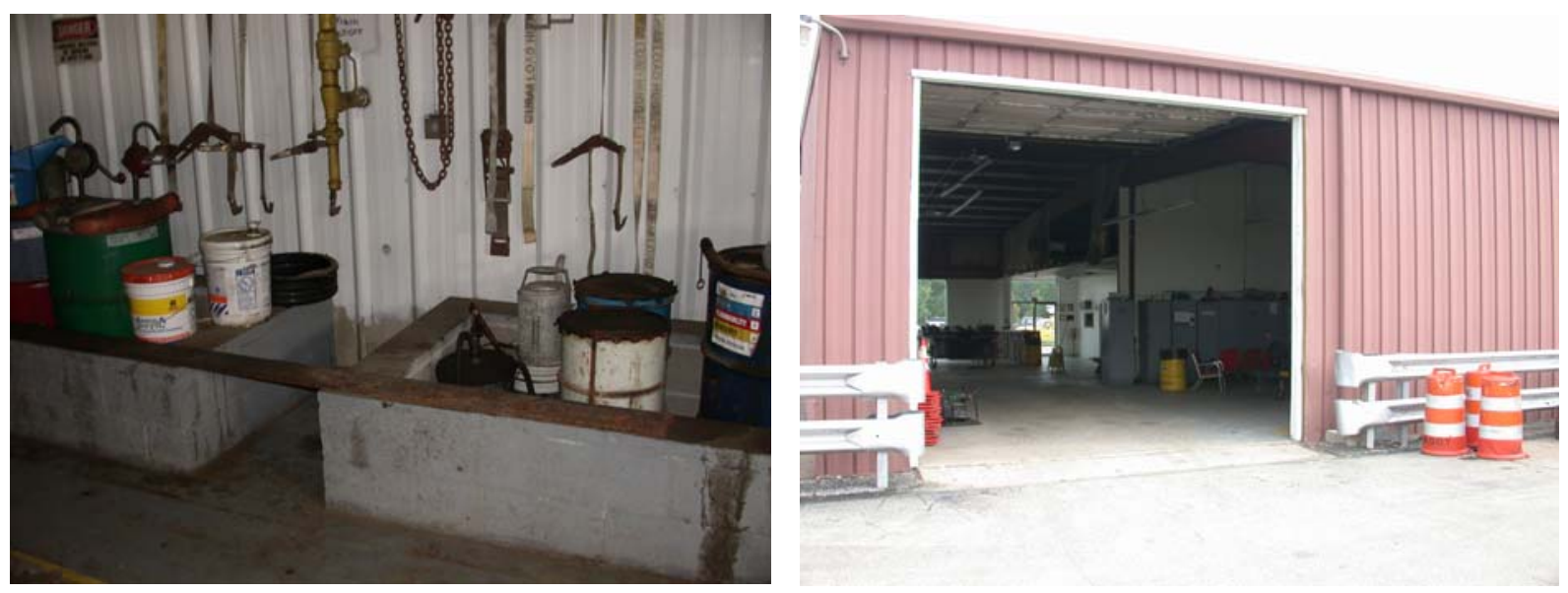


\section{* Salt Dome}

$>$ The entrance of the Salt Dome is bermed with a sand dike. Stormwater from the Salt Dome area enters a catch basin that drains into the detention pond.

* Other Buildings

There is a cold storage building on-site that is used for truck parking, road signs, and other tools. There are floor drains in this building that drain into the detention pond. 


\section{INDOT Site Assessment Report Observations and Comments}

\section{$\underline{\text { Surface Area }}$}

General

$>$ The facility is not connected to a Municipal Sewer System and is not equipped with an oil/water separator.

All stormwater and fluids from the Unit Building floor drain are piped under the east fence line where it flows into a small wetland/bog area. This wetland/bog area overflows into a ditch that eventually enters a roadside ditch.

$>$ There are 5 catch basins placed throughout the surface of the site that direct stormwater to the wetland/bog area.

The facility has a 1000 gallon above ground fuel tank that is located outside the south side of the Unit Building. The fuel tank is secondarily contained.

There is a ground water sampling well on site
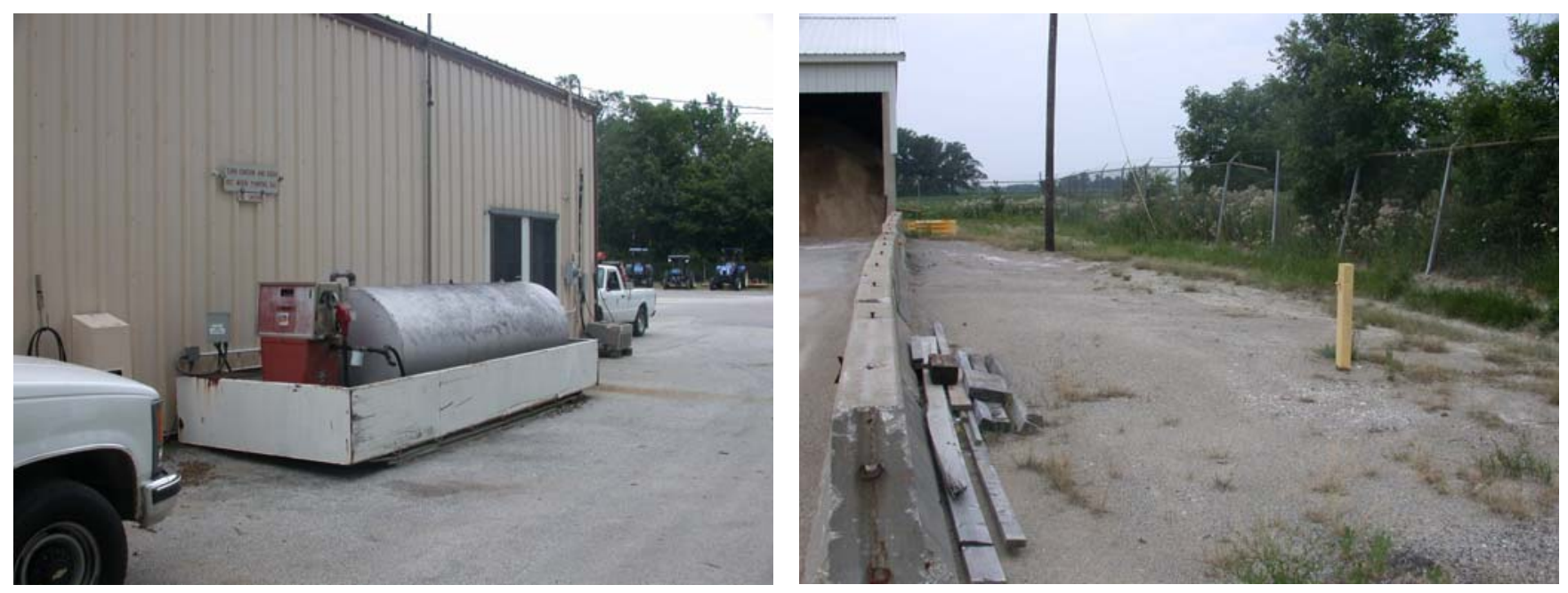


\section{* South Property Line}

$>$ The entrance to the site is off of State US HWY 35 and is located on the south side of the property

The SW portion of the property is not fenced and has been left natural and unused.

The Unit Building is located in the SW potion of the fenced area. There are two catch basins around the Unit Building that direct stormwater offsite. There is also a secondarily contained 1000 gallon fuel tank on the south side of the Unit Building.

A small Cold storage Building is located in the SW corner of the site. The area around the Cold Storage Building was not kept clean and organized. There was scrap metal laying around, several road signs, and an old brine tank laying against the fence.

$>$ The Salt Bed Racks are located on the north side of the Cold Storage Building along the west fence line. There is a catch basin under the racks that collects all stormwater in the area. The stormwater is collected is piped offsite.

There is a Brine and Calcium Chloride tank located in the SE portion of the fenced area. These tanks are connected to a bed spraying system. The tanks are secondarily contained but the spraying area is not. There is a catch basin near this area.
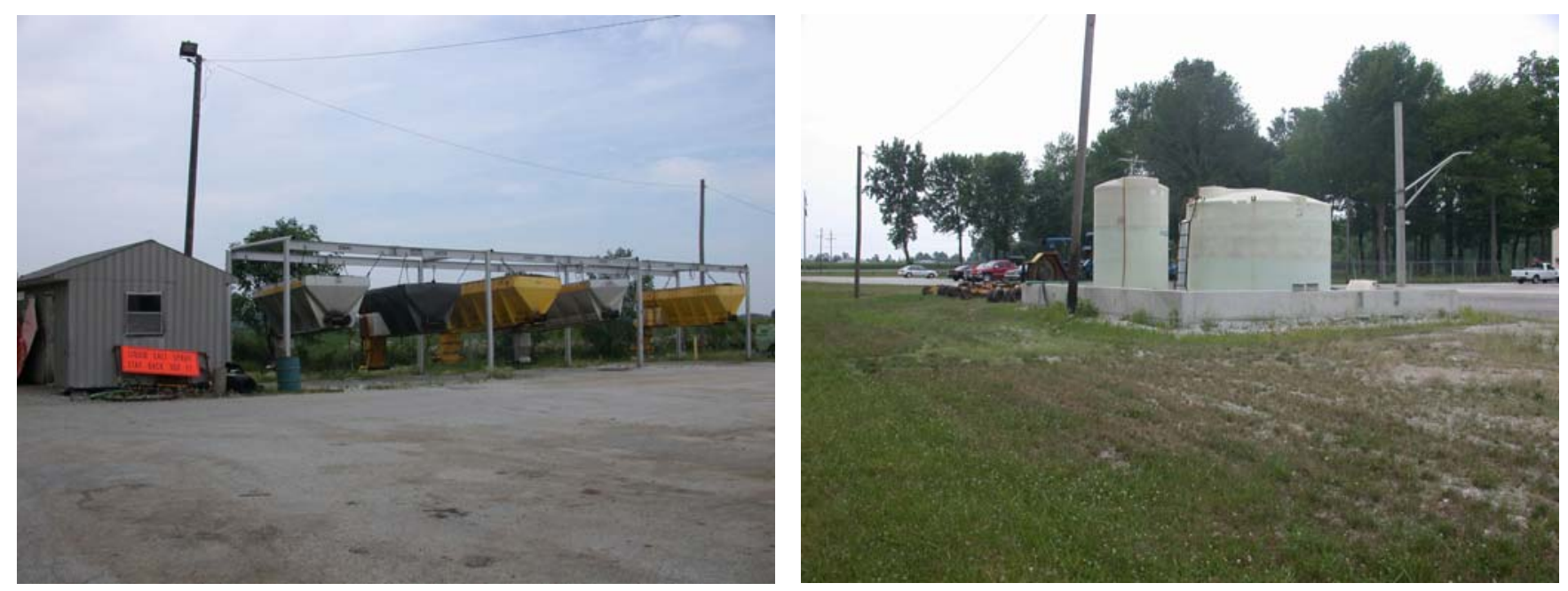
* North Property Line

$>$ An old Salt Storage Building is located in the NW corner of the site. However, salt is no longer stored in this building. Instead the building is used for sand storage.

A newer Salt Dome is located approx. 10 feet south of the Sand Storage Building. There was a significant amount of salt and sand around both buildings.
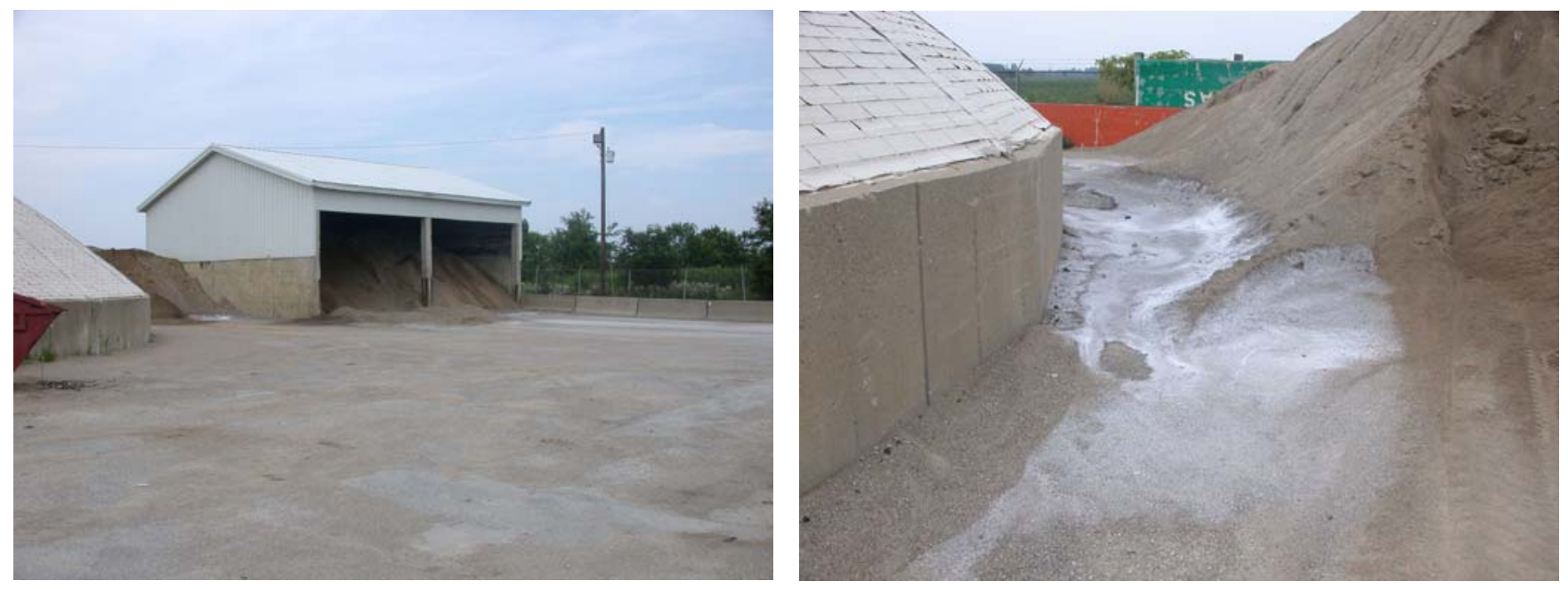

A salt loading pad is located approx. 20 feet SE of the Salt Dome. The area around the loading pad was clean.

Directly south from the Salt Dome, there is a storage area for cold patch and aggregate. The area is not bermed but the pile of cold patch was covered with a tarp at the time of the site visit. A tar kettle was parked on the north side of this area.

$>$ The North East corner of the site is used to store scrap metal, fencing, guard rail and other odds-and-ends. There is also a large pile of dirt located in this area.
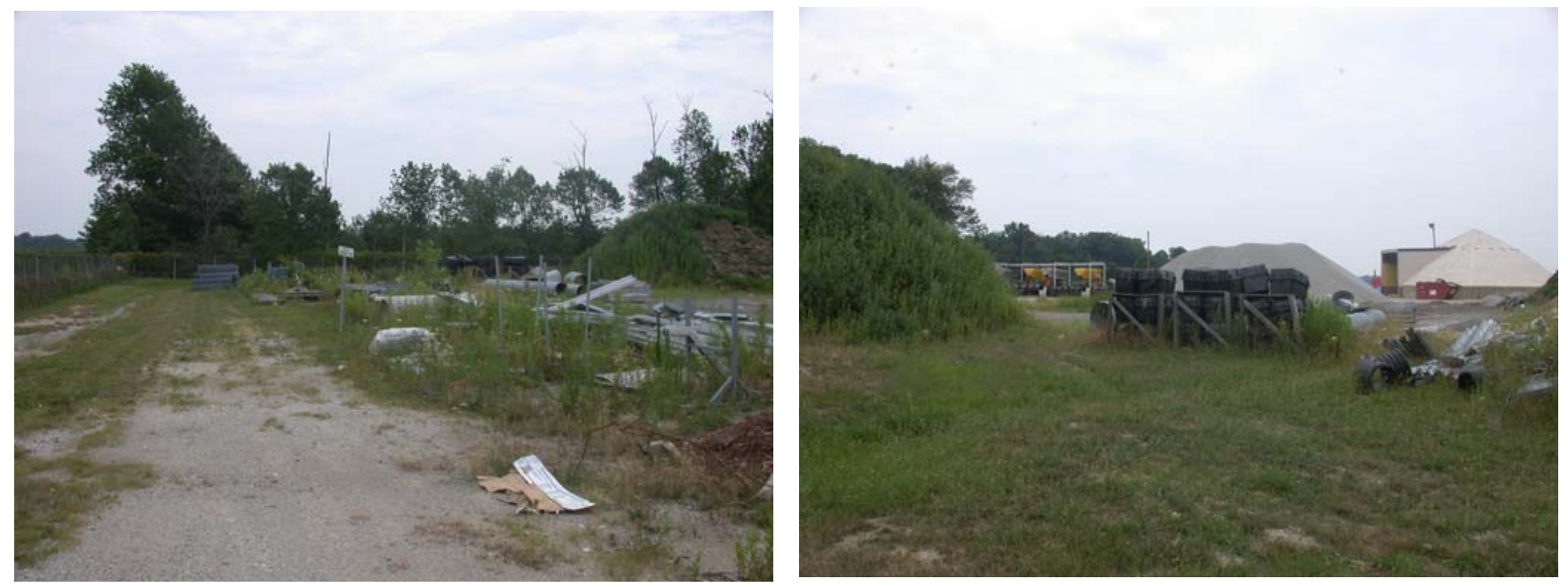


\section{Buildings}

Unit Building

At the time of the site visit, all 55-gallon drums were being stored on secondary containment pallets. However, there were several 5 gallon buckets of that were not secondarily contained.

$>$ The floor drain inside the Unit Building drains offsite to the wetland/bog area. There are also two catch basins outside the Unit Building that drain to the wetland/bog area.

$>$ The restrooms are connected to a septic system.
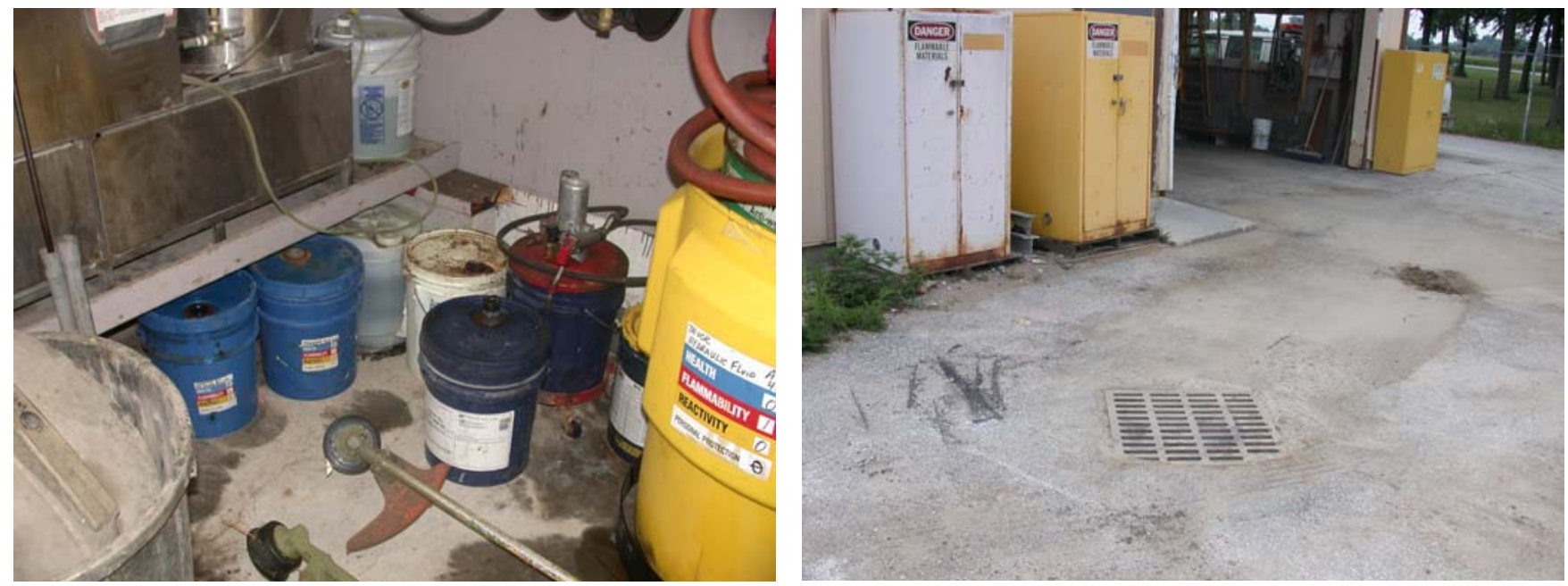

Salt Storage Buildings

D There was a significant amount of salt around the Salt Dome and Old Salt Storage building.

There is a large area of dead vegetation along the NW fence line. This is most likely being caused by salt contaminated runoff. (See bottom right picture on pg. 1)

* Cold Storage Building

The small Cold Storage Building was used to store road signs and other small objects 


\section{INDOT Site Assessment Report Observations and Comments}

\section{Surface Area}

General

$>$ This facility is equipped with an oil/water separator and the floor drains are connected to a POTW.

$>$ Stormwater from the site flows into a roadside ditch that empties into Big Blue Creek approx. 0.5 miles SE of the facility.

> This facility has a Salt Dome and a rectangular salt storage building.

North Portion of Property

$>$ The Unit Building is located in the NW corner of the property. There is a tar kettle parked on the east side of the Unit Building that is not bermed.

$>$ There is a large pole barn located south of the Unit Building. This pole barn is used as truck parking and to store cold patch.

$>$ The Salt Dome is located in the NE corner of the property. All the stormwater from this area flows under the NE corner fence line and into the roadside ditch. There are also tractors parked around the Salt Dome.

$>$ There is a scrap metal storage area located south of the Salt Dome. This area contains guard rail, metal sheeting, and other miscellanea. This area is not bermed. There are also dumpsters in this area that are used to store road debris. 

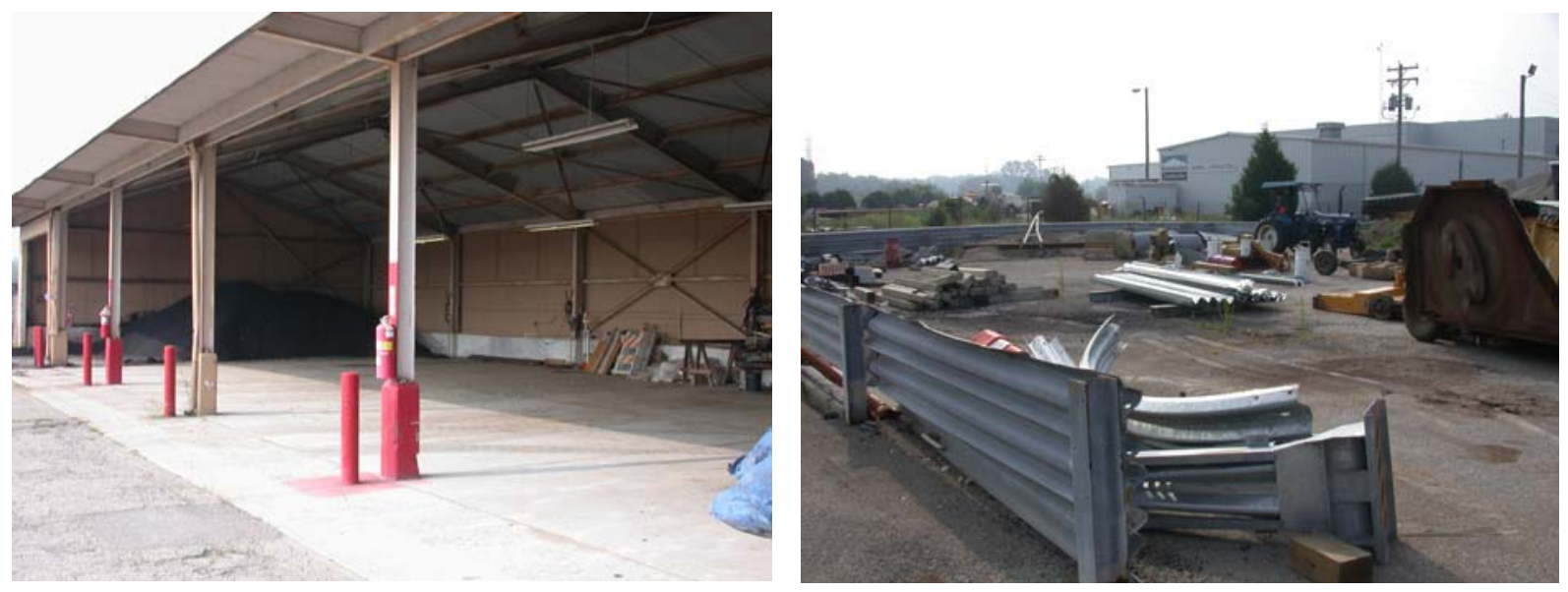

\section{South Portion of Property}

There is a rectangular salt storage building located in the SW corner of the property. This building was full of salt.

> There is a secondarily contained tank of "Liquid Armor" located on the south side of the rectangular salt storage building. There is also a bed spraying bar connected to this tank. This area is not bermed.

$>$ The salt bed racks are located on the north side of the rectangular salt storage building. This area is not bermed.
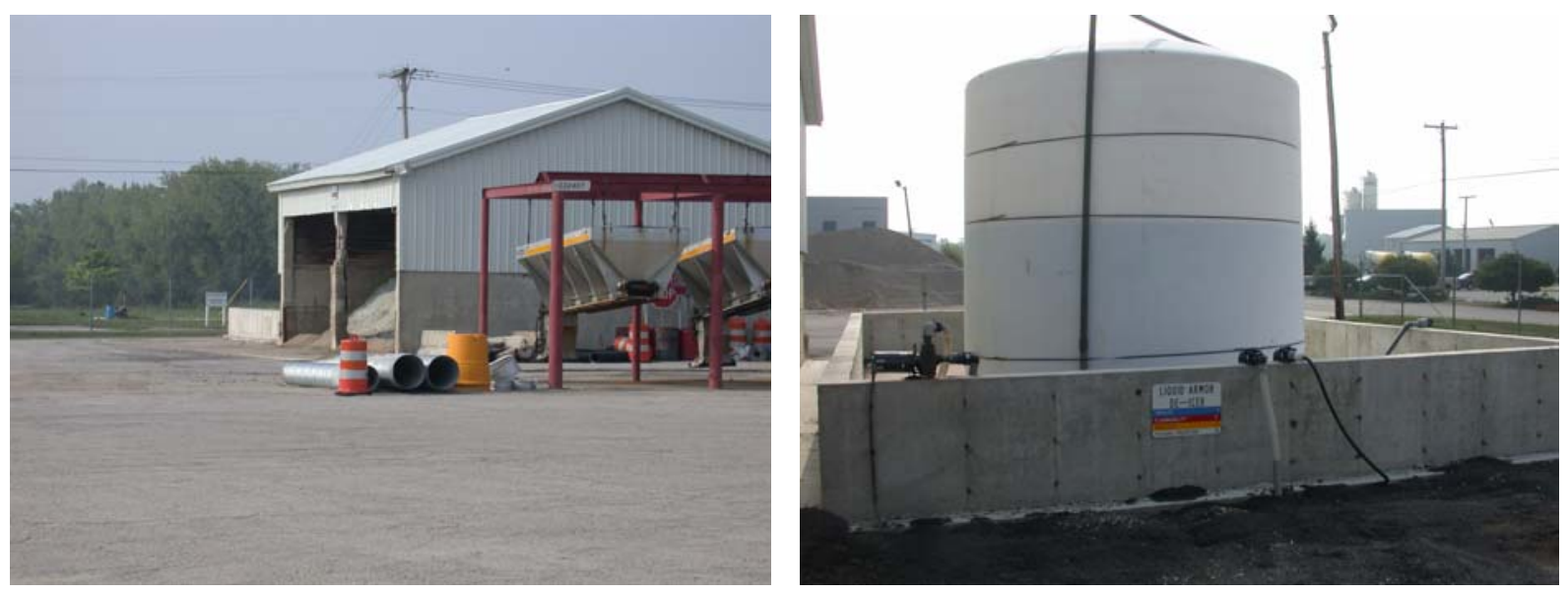

There are several concrete aggregate bins located in the SW corner of the site. 

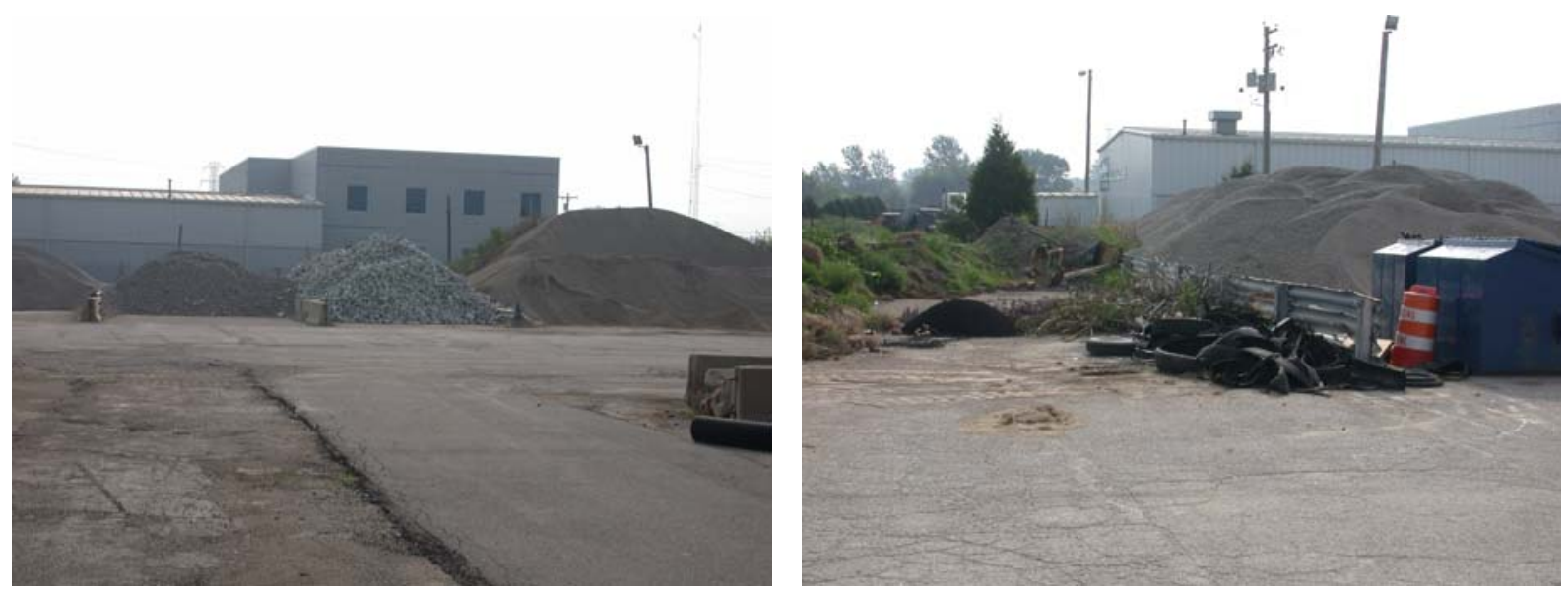

\section{$\underline{\text { Buildings }}$}

\section{Unit Building}

$>$ There is an oil/water separator in the Unit Building and the floor drains are connected to a POTW. Salt bed washing and vehicle maintenance are performed inside the Unit Building.

> All drums of oil and hydraulic fluid inside the Unit Building were secondarily contained.
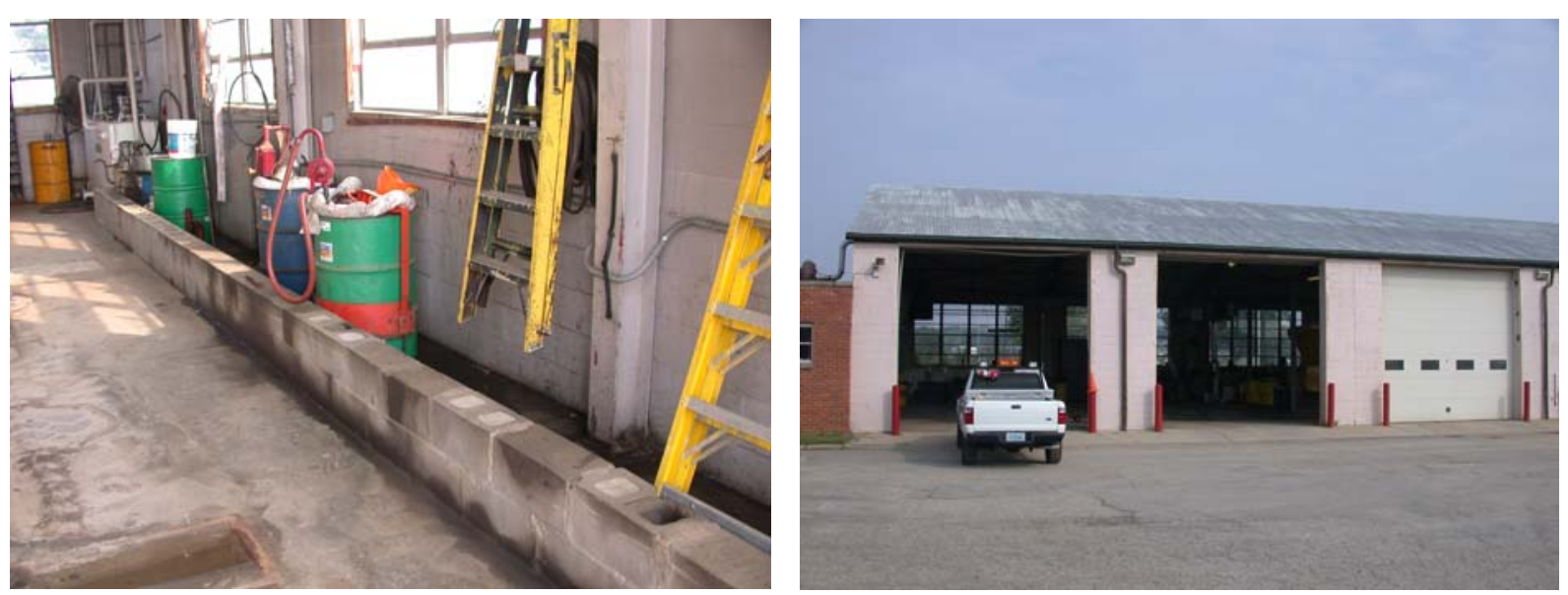

\section{Salt Dome}

$>$ The entrance to the Salt Dome is bermed with a sand dike. There was very little salt on the ground around the Salt Dome.

* Other Buildings

$>$ There is a pole barn and a rectangular salt storage building on-site. There are no drains in these buildings. The pole barn is used to store cold patch. 


\section{INDOT Site Assessment Report Observations and Comments}

\section{$\underline{\text { Surface Area }}$}

\section{General}

$>$ There stormwater from the southern half of the site enters an asphalt paved retention pond. The stormwater from the northern half of the site enters a wetland/bog area that is located in the NE corner of the site. The retention pond has an overflow pipe that drains to the wetland/bog area.
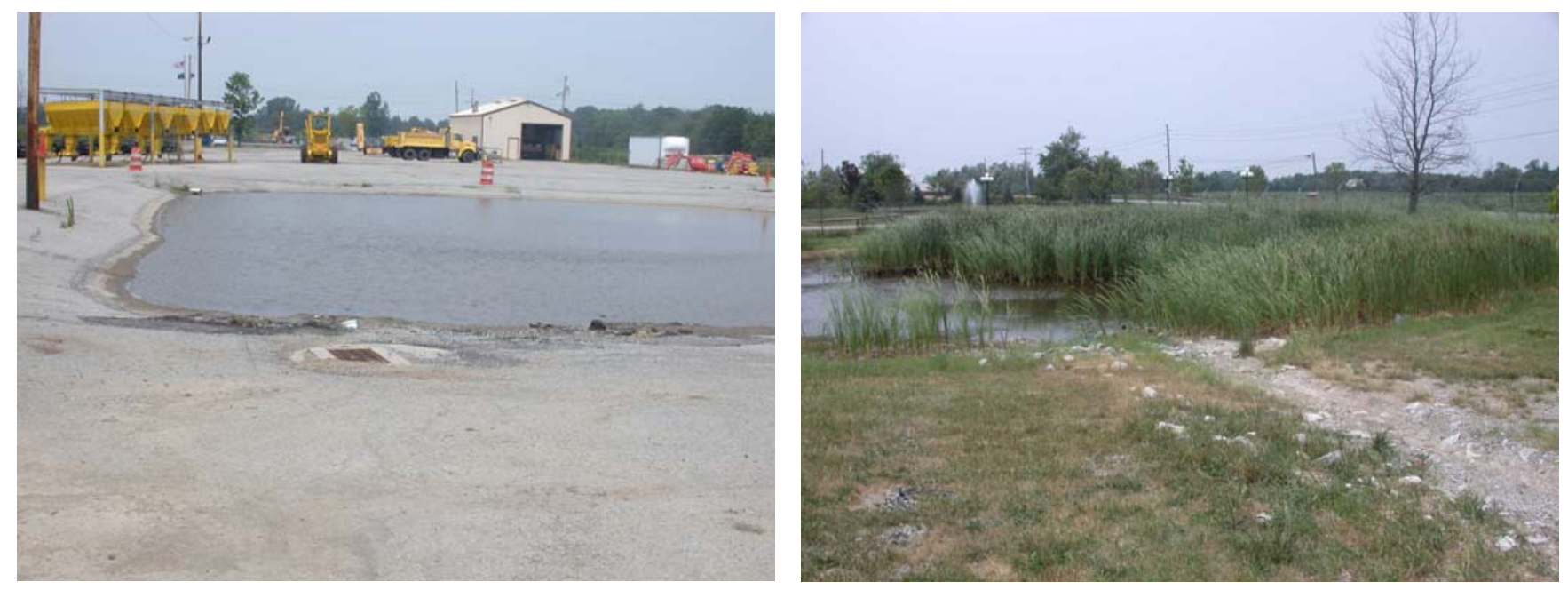

This facility is not connected to a Municipal Sewer System and is not equipped with an oil/water separator. All water collected in the Unit Building floor drain runs out onto the ground on the west side of the Unit Building and eventually flows into a neighboring soybean field.

$>$ The restroom in the Unit Building is connected to a septic system. The Unit Foreman said that the septic system did not work properly due to the tile field being in a low-lying area. During wet weather, the restroom cannot be used because of overflowing problems. 


\section{* Northern Portion of Property}

$>$ The Unit Building is located in the NE corner of the property. The floor drain in the Unit Building drains out onto the ground on the east side of the building. The drainage water then flows onto a neighboring soybean field. The vegetation in this portion of the field was dead.(see pic. at bottom right)

$>$ A tractor-trailer, which has been converted to a cold storage area, is located south of the Unit Building. This trailer is used to store tools, road signs, and other oddsand-ends. There are also traffic cones stored around the outside of the trailer.

$>$ The truck parking area is along the west side of the Unit Building. The water from the areas drains west into a wetland/bog area.

A wetland/bog area is located in the NW corner of the site. This area receives stromwater from the Northern portion of the site and receives overflow water from the retention pond located in the southern portion of the site.

The Salt Bed Racks and Snow Plow storage area are located approx. 20 feet SE of the wetland/bog area. All stormwater from the area enters the wetland/bog area.

There are aggregate storage bins, a large pile of dirt and a brine tank used for road application located approx. 20 feet SW of the Salt Bed Racks. The stormwater from this area also enters the wetland/bog area.
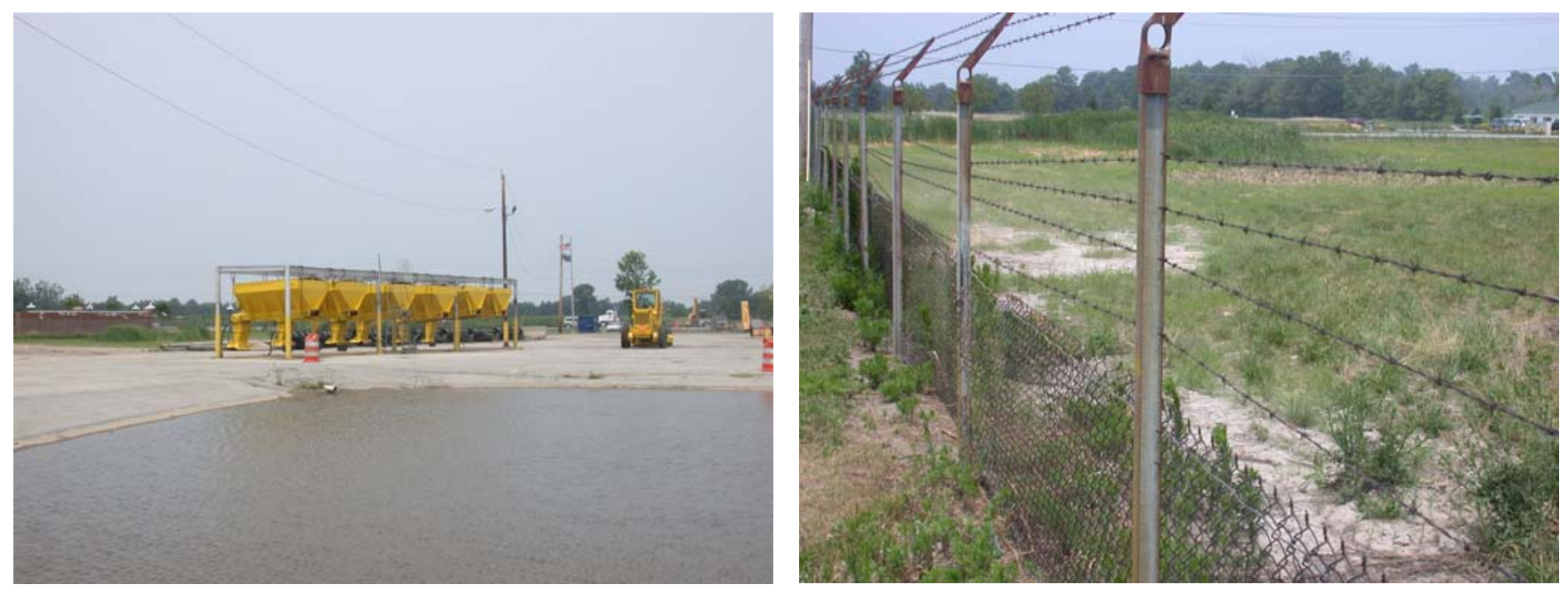
* Southern Portion of the Property

$>$ A large retention pond is located in the center of the Southern portion of the site. This retention pond is paved with asphalt. It receives all stormwater from the Southern portion of the site. There is an overflow pipe in the NW corner of the pond that empties into the wetland/bog area.

$>$ The Salt Dome is located in the SW corner of the site. There is one catch basin located behind the dome and one catch basin located near the entrance of the dome, which both empty into the retention pond. The entrance of the Salt Dome was not properly bermed, which allowed the salt to come in contact with stormwater and migrate out of the entrance.
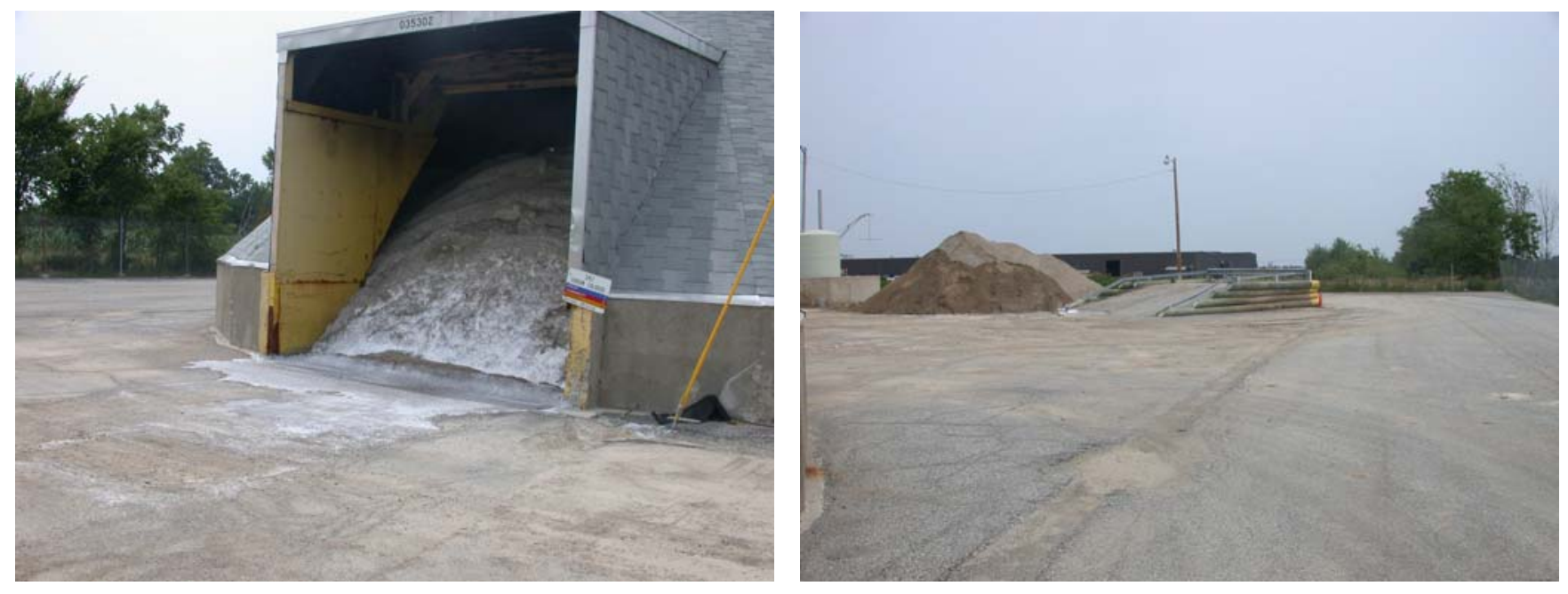

There is also a storage area for scrap metal, scrap tires, and scrap wood located in the SW corner of the property, behind the Salt Dome.

There is a large building located approx. 15 feet north of the Salt Dome. This building is divided into two areas: A Brine Production area with brine production equipment and brine tanks, and a Cold Storage area. All brine tanks are secondarily contained. A salt bed spraying device is located outside of the northern side of the building. All stormwater from this area enters the retention pond.

A Salt Bed Loading Ramp and a Calcium Chloride Tank are located in the SE corner of the site. The Calcium Chloride tank is secondarily contained and there is a salt bed spraying device attached to the Calcium Chloride tank. There is also a large pile of sand used for salt/sand mixing next to the loading ramp. All water from this area enters the retention pond.(see above picture on right) 


\section{Buildings}

Unit Building

The Unit Building is not connected to a sewer system and is not equipped with an oil/water separator. The liquids that are collected in the floor drains flow onto the ground on the east side of the building and eventually enter the neighboring soybean field. This has resulted in a vegetation kill in the neighboring field.
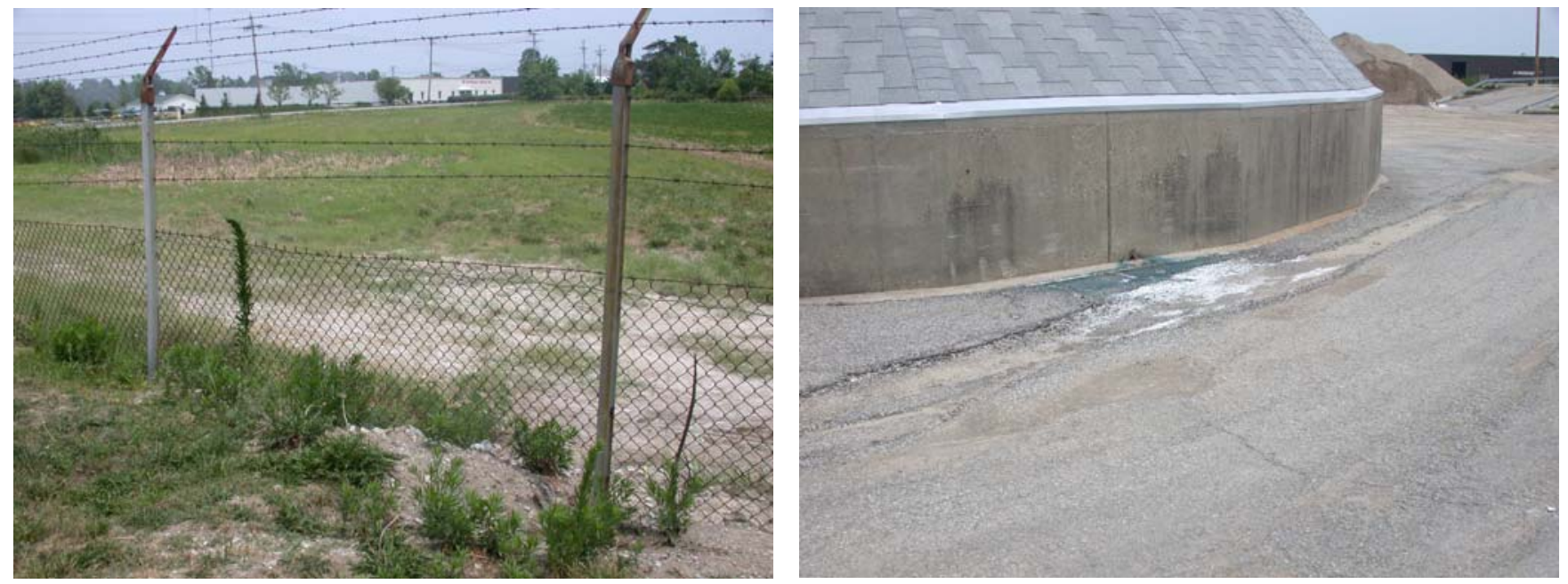

The septic system used for the restrooms in the Unit Building is not properly working due to the fact that the field lines were constructed in a low lying area that collects stromwater during rain events. This causes the septic system to back up and overflow during rain events.

\section{* Salt Dome}

> The entrance to the Salt Dome was not bermed properly, which allowed salt contaminated stormwater to migrate out onto the active surface.

> There are several "weep holes" located at the base of the Salt Dome, which allows water from inside the Salt Dome to drain out onto the ground. There is significant amounts of salt residue located around these drainage holes. This indicates that a significant amount of stormwater is getting into the Salt Dome.(see above pic. at right)

* Cold Storage/Brine Production Building

$>$ This building is divided into two large rooms, which are used for Cold Storage and Brine Production.

The Cold Storage area is used to store tools, small tractors, and odds-and-ends.

$>$ The Brine Production and Storage area is secondarily contained and houses a brine mixing tank and several large brine storage tanks. 


\section{INDOT Site Assessment Report \\ Observations and Comments}

Facility: Winchester Unit

August 18, 2005

\section{$\underline{\text { Surface Area }}$}

General

$>$ There are several catch basins throughout the surface of the site that collect surface water and convey it to a roadside ditch. The roadside ditch drains into Sugar Creek approx. 0.25 miles east of the facility.

There are large vegetation kills on the site. These vegetation kills were caused by salt contaminated runoff.
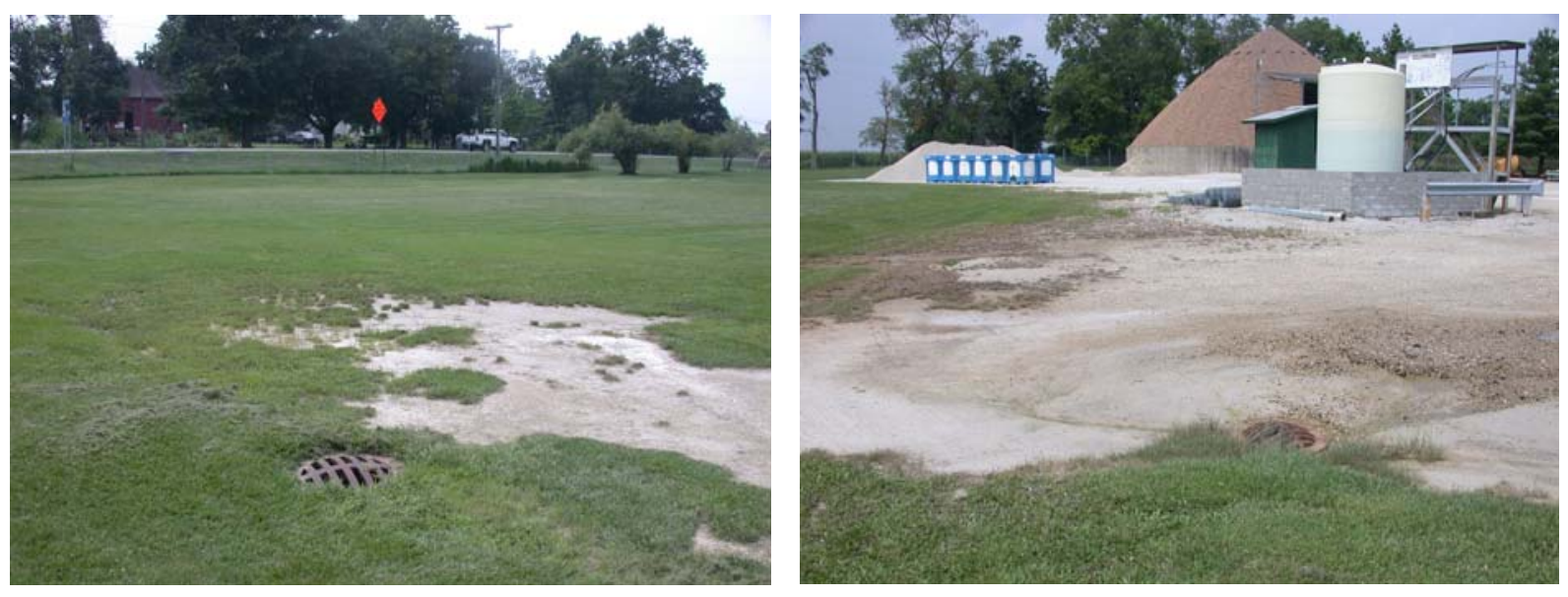

At the time of the site visit, truck painting was taking place in the Unit Building.

This facility is equipped with an oil/water separator and the floor drains are connected to a POTW. 
East Portion of Property

$>$ The Unit Building is located in the NE corner of the site. There is an underground waste oil tank on the south side of the building. There are snow plows lining the north side of the Unit Building.

$>$ The salt bed racks are located approx. 20 feet north of the Salt Dome. This area is not bermed.

There are aggregate bins located west of the salt bed racks. There is a cold patch pile in this area that is not bermed or covered. All stormwater from this area flows south to a catch basin that drains into the roadside ditch.

There is a truck parking area west of the aggregate bins. This area is not bermed.
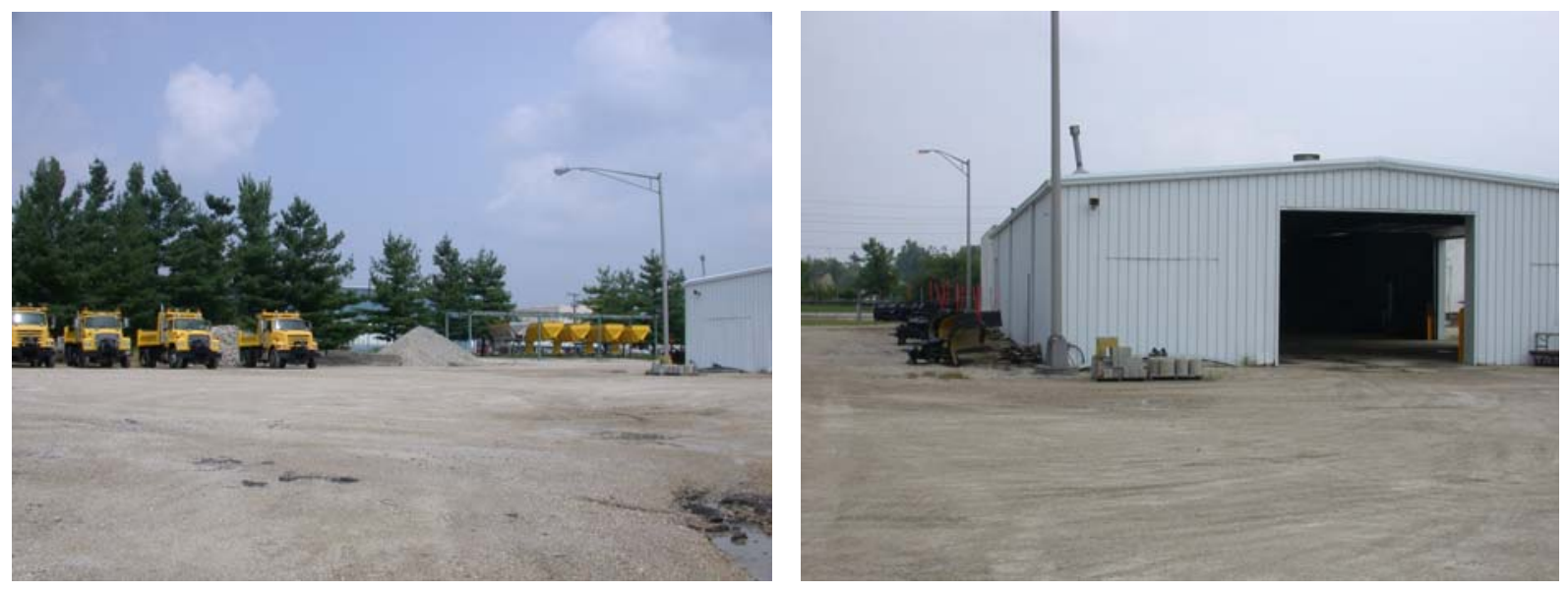

West Portion of Property

The Salt Dome is located in the NE corner of the site. There was a substantial amount of salt on the ground around the entrance of the Salt Dome. There is evidence that salt is being transported via stormwater into the catch basins on the south side of the property and causing vegetation kills.

There is a secondarily contained Calcium Chloride tank located approx. 20 yards SE of the Salt Dome. The grass around this area is dead.

There are several catch basins located on the south side of the site. There are also large vegetation kills around the catch basins. 


\section{Buildings}

\section{Unit Building}

$>$ There is an oil/water separator in the Unit Building and an underground waste oil tank on the south side of the Unit Building. All floor drains and restrooms are connected to the city sewer.

D There is a large washbay in the Unit Building. During the site visit there was a man spray painting a truck in this large washbay.
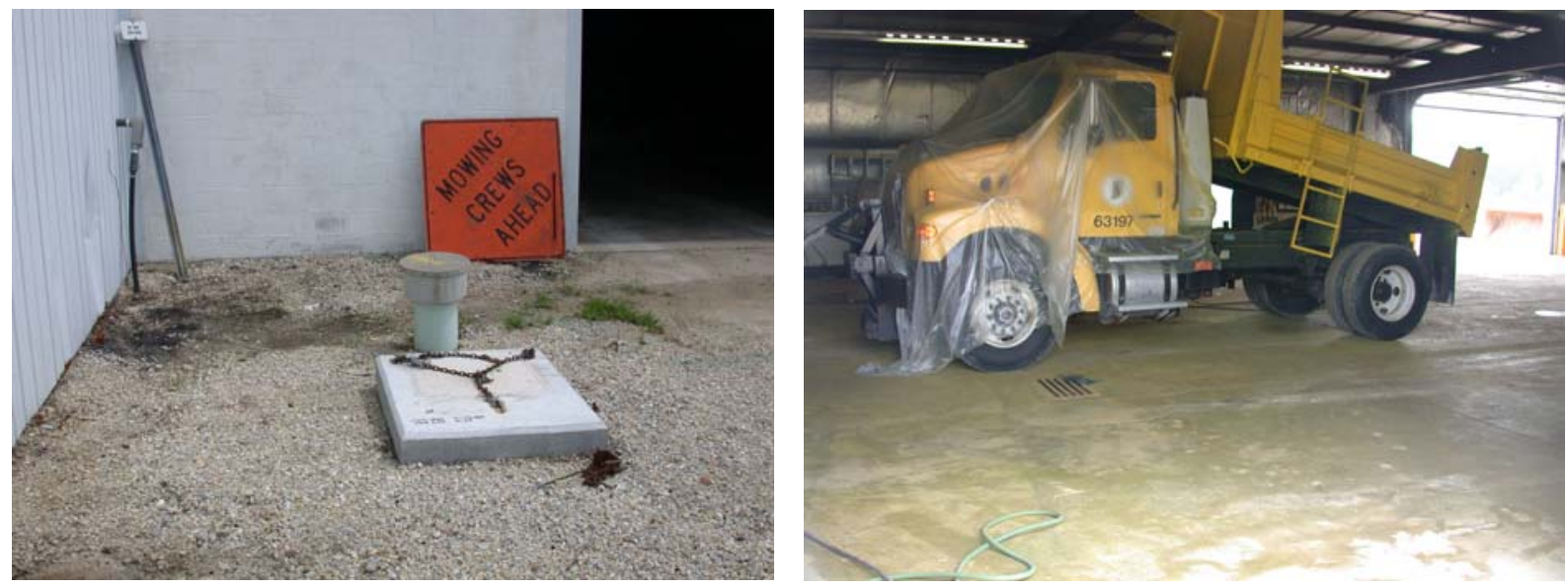

\section{* Salt Dome}

$>$ There was a substantial amount of salt on the active surface near the Salt Dome entrance. The entrance is not bermed.
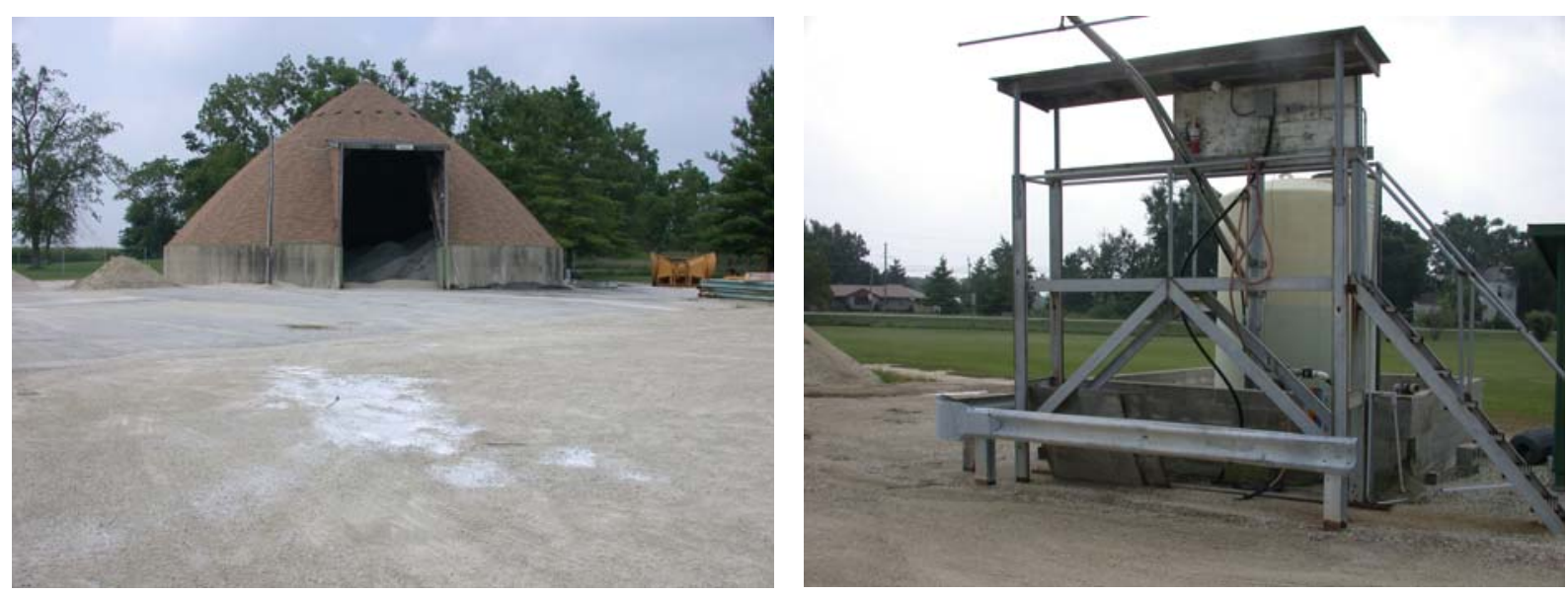
FACILITY SITE ASSESSMENT REPORTS

\section{LAPORTE DISTRICT}


Date_7/19/05

\section{INDOT Facility Stormwater and Washwater Effluent Drainage Assessment}

\section{Name of Facility __Crown Point Unit}

District/Subdistrict __LaPorte

\section{$\underline{\text { Surface Water }}$}

1. Does any area of the active surface collect storm water or facility-generated wash water (such as from washing trucks outdoors)? _

2. Is there any movement of surface water from one area to another on-site by ditch, drain tile or natural channel? _ Yes

3. Is there any movement of surface water off-site (e.g., beneath the perimeter fence) via sheet flow, ditch, pipe or channel to adjacent property? __ $\underline{\text { Yes }}$

4. Is the surface water discharged directly to (check all that apply) -

$\square$ drainage ditch or roadside ditch

$\square$ county-regulated drain

$\square \quad$ state highway drainage system

$\square$ a nearby creek, river or other water body

$\square \quad$ lagoon or holding pond

$\square$ settling basin, catch basin, or other constructed retention structure

$\square$ underground tank

$\square$ municipal storm sewer Owner

$\square$ municipal combined storm/sanitary sewer Owner

$\square$ POTW Owner:

$\square$ Other

5. If surface water is discharged, other than to a municipal storm, sanitary or combined sewer, does it ultimately reach "waters of the state” (e.g., farm ditch, creek, stream, river, lake or pond)? If yes, name of that water body. _ Y Yes, the name of the creek or _ditch could not be found but it empties into Niles Ditch approx. 2 miles from the site

6. What is the estimated distance of this water body from the facility? _ The facility surface water is discharged to a roadside ditch that drains into the unknown creek approx.

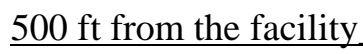


Shop Floor Drain \& Wash Bay Effluent

1. Are there drains in shop floors and wash bays that remove liquids and wash water effluent from the building(s)? _

2. Does the effluent flow to -

$\square$ aboveground oil/water separator

$\square$ aboveground tank

$\square$ below ground oil/water separator

$\square$ below ground tank

$\square$ settling basin, catch basin, lagoon, holding pond or other constructed retention structure

$\checkmark$ none of the above

3. If the effluent is captured by the devices in 2., above, is it contained until pumped and hauled to a POTW or until it evaporates, or does it overflow to a drainage system?

4. If the effluent overflows to a drainage system, is the system above or below ground?

5. If the effluent overflows to a drainage system, does it mix with storm water?

6. If the effluent does mix with storm water, see "Surface Water" section (preceding page, \#4 and \#5) for discharge.

7. If the effluent doesn't mix with storm water, is it discharged to -

$\square \quad$ subsurface soils

$\square \quad$ on-site septic system

$\square$ drainage ditch or roadside ditch

$\square$ a nearby creek, river or other water body

$\square \quad$ lagoon or holding pond

$\square$ municipal storm sewer Owner

$\square$ municipal combined storm/sanitary sewer Owner

$\square$ municipal POTW Owner

(Rev 2/7/05) 
8. If shop floor drain and wash bay effluent is discharged, other than to a municipal storm, sanitary or combined sewer, does it ultimately reach "waters of the state?" If yes, name of that water body: __ Yes, name is unknown but it drains into Niles Ditch

Activity Areas (check those that apply and describe (1) whether they are bermed to prevent storm water runoff or (2) if there are drains and their locations in the activity areas)

$\square$ salt storage (pads or domes) __ No berms or drains

$\square$ salt/sand mixing _ _ No berms or drains

$\square$ salt bed loading/wetting _ _ No berms or drains

$\square$ salt bed washout _ Performed inside and outside of Unit Building with no berm. The Unit Building is equipped with a floor drain that empties into the roadside ditch

$\square$ salt bed storage _ No berms or drains

$\square$ vehicle and equipment washing (inside) _ _ No berm, floor drain is present

$\square \quad$ vehicle and equipment washing (outside) _ _ No berm or drains

$\square$ asphalt equipment clean-out __ No berm or drains

$\square$ herbicide mixing and tank rinsing

$\square \quad$ traffic paint mixing and transfer

$\square$ bulk tank off-loading and storage

$\square$ waste piles (e.g., ROW trash, street sweeping debris) __ No berm or drains

$\square$ truck/equipment parking __ No berm or drain

$\square \quad$ truck/equipment fueling

$\square$ materials storage (210 lot, fencing, etc.) __ No berm or drains

$\square$ aggregate storage _

$\square$ hot/cold patch storage __ No berm or drains

$\square$ storage of “scalp” and dirt from R/W maintenance 
Date_ 5/10/05

\section{INDOT Facility Stormwater and Washwater Effluent Drainage Assessment}

Name of Facility __Chesterton Unit

District/Subdistrict___LaPorte District

\section{$\underline{\text { Surface Water }}$}

1. Does any area of the active surface collect storm water or facility-generated wash water (such as from washing trucks outdoors)? _

2. Is there any movement of surface water from one area to another on-site by ditch, drain tile or natural channel? _ Yes

3. Is there any movement of surface water off-site (e.g., beneath the perimeter fence) via sheet flow, ditch, pipe or channel to adjacent property? __ $\underline{\text { Yes }}$

4. Is the surface water discharged directly to (check all that apply) -

$\square$ drainage ditch or roadside ditch

$\square$ county-regulated drain

$\square \quad$ state highway drainage system

$\square$ a nearby creek, river or other water body

$\square$ lagoon or holding pond

$\square \quad$ settling basin, catch basin, or other constructed retention structure

$\square$ underground tank

$\square$ municipal storm sewer Owner

$\square$ municipal combined storm/sanitary sewer Owner

$\square$ POTW Owner:

$\square$ Other

5. If surface water is discharged, other than to a municipal storm, sanitary or combined sewer, does it ultimately reach "waters of the state” (e.g., farm ditch, creek, stream, river, lake or pond)? If yes, name of that water body. _ _ Yes, Munson Ditch, which_ _eventually drains into Dunes Creek

6. What is the estimated distance of this water body from the facility? _ approx. 30 yards to Munson Ditch, which flows 1.5 miles to Dunes Creek. 


\section{Shop Floor Drain \& Wash Bay Effluent}

1. Are there drains in shop floors and wash bays that remove liquids and wash water effluent from the building(s)? _ Y Yes

2. Does the effluent flow to -

$\square$ aboveground oil/water separator

$\square$ aboveground tank

$\square$ below ground oil/water separator

$\square$ below ground tank

$\square$ settling basin, catch basin, lagoon, holding pond or other constructed retention structure

$\square$ none of the above

3. If the effluent is captured by the devices in 2., above, is it contained until pumped and hauled to a POTW or until it evaporates, or does it overflow to a drainage system?__ It overflows to a drainage system

4. If the effluent overflows to a drainage system, is the system above or below ground? _ _ Above ground ditch

5. If the effluent overflows to a drainage system, does it mix with storm water?__ Yes

6. If the effluent does mix with storm water, see "Surface Water" section (preceding page, \#4 and \#5) for discharge.

7. If the effluent doesn't mix with storm water, is it discharged to -

$\square$ subsurface soils

$\square \quad$ on-site septic system

$\square$ drainage ditch or roadside ditch

$\square$ a nearby creek, river or other water body

$\square \quad$ lagoon or holding pond

$\square$ municipal storm sewer Owner

$\square$ municipal combined storm/sanitary sewer Owner

$\square \quad$ municipal POTW Owner 
8. If shop floor drain and wash bay effluent is discharged, other than to a municipal storm, sanitary or combined sewer, does it ultimately reach "waters of the state?" If yes, name of that water body: __ Yes, Munson Ditch

Activity Areas (check those that apply and describe (1) whether they are bermed to prevent storm water runoff or (2) if there are drains and their locations in the activity areas)

$\square$ salt storage (pads or domes) __ All storm water from the Salt Dome area enters a _detention pond by way of sheet flow

$\square$ salt/sand mixing__ Also enters the detention pond

$\square$ salt bed loading/wetting__Also enters detention pond

$\square \quad$ salt bed washout

$\square$ salt bed storage The storm water from this area enters a catch basin that is piped to the detention pond

$\square \quad$ vehicle and equipment washing (inside)

$\square \quad$ vehicle and equipment washing (outside)

$\square$ asphalt equipment clean-out __performed on job site

$\square \quad$ herbicide mixing and tank rinsing

$\square \quad$ traffic paint mixing and transfer

$\square$ bulk tank off-loading and storage

$\square \quad$ waste piles (e.g., ROW trash, street sweeping debris) _ _ No berm or drain

$\square$ truck/equipment parking_ The storm water from this area enters a catch basin that _is piped to the detention pond

$\square$ truck/equipment fueling

$\square$ materials storage (210 lot, fencing, etc.) __ No berm or drain

$\square$ aggregate storage__ No berm or drain

$\square$ hot/cold patch storage _ The storm water from this area enters the detention pond as _sheet flow

$\square$ storage of “scalp” and dirt from R/W maintenance 
Date_3/30/05

INDOT Facility Stormwater and Washwater Effluent Drainage Assessment

Name of Facility __Flora Unit

District/Subdistrict __Laporte

\section{$\underline{\text { Surface Water }}$}

1. Does any area of the active surface collect storm water or facility-generated wash water (such as from washing trucks outdoors)? _

2. Is there any movement of surface water from one area to another on-site by ditch, drain tile or natural channel? _ Yes, by drain pipe

3. Is there any movement of surface water off-site (e.g., beneath the perimeter fence) via sheet flow, ditch, pipe or channel to adjacent property? __ $\underline{\text { Yes }}$

4. Is the surface water discharged directly to (check all that apply) -

$\square$ drainage ditch or roadside ditch

$\square$ county-regulated drain

$\square$ state highway drainage system

$\square$ a nearby creek, river or other water body

$\square \quad$ lagoon or holding pond

$\square$ settling basin, catch basin, or other constructed retention structure

$\square$ underground tank

$\square$ municipal storm sewer Owner

$\square$ municipal combined storm/sanitary sewer Owner

$\square$ POTW Owner:

$\square$ Other

5. If surface water is discharged, other than to a municipal storm, sanitary or combined sewer, does it ultimately reach "waters of the state” (e.g., farm ditch, creek, stream, river, lake or pond)? If yes, name of that water body. _ Y Yes, Ayres Ditch

6. What is the estimated distance of this water body from the facility?

Ayres Ditch borders the NW property line

(Rev 2/7/05) 


\section{Shop Floor Drain \& Wash Bay Effluent}

1. Are there drains in shop floors and wash bays that remove liquids and wash water effluent from the building(s)? __ Yes

2. Does the effluent flow to -

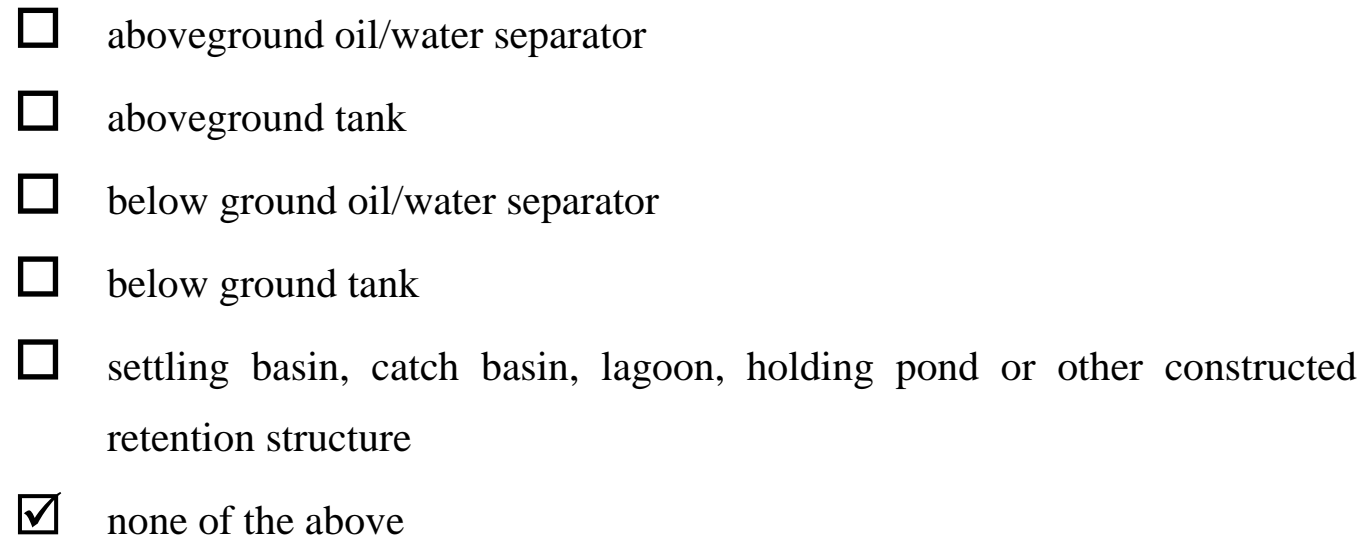

3. If the effluent is captured by the devices in 2., above, is it contained until pumped and hauled to a POTW or until it evaporates, or does it overflow to a drainage system?

4. If the effluent overflows to a drainage system, is the system above or below ground? __Below ground

5. If the effluent overflows to a drainage system, does it mix with storm water?_No

6. If the effluent does mix with storm water, see "Surface Water" section (preceding page, \#4 and \#5) for discharge.

7. If the effluent doesn't mix with storm water, is it discharged to -

$\square \quad$ subsurface soils

$\square$ on-site septic system

$\square$ drainage ditch or roadside ditch

$\square$ a nearby creek, river or other water body

$\square \quad$ lagoon or holding pond

$\square$ municipal storm sewer Owner

$\square$ municipal combined storm/sanitary sewer Owner

$\square$ municipal POTW Owner 
8. If shop floor drain and wash bay effluent is discharged, other than to a municipal storm, sanitary or combined sewer, does it ultimately reach "waters of the state?" If yes, name of that water body: _Y Yes, Ayres Ditch

Activity Areas (check those that apply and describe (1) whether they are bermed to prevent storm water runoff or (2) if there are drains and their locations in the activity areas)

$\square$ salt storage (pads or domes) _ _ No berm, there is a drain that catches stormwater from -

$\square$ salt/sand mixing

$\square$ salt bed loading/wetting_ There is a berm on one side of the storage tanks but it is not proper secondary containment. A drain catches the stormwater and leaks from this area

$\square$ salt bed washout

$\square$ salt bed storage _No berm, there is a drain in the area

$\square \quad$ vehicle and equipment washing (inside)

$\square \quad$ vehicle and equipment washing (outside)

$\square$ asphalt equipment clean-out _ Performed on the job site

$\square$ herbicide mixing and tank rinsing__ Performed inside Unit Building

$\square \quad$ traffic paint mixing and transfer

$\square$ bulk tank off-loading and storage

$\square \quad$ waste piles (e.g., ROW trash, street sweeping debris) __ No berm or drain

$\square$ truck/equipment parking__No berm, there is a drain

$\square \quad$ truck/equipment fueling

$\square$ materials storage (210 lot, fencing, etc.) __ No berm or drain

$\square$ aggregate storage__ No berm or drain

$\square$ hot/cold patch storage __ No berm, a drain catches some stormwater from this area

$\square$ storage of “scalp” and dirt from R/W maintenance_№ berm or drain 
Date_ $7 / 20 / 2005$

\title{
INDOT Facility Stormwater and Washwater Effluent Drainage Assessment
}

\author{
Name of Facility __Michigan City \\ District/Subdistrict __LaPorte
}

\section{$\underline{\text { Surface Water }}$}

1. Does any area of the active surface collect storm water or facility-generated wash water (such as from washing trucks outdoors)? _ Yes

2. Is there any movement of surface water from one area to another on-site by ditch, drain tile or natural channel? __ Yes

3. Is there any movement of surface water off-site (e.g., beneath the perimeter fence) via sheet flow, ditch, pipe or channel to adjacent property? _

4. Is the surface water discharged directly to (check all that apply) -

$\square$ drainage ditch or roadside ditch

$\square$ county-regulated drain

$\square$ state highway drainage system

$\square$ a nearby creek, river or other water body

$\square$ lagoon or holding pond

$\square$ settling basin, catch basin, or other constructed retention structure

$\square$ underground tank

$\square$ municipal storm sewer Owner

$\square$ municipal combined storm/sanitary sewer Owner

$\square$ POTW Owner:

$\square$ Other

5. If surface water is discharged, other than to a municipal storm, sanitary or combined sewer, does it ultimately reach "waters of the state" (e.g., farm ditch, creek, stream, river, lake or pond)? If yes, name of that water body. _Y Yes, the surface water enters a drainage ditch approx. 75 feet south of the site. The name of the ditch is unknown.

6. What is the estimated distance of this water body from the facility? $\_75$ feet from the south property line 


\section{Shop Floor Drain \& Wash Bay Effluent}

1. Are there drains in shop floors and wash bays that remove liquids and wash water effluent from the building(s)? _ Y Yes

2. Does the effluent flow to -

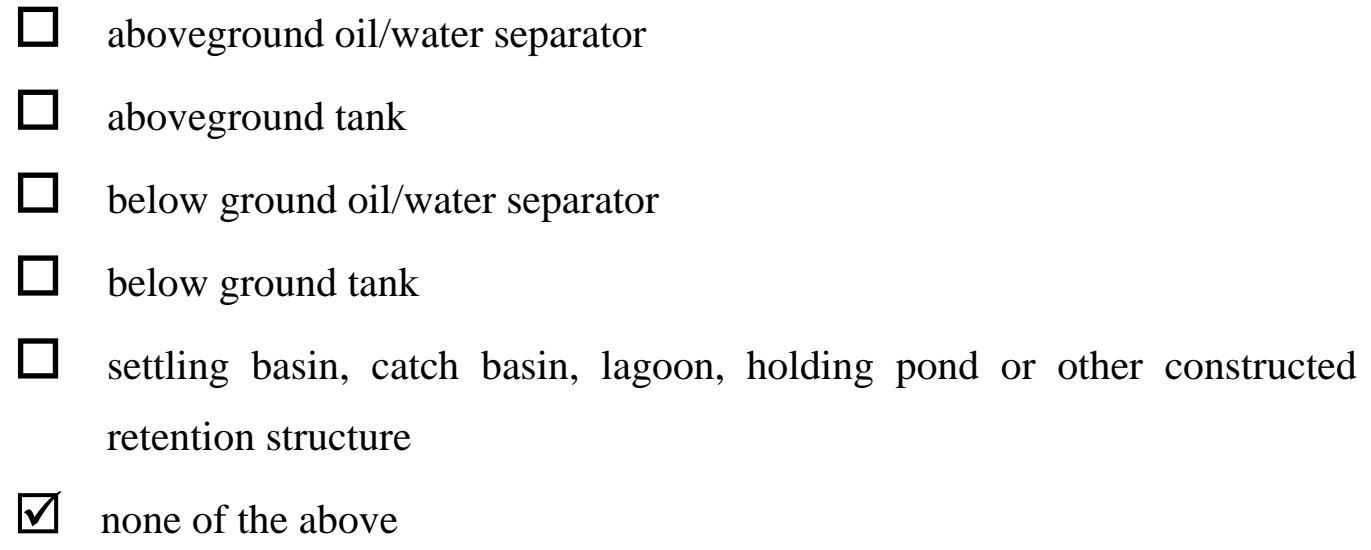

3. If the effluent is captured by the devices in 2., above, is it contained until pumped and hauled to a POTW or until it evaporates, or does it overflow to a drainage system?

4. If the effluent overflows to a drainage system, is the system above or below ground?

5. If the effluent overflows to a drainage system, does it mix with storm water?

6. If the effluent $\underline{\text { does }}$ mix with storm water, see "Surface Water" section (preceding page, \#4 and \#5) for discharge.

7. If the effluent doesn't mix with storm water, is it discharged to -

$\square \quad$ subsurface soils

$\square$ on-site septic system

$\square$ drainage ditch or roadside ditch

$\square$ a nearby creek, river or other water body

$\square \quad$ lagoon or holding pond

$\square \quad$ municipal storm sewer Owner

$\square$ municipal combined storm/sanitary sewer Owner

$\square$ municipal POTW Owner 
8. If shop floor drain and washbay effluent is discharged, other than to a municipal storm, sanitary or combined sewer, does it ultimately reach "waters of the state?" If yes, name of that water body: ___ Yes, name of drainage ditch is unknown

Activity Areas (check those that apply and describe (1) whether they are bermed to prevent storm water runoff or (2) if there are drains and their locations in the activity areas)

$\square$ salt storage (pads or domes) _ There are no drains are berms in the area

$\square$ salt/sand mixing __ No drains or berms

$\square$ salt bed loading/wetting __ No berms or drains

$\square$ salt bed washout __ Some washing is performed outside with no drains or berms.

$\square$ salt bed storage __ No berms or drains

$\square \quad$ vehicle and equipment washing (inside)

$\square \quad$ vehicle and equipment washing (outside) __ No berms or drains

$\square$ asphalt equipment clean-out

$\square \quad$ herbicide mixing and tank rinsing

$\square \quad$ traffic paint mixing and transfer

$\square$ bulk tank off-loading and storage

$\square$ waste piles (e.g., ROW trash, street sweeping debris) __ No berms or drains

$\square$ truck/equipment parking __ No berms or drains

$\square \quad$ truck/equipment fueling

$\square$ materials storage (210 lot, fencing, etc.) __ No berms or drains

$\square$ aggregate storage __ No berms or drains

$\square$ hot/cold patch storage _ Stored outside with no berm, cover, or drain

$\square$ storage of “scalp” and dirt from R/W maintenance __ Piles stored with no berm or drain 
Date_7/11/05

\section{INDOT Facility Stormwater and Washwater Effluent Drainage Assessment}

Name of Facility __Logansport Unit

District/Subdistrict __LaPorte

\section{$\underline{\text { Surface Water }}$}

1. Does any area of the active surface collect storm water or facility-generated wash water (such as from washing trucks outdoors)? _

2. Is there any movement of surface water from one area to another on-site by ditch, drain tile or natural channel? ___ Yes

3. Is there any movement of surface water off-site (e.g., beneath the perimeter fence) via sheet flow, ditch, pipe or channel to adjacent property? __ $\underline{\text { Yes }}$

4. Is the surface water discharged directly to (check all that apply) -

$\square$ drainage ditch or roadside ditch

$\square$ county-regulated drain

$\square$ state highway drainage system

$\square$ a nearby creek, river or other water body

$\square \quad$ lagoon or holding pond

$\square$ settling basin, catch basin, or other constructed retention structure

$\square$ underground tank

$\square$ municipal storm sewer Owner

$\square$ municipal combined storm/sanitary sewer Owner

$\square$ POTW Owner:

$\square$ Other

5. If surface water is discharged, other than to a municipal storm, sanitary or combined sewer, does it ultimately reach "waters of the state” (e.g., farm ditch, creek, stream, river, lake or pond)? If yes, name of that water body. _ _ Yes, the surface water enters _a small creek with an Unknown Name, which flows approx. 1 mile into the Wabash River

6. What is the estimated distance of this water body from the facility? 20 feet from -the South West corner of the property 


\section{$\underline{\text { Shop Floor Drain \& Wash Bay Effluent }}$}

1. Are there drains in shop floors and wash bays that remove liquids and wash water effluent from the building(s)? __ Yes

2. Does the effluent flow to -

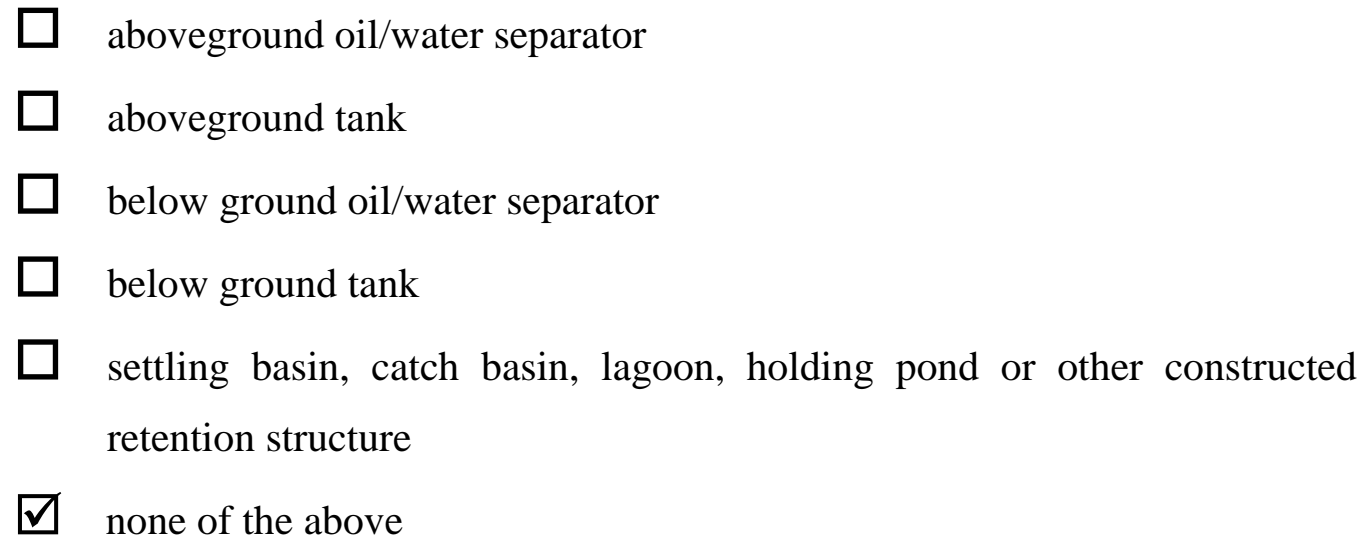

3. If the effluent is captured by the devices in 2., above, is it contained until pumped and hauled to a POTW or until it evaporates, or does it overflow to a drainage system?

4. If the effluent overflows to a drainage system, is the system above or below ground?

5. If the effluent overflows to a drainage system, does it mix with storm water?_No

6. If the effluent does mix with storm water, see "Surface Water" section (preceding page, \#4 and \#5) for discharge.

7. If the effluent doesn't mix with storm water, is it discharged to -

$\square \quad$ subsurface soils

$\square$ on-site septic system

$\square$ drainage ditch or roadside ditch

$\square$ a nearby creek, river or other water body

$\square \quad$ lagoon or holding pond

$\square$ municipal storm sewer Owner

$\square$ municipal combined storm/sanitary sewer Owner

$\square$ municipal POTW Owner 
8. If shop floor drain and wash bay effluent is discharged, other than to a municipal storm, sanitary or combined sewer, does it ultimately reach "waters of the state?" If yes, name of that water body: __ Yes, Wabash river approx. 1 mile from the site

Activity Areas (check those that apply and describe (1) whether they are bermed to prevent storm water runoff or (2) if there are drains and their locations in the activity areas)

$\square$ salt storage (pads or domes)_Bermed on East end, No berm on West end

$\square$ salt/sand mixing _Berm on NE corner

$\square$ salt bed loading/wetting _Stormwater from the area flows into the NE corner, which is bermed

$\square$ salt bed washout

$\square$ salt bed storage _No berm or drain

$\square \quad$ vehicle and equipment washing (inside)

$\square \quad$ vehicle and equipment washing (outside)

$\square$ asphalt equipment clean-out _ No berm

$\square$ herbicide mixing and tank rinsing

$\square \quad$ traffic paint mixing and transfer

$\square$ bulk tank off-loading and storage

$\square$ waste piles (e.g., ROW trash, street sweeping debris)__Dumpsters

$\square$ truck/equipment parking__No berm or drain

$\square \quad$ truck/equipment fueling

$\square$ materials storage (210 lot, fencing, etc.) __Most is stored in a covered building, _ Some is stored with no cover

$\square$ aggregate storage _ No berm or drain

$\square$ hot/cold patch storage _ Stored inside a covered building

$\square$ storage of “scalp” and dirt from R/W maintenance 
Date_

\section{INDOT Facility Stormwater and Washwater Effluent Drainage Assessment}

Name of Facility __Mishawaka Unit
District/Subdistrict__Laporte___

\section{Surface Water}




\section{Shop Floor Drain \& Wash Bay Effluent}

1. Are there drains in shop floors and wash bays that remove liquids and wash water effluent from the building(s)? _ Y Yes

2. Does the effluent flow to -

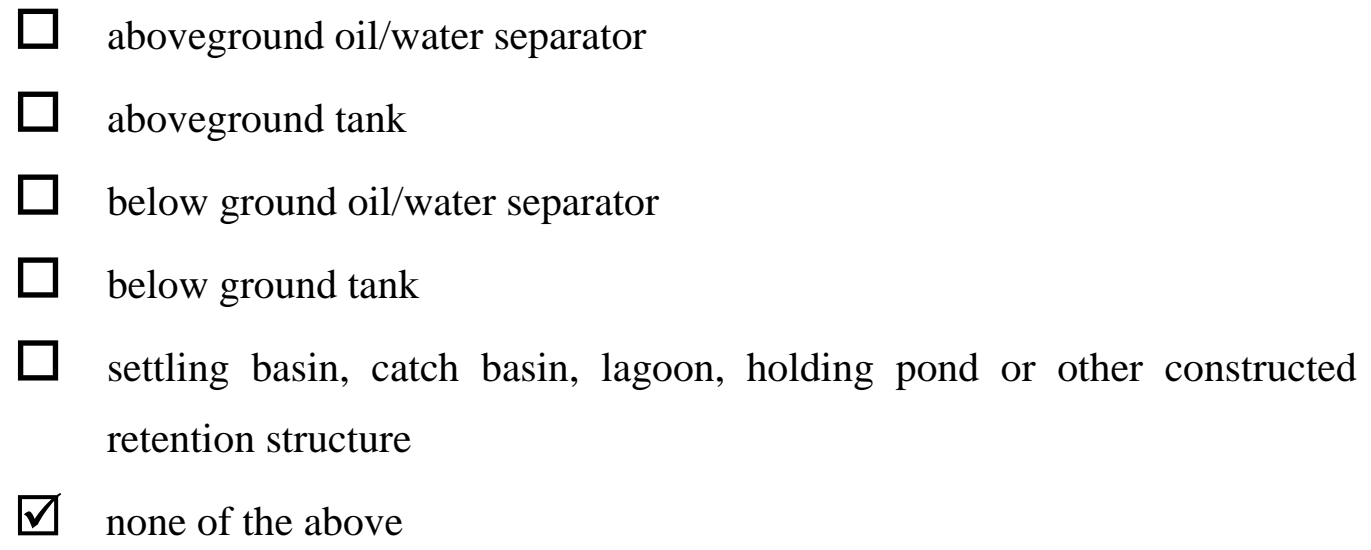

3. If the effluent is captured by the devices in 2., above, is it contained until pumped and hauled to a POTW or until it evaporates, or does it overflow to a drainage system?

4. If the effluent overflows to a drainage system, is the system above or below ground?

5. If the effluent overflows to a drainage system, does it mix with storm water?

6. If the effluent $\underline{\text { does }}$ mix with storm water, see "Surface Water" section (preceding page, \#4 and \#5) for discharge.

7. If the effluent doesn't mix with storm water, is it discharged to -

$\square \quad$ subsurface soils

$\square \quad$ on-site septic system

$\square$ drainage ditch or roadside ditch

$\square$ a nearby creek, river or other water body

$\square$ lagoon or holding pond

$\square \quad$ municipal storm sewer Owner

$\square$ municipal combined storm/sanitary sewer Owner

$\square$ municipal POTW Owner 
8. If shop floor drain and washbay effluent is discharged, other than to a municipal storm, sanitary or combined sewer, does it ultimately reach "waters of the state?" If yes, name of that water body: __ No

Activity Areas (check those that apply and describe (1) whether they are bermed to prevent storm water runoff or (2) if there are drains and their locations in the activity areas)

$\square$ salt storage (pads or domes) _ There was a sand berm at the entrance of the _ Dome but no drains in the area

$\square$ salt/sand mixing __ No berm or drains in the area

$\square$ salt bed loading/wetting _ _ No berms or drains in the area

$\square$ salt bed washout _ _ Performed inside a building with floor drains

$\square$ salt bed storage _

$\square \quad$ vehicle and equipment washing (inside) __ Floor drains inside the building

$\square$ vehicle and equipment washing (outside)

$\square$ asphalt equipment clean-out _ No berms or drains

$\square \quad$ herbicide mixing and tank rinsing

$\square \quad$ traffic paint mixing and transfer

$\square \quad$ bulk tank off-loading and storage

$\square$ waste piles (e.g., ROW trash, street sweeping debris) __ stored inside dumpsters

$\square$ truck/equipment parking __ No berm or drain

$\square \quad$ truck/equipment fueling

$\square$ materials storage (210 lot, fencing, etc.) __ No berms or drains

$\square$ aggregate storage _

$\checkmark$ hot/cold patch storage __ No berms or drains

$\square$ storage of “scalp” and dirt from R/W maintenance 
Date_ $7 / 20 / 2005$

\section{INDOT Facility Stormwater and Washwater Effluent Drainage Assessment}

Name of Facility __ South Bend
District/Subdistrict ___ LaPorte__

\section{$\underline{\text { Surface Water }}$}

1. Does any area of the active surface collect storm water or facility-generated wash water (such as from washing trucks outdoors)? Y Yes

2. Is there any movement of surface water from one area to another on-site by ditch, drain tile or natural channel? ___ Yes

3. Is there any movement of surface water off-site (e.g., beneath the perimeter fence) via sheet flow, ditch, pipe or channel to adjacent property? __ №

4. Is the surface water discharged directly to (check all that apply) -

$\square$ drainage ditch or roadside ditch

$\square$ county-regulated drain

$\square \quad$ state highway drainage system

$\square$ a nearby creek, river or other water body

$\square$ lagoon or holding pond (A low wooded area on-site)

$\square$ settling basin, catch basin, or other constructed retention structure

$\square$ underground tank

$\square$ municipal storm sewer Owner

$\square$ municipal combined storm/sanitary sewer Owner

$\square$ POTW Owner:

$\square$ Other

5. If surface water is discharged, other than to a municipal storm, sanitary or combined sewer, does it ultimately reach "waters of the state” (e.g., farm ditch, creek, stream, river, lake or pond)? If yes, name of that water body. No

6. What is the estimated distance of this water body from the facility? 


\section{Shop Floor Drain \& Wash Bay Effluent}

1. Are there drains in shop floors and wash bays that remove liquids and wash water effluent from the building(s)? _ Y Yes

2. Does the effluent flow to -

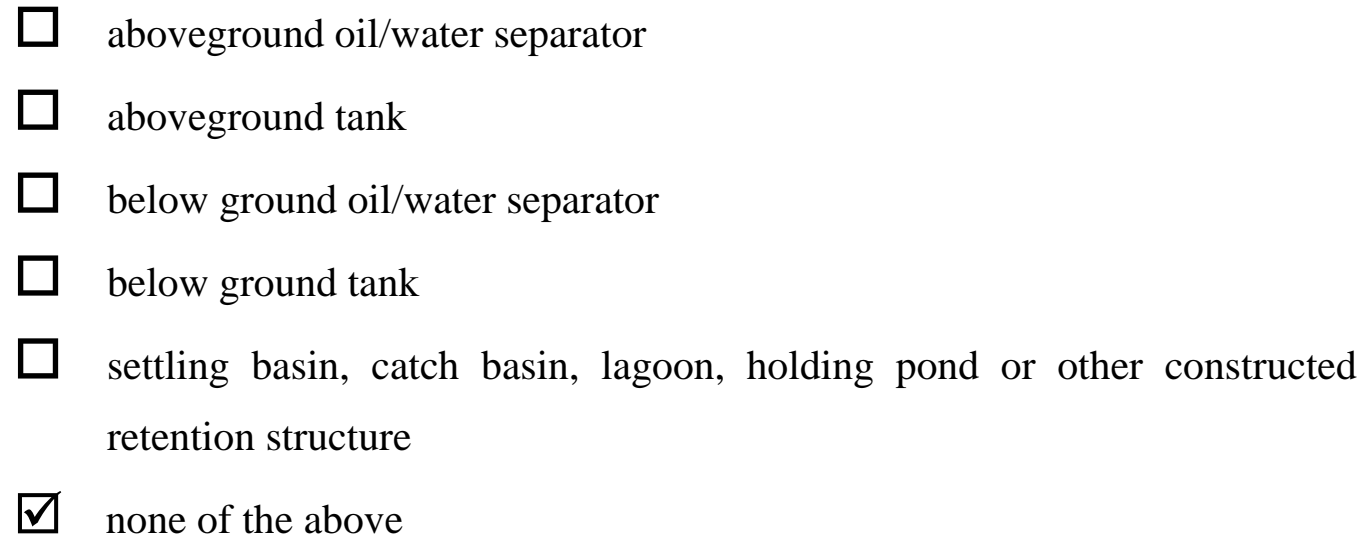

3. If the effluent is captured by the devices in 2., above, is it contained until pumped and hauled to a POTW or until it evaporates, or does it overflow to a drainage system?

4. If the effluent overflows to a drainage system, is the system above or below ground?

5. If the effluent overflows to a drainage system, does it mix with storm water?

6. If the effluent $\underline{\text { does }}$ mix with storm water, see "Surface Water" section (preceding page, \#4 and \#5) for discharge.

7. If the effluent doesn't mix with storm water, is it discharged to -

$\square \quad$ subsurface soils

$\square \quad$ on-site septic system

$\square$ drainage ditch or roadside ditch

$\square$ a nearby creek, river or other water body

$\square \quad$ lagoon or holding pond

$\square \quad$ municipal storm sewer Owner

$\square$ municipal combined storm/sanitary sewer Owner

$\square$ municipal POTW Owner _ South Bend 
8. If shop floor drain and washbay effluent is discharged, other than to a municipal storm, sanitary or combined sewer, does it ultimately reach "waters of the state?" If yes, name of that water body:

Activity Areas (check those that apply and describe (1) whether they are bermed to prevent storm water runoff or (2) if there are drains and their locations in the activity areas)

$\square \quad$ salt storage (pads or domes)__No berm or drain

$\square$ salt/sand mixing __ No berm or drain

$\square$ salt bed loading/wetting _ There is a berm around the brine tanks. There is _no berm or drain around the loading area

$\square \quad$ salt bed washout

$\square$ salt bed storage _ This facility is unmanned so there is no bed storage

$\square \quad$ vehicle and equipment washing (inside)

$\square \quad$ vehicle and equipment washing (outside)

$\square$ asphalt equipment clean-out

$\square \quad$ herbicide mixing and tank rinsing

$\square \quad$ traffic paint mixing and transfer

$\square$ bulk tank off-loading and storage

$\square$ waste piles (e.g., ROW trash, street sweeping debris) __ No berm or drain

$\square \quad$ truck/equipment parking

$\square$ truck/equipment fueling

$\square$ materials storage (210 lot, fencing, etc.)

$\square$ aggregate storage _ No berm or drains

$\square$ hot/cold patch storage __ No berm or drain

$\square$ storage of “scalp” and dirt from R/W maintenance 
Date_07/19/2005

\section{INDOT Facility Stormwater and Washwater Effluent Drainage Assessment}

Name of Facility __ New Gary Subdistrict and Miller Unit

District/Subdistrict __ Laporte

\section{$\underline{\text { Surface Water }}$}

1. Does any area of the active surface collect storm water or facility-generated wash water (such as from washing trucks outdoors)? _ Y Yes

2. Is there any movement of surface water from one area to another on-site by ditch, drain tile or natural channel? ___ Yes

3. Is there any movement of surface water off-site (e.g., beneath the perimeter fence) via sheet flow, ditch, pipe or channel to adjacent property? _

4. Is the surface water discharged directly to (check all that apply) -

$\square$ drainage ditch or roadside ditch

$\square$ county-regulated drain

$\square \quad$ state highway drainage system

$\square$ a nearby creek, river or other water body

$\square \quad$ lagoon or holding pond

$\square$ settling basin, catch basin, or other constructed retention structure

$\square$ underground tank

$\square$ municipal storm sewer Owner

$\square$ municipal combined storm/sanitary sewer Owner

$\square$ POTW Owner:

$\square$ Other

5. If surface water is discharged, other than to a municipal storm, sanitary or combined sewer, does it ultimately reach "waters of the state” (e.g., farm ditch, creek, stream, river, lake or pond)? If yes, name of that water body. ___ No, the stormwater enters a low wooded swampy area

6. What is the estimated distance of this water body from the facility? the swampy area is located approx. $100 \mathrm{ft}$ from the SW corner of the property 


\section{Shop Floor Drain \& Wash Bay Effluent}

1. Are there drains in shop floors and wash bays that remove liquids and wash water effluent from the building(s)? _

2. Does the effluent flow to -

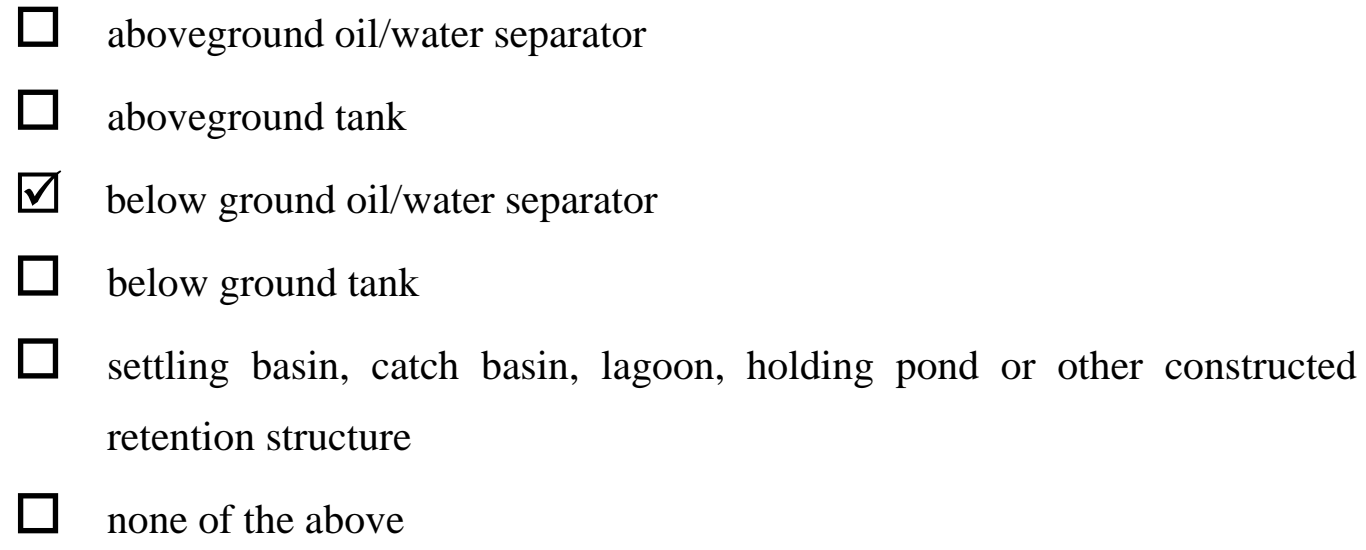

3. If the effluent is captured by the devices in 2., above, is it contained until pumped and hauled to a POTW or until it evaporates, or does it overflow to a drainage system? _ It overflows to a drainage system

4. If the effluent overflows to a drainage system, is the system above or below ground? _ Below ground sewer system

5. If the effluent overflows to a drainage system, does it mix with storm water?__No

6. If the effluent $\underline{\text { does }}$ mix with storm water, see "Surface Water" section (preceding page, \#4 and \#5) for discharge.

7. If the effluent doesn't mix with storm water, is it discharged to -

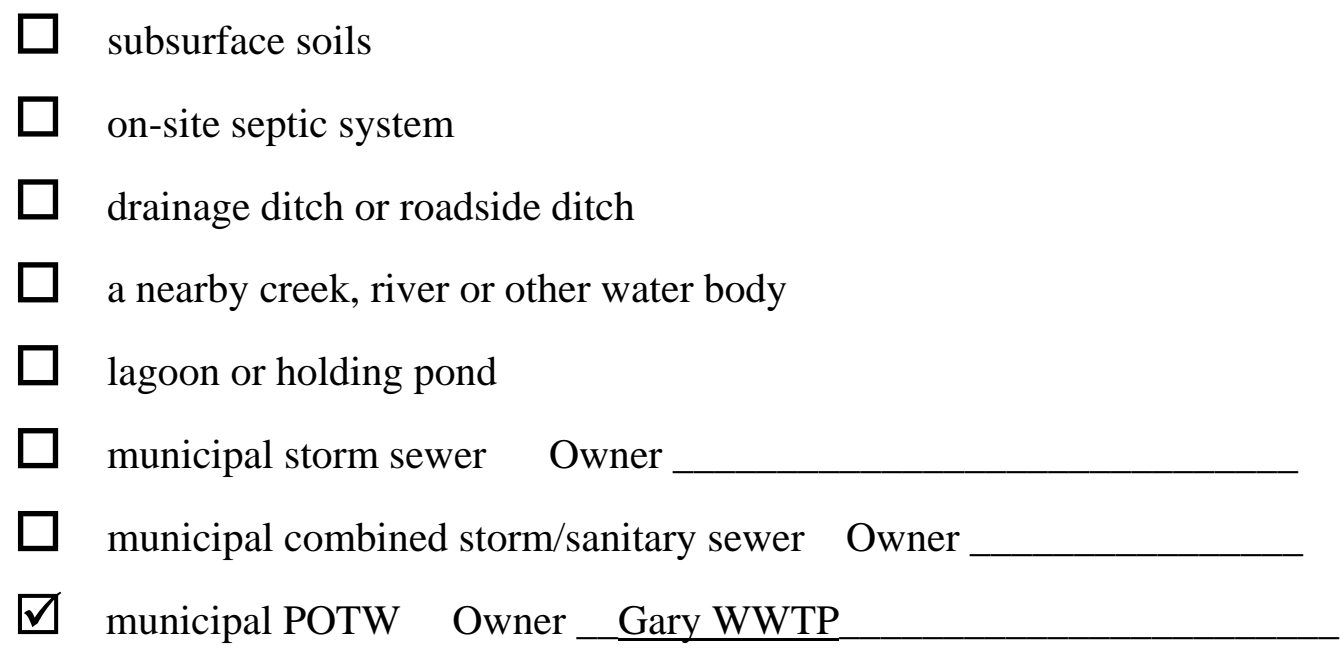


8. If shop floor drain and washbay effluent is discharged, other than to a municipal storm, sanitary or combined sewer, does it ultimately reach "waters of the state?" If yes, name of that water body: __ No

Activity Areas (check those that apply and describe (1) whether they are bermed to prevent storm water runoff or (2) if there are drains and their locations in the activity areas)

$\square$ salt storage (pads or domes) __ All activities are performed under roof and there _is no chance of stormwater contact

$\square$ salt/sand mixing _ _ Performed under roof with no chance of contact with _stormwater

$\square$ salt bed loading/wetting ___ Loading is performed under roof and wetting is _accomplished with trucks equipped with saddle tanks(wetting at the point of application)

$\square$ salt bed washout_Performed in a washbay. The washwater is reused for brine _production

$\square$ salt bed storage _

$\square$ vehicle and equipment washing (inside) __ Performed in washbay

$\square \quad$ vehicle and equipment washing (outside)

$\square$ asphalt equipment clean-out __ Performed on job site

$\square$ herbicide mixing and tank rinsing

$\square \quad$ traffic paint mixing and transfer

$\square$ bulk tank off-loading and storage

$\square$ waste piles (e.g., ROW trash, street sweeping debris) __ Stored in dumpsters

$\square$ truck/equipment parking __ Outside with no berm or drains

$\square \quad$ truck/equipment fueling

$\square$ materials storage (210 lot, fencing, etc.)

$\square$ aggregate storage __outside with no berm or drains

$\square$ hot/cold patch storage _outside with no cover, berm, or drain

$\square$ storage of "scalp” and dirt from R/W maintenance __ Outside with no berm or drain 
Date_5/20/2005

\section{INDOT Facility Stormwater and Washwater Effluent Drainage Assessment}

Name of Facility __Wanatah Unit
District/Subdistrict__LaPorte___

\section{Surface Water}

Name of Facility _ Wanatah Unit

1. Does any area of the active surface collect storm water or facility-generated wash water (such as from washing trucks outdoors)? _ _ Yes

2. Is there any movement of surface water from one area to another on-site by ditch, drain tile or natural channel? __ Yes

3. Is there any movement of surface water off-site (e.g., beneath the perimeter fence) via sheet flow, ditch, pipe or channel to adjacent property? __ A small amount

4. Is the surface water discharged directly to (check all that apply) -

$\square$ drainage ditch or roadside ditch

$\square$ county-regulated drain

$\square$ state highway drainage system

$\square$ a nearby creek, river or other water body

$\square \quad$ lagoon or holding pond

$\square$ settling basin, catch basin, or other constructed retention structure

$\square$ underground tank

$\square$ municipal storm sewer Owner

$\square$ municipal combined storm/sanitary sewer Owner__Wanatah_WWTP___

$\square$ POTW Owner:

$\square$ Other

5. If surface water is discharged, other than to a municipal storm, sanitary or combined sewer, does it ultimately reach "waters of the state" (e.g., farm ditch, creek, stream, river, lake or pond)? If yes, name of that water body. _No, if the detention ponds do _not overflow; otherwise Slocum Ditch.

6. What is the estimated distance of this water body from the facility? approx. 150 feet from the NE corner of the site 


\section{Shop Floor Drain \& Wash Bay Effluent}

1. Are there drains in shop floors and wash bays that remove liquids and wash water effluent from the building(s)? ___ Yes

2. Does the effluent flow to -

$\square \quad$ aboveground oil/water separator

$\square$ aboveground tank

$\square$ below ground oil/water separator

$\square$ below ground tank

$\square$ settling basin, catch basin, lagoon, holding pond or other constructed retention structure

$\square$ none of the above

3. If the effluent is captured by the devices in 2., above, is it contained until pumped and hauled to a POTW or until it evaporates, or does it overflow to a drainage system? _ Municipal Sewer System

4. If the effluent overflows to a drainage system, is the system above or below ground? __ Below ground

5. If the effluent overflows to a drainage system, does it mix with storm water?_Yes, stormwater from the parking area, salt bed racks, and Salt Dome area enter the sewer system

6. If the effluent does mix with storm water, see "Surface Water" section (preceding page, \#4 and \#5) for discharge.

7. If the effluent doesn't mix with storm water, is it discharged to -

$\square \quad$ subsurface soils

$\square$ on-site septic system

$\square$ drainage ditch or roadside ditch

$\square \quad$ a nearby creek, river or other water body

$\square \quad$ lagoon or holding pond

$\square$ municipal storm sewer Owner

$\square$ municipal combined storm/sanitary sewer Owner_Wanatah WWTP

municipal POTW Owner

(Rev 2/7/05) 
8. If shop floor drain and wash bay effluent is discharged, other than to a municipal storm, sanitary or combined sewer, does it ultimately reach "waters of the state?" If yes, name of that water body:

Activity Areas (check those that apply and describe (1) whether they are bermed to prevent storm water runoff or (2) if there are drains and their locations in the activity areas)

\begin{tabular}{|c|c|}
\hline$\square$ & $\begin{array}{l}\text { salt storage (pads or domes) _ } \text { The entrance of the dome is covered to prevent } \\
\text { _storm water contact }\end{array}$ \\
\hline$\nabla$ & $\begin{array}{l}\text { salt/sand mixing_The facility is equipped with a Load-out building on the front of the } \\
\text { _salt dome. All salt/sand mixing and loading is performed in this building }\end{array}$ \\
\hline$\nabla$ & $\begin{array}{l}\text { salt bed loading/wetting __Loading is performed in the Load-out building. There is } \\
\text { no bed spraying performed }\end{array}$ \\
\hline$\nabla$ & salt bed washout _ Performed in a washbay that is connected to the Sewer System \\
\hline$\nabla$ & salt bed storage __ Area is bermed and contains a drain to the sewer system \\
\hline$\nabla$ & vehicle and equipment washing (inside) __ Performed in the washbay \\
\hline & vehicle and equipment washing (outside) \\
\hline & asphalt equipment clean-out \\
\hline & herbicide mixing and tank rinsing \\
\hline & traffic paint mixing and transfer \\
\hline & bulk tank off-loading and storage \\
\hline$\sqrt{ }$ & $\begin{array}{l}\text { waste piles (e.g., ROW trash, street sweeping debris)__Stormwater from the area } \\
\text { _enters a large retention pond }\end{array}$ \\
\hline$\nabla$ & $\begin{array}{l}\text { truck/equipment parking Area contains catch basins that drain to the sewer system } \\
\text { - The area is also graveled to reduce runoff }\end{array}$ \\
\hline & truck/equipment fueling ___ \\
\hline$\nabla$ & $\begin{array}{l}\text { materials storage ( } 210 \text { lot, fencing, etc.) _ S Stormwater from the area enters a large } \\
\text { _retention pond }\end{array}$ \\
\hline$\nabla$ & aggregate storage __ Stormwater from the area enters a large retention pond \\
\hline$\nabla$ & $\begin{array}{l}\text { hot/cold patch storage __ Not bermed _ Stormwater from this area may flow onto } \\
\text { adjacent propery }\end{array}$ \\
\hline$\nabla$ & $\begin{array}{l}\text { storage of "scalp" and dirt from R/W maintenance _ } \underline{\text { Stormwater from this area }} \\
\text { enters a large retention pond }\end{array}$ \\
\hline
\end{tabular}


Date $1 / 28 / 2005$

INDOT Facility Stormwater and Washwater Effluent Drainage Assessment

Name of Facility _New Winamac Subdistrict and Unit District/Subdistrict_LaPorte

\section{$\underline{\text { Surface Water }}$}

1. Does any area of the active surface collect storm water or facility-generated wash water (such as from washing trucks outdoors)?_Yes

2. Is there any movement of surface water from one area to another on-site by ditch, drain tile or natural channel? Yes, by ditch and drain tile

3. Is there any movement of surface water off-site (e.g., beneath the perimeter fence) via sheet flow, ditch, pipe or channel to adjacent property? _ The entire site is surrounded by a ditch, which empties into Stone Dilts Ditch on the South property line.

4. Is the surface water discharged directly to (check all that apply) -

$\square$ drainage ditch or roadside ditch

$\square$ county-regulated drain

$\square$ state highway drainage system

$\square$ a nearby creek, river or other water body

$\square$ lagoon or holding pond

$\square$ settling basin, catch basin, or other constructed retention structure

$\square$ underground tank

$\square$ municipal storm sewer Owner_Wwinamc City

$\square$ municipal combined storm/sanitary sewer Owner

$\square$ POTW Owner:

$\square$ Other

5. If surface water is discharged, other than to a municipal storm, sanitary or combined sewer, does it ultimately reach "waters of the state" (e.g., farm ditch, creek, stream, river, lake or pond)? If yes, name of that water body. Yes, Stone Dilts Ditch, which_ drains into the Tippecanoe River approx. 1.5 miles from the site

6. What is the estimated distance of this water body from the facility? _Stone Dilts Ditch runs along the South property line 


\section{Shop Floor Drain \& Wash Bay Effluent}

1. Are there drains in shop floors and wash bays that remove liquids and wash water effluent from the building(s)? __Yes

2. Does the effluent flow to -

$\square$ aboveground oil/water separator

$\square$ aboveground tank

$\square$ below ground oil/water separator

$\square$ below ground tank

NOTE: There are 2 Oil/Water separators on the site: One in the Sub Building that is below ground and one in the Unit Building that is above ground.

$\square$ settling basin, catch basin, lagoon, holding pond or other constructed retention structure

$\square$ none of the above

3. If the effluent is captured by the devices in 2., above, is it contained until pumped and hauled to a POTW or until it evaporates, or does it overflow to a drainage system? Both separators are connected to a combined sewer system

4. If the effluent overflows to a drainage system, is the system above or below ground? Underground sewer line

5. If the effluent overflows to a drainage system, does it mix with storm water?_No

6. If the effluent does mix with storm water, see "Surface Water" section (preceding page, \#4 and \#5) for discharge.

7. If the effluent doesn't mix with storm water, is it discharged to -

$\square$ subsurface soils

$\square \quad$ on-site septic system

$\square$ drainage ditch or roadside ditch

$\square$ a nearby creek, river or other water body

$\square \quad$ lagoon or holding pond

$\square$ municipal storm sewer Owner

$\square$ municipal combined storm/sanitary sewer Owner_Winamac City

$\square \quad$ municipal POTW Owner 
8. If shop floor drain and wash bay effluent is discharged, other than to a municipal storm, sanitary or combined sewer, does it ultimately reach "waters of the state?" If yes, name of that water body: _No, Combined Sewer

Activity Areas (check those that apply and describe (1) whether they are bermed to prevent storm water runoff or (2) if there are drains and their locations in the activity areas)

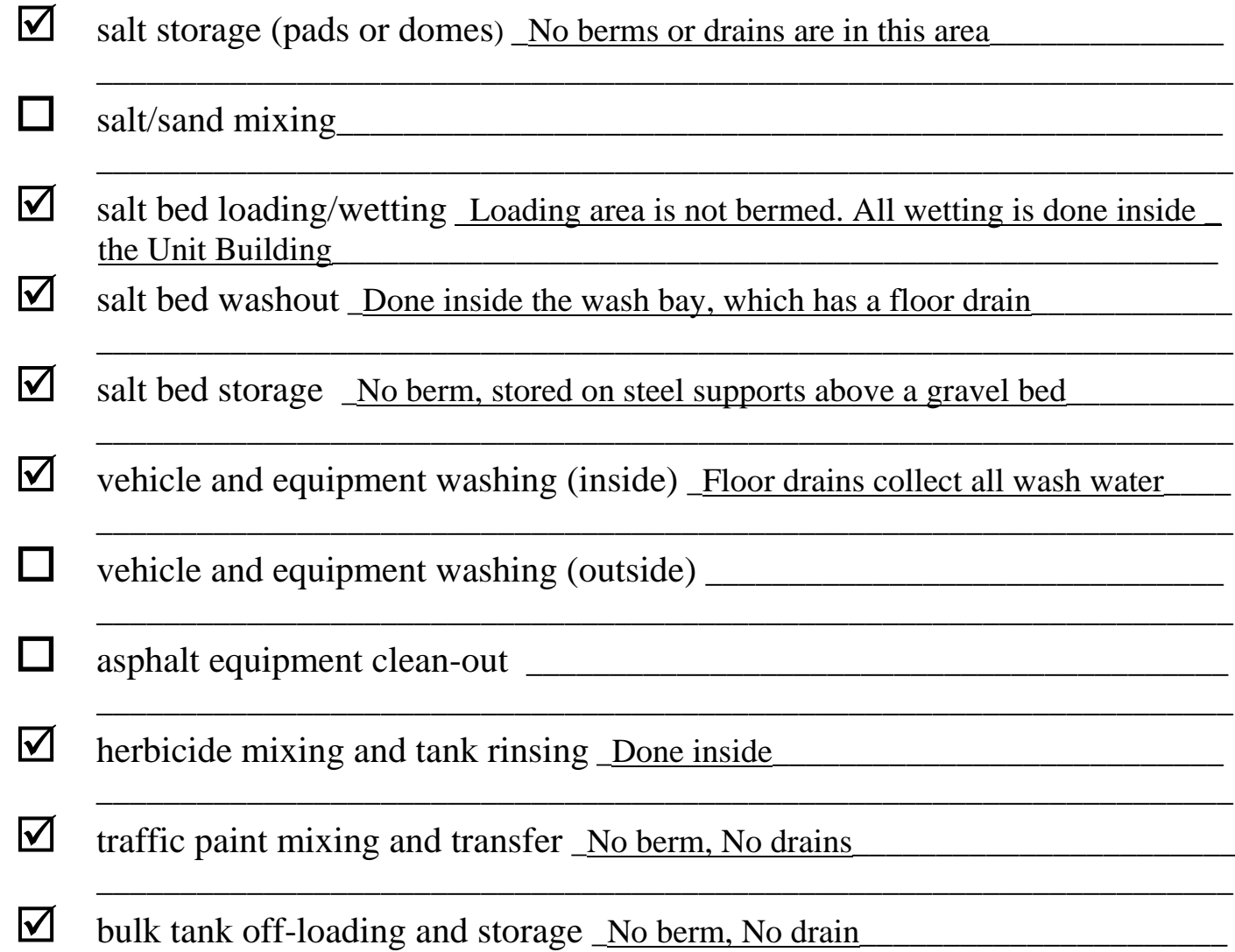

$\square$ waste piles (e.g., ROW trash, street sweeping debris) _ There is a large trash pile on the property with no berm

$\square$ truck/equipment parking _No berm, One parking area has a drain but the majority does not

$\square$ truck/equipment fueling

$\square$ materials storage (210 lot, fencing, etc.) _No berm, No drain

$\square$ aggregate storage _No berm, No drain

$\square$ hot/cold patch storage _ A small amount of cold patch was being stored next to the salt dome_with no cover, berm, or drain

$\square$ storage of “scalp” and dirt from R/W maintenance 


\section{INDOT Site Assessment Report \\ Observations and Comments}

Facility: Crown Point Unit

July 19, 2005

\section{Surface Area}

\section{General}

This facility is not connected to a Municipal Sewer System and is not equipped with an oil/water separator

All truck and salt bed washing is performed onsite. The wash water is collected in the Unit Building floor drain, which empties into the roadside ditch. The roadside ditch flows into a creek approx. $500 \mathrm{ft}$ from the site.

$>$ The area along the east property line is wet and tends to hold water. There is tall wetland type grass along this property line.
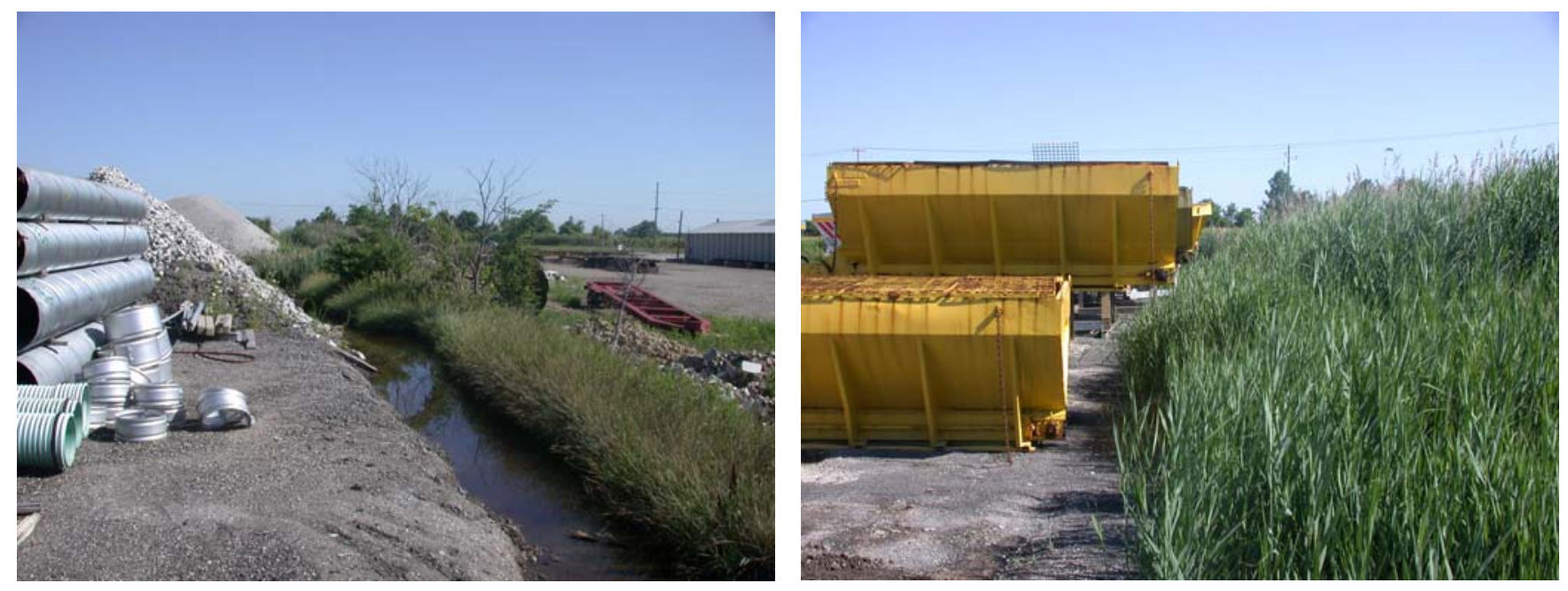

Northern Portion of Property

$>$ The Unit Building is located in the NW corner of the site. The liquids collected in the Unit Building floor drain flow north through an underground pipe that empties into a roadside ditch. 
On the south side of the Unit Building there is a small tool shed. This is used to store primarily asphalt tools.

South of the tool shed there is a truck parking area. This area is not bermed.

There are two large role-off dumpsters located in the center of the property. The snow plows, tar kettles, and tractors are also kept in this area. This area is not bermed and the stormwater from the area flows into the roadside ditch to the north.
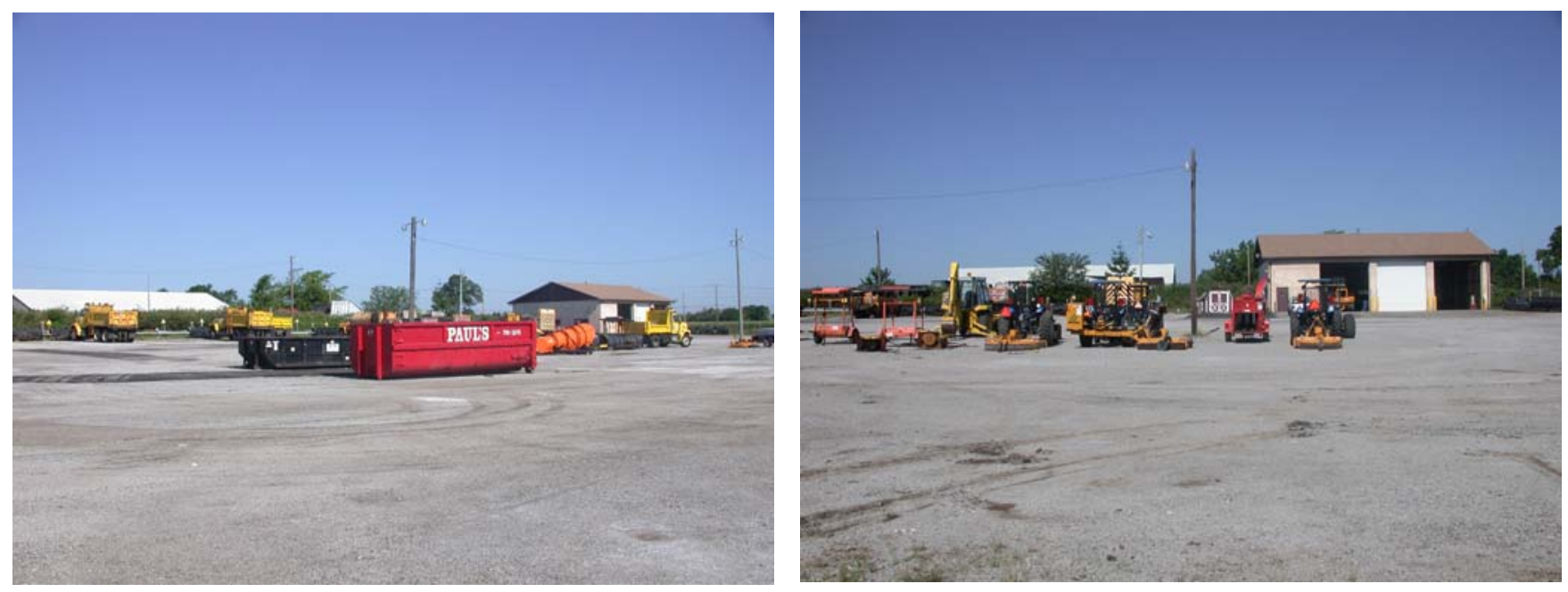

The Salt Bed Racks are located in the NE corner of the property, along the fence. The area is not bermed and the stormwater from the area enters the roadside ditch to the north.

$>$ South of the Salt Bed Racks, there are several large piles of aggregate and dirt. The area along the east property line holds water and is very wetland like. There is a neighboring business on the other side of the wet area.
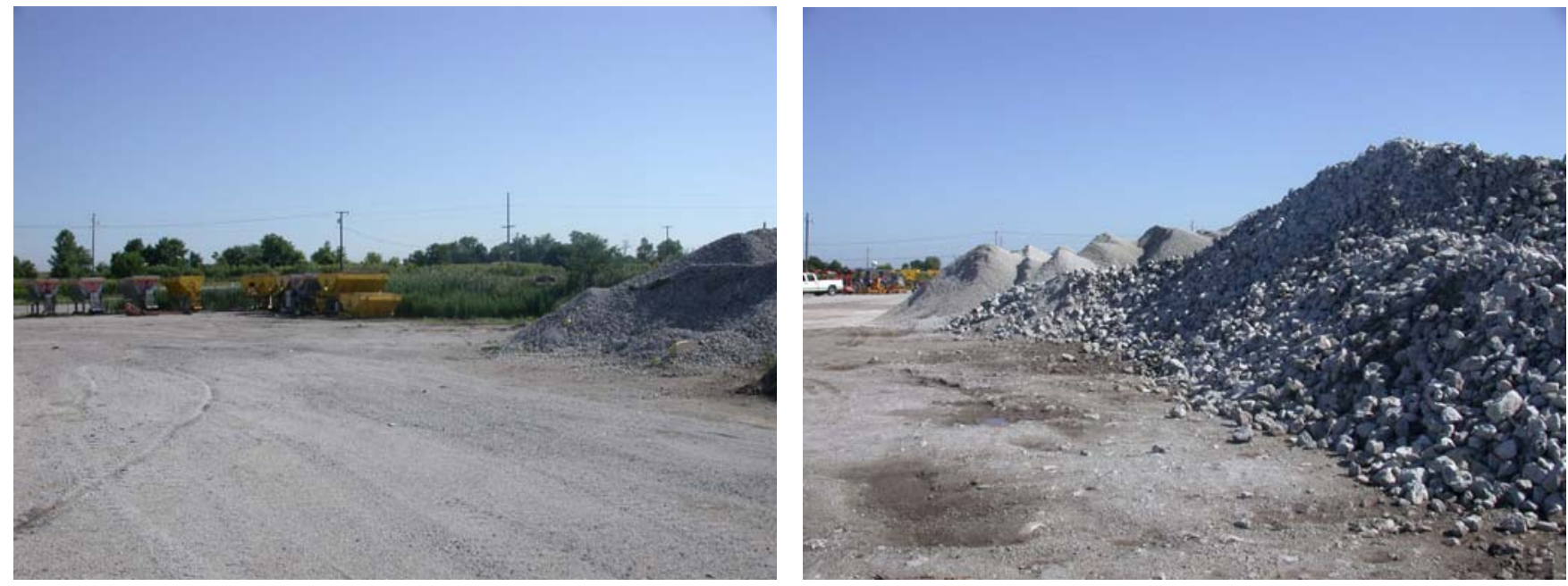
Southern Portion of Property

$>$ The Salt Dome is located in the SW corner of the property. The entrance was not bermed but the area free of salt residue.

$>$ There are four large tanks on the SE side of the Salt Dome that contain brine and calcium chloride. Two of the tanks are double-walled and two are single-walled. There is no secondary containment besides the double-walled feature on two tanks(no secondary containment for pipes incase of breaks or leaks).

On the NW side of the Salt Dome is a large pile of sand and a large pile of asphalt grindings.
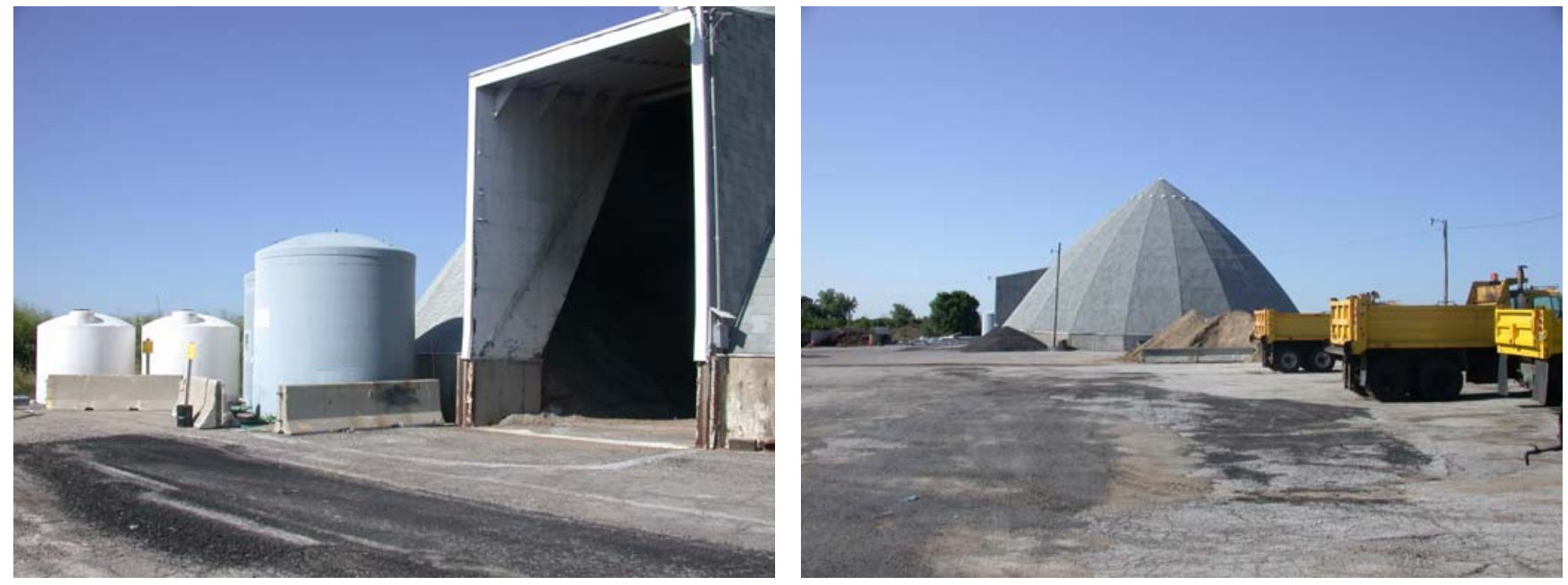

East of the brine and calcium chloride tanks, there is a four compartment concrete composting bin.

The SE corner of the site is used to store large metal stormwater pipe, metal guard railing, and other metal objects. This area is not bermed.
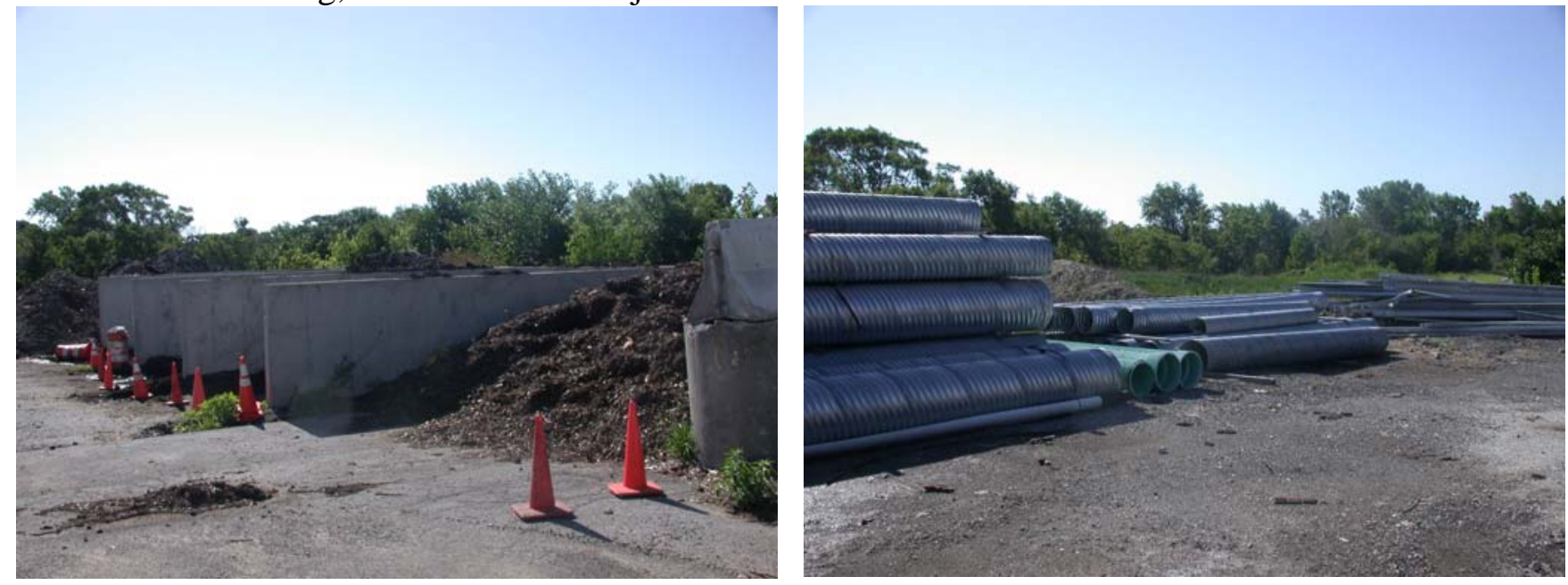


\section{Buildings}

\section{Unit Building}

There were two secondary containment pallets in the Unit Building for drums of oil and other fluids. However, there were drums of used oil and new oil that were not on the secondary containment pallets. Any leaks will be collected in the floor drains and conveyed to the roadside ditch.
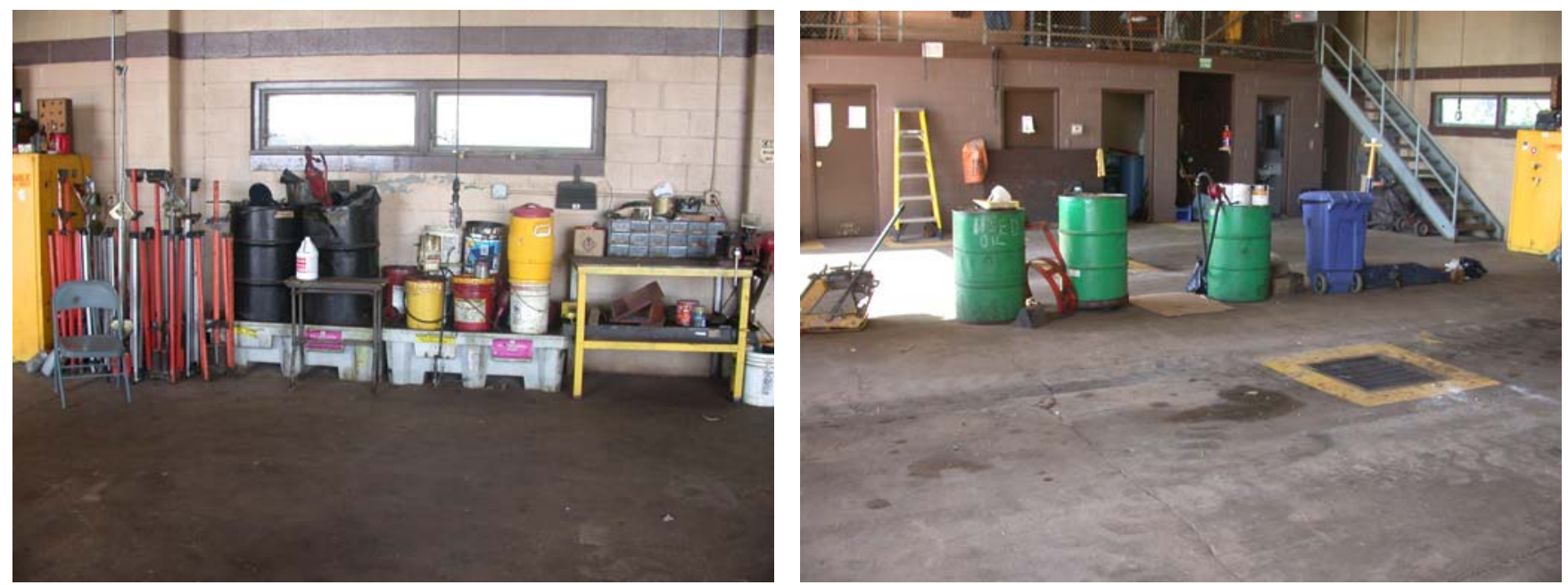

There is no oil/water separator in the Unit Building.

Salt Dome

There was no berm at the entrance of the Salt Dome but the area was free of salt.

The stormwater from this area flows to the east property line, which flows into the roadside ditch.

* Other Buildings

There is a small tool shed onsite, which is used to store asphalt tools and digging equipment. 


\section{INDOT Site Assessment Report \\ Observations and Comments}

Facility: Chesterton Unit

May 19, 2005

\section{$\underline{\text { Surface Area }}$}

General

$>$ This facility is not connected to a sewer system. The liquids that are collected in the shop floor drain are sent through an oil/water separator and then to the roadside ditch, which empties into Munson Ditch approx. 30 yards west of the site.

An onsite detention pond receives all the storm water from the Salt Dome, Salt Mixing, Brine Storage, Cold Patch Storage, Truck Parking, and Salt Bed Storage areas. Two catch basins collect the storm water and convey it to the detention pond. When the detention pond overflows, the overflow water is piped to the roadside ditch, which empties into Munson Ditch.

There is no salt bed washing onsite. All washing is said to be done at the LaPorte Subdistrict, which is approx. 24 miles from the facility.

\section{East Property Line}

The NE corner of the site is used as a tractor and lawn mower parking area. This area drains into the East property line ditch, which empties into the roadside ditch.

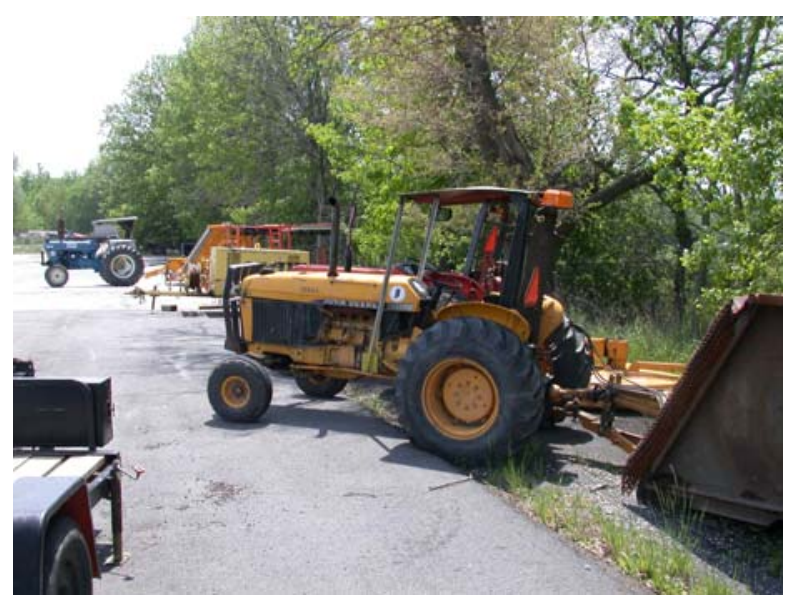


> The Unit Building is located on the North property line, just west of the tractor parking area. The storm water from this area also drains into the roadside ditch.

The truck parking and salt bed storage areas are located south of the Unit Building. The salt beds are stored on a strip of gravel in the center of the active surface. This strip of gravel is surrounded by asphalt pavement. Trucks are parked parallel to the salt beds on asphalt.
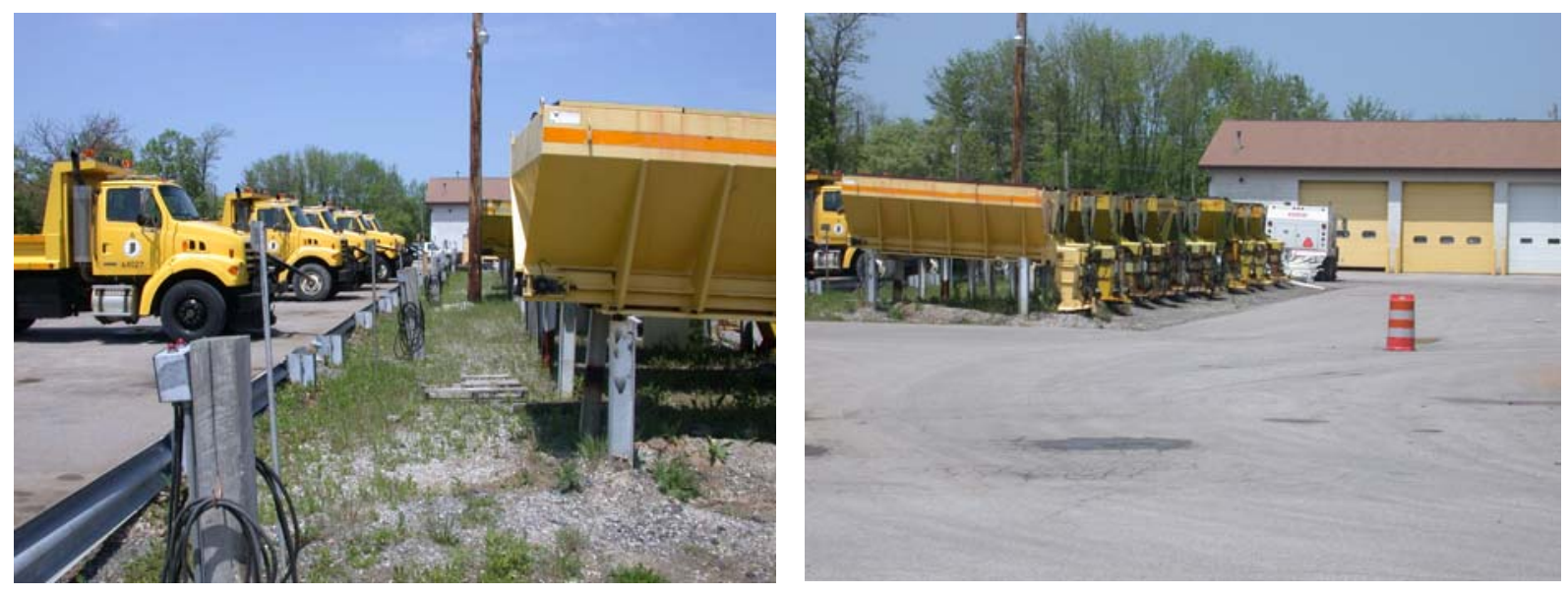

There is a catch basin located approx. 20 feet west of the salt bed storage area. The storm water captured by this catch basin is piped to the detention pond.

The Salt Dome and Ice Ban storage tanks are located south of the salt bed and truck parking areas. The storm water from this area drains into the detention pond.
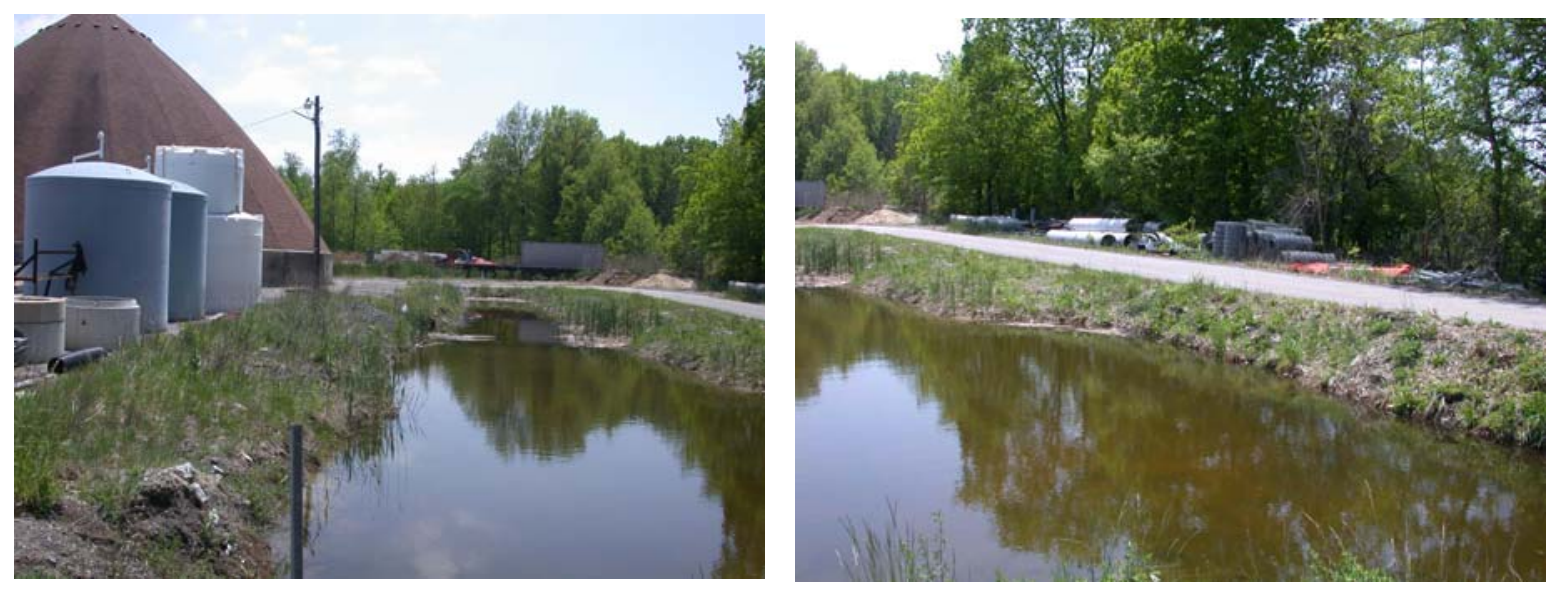

East of the detention pond, there are several piles of metal pipe segments and fencing. 
* West Property Line

A West property line drainage ditch is shared with a privately owned company. The company performs maintenance on large trucks.
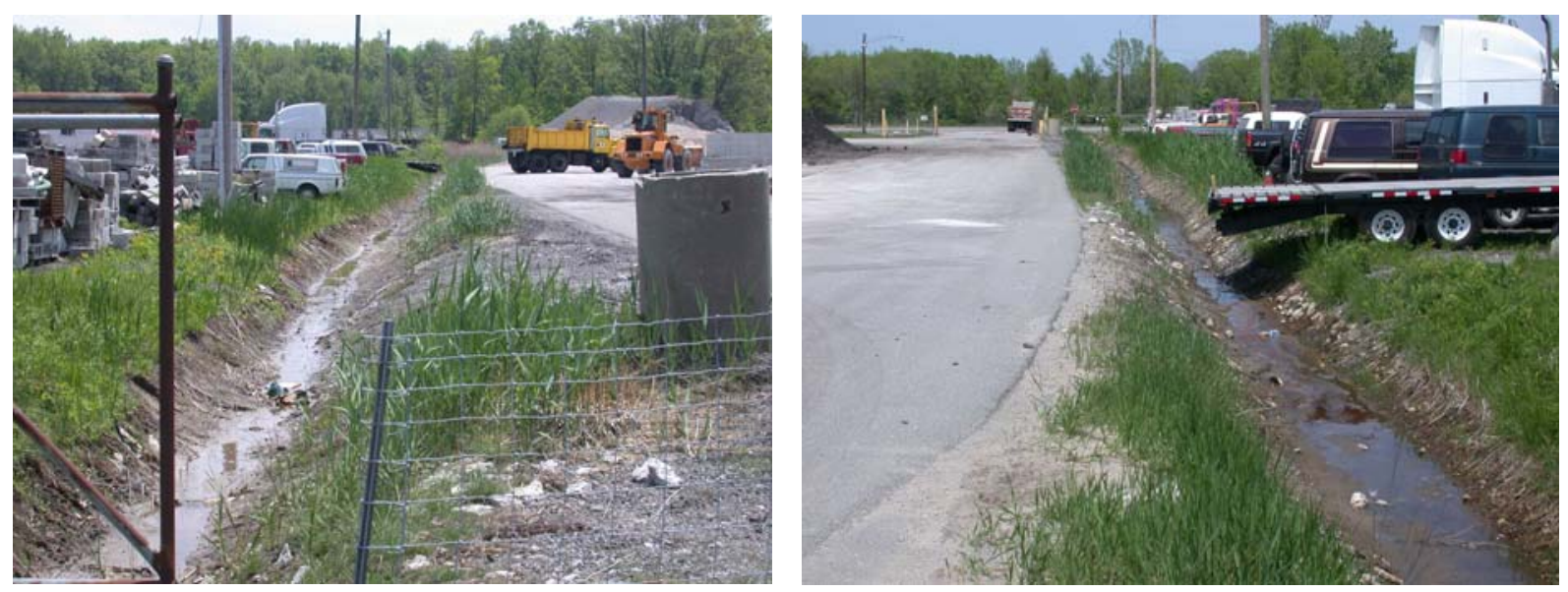

The majority of the west side of the site is used to store aggregate piles and composting piles. The storm water from this side of the site enters the west property line ditch, which empties into the roadside ditch.
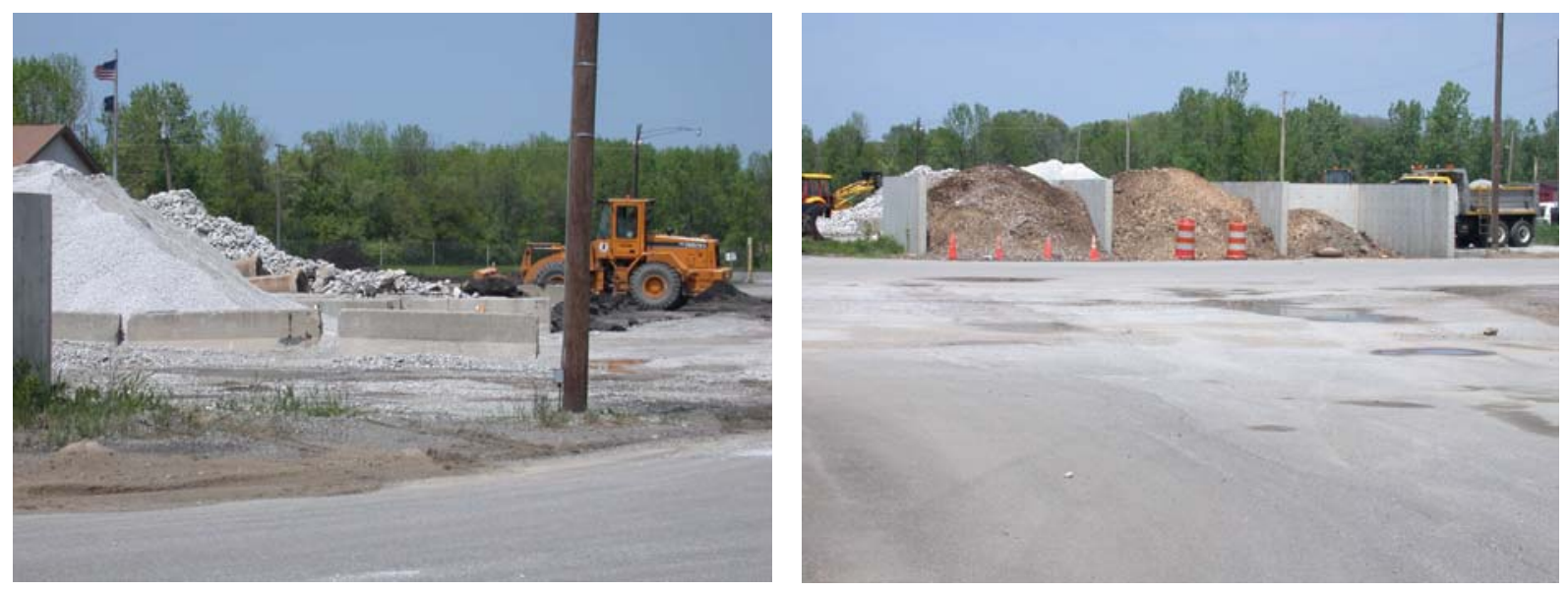


\section{Buildings}

* Unit Building

> The liquids that are captured in the Unit Building floor drain are sent through an oil/water separator before being piped to the roadside ditch, which empties into Munson Ditch. The bathroom is connected to a septic system.

There was some evidence of liquids, such as oil, getting into the Unit Building floor drains.

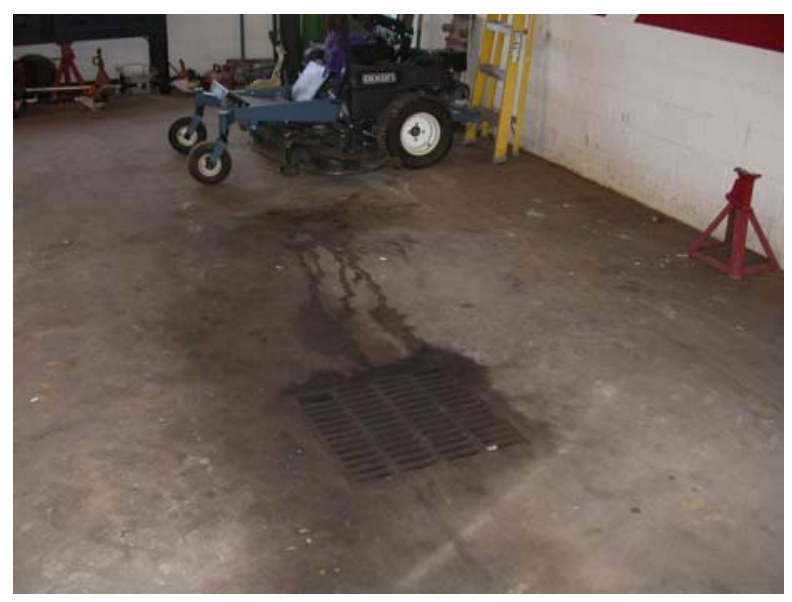

* Salt Dome

There was very little salt around the entrance of the Salt Dome at the time of the site visit.

A cold patch pile is stored against the north side of the Salt Dome. The entire area drains into the detention pond. 


\section{INDOT Site Assessment Report Observations and Comments}

\section{$\underline{\text { Surface Area }}$}

General

$>$ This facility is not connected to a sewer system and is not equipped with an oil/water separator. All effluent from the Unit Building floor drain enters Ayres Ditch.
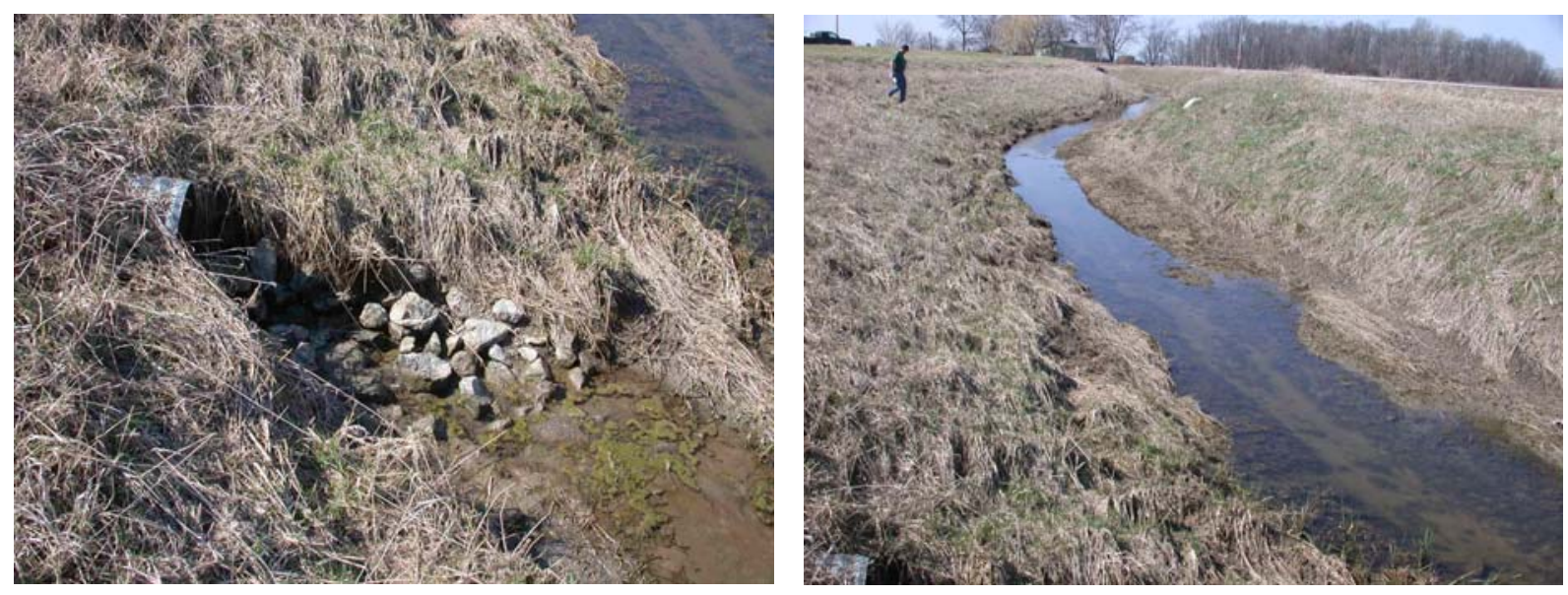

In the Unit Building, there were drums of oil and hydraulic fluid on secondary containment pallets. However, a 55-gallon drum of waste oil was sitting directly on the floor with no secondary containment, approx. 5 feet from the floor drain. Any leaks or spills in this area will migrate to the floor drain and be piped to Ayres Ditch. 
Much of the active surface at this facility was covered with salt. There are at least three catch basins spaced throughout the site that collect storm water and convey it to Ayres Ditch. There was evidence that a large amount of salt is being transported by these catch basins to Ayres Ditch.
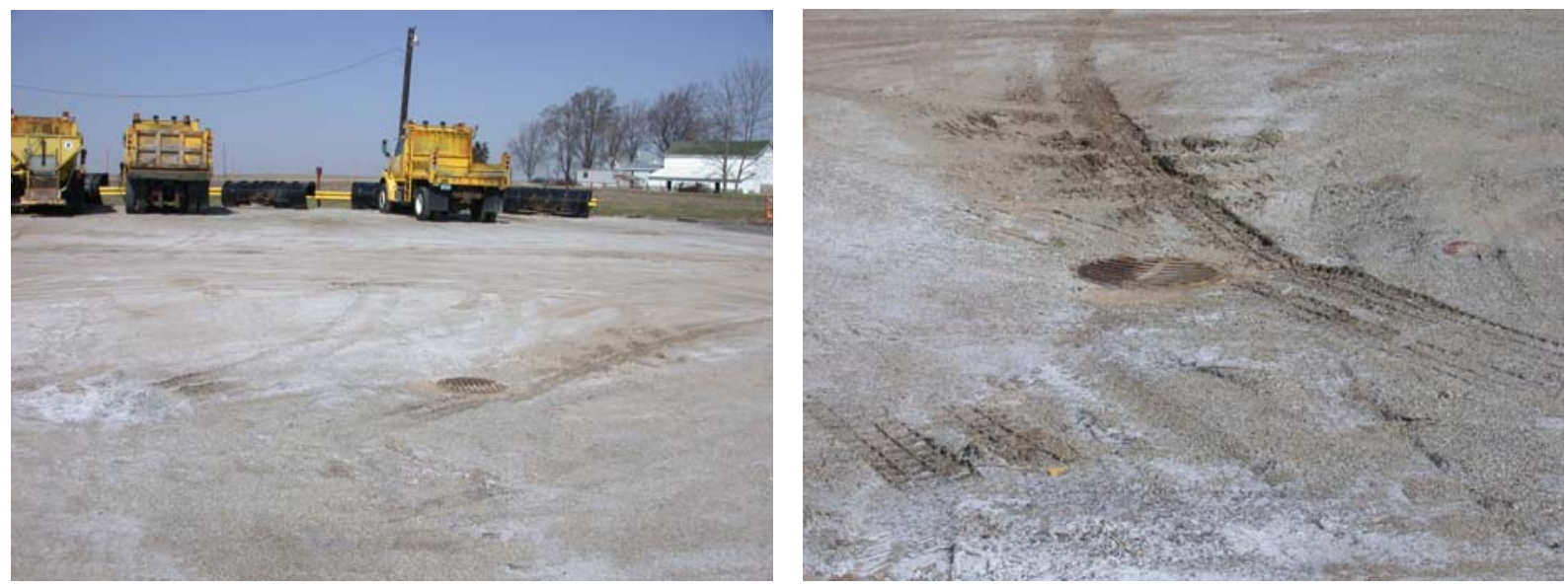

Several large tanks on site hold Brine, Calcium Chloride, and Ice Ban. These tanks do not have proper secondary containment. A large leak could easily migrate to one of the catch basins and be piped to Ayres Ditch.
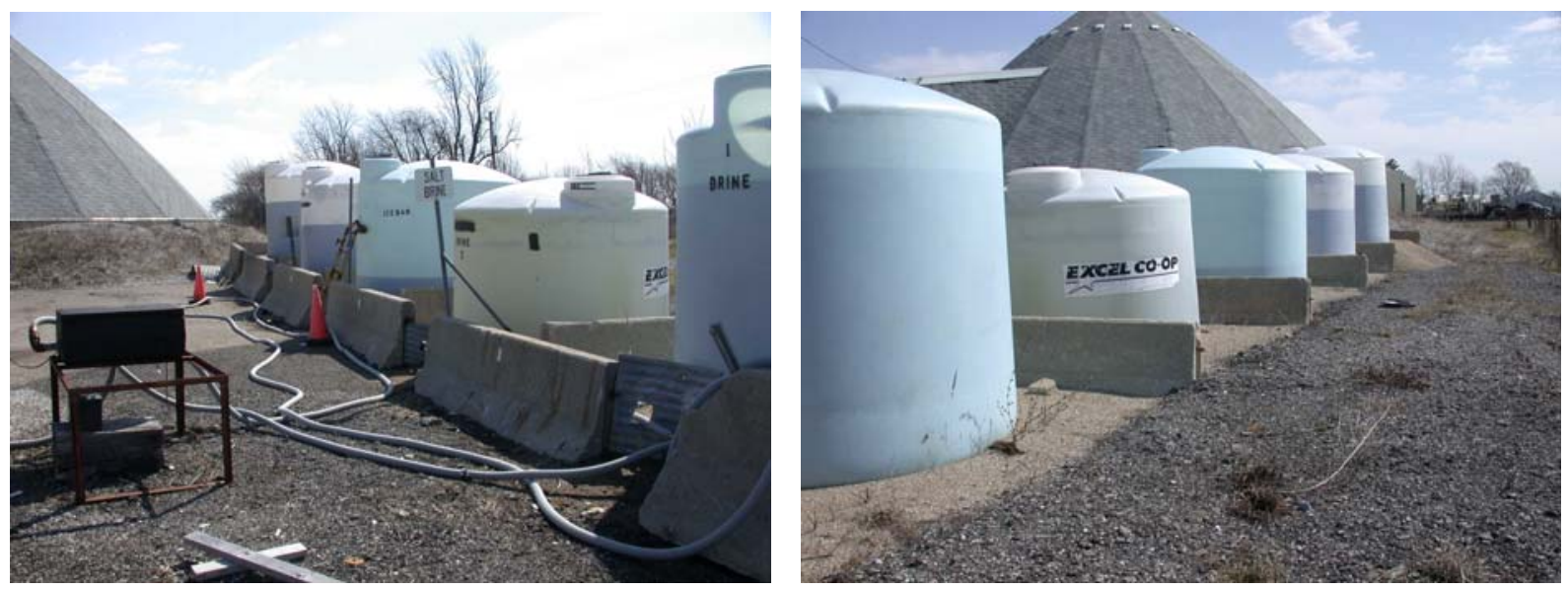

There is no vehicle or salt bed washing performed at this facility.

* South Property Line

The Unit Building is located at the entrance of the site, which is in the SW corner.

The Salt Dome along with the Brine, Calcium Chloride, and Ice Ban tanks are located in the SE corner of the site. 
There is a pile of cold patch north of Salt Dome that was not covered with a tarp.

* North West Property Line (bordered by Ayres Ditch)

$>$ The truck parking area is located NE of the Unit Building on the NW property line. There was a large amount of salt on the ground in this area. All the storm water from this area is collected by a catch basin and piped to Ayres Ditch.

$>$ The salt bed storage area is located NE of the truck parking area. There was also a noticeable amount of salt on the ground in this area. The storm water from this area is also collected by a catch basin and piped to Ayres Ditch.

SE of the salt beds there is a Cold Storage Building. This building is used to store tractors and various tools.

The entire NE corner of the site is used to store aggregate piles and various metal objects such as pipe segments and guard rails. The storm water from this area flows east into a drainage ditch, which empties into Ayres Ditch.

\section{$\underline{\text { Buildings }}$}

Unit Building

This facility has no oil/water separator and is not connected to a sewer system. The liquid, which is collected in the floor drain, is piped directly to Ayres Ditch.

There was a waste oil drum with no secondary containment approx. 5 feet from the floor drain. There was some evidence of oil spillage near the floor drain.
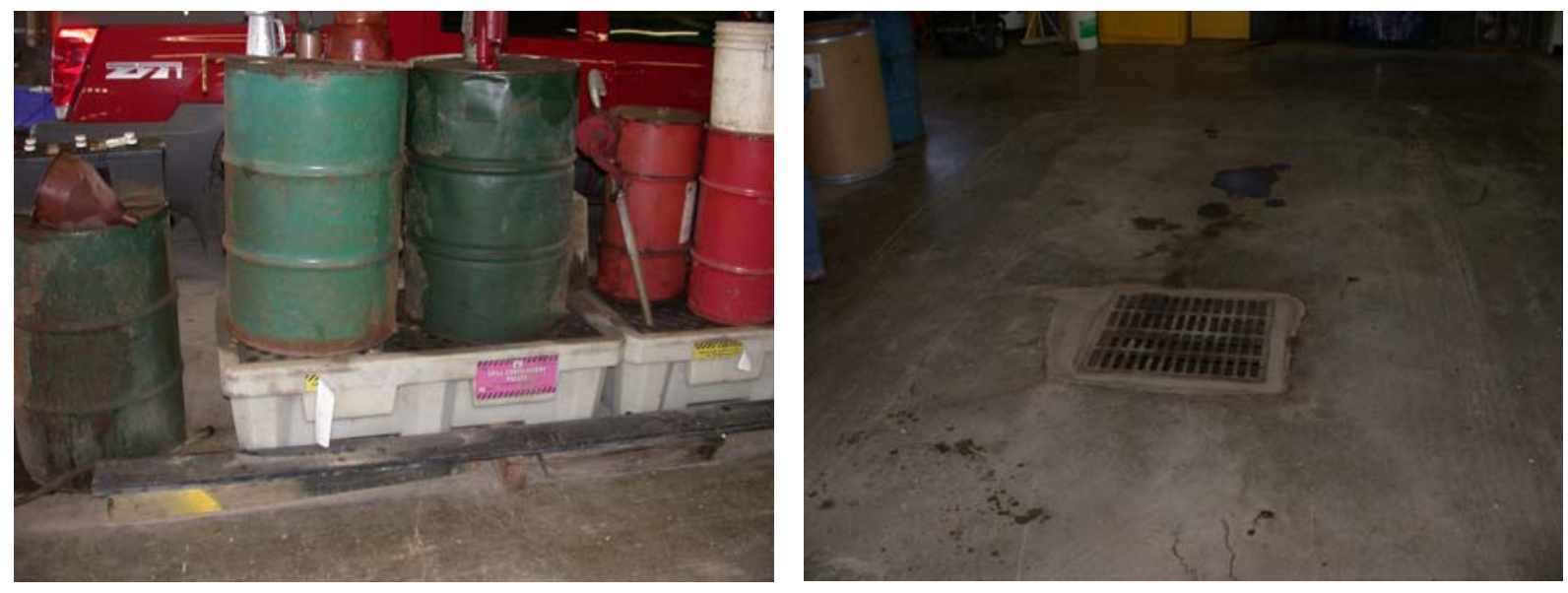
Salt Dome

$>$ There was a noticeable amount of salt outside the entrance of the Salt Dome. There were several salt trails leading toward the catch basins at the center of the active surface.
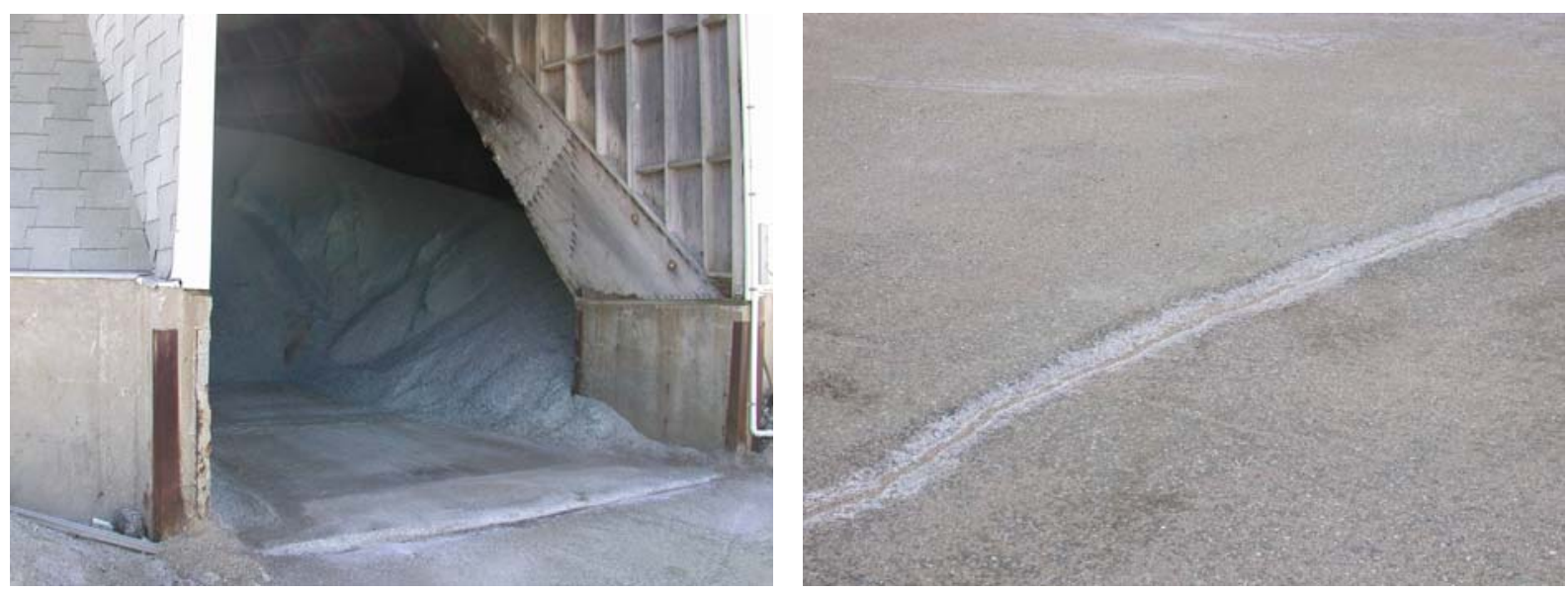

\section{* Cold Storage Building}

The Cold Storage Building is used to store small tractors and various other tools. There was a floor drain in this building that drained into Ayres Ditch. There were several gas cans on the floor of the building and there was some evidence of past oil spills on the floor. This floor drain should be filled in if possible. 


\section{INDOT Site Assessment Report Observations and Comments}

\section{Surface Area}

\section{General}

This site is located approximately 20 feet from a creek that drains into the Wabash River approximately 1 mile from the site. The name of the Creek is Unknown.

All floor drains in the Unit building and drains in the cold storage building drain directly into the creek.

The Unit is not equipped with an oil/water separator and is not connected to a Municipal Sewer System.

> The backside of the barn shaped Salt Storage Building was knocked out accidentally and has not been repaired. This results in more stormwater coming in contact with the salt and leads to more salt contaminated runoff leaving the site.
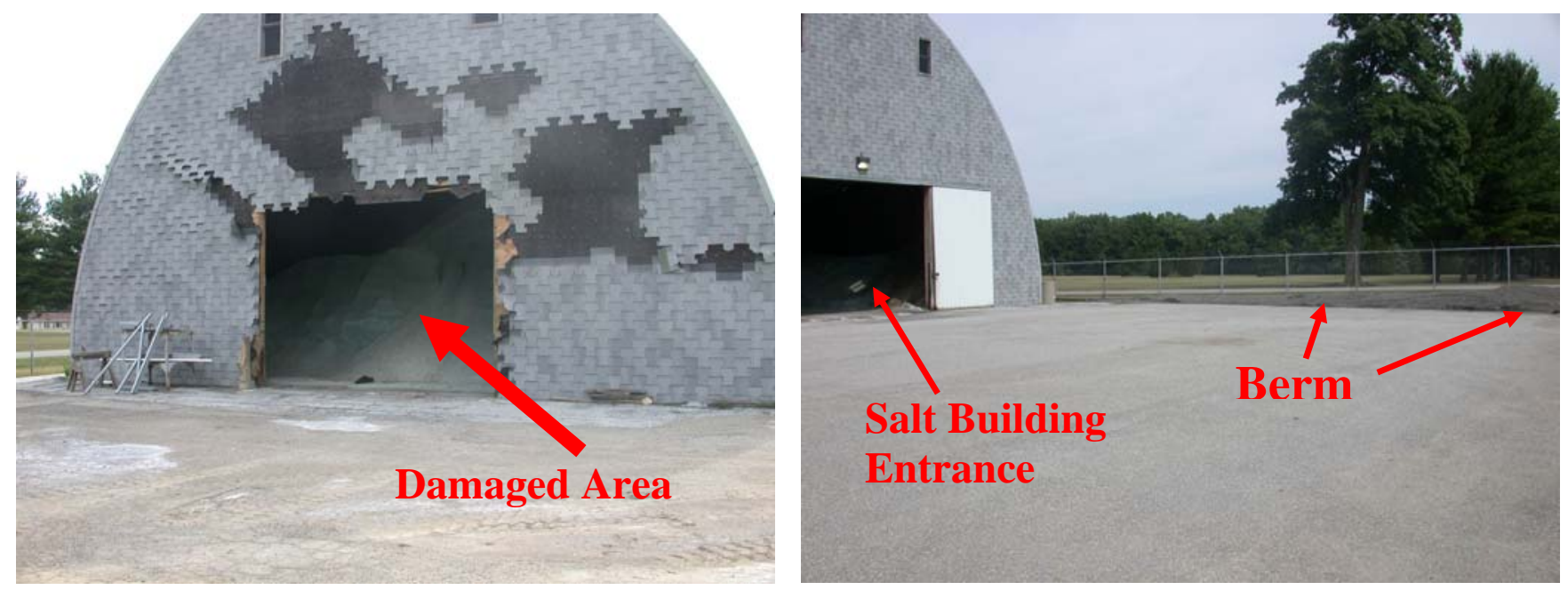

The corner of the property that the entrance of the salt storage building is located in is bermed to prevent salt contaminated runoff from leaving the site. However, the backside of the building is not bermed and there is evidence that salt is being transported offsite from this area. 
Site Layout

The entrance to the site is off of State HWY 25 and is located on the south side of the property

A creek runs down the West side of the site and at the closest point is approx. 20 feet from the South West corner of the property

The Unit Building is located on the South side of the property. The trucks are parked around the Unit building. There are no berms or drains in this area. The stormwater from this area flows SW toward the creek.

A large amount of metal guardrail is stored in piles along the SE fence line. This area is not bermed and the stormwater from the area flows onto a neighboring corn field
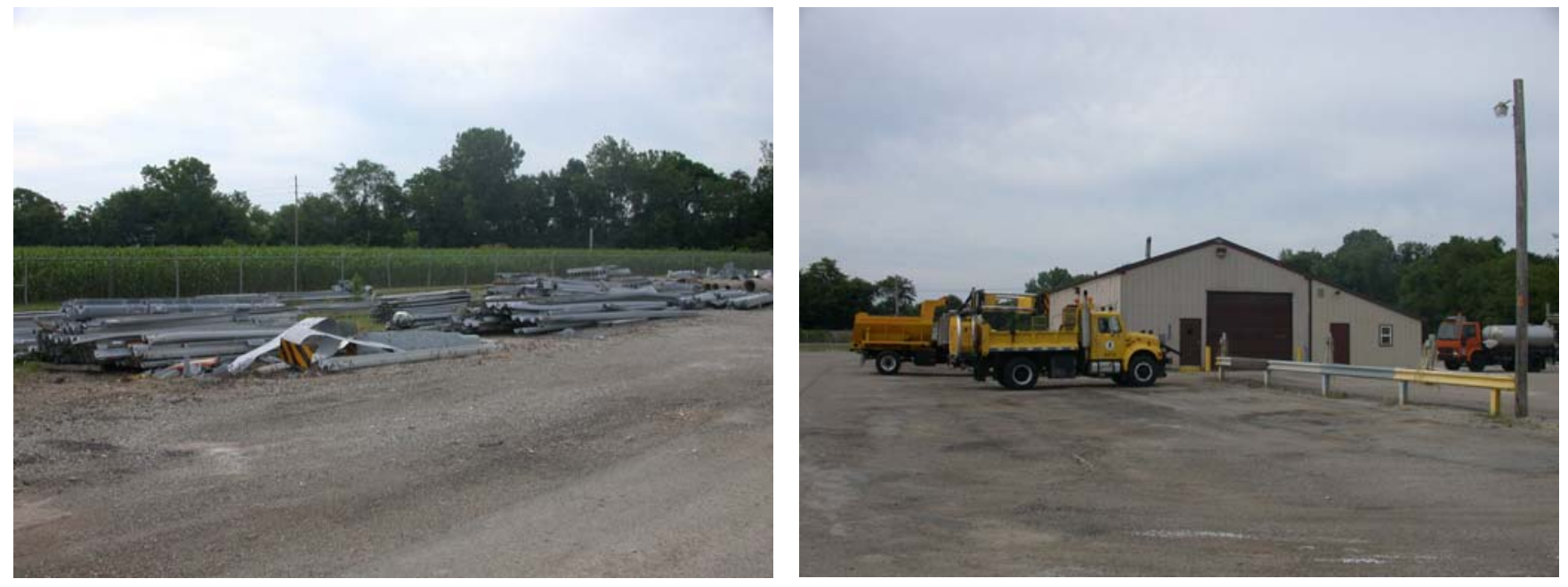

North of the metal storage area is a three compartment concrete storage bin that contains three piles of composting material. There is also a large pile of asphalt grindings located next to the composting bin.

There are several aggregate piles located approx. 20 yards south of the Unit Building

A large cold storage building is located west of the aggregate piles, along the west fence line. There is a floor drain in this building that drains to the creek.

Large corrugated stormwater pipe is stored in the SW corner of the site. There is also a tar kettle stored in the SW corner of the site. 
North of the stormwater pipes there is an old brine production system that is not in use. This equipment should be disposed of properly.
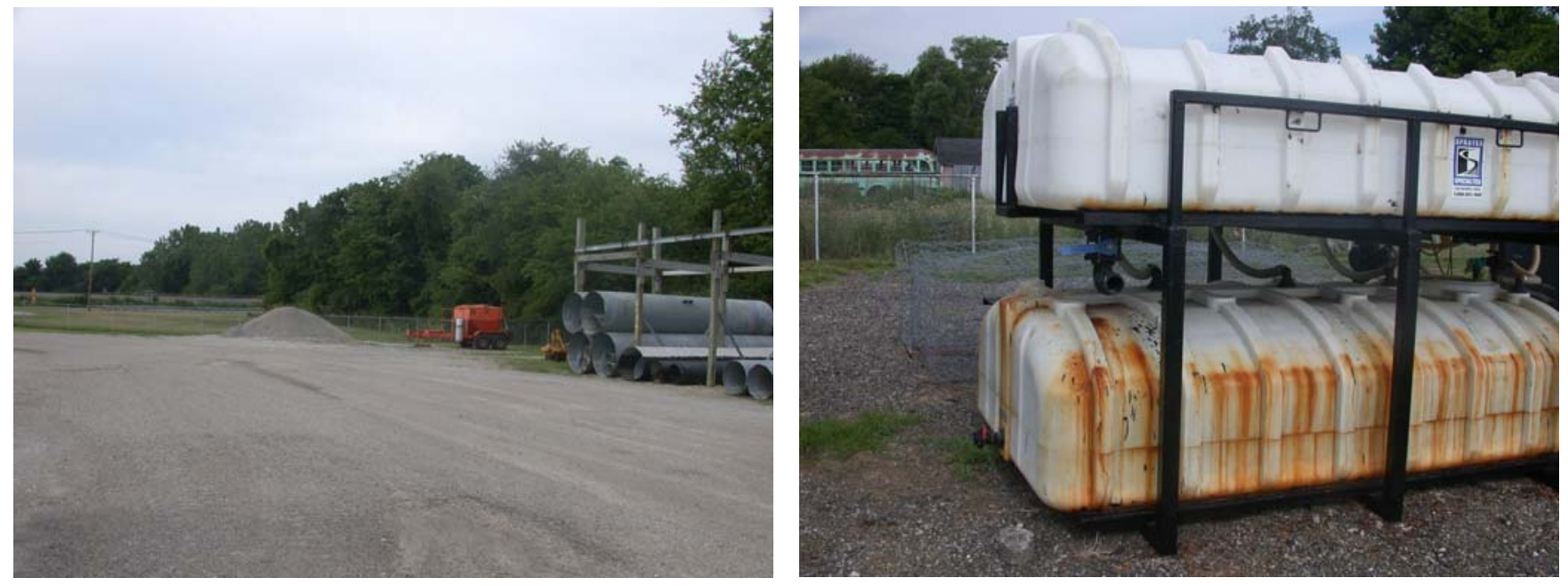

The Salt Storage Building is located along the North fence line. The entrance is on the east side of the building. The stormwater from the active surface around the entrance drains into the NE corner, which is bermed to prevent water from draining offsite.

$>$ The salt beds racks are positioned along the south side of the Salt Storage Building.

$>$ There are 6 tanks containing salt brine and calcium chloride located at the SE corner of the Salt Storage Building. These tanks are not secondarily contained but the stormwater from this area flows into the NE corner of the site, which is bermed.
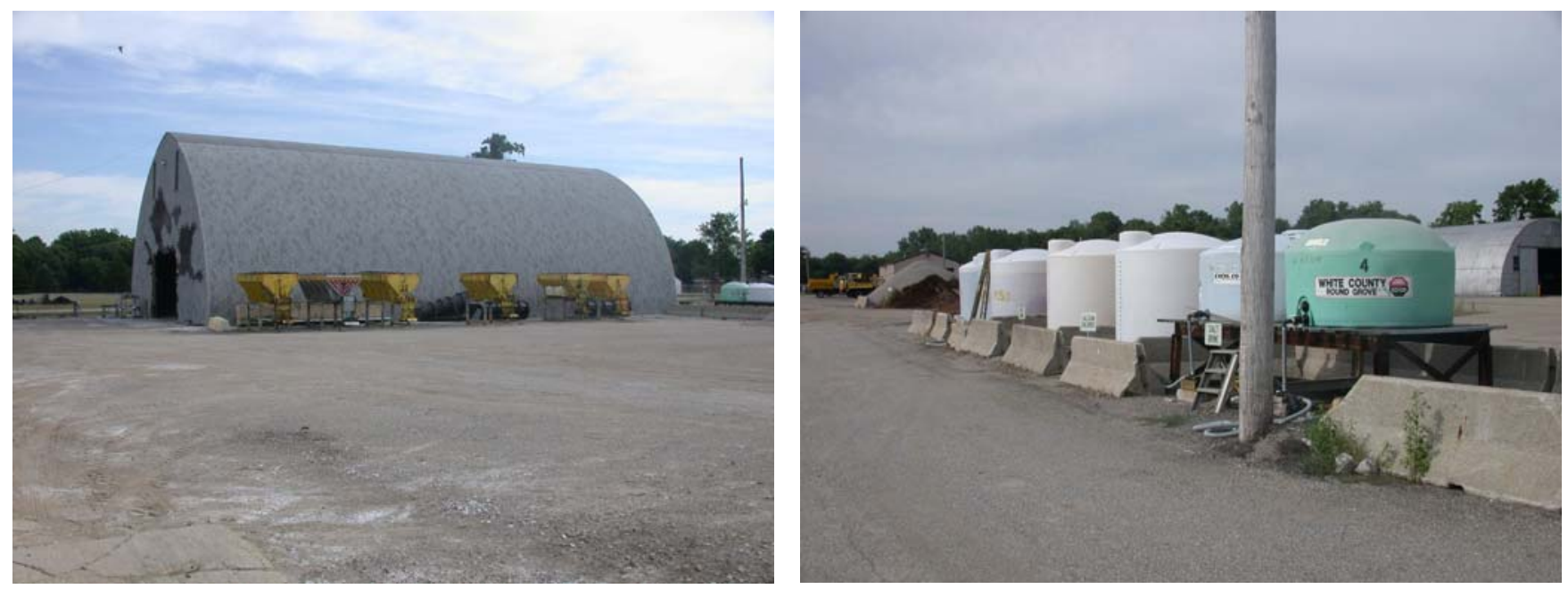


\section{Buildings}

* Unit Building

All drums inside the Unit Building are stored on secondary containment pallets.

D The floor drain inside the Unit Building drains directly into the creek that runs down the west property line.

\section{* Cold Storage Building}

$>$ The following is stored in the Cold Storage Building: a tractor, a lawn mower, a generator, several oil drums, cold patch, asphalt tools, road signs, and traffic cones.

$>$ There is a floor drain in the building that drains directly into the creek that runs down the west property line.

There were several 55-gallon drums of oil in the Cold Storage Building that were not secondarily contained.

The asphalt tools inside the building were not cleaned properly and had created stains on the floor.
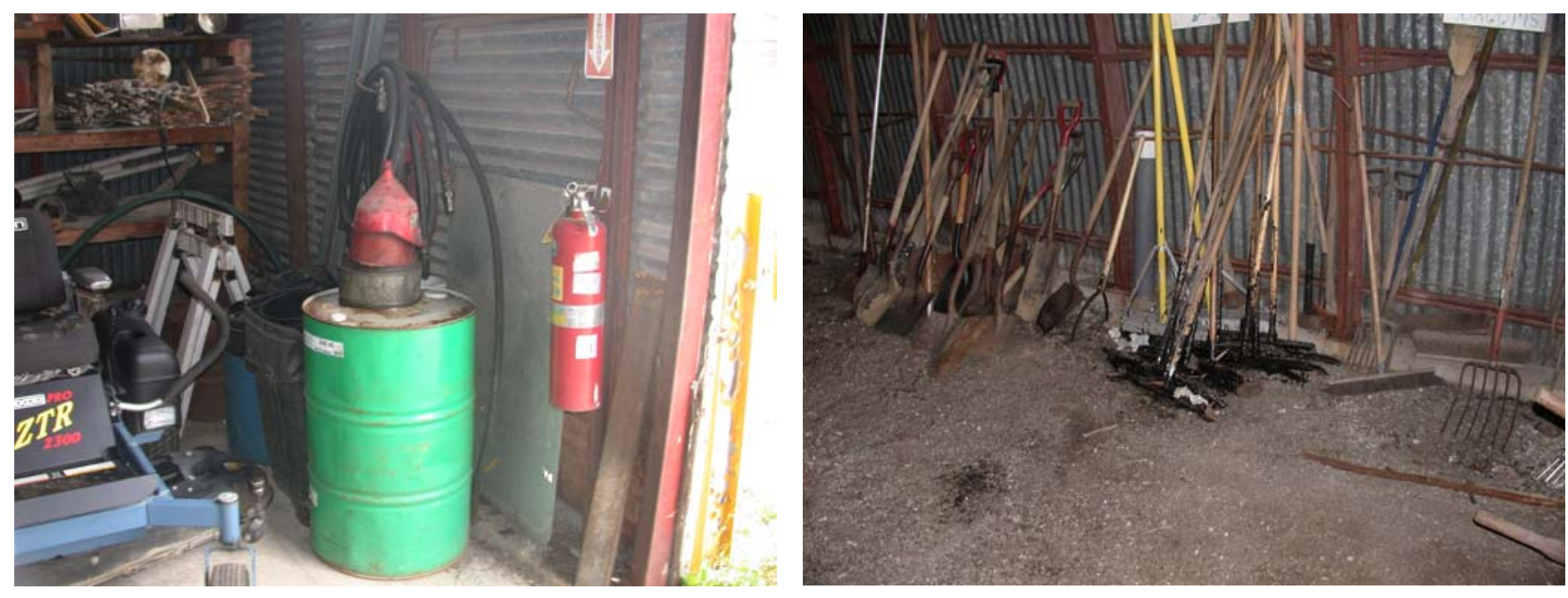


\section{* Salt Storage Building}

$>$ The ground around the backside of the Salt Storage Building had a significant amount of salt on it. There is evidence that salt is being transported offsite by stormwater. There was a small vegetation kill just outside the perimeter fence.
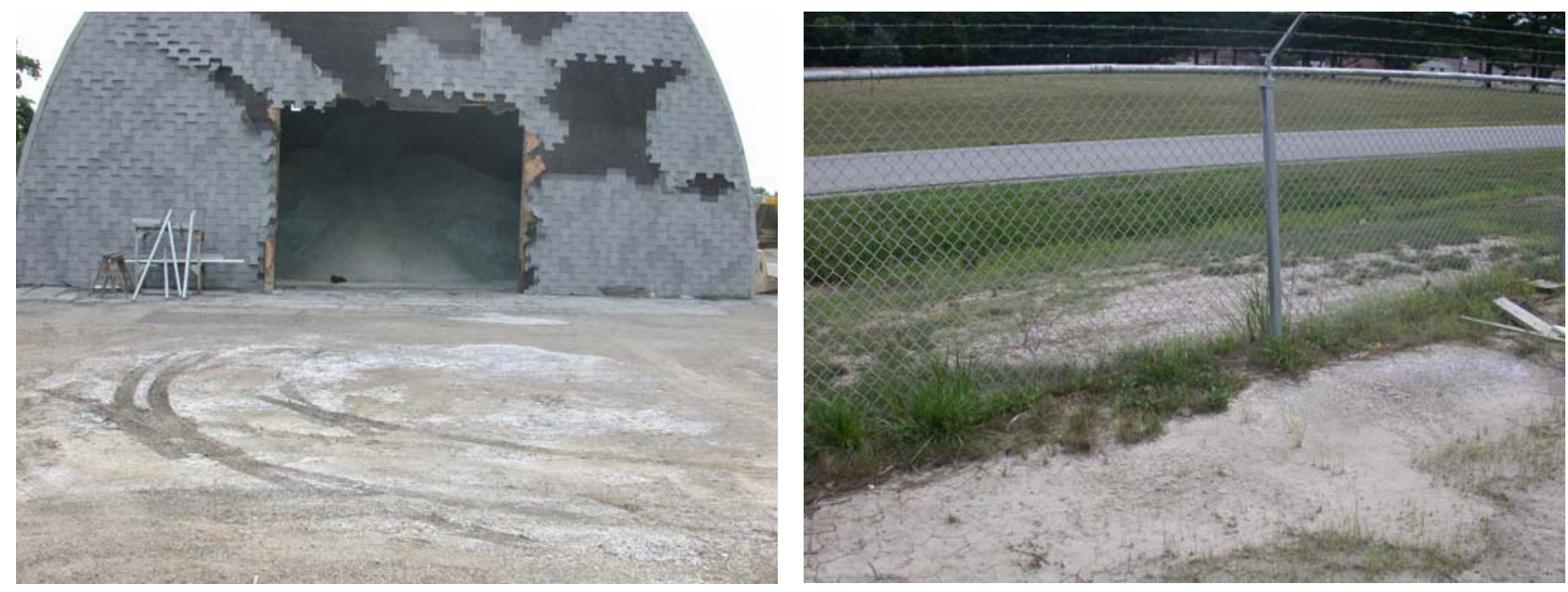

The Entrance of the Salt Building faces toward the NE corner of the site. The entire NE corner is bermed. The water that flows into this corner eventually evaporates. There is also a testing well in this corner.
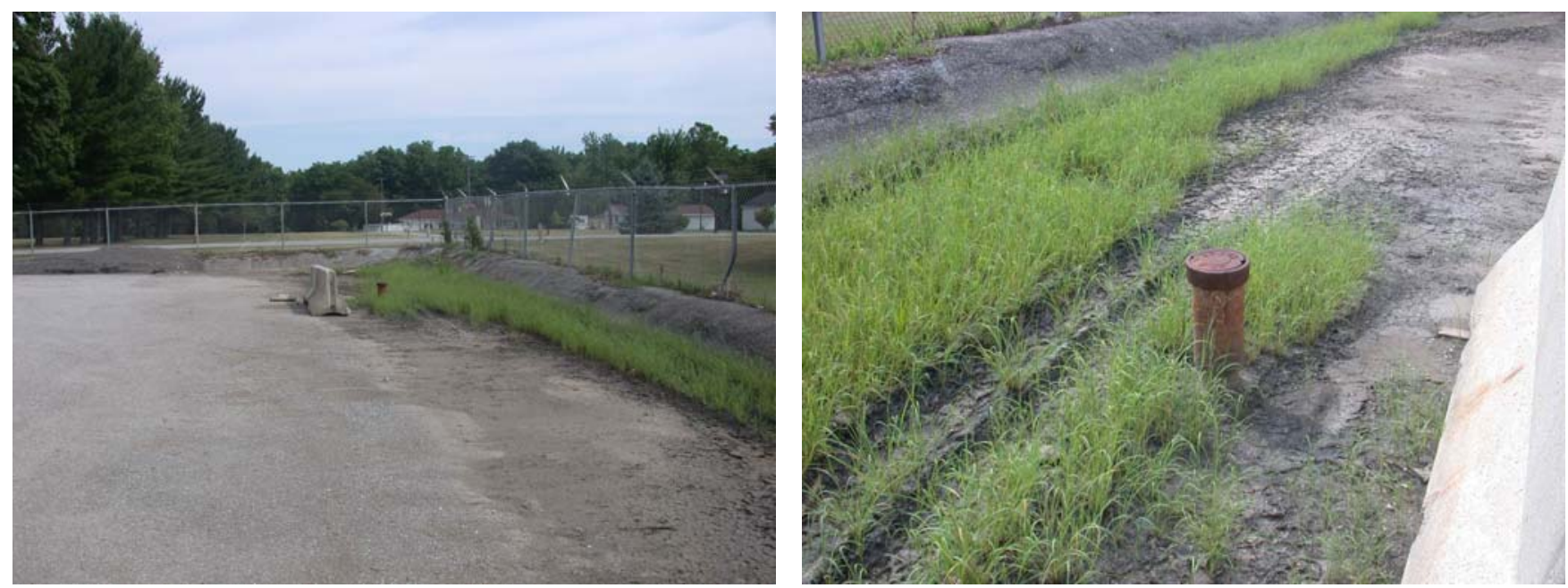


\section{INDOT Site Assessment Report Observations and Comments}

\section{$\underline{\text { Surface Area }}$}

General

$>$ This facility is connected to a Municipal Sewer System and is equipped with an oil/water separator.

$>$ The Salt Storage Building at this facility is not a Dome. It is a large rectangular building that is large enough to enclose all salt operations including: bulk offloading, salt/sand mixing, salt bed loading, and brine production. Brine and calcium chloride tanks and salt bed racks are stored outside the Salt Storage Building. However the brine and calcium chloride tanks are secondarily contained and stored under roof.

$>$ All salt bed washwater is reused to produce brine at this facility.

* Northern Portion of Property

$>$ There is a large building at the entrance of the site that consists of offices, the truck maintenance area, and the washbay.

East of the building, there is a parking area for salt trucks and visitors. This area drains into a roadside ditch that eventually empties into a swamp area on the south side of the property.

$>$ West of the building, there is another truck parking area. However, in this parking area there are salt trucks, tractors, a tar kettle, and large brine trailers. The stormwater from this area flows south and eventually enters the swamp area.

South of this parking area, there is a cold storage building that houses tractors, road signs, and tools. There are no drains in the cold storage building. 
Southern Portion of the Property

$>$ The Salt Storage Building is located approx. $75 \mathrm{ft}$ south of the truck maintenance building.

$>$ On the north side of the Salt Storage Building, there are several large secondarily contained brine and calcium chloride tanks. These tanks are covered.

$>$ The salt bed racks are located on the west side of the Salt Storage Building. This area is not covered or bermed. There is also additional truck parking west of the salt bed racks.
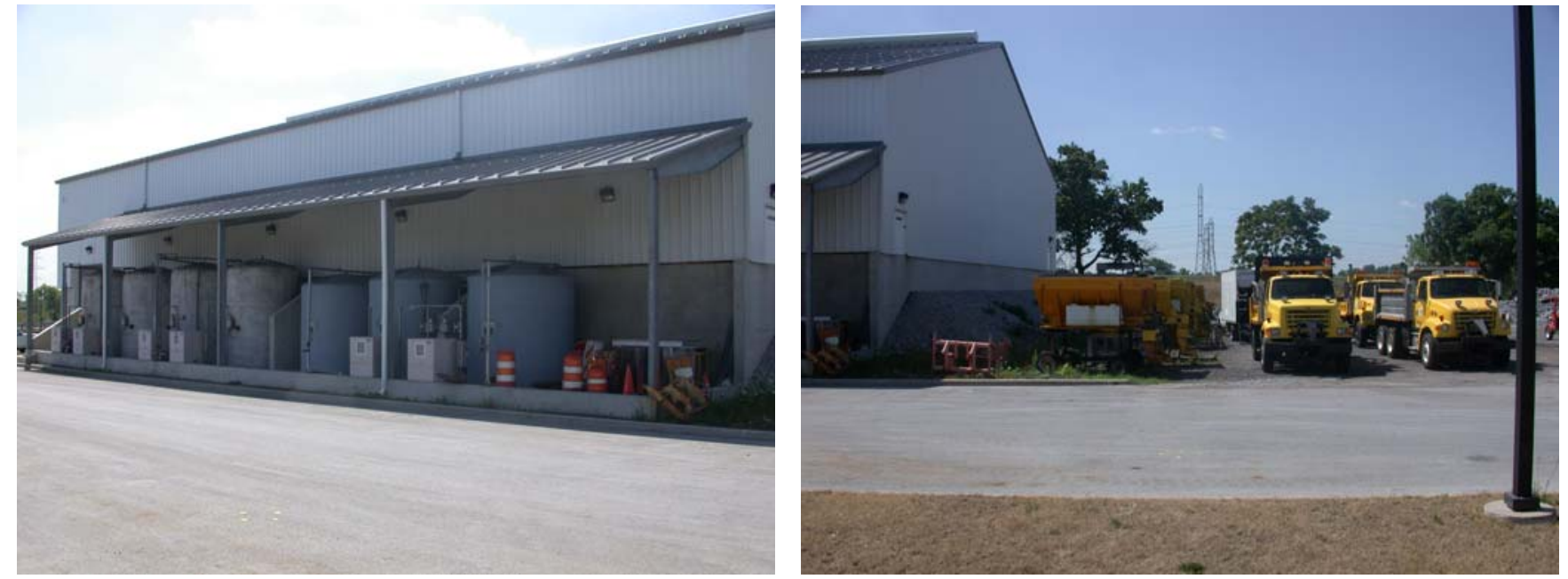

Snow plows are stored on the east side of the Salt Storage Building.

Several large aggregate piles are located approx. 50 feet SW of the Salt Storage Building.
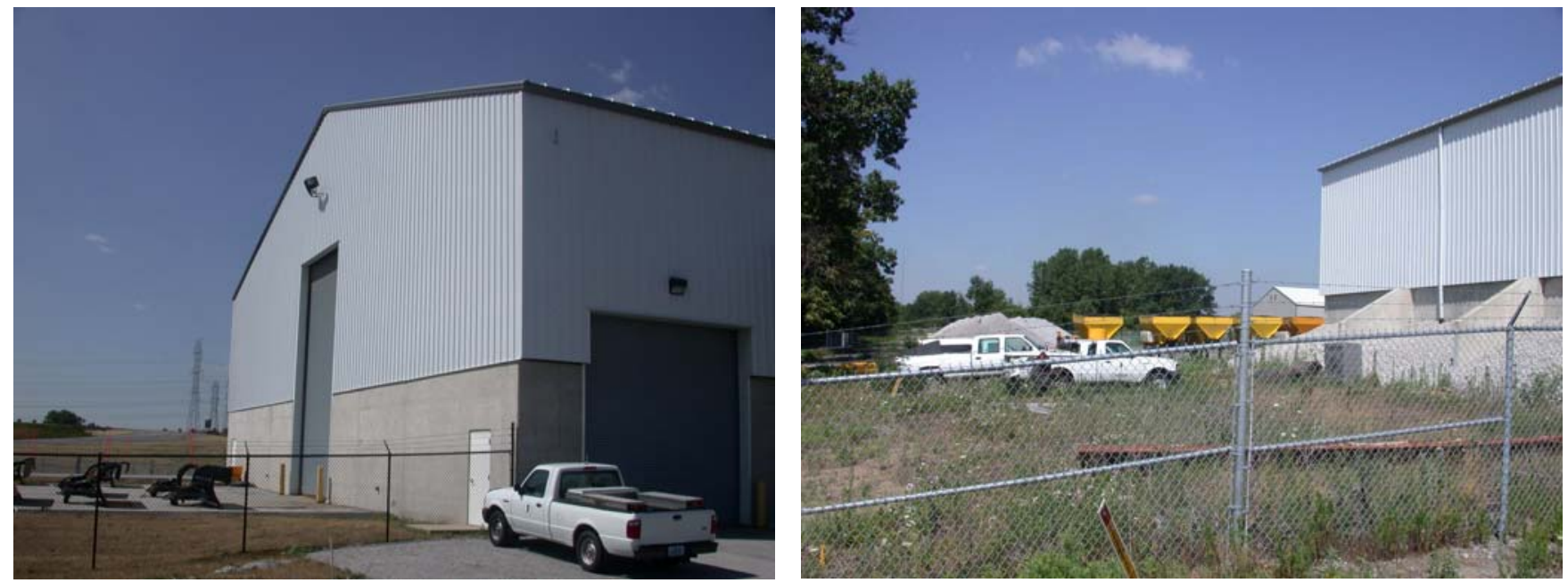
There is a large, empty paved area south of the Salt Storage Building. There is only a pile of cold patch, two dumpsters, a pile of sand, and a work truck in this large area. The swamp area is on the west side of this paved area. All stormwater from the site flows into the swamp area.
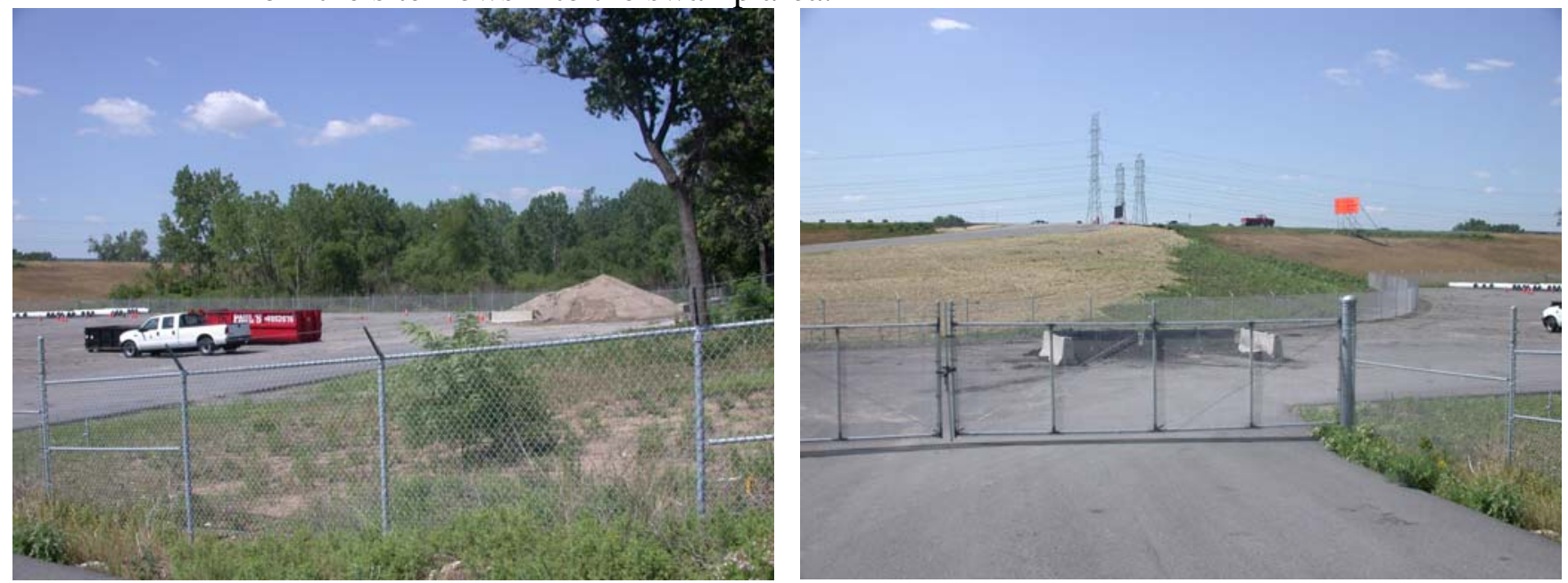

Buildings

* Sub and Unit Building

$>$ The Sub and Unit Building consists of an office area, a truck maintenance area, and a washbay.

$>$ All vehicle fluids were secondarily contained. Oil drums are kept in a small room with a collection pit at the center to prevent any leaks from leaving the building.

$>$ The washwater from the washbay is pumped to the brine production equipment were it is used to produce brine.

All washwater goes through the oil/water separator before being used for brine production.
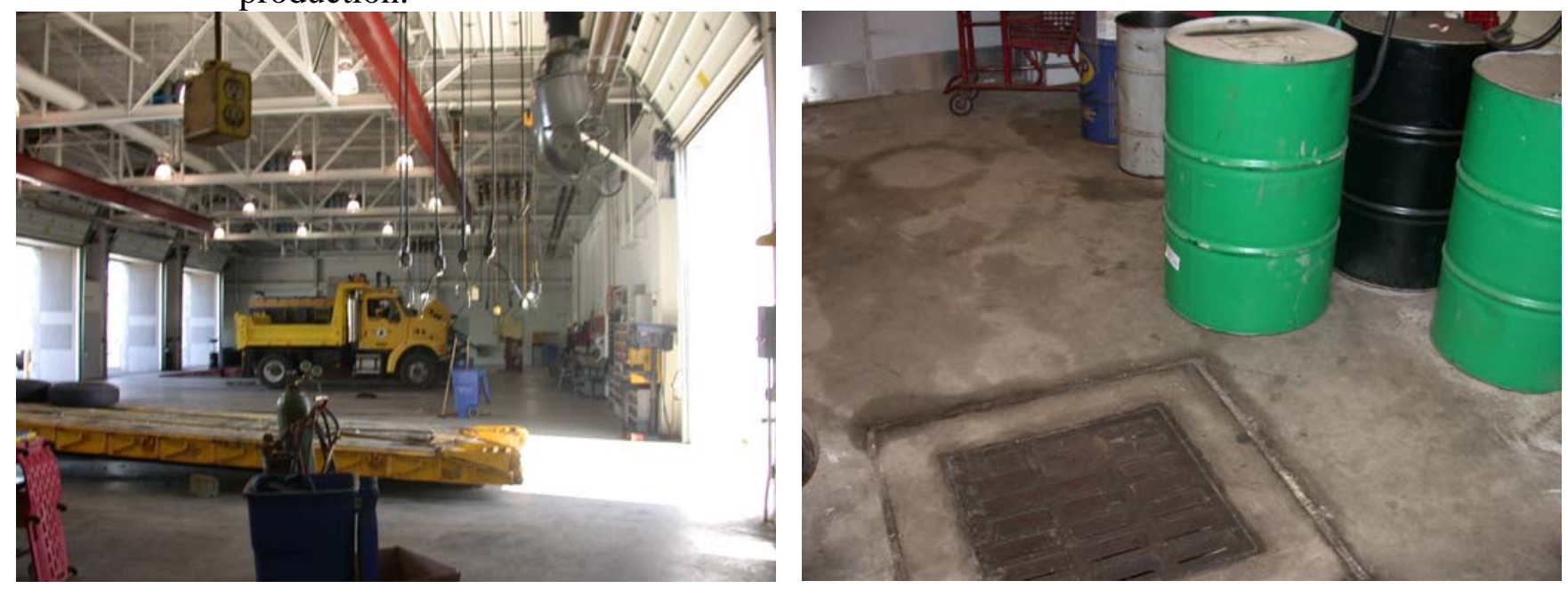
Salt Storage Building

$>$ The Salt Storage Building is large enough to accommodate full operations to be performed inside. All salt loading, sand mixing, and brine production takes place under roof. Also the brine and calcium chloride is stored under roof but not inside.

* Other Buildings

There is a Cold Storage Building onsite that is used to store tractors, road signs, tools, and other odds-and-ends.

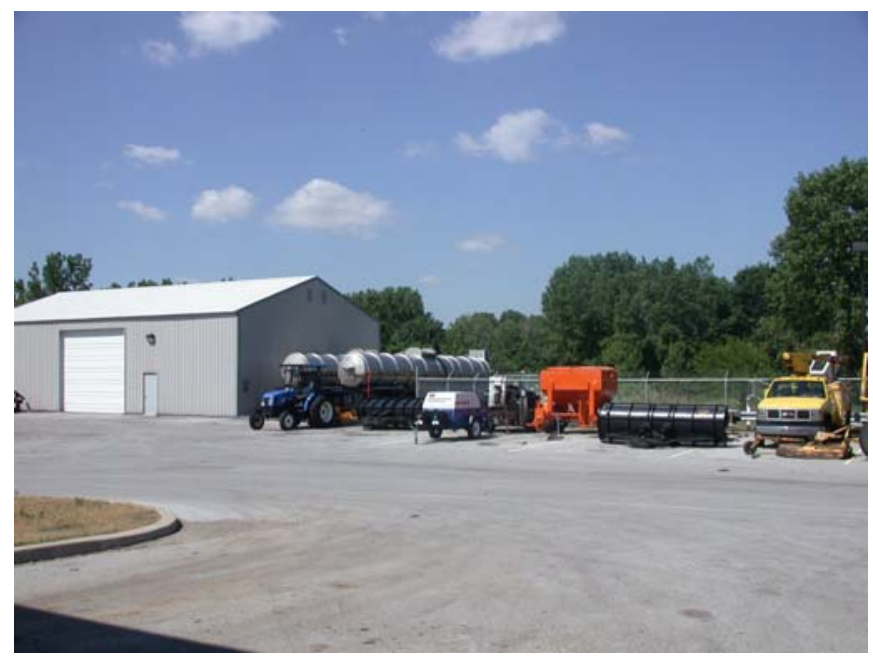




\section{INDOT Site Assessment Report Observations and Comments}

\section{$\underline{\text { Surface Area }}$}

General

$>$ This facility is not connected to a Municipal Sewer System and is not equipped with an oil/water separator.

Salt bed and truck washing is performed outside at this facility. There is a fire hydrant that is fitted with a hose, which is used to wash the equipment. However, some washing is performed at the Laporte Subdistrict.

$>$ In the NW corner of the perimeter fence there was a large area of spilled asphalt. It looked like a tar kettle had been emptied onto the ground in this corner. When the Unit Foreman was asked were it came from, he said he didn't know it was there.
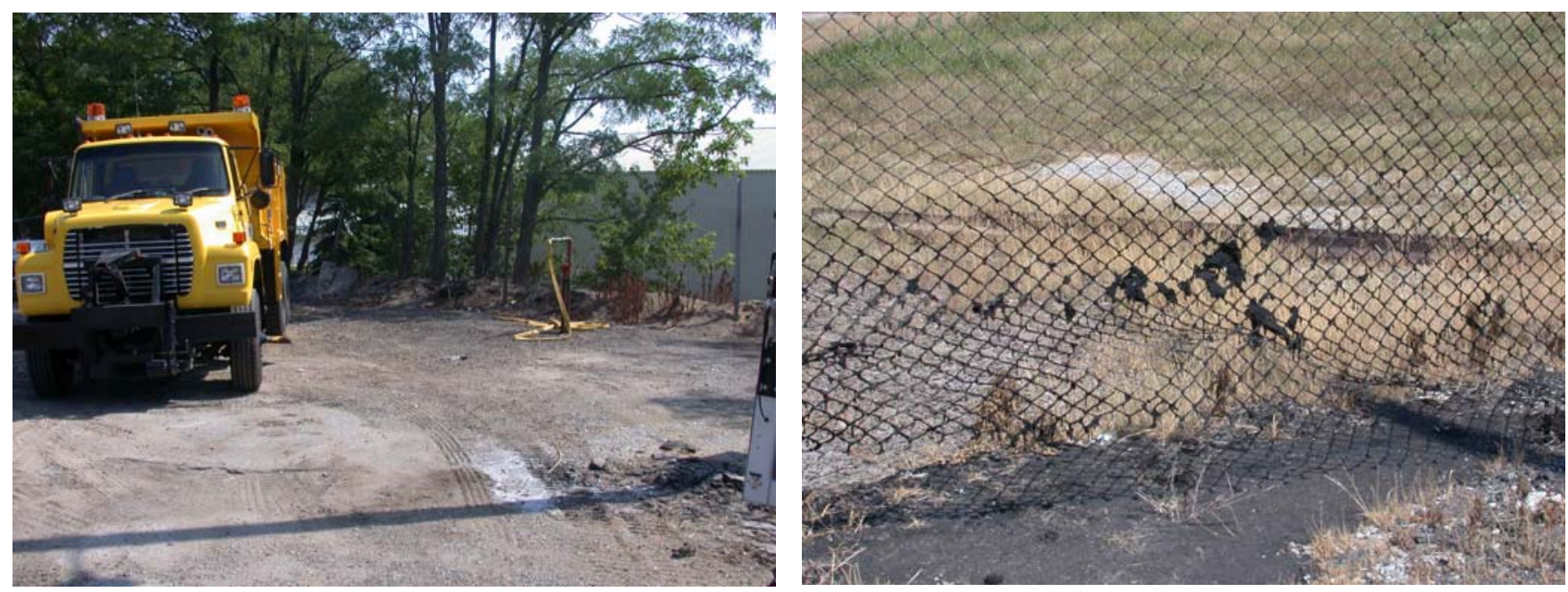
There were large piles of dirt that with paint chips and other trash in them. This could have been scalp or street sweepings. There were also large piles of asphalt grindings on site.
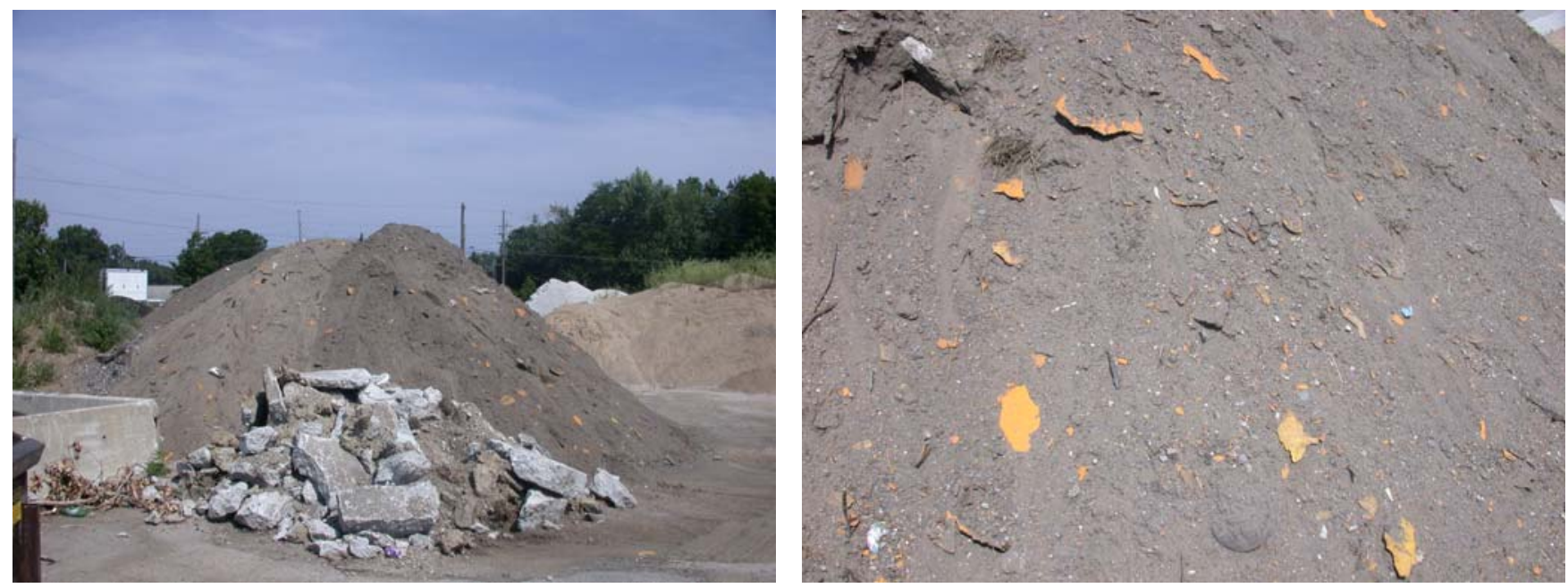

Northern Portion of Property

$>$ The entrance to the site is in the NE corner of the property. Snow plows and a tar kettle are stored against the NE fence line.

$>$ The entire NW corner of the property is used to store aggregate piles, asphalt grinding piles, cold patch, and a dumpster. There are no berms or drains in this area and the stormwater from this area flows to the NW, under the perimeter fence. The stormwater then flows north into the roadside ditch, which eventually empties into a larger drainage ditch. The name of the larger drainage ditch is unknown.

$>$ The ground outside the NW perimeter fence has salt residue on it and has suffered some vegetation kills due to salt runoff.
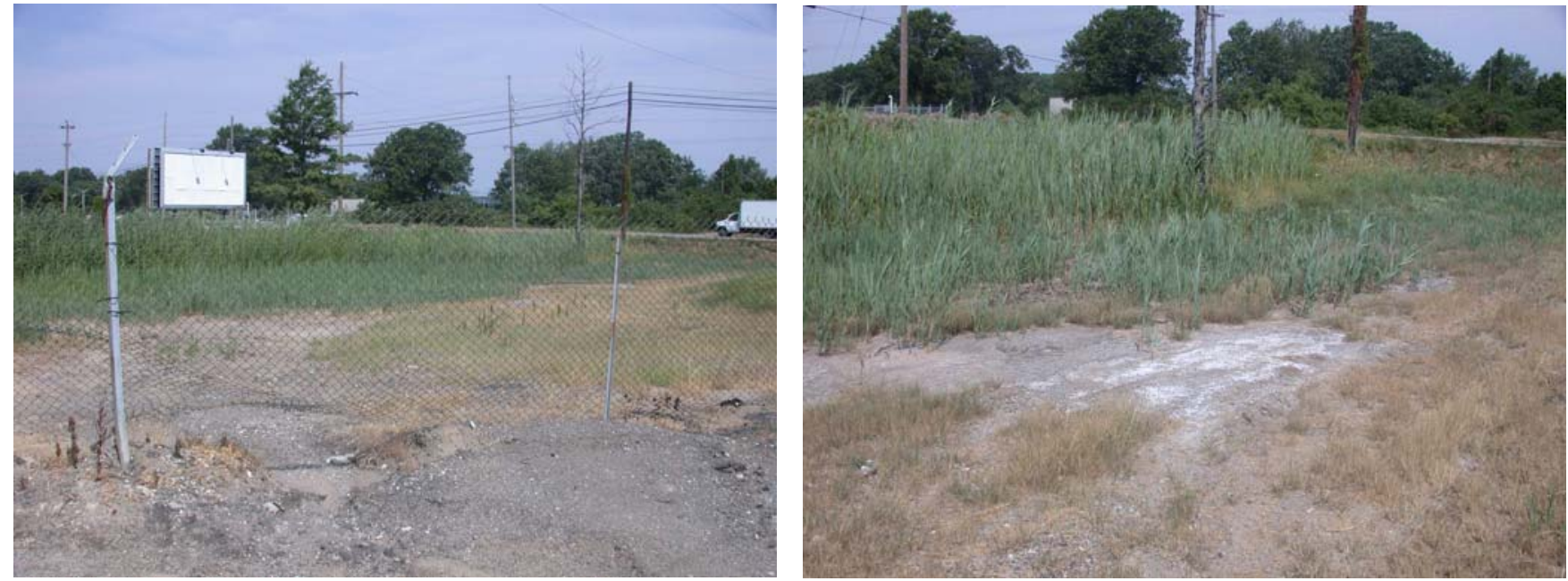
$>$ There is also a small cold storage building in the NW portion of the property that houses street signs and pressurized tanks.

Southern Portion of the Property

$>$ The Unit Building is located against the west fence line. The truck parking area is on the east side of the Unit Building.

There is a small cold storage building located on the south wall of the Unit Building. This building holds tools and other odds-and-ends.

The liquid collected in the Unit Building floor drains is conveyed onto the ground on the west side of the Unit Building, where it flows under the perimeter fence and collects in a low lying area. When this area overflows, the water flows north to the roadside ditch. There is salt residue on the ground in this area.

$>$ The Salt Dome is located in the SW corner of the site. This Salt Dome is in bad condition. There are holes in the roof that allow stormwater to enter.

$>$ On the east side of the Salt Dome, there are brine and calcium chloride tanks that are not secondarily contained. There is also scrap metal and guardrail scattered around the Salt Dome.
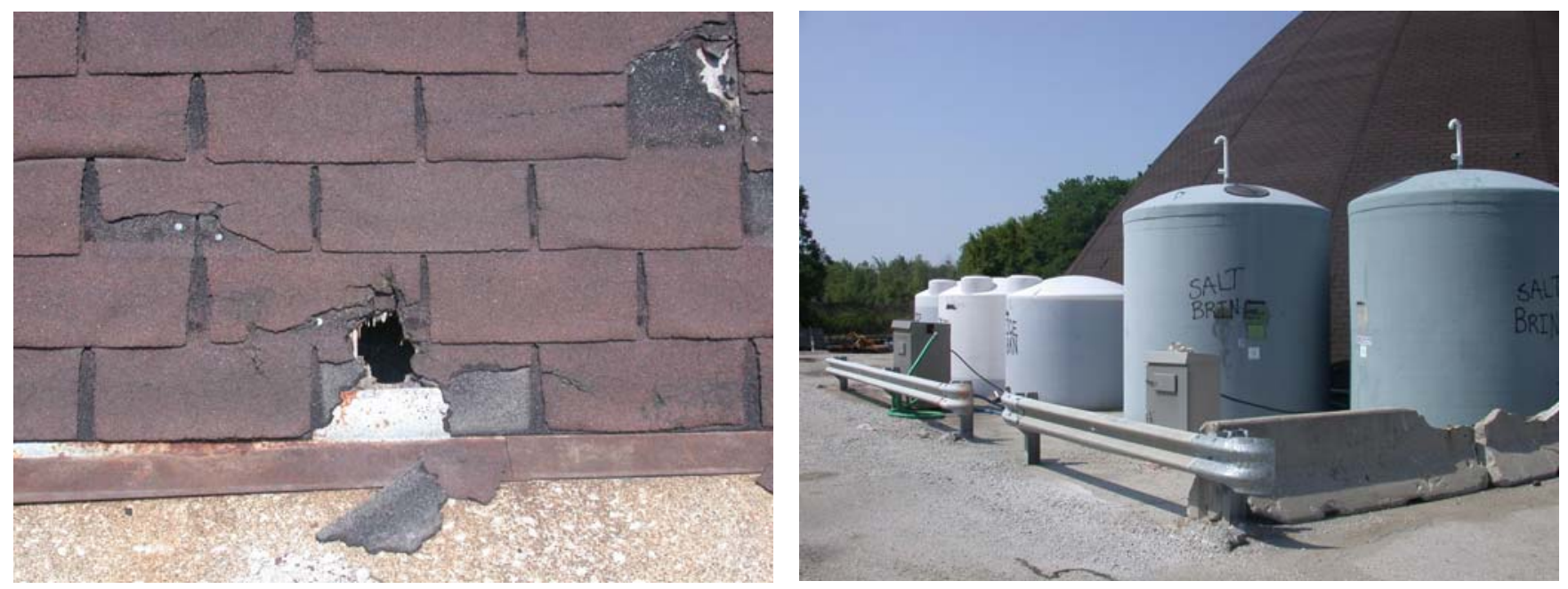

The Salt Bed Racks are located in the SE corner of the site. The area under the racks was fairly clean and free of salt.

The truck washing area is north of the salt bed racks. There is a hose connected to a fire hydrant that is used to spray the equipment. 


\section{Buildings}

Unit Building

The Unit Building is small compared to other facilities. The Unit Foreman wanted to build a pole barn for truck storage but found that the site was too narrow to accommodate for the building.

All drains from the Unit Building empty onto the ground on the west side of the building.

\section{Salt Dome}

The Salt Dome is in bad condition and needs to be repaired or replaced. The Unit Forman suggested that there had been talk of building a new facility on a new site and shutting the existing facility down. However, he was not sure if it would happen anytime soon.

There are weep holes that allow water inside the Salt Dome to drain outside, onto the ground. Due to the holes in the Salt Dome, more salt contaminated water than usual is exiting at these points.

\section{* Other Buildings}

> There are two small cold storage buildings at this facility. Both are used to store tools, road signs, traffic cones, and other odds-and-ends.
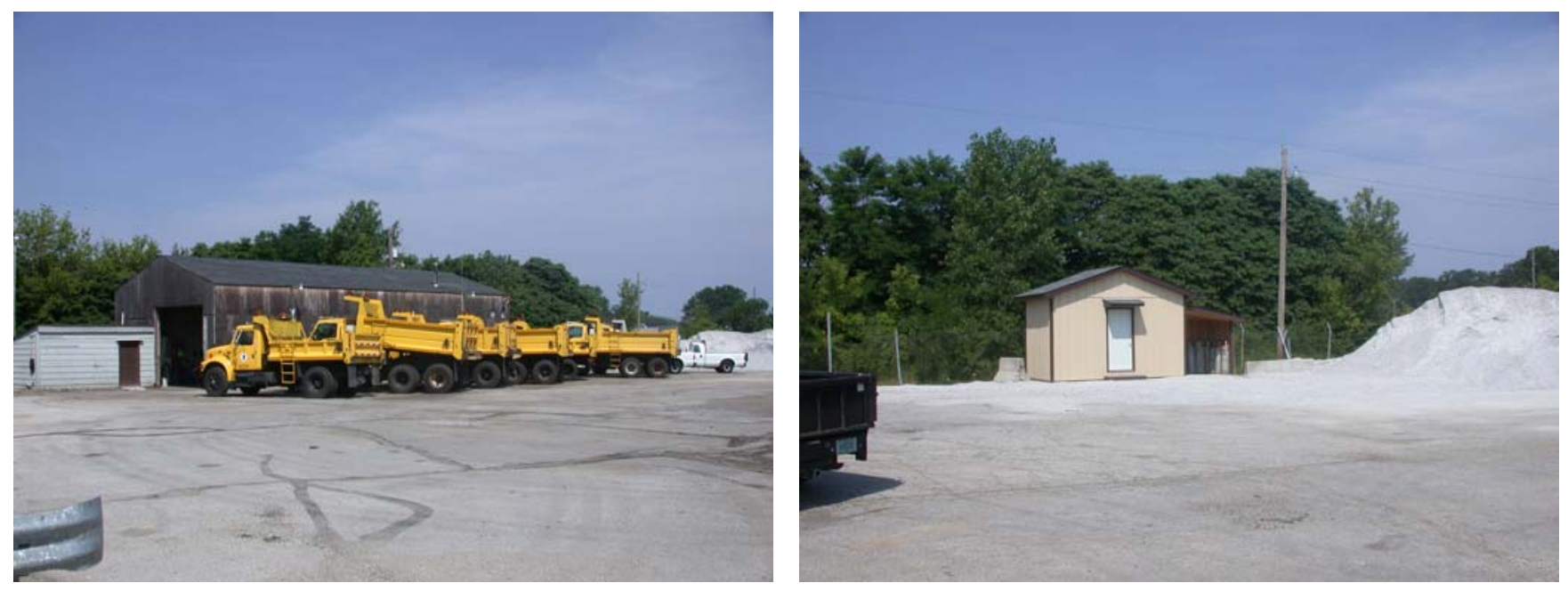


\section{INDOT Site Assessment Report Observations and Comments}

\section{$\underline{\text { Surface Area }}$}

General

$>$ This facility is not manned but it is still used for salt, brine, cold patch, and aggregate storage. Street sweepings and road debris is also dumped at this site.

$>$ What was the Unit Building has been converted into an asphalt testing lab. The drains in the testing lab drain into the city sewer.

This facility is located on a large portion of land. Over half of the property is wooded. There is a low wooded area that all surface water from the site drains to. Therefore, no surface water leaves the property.

There is a large amount of street sweepings and road debris stored on the ground at this facility.
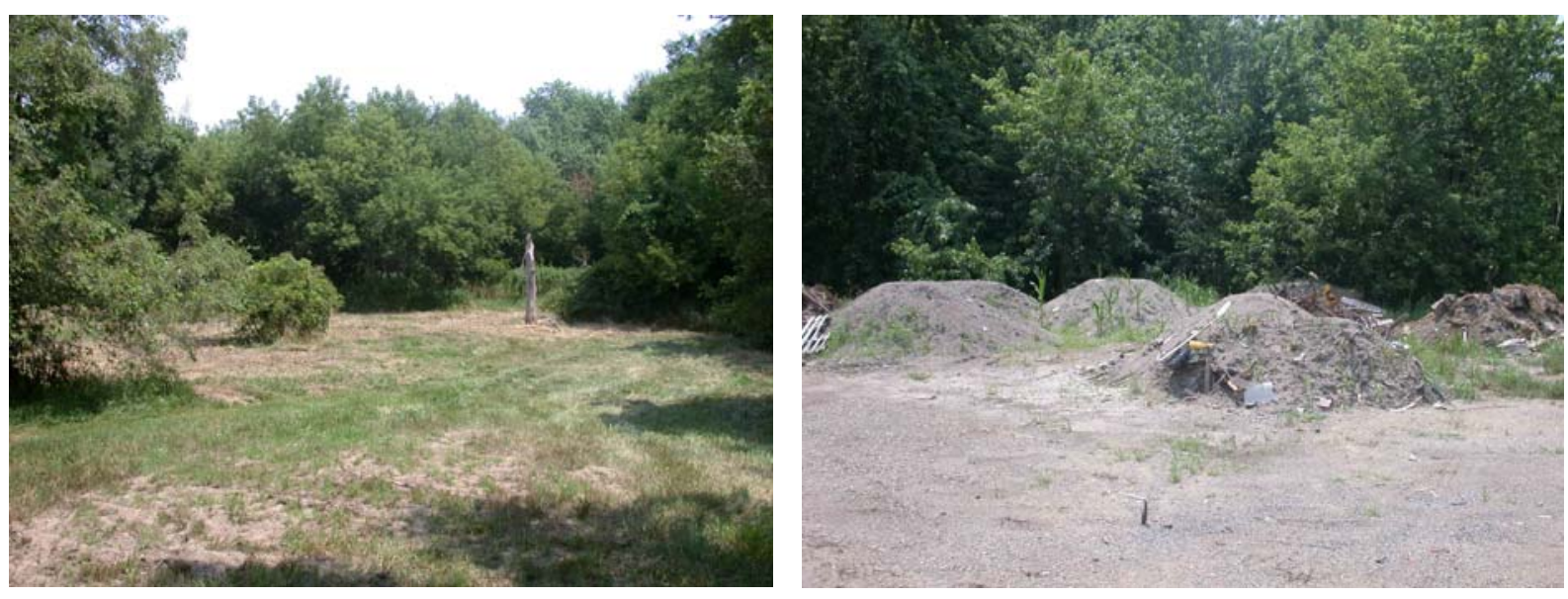
North Portion of Property

The asphalt testing lab is located in the NW corner of the site. This building used to be the Unit Building.

$>$ There are several piles of aggregate stored east of the testing lab. Most of the north property line is wooded. The perimeter is kept mowed but nothing else.

A railroad runs along the north property line.

\section{South Portion of Property}

The Salt Storage Building is located in the SE corner of the property. A sand berm is kept at the entrance of the building to prevent salt from spilling out.

There are three large brine storage tanks located on the north side of the salt storage building. There is an asphalt berm that encompasses these three tanks and acts as secondary containment.
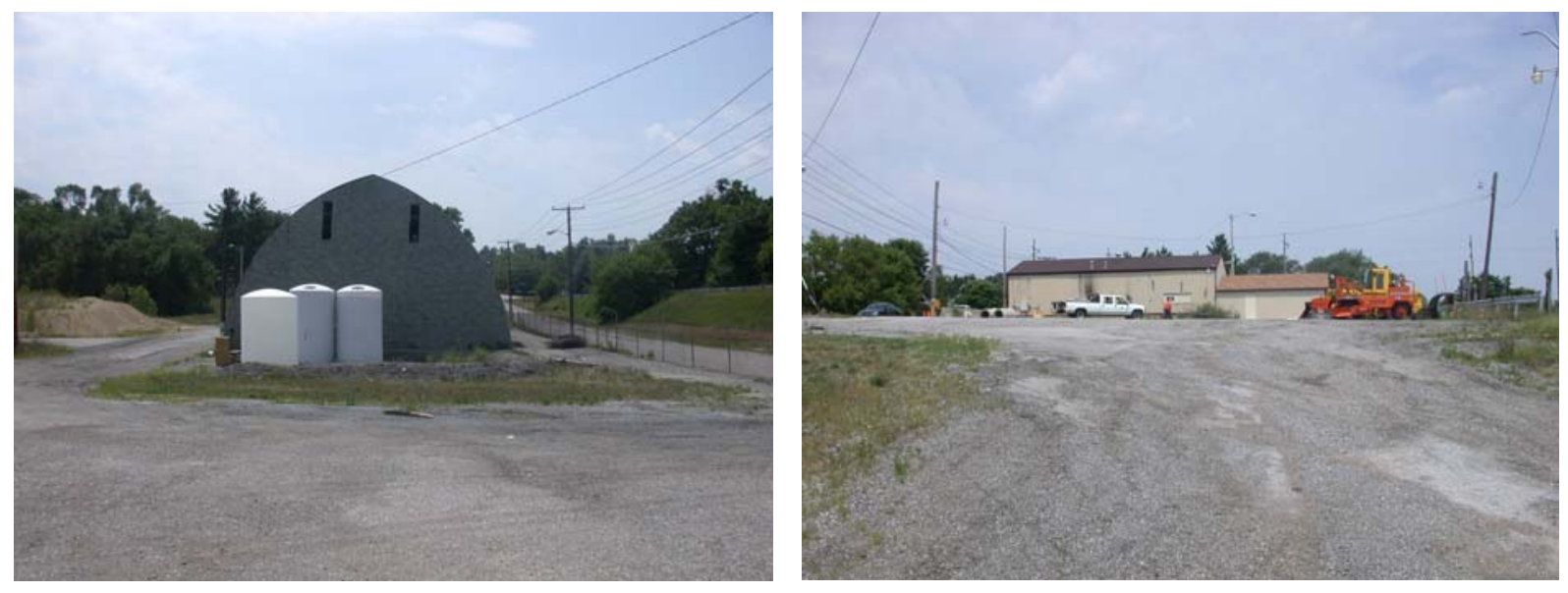

There is a pile of cold patch stored along the south fence line. This pile is not bermed and is not covered.

There are several aggregate piles stored approx. 25 yards east of the salt storage building. 

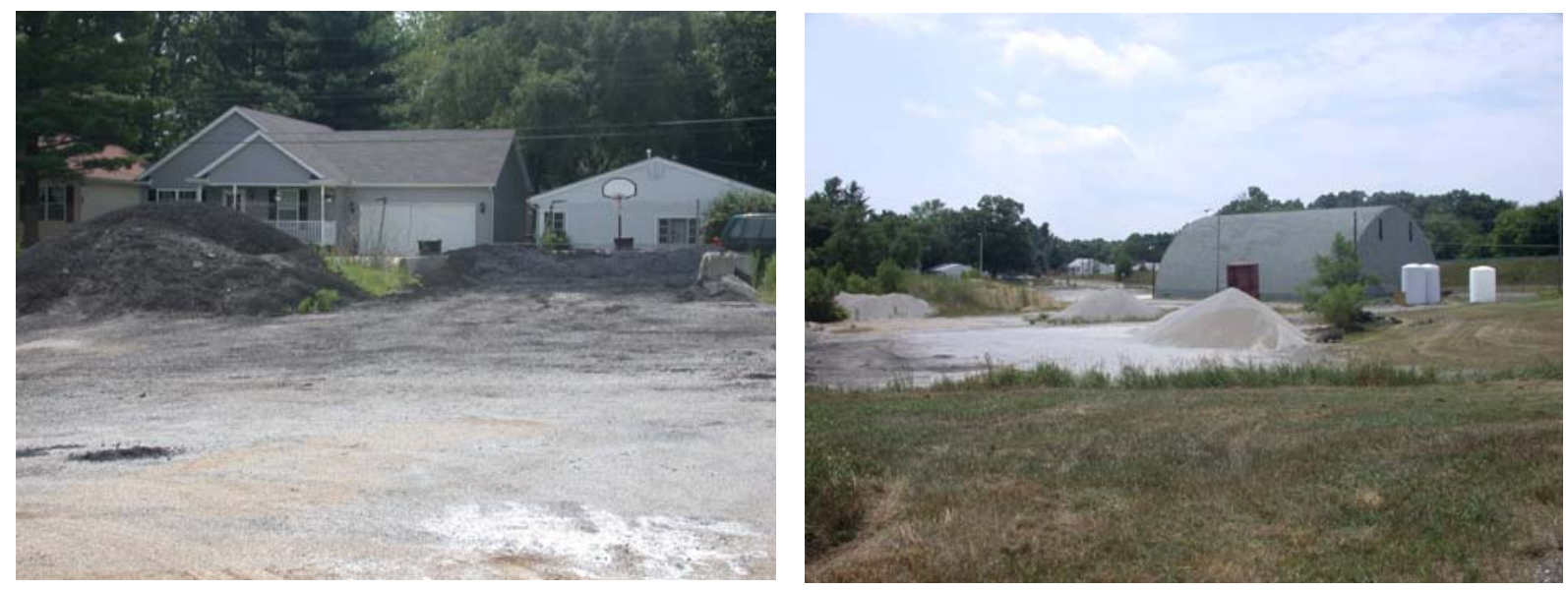

\section{Buildings}

Asphalt Testing Lab

The drains in the asphalt lab are connected to the City Sewer System

This building used to be the Unit Building when the facility was manned.

Salt Storage Building

> There was very little salt being stored in the salt storage building. There is a sand bermed at the entrance to prevent stormwater contamination. 


\section{INDOT Site Assessment Report Observations and Comments}

\section{$\underline{\text { Surface Area }}$}

General

> The facility floor drains are not connected to a Municipal Sewer System and the facility is not equipped with an oil/water separator. However, the Unit Foreman said that the bathrooms are connected to the city sewer.

D All truck and salt bed washing is performed on site. The floor drains in the Unit Building drain outside into a small ditch, which drains into an underground tile.

Asphalt tools are soaked in a 55-gallon drum of diesel fuel that is not secondarily contained or on an impervious surface.
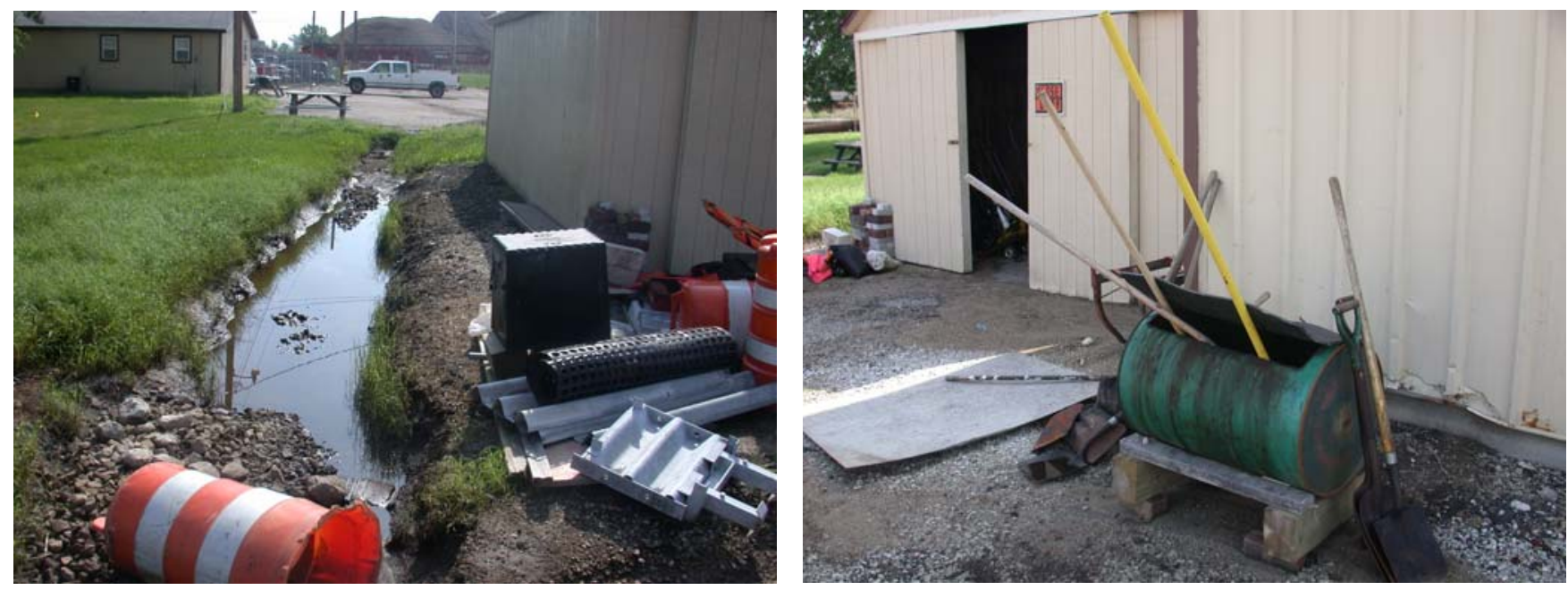

The stormwater from the site flows into a retention pond that is owned by a neighboring business. This retention pond is located just off the SW corner of the property. 
There were a large amount of unused batch asphalt bags lying in the SW corner of the property. These bags were exposed to stormwater and some were torn open and spilling onto the ground.
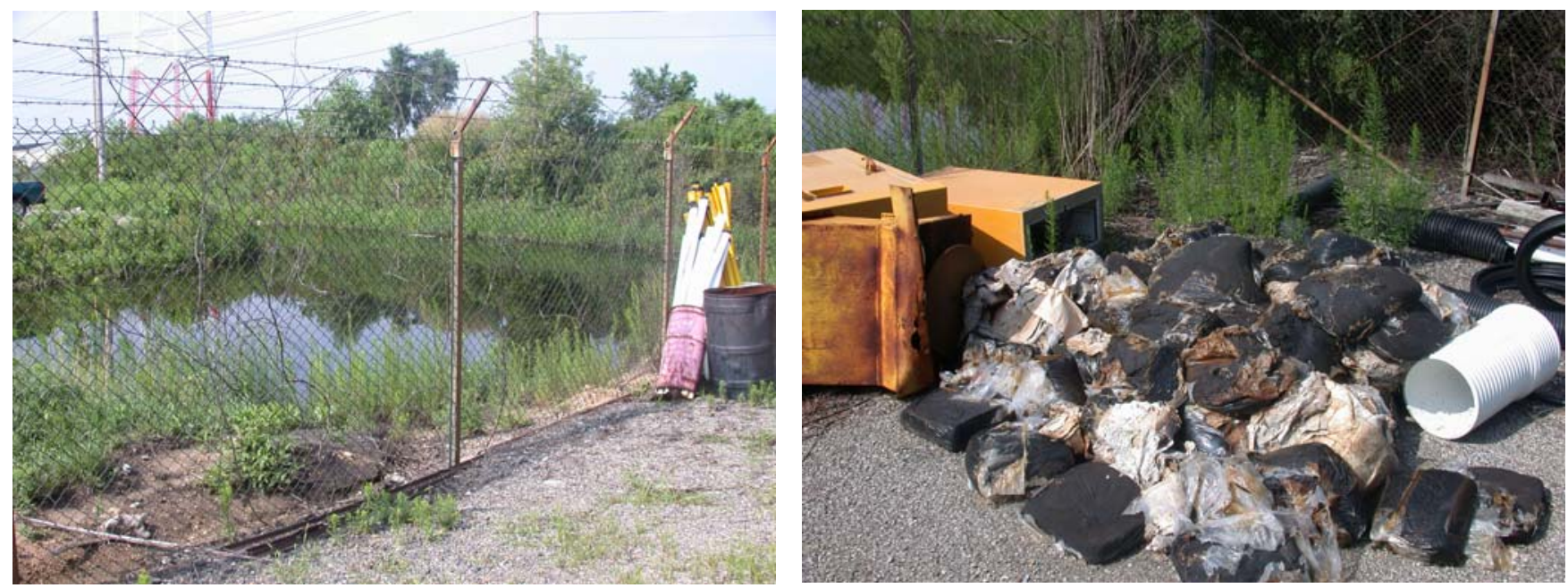

East Portion of Property

$>$ There is a small building in the NE corner of the property that has offices and a break room.

> The Unit Building is located approx. $50 \mathrm{ft}$ SW of the office building. There is a small cold storage building and a ditch on the north side of the Unit Building.

$>$ There are two large role-off dumpsters and one smaller dumpster located NW of the cold storage building.

$>$ North of the dumpsters, there is a cold patch and aggregate area. This area is located against the north fence line.
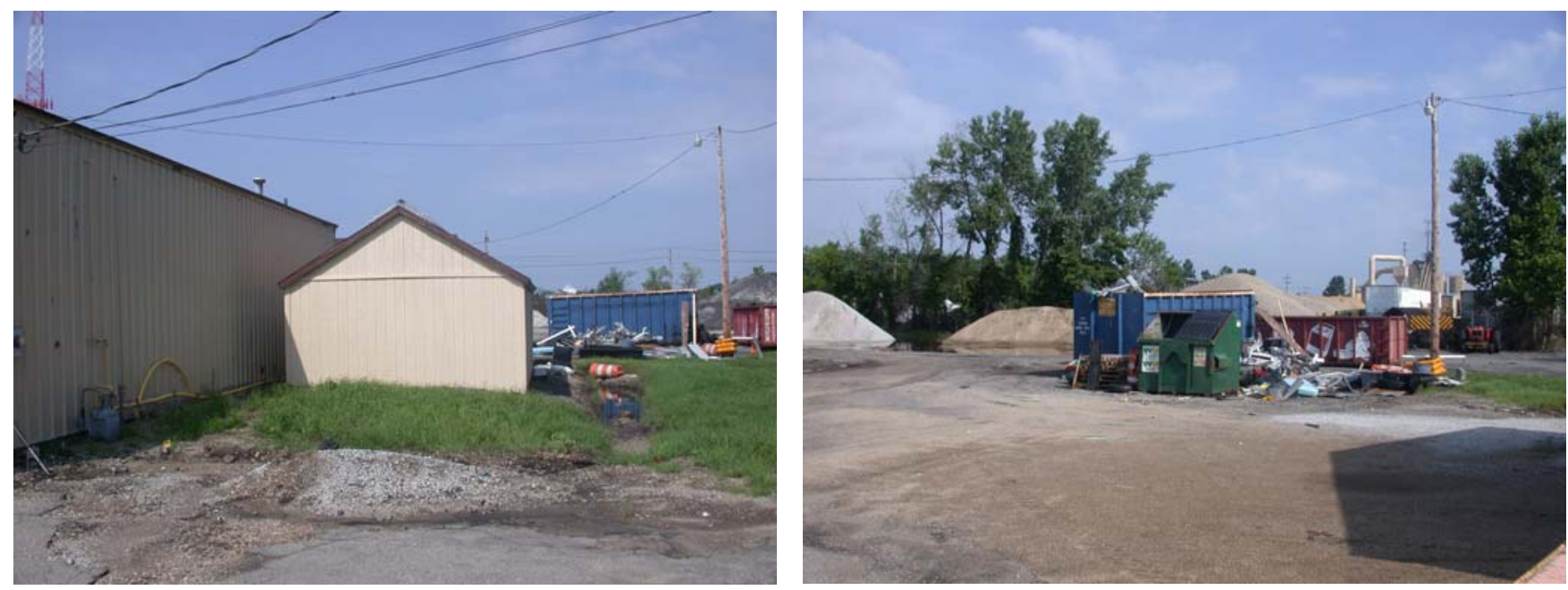
Salt trucks are parked along the SE corner of the property. This area is not bermed. The stormwater from the area flows into the perimeter ditch and eventually enters the retention pond previously described.

Salt bed racks line the south fence line along with more salt trucks. The stormwater from this area also enters the retention pond.

West Portion of Property

$>$ The Salt Dome is located in the SW corner of the property. The stormwater from this area enters the retention pond, which is only $20 \mathrm{ft}$ from the Dome.

There were a large amount of batch asphalt bags on the SW side of the Salt Dome along with metal scrap and other trash that should be disposed of properly.

$>$ There is a vehicle maintenance building located approx. $100 \mathrm{ft}$ east of the Salt Dome. There are no floor drains in this building. All drums of vehicle fluid were secondarily contained at the time of the site visit.

$>$ There are 3 brine and calcium chloride tanks located on the west side of the vehicle maintenance building. These tanks are bermed with an asphalt curb.
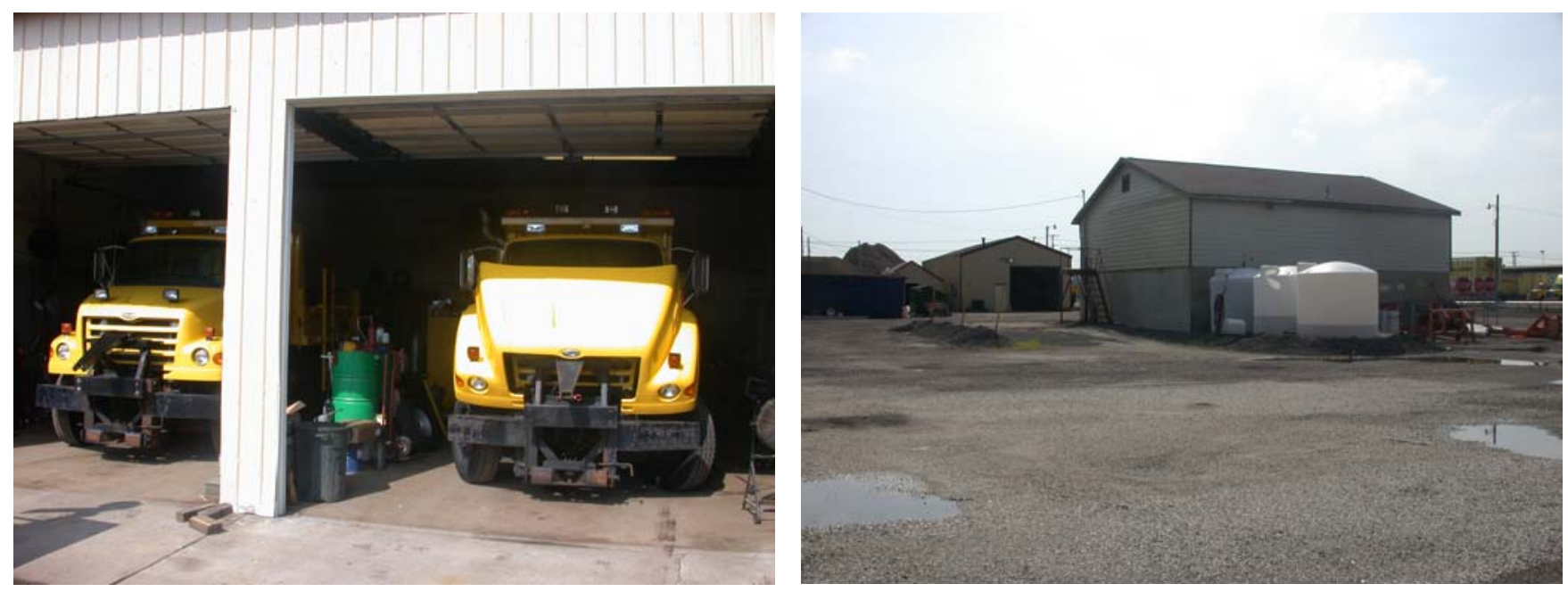
The entire NW corner of the property is filled with piles of aggregate and asphalt grindings. This corner is low and holds some water during wet periods.
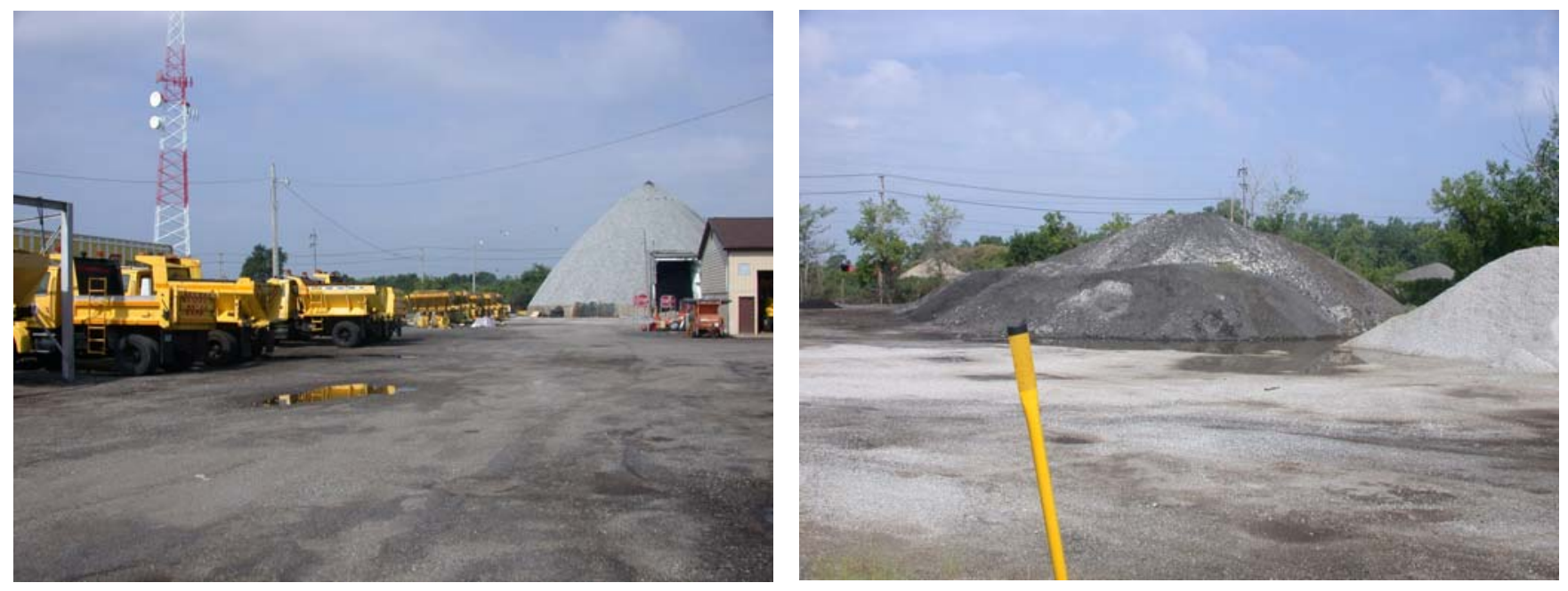

$\underline{\text { Buildings }}$

* Unit Building

The Unit Building contains a large water tank that is used to wash salt beds and trucks. This tank and a water pump allows for higher pressure water, which makes cleaning the salt beds and trucks easier.

The floor drains collect all liquid and conveys it to a small ditch outside the Unit Building. This ditch drains into an underground corrugate pipe.

Salt Dome

The Salt Dome entrance was bermed with a sand dike. The area around the entrance was fairly clean and free of salt at the time of the site visit

Vehicle Maintenance Building

This building is only large enough to hold two trucks at one time. All drums were secondarily contained. There are no drains in this building.

* Cold Storage Building

$>$ The small cold storage building is used to store tools, signs, and herbicide. The containers of herbicide were not secondarily contained.

* Office building

This building housed offices, a break room, and bathrooms. The Unit Foreman said that the bathrooms are the only thing connected to the city sewer. 


\section{INDOT Site Assessment Report Observations and Comments}

\section{Surface Area}

General

$>$ This Facility is connected to a sewer system, which is owned by the city of Wanatah. Wastewater from the washbay and facility floor drains is treated by an oil/water separator before entering the sewer system. Several on-site storm drains also discharge to the sewer system.

There are two large detention ponds on site. The smaller of the two(pictured on left) is in the Southwest corner of the property and has dimensions of 150' $x$ 170' $x$ 7'. The larger detention pond(pictured on right) is in the Northeast corner of the property and has dimensions of 610' $x$ 100' $x$ 7'.
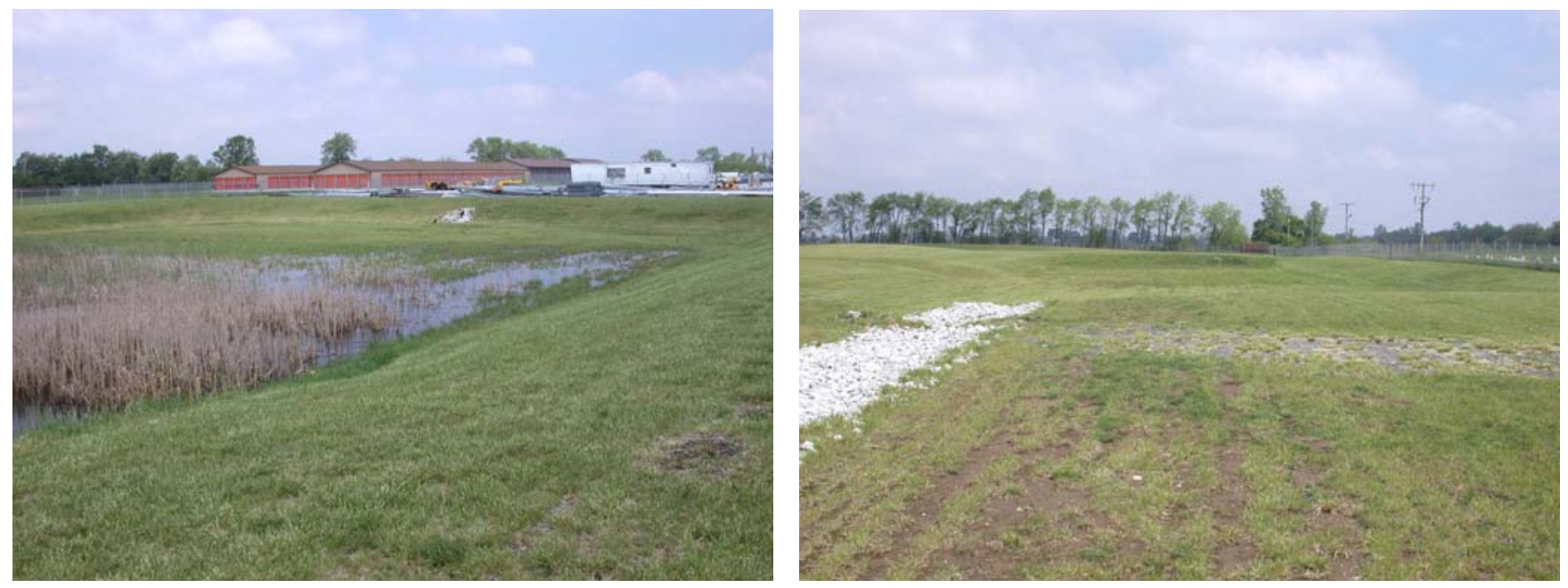

There is a 210 lot on the Southwest portion of the site.

The Salt Dome is equipped with a Load-Out Building in which all salt/sand mixing and salt bed loading is performed.

The area under the salt bed racks is bermed. A catch basin captures all stormwater inside this bermed area and it is conveyed to the sewer system. 
South Property Line

The entrance to the site is on the South property line. The employee parking lot and the Unit Building is in the Southeast corner of the site.

The washbay is housed in the Unit Building and contains brine production equipment.

A secondarily contained waste oil tank is located on the north side of the Unit Building.

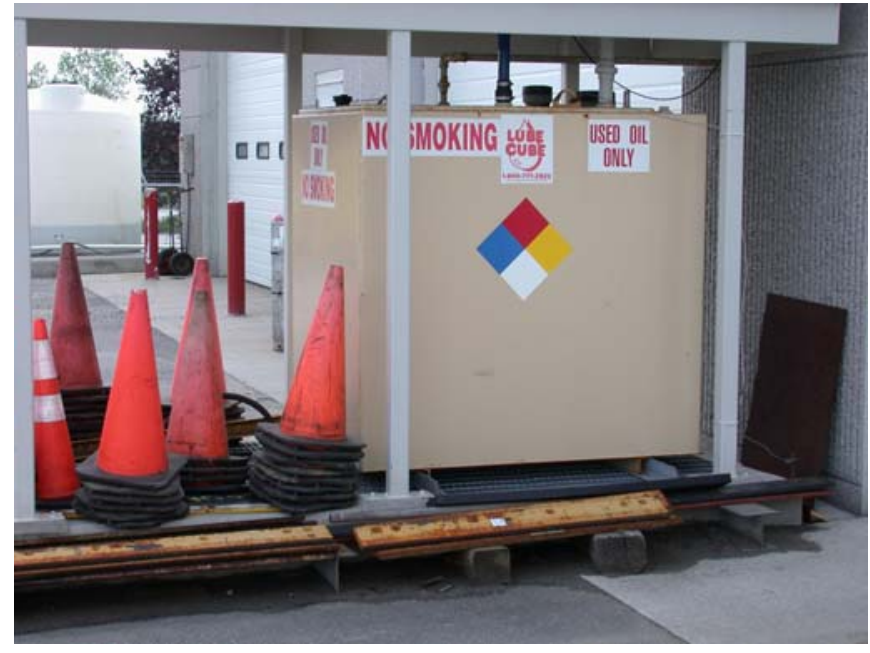

$>$ The brine storage tanks are on the East side of the Unit Building and are NOT secondarily contained. There is a vegetation kill on the East property line, which is coming from the brine storage tanks. Any leakage from the tanks flows under the perimeter fence onto adjacent property.
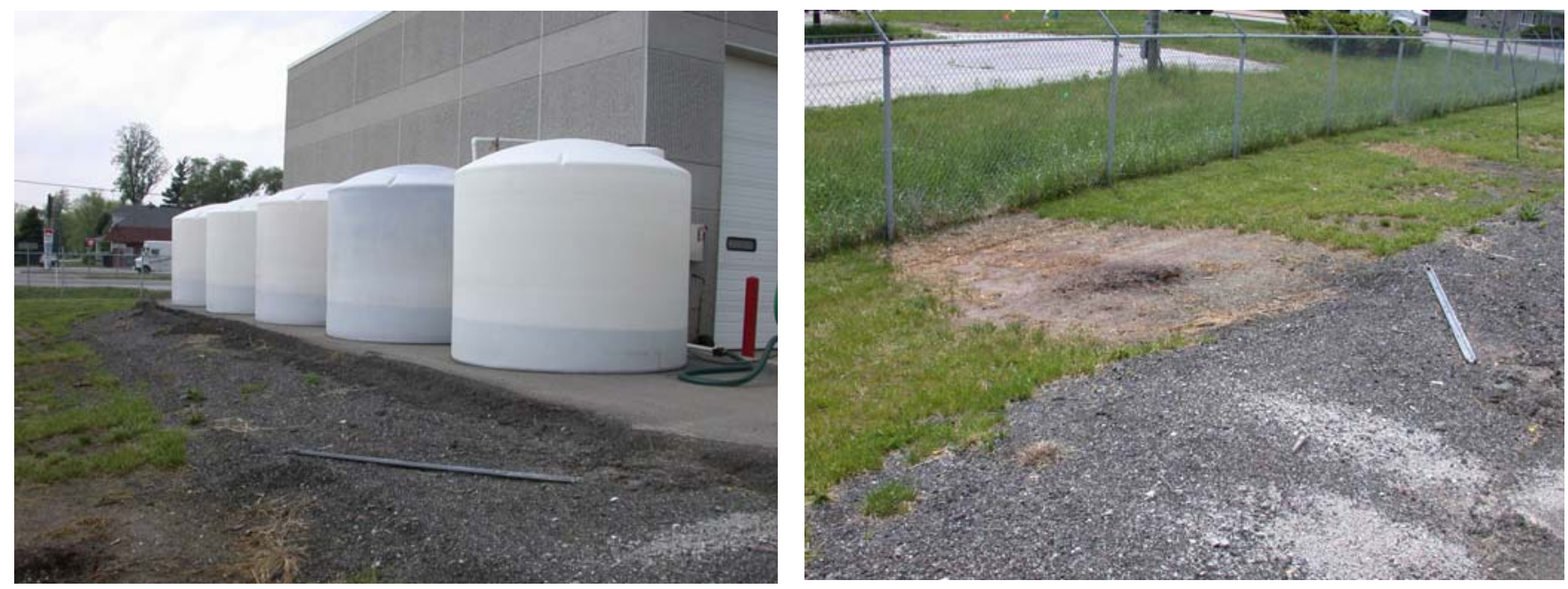
As previously stated, there is a detention pond in the Southwest corner of the site. This detention pond receives stormwater from the employee parking lot, the main driveway, and the 210 lot. The pond has an overflow pipe to the roadside ditch, which runs along the South property line. However, considering the size of the detention pond the overflow is not used often.

The 210 lot is located on the west property line, north of the detention pond. At the time of the site visit, the only thing being stored on the 210 lot were several INDOT vehicles awaiting auction.

$>$ The area north of the Unit Building, along the east property line, is used to store cold patch and snow plows. The cold patch is not bermed and was not covered with a tarp. The stormwater from this area flows under the perimeter fence onto adjacent property.

$>$ The vehicle parking area is located approximately 70 yards west of the cold patch storage area. The parking area is a gravel strip surrounded by asphalt. There is a catch basin located 10 feet east of the gravel area that discharges to the sewer system.

$>$ The Salt Dome is located approximately 25 yards north of the vehicle parking area. This dome is equipped with a Load-Out Building, which covers the entrance. All salt/sand mixing and salt bed loading is performed inside this building. No stormwater comes in contact with this area. There is also a trench drain in the Load-Out Building, which discharges to the sewer system.
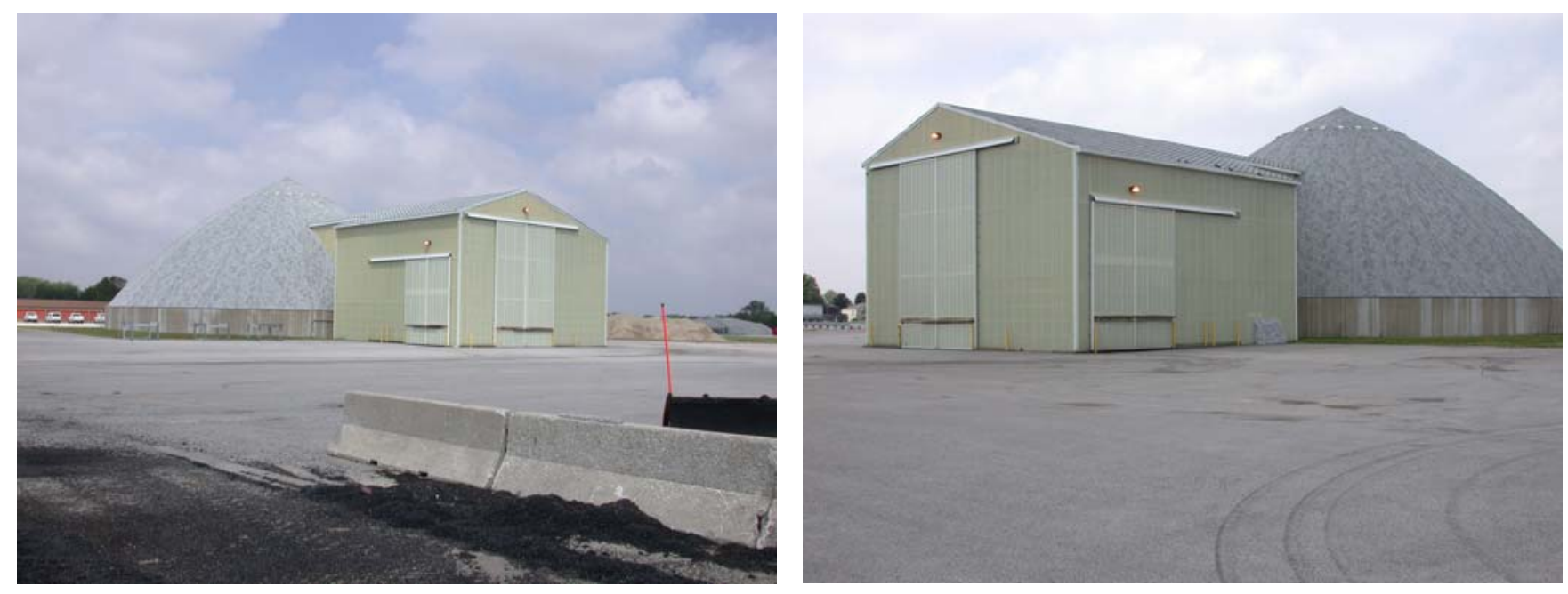
The salt bed racks are located northeast of the Salt Dome along the East property line. The area under the racks slopes toward the east property line and is bermed with a concrete curb. A catch basin captures all stormwater collected inside the bermed area and it is conveyed to the sewer system.
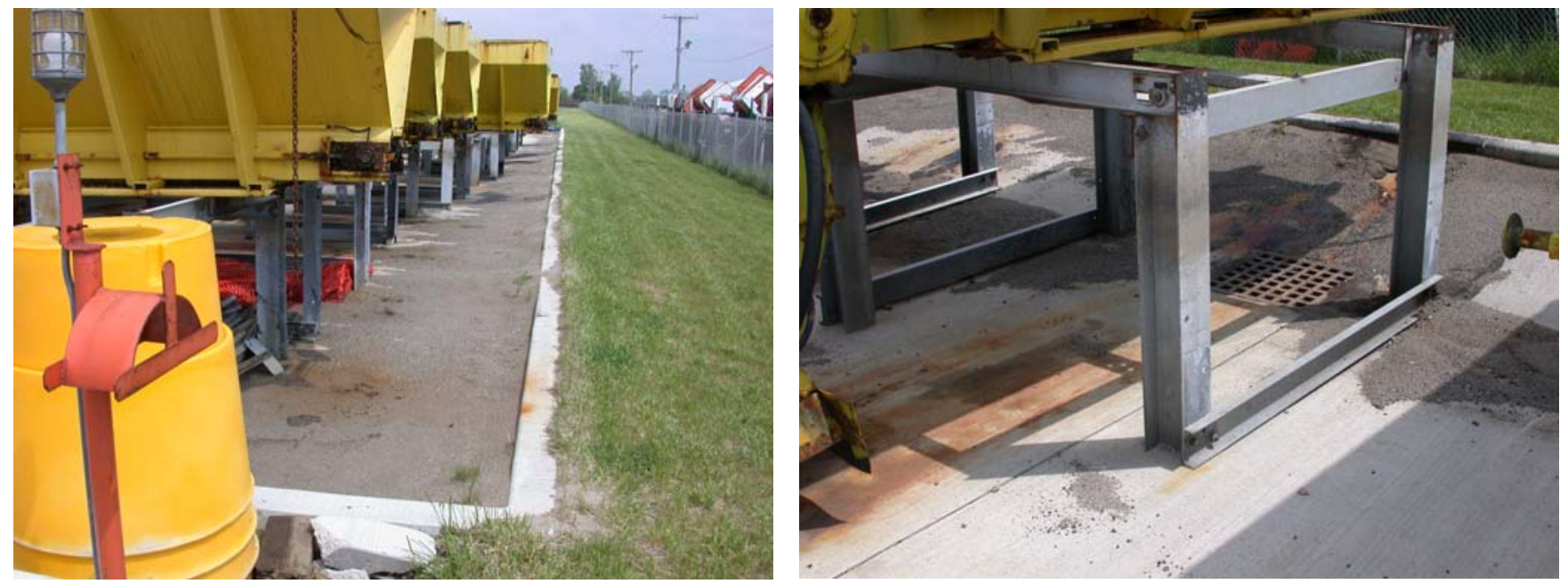

\section{* North Property Line}

$>$ The detention pond on the Northern portion of the site takes up nearly the entire Northeast property line. This Pond receives the surface water from the Northern half of the site and some from the northern portion of the 210 lot. This pond has an overflow pipe on the northeast corner that leads off site and drains directly into Slocum Ditch. However, considering the size of the detention pond the overflow is not used often.

$>$ The Northwest property line is used to store several aggregate piles, scrap metal, and a compost pile. The stormwater from this area enters a perimeter ditch that eventually empties into the Northeast detention pond.
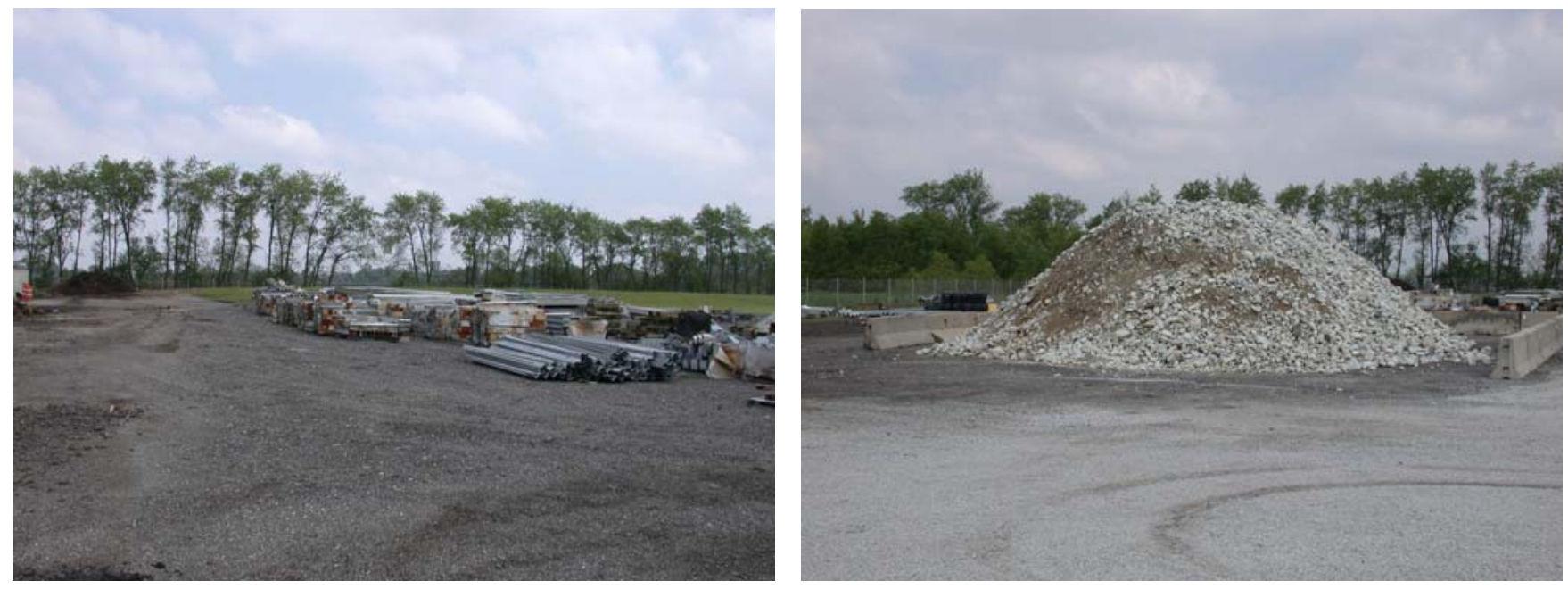
Buildings

* Unit Building

The Unit Building is divided into three areas: Offices, Vehicle Maintenance, and Washbay. Water collected in all floor drains flows through the oil/water separator before being discharged into the sewer system. This facility is not equipped with a washwater reuse system.

$>$ Brine production equipment is housed in the washbay. The brine storage tanks are located on the east side of the building and are not secondarily contained.

$>$ Inside the Unit Building, all drums were properly secondarily contained on either containment pallets or constructed containment pits.

$>$ Waste oil is stored in an outside tank that is located on the north side of the building. This waste oil tank is secondarily contained.

* Salt Dome

The Salt Dome is described and pictured on page 3. 


\section{INDOT Site Assessment Report Observations and Comments}

\section{Surface Area}

General

$>$ There was snow on the ground on the day of the visit, which made it difficult to see any signs of salt or oil residue.

There is a fence along the East side of the property(road side), however, no other property line is fenced.

The site is connected to a combined sewer system which is owned by the City of Winamac.

$>$ Two catch basins, which are located between the Sub and Unit Buildings, are connected to the combined sewer. They are spaced approx. 35 feet apart and are used for storm water collection. All other storm water on the property flows into Stone Dilts Ditch, which I was informed by the Foreman, flows into the Tippeconoe River approx. 1.5 miles from the site.

* South Property Line (bordered entirely by Stone Dilts Ditch)

$>$ The Unit Building is located on the SE corner of the property. Behind this building are large containers of Calcium Chloride, Brine, and Ice Ban. These containers are protected by concrete barricades but have no secondary containment for leaks. Any leak or spillage will drain into Stone Dilts Ditch (approximately 40 feet south of the building).

West of the Unit Building is a parking area for trucks and tractors. This area slopes toward Stone Dilts Ditch and is not bermed. Runoff easily flows under the trucks and directly into the ditch. The Foreman also explained that this is the area were the asphalt truck sits while off-loading. He mentioned that these trucks often leak asphalt onto the ground. 
West of the parking area is a small building that stores herbicide chemicals. We did not enter this building. A 4 to 5 inch concrete curb surrounding the building serves as secondary containment.

$>$ In the SW corner of the property there is a paint storage building. We did not enter the building, and there were no berms visible. This area also slopes toward Stone Dilts Ditch.

- West Property Line (bordered by a small ditch which drains into Stone Dilts Ditch)

$>$ The Salt Dome is located north of the paint building on the West property line. Between the paint building and the dome, there is an area of asphalt which is covered with, what looked like, paint overspray. The Foreman said that some paint mixing and sign painting took place in this area. There were no berms, and the property sloped toward the West ditch (which was approx. 15 feet to the West).

Just west of the painting area, there were approx. 15-20 empty 55-gallon paint drums stacked on their sides at the edge of the ditch. One drum was missing its lid, and a significant amount of yellow paint had poured out onto the ground and mixed with snow. This area was not bermed, and it sloped into the West ditch.

The Foreman stated that he paid very little attention to the paint area because it was handled by an outside contractor.

$>$ North of the Salt Dome is a storage area for large drain pipes. A few feet north is the salt bed storage area (racks). This area is gravel, has no berm, and is approx. 20 feet from the West ditch.

On the NW corner of the site there are several large piles of aggregate. There is also a large pile of trash (wooden pallets, tree limbs, etc.) and a compost pile for road kill, surrounded by concrete barricades, located approx. 30 yds from the ditch. The entire NW corner slopes toward the North and West ditches that border the property.

\section{Buildings}

Sub and Unit Buildings

There is an Oil/Water separator in both the Unit Building and the Sub Building. The Oil/Water separator in the Sub Building is below ground, and in the Unit Building it is above ground. 
There are lateral drains in both buildings which run down the center of the floor in order to collect any spills from truck maintenance. The floors are sloped toward the center of the building to prevent any spilled liquids from exiting the building. These drains run to the Oil/Water separator and then to the combined sewer.

$>$ There is a separate room in the Sub Building for washing trucks and salt beds. This room also has a drain which runs to the Oil/Water separator and then to the combined sewer.

$>$ Old and new oil along with other engine fluids are stored in the Sub Building, adjacent to the wash bay. There were approx. 5-10 55 gallon drums kept in this fenced area. Spills will migrate to the floor drain, then to the oil/water separator and on to the combined sewer system. Therefore, secondary containment is needed beneath the drums to allow for capture, collection, and recovery of spills and leaks.

* Salt Dome

$>$ There was a small amount of salt outside the door of the dome but there was no evidence of any salt running off onto the ground.

There was a small pile of cold patch sitting on the concrete pad in front of the dome. Don Arnold recommended that the pile be covered with a tarp to prevent it from coming in contact with storm water.

$>$ When asked if storm water, in front of the salt dome, drained from the loading area and onto the ground, the Foreman's response was that much of the water flows into the salt dome were it evaporates, implying that very little salt was lost onto the ground.

* Other Buildings

$>$ There were several buildings on the property which we did not enter: the herbicide building, the paint storage building, the flower and seed storage building, and the cold storage building. 
FACILITY SITE ASSESSMENT REPORTS SEYMOUR DISTRICT 
Date_3/2/2005

INDOT Facility Stormwater and Washwater Effluent Drainage Assessment

Name of Facility __Beanblossom Unit

District/Subdistrict__Seymour

\section{$\underline{\text { Surface Water }}$}

1. Does any area of the active surface collect storm water or facility-generated wash water (such as from washing trucks outdoors)? _

2. Is there any movement of surface water from one area to another on-site by ditch, drain tile or natural channel? _ Yes, by ditch

3. Is there any movement of surface water off-site (e.g., beneath the perimeter fence) via sheet flow, ditch, pipe or channel to adjacent property? __ $\underline{\text { Yes }}$

4. Is the surface water discharged directly to (check all that apply) -

$\square$ drainage ditch or roadside ditch

$\square$ county-regulated drain

$\square$ state highway drainage system

$\square$ a nearby creek, river or other water body

$\square \quad$ lagoon or holding pond

$\square$ settling basin, catch basin, or other constructed retention structure

$\square$ underground tank

$\square$ municipal storm sewer Owner

$\square$ municipal combined storm/sanitary sewer Owner

$\square$ POTW Owner:

$\square$ Other

5. If surface water is discharged, other than to a municipal storm, sanitary or combined sewer, does it ultimately reach "waters of the state” (e.g., farm ditch, creek, stream, river, lake or pond)? If yes, name of that water body. _ Y Yes, North Fork Creek

6. What is the estimated distance of this water body from the facility? 350 feet from the property line 


\section{$\underline{\text { Shop Floor Drain \& Wash Bay Effluent }}$}

1. Are there drains in shop floors and wash bays that remove liquids and wash water effluent from the building(s)? _ Y Yes

2. Does the effluent flow to -

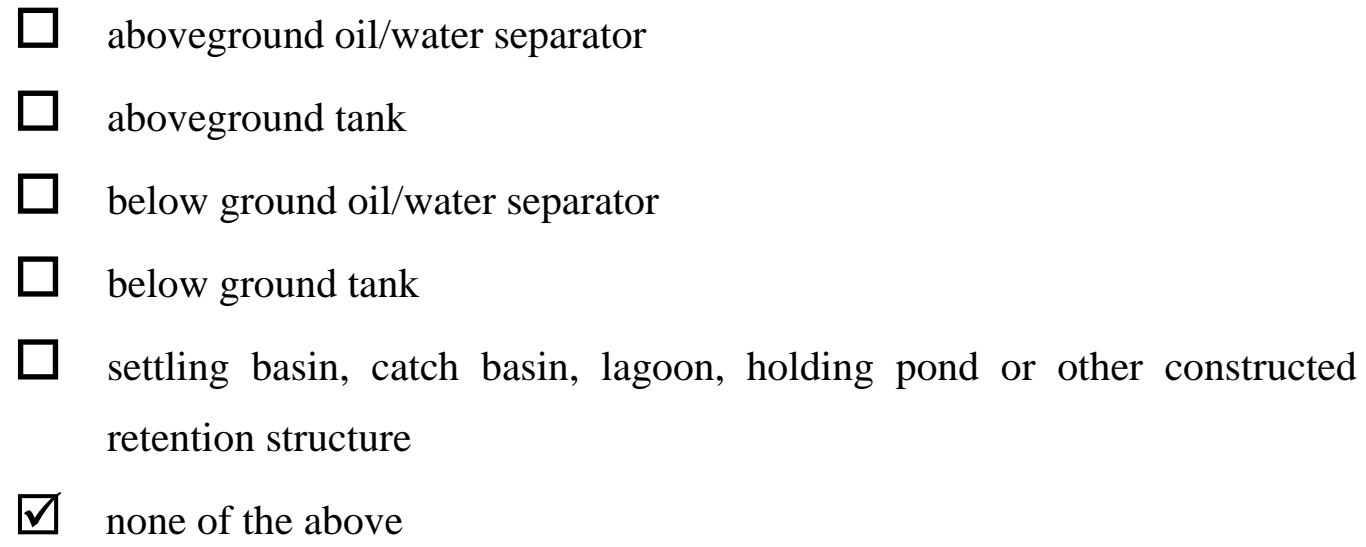

3. If the effluent is captured by the devices in 2., above, is it contained until pumped and hauled to a POTW or until it evaporates, or does it overflow to a drainage system?

4. If the effluent overflows to a drainage system, is the system above or below ground? __Below ground

5. If the effluent overflows to a drainage system, does it mix with storm water?_Y Yes

6. If the effluent does mix with storm water, see "Surface Water" section (preceding page, \#4 and \#5) for discharge.

7. If the effluent doesn't mix with storm water, is it discharged to -

$\square$ subsurface soils

$\square$ on-site septic system

$\square$ drainage ditch or roadside ditch

$\square$ a nearby creek, river or other water body

$\square \quad$ lagoon or holding pond

$\square$ municipal storm sewer Owner

$\square$ municipal combined storm/sanitary sewer Owner

$\square$ municipal POTW Owner 
8. If shop floor drain and wash bay effluent is discharged, other than to a municipal storm, sanitary or combined sewer, does it ultimately reach "waters of the state?" If yes, name of that water body: __ Yes, North Fork Creek

Activity Areas (check those that apply and describe (1) whether they are bermed to prevent storm water runoff or (2) if there are drains and their locations in the activity areas)

$\square \quad$ salt storage (pads or domes) ___ No berm or drain

$\square$ salt/sand mixing__ Done inside salt storage building

$\square$ salt bed loading/wetting___Loading is done inside salt storage building, there is no_ salt bed wetting performed at this facility

$\square$ salt bed washout

$\square$ salt bed storage _ No berm or drain

$\square \quad$ vehicle and equipment washing (inside)

$\square$ vehicle and equipment washing (outside)

$\square \quad$ asphalt equipment clean-out

$\square$ herbicide mixing and tank rinsing__ Storage and mixing take place onsite. No berm or drains

$\square \quad$ traffic paint mixing and transfer

$\square \quad$ bulk tank off-loading and storage

$\square$ waste piles (e.g., ROW trash, street sweeping debris)

$\square \quad$ truck/equipment parking__No berm or drain

$\square \quad$ truck/equipment fueling

$\square$ materials storage (210 lot, fencing, etc.) __ No berm or drain

$\square$ aggregate storage__ No berm or drain

$\square$ hot/cold patch storage __ No berm or drain

$\square$ storage of “scalp” and dirt from R/W maintenance__ No berm or drain 
Date_8/17/2005

\section{INDOT Facility Stormwater and Washwater Effluent Drainage Assessment}

Name of Facility __old Amity Unit
District/Subdistrict___ Seymour__

\section{$\underline{\text { Surface Water }}$}

1. Does any area of the active surface collect storm water or facility-generated wash water (such as from washing trucks outdoors)? _

2. Is there any movement of surface water from one area to another on-site by ditch, drain tile or natural channel? ___ Yes

3. Is there any movement of surface water off-site (e.g., beneath the perimeter fence) via sheet flow, ditch, pipe or channel to adjacent property? _

4. Is the surface water discharged directly to (check all that apply) -

$\square$ drainage ditch or roadside ditch

$\square$ county-regulated drain

$\square \quad$ state highway drainage system

$\square$ a nearby creek, river or other water body

$\square \quad$ lagoon or holding pond

$\square$ settling basin, catch basin, or other constructed retention structure

$\square$ underground tank

$\square \quad$ municipal storm sewer Owner

$\square$ municipal combined storm/sanitary sewer Owner

$\square$ POTW Owner:

$\square$ Other

5. If surface water is discharged, other than to a municipal storm, sanitary or combined sewer, does it ultimately reach "waters of the state” (e.g., farm ditch, creek, stream, river, lake or pond)? If yes, name of that water body. __ Yes, Sugar Creek

6. What is the estimated distance of this water body from the facility? 300 yards 


\section{Shop Floor Drain \& Wash Bay Effluent}

1. Are there drains in shop floors and wash bays that remove liquids and wash water effluent from the building(s)? _ Yes

2. Does the effluent flow to -

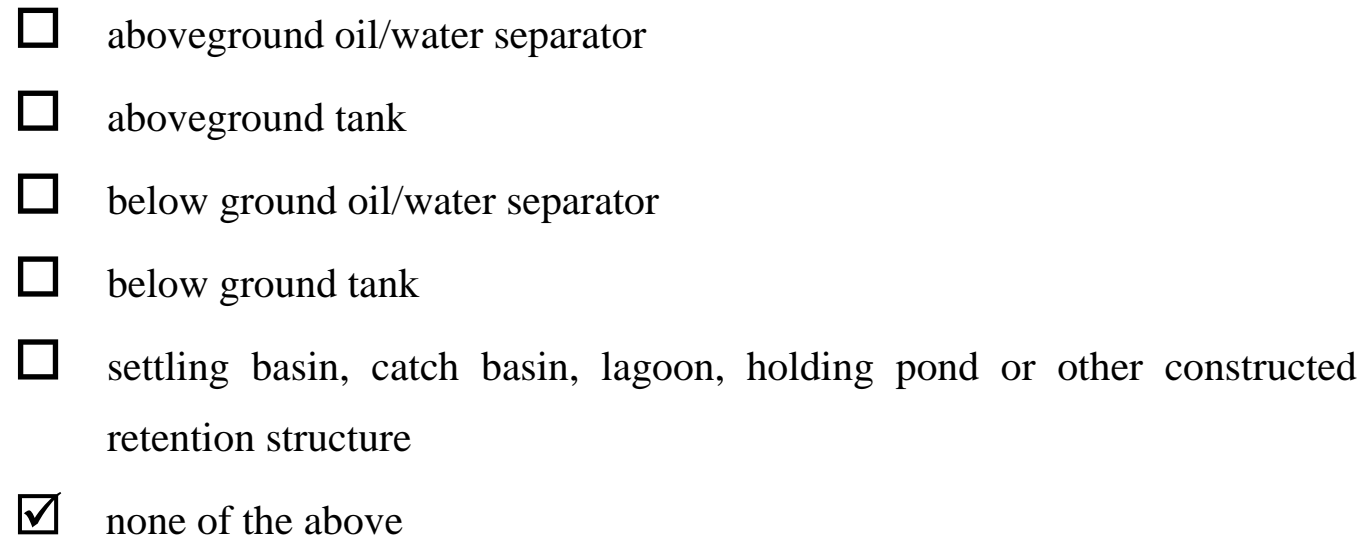

3. If the effluent is captured by the devices in 2., above, is it contained until pumped and hauled to a POTW or until it evaporates, or does it overflow to a drainage system?

4. If the effluent overflows to a drainage system, is the system above or below ground?

5. If the effluent overflows to a drainage system, does it mix with storm water?

6. If the effluent $\underline{\text { does }}$ mix with storm water, see "Surface Water" section (preceding page, \#4 and \#5) for discharge.

7. If the effluent doesn't mix with storm water, is it discharged to -

$\square \quad$ subsurface soils

$\square \quad$ on-site septic system

$\square$ drainage ditch or roadside ditch

$\square$ a nearby creek, river or other water body

$\square \quad$ lagoon or holding pond

$\square \quad$ municipal storm sewer Owner

$\square$ municipal combined storm/sanitary sewer Owner

$\square$ municipal POTW Owner 
8. If shop floor drain and washbay effluent is discharged, other than to a municipal storm, sanitary or combined sewer, does it ultimately reach "waters of the state?" If yes, name of that water body: _ Y Yes, Sugar Creek

Activity Areas (check those that apply and describe (1) whether they are bermed to prevent $\underline{\text { storm water runoff or (2) if there are drains and their locations in the activity areas) }}$

$\square$ salt storage (pads or domes) __ No berm or drain

$\square$ salt/sand mixing _ No berm or drain

$\square$ salt bed loading/wetting _No berm or drain

$\square \quad$ salt bed washout

$\square \quad$ salt bed storage __ No berm or drain

$\square \quad$ vehicle and equipment washing (inside)

$\square \quad$ vehicle and equipment washing (outside)

$\square$ asphalt equipment clean-out __ No berm or drain

$\square \quad$ herbicide mixing and tank rinsing

$\square \quad$ traffic paint mixing and transfer

$\square$ bulk tank off-loading and storage

$\square \quad$ waste piles (e.g., ROW trash, street sweeping debris) __ Dumpsters

$\square \quad$ truck/equipment parking __ No berm or drain

$\square \quad$ truck/equipment fueling

$\square$ materials storage (210 lot, fencing, etc.)

$\square$ aggregate storage __ No berm or drain

$\square$ hot/cold patch storage __ No berm or drain

$\square$ storage of “scalp” and dirt from R/W maintenance 
Date__8/3/2005

\section{INDOT Facility Stormwater and Washwater Effluent Drainage Assessment}

Name of Facility __Brookville Unit__
District/Subdistrict___ Seymour

\section{$\underline{\text { Surface Water }}$}

Name of Facility __Brookville Unit

1. Does any area of the active surface collect storm water or facility-generated wash water (such as from washing trucks outdoors)? _ Y Yes

2. Is there any movement of surface water from one area to another on-site by ditch, drain tile or natural channel?

3. Is there any movement of surface water off-site (e.g., beneath the perimeter fence) via sheet flow, ditch, pipe or channel to adjacent property? _

4. Is the surface water discharged directly to (check all that apply) -

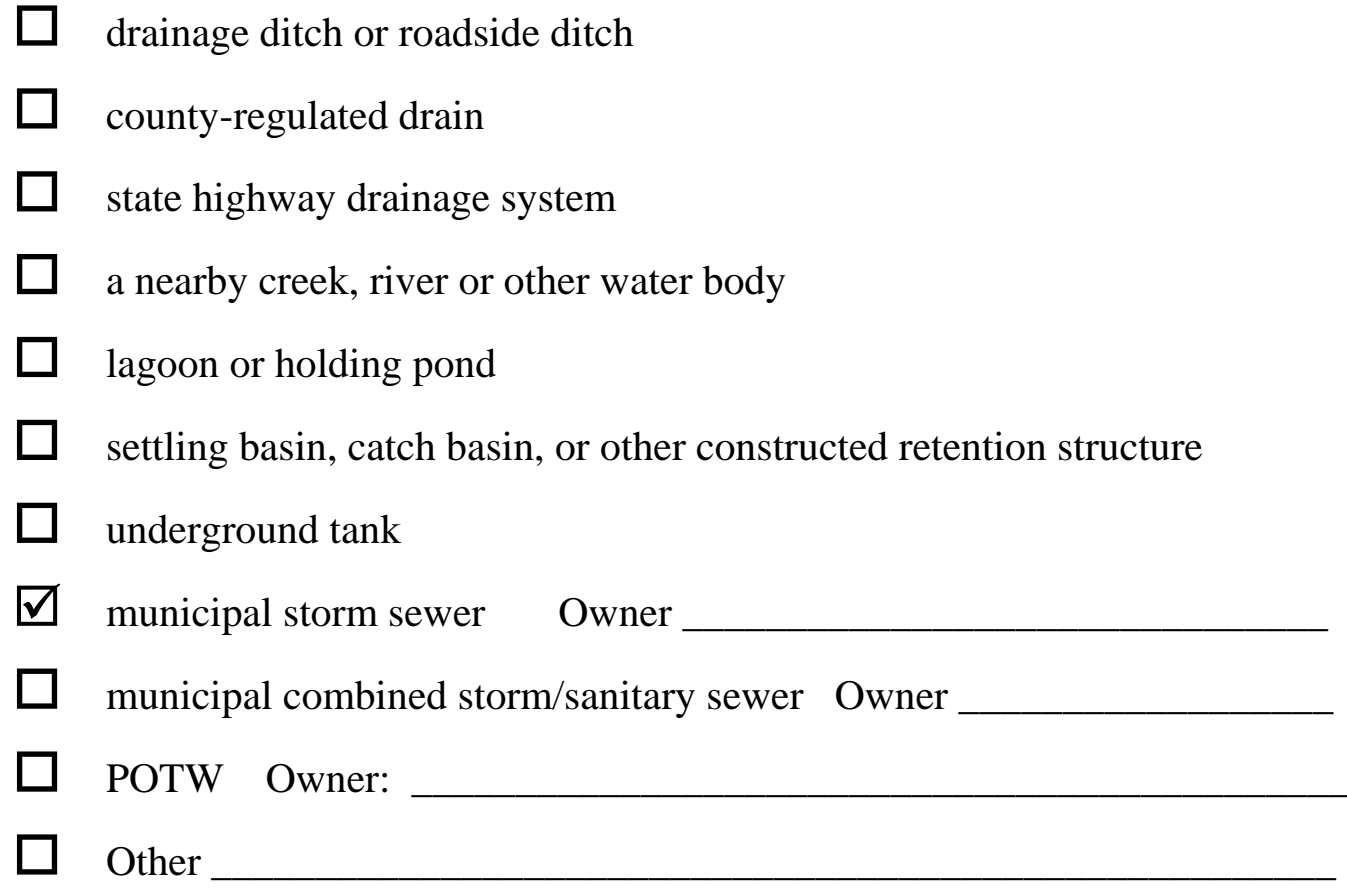

5. If surface water is discharged, other than to a municipal storm, sanitary or combined sewer, does it ultimately reach "waters of the state” (e.g., farm ditch, creek, stream, river, lake or pond)? If yes, name of that water body. __ To municipal storm sewer only

6. What is the estimated distance of this water body from the facility? 


\section{Shop Floor Drain \& Wash Bay Effluent}

1. Are there drains in shop floors and wash bays that remove liquids and wash water effluent from the building(s)? _

2. Does the effluent flow to -

$\square$ aboveground oil/water separator

$\square$ aboveground tank

$\square$ below ground oil/water separator

$\square$ below ground tank

$\square$ settling basin, catch basin, lagoon, holding pond or other constructed retention structure

$\square$ none of the above

3. If the effluent is captured by the devices in 2., above, is it contained until pumped and hauled to a POTW or until it evaporates, or does it overflow to a drainage system?___overflows to a municipal sewer system

4. If the effluent overflows to a drainage system, is the system above or below ground? _ below

5. If the effluent overflows to a drainage system, does it mix with storm water? _ No

6. If the effluent $\underline{\text { does }}$ mix with storm water, see "Surface Water" section (preceding page, \#4 and \#5) for discharge.

7. If the effluent doesn't mix with storm water, is it discharged to -

$\square \quad$ subsurface soils

$\square \quad$ on-site septic system

$\square$ drainage ditch or roadside ditch

$\square \quad$ a nearby creek, river or other water body

$\square \quad$ lagoon or holding pond

$\square \quad$ municipal storm sewer Owner

$\square$ municipal combined storm/sanitary sewer Owner

$\square$ municipal POTW Owner__Brookville WWTP 
8. If shop floor drain and washbay effluent is discharged, other than to a municipal storm, sanitary or combined sewer, does it ultimately reach "waters of the state?" If yes, name of that water body:

Activity Areas (check those that apply and describe (1) whether they are bermed to prevent storm water runoff or (2) if there are drains and their locations in the activity areas)

$\square$ salt storage (pads or domes) _ _ No berms or drains in area

$\square$ salt/sand mixing __ Performed inside salt dome

$\square$ salt bed loading/wetting ___ Loading is peformed outside salt dome. _ All trucks are equipped with saddle tanks so there is no bed spraying

$\square$ salt bed washout _ Performed inside Unit Building over a catch basin

$\square$ salt bed storage __ No berms or drains

$\square \quad$ vehicle and equipment washing (inside) __ Performed inside Unit Building

$\square$ vehicle and equipment washing (outside) __ Performed near stormwater catch - basin

$\square$ asphalt equipment clean-out __ Performed on job site

$\square \quad$ herbicide mixing and tank rinsing

$\square \quad$ traffic paint mixing and transfer

$\square$ bulk tank off-loading and storage

$\square \quad$ waste piles (e.g., ROW trash, street sweeping debris) __ Dumpsters

$\square \quad$ truck/equipment parking _ _ No berm or drains

$\square \quad$ truck/equipment fueling

$\square$ materials storage (210 lot, fencing, etc.) __ No berm or drains

$\square$ aggregate storage __ No berms or drains

$\square$ hot/cold patch storage _ Covered with tarp, No berm

$\square$ storage of “scalp” and dirt from R/W maintenance 
Date_ $3 / 2 / 2005$

\section{INDOT Facility Stormwater and Washwater Effluent Drainage Assessment}

Name of Facility ___ Columbus Sub
District/Subdistrict__ Seymour___

\section{$\underline{\text { Surface Water }}$}

1. Does any area of the active surface collect storm water or facility-generated wash water (such as from washing trucks outdoors)? _ Yes

2. Is there any movement of surface water from one area to another on-site by ditch, drain tile or natural channel? __ Yes, ditch and drain tile

3. Is there any movement of surface water off-site (e.g., beneath the perimeter fence) via sheet flow, ditch, pipe or channel to adjacent property? __ Yes, by ditch

4. Is the surface water discharged directly to (check all that apply) -

$\square$ drainage ditch or roadside ditch

$\square$ county-regulated drain

$\square \quad$ state highway drainage system

$\square$ a nearby creek, river or other water body

$\square \quad$ lagoon or holding pond

$\square \quad$ settling basin, catch basin, or other constructed retention structure

$\square$ underground tank

$\square$ municipal storm sewer Owner

$\square$ municipal combined storm/sanitary sewer Owner

$\square$ POTW Owner:

$\square$ Other

5. If surface water is discharged, other than to a municipal storm, sanitary or combined sewer, does it ultimately reach "waters of the state" (e.g., farm ditch, creek, stream, river, lake or pond)? If yes, name of that water body. __ Yes, Driftwood River

6. What is the estimated distance of this water body from the facility?

Approx. $1 / 2$ to $2 / 3$ miles

(Rev 2/7/05) 


\section{$\underline{\text { Shop Floor Drain \& Wash Bay Effluent }}$}

1. Are there drains in shop floors and wash bays that remove liquids and wash water effluent from the building(s)? _ Yes

2. Does the effluent flow to -

$\square$ aboveground oil/water separator

$\square \quad$ aboveground tank

$\square$ below ground oil/water separator

$\square$ below ground tank

$\square$ settling basin, catch basin, lagoon, holding pond or other constructed retention structure

$\square$ none of the above

3. If the effluent is captured by the devices in 2., above, is it contained until pumped and hauled to a POTW or until it evaporates, or does it overflow to a drainage system? Enters the Sanitary Sewer System

4. If the effluent overflows to a drainage system, is the system above or below ground? Below ground

5. If the effluent overflows to a drainage system, does it mix with storm water? №

6. If the effluent does mix with storm water, see "Surface Water" section (preceding page, \#4 and \#5) for discharge.

7. If the effluent doesn't mix with storm water, is it discharged to -

$\square$ subsurface soils

$\square \quad$ on-site septic system

$\square$ drainage ditch or roadside ditch

$\square$ a nearby creek, river or other water body

$\square \quad$ lagoon or holding pond

$\square$ municipal storm sewer Owner

$\square$ municipal combined storm/sanitary sewer Owner

$\square$ municipal POTW Owner_Columbus City 
8. If shop floor drain and wash bay effluent is discharged, other than to a municipal storm, sanitary or combined sewer, does it ultimately reach "waters of the state?" If yes, name of that water body: __ No

Activity Areas (check those that apply and describe (1) whether they are bermed to prevent storm water runoff or (2) if there are drains and their locations in the activity areas)

$\square$ salt storage (pads or domes) _ No berm, there is a drain in the vicinity

$\square$ salt/sand mixing _ No berm, there is a drain in the vicinity

$\square \quad$ salt bed loading/wetting _ No berm or drain

$\square$ salt bed washout__ Done inside over drain

$\square$ salt bed storage _ No berm, there is a drain in this area

$\square \quad$ vehicle and equipment washing (inside) __ Done in wash bay over a floor drain

$\square \quad$ vehicle and equipment washing (outside)

$\square$ asphalt equipment clean-out _ Tools are cleaned inside near a drain

$\square$ herbicide mixing and tank rinsing _ mixing is performed inside

$\square \quad$ traffic paint mixing and transfer

$\square$ bulk tank off-loading and storage

$\square \quad$ waste piles (e.g., ROW trash, street sweeping debris) __ No berm or drain

$\square$ truck/equipment parking__No berm, there is a drain in this area

$\square \quad$ truck/equipment fueling

$\square$ materials storage (210 lot, fencing, etc.) __ No berms or drains

$\square$ aggregate storage_ No berms, a drain is in this area

$\square$ hot/cold patch storage _

$\square$ storage of "scalp" and dirt from R/W maintenance__ No berm, there is a drain in this area 
Date_ $3 / 2 / 2005$

\section{INDOT Facility Stormwater and Washwater Effluent Drainage Assessment}

Name of Facility __Brownstown Unit

District/Subdistrict_Seymour

\section{$\underline{\text { Surface Water }}$}

1. Does any area of the active surface collect storm water or facility-generated wash water (such as from washing trucks outdoors)? _- No

2. Is there any movement of surface water from one area to another on-site by ditch, drain tile or natural channel? _ No

3. Is there any movement of surface water off-site (e.g., beneath the perimeter fence) via sheet flow, ditch, pipe or channel to adjacent property? __ $\underline{\text { Yes }}$

4. Is the surface water discharged directly to (check all that apply) -

$\square$ drainage ditch or roadside ditch

$\square$ county-regulated drain

$\square$ state highway drainage system

$\square$ a nearby creek, river or other water body

$\square \quad$ lagoon or holding pond

$\square \quad$ settling basin, catch basin, or other constructed retention structure

$\square$ underground tank

$\square$ municipal storm sewer Owner

$\square$ municipal combined storm/sanitary sewer Owner

$\square$ POTW Owner:

$\square$ Other

5. If surface water is discharged, other than to a municipal storm, sanitary or combined sewer, does it ultimately reach "waters of the state” (e.g., farm ditch, creek, stream, river, lake or pond)? If yes, name of that water body. _ Y Yes, Wayman Ditch, which empties into White River approx. 13/4 miles south of the facility

6. What is the estimated distance of this water body from the facility? _ Waymen Ditch borders the East property line 


\section{$\underline{\text { Shop Floor Drain \& Wash Bay Effluent }}$}

1. Are there drains in shop floors and wash bays that remove liquids and wash water effluent from the building(s)? _ Y Yes

2. Does the effluent flow to -

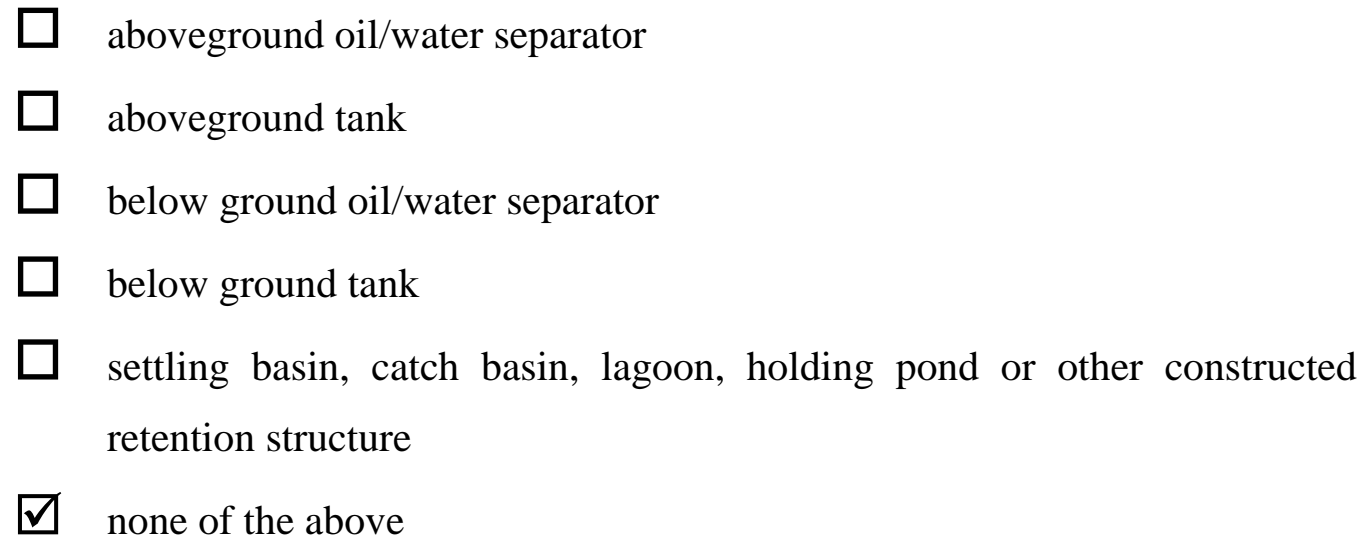

3. If the effluent is captured by the devices in 2., above, is it contained until pumped and hauled to a POTW or until it evaporates, or does it overflow to a drainage system?

4. If the effluent overflows to a drainage system, is the system above or below ground?

5. If the effluent overflows to a drainage system, does it mix with storm water?

6. If the effluent does mix with storm water, see "Surface Water" section (preceding page, \#4 and \#5) for discharge.

7. If the effluent doesn't mix with storm water, is it discharged to -

$\square \quad$ subsurface soils

$\square$ on-site septic system

$\square$ drainage ditch or roadside ditch

$\square$ a nearby creek, river or other water body

$\square \quad$ lagoon or holding pond

$\square$ municipal storm sewer Owner

$\square$ municipal combined storm/sanitary sewer Owner

$\square \quad$ municipal POTW Owner 
8. If shop floor drain and wash bay effluent is discharged, other than to a municipal storm, sanitary or combined sewer, does it ultimately reach "waters of the state?" If yes, name of that water body: _ Yes, it enters directly into Wayman Ditch

Activity Areas (check those that apply and describe (1) whether they are bermed to prevent storm water runoff or (2) if there are drains and their locations in the activity areas)

$\square \quad$ salt storage (pads or domes)

$\square$ salt/sand mixing

$\square$ salt bed loading/wetting

$\square$ salt bed washout__ performed offsite at a truck wash

$\square$ salt bed storage _ No berm or drain

$\square \quad$ vehicle and equipment washing (inside)

$\square$ vehicle and equipment washing (outside)

$\square$ asphalt equipment clean-out _ Done on the job

$\square$ herbicide mixing and tank rinsing

$\square \quad$ traffic paint mixing and transfer

$\square$ bulk tank off-loading and storage

$\square$ waste piles (e.g., ROW trash, street sweeping debris) __ No berm or drain

$\square \quad$ truck/equipment parking__ No berm or drain

$\square \quad$ truck/equipment fueling

$\square$ materials storage (210 lot, fencing, etc.)

$\square$ aggregate storage__ No berm or drain

$\square$ hot/cold patch storage _ _ No berm or drain

$\square$ storage of “scalp” and dirt from R/W maintenance_No berm or drain 
Date_8/4/2005

INDOT Facility Stormwater and Washwater Effluent Drainage Assessment

Name of Facility __Corydon Unit

District/Subdistrict _ Seymour

\section{$\underline{\text { Surface Water }}$}

1. Does any area of the active surface collect storm water or facility-generated wash water (such as from washing trucks outdoors)? _ _ Yes

2. Is there any movement of surface water from one area to another on-site by ditch, drain tile or natural channel? ___ Yes

3. Is there any movement of surface water off-site (e.g., beneath the perimeter fence) via sheet flow, ditch, pipe or channel to adjacent property? __ Yes

4. Is the surface water discharged directly to (check all that apply) -

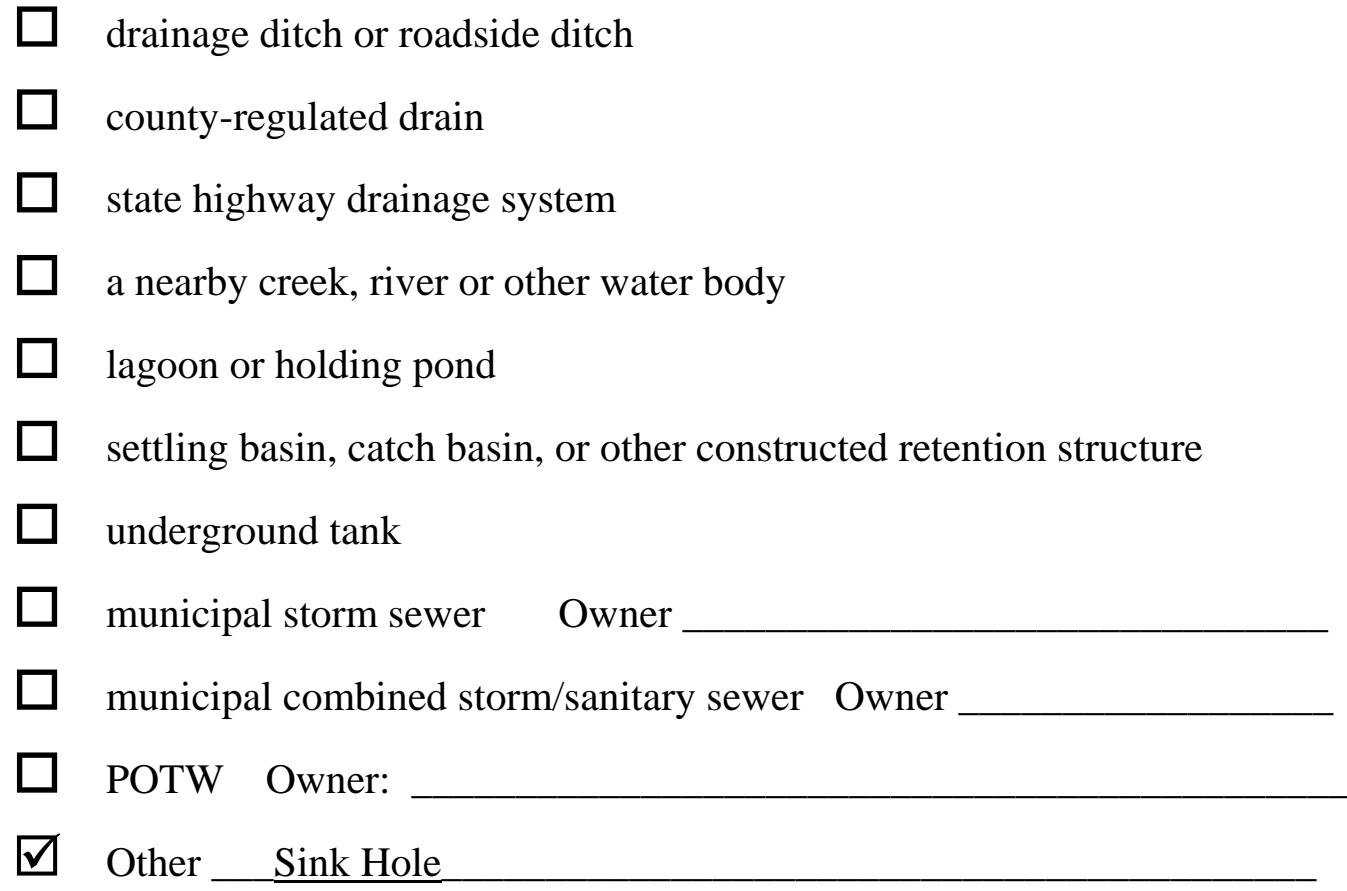

5. If surface water is discharged, other than to a municipal storm, sanitary or combined sewer, does it ultimately reach "waters of the state” (e.g., farm ditch, creek, stream, river, lake or pond)? If yes, name of that water body. ___ It unknown were the sink hole goes

6. What is the estimated distance of this water body from the facility? 


\section{Shop Floor Drain \& Wash Bay Effluent}

1. Are there drains in shop floors and wash bays that remove liquids and wash water effluent from the building(s)? _ Yes

2. Does the effluent flow to -

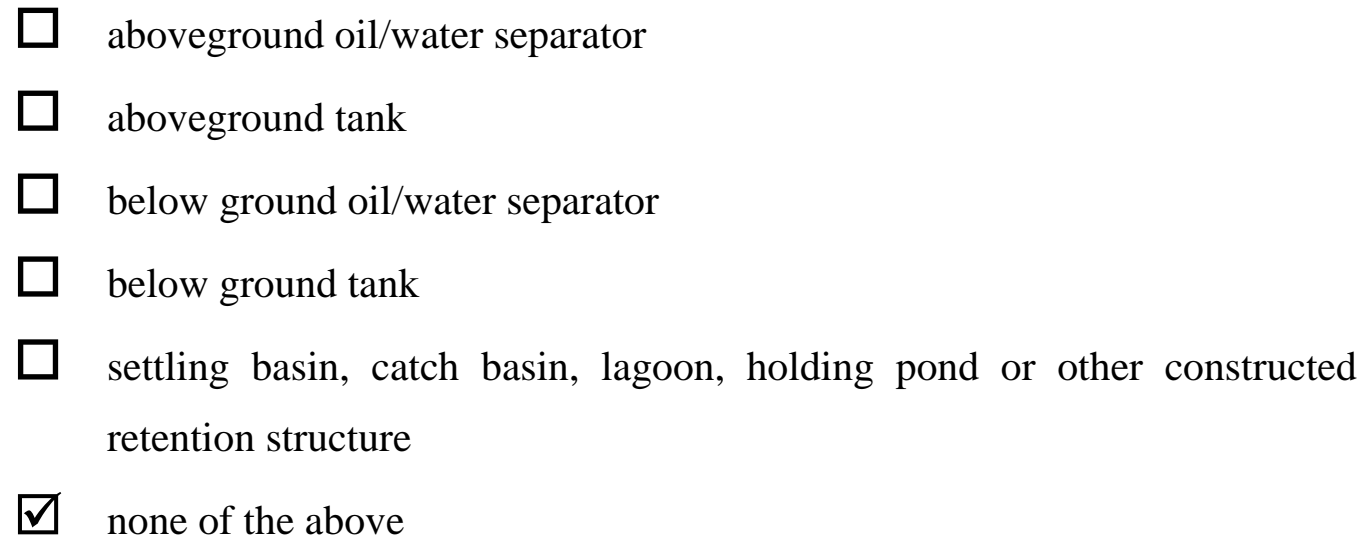

3. If the effluent is captured by the devices in 2., above, is it contained until pumped and hauled to a POTW or until it evaporates, or does it overflow to a drainage system?

4. If the effluent overflows to a drainage system, is the system above or below ground?

5. If the effluent overflows to a drainage system, does it mix with storm water?

6. If the effluent $\underline{\text { does }}$ mix with storm water, see "Surface Water" section (preceding page, \#4 and \#5) for discharge.

7. If the effluent doesn't mix with storm water, is it discharged to -

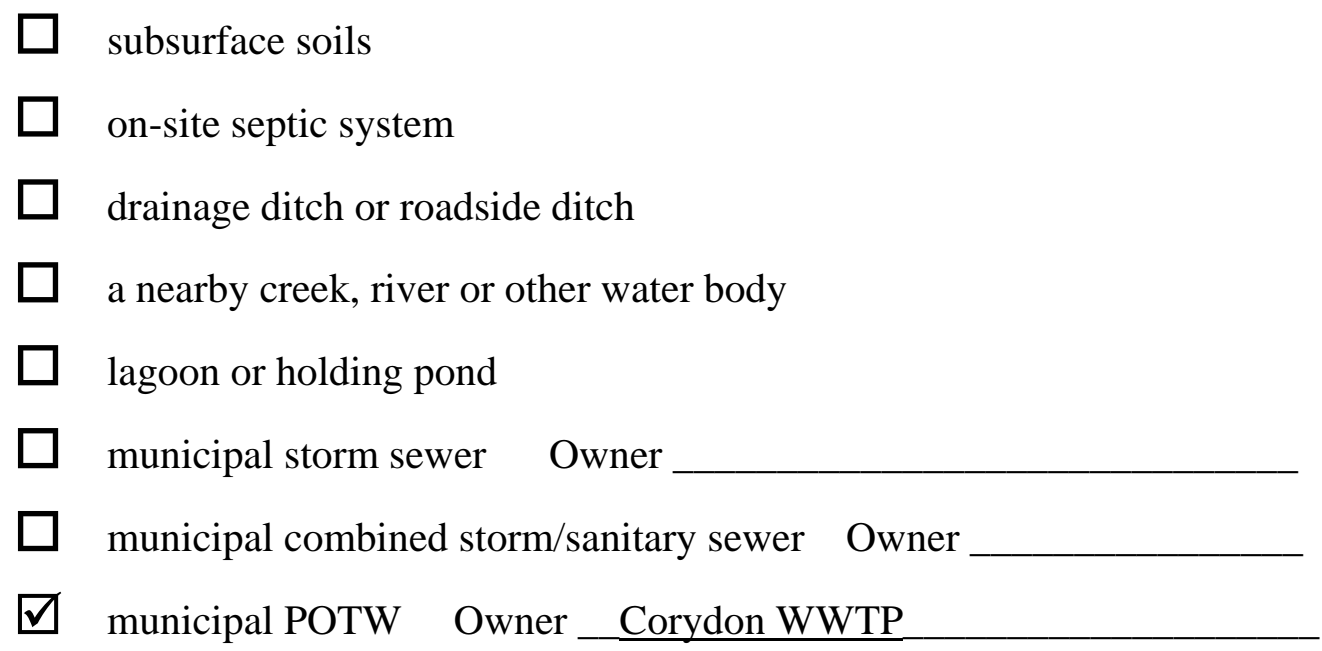


8. If shop floor drain and washbay effluent is discharged, other than to a municipal storm, sanitary or combined sewer, does it ultimately reach "waters of the state?" If yes, name of that water body:

Activity Areas (check those that apply and describe (1) whether they are bermed to prevent storm water runoff or (2) if there are drains and their locations in the activity areas)

$\square$ salt storage (pads or domes) _ The stormwater from the area drains into a _ sink hole. No berm

$\square$ salt/sand mixing _ stormwater from the area drains into a sink hole. No berm

$\square \quad$ salt bed loading/wetting

$\square \quad$ salt bed washout

$\square$ salt bed storage _

$\square \quad$ vehicle and equipment washing (inside)

$\square \quad$ vehicle and equipment washing (outside)

$\square$ asphalt equipment clean-out _ Performed inside Unit Building or on the job site

$\square \quad$ herbicide mixing and tank rinsing

$\square \quad$ traffic paint mixing and transfer

$\square$ bulk tank off-loading and storage

$\square \quad$ waste piles (e.g., ROW trash, street sweeping debris) _ Dumpsters

$\square$ truck/equipment parking _stormwater from the area drains into a sink hole. No berm

$\square \quad$ truck/equipment fueling

$\square$ materials storage (210 lot, fencing, etc.)

$\square$ aggregate storage _ stormwater from the area drains into a sink hole. No berm

$\square$ hot/cold patch storage _ stormwater from the area drains into a sink hole. No berm

$\square$ storage of “scalp” and dirt from R/W maintenance 
Date_6/9/2005

\section{INDOT Facility Stormwater and Washwater Effluent Drainage Assessment}

Name of Facility __Greensburg Unit
District/Subdistrict__Seymour

\section{$\underline{\text { Surface Water }}$}

1. Does any area of the active surface collect storm water or facility-generated wash water (such as from washing trucks outdoors)? _

2. Is there any movement of surface water from one area to another on-site by ditch, drain tile or natural channel? _ Yes

3. Is there any movement of surface water off-site (e.g., beneath the perimeter fence) via sheet flow, ditch, pipe or channel to adjacent property? _

4. Is the surface water discharged directly to (check all that apply) -

$\square$ drainage ditch or roadside ditch

$\square$ county-regulated drain

$\square$ state highway drainage system

$\square$ a nearby creek, river or other water body

$\square \quad$ lagoon or holding pond

$\square \quad$ settling basin, catch basin, or other constructed retention structure

$\square$ underground tank

$\square$ municipal storm sewer Owner

$\square$ municipal combined storm/sanitary sewer Owner

$\square$ POTW Owner:

$\square$ Other

5. If surface water is discharged, other than to a municipal storm, sanitary or combined sewer, does it ultimately reach "waters of the state” (e.g., farm ditch, creek, stream, river, lake or pond)? If yes, name of that water body. _ Y Yes, Muddy Fork Sand Creek

6. What is the estimated distance of this water body from the facility? $400-500$ yards NE of the facility 


\section{$\underline{\text { Shop Floor Drain \& Wash Bay Effluent }}$}

1. Are there drains in shop floors and wash bays that remove liquids and wash water effluent from the building(s)? _ Y Yes

2. Does the effluent flow to -

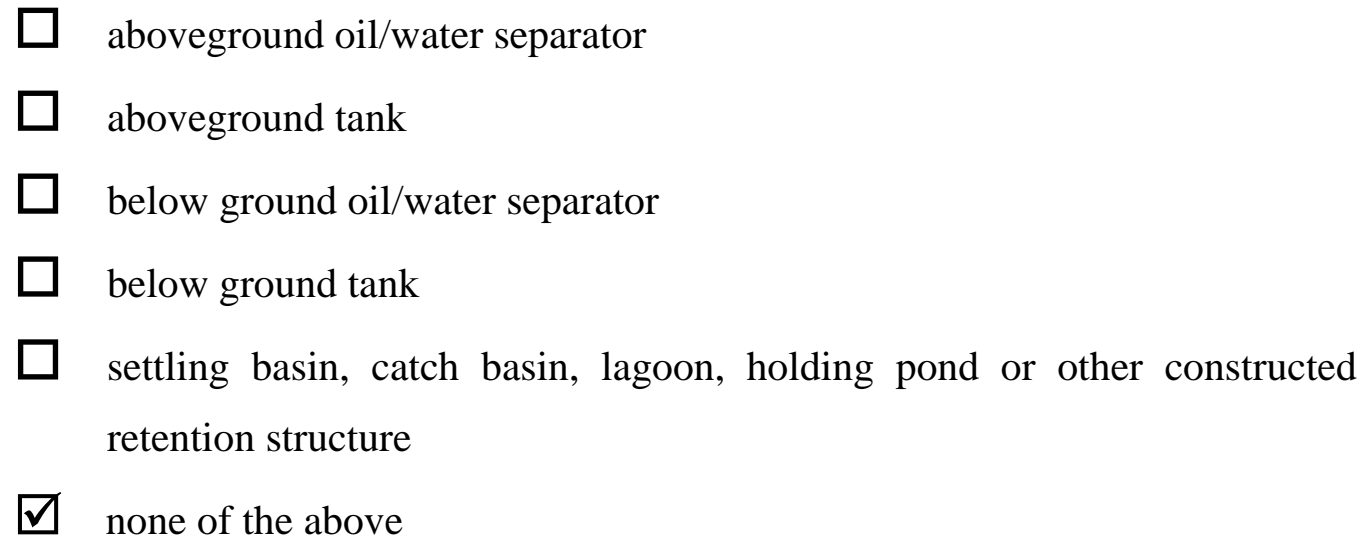

3. If the effluent is captured by the devices in 2., above, is it contained until pumped and hauled to a POTW or until it evaporates, or does it overflow to a drainage system?

4. If the effluent overflows to a drainage system, is the system above or below ground?

5. If the effluent overflows to a drainage system, does it mix with storm water?

6. If the effluent does mix with storm water, see "Surface Water" section (preceding page, \#4 and \#5) for discharge.

7. If the effluent doesn't mix with storm water, is it discharged to -

$\square \quad$ subsurface soils

$\square$ on-site septic system

$\square$ drainage ditch or roadside ditch

$\square \quad$ a nearby creek, river or other water body

$\square \quad$ lagoon or holding pond

$\square$ municipal storm sewer Owner

$\square$ municipal combined storm/sanitary sewer Owner

$\square$ municipal POTW Owner 
8. If shop floor drain and wash bay effluent is discharged, other than to a municipal storm, sanitary or combined sewer, does it ultimately reach "waters of the state?" If yes, name of that water body: _ Yes, Muddy Fork

Activity Areas (check those that apply and describe (1) whether they are bermed to prevent storm water runoff or (2) if there are drains and their locations in the activity areas)

$\square$ salt storage (pads or domes) _ There is a drain near the entrance of the salt dome that catches runoff from the area. There is also a small berm on the NE side of the dome.

$\square$ salt/sand mixing _ The mixing is performed at the entrance of the salt dome. There is _ a drain and a small berm in this area.

$\square$ salt bed loading/wetting __Loading is performes in the same area as mixing. There is no bed spraying on this site. All trucks are equipped with holding tanks

$\square$ salt bed washout

$\square$ salt bed storage _ No berm or drain

$\square \quad$ vehicle and equipment washing (inside)

$\square \quad$ vehicle and equipment washing (outside)

$\square$ asphalt equipment clean-out_Performed outside Unit Building or on job site. No berm or drain

$\square$ herbicide mixing and tank rinsing Very small amount performed outside. No berm -or drain

$\square \quad$ traffic paint mixing and transfer

$\square$ bulk tank off-loading and storage

$\square \quad$ waste piles (e.g., ROW trash, street sweeping debris) __ Stored in dumpsters

$\square$ truck/equipment parking __ No Berm or drain

$\square \quad$ truck/equipment fueling

$\square$ materials storage (210 lot, fencing, etc.) __No berm or drain

$\square$ aggregate storage __ No berm or drain

$\square$ hot/cold patch storage __ No berm or drain

$\square$ storage of “scalp” and dirt from R/W maintenance 
Date_ $8 / 3 / 2005$

\section{INDOT Facility Stormwater and Washwater Effluent Drainage Assessment}

Name of Facility __Salem Unit
District/Subdistrict __ Seymour__

\section{$\underline{\text { Surface Water }}$}

1. Does any area of the active surface collect storm water or facility-generated wash water (such as from washing trucks outdoors)? _

2. Is there any movement of surface water from one area to another on-site by ditch, drain tile or natural channel? ___ Yes

3. Is there any movement of surface water off-site (e.g., beneath the perimeter fence) via sheet flow, ditch, pipe or channel to adjacent property? _

4. Is the surface water discharged directly to (check all that apply) -

$\square$ drainage ditch or roadside ditch

$\square$ county-regulated drain

$\square \quad$ state highway drainage system

$\square$ a nearby creek, river or other water body

$\square \quad$ lagoon or holding pond

$\square$ settling basin, catch basin, or other constructed retention structure

$\square$ underground tank

$\square$ municipal storm sewer Owner

$\square$ municipal combined storm/sanitary sewer Owner

$\square$ POTW Owner:

$\square$ Other

5. If surface water is discharged, other than to a municipal storm, sanitary or combined sewer, does it ultimately reach "waters of the state” (e.g., farm ditch, creek, stream, river, lake or pond)? If yes, name of that water body. _ Y Yes, Mill Creek

6. What is the estimated distance of this water body from the facility? approximately 0.25 miles from the facility 


\section{Shop Floor Drain \& Wash Bay Effluent}

1. Are there drains in shop floors and wash bays that remove liquids and wash water effluent from the building(s)? _ Y Yes

2. Does the effluent flow to -

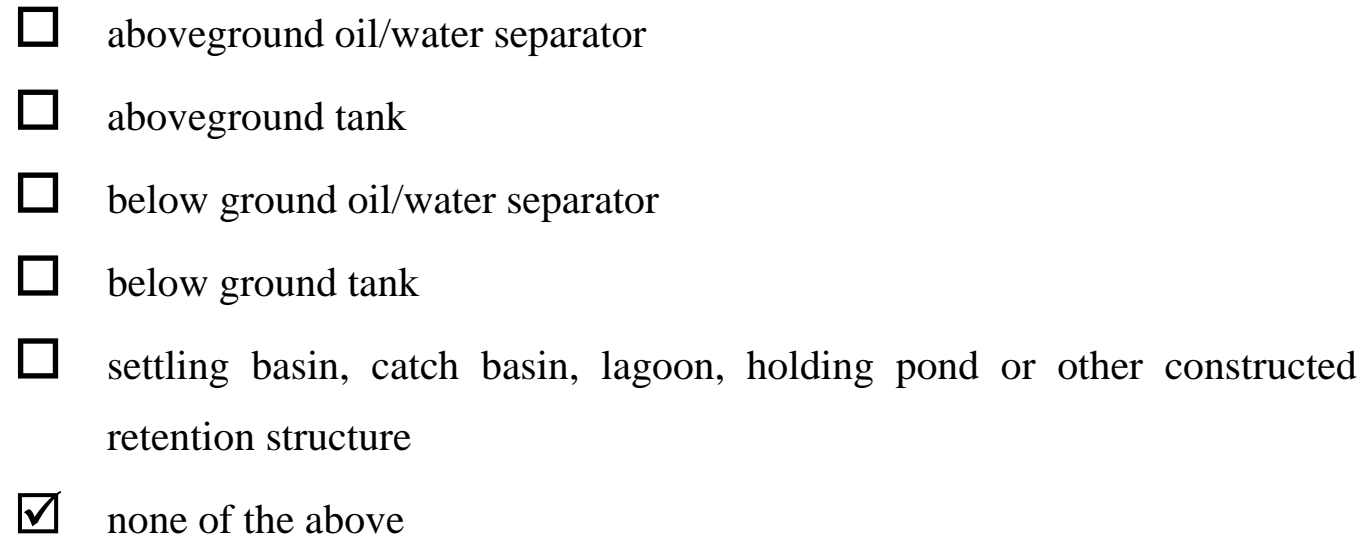

3. If the effluent is captured by the devices in 2., above, is it contained until pumped and hauled to a POTW or until it evaporates, or does it overflow to a drainage system?

4. If the effluent overflows to a drainage system, is the system above or below ground?

5. If the effluent overflows to a drainage system, does it mix with storm water? _ No

6. If the effluent $\underline{\text { does }}$ mix with storm water, see "Surface Water" section (preceding page, \#4 and \#5) for discharge.

7. If the effluent doesn't mix with storm water, is it discharged to -

$\square \quad$ subsurface soils

$\square$ on-site septic system

$\square$ drainage ditch or roadside ditch

$\square$ a nearby creek, river or other water body

$\square \quad$ lagoon or holding pond

$\square \quad$ municipal storm sewer Owner

$\square$ municipal combined storm/sanitary sewer Owner

$\square$ municipal POTW Owner 
8. If shop floor drain and washbay effluent is discharged, other than to a municipal storm, sanitary or combined sewer, does it ultimately reach "waters of the state?" If yes, name of that water body: _ Y Yes, Mill Creek

Activity Areas (check those that apply and describe (1) whether they are bermed to prevent storm water runoff or (2) if there are drains and their locations in the activity areas)

$\square$ salt storage (pads or domes) _ A Sand dike is placed at the entrance of the _Salt Dome

$\square$ salt/sand mixing _ _ No berms or drains

$\square \quad$ salt bed loading/wetting

$\square \quad$ salt bed washout

$\square \quad$ salt bed storage __ No berm or drains

$\square \quad$ vehicle and equipment washing (inside)

$\square \quad$ vehicle and equipment washing (outside) _ No berm or drains

$\square$ asphalt equipment clean-out _ Performed on job site

$\square$ herbicide mixing and tank rinsing __ Performed outside near no drains

$\square \quad$ traffic paint mixing and transfer

$\square$ bulk tank off-loading and storage

$\square \quad$ waste piles (e.g., ROW trash, street sweeping debris) __ Dumpsters

$\square \quad$ truck/equipment parking __ No berms or drains

$\square \quad$ truck/equipment fueling

$\square$ materials storage (210 lot, fencing, etc.)

$\square$ aggregate storage __ No berms or drains

$\square$ hot/cold patch storage _ Stored in a small metal shed protected from rain

$\square$ storage of “scalp” and dirt from R/W maintenance 
Date_ $8 / 3 / 2005$

\section{INDOT Facility Stormwater and Washwater Effluent Drainage Assessment}

Name of Facility __ North Vernon Unit
District/Subdistrict __ Seymour

\section{$\underline{\text { Surface Water }}$}

1. Does any area of the active surface collect storm water or facility-generated wash water (such as from washing trucks outdoors)? _

2. Is there any movement of surface water from one area to another on-site by ditch, drain tile or natural channel? ___ Yes

3. Is there any movement of surface water off-site (e.g., beneath the perimeter fence) via sheet flow, ditch, pipe or channel to adjacent property? _

4. Is the surface water discharged directly to (check all that apply) -

$\square$ drainage ditch or roadside ditch

$\square$ county-regulated drain

$\square \quad$ state highway drainage system

$\square$ a nearby creek, river or other water body

$\square \quad$ lagoon or holding pond

$\square$ settling basin, catch basin, or other constructed retention structure

$\square$ underground tank

$\square$ municipal storm sewer Owner

$\square$ municipal combined storm/sanitary sewer Owner

$\square$ POTW Owner:

$\square$ Other

5. If surface water is discharged, other than to a municipal storm, sanitary or combined sewer, does it ultimately reach "waters of the state” (e.g., farm ditch, creek, stream, river, lake or pond)? If yes, name of that water body. _ Y Yes, it eventually reaches _Six Mile Creek approximately 3 miles from the facility

6. What is the estimated distance of this water body from the facility? 


\section{Shop Floor Drain \& Wash Bay Effluent}

1. Are there drains in shop floors and wash bays that remove liquids and wash water effluent from the building(s)? _

2. Does the effluent flow to -

$\square \quad$ aboveground oil/water separator

$\square$ aboveground tank

$\square$ below ground oil/water separator

$\square$ below ground tank

$\square$ settling basin, catch basin, lagoon, holding pond or other constructed retention structure

$\square$ none of the above

3. If the effluent is captured by the devices in 2., above, is it contained until pumped and hauled to a POTW or until it evaporates, or does it overflow to a drainage system?__overflows into a sewer system

4. If the effluent overflows to a drainage system, is the system above or below ground? _ Below ground

5. If the effluent overflows to a drainage system, does it mix with storm water?_No

6. If the effluent $\underline{\text { does }}$ mix with storm water, see "Surface Water" section (preceding page, \#4 and \#5) for discharge.

7. If the effluent doesn't mix with storm water, is it discharged to -

$\square$ subsurface soils

$\square \quad$ on-site septic system

$\square$ drainage ditch or roadside ditch

$\square$ a nearby creek, river or other water body

$\square \quad$ lagoon or holding pond

$\square \quad$ municipal storm sewer Owner

$\square$ municipal combined storm/sanitary sewer Owner_North Vernon WWTP

$\square$ municipal POTW Owner 
8. If shop floor drain and washbay effluent is discharged, other than to a municipal storm, sanitary or combined sewer, does it ultimately reach "waters of the state?" If yes, name of that water body:

Activity Areas (check those that apply and describe (1) whether they are bermed to prevent storm water runoff or (2) if there are drains and their locations in the activity areas)

$\square \quad$ salt storage (pads or domes) _ N No berms or drains in the area

$\square$ salt/sand mixing __ No berms or drains

$\square$ salt bed loading/wetting

$\square$ salt bed washout _ Performed inside a washbay that contains drains that are _connected to the sewer system

$\square$ salt bed storage __ No berms or drains

$\square \quad$ vehicle and equipment washing (inside) __ Performed in a washbay

$\square \quad$ vehicle and equipment washing (outside)

$\square$ asphalt equipment clean-out _ Performed at job site

$\square$ herbicide mixing and tank rinsing

$\square \quad$ traffic paint mixing and transfer

$\square$ bulk tank off-loading and storage

$\square \quad$ waste piles (e.g., ROW trash, street sweeping debris) __ Stored on the ground -with no berms or drains in the area

$\square$ truck/equipment parking __ No berms or drains

$\square \quad$ truck/equipment fueling

$\square$ materials storage (210 lot, fencing, etc.) __ Stored on the ground with no berms _or drains in the area

$\square$ aggregate storage __ No berms or drains

$\square$ hot/cold patch storage __ No berms, drains, or tarp

$\square$ storage of “scalp” and dirt from R/W maintenance __ No berms or drains 
Date_6/9/2005

\section{INDOT Facility Stormwater and Washwater Effluent Drainage Assessment}

Name of Facility __Falls City Sub and Sellersburg Unit

\section{$\underline{\text { Surface Water }}$}

\section{District/Subdistrict_Seymour}

1. Does any area of the active surface collect storm water or facility-generated wash water (such as from washing trucks outdoors)? _

2. Is there any movement of surface water from one area to another on-site by ditch, drain tile or natural channel? _ Yes

3. Is there any movement of surface water off-site (e.g., beneath the perimeter fence) via sheet flow, ditch, pipe or channel to adjacent property? __ $\underline{\text { Yes }}$

4. Is the surface water discharged directly to (check all that apply) -

$\square$ drainage ditch or roadside ditch

$\square$ county-regulated drain

$\square$ state highway drainage system

$\square$ a nearby creek, river or other water body

$\square \quad$ lagoon or holding pond

$\square \quad$ settling basin, catch basin, or other constructed retention structure

$\square$ underground tank

$\square$ municipal storm sewer Owner

$\square$ municipal combined storm/sanitary sewer Owner

$\square$ POTW Owner:

$\square$ Other

5. If surface water is discharged, other than to a municipal storm, sanitary or combined sewer, does it ultimately reach "waters of the state” (e.g., farm ditch, creek, stream, river, lake or pond)? If yes, name of that water body. __ Yes, Silver Creek

6. What is the estimated distance of this water body from the facility?__Approx. 1 mile north west of the facility 


\section{Shop Floor Drain \& Wash Bay Effluent}

1. Are there drains in shop floors and wash bays that remove liquids and wash water effluent from the building(s)? _ Yes

2. Does the effluent flow to -

$\square$ aboveground oil/water separator

$\square$ aboveground tank

$\square$ below ground oil/water separator

$\square$ below ground tank

$\square$ settling basin, catch basin, lagoon, holding pond or other constructed retention structure

$\square$ none of the above

3. If the effluent is captured by the devices in 2., above, is it contained until pumped and hauled to a POTW or until it evaporates, or does it overflow to a drainage system? _ It overflows to a sewer system

4. If the effluent overflows to a drainage system, is the system above or below ground? __Below ground

5. If the effluent overflows to a drainage system, does it mix with storm water?__ No

6. If the effluent does mix with storm water, see "Surface Water" section (preceding page, \#4 and \#5) for discharge.

7. If the effluent doesn't mix with storm water, is it discharged to -

$\square$ subsurface soils

$\square \quad$ on-site septic system

$\square$ drainage ditch or roadside ditch

$\square$ a nearby creek, river or other water body

$\square \quad$ lagoon or holding pond

$\square$ municipal storm sewer Owner

$\square$ municipal combined storm/sanitary sewer Owner

$\square$ municipal POTW Owner__ Silver Creek 
8. If shop floor drain and wash bay effluent is discharged, other than to a municipal storm, sanitary or combined sewer, does it ultimately reach "waters of the state?" If yes, name of that water body:

Activity Areas (check those that apply and describe (1) whether they are bermed to prevent storm water runoff or (2) if there are drains and their locations in the activity areas)

$\square$ salt storage (pads or domes) _ The salt dome is outfitted with a large enclosure that - covers the entrance and the loading area. There is a drain in this building that is discharges to the brine production equipment

$\square$ salt/sand mixing _Performed in the previously mentioned building, which is equipped _with a floor drain.

$\square$ salt bed loading/wetting_Salt bed loading is performed in the previously mentioned building, and $\mathrm{MgCl}$ storage area has a drain that discharges to the brine system

$\square$ salt bed washout All washing takes place inside a wash bay that is connected to the _sewer system

$\square \quad$ salt bed storage $\_$Salt beds are stored outside near a drainage ditch. There are no _berms or drains in this area

$\square$ vehicle and equipment washing (inside) _ Performed in the wash bay

$\square \quad$ vehicle and equipment washing (outside)

$\square$ asphalt equipment clean-out _ this activity takes place on the job site

$\square \quad$ herbicide mixing and tank rinsing

$\square \quad$ traffic paint mixing and transfer

$\square$ bulk tank off-loading and storage

$\square$ waste piles (e.g., ROW trash, street sweeping debris) __ Stored in dumpsters

$\square \quad$ truck/equipment parking _ No berms or drains

$\square \quad$ truck/equipment fueling

$\square$ materials storage (210 lot, fencing, etc.)

$\square$ aggregate storage _ No berms or drains

$\square$ hot/cold patch storage __ Most stored under roof but a few small piles are stored in the aggregate area with no berms or drain

$\square$ storage of “scalp” and dirt from R/W maintenance 
Date_ 8/17/2005

\section{INDOT Facility Stormwater and Washwater Effluent Drainage Assessment}

Name of Facility __Spencer Unit
District/Subdistrict___Seymour___

\section{$\underline{\text { Surface Water }}$}

1. Does any area of the active surface collect storm water or facility-generated wash water (such as from washing trucks outdoors)? _

2. Is there any movement of surface water from one area to another on-site by ditch, drain tile or natural channel? ___ Yes

3. Is there any movement of surface water off-site (e.g., beneath the perimeter fence) via sheet flow, ditch, pipe or channel to adjacent property? _

4. Is the surface water discharged directly to (check all that apply) -

$\square$ drainage ditch or roadside ditch

$\square$ county-regulated drain

$\square \quad$ state highway drainage system

$\square$ a nearby creek, river or other water body

$\square \quad$ lagoon or holding pond

$\square$ settling basin, catch basin, or other constructed retention structure

$\square$ underground tank

$\square$ municipal storm sewer Owner

$\square$ municipal combined storm/sanitary sewer Owner

$\square$ POTW Owner:

$\square$ Other

5. If surface water is discharged, other than to a municipal storm, sanitary or combined sewer, does it ultimately reach "waters of the state” (e.g., farm ditch, creek, stream, river, lake or pond)? If yes, name of that water body. __ Yes, White River

6. What is the estimated distance of this water body from the facility? Approximately 2 miles west of the facility 


\section{Shop Floor Drain \& Wash Bay Effluent}

1. Are there drains in shop floors and wash bays that remove liquids and wash water effluent from the building(s)? _ Y Yes

2. Does the effluent flow to -

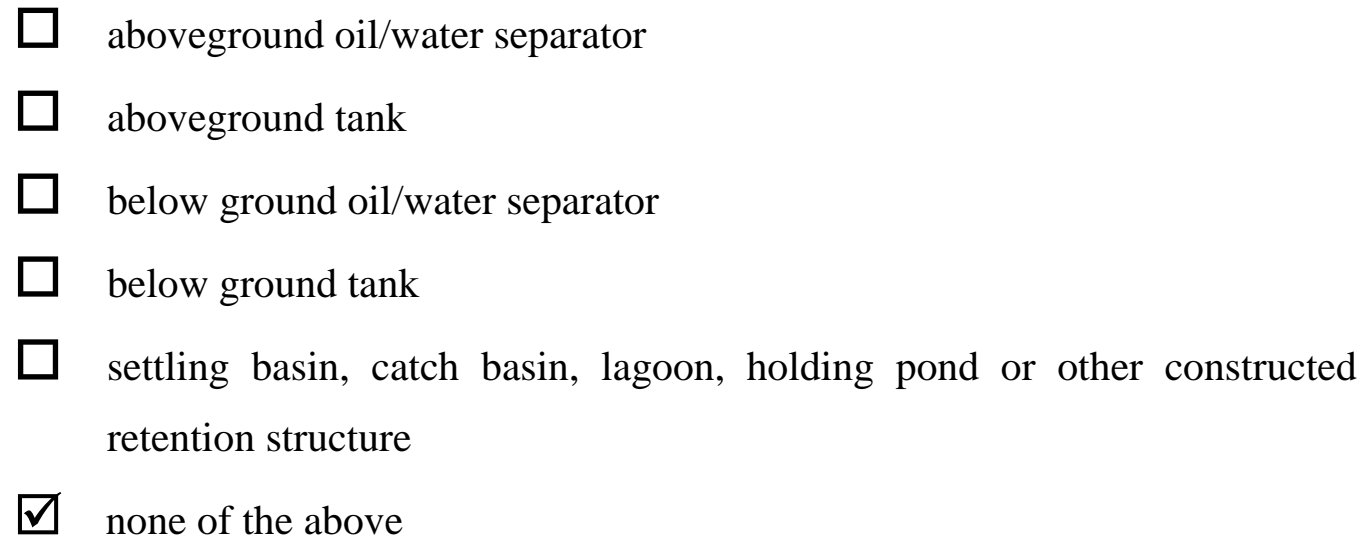

3. If the effluent is captured by the devices in 2., above, is it contained until pumped and hauled to a POTW or until it evaporates, or does it overflow to a drainage system?

4. If the effluent overflows to a drainage system, is the system above or below ground?

5. If the effluent overflows to a drainage system, does it mix with storm water?

6. If the effluent $\underline{\text { does }}$ mix with storm water, see "Surface Water" section (preceding page, \#4 and \#5) for discharge.

7. If the effluent doesn't mix with storm water, is it discharged to -

$\square \quad$ subsurface soils

$\square \quad$ on-site septic system

$\square$ drainage ditch or roadside ditch

$\square \quad$ a nearby creek, river or other water body

$\square \quad$ lagoon or holding pond

$\square \quad$ municipal storm sewer Owner

$\square$ municipal combined storm/sanitary sewer Owner

$\square$ municipal POTW Owner 
8. If shop floor drain and washbay effluent is discharged, other than to a municipal storm, sanitary or combined sewer, does it ultimately reach "waters of the state?" If yes, name of that water body: _ _ Yes, the White River

Activity Areas (check those that apply and describe (1) whether they are bermed to prevent storm water runoff or (2) if there are drains and their locations in the activity areas)

$\square$ salt storage (pads or domes) _ _ No berm or drain

$\square$ salt/sand mixing __ No berm or drain

$\square$ salt bed loading/wetting _ _salt bed wetting takes place at this facility

$\square \quad$ salt bed washout

$\square$ salt bed storage __ No berm or drain

$\square \quad$ vehicle and equipment washing (inside)

$\square \quad$ vehicle and equipment washing (outside)

$\square$ asphalt equipment clean-out __ Performed on job site

$\square \quad$ herbicide mixing and tank rinsing

$\square \quad$ traffic paint mixing and transfer

$\square$ bulk tank off-loading and storage

$\square$ waste piles (e.g., ROW trash, street sweeping debris) __ No berm or drain

$\square$ truck/equipment parking __ No berm or drain

$\square \quad$ truck/equipment fueling

$\square$ materials storage (210 lot, fencing, etc.) __ No berm or drain

$\square$ aggregate storage __ No berm or drain

$\square$ hot/cold patch storage The cold patch pile is covered with a tarp.

$\square$ storage of “scalp” and dirt from R/W maintenance 
Date_ $8 / 3 / 2005$

\section{INDOT Facility Stormwater and Washwater Effluent Drainage Assessment}

Name of Facility __Versailles Unit
District/Subdistrict___Seymour

\section{$\underline{\text { Surface Water }}$}

\section{Name of Facility _ Versailles Unit}

1. Does any area of the active surface collect storm water or facility-generated wash water (such as from washing trucks outdoors)? _ Y Yes

2. Is there any movement of surface water from one area to another on-site by ditch, drain tile or natural channel? ___ Yes

3. Is there any movement of surface water off-site (e.g., beneath the perimeter fence) via sheet flow, ditch, pipe or channel to adjacent property? _

4. Is the surface water discharged directly to (check all that apply) -

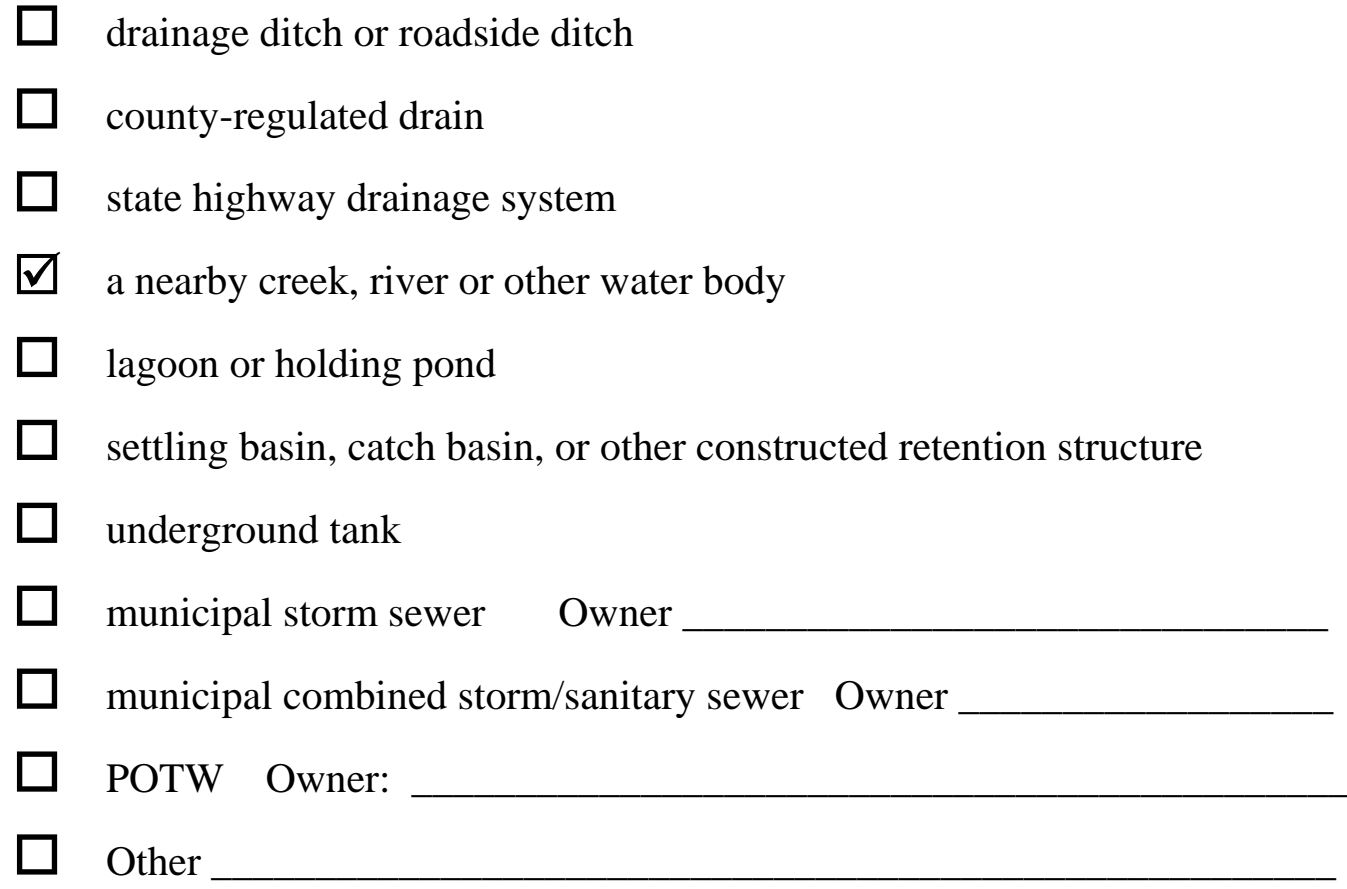

5. If surface water is discharged, other than to a municipal storm, sanitary or combined sewer, does it ultimately reach "waters of the state” (e.g., farm ditch, creek, stream, river, lake or pond)? If yes, name of that water body. _ Y Yes, Gram Creek

6. What is the estimated distance of this water body from the facility? 100 yards 


\section{Shop Floor Drain \& Wash Bay Effluent}

1. Are there drains in shop floors and wash bays that remove liquids and wash water effluent from the building(s)? _ Yes

2. Does the effluent flow to -

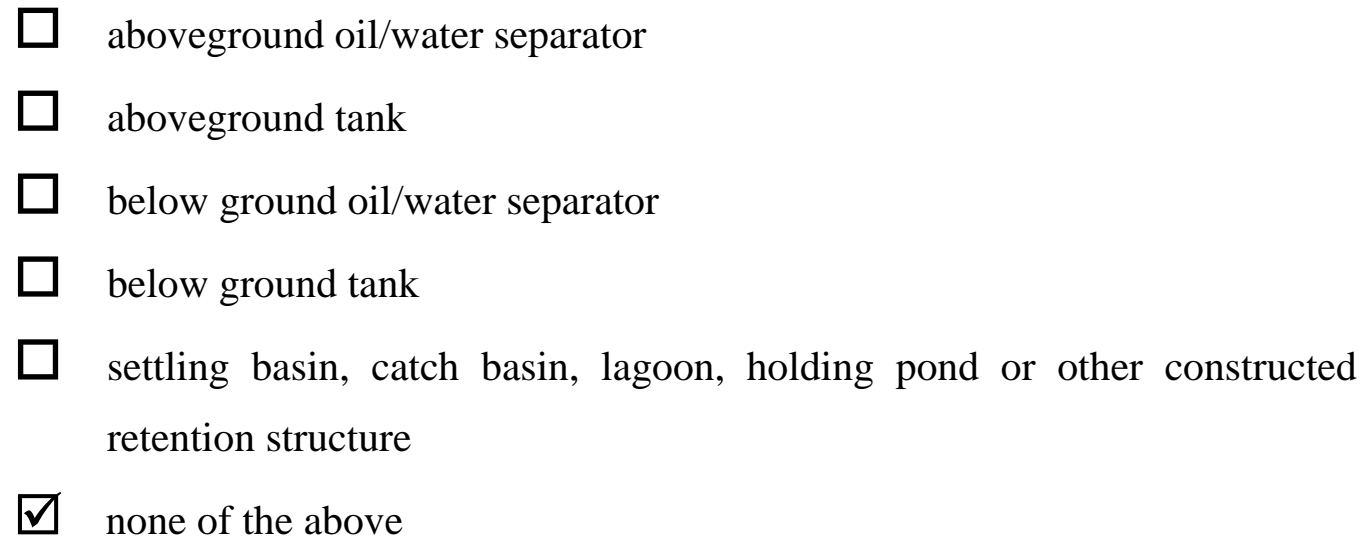

3. If the effluent is captured by the devices in 2., above, is it contained until pumped and hauled to a POTW or until it evaporates, or does it overflow to a drainage system?

4. If the effluent overflows to a drainage system, is the system above or below ground?

5. If the effluent overflows to a drainage system, does it mix with storm water?

6. If the effluent $\underline{\text { does }}$ mix with storm water, see "Surface Water" section (preceding page, \#4 and \#5) for discharge.

7. If the effluent doesn't mix with storm water, is it discharged to -

$\square \quad$ subsurface soils

$\square \quad$ on-site septic system

$\square$ drainage ditch or roadside ditch

$\square$ a nearby creek, river or other water body

$\square \quad$ lagoon or holding pond

$\square \quad$ municipal storm sewer Owner

$\square$ municipal combined storm/sanitary sewer Owner

$\square$ municipal POTW Owner 
8. If shop floor drain and washbay effluent is discharged, other than to a municipal storm, sanitary or combined sewer, does it ultimately reach "waters of the state?" If yes, name of that water body:

Activity Areas (check those that apply and describe (1) whether they are bermed to prevent storm water runoff or (2) if there are drains and their locations in the activity areas)

$\square$ salt storage (pads or domes) __ Inside Dome, No berms or drains

$\square$ salt/sand mixing __ No berms or drains

$\square$ salt bed loading/wetting __ No berms or drains

$\square$ salt bed washout __ Performed at Madison Sub

$\square$ salt bed storage __ No berms or drains

$\square \quad$ vehicle and equipment washing (inside)

$\square$ vehicle and equipment washing (outside) _ There are drains around the Unit _Building that empty into a drainage ditch that flows into Gram Creek

$\square$ asphalt equipment clean-out _

$\square \quad$ herbicide mixing and tank rinsing

$\square \quad$ traffic paint mixing and transfer

$\square$ bulk tank off-loading and storage

$\square \quad$ waste piles (e.g., ROW trash, street sweeping debris) __ Dumpsters

$\square$ truck/equipment parking _ There are catch basins in this area that empty into _ a drainage ditch the flows into Gram Creek

$\square$ truck/equipment fueling

$\square$ materials storage (210 lot, fencing, etc.)

$\square$ aggregate storage __ No berms or drains

$\square$ hot/cold patch storage _ Stored in a bermed area

$\square$ storage of “scalp” and dirt from R/W maintenance 
FACILITY SITE ASSESSMENT REPORTS VINCENNES DISTRICT 
Date_6/8/2005

\section{INDOT Facility Stormwater and Washwater Effluent Drainage Assessment}

Name of Facility __Bloomfield Unit

District/Subdistrict_Vincennes

\section{$\underline{\text { Surface Water }}$}

1. Does any area of the active surface collect storm water or facility-generated wash water (such as from washing trucks outdoors)? _

2. Is there any movement of surface water from one area to another on-site by ditch, drain tile or natural channel? __ Yes

3. Is there any movement of surface water off-site (e.g., beneath the perimeter fence) via sheet flow, ditch, pipe or channel to adjacent property? __ $\underline{\text { Yes }}$

4. Is the surface water discharged directly to (check all that apply) -

$\square$ drainage ditch or roadside ditch

$\square$ county-regulated drain

$\square$ state highway drainage system

$\square \quad$ a nearby creek, river or other water body

$\square \quad$ lagoon or holding pond

$\square$ settling basin, catch basin, or other constructed retention structure

$\square$ underground tank

$\square$ municipal storm sewer Owner

$\square$ municipal combined storm/sanitary sewer Owner

$\square$ POTW Owner:

$\square$ Other

5. If surface water is discharged, other than to a municipal storm, sanitary or combined sewer, does it ultimately reach "waters of the state” (e.g., farm ditch, creek, stream, river, lake or pond)? If yes, name of that water body. _ Y Yes, Name is unknown

6. What is the estimated distance of this water body from the facility? $\quad 0.5$ miles 


\section{Shop Floor Drain \& Wash Bay Effluent}

1. Are there drains in shop floors and wash bays that remove liquids and wash water effluent from the building(s)? ___ Yes

2. Does the effluent flow to -

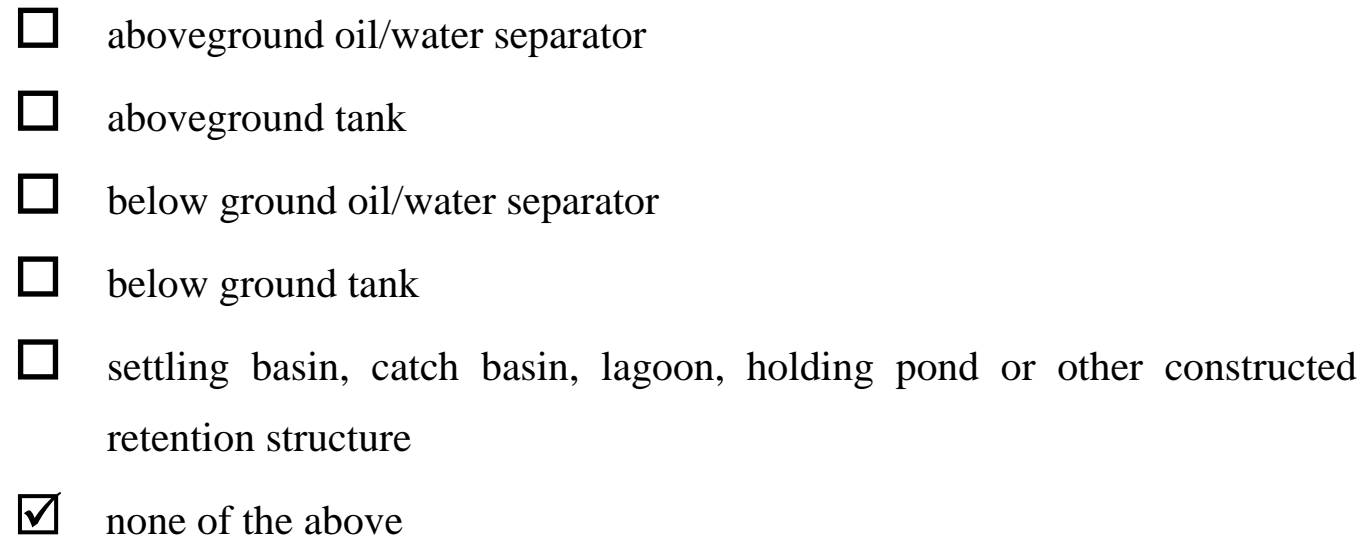

3. If the effluent is captured by the devices in 2., above, is it contained until pumped and hauled to a POTW or until it evaporates, or does it overflow to a drainage system?

4. If the effluent overflows to a drainage system, is the system above or below ground?

5. If the effluent overflows to a drainage system, does it mix with storm water?

6. If the effluent does mix with storm water, see "Surface Water" section (preceding page, \#4 and \#5) for discharge.

7. If the effluent doesn't mix with storm water, is it discharged to -

$\square$ subsurface soils

$\square \quad$ on-site septic system

$\square$ drainage ditch or roadside ditch

$\square$ a nearby creek, river or other water body

$\square \quad$ lagoon or holding pond

$\square$ municipal storm sewer Owner

$\square$ municipal combined storm/sanitary sewer Owner_Bloomfield WWTP

$\square \quad$ municipal POTW Owner 
8. If shop floor drain and wash bay effluent is discharged, other than to a municipal storm, sanitary or combined sewer, does it ultimately reach "waters of the state?" If yes, name of that water body:

Activity Areas (check those that apply and describe (1) whether they are bermed to prevent storm water runoff or (2) if there are drains and their locations in the activity areas)

$\square$ salt storage (pads or domes) _ _ No berm at entrance, There is a drain near the _ entrance that runs to the perimeter ditch

$\square$ salt/sand mixing__ No berm but there is drain in the area that runs to the perimeter ditch

$\square$ salt bed loading/wetting _ The loading area is the same as the mixing area. The bed spraying area is covered

$\square$ salt bed washout_Performed outside near a catch basin that drains to the sewer There is a valve in place that allows them to discharge the water to the sewer or ditch

$\square$ salt bed storage _ No berm or drain

$\square \quad$ vehicle and equipment washing (inside)

$\square$ vehicle and equipment washing (outside) __ Same as "salt bed washout"

$\square \quad$ asphalt equipment clean-out

$\square \quad$ herbicide mixing and tank rinsing

$\square \quad$ traffic paint mixing and transfer

$\square$ bulk tank off-loading and storage

$\square$ waste piles (e.g., ROW trash, street sweeping debris) __ No berm or drain

$\square \quad$ truck/equipment parking__No berm or drain

$\square \quad$ truck/equipment fueling

$\square$ materials storage (210 lot, fencing, etc.)

$\square$ aggregate storage__ No berm or drain

$\square$ hot/cold patch storage _ _ No berm or drain

$\square$ storage of “scalp” and dirt from R/W maintenance__ No berm or drain 
Date_8/17/2005

\section{INDOT Facility Stormwater and Washwater Effluent Drainage Assessment}

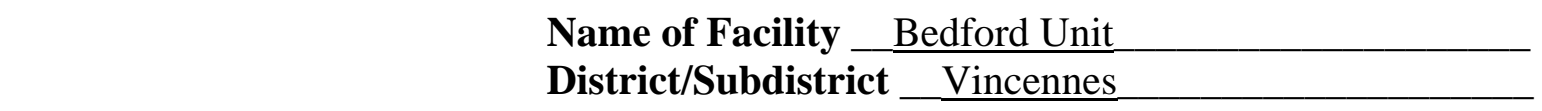

\section{$\underline{\text { Surface Water }}$}

1. Does any area of the active surface collect storm water or facility-generated wash water (such as from washing trucks outdoors)? Y Yes

2. Is there any movement of surface water from one area to another on-site by ditch, drain tile or natural channel? ___ Yes

3. Is there any movement of surface water off-site (e.g., beneath the perimeter fence) via sheet flow, ditch, pipe or channel to adjacent property? _

4. Is the surface water discharged directly to (check all that apply) -

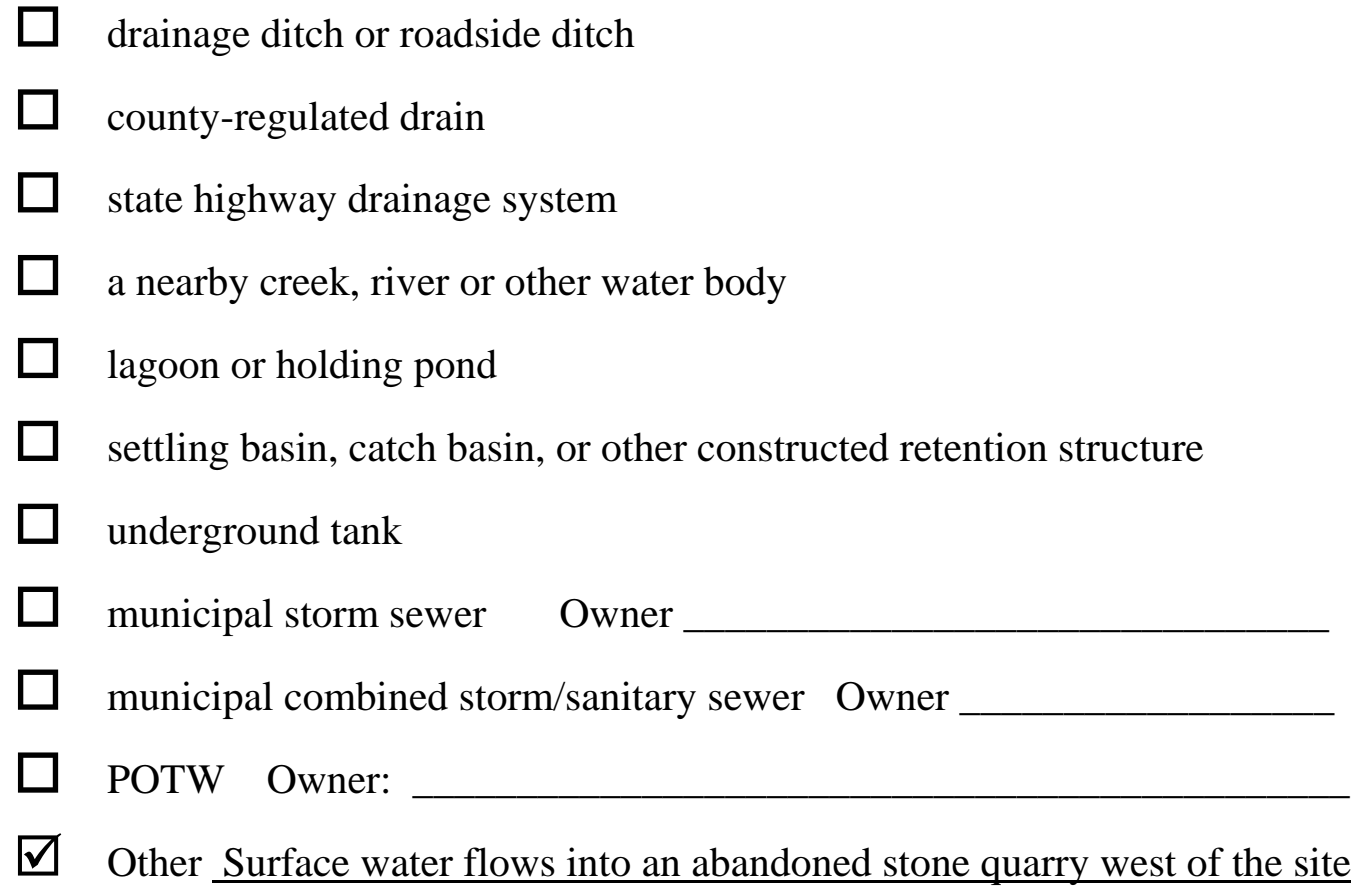

5. If surface water is discharged, other than to a municipal storm, sanitary or combined sewer, does it ultimately reach "waters of the state” (e.g., farm ditch, creek, stream, river, lake or pond)? If yes, name of that water body. No, Surface water is discharged to an abandoned stone quarry.

6. What is the estimated distance of this water body from the facility? _of the facility. 


\section{Shop Floor Drain \& Wash Bay Effluent}

1. Are there drains in shop floors and wash bays that remove liquids and wash water effluent from the building(s)? _ Y Yes

2. Does the effluent flow to -

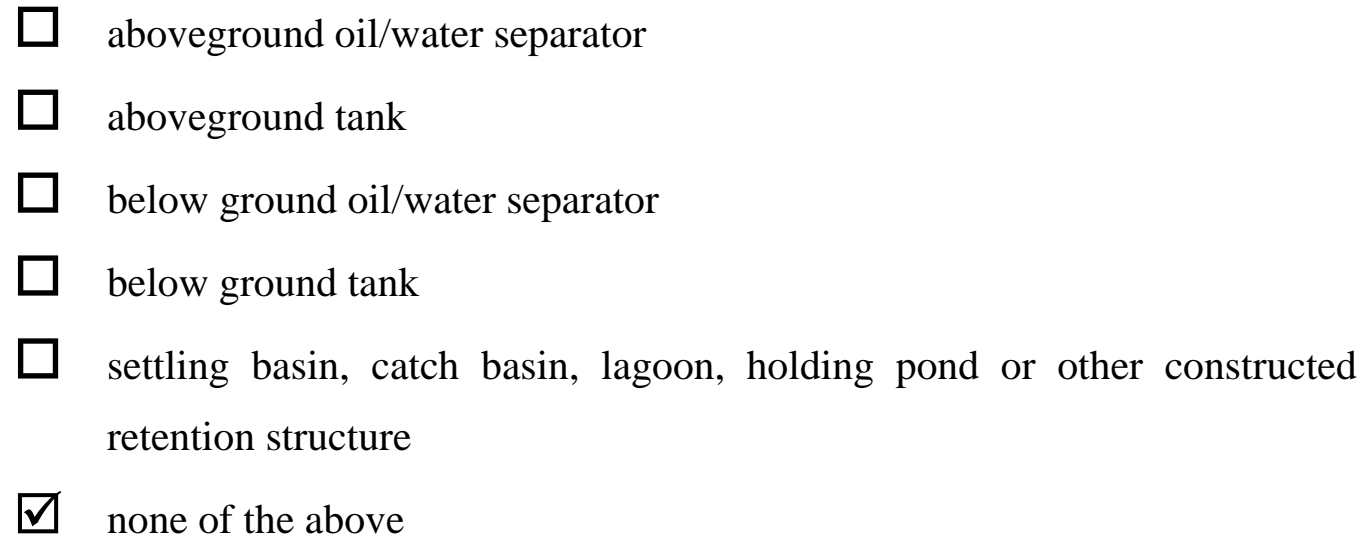

3. If the effluent is captured by the devices in 2., above, is it contained until pumped and hauled to a POTW or until it evaporates, or does it overflow to a drainage system?

4. If the effluent overflows to a drainage system, is the system above or below ground?

5. If the effluent overflows to a drainage system, does it mix with storm water?

6. If the effluent $\underline{\text { does }}$ mix with storm water, see "Surface Water" section (preceding page, \#4 and \#5) for discharge.

7. If the effluent doesn't mix with storm water, is it discharged to -

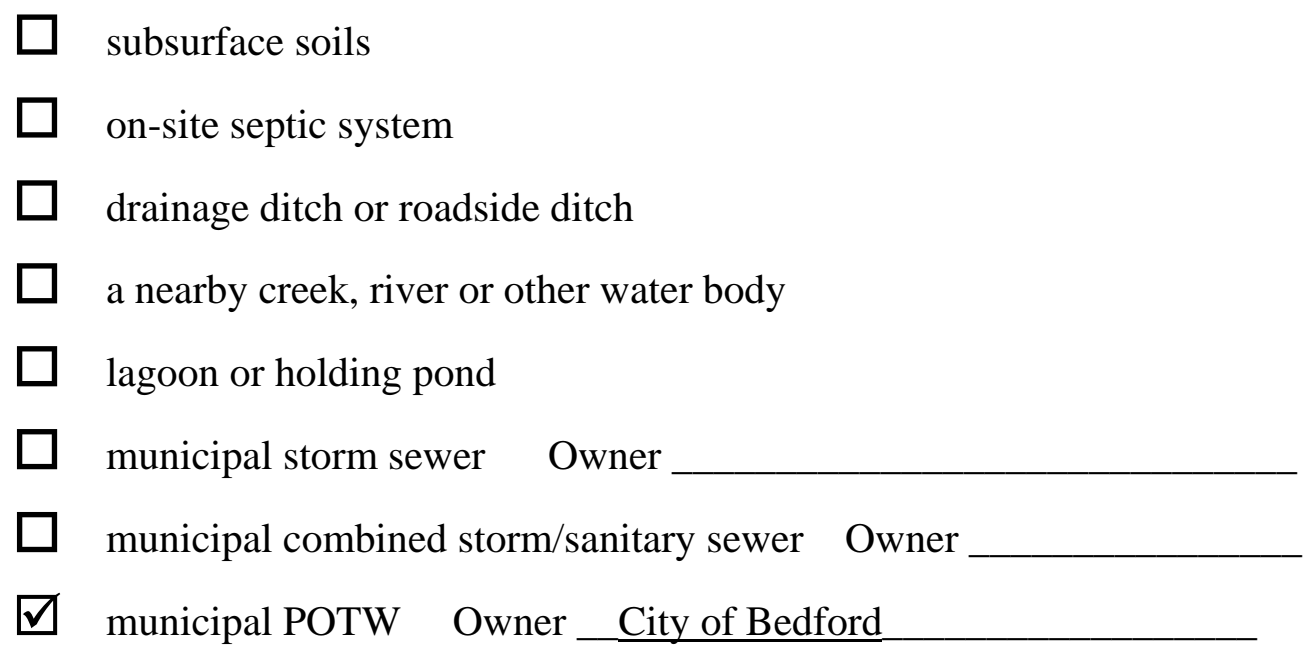


8. If shop floor drain and washbay effluent is discharged, other than to a municipal storm, sanitary or combined sewer, does it ultimately reach "waters of the state?" If yes, name of that water body:

Activity Areas (check those that apply and describe (1) whether they are bermed to prevent storm water runoff or (2) if there are drains and their locations in the activity areas)

$\square$ salt storage (pads or domes) _ There are catch basins near the Salt Dome that convey stormwater west to the stone quarry

$\square$ salt/sand mixing _ Same as "salt storage"

$\square$ salt bed loading/wetting _wetting is performed in a drive through shed that _contains a catch basin that drains into an underground tank that is pumped.

$\square$ salt bed washout _ Performed inside the Unit Building over floor drains that _ are connected to the sewer system

$\square$ salt bed storage _ _ catch basin in the area

$\square \quad$ vehicle and equipment washing (inside) __ Performed over floor drains

$\square \quad$ vehicle and equipment washing (outside)

$\square$ asphalt equipment clean-out

$\square$ herbicide mixing and tank rinsing

$\square \quad$ traffic paint mixing and transfer

$\square$ bulk tank off-loading and storage

$\square \quad$ waste piles (e.g., ROW trash, street sweeping debris) __ No berms or drains

$\square$ truck/equipment parking _ There is a catch basin

$\square \quad$ truck/equipment fueling

$\square$ materials storage (210 lot, fencing, etc.)

$\square$ aggregate storage _ There are catch basins in this area that drain to the quarry

$\square$ hot/cold patch storage _ Stored inside cold storage building with no drains

$\square$ storage of “scalp” and dirt from R/W maintenance 
Date_6/09/05

\section{INDOT Facility Stormwater and Washwater Effluent Drainage Assessment}

\section{Name of Facility __Chrisney_Unit}

\section{$\underline{\text { Surface Water }}$}

\section{District/Subdistrict__Vincennes}

1. Does any area of the active surface collect storm water or facility-generated wash water (such as from washing trucks outdoors)? _

2. Is there any movement of surface water from one area to another on-site by ditch, drain tile or natural channel? _ Yes

3. Is there any movement of surface water off-site (e.g., beneath the perimeter fence) via sheet flow, ditch, pipe or channel to adjacent property? __ $\underline{\text { Yes }}$

4. Is the surface water discharged directly to (check all that apply) -

$\square$ drainage ditch or roadside ditch

$\square$ county-regulated drain

$\square \quad$ state highway drainage system

$\square$ a nearby creek, river or other water body

$\square \quad$ lagoon or holding pond

$\square \quad$ settling basin, catch basin, or other constructed retention structure

$\square$ underground tank

$\square$ municipal storm sewer Owner

$\square$ municipal combined storm/sanitary sewer Owner

$\square$ POTW Owner:

$\square$ Other

5. If surface water is discharged, other than to a municipal storm, sanitary or combined sewer, does it ultimately reach "waters of the state” (e.g., farm ditch, creek, stream, river, lake or pond)? If yes, name of that water body. __Yes,_East Fork, Little Pigeon Creek

6. What is the estimated distance of this water body from the facility? _ 1 mile north of the facility 


\section{Shop Floor Drain \& Wash Bay Effluent}

1. Are there drains in shop floors and wash bays that remove liquids and wash water effluent from the building(s)? _ _ Yes

2. Does the effluent flow to -

$\square$ aboveground oil/water separator

$\square$ aboveground tank

$\square$ below ground oil/water separator

$\square$ below ground tank

$\square$ settling basin, catch basin, lagoon, holding pond or other constructed retention structure

$\square$ none of the above

3. If the effluent is captured by the devices in 2., above, is it contained until pumped and hauled to a POTW or until it evaporates, or does it overflow to a drainage system?__ It overflows to a drainage system

4. If the effluent overflows to a drainage system, is the system above or below ground? _ Below ground_sewer

5. If the effluent overflows to a drainage system, does it mix with storm water?__no

6. If the effluent $\underline{\text { does }}$ mix with storm water, see "Surface Water" section (preceding page, \#4 and \#5) for discharge.

7. If the effluent doesn't mix with storm water, is it discharged to -

$\square$ subsurface soils

$\square$ on-site septic system

$\square$ drainage ditch or roadside ditch

$\square$ a nearby creek, river or other water body

$\square \quad$ lagoon or holding pond

$\square$ municipal storm sewer Owner

$\square$ municipal combined storm/sanitary sewer Owner

$\square$ municipal POTW Owner Chrisney Municipal WWTP 
8. If shop floor drain and wash bay effluent is discharged, other than to a municipal storm, sanitary or combined sewer, does it ultimately reach "waters of the state?" If yes, name of that water body:

Activity Areas (check those that apply and describe (1) whether they are bermed to prevent storm water runoff or (2) if there are drains and their locations in the activity areas)

$\square$ salt storage (pads or domes) _ _ No berm, but there is a catch basin located directly _in front of the Salt Dome

$\square$ salt/sand mixing _

$\square$ salt bed loading/wetting _ _ Performed in a covered area, which drains to an _underground tank that is pumped and hauled periodically

$\square$ salt bed washout_Performed in the Unit Building, which drains to the sewer

$\square$ salt bed storage _ No berm, but there is a drain that catches all the runoff from this - area

$\square$ vehicle and equipment washing (inside)__Performed in the Unit Building

$\square \quad$ vehicle and equipment washing (outside)

$\square \quad$ asphalt equipment clean-out

$\square$ herbicide mixing and tank rinsing _ Performed inside Unit Building

$\square \quad$ traffic paint mixing and transfer

$\square$ bulk tank off-loading and storage

$\square$ waste piles (e.g., ROW trash, street sweeping debris)

$\square$ truck/equipment parking __ No berm or drain

$\square \quad$ truck/equipment fueling

$\square$ materials storage (210 lot, fencing, etc.) __ No berm or drain

$\square$ aggregate storage _ No berm or drain

$\square$ hot/cold patch storage __ No berm or drain

$\square$ storage of “scalp” and dirt from R/W maintenance _ No berm or drain 
Date_8/4/2005

\section{INDOT Facility Stormwater and Washwater Effluent Drainage Assessment}

Name of Facility __ Grantsburg Unit

District/Subdistrict _ _ Vinennes

\section{$\underline{\text { Surface Water }}$}

1. Does any area of the active surface collect storm water or facility-generated wash water (such as from washing trucks outdoors)? _ _ Yes

2. Is there any movement of surface water from one area to another on-site by ditch, drain tile or natural channel? ___ Yes

3. Is there any movement of surface water off-site (e.g., beneath the perimeter fence) via sheet flow, ditch, pipe or channel to adjacent property? _

4. Is the surface water discharged directly to (check all that apply) -

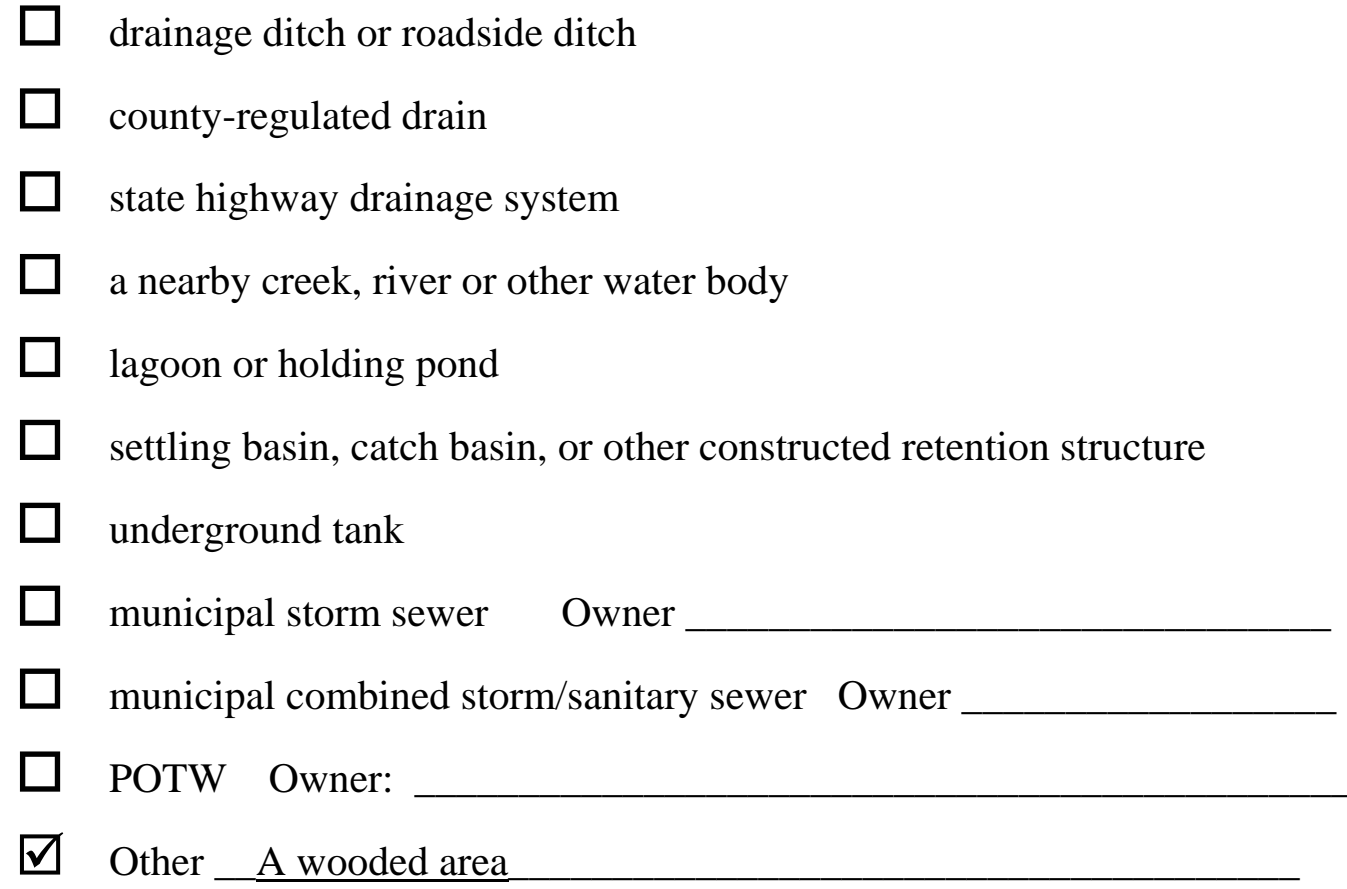

5. If surface water is discharged, other than to a municipal storm, sanitary or combined sewer, does it ultimately reach "waters of the state” (e.g., farm ditch, creek, stream, river, lake or pond)? If yes, name of that water body. __ No, the location of the stormwater discharge pipe is uknown. It is in a densely wooded area.

6. What is the estimated distance of this water body from the facility? 


\section{Shop Floor Drain \& Wash Bay Effluent}

1. Are there drains in shop floors and wash bays that remove liquids and wash water effluent from the building(s)? _ Y Yes

2. Does the effluent flow to -

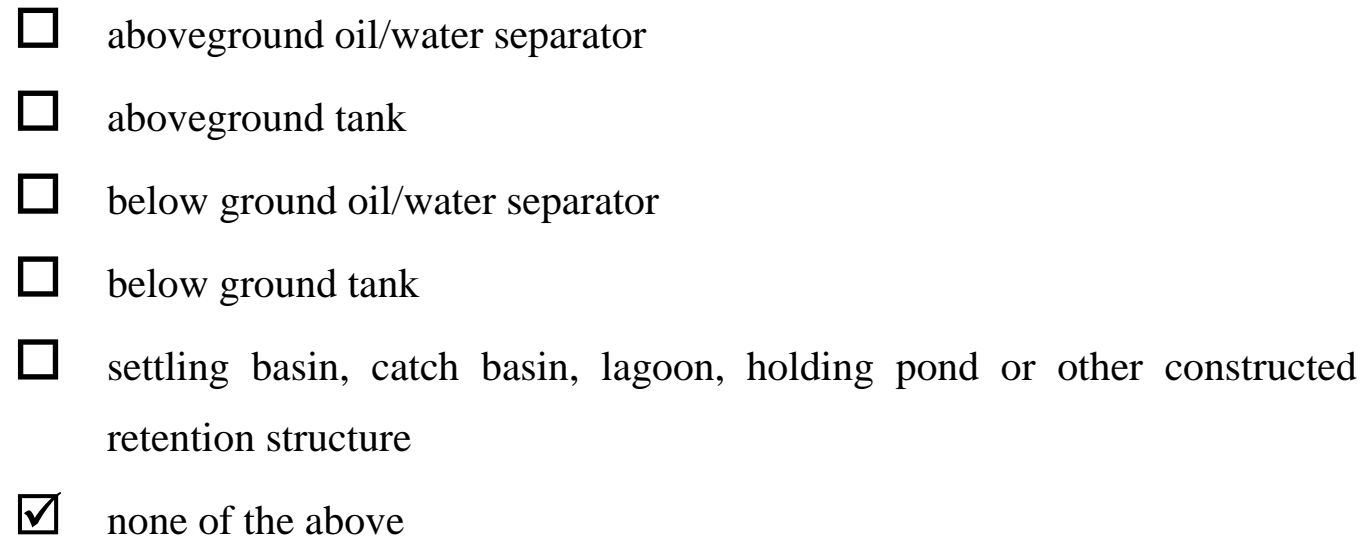

3. If the effluent is captured by the devices in 2., above, is it contained until pumped and hauled to a POTW or until it evaporates, or does it overflow to a drainage system?

4. If the effluent overflows to a drainage system, is the system above or below ground?

5. If the effluent overflows to a drainage system, does it mix with storm water?

6. If the effluent $\underline{\text { does }}$ mix with storm water, see "Surface Water" section (preceding page, \#4 and \#5) for discharge.

7. If the effluent doesn't mix with storm water, is it discharged to -

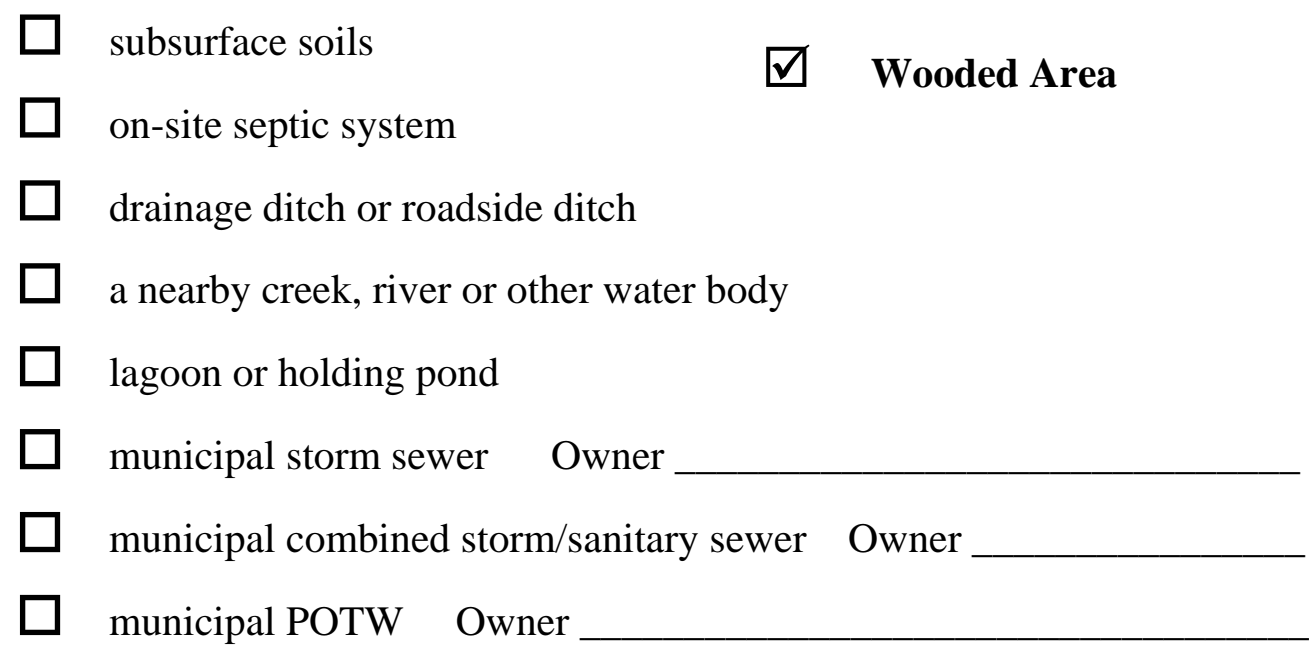


8. If shop floor drain and washbay effluent is discharged, other than to a municipal storm, sanitary or combined sewer, does it ultimately reach "waters of the state?" If yes, name of that water body:

Activity Areas (check those that apply and describe (1) whether they are bermed to prevent storm water runoff or (2) if there are drains and their locations in the activity areas)

$\square$ salt storage (pads or domes) _ There is a catch basin near the entrance of the _Salt Dome

$\square$ salt/sand mixing _ The mixing area is at the entrance of the Salt Dome

$\square$ salt bed loading/wetting _ _ The salt bed wetting area is housed in a drive through _ shed. There is a catch basin in this shed that drains into a storage tank.

$\square$ salt bed washout

$\square$ salt bed storage _ There is no drain or berm in this area

$\square \quad$ vehicle and equipment washing (inside)

$\square \quad$ vehicle and equipment washing (outside)

$\square$ asphalt equipment clean-out _ _ Performed on the job site

$\square$ herbicide mixing and tank rinsing _ _rinsed out twice per year.

$\square \quad$ traffic paint mixing and transfer

$\square$ bulk tank off-loading and storage

$\square \quad$ waste piles (e.g., ROW trash, street sweeping debris) __ Dumpsters

$\square \quad$ truck/equipment parking __ No berm or drains in this area

$\square \quad$ truck/equipment fueling

$\square$ materials storage (210 lot, fencing, etc.)

$\square$ aggregate storage __ No berms or drains in this area

$\square$ hot/cold patch storage __ Covered with a tarp. No berms or drain

$\square$ storage of “scalp” and dirt from R/W maintenance __ No berm or drain 
Date_8/4/2005

\section{INDOT Facility Stormwater and Washwater Effluent Drainage Assessment}

Name of Facility __ Petersburg Unit

District/Subdistrict __ Vincennes

\section{$\underline{\text { Surface Water }}$}

1. Does any area of the active surface collect storm water or facility-generated wash water (such as from washing trucks outdoors)? _ Y Yes

2. Is there any movement of surface water from one area to another on-site by ditch, drain tile or natural channel?

3. Is there any movement of surface water off-site (e.g., beneath the perimeter fence) via sheet flow, ditch, pipe or channel to adjacent property? _

4. Is the surface water discharged directly to (check all that apply) -

$\square$ drainage ditch or roadside ditch

$\square$ county-regulated drain

$\square \quad$ state highway drainage system

$\square$ a nearby creek, river or other water body

$\square \quad$ lagoon or holding pond

$\square$ settling basin, catch basin, or other constructed retention structure

$\square$ underground tank

$\square$ municipal storm sewer Owner

$\square$ municipal combined storm/sanitary sewer Owner_Unknown

$\square$ POTW Owner:

$\square$ Other

5. If surface water is discharged, other than to a municipal storm, sanitary or combined sewer, does it ultimately reach "waters of the state” (e.g., farm ditch, creek, stream, river, lake or pond)? If yes, name of that water body.

6. What is the estimated distance of this water body from the facility? 


\section{Shop Floor Drain \& Wash Bay Effluent}

1. Are there drains in shop floors and wash bays that remove liquids and wash water effluent from the building(s)? _ Yes

2. Does the effluent flow to -

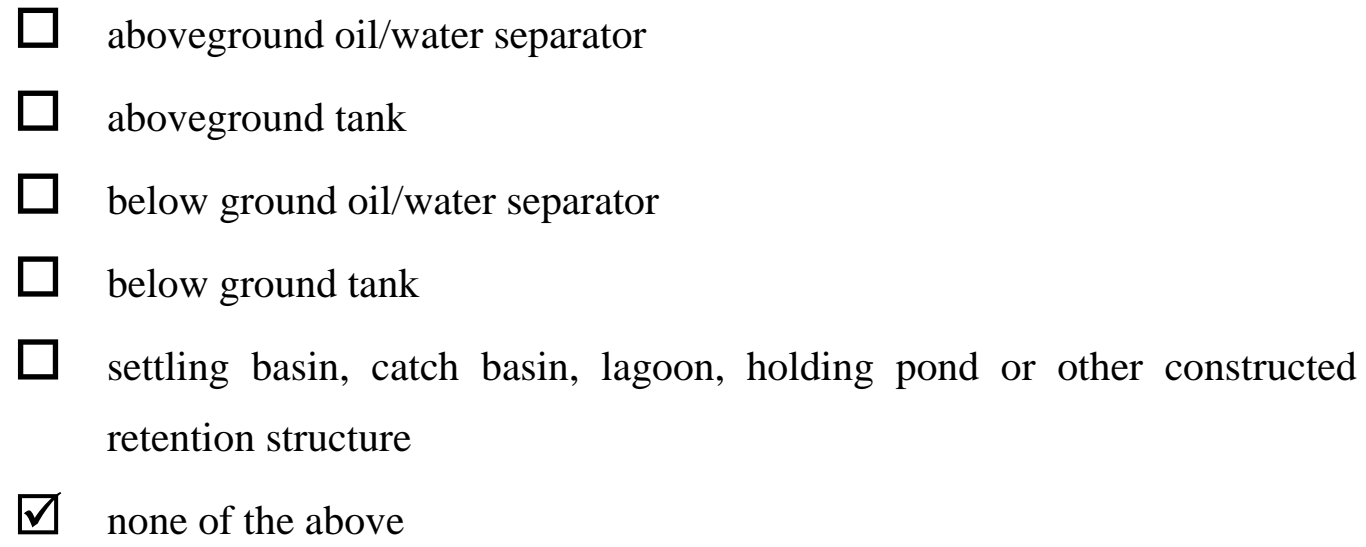

3. If the effluent is captured by the devices in 2., above, is it contained until pumped and hauled to a POTW or until it evaporates, or does it overflow to a drainage system?

4. If the effluent overflows to a drainage system, is the system above or below ground?

5. If the effluent overflows to a drainage system, does it mix with storm water?

6. If the effluent $\underline{\text { does }}$ mix with storm water, see "Surface Water" section (preceding page, \#4 and \#5) for discharge.

7. If the effluent doesn't mix with storm water, is it discharged to -

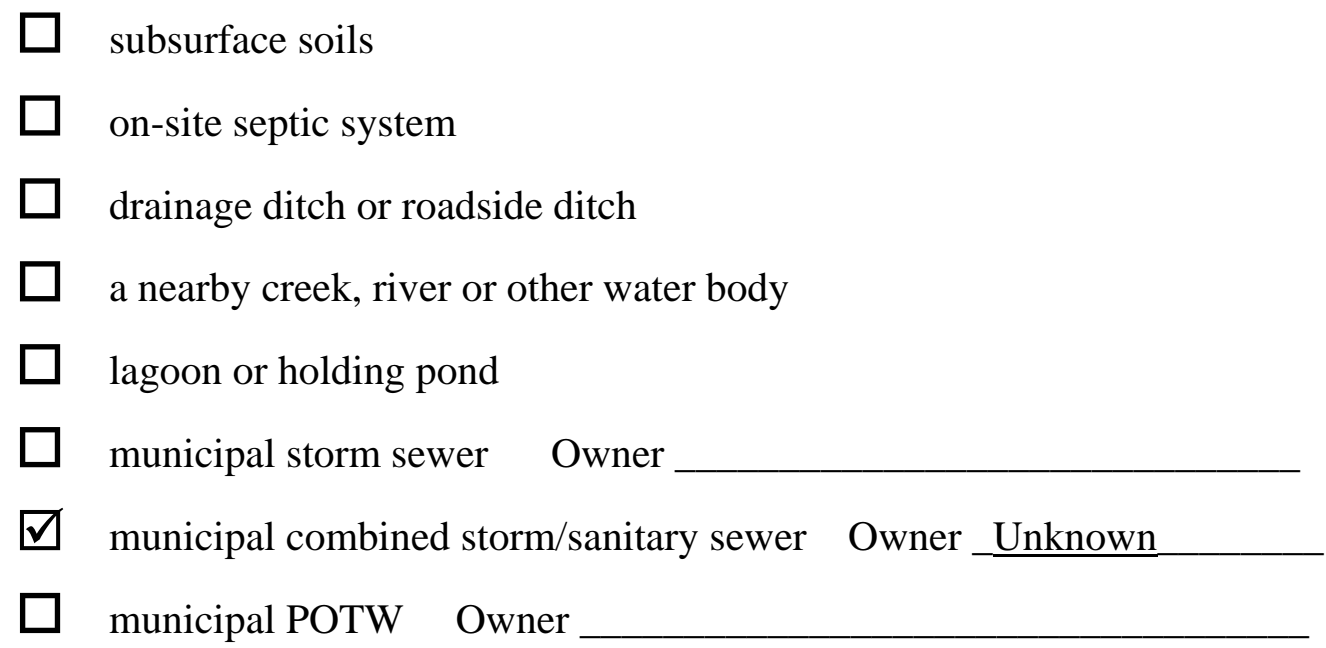


8. If shop floor drain and washbay effluent is discharged, other than to a municipal storm, sanitary or combined sewer, does it ultimately reach "waters of the state?" If yes, name of that water body:

Activity Areas (check those that apply and describe (1) whether they are bermed to prevent $\underline{\text { storm water runoff or (2) if there are drains and their locations in the activity areas) }}$

$\square$ salt storage (pads or domes) _ There is a catch basin near the salt storage _building that catches all stormwater from the area

$\square$ salt/sand mixing_Same as "Salt Storage"

$\square$ salt bed loading/wetting _ Stormwater from the area drains into a catch basin_

$\square \quad$ salt bed washout

$\square$ salt bed storage _

$\square$ vehicle and equipment washing (inside) _ There are floor drains inside the _ Unit Building that drain into the sewer system

$\square$ vehicle and equipment washing (outside)

$\square$ asphalt equipment clean-out

$\square \quad$ herbicide mixing and tank rinsing

$\square \quad$ traffic paint mixing and transfer

$\square$ bulk tank off-loading and storage

$\square \quad$ waste piles (e.g., ROW trash, street sweeping debris) __ Dumpsters

$\square$ truck/equipment parking __ Stormwater from the area drains into a catch basin

$\square \quad$ truck/equipment fueling

$\square$ materials storage (210 lot, fencing, etc.)

$\square$ aggregate storage __ Catch Basin

$\square$ hot/cold patch storage _ _ Stored inside a cold storage building with no floor drains

$\square$ storage of “scalp” and dirt from R/W maintenance 
Date_6/08/05

\section{INDOT Facility Stormwater and Washwater Effluent Drainage Assessment}

Name of Facility ___ Jasper_Unit

\section{$\underline{\text { Surface Water }}$}

\section{District/Subdistrict__Eincennes}

1. Does any area of the active surface collect storm water or facility-generated wash water (such as from washing trucks outdoors)? _

2. Is there any movement of surface water from one area to another on-site by ditch, drain tile or natural channel? _ Yes

3. Is there any movement of surface water off-site (e.g., beneath the perimeter fence) via sheet flow, ditch, pipe or channel to adjacent property? __ $\underline{\text { Yes }}$

4. Is the surface water discharged directly to (check all that apply) -

$\square$ drainage ditch or roadside ditch

$\square$ county-regulated drain

$\square$ state highway drainage system

$\square$ a nearby creek, river or other water body

$\square \quad$ lagoon or holding pond

$\square \quad$ settling basin, catch basin, or other constructed retention structure

$\square$ underground tank

$\square$ municipal storm sewer Owner

$\square$ municipal combined storm/sanitary sewer Owner

$\square$ POTW Owner:

$\square$ Other

5. If surface water is discharged, other than to a municipal storm, sanitary or combined sewer, does it ultimately reach "waters of the state” (e.g., farm ditch, creek, stream, river, lake or pond)? If yes, name of that water body. _ _Yes, the storm water enters a drainage ditch that flows into Straight River

6. What is the estimated distance of this water body from the facility? approx. 1 mile south of the facility 


\section{Shop Floor Drain \& Wash Bay Effluent}

1. Are there drains in shop floors and wash bays that remove liquids and wash water effluent from the building(s)? _ Y Yes

2. Does the effluent flow to -

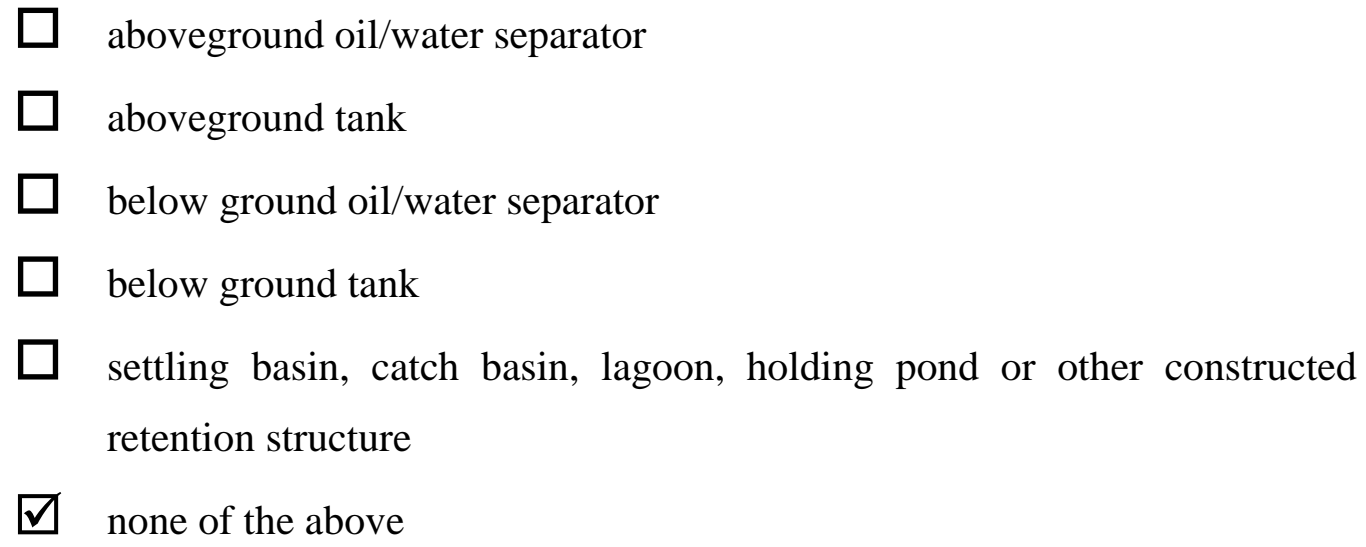

3. If the effluent is captured by the devices in 2., above, is it contained until pumped and hauled to a POTW or until it evaporates, or does it overflow to a drainage system?

4. If the effluent overflows to a drainage system, is the system above or below ground?

5. If the effluent overflows to a drainage system, does it mix with storm water?

6. If the effluent does mix with storm water, see "Surface Water" section (preceding page, \#4 and \#5) for discharge.

7. If the effluent doesn't mix with storm water, is it discharged to -

$\square$ subsurface soils

$\square$ on-site septic system

$\square$ drainage ditch or roadside ditch

$\square$ a nearby creek, river or other water body

$\square \quad$ lagoon or holding pond

$\square$ municipal storm sewer Owner

$\square$ municipal combined storm/sanitary sewer Owner

$\square$ municipal POTW Owner___asper WWTP 
8. If shop floor drain and wash bay effluent is discharged, other than to a municipal storm, sanitary or combined sewer, does it ultimately reach "waters of the state?" If yes, name of that water body:

Activity Areas (check those that apply and describe (1) whether they are bermed to prevent storm water runoff or (2) if there are drains and their locations in the activity areas)

$\square$ salt storage (pads or domes) __ No berm, but there is a catch basin approx. 10 feet from the entrance of the Salt Dome

$\square$ salt/sand mixing _

$\square \quad$ salt bed loading/wetting _ _ No berm or drain

$\square$ salt bed washout_Inside a wash bay that is connected to the sewer

$\square$ salt bed storage _ No berm or drain

$\square \quad$ vehicle and equipment washing (inside) __ Inside Wash Bay

$\square \quad$ vehicle and equipment washing (outside)

$\square \quad$ asphalt equipment clean-out

$\square$ herbicide mixing and tank rinsing _Performed inside Unit Building, which has a _floor drain. No berm

$\square \quad$ traffic paint mixing and transfer

$\square$ bulk tank off-loading and storage

$\square$ waste piles (e.g., ROW trash, street sweeping debris) __ No berm or drain

$\square \quad$ truck/equipment parking __ No berm or drain

$\square \quad$ truck/equipment fueling

$\square$ materials storage (210 lot, fencing, etc.) __ No berm or drain

$\square$ aggregate storage _ No berm or drain

$\square$ hot/cold patch storage __ No berm or drain

$\square$ storage of “scalp” and dirt from R/W maintenance _ No berm or drain 
Date__8/42005

\section{INDOT Facility Stormwater and Washwater Effluent Drainage Assessment}

Name of Facility __Poseyville Unit

District/Subdistrict __ Vincennes

\section{$\underline{\text { Surface Water }}$}

1. Does any area of the active surface collect storm water or facility-generated wash water (such as from washing trucks outdoors)? __ Yes

2. Is there any movement of surface water from one area to another on-site by ditch, drain tile or natural channel? ___ Yes

3. Is there any movement of surface water off-site (e.g., beneath the perimeter fence) via sheet flow, ditch, pipe or channel to adjacent property? __ Yes

4. Is the surface water discharged directly to (check all that apply) -

$\square$ drainage ditch or roadside ditch

$\square$ county-regulated drain

$\square \quad$ state highway drainage system

$\square$ a nearby creek, river or other water body

$\square$ lagoon or holding pond

$\square$ settling basin, catch basin, or other constructed retention structure

$\square$ underground tank

$\square$ municipal storm sewer Owner

$\square$ municipal combined storm/sanitary sewer Owner

$\square$ POTW Owner:

$\square$ Other

5. If surface water is discharged, other than to a municipal storm, sanitary or combined sewer, does it ultimately reach "waters of the state” (e.g., farm ditch, creek, stream, river, lake or pond)? If yes, name of that water body. __ No

6. What is the estimated distance of this water body from the facility? 


\section{Shop Floor Drain \& Wash Bay Effluent}

1. Are there drains in shop floors and wash bays that remove liquids and wash water effluent from the building(s)? _ Yes

2. Does the effluent flow to -

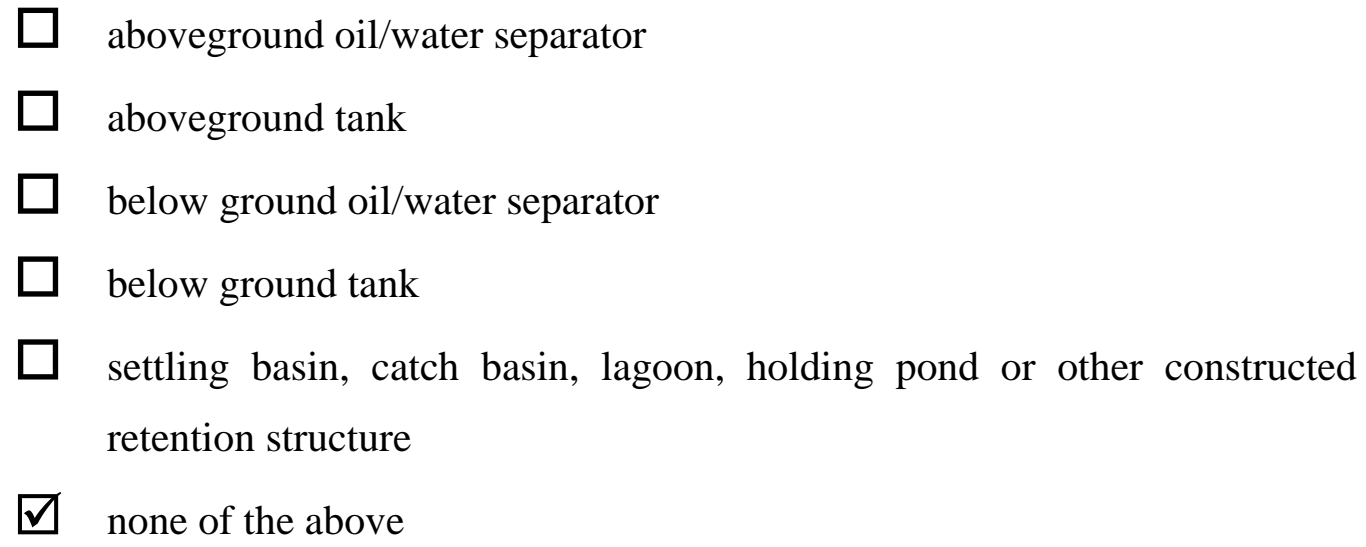

3. If the effluent is captured by the devices in 2., above, is it contained until pumped and hauled to a POTW or until it evaporates, or does it overflow to a drainage system?

4. If the effluent overflows to a drainage system, is the system above or below ground?

5. If the effluent overflows to a drainage system, does it mix with storm water?

6. If the effluent $\underline{\text { does }}$ mix with storm water, see "Surface Water" section (preceding page, \#4 and \#5) for discharge.

7. If the effluent doesn't mix with storm water, is it discharged to -

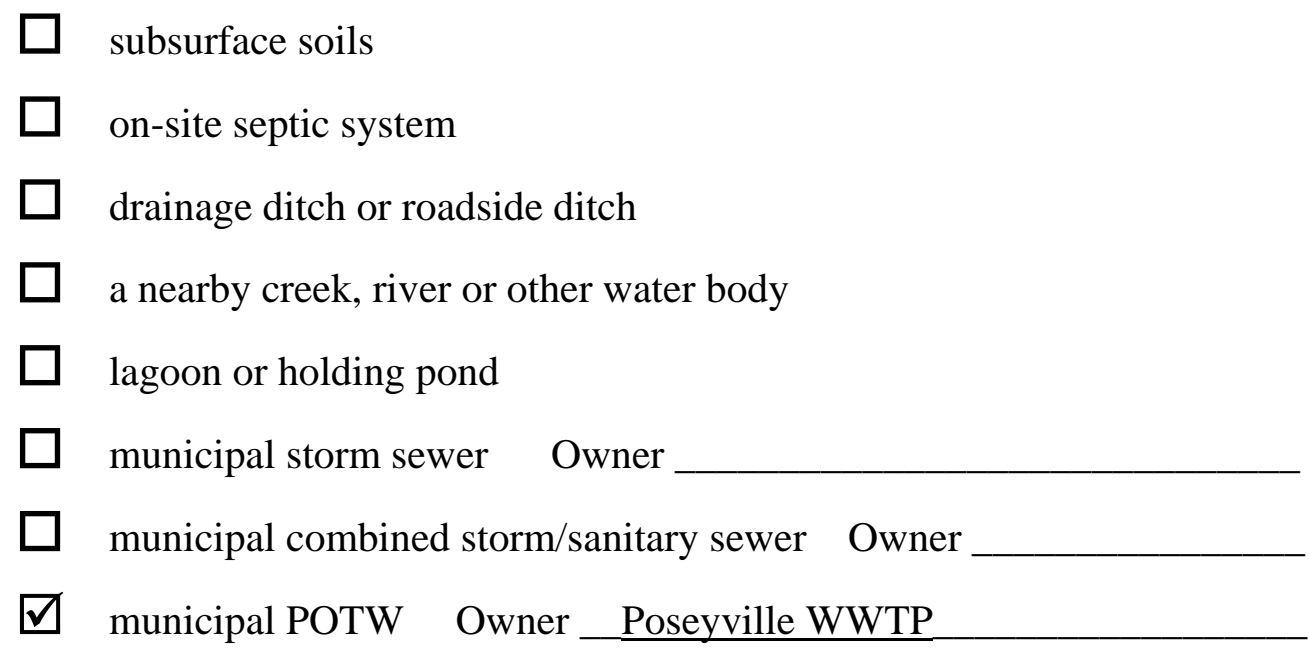


8. If shop floor drain and washbay effluent is discharged, other than to a municipal storm, sanitary or combined sewer, does it ultimately reach "waters of the state?" If yes, name of that water body:

Activity Areas (check those that apply and describe (1) whether they are bermed to prevent storm water runoff or (2) if there are drains and their locations in the activity areas)

$\square \quad$ salt storage (pads or domes) __ No berms or drains

$\square$ salt/sand mixing _ _ No berms or drains

$\square$ salt bed loading/wetting _ _ Inside covered shed with a catch basin that drains _ into a underground storage tank that is pumped and reused periodically

$\square$ salt bed washout _ Performed inside Unit Building that has floor drains _connected to a POTW

$\square$ salt bed storage _ No berms or drains

$\square \quad$ vehicle and equipment washing (inside) __ Inside Unit Building

$\square \quad$ vehicle and equipment washing (outside)

$\square$ asphalt equipment clean-out

$\square$ herbicide mixing and tank rinsing _ _ a small amount inside Unit Building

$\square \quad$ traffic paint mixing and transfer

$\square$ bulk tank off-loading and storage

$\square \quad$ waste piles (e.g., ROW trash, street sweeping debris) __ Dumpsters

$\square \quad$ truck/equipment parking __ No berm or drain

$\square \quad$ truck/equipment fueling

$\square$ materials storage (210 lot, fencing, etc.)

$\square \quad$ aggregate storage __ No berms or drain

$\square$ hot/cold patch storage _ _ stored inside a pole barn with no floor drains

$\square$ storage of “scalp” and dirt from R/W maintenance 
Date_6/08/05

INDOT Facility Stormwater and Washwater Effluent Drainage Assessment

Name of Facility __Shoals_Unit

District/Subdistrict__ Vincennes

\section{$\underline{\text { Surface Water }}$}

1. Does any area of the active surface collect storm water or facility-generated wash water (such as from washing trucks outdoors)? _

2. Is there any movement of surface water from one area to another on-site by ditch, drain tile or natural channel? _ Yes

3. Is there any movement of surface water off-site (e.g., beneath the perimeter fence) via sheet flow, ditch, pipe or channel to adjacent property? __ $\underline{\text { Yes }}$

4. Is the surface water discharged directly to (check all that apply) -

$\square$ drainage ditch or roadside ditch

$\square$ county-regulated drain

$\square$ state highway drainage system

$\square$ a nearby creek, river or other water body

$\square \quad$ lagoon or holding pond

$\square \quad$ settling basin, catch basin, or other constructed retention structure

$\square$ underground tank

$\square$ municipal storm sewer Owner

$\square$ municipal combined storm/sanitary sewer Owner

$\square$ POTW Owner:

$\square$ Other

5. If surface water is discharged, other than to a municipal storm, sanitary or combined sewer, does it ultimately reach "waters of the state” (e.g., farm ditch, creek, stream, river, lake or pond)? If yes, name of that water body. __Yes,_unknown name

6. What is the estimated distance of this water body from the facility? approximately 300 yards 


\section{Shop Floor Drain \& Wash Bay Effluent}

1. Are there drains in shop floors and wash bays that remove liquids and wash water effluent from the building(s)? _ _ Yes

2. Does the effluent flow to -

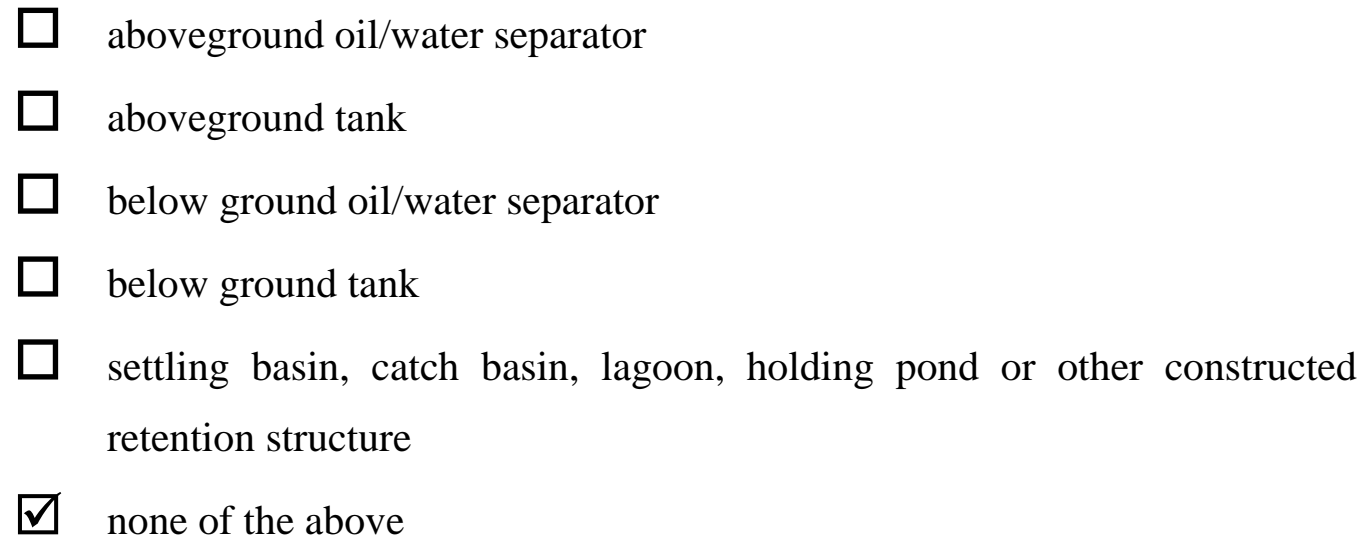

3. If the effluent is captured by the devices in 2., above, is it contained until pumped and hauled to a POTW or until it evaporates, or does it overflow to a drainage system?

4. If the effluent overflows to a drainage system, is the system above or below ground?

5. If the effluent overflows to a drainage system, does it mix with storm water?

6. If the effluent does mix with storm water, see "Surface Water" section (preceding page, \#4 and \#5) for discharge.

7. If the effluent doesn't mix with storm water, is it discharged to -

$\square$ subsurface soils

$\square$ on-site septic system

$\square$ drainage ditch or roadside ditch

$\square$ a nearby creek, river or other water body

$\square \quad$ lagoon or holding pond

$\square$ municipal storm sewer Owner

$\square$ municipal combined storm/sanitary sewer Owner

$\square$ municipal POTW Owner 
8. If shop floor drain and wash bay effluent is discharged, other than to a municipal storm, sanitary or combined sewer, does it ultimately reach "waters of the state?" If yes, name of that water body: __ Yes, unknown name

Activity Areas (check those that apply and describe (1) whether they are bermed to prevent storm water runoff or (2) if there are drains and their locations in the activity areas)

$\square$ salt storage (pads or domes) __ Sand berm at entrance of salt building, no drain

$\square$ salt/sand mixing _ _ No berm or drain

$\square$ salt bed loading/wetting _ _ No berm or drain

$\square \quad$ salt bed washout

$\square$ salt bed storage _ No berm or drain

$\square \quad$ vehicle and equipment washing (inside)

$\square \quad$ vehicle and equipment washing (outside)

$\square \quad$ asphalt equipment clean-out

$\square$ herbicide mixing and tank rinsing _.Performed inside Unit Building, which has a _floor drain. No berm

$\square \quad$ traffic paint mixing and transfer

$\square$ bulk tank off-loading and storage

$\square$ waste piles (e.g., ROW trash, street sweeping debris) __ No berm or drain

$\square$ truck/equipment parking __ No berm or drain

$\square \quad$ truck/equipment fueling

$\square$ materials storage (210 lot, fencing, etc.) __ No berm or drain

$\square$ aggregate storage _ No berm or drain

$\square$ hot/cold patch storage __ No berm or drain

$\square$ storage of “scalp” and dirt from R/W maintenance _ No berm or drain 


\section{INDOT Site Assessment Report Observations and Comments}

Facility: Bloomfield Unit

June 8, 2005

\section{$\underline{\text { Surface Area }}$}

General

This facility is not equipped with an oil/water separator.

There is an outdoor washbay at this facility. The catch basin in the center of the washbay drains into a pipe that flows through a valve that diverts washwater to either the roadside ditch or the sewer system. The Unit Foreman explained that during the winter, when salt beds are being washed, the valve is turned to allow washwater to flow into the sewer and in the summer it is turned to divert water into the roadside ditch because there is no salt in the water. The floor drains in the Unit Building are connected to the same pipe as the washbay drain. However, there is a catch basin near the Salt Dome entrance that drains into the roadside ditch at all times. The roadside ditch drains into a small creek approx. 0.5 miles from the facility.

$>$ There is an asphalt testing lab located across the street from this facility.
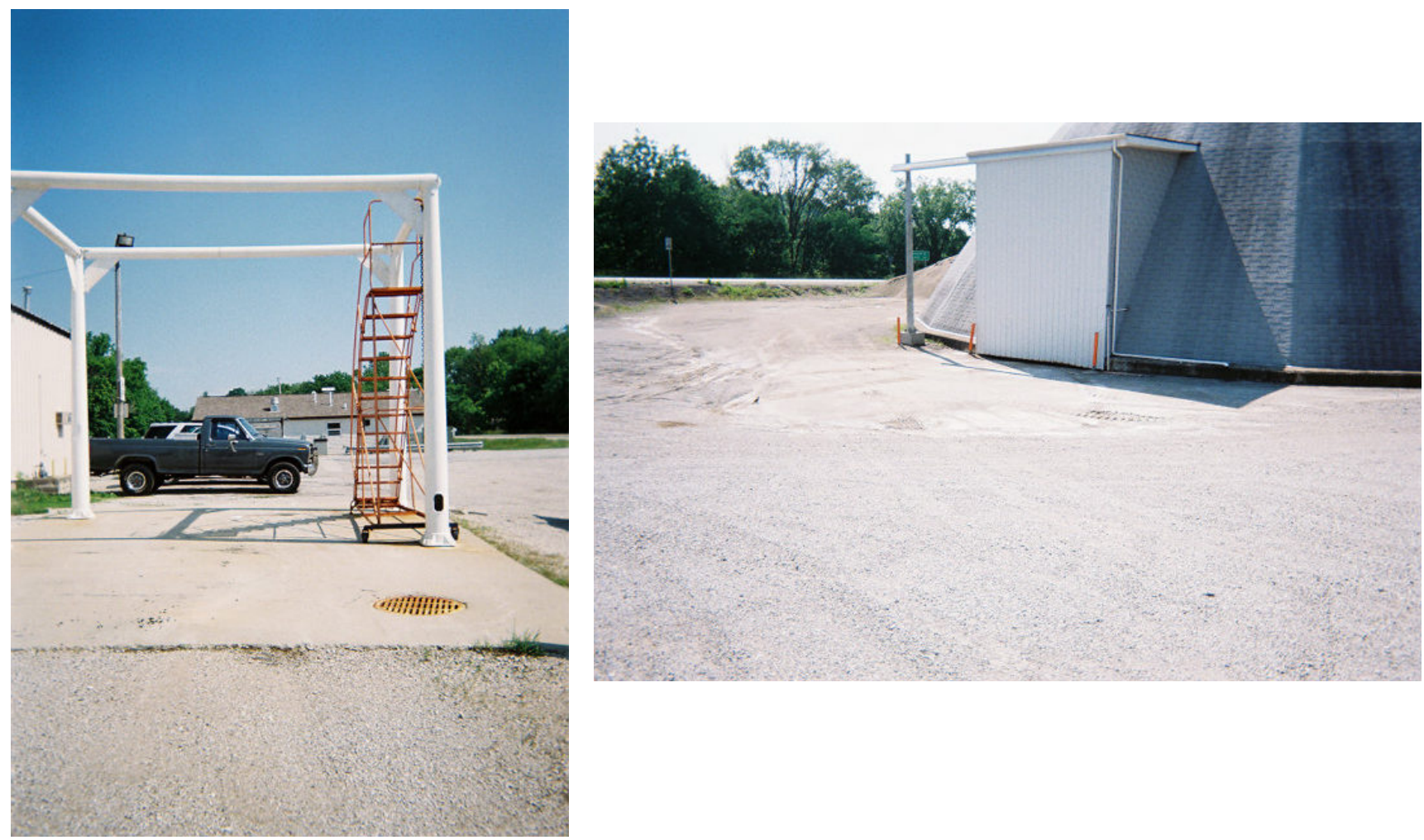
North Portion of Property

The Unit Building is located in the NW corner of the property. There is an outdoor washbay located on the east side of the Unit Building.

The Salt Dome is located approximately 20 yards SE of the washbay. There was a substantial amount of salt on the ground around the entrance of the Salt Dome. There is evidence that salt is being transported from this area into the roadside ditch, which eventually drains into a creek.

There is a secondarily contained $\mathrm{MgCl}$ tank located approx. 30 yards west of the Salt Dome. There is also a bed spraying system connected to this $\mathrm{MgCl}$ tank. This spraying system is housed in a small drive through shed to prevent contamination of stormwater. At the time of the site visit there was a tractor parked in this shed.
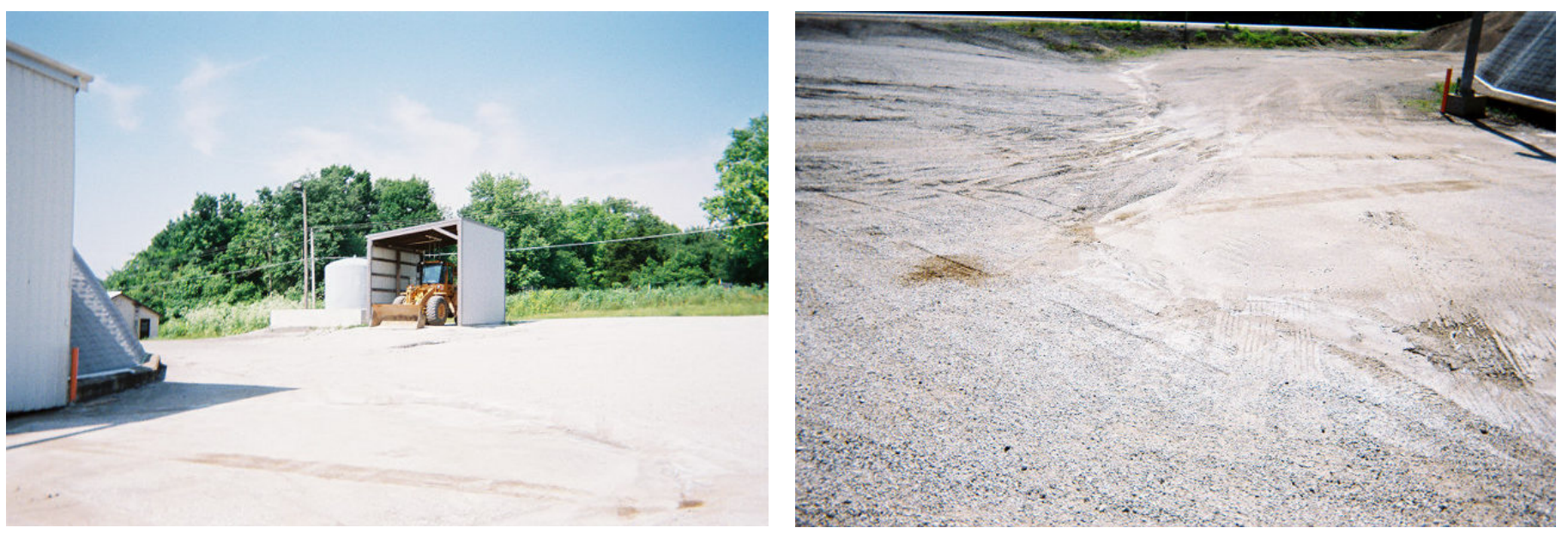

South Portion of Property

There is a cold storage building located south of the $\mathrm{MgCl}$ tank. This building is used to store tools, road signs, and a tar kettle.

$>$ The salt bed racks are located approx. 20 feet south of the Salt Dome. This area is not bermed and the stormwater from this area flows into the roadside ditch.

There is a truck parking area south of the salt bed racks. This area is not bermed.

All property south of the truck parking area is used to store aggregate piles and metal pipe segments. This area is not bermed and all the water flows into the roadside ditch. 

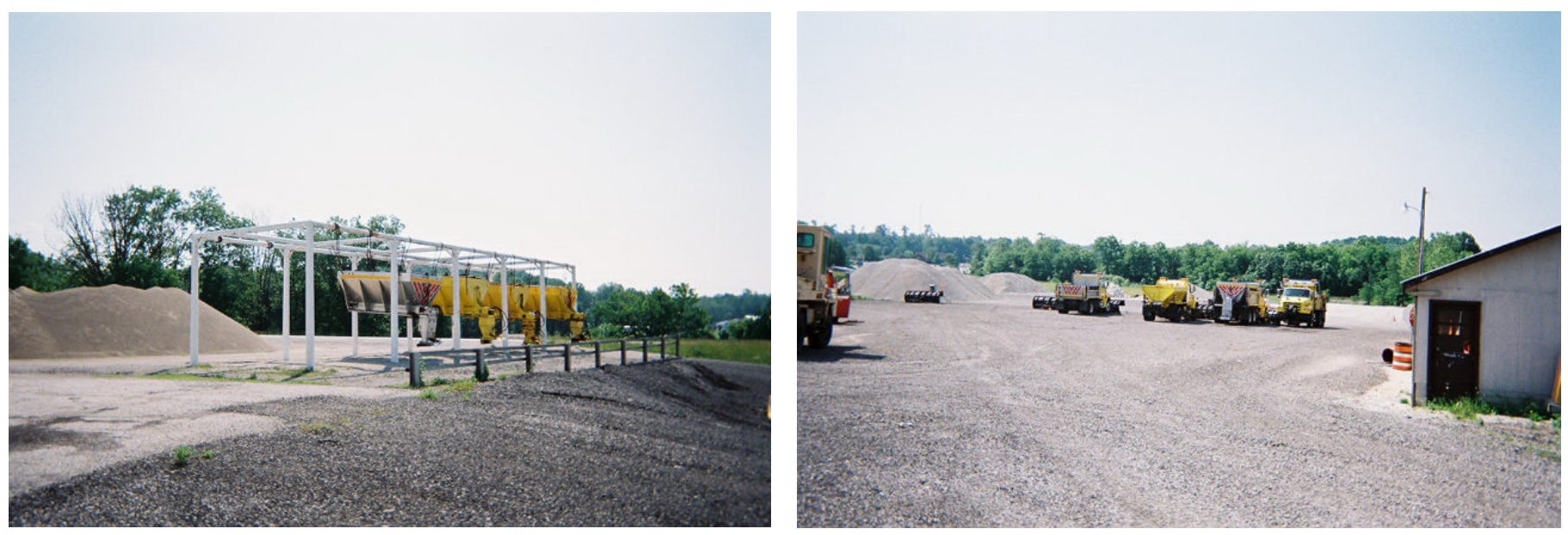

\section{$\underline{\text { Buildings }}$}

* Unit Building

The Unit Building is not equipped with an oil/water separator and the fluids collected in the floor drains can be diverted to either the roadside ditch or the sewer system.

The oil drums inside the Unit Building are secondarily contained on pallets.

* Salt Dome

There was significant amount of salt on the ground around the entrance of the Salt Dome. There is a catch basin near the entrance of the Salt Dome that collects stormwater, which drains into the roadside ditch. It was apparent that the stormwater, being collected by this catch basin, was contaminated with salt.

* Other Buildings

There is a large cold storage building on-site that is used to store a variety of materials. There are no floor drains in this building. 


\title{
INDOT Site Assessment Report Observations and Comments
}

\author{
Surface Area
}

General

$>$ This facility is not equipped with an oil/water separator but the Unit Building floor drains are connected to a POTW. Because the unit is in a low area a pump station was required to hook up to the city sewer system.

$>$ All surface water from the site is collected in catch basins and piped under the west fence line. From there the water flows into an abandoned stone quarry located on the west side of the facility.

\section{East Portion of Property}

The NE corner of the property is used to store snow plows and some road signs. The truck parking area in located along the NE fence line.

$>$ The Unit Building is located approx. 20 yards west of the truck parking area. There is a pump station located on the south side of the Unit Building. Employee vehicles are parked along the west side of the Unit Building. There is a catch basin located in the employee parking area that conveys surface water to the west fence line.

There is a large cold storage building and a small tool shed located approx. 25 yards NW of the Unit Building, along the north fence line. The cold storage building is used to store tractors, bags of cold patch, a secondarily contained chemical locker, and traffic cones and signs. The small tool shed is used to store more tools and road signs.

There is a large crack sealer tank located in the SE corner of the facility. This material looks like black tar and it has been spilled all over the area. The Unit Foreman said that people come from several other units to get this material.

There are several large stormwater pipe segments stored along the south fence line. Large piles of aggregate are also stored on the southern portion of the property. 

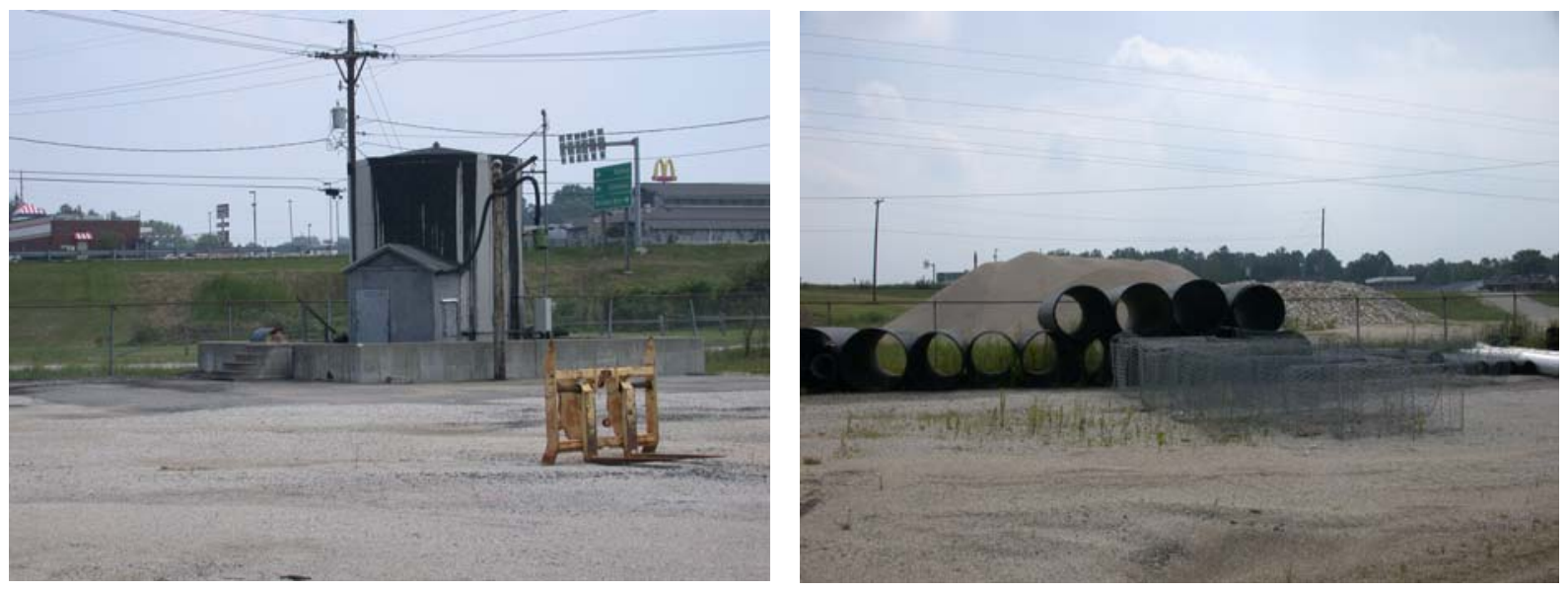

\section{West Portion of Property}

The Salt Dome is located on the west property line fence. There are several catch basins near the Salt Dome that collect stormwater and convey it under the west fence line. There was a substantial amount of salt on the ground around the Salt Dome entrance.

The SW corner of the site is filled with large aggregate piles.

The salt bed racks are located on the north side of the Salt Dome. This area is not bermed and stormwater from this area flows west under the fence.

A secondarily contained Calcium Chloride tank is located on the east side of the Salt Dome. The bed spraying system is housed in a drive through shed that has a catch basin inside that drains into an underground storage tank. The underground storage tank is pumped periodically.
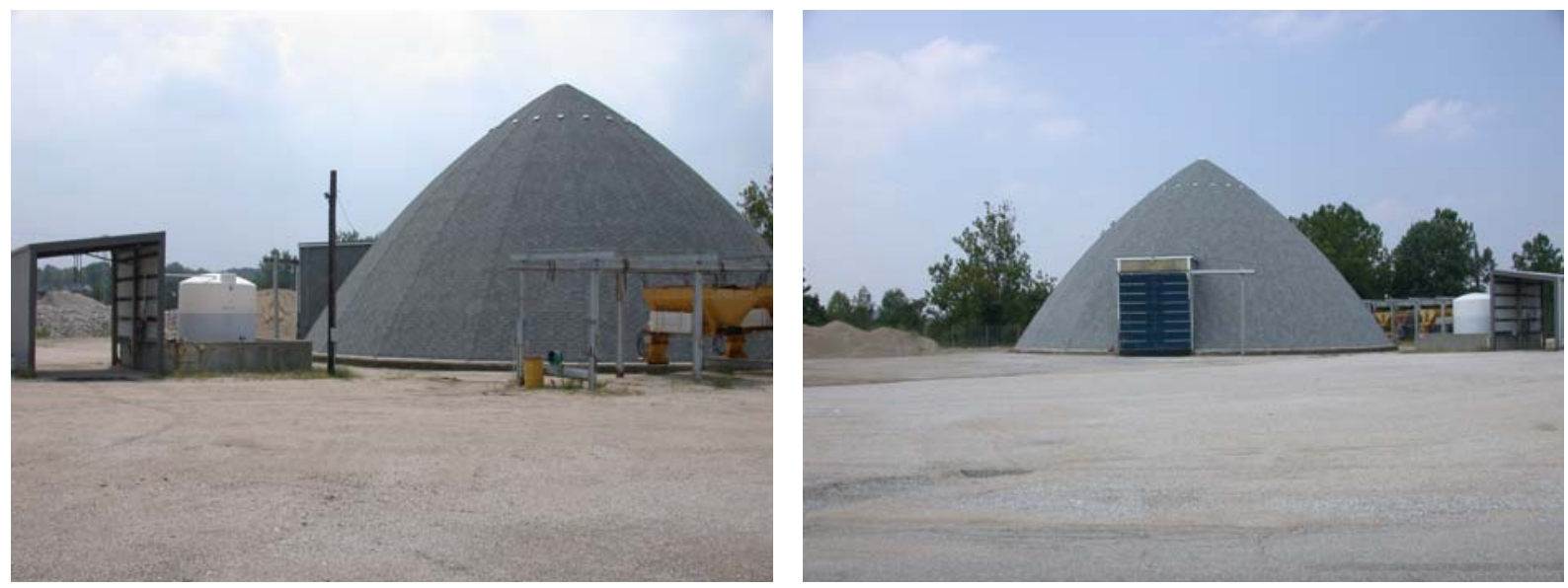


\section{Buildings}

* Unit Building

> There is no oil/water separator in the Unit Building but the floor drains are connected to a POTW. A pump station is located on the south side of the Unit Building.

All oil and hydraulic fluid drums inside the Unit Building are secondarily contained.
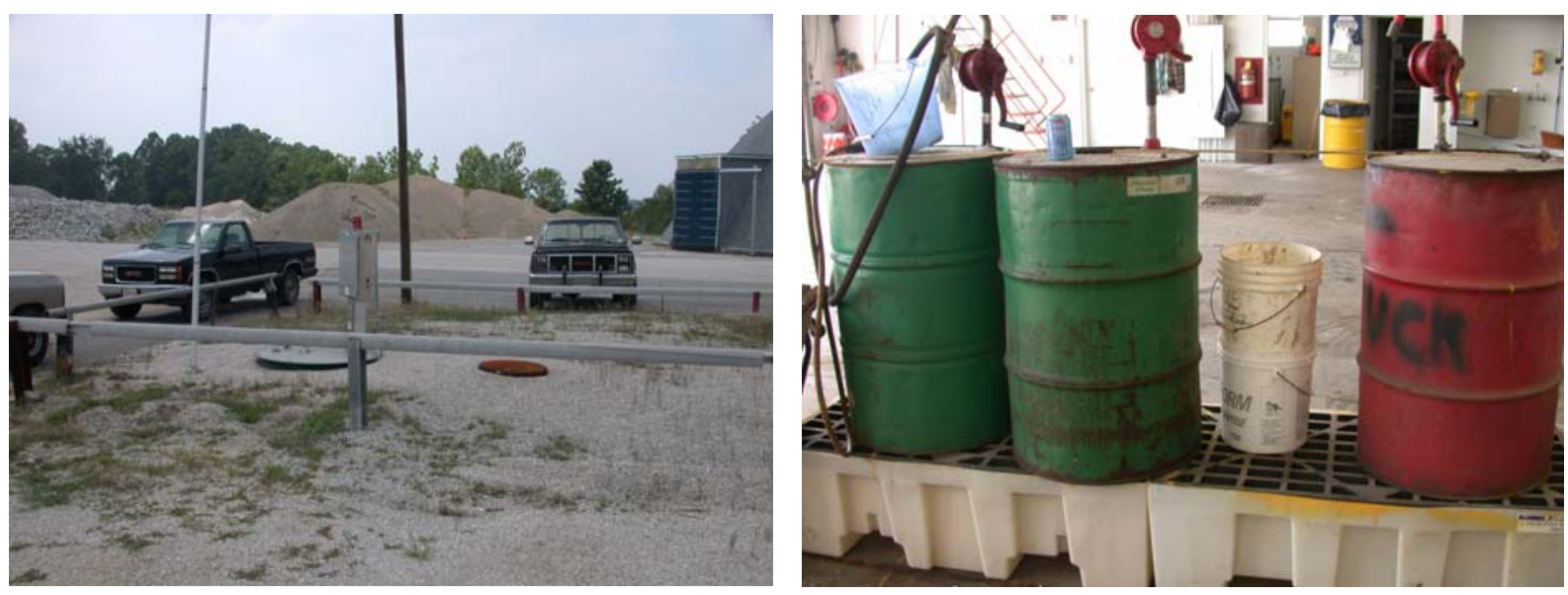

\section{Salt Dome}

$>$ There was salt around the entrance of the Salt Dome. There are several catch basins near the entrance of the Salt Dome that convey stormwater under the west fence line. The stormwater eventually flows into the stone quarry.
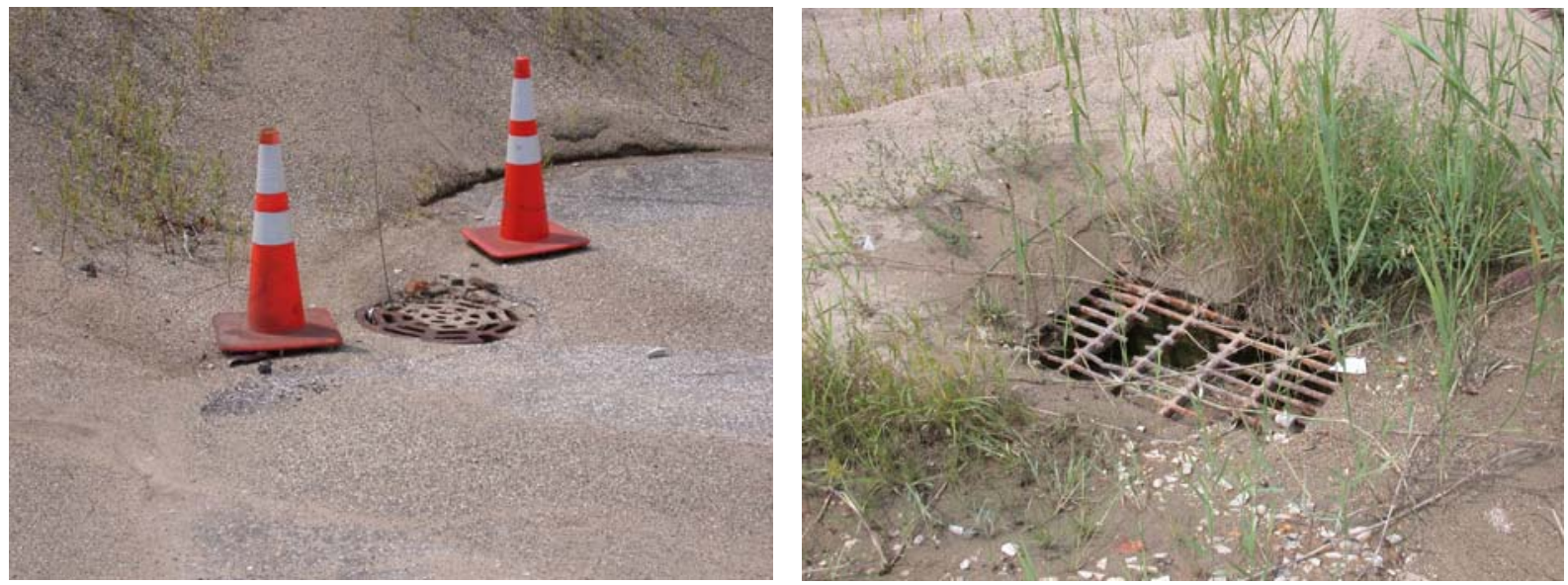

* Other Buildings

$>$ There is a large cold storage building and a small tool shed on-site. These buildings do not contain floor drains. 


\section{INDOT Site Assessment Report Observations and Comments}

Facility: Chrisney Unit

June 9, 2005

\section{Surface Area}

General

D The storm water from this site enters a railroad side ditch, which is located approx. 50 feet west of the property. This railroad side ditch flows into the East Fork of Little Pigeon Creek approx. 1 mile north of the facility.

There are catch basins placed throughout the active surface that convey storm water off of the property. The storm water flows approx. 50 feet over a grassy area and then into the drainage ditch. There is a large area, outside the west fence line, that is completely bare of any plant life. This vegetation kill is due to the large amount of salty runoff coming from the INDOT site. In addition, the lack of plant life has resulted in an erosion problem between the site and the drainage ditch.
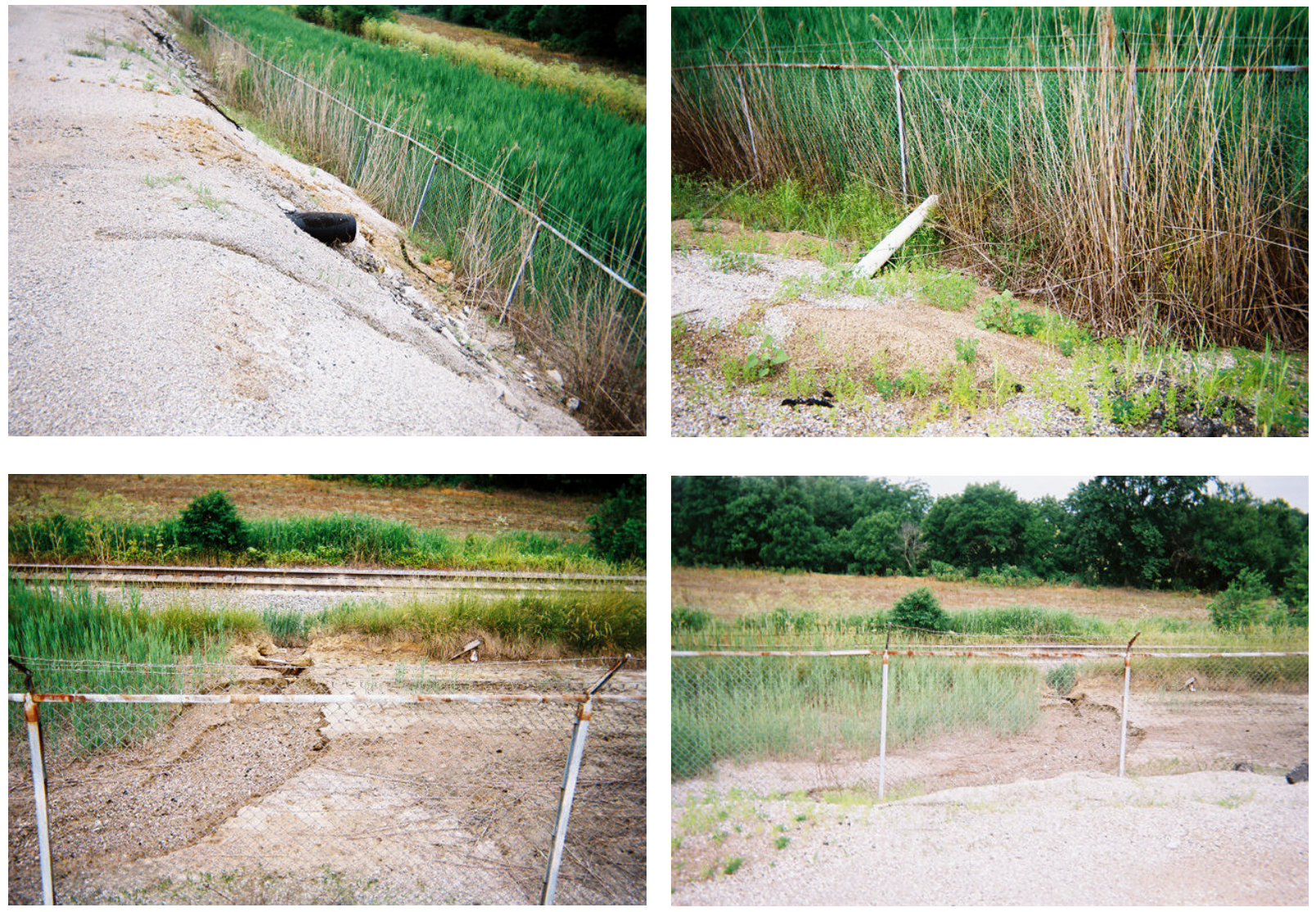
The Unit Building floor drains and the Wash Bay floor drains discharge to Chrisney Municipal WWTP. The Unit Foreman stated that the WWTP has limited the number of salt trucks allowed to be washed to 3 per day.

$>$ There is a catch basin located approx. 10 feet directly in front of the Salt Dome. This catch basin collects all the storm water that comes from the salt loading area and conveys it off the west property line.

$>$ On the day of the visit, there was a substantial amount of salt on the active surface around the entrance of the Salt Dome. All storm water that comes in contact with this salt is piped off site.

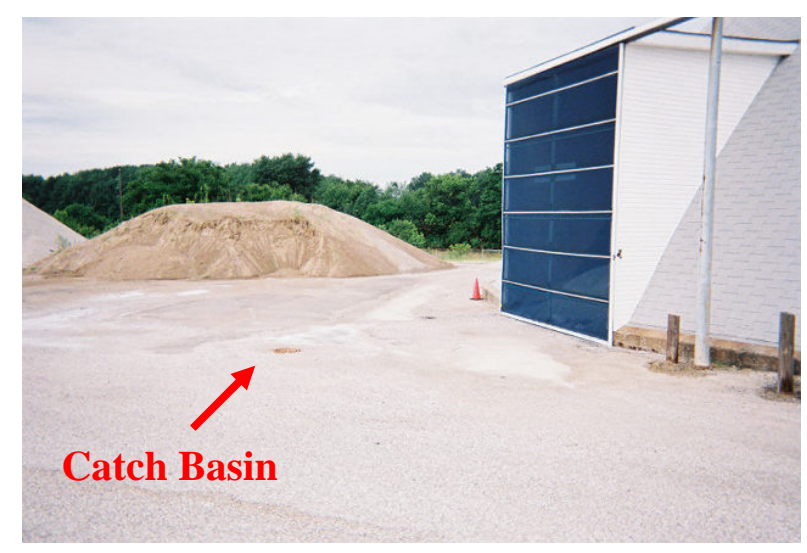

Site Layout

$>$ There is a Cold Storage building located in the NW corner of the property. A tar kettle sits on the west side of this building. On the east side of the building, there were several dark, oily stains on the gravel surface. These stains appear to have come from oil or hydraulic fluid leaks. The storm water from this area flows north to a small ditch that conveys the water to the railroad side ditch. 
The Unit Building is approx. 20 yards south of the cold storage building. While not in use, trucks are parked around this building. There are at least 3 catch basins around the outside perimeter of the Unit Building that catch roof runoff and one that catches storm water and any liquids that exit the south garage door. There are no berms on the south side of the Unit Building to prevent liquids from escaping and entering the catch basin. All catch basins are piped off the west property line.

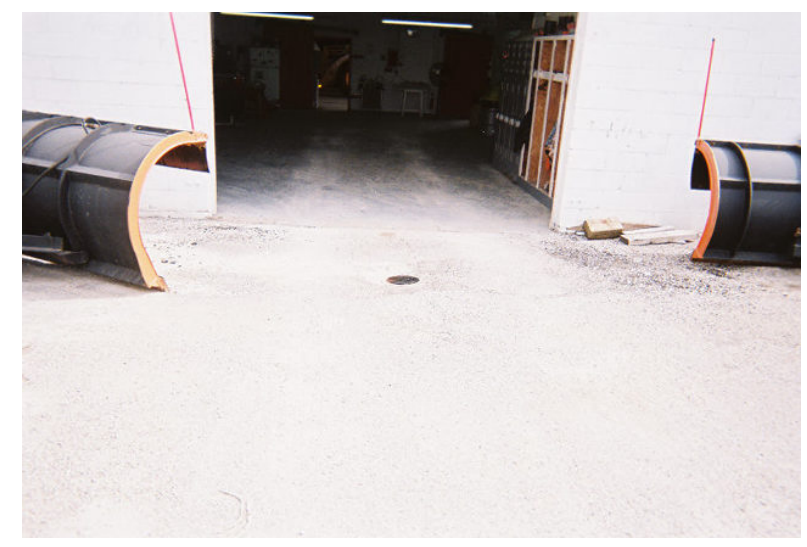

Dhere is an overhead bed spraying system approx. 25 yards south of the Unit Building. It is located on the NE side of the Salt Dome. This spraying system is housed under a roofed shed that contains a catch basin. The shed is open on two ends to allow trucks to drive through. Once water is collected in the catch basin, it is stored in a large under ground tank and pumped out when necessary.
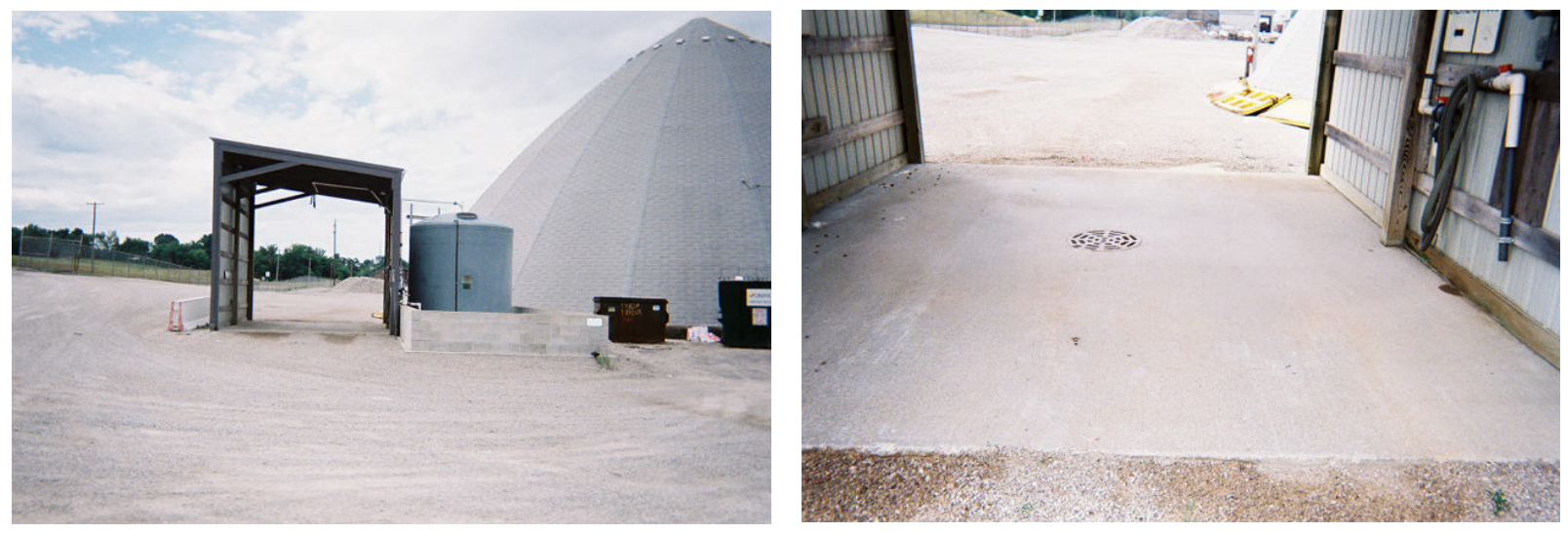
The salt racks are located on the NW side of the Salt Dome along with a small pile of cold patch. There is a catch basin west of the salt racks that conveys all the storm water from this area off the west property line.
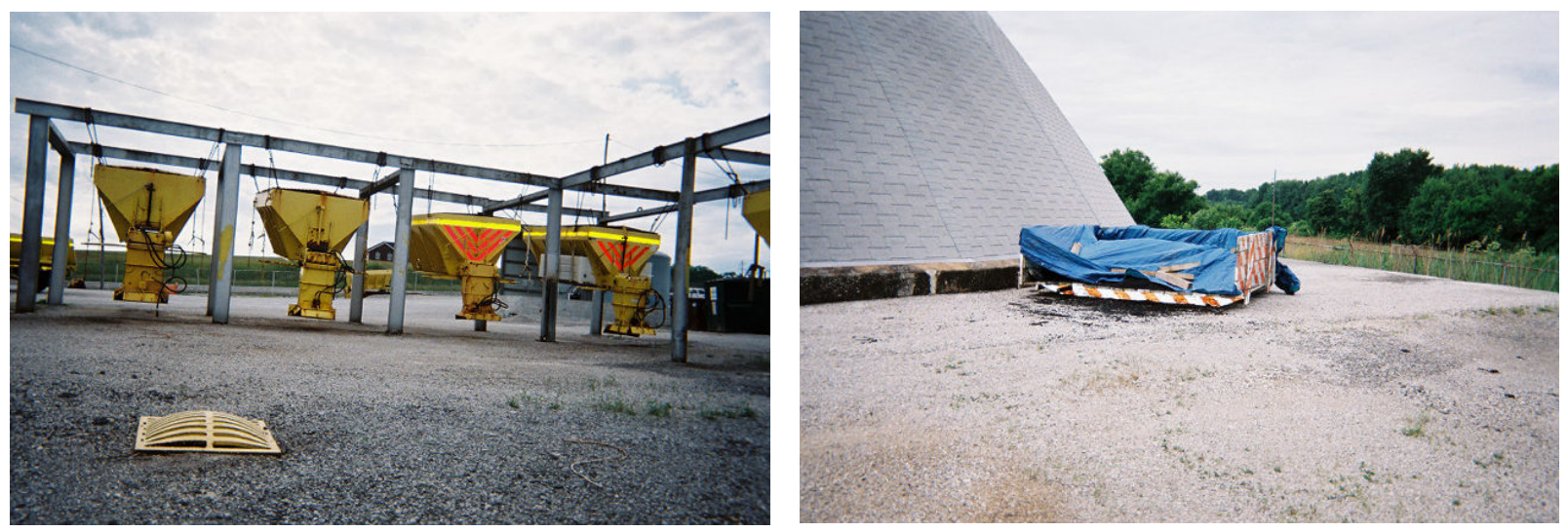

While not in use, the entrance of the Salt Dome is covered to prevent storm water from entering. The catch basin directly in front of the Salt Dome entrance was surrounded by salt residue. There was evidence of salt being transported into the catch basin, which conveys the storm water off the west property line.

There are several large aggregate piles south of the Salt Dome. A catch basin is located between two large sand piles. There was also a substantial amount of salt on the ground in this area and evidence of it being transported into the catch basin. Storm water is conveyed from this catch basin off the west property line.
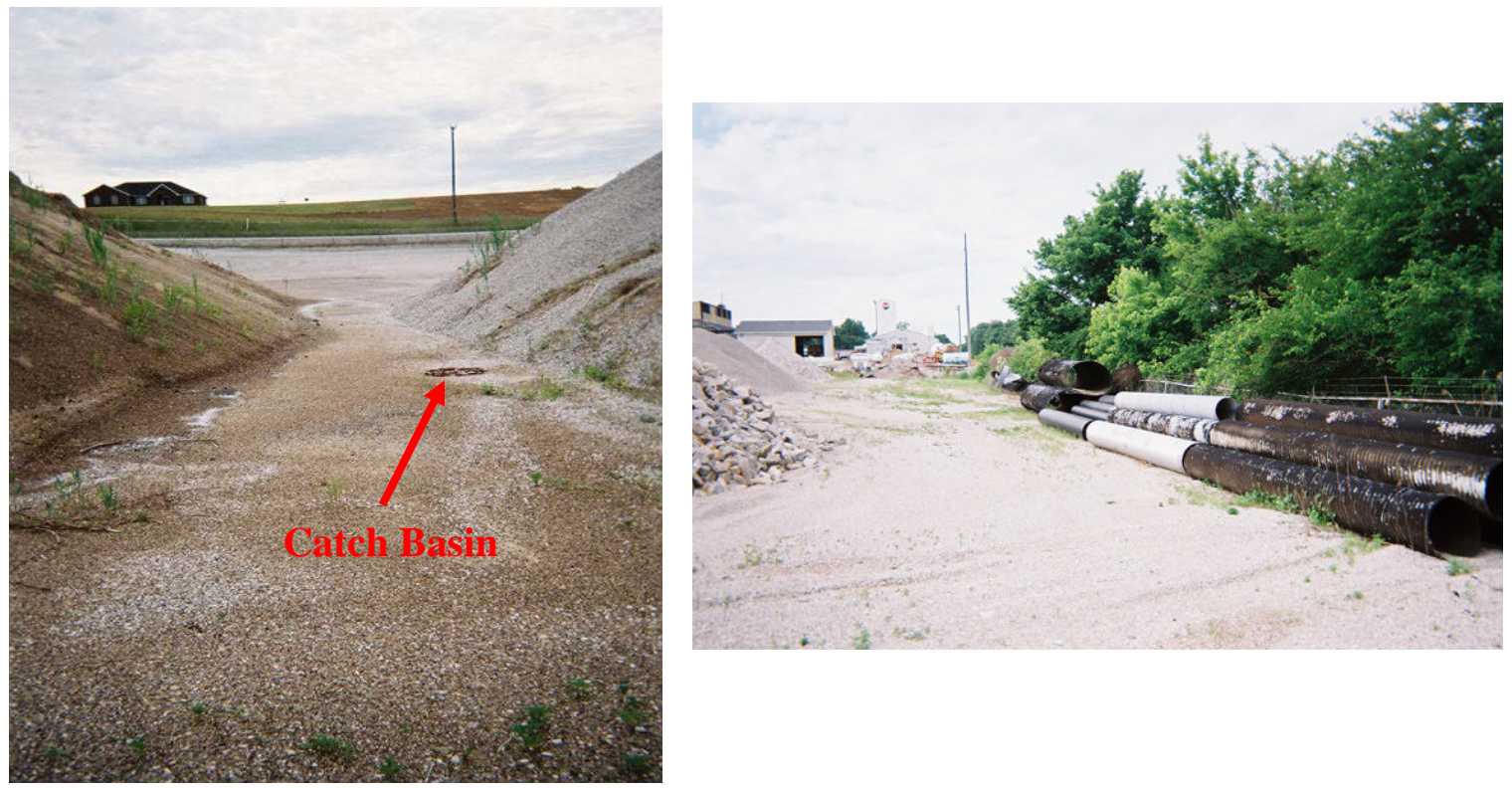
There are large metal pipe segments laying against the west fence line in the SW corner of the site. The storm water from this area flows beneath the fence and into the railroad side ditch. (pictured on the previous page)

\section{Buildings}

* Unit Building

All the drains in the Unit Building discharge to the sewer system including the drains in the wash bay.

There are several 55-gallon drums of engine fluid being stored in the Unit Building. Most of these drums were on secondary containment pallets. However, one drum was placed on the floor next to the pallets.

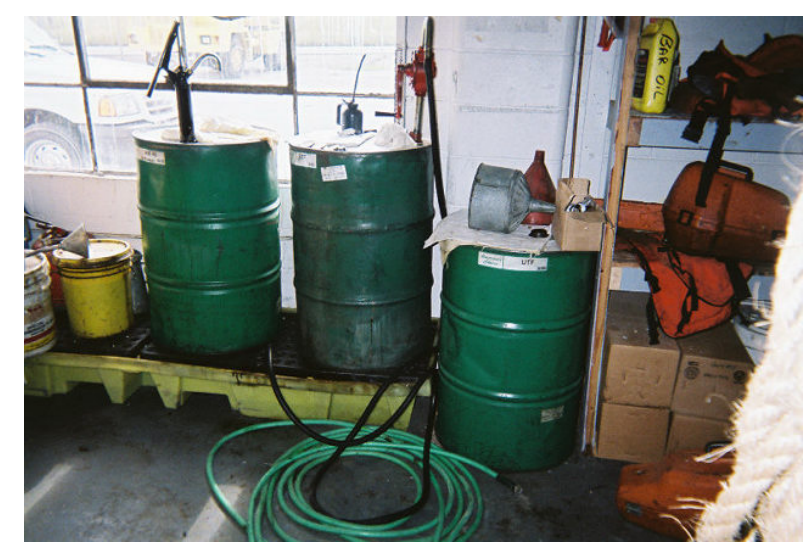

Salt Dome

The Salt Dome had a cover over the entrance that prevented storm water from entering. There was a large amount of salt around the entrance of the Salt Dome.

\section{* Cold Storage}

There were only tools and road signs stored in the cold storage building. This building contains no drains. 


\title{
INDOT Site Assessment Report Observations and Comments
}

Facility: Jasper Unit

June 6, 2005

\author{
Surface Area
}

General

A small drainage ditch runs through the center of the site. The name of the ditch has not been located, but it empties into Straight River approx. 1 mile SW of the site. All storm water from the active surface enters this drainage ditch.
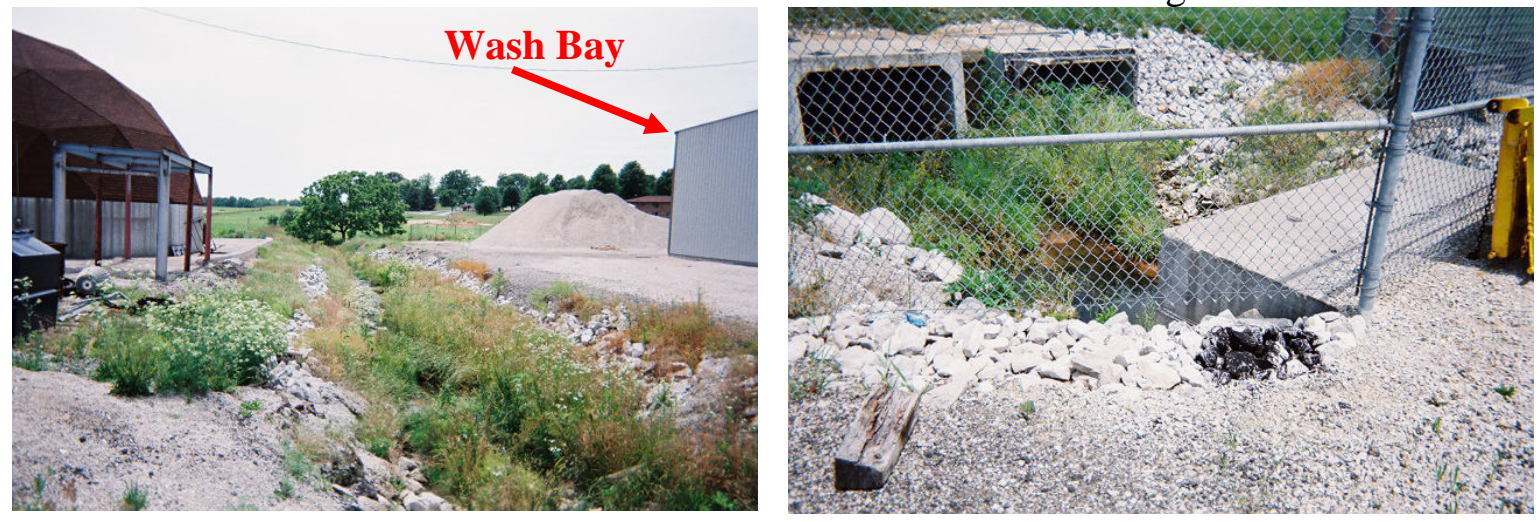

The Unit Building floor drain and the wash bay floor drain both discharge to Jasper WWTP.

There is a catch basin approx. 10 feet from the entrance of the Salt Dome that discharges directly into the drainage ditch. This catch basin captures all the storm water from the salt bed loading area. There are no berms in this area to prevent salt or sand from entering the catch basin.

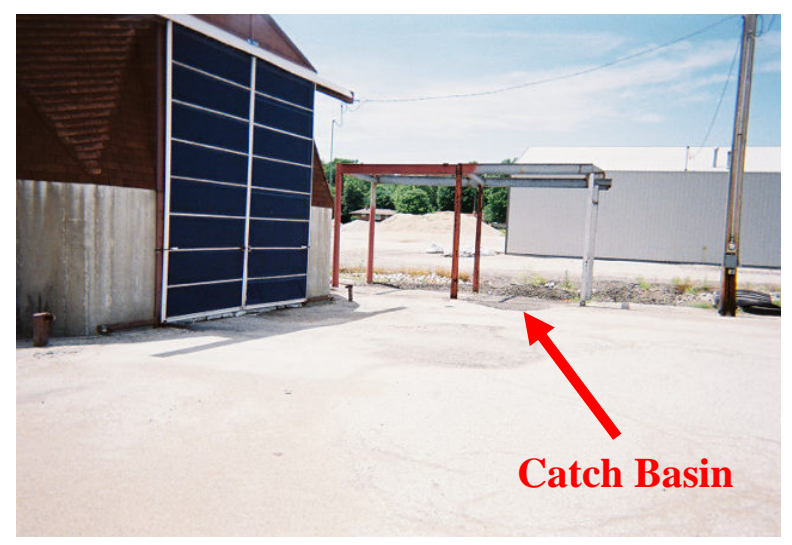


This facility is located very close to a residential neighborhood, which is west of the facility.
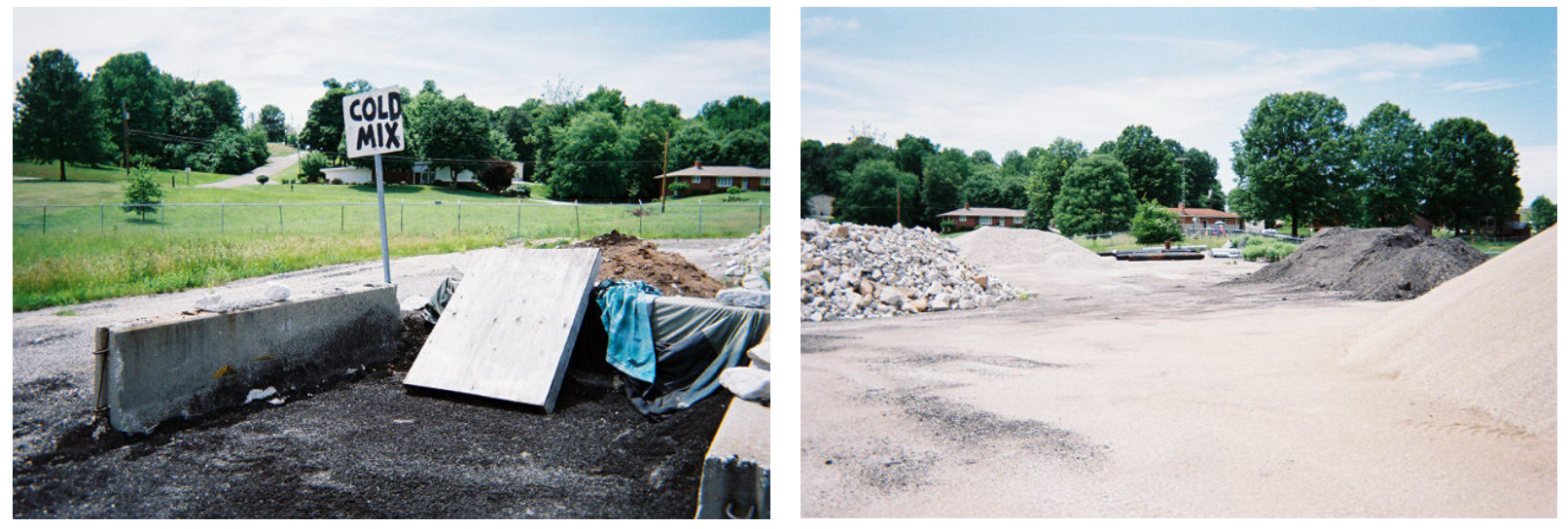

North Property Line (bordered by State HWY 162)

The Unit Building is located in the NE corner of the site. The salt trucks park around the Unit Building. The storm water from this area drains into a roadside ditch that flows into the drainage ditch in the center of the site.

$>$ The salt racks are located west of the Unit Building along with a tar kettle. This equipment is located approx. 20 feet from the drainage ditch. All runoff from this area enters the drainage ditch.
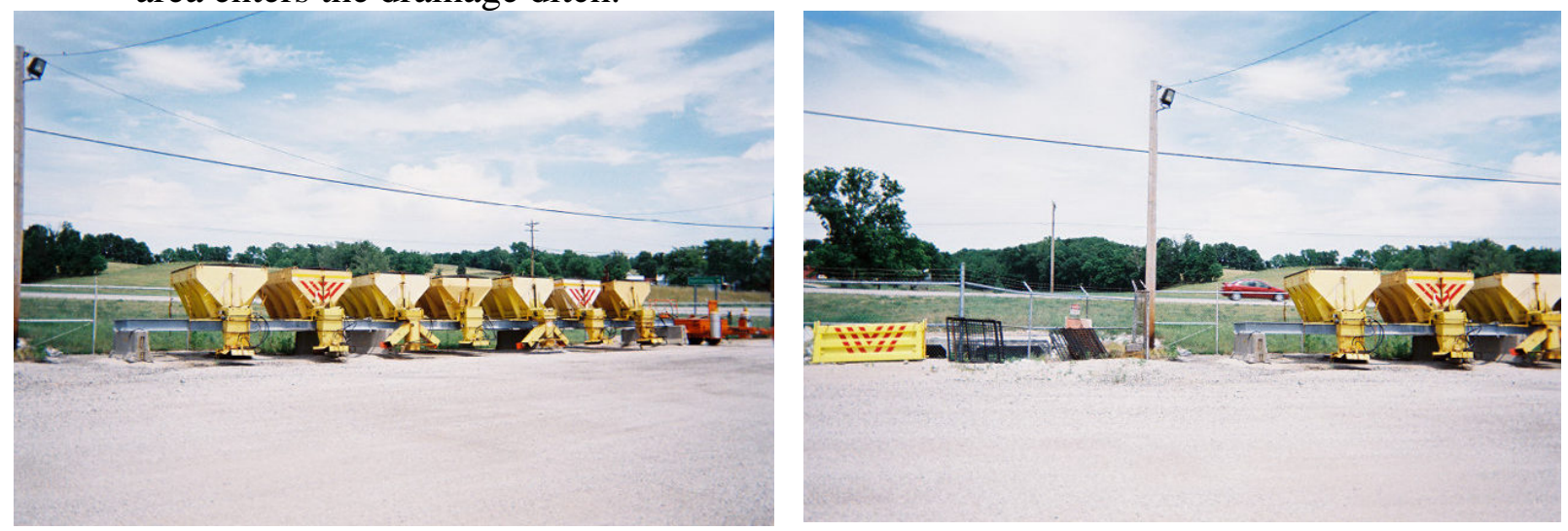

On the west side of the drainage ditch, there is an area used to store signs and other metal objects. 
In the SE corner of the site, there is a secondarily contained Calcium Chloride tank. Overhead bed spraying is no longer performed at this site. All trucks are equipped with tanks, which hold the Calcium Chloride.

A small tool shed is located approx. 10 feet east of the Calcium Chloride tank. Only tools and some road signs are stored in this shed.

There is a large pile of sand used for salt/sand mixing east of the tool shed. This area is not bermed and drains into the drainage ditch in the center of the site.

The Salt Dome is approx. 10 yards east of the sand pile and is located on the edge of the drainage ditch. As previously stated, there is a catch basin near the entrance of the Dome. All runoff from this area is captured by the catch basin and discharged directly into the drainage ditch.

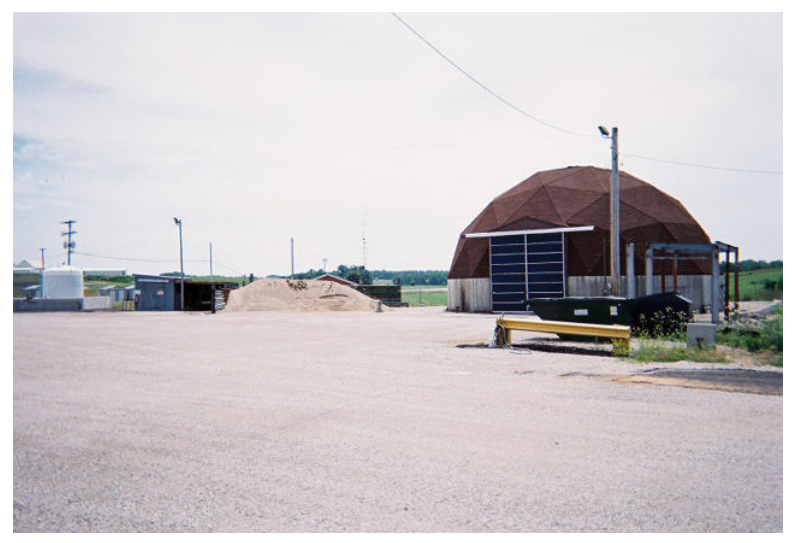

Across the drainage ditch from the Salt Dome, there is a Wash Bay. This Wash Bay is connected to a POTW. All salt bed washing is performed inside this building.

The entire SW corner of the site is used to store piles of various sized aggregate, a small pile of cold patch, and a large pile of asphalt grindings. Nothing in this area was bermed or covered including the cold patch.

\section{Buildings}

\section{Unit Building}

There is no oil/water separator in the Unit Building.

There is a lateral floor drain in the Unit Building that catches all liquids and discharges it to the POTW. 
* Salt Dome

The active surface around the Salt Dome was fairly clean and free of salt residue. There was a cover over the entrance, which prevented rain from entering the Salt Dome.

* Wash Bay

$>$ The Wash Bay is on the west side of the drainage ditch, across from the Salt Dome. All drains in this building discharge to the POTW. 


\title{
INDOT Site Assessment Report Observations and Comments
}

\author{
$\underline{\text { Surface Area }}$
}

General

$>$ This facility is not equipped with an oil/water separator and is not connected to a POTW. The floor drains in the Unit Building drain into a wooded area. The restrooms a connected to a septic system.

$>$ There are several catch basins throughout the site that drain into a wooded area. The location of the pipe outfall is unknown but it is believed to be near the SW corner of the site.

$>$ No salt beds are washed on-site and only a small amount of vehicle maintenance is performed at this site. All salt bed washing and most vehicle maintenance is performed at the Tell City Unit.

There is an extremely large amount of aggregate stored at this facility.

North Property Line.

The Unit Building is located in the NW corner of the site. There are several dumpsters at the entrance gate, which is also in the NW corner of the site. These dumpsters are used to store debris collected from the roadside.

$>$ The Salt Dome is located approx. 30 yards east of the Unit Building. There is a catch basin located 20 feet from the Salt Dome entrance. There was some salt on the ground in this area.

The salt bed racks are located approx. 10 yards east of the Salt Dome. Some stormwater from this area drains into the catch basin near the entrance of the Salt Dome. This area is not covered or bermed.

$>$ The entire east half of the site is used to store large piles of aggregate. The elevation of the east property line has been raised approx. 10 feet with aggregate and asphalt. 

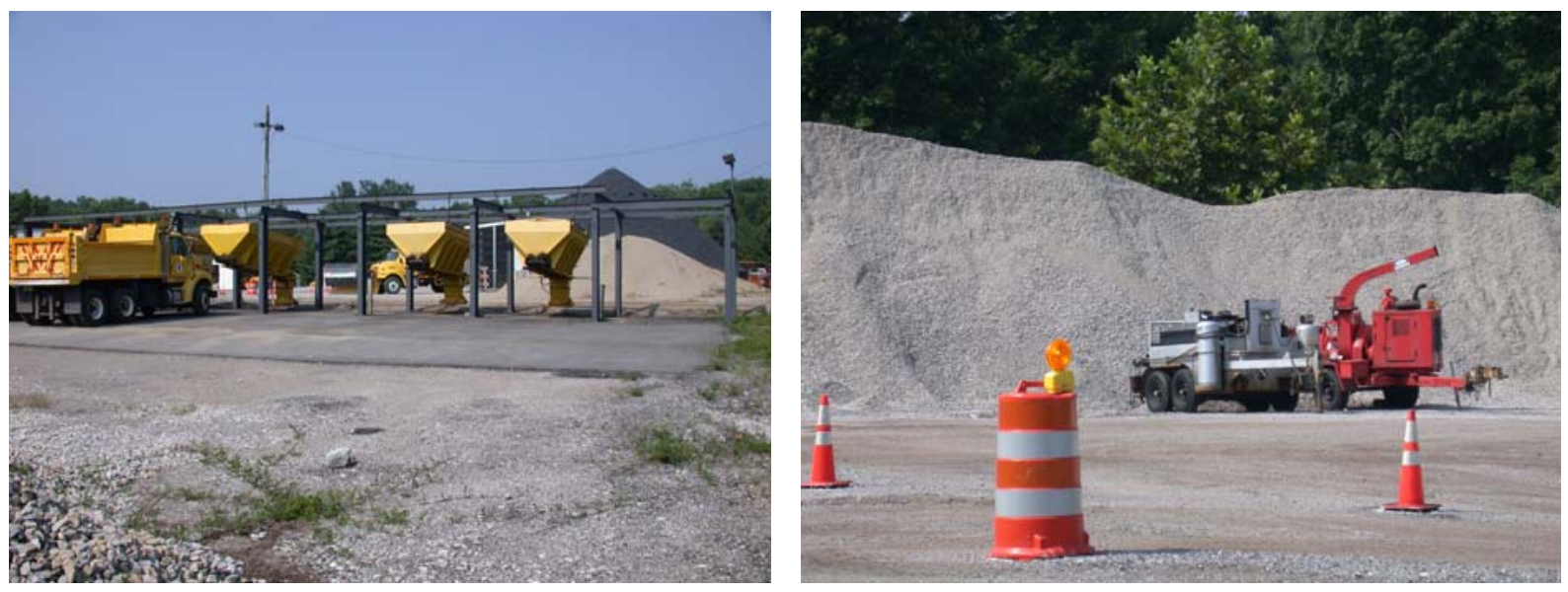

* South Property Line

There is a small tool shed located in the SW corner of the site. This shed is used to store traffic cones, road signs, and asphalt tools.

$>$ There is a large shed located approx. 10 feet east of the small tool shed. This larger shed is used to store a tar kettle, a herbicide tank, and other tools. The herbicide tank is not secondarily contained.
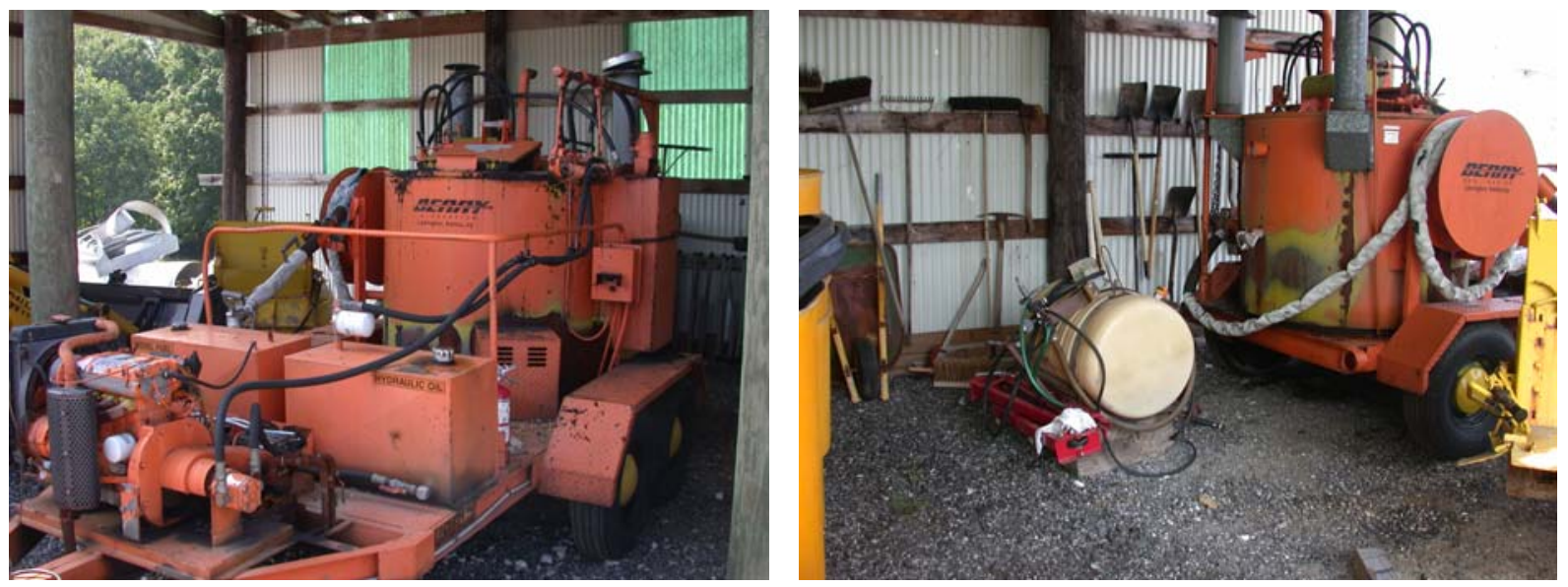

There is a catch basin on the south property line that has been covered up by a large aggregate pile.

There is a secondarily contained Calcium Chloride tank north of the aggregate pile. There is a bed spraying system housed in a drive through shed that reduces stormwater contamination. There is a catch basin in this shed that drains into an 
underground storage tank. This tank is pumped back into the above ground Calcium Chloride tank periodically.
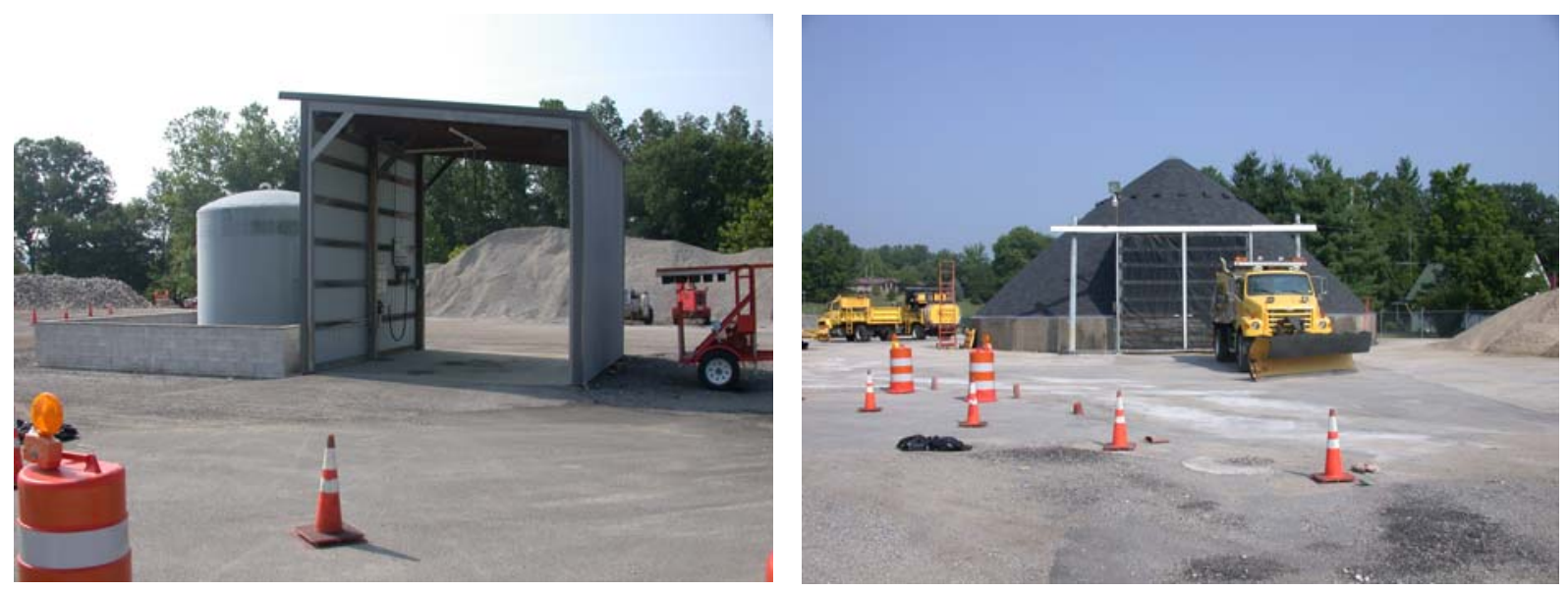

The entire east half of the property is used to store aggregate.

\section{Buildings}

* Unit Building

The oil drums inside the Unit Building were secondarily contained.

D The floor drains in the Unit Building drain into a wooded area near the SW corner of the site.

\section{Salt Dome}

There was some salt on the ground near the entrance of the Salt Dome. There is a catch basin near the entrance of the Salt Dome that drains into a wooded area near the SW corner of the site.

* Other Buildings

There are two small sheds on-site that are used to store tools and tractors. There are no drains in these sheds. 


\section{INDOT Site Assessment Report Observations and Comments}

\section{Surface Area}

General

$>$ This facility is not equipped with an oil/water separator but the floor drains inside the Unit Building are connected to a POTW.

$>$ There are several catch basins located throughout the property that catch all stormwater from the site and convey it to the city sewer system.

There is no salt bed washing at this facility and very little vehicle maintenance. These tasks take place at the Subdistrict facility.

\section{East Portion of Property}

The Unit Building is located in the NE corner of the property. The floor drains in the Unit Building are connected to a combined sewer system.

$>$ A large cold storage building is located in the SE corner of the facility. This building is used to store tractors, a tar kettle, road signs, tools, cold patch, and other miscellanea.

$>$ There are drains along the outside of this cold storage building that collect all stormwater from the area. All catch basins are connected to the sewer system.

The salt bed racks are located west of the Unit Building.

There is a secondarily contained Calcium Chloride tank located approx. 15 yards south of the salt bed racks. Stormwater from this area also enters a catch basin that is connected to the sewer system. 

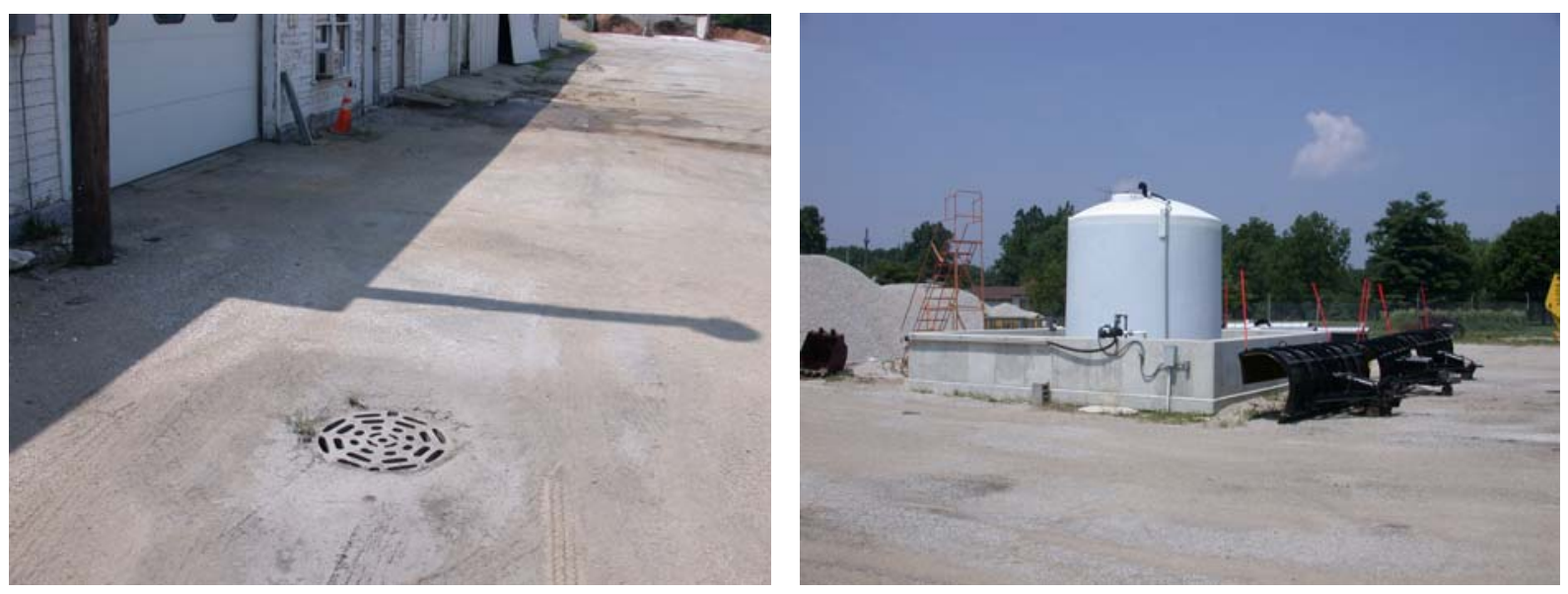

West Portion of Property

The salt storage building is located along the west fence line. This facility does not have a dome shaped salt storage building, it is a rectangular building. All stormwater from this area enters a catch basin that is connected to the sewer system.

$>$ Concrete composting bins are located in the SW corner of the site.

The area around the salt storage building and the composting bins is used to store aggregate piles. All stormwater from the west side of the property enters the sewer system.
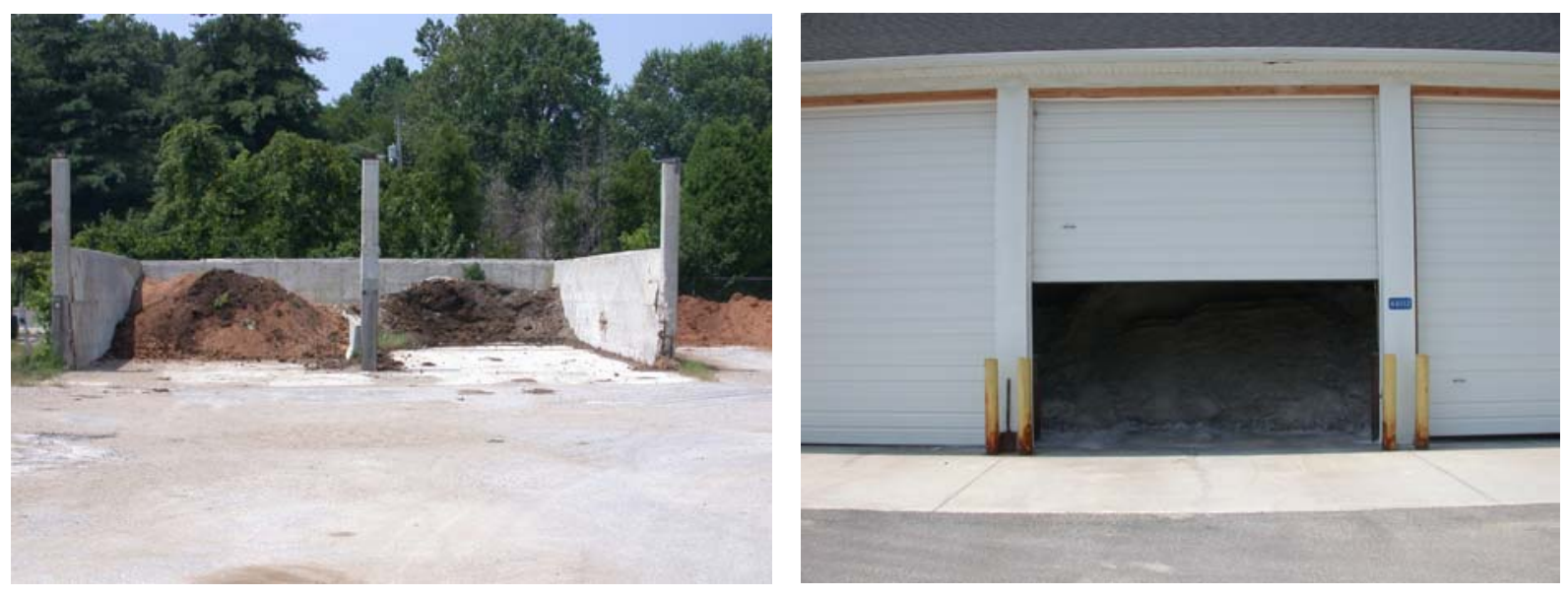


\section{Buildings}

\section{Unit Building}

There is no oil/water separator in the Unit Building but all floor drains are connected to a POTW. No salt bed washing and very little vehicle maintenance take place at this facility.

> Oil and hydraulic fluid drums are secondarily contained on pallets.

\section{Salt Storage Building}

The salt storage building is rectangular. There are three garage type doors on the salt storage building. All stormwater from the area enters a catch basin that is connected to the sewer system.

* Other Buildings

There is a large cold storage building on-site. This building is used to store a variety of tools and also cold patch.

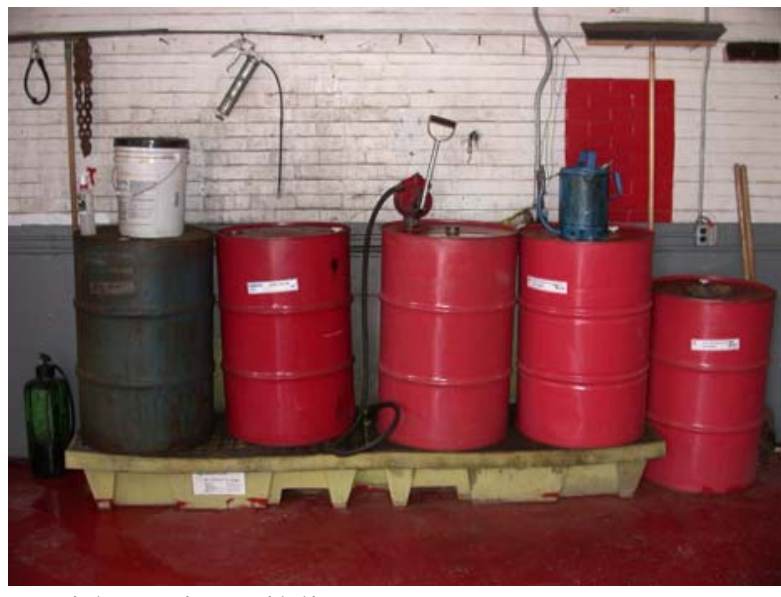

Inside Unit Building

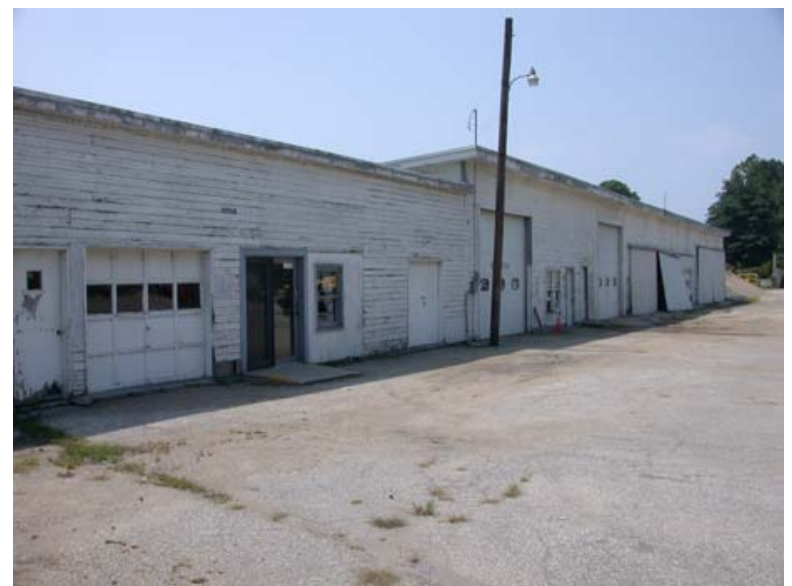

Cold Storage Building 


\title{
INDOT Site Assessment Report Observations and Comments
}

\author{
Surface Area
}

General

$>$ The facility restrooms and floor drains are connected to a POTW. There is no oil/water separator at this facility. Most vehicle maintenance is performed at the Evansville Unit.

$>$ This facility was moved from the neighboring property several years ago. The old facility property was sold and the current property was bought and built on. The Unit Foreman mentioned that there was a problem with salt contamination at the neighboring property (no longer owned by INDOT).

$>$ The Unit Foreman said that at one time there was a stormwater retention pond onsite but was filled in several years ago due to concerns of salt contamination.

North Property Line

The Unit Building is located in the NW corner of the property. The floor drains and restrooms are connected to a POTW.

$>$ The truck parking area is located east of the Unit Building. This area is not bermed.

$>$ There is a pile of sand east of the truck parking area that looks to contain salt. Salt is leaching out of the pile and onto the ground.

> There is a secondarily contained Calcium Chloride tank located SW of the sand/salt pile. The bed spraying system is housed in a drive through shed that prevents stormwater contamination. There is a catch basin in this shed that collects any spilled $\mathrm{CaCl}$ and it drains into an underground storage tank. This tank is pumped back into the $\mathrm{CaCl}$ tank periodically for reuse. 

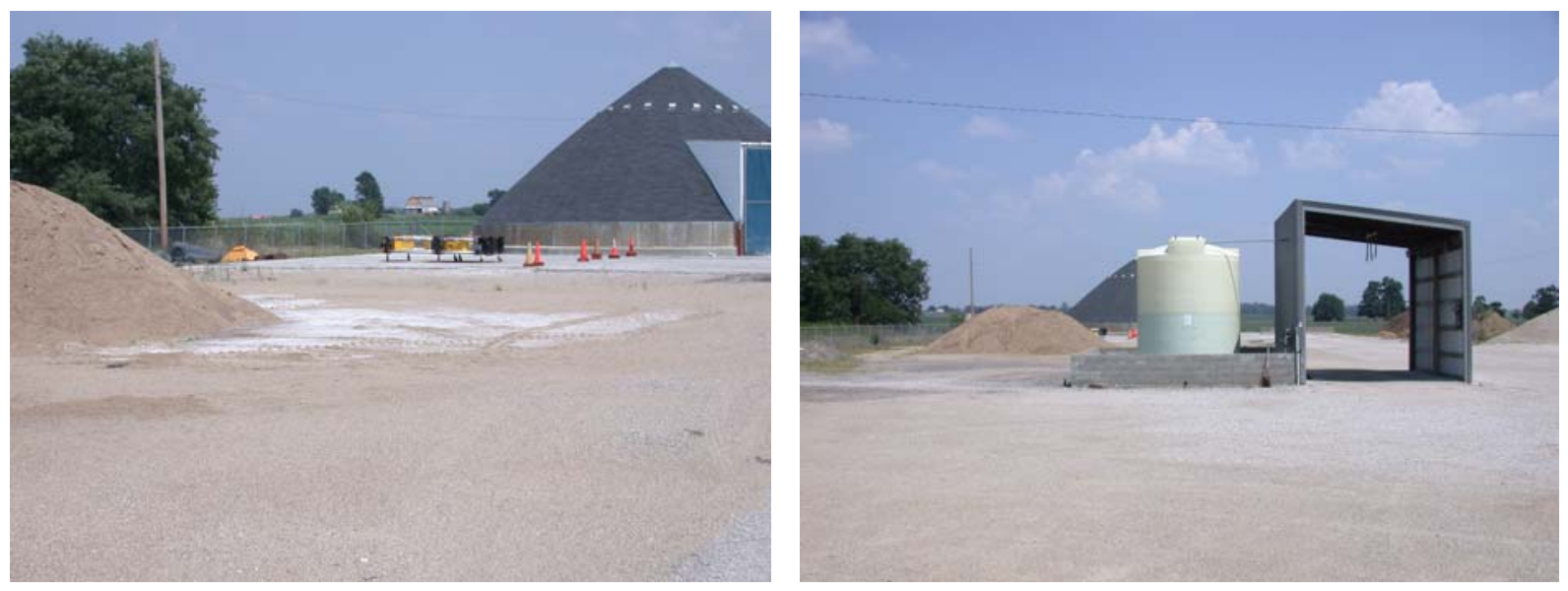

The Salt Dome is located in the NE corner of the site. A mesh curtain is kept over the entrance of the Dome to prevent stormwater contamination. However, salt was coming out from under this mesh cover and mixing with stormwater. A sand dike at the entrance would prevent this from happening.

There was a substantial amount of salt on the active surface around the Salt Dome. There is evidence that stormwater is being contaminated with salt at this facility. There is a catch basin near the Salt Dome that drains into an underground french drain style pipe. The location of the end of the pipe is unknown. This catch basin collects all stormwater from around the Salt Dome.
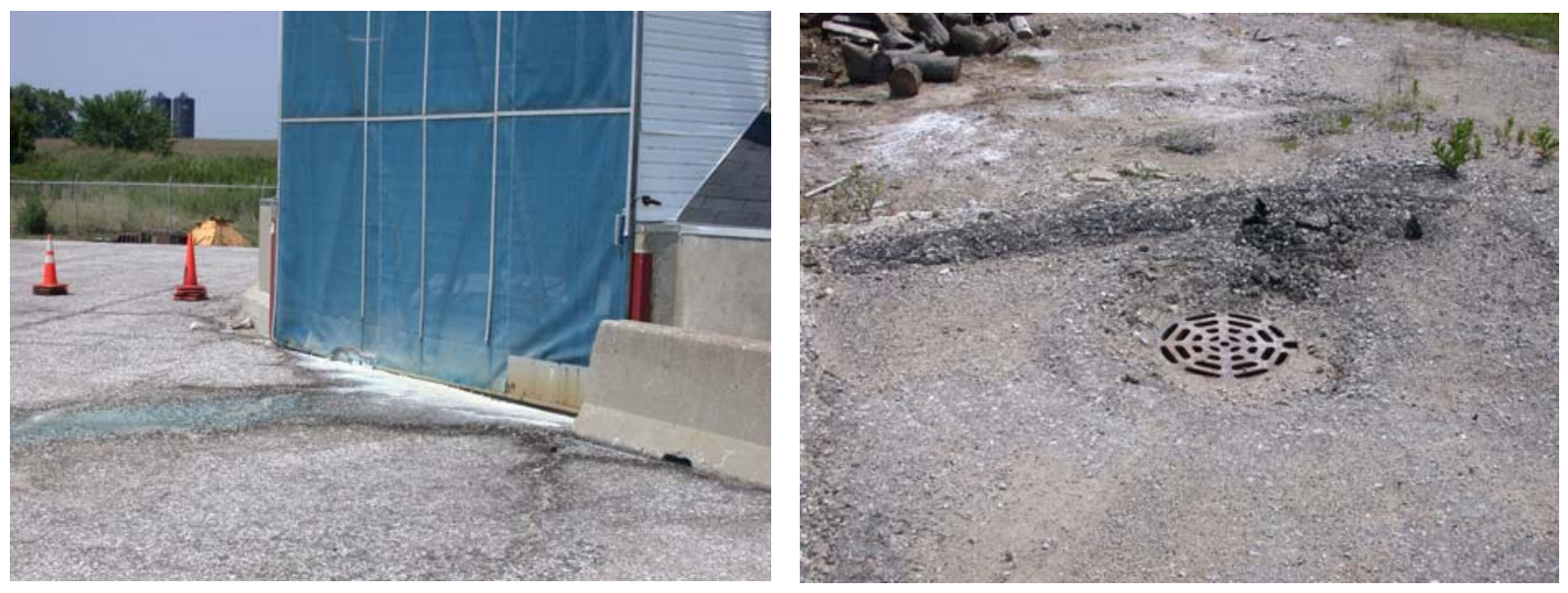
South Property Line

There is a large cold storage pole barn located in the SW corner of the site. This building is used to store cold patch among other things. The east wall of this building is open but when not in use it is covered with a mesh curtain.

There are several piles of aggregate stored east of the pole barn.

The salt bed racks are located east of the aggregate piles. This area is not bermed. There is more aggregate stored on the east side of the salt bed racks.
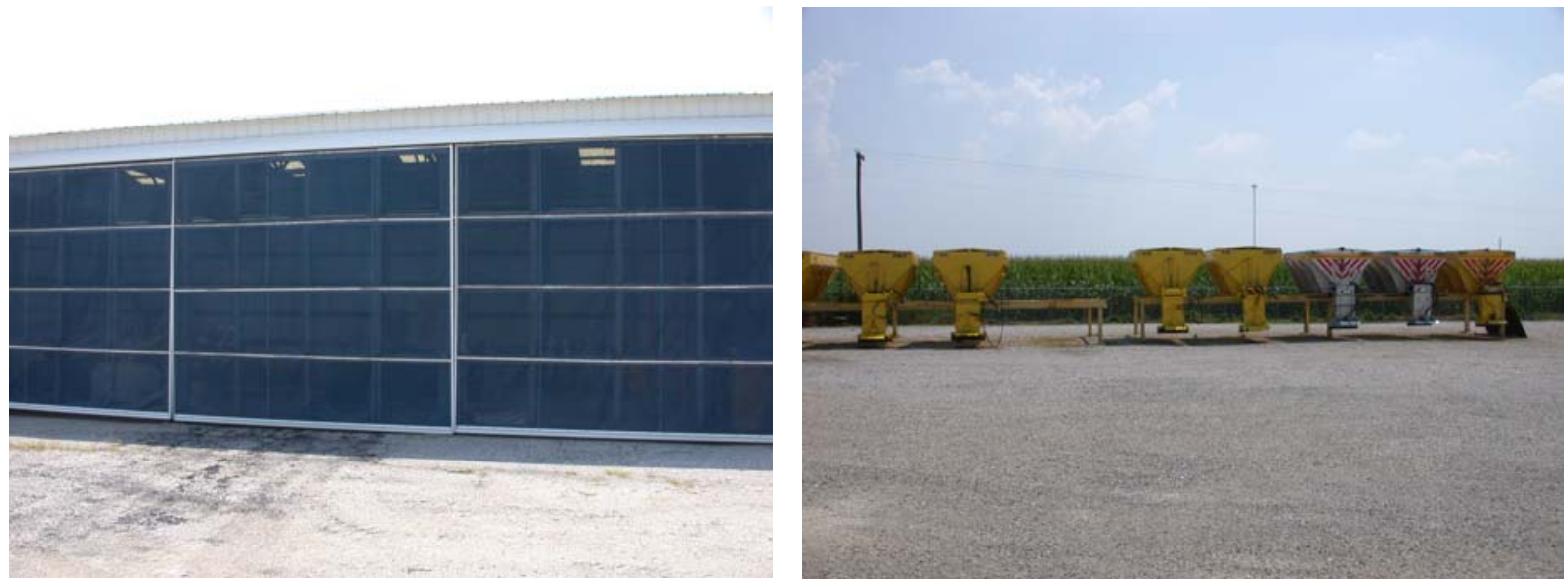

Several years ago, there was a stormwater retention pond located in the SE corner of the site. This area has been filled in with dirt but remains the lowest area on the property. During rain events, water ponds in this corner. A trench has been formed were water flows into this corner. This corner is also used to store debris.
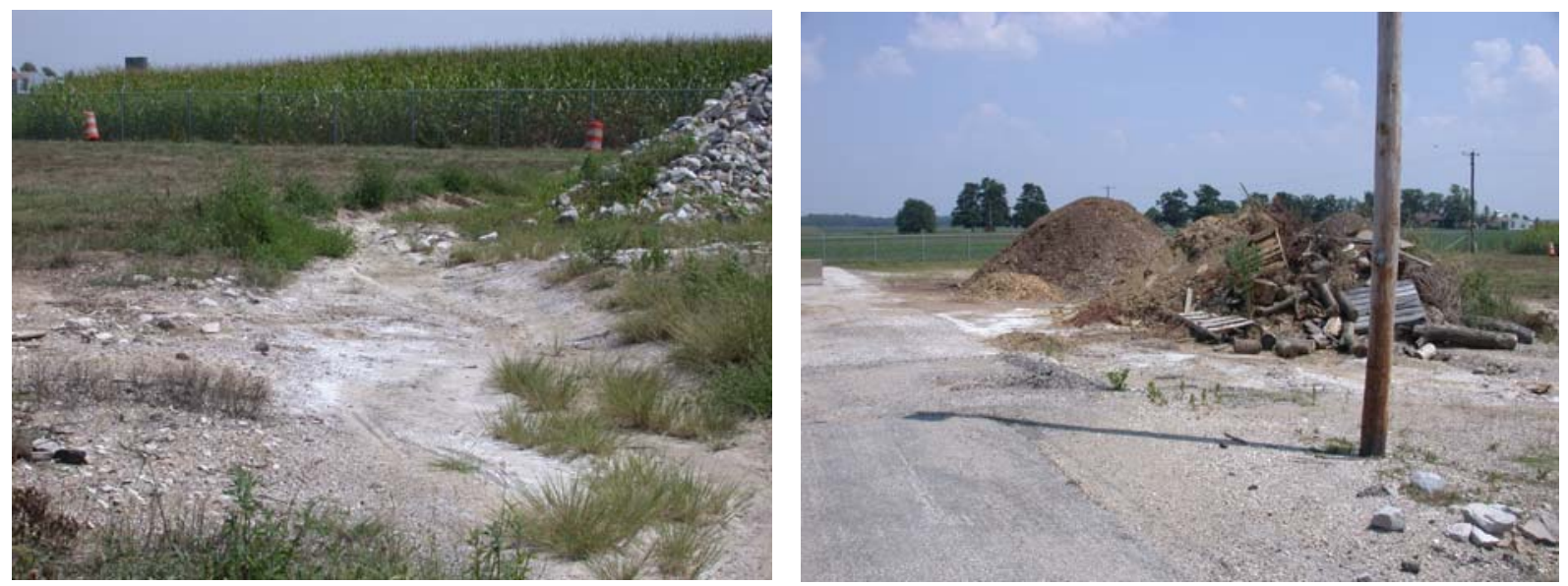


\section{Buildings}

\section{Unit Building}

$>$ There is no oil/water separator in the Unit Building but the floor drains are connected to a POTW. There is also very little vehicle maintenance performed at this facility.

All oil and hydraulic fluid drums are secondarily contained.

\section{* Salt Dome}

$>$ The entrance of the Salt Dome is covered with a mesh curtain to keep stormwater out but there is no berm at the entrance, which allows salt to spill out onto the ground.

There is a substantial amount of salt on the active surface around the Salt Dome.

\section{* Other Buildings}

The cold storage pole barn is used to store cold patch, tractors, a tar kettle, road signs, and tools. There are no drains in this building and a mesh curtain is kept over the entrance to prevent stormwater from entering. 


\section{INDOT Site Assessment Report Observations and Comments}

\section{Surface Area}

General

$>$ This site is not equipped with an oil/water separator and is not connected to a POTW. The nearest sewer connection is approx. 3 miles from the facility. All salt bed washing is performed at Paoli Subdistrict, which is 25 miles from the facility.

$>$ The site is located on a steep slope. For this reason, the site is split into 3 tiers. The top tier contains the Unit and Cold Storage Buildings, Salt Storage Building, Truck Parking, Salt Bed Racks, and Calcium Chloride Tank. The $2^{\text {nd }}$ and $3^{\text {rd }}$ tier are used to store aggregate, cold patch, debris, and scrap material.

$>$ At the base of the hill that the facility is located on, there is a creek that receives all stormwater and floor drain effluent from the facility. There is a large erosion problem at this facility due to the steep terrain.
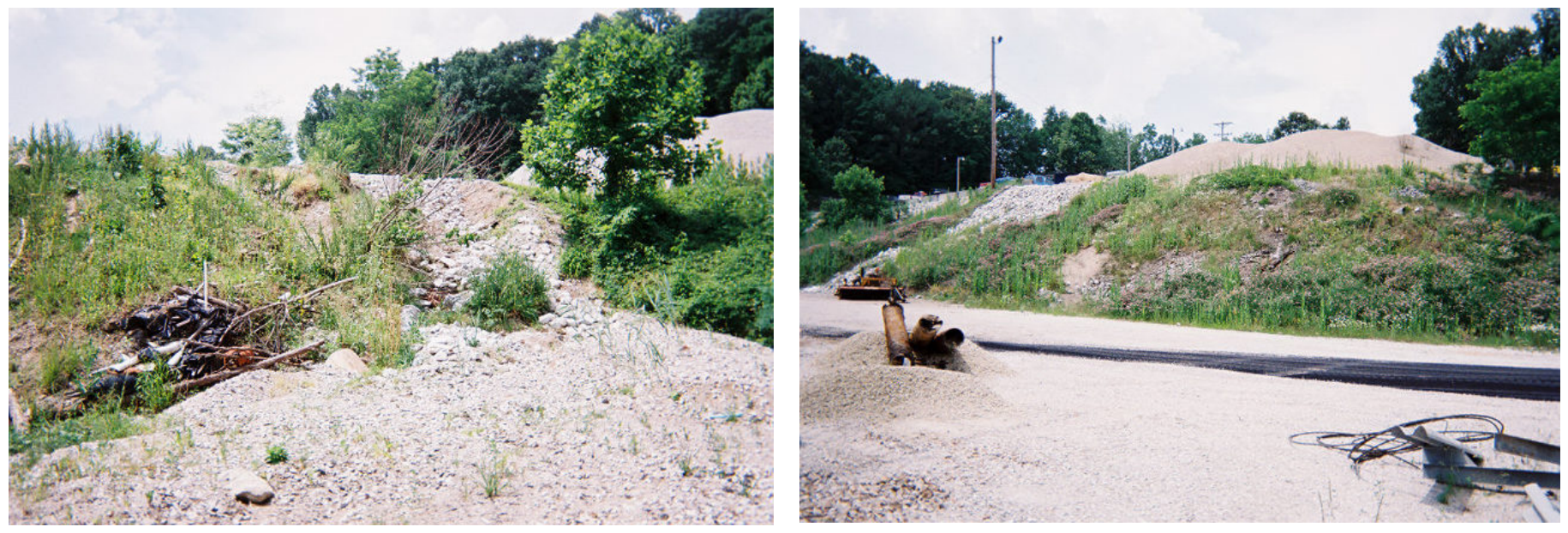
Top Tier of Property (West Portion of Property)

$>$ The Unit Building is located in the SW corner of the site on the top tier. The floor drain effluent flows out of a pipe onto the second tier.

> There is a small tool shed located along the west fence line. There is a secondarily contained Calcium Chloride tank located north of the tool shed. There are no berms in these areas.

There is a large cold storage building located north of the $\mathrm{CaCl}$ tank that is used to store tractors, road signs, and tools.

> There is a single wide trailer located south of the Unit Building that serves as an office for the Unit Foreman.

$>$ The Salt Storage Building is located on the west side of the cold storage building. There is a sand berm at the entrance of the salt building to prevent salt spillage.

The salt bed racks and truck parking area are located on the west side of the salt storage building. This area is not bermed.
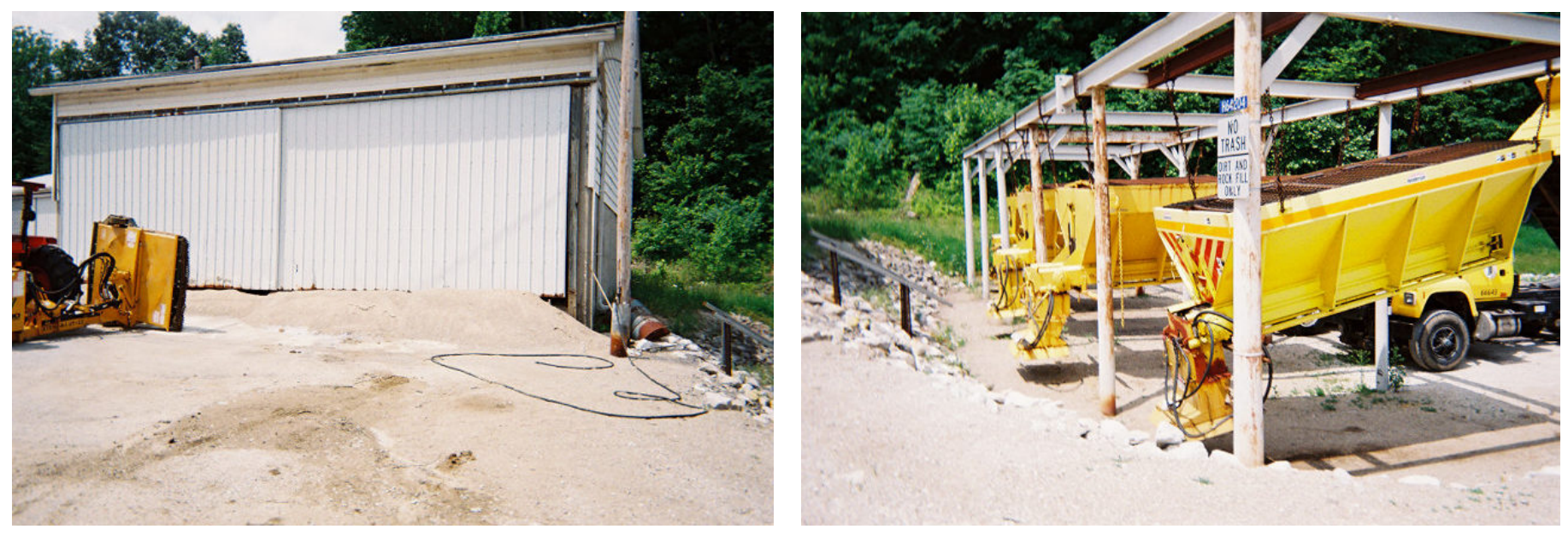

\section{Second Tier of Property}

The cold patch is stored in a pile in the south corner of the second tier. This cold patch pile is not bermed or covered with a tarp.

$>$ The rest of the second tier is used to store piles of aggregate. 
* Third Tier of Property (East Portion of Property)

$>$ There are several piles of aggregate on the $3^{\text {rd }}$ tier. Also, pipe segments, debris, and scrap are stored on the $3^{\text {rd }}$ tier.

The bottom slope of the $3^{\text {rd }}$ tier is covered with stumps and debris. This area drains into the creek approx. 300 yards down the hill.
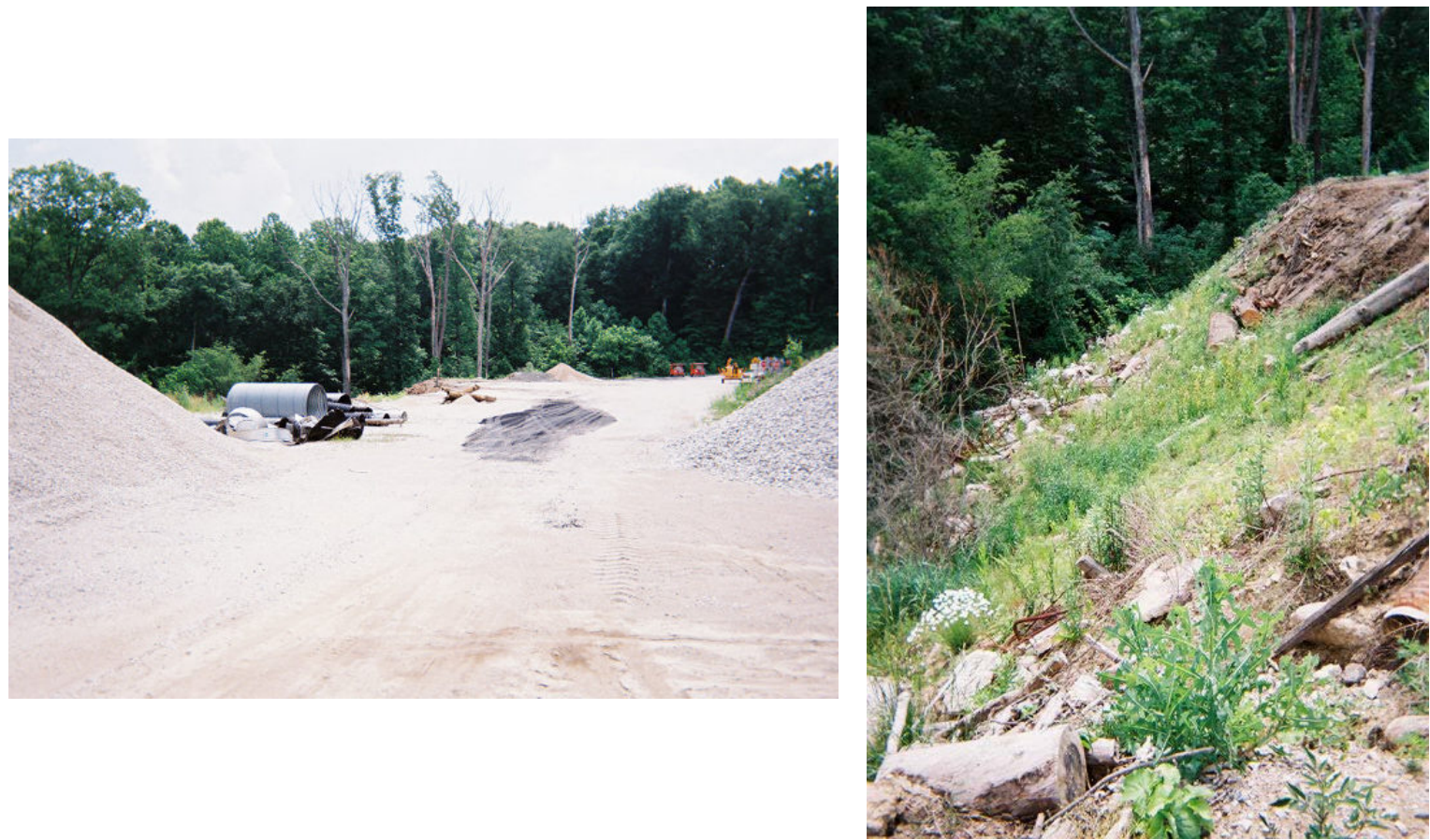

Buildings

* Unit Building

$>$ The Unit Building floor drain effluent drains out onto the $2^{\text {nd }}$ tier of the property and eventually reaches the creek at the bottom of the hill. There is also a trailer next to the Unit Building that is used as an office for the Unit Foreman.
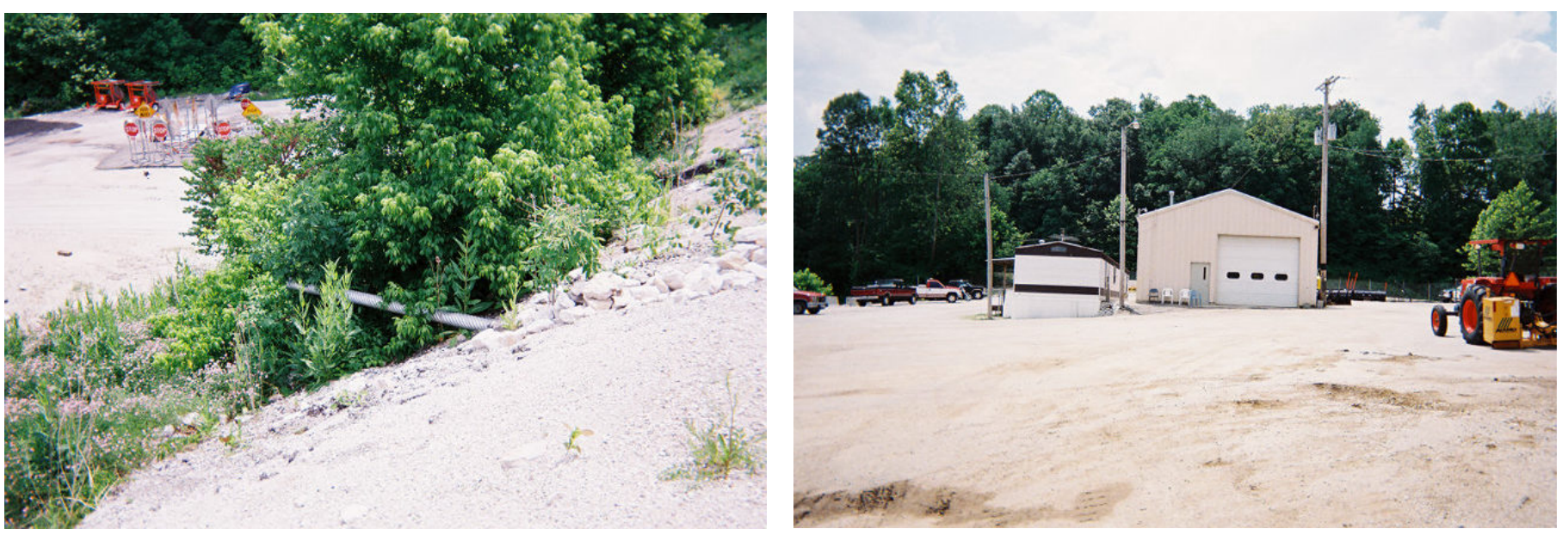
* Salt Storage Building

$>$ This facility is not equipped with a Salt Dome. The Salt Storage Building is rectangular. The area around the storage building is kept fairly clean.

\section{* Other Buildings}

> There is a large cold storage building that is used to store tractors, a tar kettle, road signs, and tools. There are no drains in this building.

$>$ There is also a small tool shed on-site that is used to store tools. There are no floor drains in this building. 


\section{APPENDIX XI}

INDOT'S ENVIRONMENTAL MANAGEMENT SYSTEMS MANUAL $-7^{\text {TH }}$ DRAFT 


\section{Indiana Department of Transportation’s}

\section{Environmental Management System Manual}

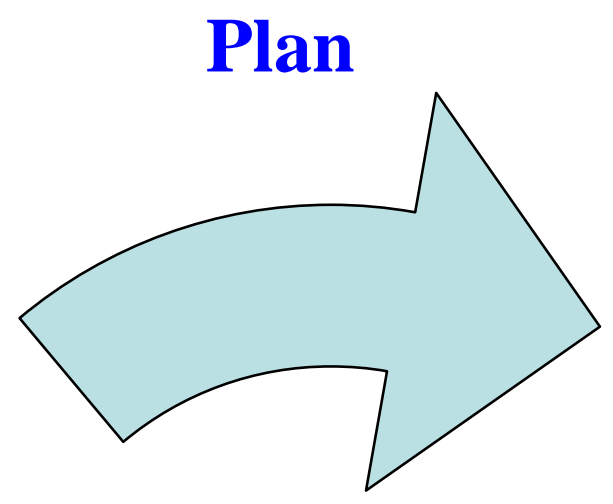

Act

Do
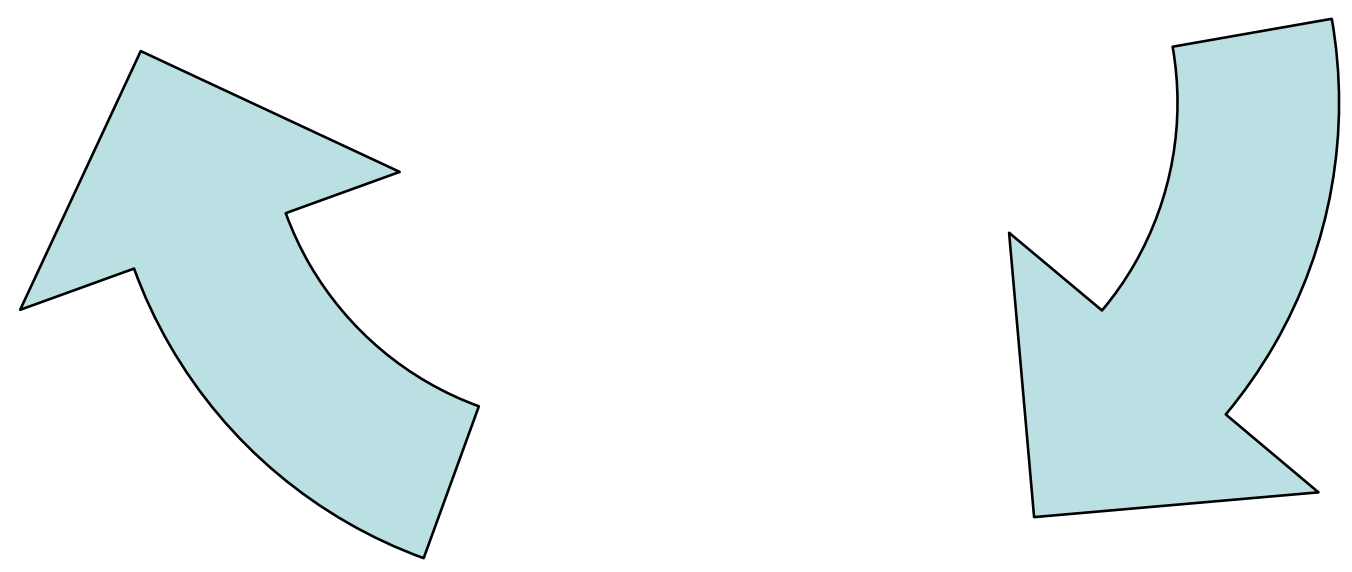

Check 


\section{Indiana Department of Transportation \\ Environmental Management System (EMS) Manual}

\section{$7^{\text {th }}$ DRAFT}

April 27, 2007

Prepared By:

(EMS Champion)

Approved and Authorized By:

$\overline{\text { (Facilities and Equipment Division Director) }}$ 


\section{Environmental Policy \\ Indiana Department of Transportation}

The Indiana Department of Transportation (INDOT) is committed to managing environmental, health and safety (EH\&S) matters as an integral part of our business. In particular, it is our policy to assure the EH\&S integrity of our processes and facilities at all times and places. We will do so by adhering to the following principles, including those of our contractor's under the department's control.

\section{Compliance}

We will comply with the applicable laws and regulations and will implement programs and procedures to assure compliance. Compliance with EH\&S standards will be a key ingredient in the training of all employees and awarding of contracts.

\section{Risk Reduction, Prevention, and Resource Management}

We will seek opportunities, beyond compliance requirements, for reducing risk and we will establish and meet our own EH\&S quality standards where appropriate.

We will employ management systems and procedures specifically designed to prevent activities and/or conditions that pose a threat to the environment, human health and safety. We will look for ways to minimize risk and protect our employees and the communities in which we operate by employing clean and safe technologies and operating procedures, as well as being prepared for emergencies.

We will strive to minimize releases to the air, land or water through use of clean technologies and the safe use of chemicals. We will minimize the amount and toxicity of waste generated and will ensure the safe treatment and disposal of waste.

We will manage scarce resources in an environmentally sensitive manner.

\section{Continuous Improvement}

We will measure our progress as best we can. We will review our progress at least on an annual basis. We will continuously seek opportunities to improve our adherence to these principles. 
EMS Document Revision Index............................................................5

1.0 Purpose of This Manual.............................................................6

2.0 Statement of Purpose.............................................................6

2.1 Environmental Policy.............................................................7

2.2 Environmental Aspects........................................................7

2.3 Legal and Other Requirements...................................................8

2.4 Objectives, Targets and Programs........................................8

2.5 Resources, Roles Responsibility and Authority................................9

2.6 Training, Awareness and Competence........................................10

2.7 Communications................................................................10

2.8 Environmental Management System Documentation...........................11

2.9 Document Control................................................................11

2.10 Operational Control............................................................11

2.11 Environmental Emergency Preparedness and Response.......................12

2.12 Monitoring and Measurement...................................................12

2.13 Evaluation of Compliance ...................................................12

2.14 Nonconformance and Corrective/Preventative Action...........................12

2.15 Records................................................................................13

2.16 Environmental Management System Audit...................................13

2.17 Management Review..........................................................13

3.0 Standard Operating Procedures.....................................................14

P-01: Structure and Responsibility..............................................15

P-02: Communications............................................................17

P-03: Environmental Aspects Identification......................................20

P-04: Legal and Other Requirements............................................22

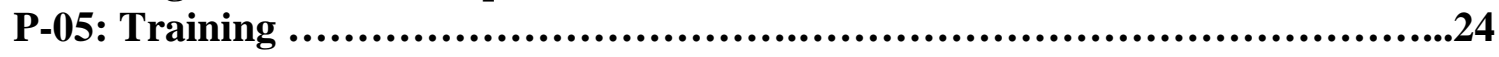

P-06: Measurement and Monitoring.................................................25

P-07: Preventive and Corrective Action...........................................27

P-08: Control of EMS Documents.............................................29

P-09: Records...................................................................31

P-10: Environmental Management System Audit...................................32

P-11: Management Review...........................................................35

Appendix A: Aspects, Objectives and Targets.......................................38

Appendix B: Legal and Other Requirements......................................43

Appendix C: Environmental Management Programs...................................45

Appendix D: Structure and Responsibilities.........................................53

Appendix E: Environmental Training Plan.......................................56

Appendix F: Communications Plan...............................................60 
EMS Document Revision Index

\begin{tabular}{|c|c|c|c|c|}
\hline $\begin{array}{l}\text { Revision } \\
\text { Date }\end{array}$ & Description & $\begin{array}{l}\text { Sections } \\
\text { Affected }\end{array}$ & $\begin{array}{l}\text { Revised By } \\
\text { (Initial) }\end{array}$ & $\begin{array}{l}\text { Approved } \\
\text { by (Initial) }\end{array}$ \\
\hline & & & & \\
\hline & & & & \\
\hline & & & & \\
\hline & & & & \\
\hline & & & & \\
\hline & & & & \\
\hline & & & & \\
\hline & & & & \\
\hline & & & & \\
\hline & & & & \\
\hline & & & & \\
\hline & & & & \\
\hline & & & & \\
\hline & & & & \\
\hline & & & & \\
\hline & & & & \\
\hline & & & & \\
\hline & & & & \\
\hline & & & & \\
\hline & & & & \\
\hline & & & & \\
\hline & & & & \\
\hline & & & & \\
\hline & & & & \\
\hline & & & & \\
\hline & & & & \\
\hline & & & & \\
\hline & & & & \\
\hline & & & & \\
\hline & & & & \\
\hline & & & & \\
\hline & & & & \\
\hline & & & & \\
\hline
\end{tabular}




\subsection{Purpose of This Manual}

In order to improve upon the environmental performance of the Indiana Department of Transportation (INDOT) an environmental management system (EMS) has been implemented. The scope of INDOT's EMS manual will focus on the Environmental Activities of INDOT employees and INDOT's contractors. This Environmental Management System (EMS) has been developed to conform to the ISO 14001: 2004 Standard for INDOT and covers all operations.

The principal elements of the EMS described in this manual are:
o Environmental Policy
o Environmental Aspects
o Legal and Other Requirements
o Objectives, Targets and Programs
o Resources, Roles, Responsibility and Authority
o Competence, Training and Awareness
o Communications
o Documentation
o Control of Documents
o Operational Control
o Environmental Emergency Preparedness and Response
o Monitoring and Measurement
o Evaluation of Compliance
o Nonconformity, Corrective Action and Preventive Action
o Control of Records
o Internal Audit
o Management Review

The EMS provides a mechanism for environmental management throughout all areas of our agency. The EMS is designed to cover environmental aspects the agency can control and directly manage as well as those aspects it does not control or directly manage but can be expected to influence. The EMS Champion or designee will control the manual. This individual will be responsible for maintaining an up-to-date manual that includes all revisions and modifications. The EMS Champion or designee is also responsible for ensuring that copies of this document and subsequent revisions are available to INDOT employees through the agency's web site.

\subsection{Statement of Purpose}

The following sections present a statement of purpose for each of the elements covered in the EMS. These statements explain why INDOT needs to conform to the particular element and assigns responsibility for implementation of each element. Each statement of purpose is quite general but references standard operating procedures and other reference material that will assist in the implementation of the element. 


\subsection{Environmental Policy}

A copy of INDOT's Environmental Policy is included at the beginning of this manual. This policy is endorsed by the highest level of management in our agency. The policy covers all activities at the agency and states in broad terms our commitment to protecting the environment. Specifically, the policy includes a commitment to continual improvement and prevention of pollution, as well as a commitment to meet or exceed relevant environmental legislation, regulations and other requirements. The policy will be reviewed annually by the EMS Team. The initial policy and all subsequent activities will be communicated to all persons working for or on behalf of INDOT and made available to the public in accordance with the Communication (P-02) and Environmental Policy (P-03) procedures.

Applicable Procedures:

P-02: Communications (p. 17)

\section{Reference Material:}

ISO 14001 Standard (4.2)

\subsection{Environmental Aspects}

The EMS Team has identified environmental aspects that the agency controls or on which it may be expected to have an influence. The EMS team has further determined those aspects that are considered significant. This activity has been completed in conformance with the Environmental Aspects Identification procedure (P-03). Information pertaining to the environmental aspects identified is included in Appendix A: Aspects, Objectives and Targets.

The EMS Champion is responsible for ensuring that all areas are aware of the significant environmental aspects that were identified. Further, each manager is responsible for ensuring that these significant environmental aspects are considered in setting their environmental objectives and targets.

The EMS Team shall be responsible for re-evaluating the list of environmental aspects and related impacts. At a minimum, the environmental aspects will be re-evaluated on an annual basis or if any process, product or infrastructure changes occur.

Applicable Procedures:

P-03: Environmental Aspects Identification (p. 20)

P-04: Legal and Other Requirements (p. 22)

Reference Material:

ISO 14001 Standard (4.3.1)

Appendix A: Aspects, Objectives and Targets (37) 


\subsection{Legal and Other Requirements}

INDOT has established an environmental procedure for the purpose of identifying, accessing and communicating legal and other requirements that are applicable to the agency. The EMS Team has developed a list of the agency's legal and other requirements (see appendix). This information is included in Appendix B: Legal and Other Requirements. (The appendices will be reviewed at a later date and currently may not conform to this manual)

The EMS Champion or designee will be responsible for ensuring that all department managers have an updated list of all applicable legal and other requirements. This will be done in accordance with the Legal and Other Requirements (P-04) and the Communications procedure (P-02). The managers will be responsible for ensuring that their staff is appropriately trained on these requirements. This will be done in accordance with the Training procedure (P-05). At least annually, the EMS Champion or designee, along with the EMS Team and department managers, will review the most current national, regional, state and local legal and other requirements as applicable to the agency. In addition, the current list will be reviewed and revised as appropriate, whenever a new requirement that is applicable to the agency is adopted.

Applicable Procedures:

P-02: Communications (p. 17)

P-04: Legal and Other Requirements ( $p .22)$

P-05: Training (p. 24)

Reference Materials:

Appendix B: Legal and Other Requirements (p. 42)

ISO 14001 Standard (4.3.2)

\subsection{Objectives, Targets and Programs}

The EMS Team has set objectives to improve upon the environmental performance of INDOT. More information on the objectives can be found in Appendix A - Aspects, Objectives and Targets. (The appendices will be reviewed at a later date and currently may not conform to this manual)

Objectives and targets are developed considering significant environmental aspects; technological options; prevention of pollution; financial, operational and business plans; legal and other requirements.

On at least an annual basis, the EMS Champion or designee and the EMS Team will be responsible for evaluating the progress made toward meeting existing objectives and for considering the need to develop new objectives. The findings from this annual evaluation should be incorporated into the management review. These activities will be completed in accordance with the Management Review procedure (P-11). In addition, the EMS Team will be responsible for amending objectives and targets, if deemed necessary, as a result of new or revised operations, activities, and/or regulations. 
The EMS Team establishes environmental management programs (EMPs) as a means for achieving objectives and targets. These programs define the principal actions to be taken, those responsible for undertaking those actions and the scheduled times for their implementation. The EMS Team develops the EMPs with input provided by managers. The EMPs will be placed in Appendix C - Environmental Management Programs. (The appendices will be reviewed at a later date and currently may not conform to this manual)

The specific roles associated with the implementation of the EMP will be included in the EMP documentation. Aside from these specific responsibilities, the EMS Champion will coordinate the effort to ensure that the EMP is being implemented, monitored and maintained in an appropriate fashion. On an annual basis, the EMS Team will evaluate the progress of the EMP and document their findings and recommendations. Management will consider these findings and recommendations during the EMS Management Review. These activities will be conducted in accordance with the Management Review Procedure (P-11).

Applicable Procedures:

P-11: Management Review (p. 35)

Reference Material:

ISO 14001 Standard (4.3.3)

Appendix A - Aspects, Objectives and Targets (p. 37)

Appendix C - Environmental Management Programs (p. 44)

\subsection{Resources, Roles, Responsibility and Authority}

Environmental Management System roles, responsibilities and authorities are defined at relevant functions and levels within the agency. INDOT Executive Management will provide the resources essential to the implementation and control of the EMS. The EMS Champion has primary responsibility for establishing, operating and maintaining the EMS. In this capacity the EMS Champion will report on the performance of the EMS to management. The EMS Team will provide routine EMS support as directed by the EMS Champion. Documentation of the EMS structure and various responsibilities of personnel are included in Appendix D - Structure and Responsibilities. The structure and responsibilities of the EMS will be developed in accordance with the Structure and Responsibility procedure (P-01).

Applicable Procedures:

P-01: Structure and Responsibility (p. 15)

Reference Material:

ISO 14001 Standard (4.4.1)

Appendix D - Structure and Responsibilities (p. 52) 


\subsection{Competence, Training and Awareness}

All employees within INDOT will be made aware of the EMS. In addition, the EMS team, with input from managers, has developed an Environmental Training Program (ETP) that identifies, plans, monitors and records training needs for personnel whose work may create a significant impact upon the environment. The training program will also document specific competence levels required for certain key positions in the agency. The development of the ETP will be done in accordance with the Training procedure (P-05).

The ETP will be updated on an annual basis by the EMS team when they evaluate the agency's list of environmental aspects. In addition, the EMS Team will be responsible for amending the ETP, if deemed necessary, as a result of new or revised operations, activities, and regulations. An ETP is included in Appendix E - Environmental Training Program.

Applicable Procedures:

P-05: Training (p. 24)

Reference Material:

ISO 14001 Standard (4.4.2)

Appendix E - Environmental Training Plan (p. 55)

\subsection{Communications}

INDOT has developed a Communications Procedure (CP) within the EMS Manual also known as P-02 to ensure that information regarding our environmental aspects and EMS is appropriately communicated to internal personnel. External stakeholders will have access to the EMS Environmental Policy as defined in P-02. The communications plan has been developed to handle internal communications between various levels and functions of the agency, and to receive, document and respond to relevant communications from external stakeholders. The EMS Champion is responsible for communicating information relevant to the EMS to the agency's management. As authorized by the EMS Champion, the EMS team and managers will communicate information to their staff and to other external stakeholders. All communications relevant to the EMS and the development of the Communications Plan will be conducted in accordance with the Communications Procedure (P-02).

Applicable Procedures:

P-02: Communications (p. 17)

Reference Material:

ISO 14001 Standard (4.4.3)

Appendix F - Communications Plan (p. 59) 


\subsection{Environmental Management System Documentation}

To ensure effective operation of the EMS, INDOT is committed to documenting the EMS process and the records associated with the outcome of the process. This Manual identifies all documents relevant to the EMS. A copy of EMS documents, other than visual aids and records, can be obtained from the EMS Champion or designee.

Applicable Procedures:

P-08: Control of EMS Documents (p. 29)

P-09: Records (p. 31)

Reference Material:

ISO 14001 Standard (4.4.4)

EMS Manual

\subsection{Control of Documents}

INDOT has established the Control of EMS Documents procedure (P-08) for controlling documents related to the EMS. This procedure describes where documents are located and how and when they are reviewed. The procedure gives the EMS Champion the responsibility of ensuring that current versions are available and that obsolete documents are promptly removed from use or are suitably identified.

Applicable Procedures:

P-08: Control of EMS Documents (p. 29)

Reference Material:

ISO 14001 Standard (4.4.5)

\subsection{Operational Control}

The EMS Team, along with managers, will identify operations and activities related to compliance and the identified significant environmental aspects. If applicable, operational controls will be developed or existing controls will be evaluated for each identified operation and activity.

Applicable Procedures:

None

INDOT Standard Operating Procedures: (need to be updated at next meeting)

Salt Building Loading SOP

Salt Loading by Vendor SOP

Unloading Salt after Storm Event SOP

Salt Brine Loading/Transfer SOP

Salt Bed Rack SOP

Lubricating Chain SOP

Reference Material:

ISO 14001 Standard (4.4.6)

Appendix C: Environmental Management Programs (p. 44) 


\subsection{Environmental Emergency Preparedness and Response}

INDOT has developed an Environmental Emergency Preparedness and Response procedure to identify the potential for and to respond to accidents and emergency situations, and to prevent and mitigate the environmental impacts that may be associated with them. The Environmental Emergency Preparedness and Response plans are reviewed by the EMS Team on an annual basis or as deemed necessary.

Applicable Procedures:

INDOT Wastewater SOP

INDOT Operating Procedure 20

INDOT Spill Prevention Control and Countermeasures Plan (SPCC)—should this be removed?

Reference Material:

ISO 14001 Standard (4.4.7)

Environmental Emergency Preparedness and Response Plans

\subsection{Monitoring and Measurement}

INDOT has established the Measurement and Monitoring procedure (P-06) to monitor and measure the key characteristics of its operations and activities that can impact compliance and that have a significant impact on the environment. Performance relevant data that is obtained from these monitoring and measurement efforts will be utilized in the management review in accordance with the Management Review procedure (P-11).

Applicable Procedures:

P-06: Monitoring and Measurement (p. 25)

P-11: Management Review (p. 35)

Reference Material:

ISO 14001 Standard (4.5.1)

Compliance Audit Procedures and Documentation

\subsection{Evaluation of Compliance}

INDOT will periodically evaluate compliance with applicable legal and other requirements following the Measurement and Monitoring Procedure (P-06).

Applicable Procedures:

P-06: Measurement and Monitoring ( $p .25)$

\subsection{Nonconformity, Corrective Action and Preventive Action}

INDOT has developed the Preventive and Corrective Action procedure (P-07) to define responsibility and authority for handling and investigating nonconformity, for taking action to mitigate impacts, and for initiating and completing corrective and preventive action. 
Applicable Procedures:

P-07: Preventive and Corrective Action (p. 27)

Reference Material:

ISO 14001 Standard (4.5.3)

\subsection{Control of Records}

INDOT has a Records Procedure (P-09) for the identification, maintenance and disposition of environmental records. These records include training records and the results of audits and reviews. These records are kept to demonstrate conformance with the EMS and applicable regulations. The EMS Champion is responsible for maintaining records that are relevant to the EMS.

Applicable Procedures:

P-09: Records (p. 31)

Reference Material:

ISO 14001 Standard (4.5.4)

\subsection{Internal Audit}

INDOT incorporates the Environmental Management System Audit Procedure (P-10) to ensure that the EMS has been properly implemented and maintained. The EMS audits are coordinated by the EMS Champion and conducted on an annual basis. The results are provided to management in accordance with the Management Review Procedure (P-11). Audits are performed according to a schedule that is based on the environmental importance of an activity and the results of previous audits.

Applicable Procedures:

P-10: Environmental Management System Audit (p. 32)

P-11: Management Review (p. 35)

Reference Material:

ISO 14001 Standard (4.5.5)

\subsection{Management Review}

INDOT management reviews all elements of the EMS annually to ensure its continuing suitability, adequacy and effectiveness. This review is conducted in accordance with the Management Review Procedure (P-11). The management review will address the need for changes to the environmental policy, objectives, and other EMS elements. All applicable observations, conclusions and recommendations that result from the management review will be documented and used by the EMS Team to modify the EMS as necessary.

Applicable Procedures:

P-11: Management Review (p. 35)

Reference Material:

ISO 14001 Standard (4.6) 


\subsection{Standard Operating Procedures}

A statement of purpose has been developed for each of the EMS elements and presented in section 2.0 of this manual. In order to properly implement each of these EMS elements INDOT has developed standard operating procedures (SOP). The SOPs that have been developed to implement INDOT’s EMS are included in this section. 


\section{Standard Operating Procedure}

\section{P-01: Resources, Roles, Responsibility and Authority}

\subsection{Purpose/Scope}

This procedure is used to determine the agency's roles and personnel responsibilities for the department's EMS.

\subsection{Definitions}

EMS Champion - an INDOT representative designated by management who will be responsible for leading the implementation of the EMS.

EMS Team - a group of 6 to 8 employees who will assist with the development and implementation of the EMS.

EMS Auditor - an INDOT representative designated by management who will be responsible for conducting the audits of the Environmental Management System.

\subsection{Responsibilities}

The EMS Champion has the primary responsibility for assuring that the appropriate structure is in place to develop and implement the EMS. As needed the EMS Champion will ensure that responsibility for specific tasks are assigned to EMS Team members and other agency personnel.

\subsection{Procedure}

A. INDOT will first designate an EMS Champion whose role is to provide general oversight of the implementation of the EMS. The EMS Champion and EMS Team will be responsible for implementing the EMS.

B. The EMS Champion will develop and assign EMS roles and responsibilities and document them using standard correspondence and/or the following records:

1. R-01: Persons Responsible for EMS Development (see Appendix D)

C. The EMS Champion or designee will communicate EMS roles and responsibilities to all applicable employees.

D. The EMS Champion and EMS Team will review and update the EMS roles and responsibilities on an annual basis, or as needed.

E. Roles and responsibilities documentation will be retained in Appendix D: Structure and Responsibility of the EMS manual. 


\subsection{Related Documents}

Records

R-01: Persons Responsible for EMS Development (p. 53)

References

Appendix D: Structure and Responsibilities (p. 52) 


\section{Standard Operating Procedure \\ P-02: Communications}

\subsection{Purpose/Scope}

The purpose of this procedure is to ensure effective and timely communication of environmentally related information within the organization and to external entities. This procedure describes processes for communications on various elements of the organization's EMS.

A variety of processes are used for communication on environmentally related matters. The effectiveness of these communication processes is evaluated on an ongoing basis, through, environmental training programs, organizational assessments and inspections, and informal discussions.

Major topics of communication include:

o Environmental policy, objectives, and targets.

o Environmental management roles and responsibilities.

o Organization performance compared to environmental compliance requirements.

o Organization performance compared to environmental objectives and targets.

o Environmental policies and procedures.

o Hazards and emergency situations.

o Response to queries, comments, or complaints from stakeholders, including significant environmental aspects.

\subsection{Definitions}

Internal Communication - all forms of communications between those within the organization.

External Communication - all forms of communication between the organization's personnel and external stakeholders (Questions from and answers to will need to be documented).

Stakeholders - individual or group concerned with or affected by the environmental performance of an organization.

\subsection{Responsibilities}

A. The EMS Champion or designee is responsible for communicating the organization's environmental policies and procedures to all applicable employees. The EMS Champion is also responsible for communicating roles and responsibilities for the environmental management system and the results of INDOT environmental monitoring and measurement activities.

B. All managers are responsible for communicating environmental targets to the management team and employees. They are also responsible for communicating environmental procedures (and any changes to the procedures), results of investigations in their areas and other significant environmentally-related information (such as upcoming training classes). In addition, all managers will be responsible for responding to communications from external stakeholders when requested to do so. 
4.0 Procedure

A. Internal Communication

All internal communication will be conducted in accordance with this procedure. At a minimum, internal communications should be conducted as follows:

o All communications with internal personnel that are relevant to the EMS should be initiated and coordinated by the EMS Champion.

o The EMS Champion will ensure that all employees are aware of INDOT's Environmental Management System. The EMS Champion will also ensure that all managers are aware of relevant significant aspects, legal requirements, objectives and targets, environmental management programs, and all information required to ensure that the EMS is being implemented correctly.

o The EMS Champion will ensure that facility management is communicating the vision reflected in the Environmental Management System policy to all employees.

o The EMS Champion will delegate authority to communicate some of the items listed above to EMS team members and other personnel.

o All managers will communicate to their staff all relevant procedures, operational controls, objectives and targets that they should be familiar with in order to meet the requirements of the EMS.

\section{B. External Communication}

All external communication will be conducted in accordance with this procedure. At a minimum, external communications should be conducted as follows:

o The EMS Champion will ensure that management is communicating the vision reflected in the EMS policy to all external stakeholders as needed.

o All communications relevant to environmental issues should be forwarded to the appropriate INDOT representative.

o The appropriate personnel will document the receipt of the correspondence on R-07: External Communications Log.

o The EMS Champion will respond to the external communication or forward the communication to an applicable manager to prepare a response.

o If a manager is asked to respond to external communication, the EMS Champion should receive a copy of the response.

o The EMS Champion will be responsible for tracking all external communications on R-07: External Communications Log. This information will be included in Appendix F along with the Communications Plan.

o INDOT will not communicate significant aspects externally. 


\subsection{Related Documents}

Records

R-03: Communications Work Plan (p. 60)

R-07: External Communications Log (p. 62)

References

Appendix F: Communications Plan (p. 59) 


\section{Standard Operating Procedure P-03: Environmental Aspects Identification}

\subsection{Purpose/Scope}

To identify the environmental aspects of the organization's activities, products and services in order to determine those which may have a significant impact on the environment.

This procedure covers those environmental aspects of activities, products and services that the organization can control or over which it can be expected to have an influence. Significant environmental aspects identified through this process are considered in the setting of environmental objectives and targets.

\subsection{Definitions}

Environment - surroundings in which an organization operates, including air, water, land, natural resources, flora, fauna, humans, and their interactions.

Environmental Aspects - element of an organization's activities, products or services that can interact with the environment.

Significant Environmental Aspect - an environmental aspect (cause) that has or can have a significant environmental impact (effect).

Environmental Impact - any change to the environment, whether adverse or beneficial, wholly or partially resulting from the activities, products or services of the organization.

\subsection{Responsibilities}

The EMS Champion and the EMS Team are responsible for maintaining a list of environmental aspects, and determining which of the aspects are considered significant. The Facilities and Equipment Division Director will be responsible for approving the list of significant environmental aspects that are developed by the EMS Team.

\subsection{Procedure}

A. The EMS Team will evaluate the list of compliance requirements that have been developed in accordance with the Legal and Other Requirements Procedure (P-04) in order to ensure that compliance requirements are given consideration when developing a list of environmental aspects.

B. The EMS Team will solicit input from representatives throughout the agency as appropriate in order to develop a list of environmental aspects. Separate teams may be formed to evaluate particular groups of products, activities and services. The EMS Team may call upon other individuals in the organization, as needed.

C. The Environmental Management System considers each of the stages in the life cycle of the organization's products (roads), services (keeping roads functional) and activities (plowing snow, spreading salt, sealing cracks, filling pot holes, etc.). 
D. Aspects will be documented. If the EMS Team determines that additional information is needed to evaluate a particular product or activity, the EMS Champion assigns the responsibility for collecting that information to an appropriate team member.

E. The EMS Champion will be responsible for maintaining the list of environmental aspects on form R-08: Identifying Environmental Aspects. A completed copy of this form should be included in Appendix A: Aspects, Objectives and Targets.

F. After developing a list of environmental aspects, the EMS Team will determine which aspects are significant. This determination will be conducted as follows:

1. Any environmental aspects that are associated with non-compliant activities will be considered significant.

2. Additional aspects will be considered significant based on achieving uniformity of specific programs throughout the department.

G. When the EMS Team determines which environmental aspects are significant, the EMS Champion will document the list of significant aspects and obtain approval for the list from the Facility and Equipment Division Director. Documentation of the list of significant environmental aspects for each year should be included in Appendix A of the EMS Manual.

H. The EMS Champion is responsible for working with managers to ensure that significant environmental aspects identified by the team are considered in setting environmental objectives and targets for the department. This should be conducted in accordance with the Communications Procedure (P-02).

I. The EMS Team shall review the Environmental Aspects on an annual basis, or more often as needed. The EMS Team shall document their recommended changes to the list of significant environmental aspects. These recommendations will be submitted to the Facilities and Equipment Division Director and considered as part of the annual management review in accordance with the Management Review procedure (P-11).

\subsection{Related Documents}

Records (Forms in Appendix)

R-08: Identifying Environmental Aspects (p. 38)

Applicable Procedures

P-02: Communications (p. 17)

P-05: Legal and Other Requirements (p. 22)

P-11: Management Review (p. 35)

References

Appendix A: Aspects, Objectives and Targets (p.37) 


\section{Standard Operating Procedure \\ P-04: Legal and Other Requirements}

\subsection{Purpose/Scope}

To ensure that the organization identifies, has access to, and evaluates laws, regulations, and internal organizational requirements that apply to the environmental aspects of its activities, products, and services.

This procedure covers laws, regulations, and other requirements established at the federal, state, and local level that apply to the environmental aspects of the organization's activities, services and products. The organization takes these requirements into account when developing a list of significant environmental aspects in accordance with the Environmental Aspects Identification procedure (P-03).

\subsection{Definitions}

Applicable laws and regulations - Legal requirements brought into law by federal, state or local government authorities that apply to environmental aspects of the organization's products, activities and services.

\subsection{Responsibilities}

The EMS Champion or designee is responsible for maintaining a current listing of applicable laws and regulations, and communicating this information to managers. The managers are responsible for ensuring their employees are aware of the laws and regulations that are applicable to their work assignments and their activities are in compliance with applicable requirements.

\subsection{Procedure}

A. The EMS Champion or designee is responsible for maintaining a listing of applicable laws and regulations. A current list of applicable laws and regulations will be documented on form R-10: Applicable Legal Requirements, and included in Appendix B: Legal and Other Requirements. The EMS Champion will utilize internal personnel resources such as members of the EMS Team, as well as INDOT Management, to assist with this effort and to identify how these laws and regulations impact specific facility functions.

B. The department will utilize a variety of information sources to maintain a current listing of applicable laws and regulations. These include, but are not limited to: communications with federal and state regulatory agencies; environmental meetings; and periodic environmental refresher training. The information sources will be monitored on a regular basis to ensure that new issues are identified on a timely basis.

C. As necessary, "off-site" resources (such as consultants and attorneys) may be called upon to assist INDOT in evaluating applicable laws and regulations or in developing programs in response to applicable laws and regulations. 
D. All managers will be responsible for ensuring their employees are appropriately trained on these requirements. This will be done in accordance with the Training Procedure (P-05).

E. R-10 will be reviewed and revised as appropriate at a minimum annually.

\subsection{Related Documents}

Records

R-10: Applicable Legal Requirements (p. 43)

Applicable Procedures

P-02: Communications (p. 17)

P-03: Environmental Aspects Identification (p. 20)

P-05: Training (p. 24)

References

Appendix B: Legal and Other Requirements (p.42) 


\section{Standard Operating Procedure \\ P-05: Competence, Training and Awareness}

\subsection{Purpose/Scope}

This procedure is used to develop and implement a training program that complies with environmental regulations requiring training and addresses significant environmental aspects and objectives and targets.

\subsection{Definitions}

None

\subsection{Responsibility}

The EMS Team, in conjunction with managers, will be responsible for the identification of an environmental training plan. The managers are responsible for ensuring that employees receive training required under the program (R-14).

4.0. Procedure

A. Task-Specific Training

1. A training program will be developed to ensure that employees are capable of accomplishing the tasks required to meet EMS objectives and targets.

2. The EMS Champion will document the training plan on form R-14: Training Plan and include a copy in Appendix E: Environmental Training Program.

3. The managers will ensure documentation of EMS training is entered in INDOT Peoplesoft.

4. Training effectiveness will be evaluated to ensure that the EMS is being implemented effectively when changes are made to significant environmental aspects, objectives, targets or operational controls. Improvements to the training program will be made accordingly.

\subsection{Related Documents}

\section{Records}

R-14: Training Program (p. 56)

\section{References}

Appendix E: Training Program (p. 55) 


\section{Standard Operating Procedure P-06: Monitoring and Measurement}

\subsection{Purpose/Scope}

This procedure is used to implement a monitoring and measurement program designed to support the EMS and specific EMS objectives and targets.

2.0 Definitions

None

\subsection{Responsibility}

The managers will be responsible for providing data and monitoring operations that are specific to their functions. The EMS Champion and Team will be responsible for consolidating all the data and conducting agency-wide monitoring.

\subsection{Procedure}

A. Measurement

1. The managers will track the following metrics by collecting and charting data relevant to the metric at the frequency indicated below. The EMS Champion and Team shall be responsible for consolidating the data and document the following metrics on an agency wide basis.

\begin{tabular}{|l|l|}
\hline Metric (examples only) & Data Collection Frequency \\
\hline Shop Waste & Bi-Annually \\
\hline Hazardous Waste & Bi-Annually \\
\hline Universal Waste & Bi-Annually \\
\hline WWT Plants & Bi-Annually \\
\hline Salt Storage Area & Bi-Annually \\
\hline
\end{tabular}

2. Parameters will be developed along with Tracking Environmental Objectives and Targets.

3. Instances of non-compliance will be measured in each area. The EMS Champion and Team will consolidate the data in order to assess agency wide compliance. The Management Analyst under the Highway Operations Director in each District will be consulted in relation to the non-compliance issue. This will be in relation to operations and construction non-compliance issues.

4. The developed metrics shall be evaluated and revised as objectives and targets are modified and/or added. 
B. Monitoring

1. The EMS Champion and Team and key staff will review target-specific measurement and monitoring data annually or as needed to identify trends, evaluate progress toward meeting EMS objectives and targets, and discuss overall environmental performance.

2. The managers will ensure that data obtained to monitor their specific activities is continually evaluated to ensure compliance with applicable environmental statutes and regulations.

3. The EMS Champion and Team will be responsible for providing an annual summary of the results of the monitoring program to management. The EMS Champion and Team will also be responsible for ensuring that the results of the monitoring program are communicated to employees in accordance with the Communications Procedure (P-02).

4. The Management Team will review the annual monitoring report during their management review in accordance with the Management Review procedure (P-11).

\subsection{Related Documents}

Applicable Procedures

P-02: Communications (p. 17)

P-04: Legal and Other Requirements (p. 22)

P-11 Management Review (p. 35)

References

Annual EMS Monitoring Report 


\section{Standard Operating Procedure P-07: Preventive and Corrective Action}

\subsection{Purpose/Scope}

The purpose of this procedure is to establish and outline the process for identifying, documenting, analyzing and implementing preventive and corrective actions. Preventive or corrective actions may be initiated using this procedure for any environmental problem affecting the organization.

\subsection{Definitions}

Preventive Action - a proactive process intended to prevent potential problems before they occur or become more severe.

Corrective Action - a reactive process used to address problems after they have occurred.

\subsection{Responsibility}

The EMS Champion and Team are responsible for ensuring that actions are taken to prevent and correct identified problems. The EMS Champion shall communicate identified problems to management. Management and the EMS Team are responsible for the development and implementation of the preventive and corrective actions.

\subsection{Procedure}

\section{A. General}

1. Corrective action is initiated using the Corrective Action Notice (CAN) document as the primary vehicle for communication. Corrective action may be triggered by a variety of events, including internal audits and management reviews. Other items that might result in a CAN include neighbor complaints or results of monitoring and measurement.

2. Preventive action is initiated using the Preventive Action Notice (PAN). Preventive action focuses on identifying negative trends and addressing them before they become significant. Events that might trigger a PAN include monitoring and measurement, trends analysis, tracking of progress on achieving objectives and targets, response to emergencies and near misses, and customer or neighbor complaints, among other events.

3. Preventive and corrective action notices are prepared, managed and documented.

4. Personnel receiving PANs and CANs are responsible for implementing the required preventive or corrective action, reporting completion of the required action to the EMS Champion, and assuring sustained effectiveness. 
5. The EMS Champion (or designee) is responsible for reviewing issues affecting the EMS, the application and maintenance of this procedure, and any updates to EMS documents affected by the preventive and corrective actions.

6. The EMS Champion maintains completed records of PANs and CANs for at least seven years after completion of the corrective or preventive action.

B. Issuing a CAN or PAN

1. Any employee may request a CAN or PAN (This provides an opportunity for the employee to voice their opinion). The employee requesting the CAN or PAN is responsible for bringing the problem to the attention of their manager. Responsibility for resolving the problem is assigned to a specific individual ("the recipient").

2. Management, working with the recipient, determines an appropriate due date for resolving the CAN or PAN.

C. Determining and Implementing Corrective and Preventive Actions

1. The CAN or PAN is issued to the recipient, who is responsible for investigation and resolution of the problem. The recipient is also responsible for communicating the corrective or preventive action taken.

2. If the recipient cannot resolve the problem by the specified due date, the recipient is responsible for determining an acceptable alternate due date with management.

D. Tracking Effectiveness of Solutions

1. The recipient of a CAN or PAN, in conjunction with the requester, is responsible for verifying the effectiveness of the solution. If the solution is not deemed effective, the CAN or PAN will be returned to the original recipient with written explanation.

5.0 Related Documents

Records

Corrective Action Notices (CANs)

Preventive Action Notices (PANs) 


\section{Standard Operating Procedure P-08: Control of EMS Documents}

1.0 Purpose/Scope

This procedure establishes a process for the review, distribution, and implementation of documents that describe and control the EMS.

2.0 Definitions

None

3.0 Responsibility

The EMS Champion controls the EMS manual and all associated procedures and records. Applicable managers control process-specific and activity-specific procedures and records.

\subsection{Procedure}

\section{A. General}

1. Distribution lists are maintained by the EMS Champion or designee. Document distribution may be either controlled or uncontrolled. The EMS Champion and Team will determine which documents are controlled and uncontrolled.

2. Depending on the type of document, controlled copies are identified by stamp, signature or other similar means.

3. Uncontrolled copies of documents may exist for illustrative, instructional, knowledge preservation, or external distribution purposes.

4. All controlled documents are approved prior to issue and are marked with the revision number and date.

5. The EMS Champion or designee may determine the initial distribution of documents.

6. The EMS Manual will be reviewed on an annual basis or as needed.

7. The EMS Champion or designee is responsible for communicating the need to remove obsolete controlled documents from all points of issue and use.

8. The EMS Champion or designee is responsible for ensuring that changes to controlled documents are understood, distributed, and communicated to the department.

9. All controlled documents are listed on the EMS Document Index (R-16). The Index shows the date(s) of any revisions and the person(s) initiating the revisions. The EMS Champion shall be responsible for maintaining this list. 
B. EMS Manual

1. Distribution of the EMS manual is the responsibility of the EMS Champion or designee.

2. The EMS Manual will be posted on the INDOT Intranet.

C. Agency-wide Procedures

1. Revision of EMS Manual procedures are controlled and are the responsibility of the EMS Champion.

2. The EMS Champion or designee is responsible for posting new and revised procedures as well as making INDOT managers aware of these changes.

D. Other Procedures and Work Instructions (Process-Specific or Activity-Specific)

1. Revision of process-specific or activity-specific procedures and work instructions is the responsibility of the applicable manager or designee.

2. The manager or designee is responsible for distribution of new or revised activityspecific procedures and work instructions.

5.0 Related Documents

Records

EMS Document Revision Index (p. 5)

Applicable Procedures

P-09: Records (p. 31)

References

None 


\section{Standard Operating Procedure \\ P-09: Control of Records}

\subsection{Purpose/Scope}

This procedure is used to identify, maintain or dispose of EMS records. The procedure is applicable to all agency activities creating records associated with the EMS.

\subsection{Definitions}

Records - documented information that is evidence of an environmental activity or event that has been performed or that is required to be retained for future reference.

\subsection{Responsibility}

The EMS Champion and Team are responsible for identifying records that must be maintained as part of the EMS. The EMS Champion will maintain the records that pertain to the agency. The applicable manager will maintain the records that are specific to a process or activity.

4.0 Procedure

A. The EMS Champion and Team are responsible for identifying records maintained by the agency as part of the EMS and ensuring compliance with environmental statutes and regulations.

B. The EMS Champion will maintain all records pertaining to the entire agency in a single location. The managers will be responsible for maintaining records applicable to their specific operations and activities.

5.0 Related Documents

Applicable Procedures

P-08: Control of EMS Documents (p. 29)

References

EMS Document Revision Index 


\section{Standard Operating Procedure \\ P-10: Environmental Management System Audit (Internal Audit)}

1.0 Purpose/Scope

This procedure defines the process for scheduling, conducting, and reporting of EMS audits.

The scope of EMS audits may cover all activities and processes comprising the EMS or selected elements thereof.

\subsection{Definitions}

Auditor - an individual(s) responsible for conducting the audit and documenting the results. Personnel conducting the audits will operate from INDOT's Office of Facilities Management.

\subsection{Responsibility}

The EMS Champion is responsible for coordinating the completion of all audits and maintaining relevant records. The Auditor is responsible for conducting the audit and documenting the results. The managers are responsible for implementing any follow-up activities resulting from the audit.

\subsection{Procedure}

\section{A. General}

1. EMS audits will focus on verifying that activities conform to documented procedures and corrective actions are undertaken and are effective.

2. The EMS Champion is responsible for maintaining EMS audit records, audit schedules and protocols, and audit reports.

3. EMS audits are scheduled to ensure that all EMS elements are audited annually.

4. The Auditor is responsible for ensuring that the audit, audit report and any feedback to the relevant location covered by the audit is completed per the audit schedule.

5. The EMS Champion is responsible for notifying EMS auditors of any upcoming audits within five working days prior to the scheduled audit date. Management of the focused audit will be notified within one working day.

6. The EMS Champion, in conjunction with the Auditor, is responsible for ensuring Corrective Action Notices are prepared for audit findings, as appropriate. This shall be conducted in accordance with the Preventive and Corrective Action Procedure (P07). 
B. The Auditor is responsible for ensuring the preparation of a written plan for the audit. The EMS Audit Plan Summary form may be used as a guide for this plan.

C. Conducting the Audit

1. A pre-audit conference is held with appropriate personnel to review the scope, plan and schedule for the audit.

2. Auditors are at liberty to modify the audit scope and plan if conditions warrant.

3. Objective evidence is examined to verify conformance to EMS requirements, including operating procedures. All audit findings must be documented.

4. Specific attention is given to corrective actions for audit findings from previous audits.

5. A post-audit conference is held to present audit findings, clarify any misunderstandings, and summarize the audit results.

D. Reporting Audit Results

1. The Auditor prepares the audit report, which summarizes the audit scope, identifies the auditor(s), describes sources of evidence used and summarizes the audit results.

2. Findings requiring corrective action shall be dealt with in accordance with the Preventive and Corrective Action procedure (P-07).

E. Audit Report Distribution

1. The Auditor is responsible for communicating the audit results to applicable managers. The Auditor will make copies of the audit report available to the EMS Champion and relevant INDOT personnel.

2. The EMS Champion is responsible for ensuring availability of audit reports for purposes of the annual management review.

F. Audit Follow-up

1. Management in the targeted audit location is responsible for any follow-up actions needed as a result of the audit.

2. The EMS Champion is responsible for tracking the completion and effectiveness of corrective actions.

G. Record Keeping

1. Audit reports are retained for at least seven years after the date of audit completion. 
5.0 Related Documents

Records

EMS Audit Report

Corrective Action Notices (CANs)

Applicable Procedures

P-07: Preventive and Corrective Action (p. 27)

P-09: Records (p. 31)

P-11: Management Review (p. 35)

References

EMS Audit Plans (see below)

EMS Audit Plan Summary

\begin{tabular}{|l|l|l|l|}
\hline $\begin{array}{c}\text { Location to be } \\
\text { Audited }\end{array}$ & Auditor & Audit Date & $\begin{array}{c}\text { Special } \\
\text { Instructions }\end{array}$ \\
\hline & & & \\
\hline & & & \\
\hline & & & \\
\hline & & & \\
\hline & & & \\
\hline & & & \\
\hline & & & \\
\hline & & & \\
\hline & & & \\
\hline & & & \\
\hline & & & \\
\hline
\end{tabular}




\section{Standard Operating Procedure \\ P-11: Management Review}

\subsection{Purpose/Scope}

The purpose of this procedure is to document the process and primary agenda to be included in the Management Review meetings for evaluating the status of the organization's EMS. This procedure applies to all Management Review meetings conducted by the organization.

\subsection{Definitions}

Management Team - members include the Facilities and Equipment Division Director, the District's Highway Operations Director or designee and the Business and Human Resources Director or designee and the EMS Champion

\subsection{Procedure}

A. The Management Review process is intended to provide a forum for discussing needed improvements to the EMS. It provides management with a vehicle for making changes to the EMS necessary to achieve the organization's goals.

B. The EMS Champion is responsible for scheduling and conducting at least one Management Review meeting per year. The EMS Champion is also responsible for ensuring that necessary data and information are collected prior to the meeting.

C. At a minimum, each Management Review meeting will consider the following:

1. The suitability, adequacy and effectiveness of the environmental policy,

2. The suitability, adequacy and effectiveness of the environmental objectives and targets (as well as the organization's current status regarding these objectives and targets),

3. The overall suitability, adequacy and effectiveness of the EMS reflecting changing circumstances and overall environmental performance,

4. The status of corrective and preventive actions,

5. The results of any EMS audits and regulatory compliance evaluations conducted since the last Management Review meeting,

6. Communications from external interested parties, including complaints,

7. Recommendations for improvements,

8. The results of any action items from the previous Management Review meeting. 
D. Minutes of the Management Review meeting will be documented. These meeting minutes will include, at a minimum:

1. A list of attendees,

2. A summary of key issues discussed,

3. Any action items arising from the meeting, person responsible and completion due date.

E. A copy of the meeting minutes will be distributed to attendees and to any individual assigned action items. A copy of the meeting minutes will also be retained on file.

F. The EMS Champion is responsible for ensuring that action items resulting from the Management Review receive appropriate attention. These action items shall be dealt with in accordance with the applicable standard operating procedures.

4.0 Related Documents

Records

Management Review Meeting Minutes

Applicable Procedures

P-06: Measurement and Monitoring (p. 25)

P-07: Preventive and Corrective Action (p. 27)

P-10: Environmental Management System Audits (p. 32) 
Appendix A: Aspects, Objectives, and Targets 


\section{Environmental Aspects}

\section{Form R-08: Identifying Environmental Aspects}

\section{Activities:}

Office

Vehicle Maintenance

Rest Park (wastewater, drinking, water, trash, etc.)

Equipment Maintenance

Landscaping (mowing, seeding, spraying, etc.)

Trash Pick-up (roadside and facility)

Dead Animal Disposal

Testing Labs

Snow and Ice Removal

Road Maintenance

Road Construction

\section{Office Aspects:}

Solid Waste (trash)

Universal Waste (bulbs, batteries, computers/monitors, etc.)

Energy (electric, gas)

Water

Supplies (new materials, depletion of natural resources)

Recycling (paper, aluminum, cardboard, toner cartridges)

Emissions

\section{Equipment and Vehicle Maintenance Aspects:}

Shop Waste (oil, antifreeze, filters, contaminated fuels, etc.)

Universal Waste

Waste Tires

Solid Waste

Energy

Water

Supplies

Recycling

Reuse (waste oil, mineral spirits) 


\section{Form R-08 continued:}

\section{$\underline{\text { Trash Pick-Up Aspects: }}$}

Solid Waste

Hazardous Waste/Bio-Hazards

Waste Tires

Universal Waste

Energy

Emissions

\section{Rest Park Aspects:}

Wastewater

Drinking Water

Solid Waste

Recycling

Energy

Supplies

Universal Waste

Hazardous Waste/Biohazard Wastes

Emissions

\section{Landscaping and Roadside Maintenance Aspects:}

Herbicides

Insecticides

Water

Solid Waste

Energy

Hazardous Waste/Biohazard Waste

Emissions

\section{Dead Animal Disposal Aspects:}

Emissions

Energy

Reuse

Solid Waste

\section{Testing Lab Aspects:}

Hazardous Waste (Trichlor, EC578, Mineral Spirits, mercury, waste gas, perc.) Solid Waste (Concrete, Asphalt) Universal Waste (Bulbs, Batteries, etc.) Nuclear Waste (Density Gages and Geiger Counters-low level radio active waste) Recycling

Emissions 


\section{Form R-08 continued:}

Snow and Ice Removal Aspects:

Salt

Calcium/Magnesium/Ice Ban/Salt Brine (S\&I Liquids)

Sand

Energy

Emissions

\section{Road Construction Aspects:}

Stormwater (Erosion Control)

Construction and Demolition Waste

Energy

Emissions

Reuse

$\underline{\text { Road Maintenance Activities: }}$

See various aspects below

$\underline{\text { Roadway and Shoulder Maintenance Aspects: }}$

Energy

Raw Materials

Emissions

Solid Waste

Aspect: Drainage Maintenance Aspects:

Raw Materials

Emissions

Energy

Recycling/Reuse

Stormwater

Solid Waste

Bridge Maintenance Aspects:

Raw Materials

Emissions

Energy

Recycling

Stormwater

Solid Waste 
Form R-08 continued:

$\underline{\text { Traffic Maintenance Aspects: }}$

Emissions

Raw Materials

Energy

Solid Waste

Universal Waste

Recycling 
Appendix B: Legal and Other Requirements 


\section{R-10: Applicable Legal Requirements}

\section{Responsibility of Facilities Environmental Engineer}

\begin{tabular}{|l|l|l|}
\hline \multicolumn{1}{|c|}{ Regulatory Agency } & $\begin{array}{c}\text { Regulation and Specific } \\
\text { Provision }\end{array}$ & \multicolumn{1}{c|}{$\begin{array}{c}\text { Operation to which } \\
\text { Provision Applies }\end{array}$} \\
\hline IDEM & Agreed Order & Wastewater Treatment Plant \\
\hline IDEM & Agreed Order & Underground Storage Tanks \\
\hline IDEM & & Waste Oil \\
\hline & & \\
\hline & & \\
\hline & & \\
\hline & & \\
\hline & & \\
\hline & & \\
\hline & & \\
\hline & & \\
\hline & & \\
\hline & & \\
\hline & & \\
\hline & & \\
\hline & & \\
\hline & & \\
\hline & & \\
\hline
\end{tabular}

Provide list of all regulations, agreed orders, rules on table above pertaining to INDOT's list of aspects.

Reference form R-08 for specific aspects pertaining to INDOT EMS.

A list of the regulations/rules and agreed orders may already exist. 
Appendix C: Environmental Management Programs 


\section{R-13: Significant Environmental Aspects/ Objectives and Targets/ Environmental Management Program}

INDOT Wastewater Treatment Plants (WWTP)

\begin{tabular}{|c|c|}
\hline $\begin{array}{l}\text { Objective: Wastewater } \\
\text { NPDES permits. }\end{array}$ & reatment Plants will be operating at compliance with their \\
\hline Target \#1 & 100\% of facilities by December 31, 2007. \\
\hline Action Items & $\begin{array}{l}\text { Physically reconfigure WWTP's so they are capable of } \\
\text { compliance. } \\
\text { Write and comply with Standard Operating Procedure (SOP) } \\
\text { guiding the operation of the plants. }\end{array}$ \\
\hline Operational Controls & Reference WWTP SOP \\
\hline Responsible Person(s) & Facilities Environmental Engineer/ INDOT WWTP Operators \\
\hline Schedule & $\begin{array}{l}\text { WWTP SOP second revision by April 31st, } 2007 \\
\text { Conduct semi-annual assessments (spring and fall). }\end{array}$ \\
\hline Comments & \\
\hline Target \#2 & \\
\hline Action Items & \\
\hline Operational Controls & \\
\hline Responsible Person(s) & \\
\hline $\begin{array}{r}\text { Schedule } \\
\end{array}$ & \\
\hline Budget & \\
\hline Comments & \\
\hline Target \#3 & \\
\hline Action Items & \\
\hline Operational Controls & \\
\hline Responsible Person(s) & \\
\hline Schedule & \\
\hline Budget & \\
\hline Comments & \\
\hline
\end{tabular}




\section{R-13: Significant Environmental Aspects/ Objectives and Targets/ Environmental Management Program}

INDOT Underground Storage Tanks (UST’s) at INDOT Facility Sites

\begin{tabular}{|c|c|}
\hline \multicolumn{2}{|c|}{$\begin{array}{l}\text { Objective: Removal of contaminated soil and groundwater from INDOT properties that } \\
\text { were contaminated incidental to their former underground storage tanks. }\end{array}$} \\
\hline Target \#1 & $\begin{array}{l}\text { To secure letters of No Further Action (NFA) from the } \\
\text { Indiana Department of Environmental Management (IDEM) } \\
\text { for } 100 \% \text { of INDOT facilities by December 31, } 2008 .\end{array}$ \\
\hline Action Items & $\begin{array}{l}\text { Dig and haul contaminated soil and groundwater and dispose } \\
\text { of through legal means. }\end{array}$ \\
\hline Operational Controls & $\begin{array}{l}\text { Corrective Action Plans (CAP) } \\
\text { IDEM RISC Guidelines }\end{array}$ \\
\hline Responsible Person(s) & Facilities Engineer/Facilities and Equipment Division \\
\hline Schedule & $\begin{array}{l}\text { All INDOT sites remediated and letters of No Further Action } \\
\text { (NFA) received from IDEM by December } 31^{\text {st }}, 2008\end{array}$ \\
\hline Budget & $\$ 5,328,000.00$ \\
\hline \multicolumn{2}{|l|}{ Comments } \\
\hline \multicolumn{2}{|l|}{ Target \#2 } \\
\hline \multicolumn{2}{|l|}{ Action Items } \\
\hline \multicolumn{2}{|l|}{ Operational Controls } \\
\hline \multicolumn{2}{|l|}{ Responsible Person(s) } \\
\hline \multicolumn{2}{|l|}{ Schedule } \\
\hline \multicolumn{2}{|l|}{ Budget } \\
\hline \multicolumn{2}{|l|}{ Comments } \\
\hline \multicolumn{2}{|l|}{ Target \#3 } \\
\hline \multicolumn{2}{|l|}{ Action Items } \\
\hline \multicolumn{2}{|l|}{ Operational Controls } \\
\hline \multicolumn{2}{|l|}{ Responsible Person(s) } \\
\hline \multicolumn{2}{|l|}{ Schedule } \\
\hline \multicolumn{2}{|l|}{ Budget } \\
\hline Comments & \\
\hline
\end{tabular}




\section{R-13: Significant Environmental Aspects/ Objectives and Targets/ Environmental Management Program}

INDOT Underground Storage Tanks (UST’s) at INDOT Construction Sites

\begin{tabular}{|c|c|}
\hline \multicolumn{2}{|c|}{$\begin{array}{l}\text { Objective: Remove underground storage tanks at INDOT construction sites and any } \\
\text { associated soil and groundwater contamination. }\end{array}$} \\
\hline Target \#1 & Remove and remediate as found. \\
\hline Action Items & $\begin{array}{l}\text { Initiate change order in reference to Underground Storage } \\
\text { Tank. Dig and haul contaminated soil and water and dispose } \\
\text { of through legal means. }\end{array}$ \\
\hline Operational Controls & IDEM RISC Guidelines \\
\hline Responsible Person(s) & INDOT Project Manager \\
\hline Schedule & Address as they are discovered. \\
\hline Budget & Undetermined \\
\hline \multicolumn{2}{|l|}{ Comments } \\
\hline \multicolumn{2}{|l|}{ Target \#2 } \\
\hline \multicolumn{2}{|l|}{ Action Items } \\
\hline \multicolumn{2}{|l|}{ Operational Controls } \\
\hline \multicolumn{2}{|l|}{ Responsible Person(s) } \\
\hline \multicolumn{2}{|l|}{ Schedule } \\
\hline \multicolumn{2}{|l|}{ Budget } \\
\hline \multicolumn{2}{|l|}{ Comments } \\
\hline \multicolumn{2}{|l|}{ Target \#3 } \\
\hline \multicolumn{2}{|l|}{ Action Items } \\
\hline \multicolumn{2}{|l|}{ Operational Controls } \\
\hline \multicolumn{2}{|l|}{ Responsible Person(s) } \\
\hline \multicolumn{2}{|l|}{ Schedule } \\
\hline \multicolumn{2}{|l|}{ Budget } \\
\hline Comments & \\
\hline
\end{tabular}




\section{R-13: Significant Environmental Aspects/ Objectives and Targets/ Environmental Management Program}

\begin{tabular}{|c|c|}
\hline \multicolumn{2}{|c|}{ Objective: Keep $100 \%$ of road salt loading and storage at INDOT facilities under roof. } \\
\hline Target \#1 & $\begin{array}{l}\text { Have road salt loading areas under roof at the minimum rate } \\
\text { of } 2 \text { facilities per year until the department reaches } 100 \% \text {. }\end{array}$ \\
\hline Action Items & $\begin{array}{l}\text { Build road salt storage buildings (coverall) to accommodate } \\
\text { all salt storage and loading under roof. }\end{array}$ \\
\hline Operational Controls & $\begin{array}{l}\text { Construct to specifications according to INDOT Facilities and } \\
\text { Equipment Division. }\end{array}$ \\
\hline Responsible Person(s) & $\begin{array}{l}\text { Office of Facilities Management Manager/Facilities and } \\
\text { Equipment Division }\end{array}$ \\
\hline Schedule & Fiscal Year \\
\hline Budget & Minimum \$1,800,000.00/year \\
\hline Comments & $\begin{array}{l}\text { Reference Facilities Inventory Specialist } \\
\text { (Dave Piepho)/Facilities and Equipment Division for more } \\
\text { information. }\end{array}$ \\
\hline \multicolumn{2}{|r|}{ 些 } \\
\hline \multicolumn{2}{|l|}{ Action Items } \\
\hline \multicolumn{2}{|l|}{ Operational Controls } \\
\hline \multicolumn{2}{|l|}{ Responsible Person(s) } \\
\hline \multicolumn{2}{|l|}{ Schedule } \\
\hline \multicolumn{2}{|l|}{ Budget } \\
\hline \multicolumn{2}{|l|}{ Comments } \\
\hline \multicolumn{2}{|l|}{ Target \#3 } \\
\hline \multicolumn{2}{|l|}{ Action Items } \\
\hline \multicolumn{2}{|l|}{ Operational Controls } \\
\hline \multicolumn{2}{|l|}{ Responsible Person(s) } \\
\hline \multicolumn{2}{|l|}{ Schedule } \\
\hline \multicolumn{2}{|l|}{ Budget } \\
\hline Comments & \\
\hline
\end{tabular}




\section{R-13: Significant Environmental Aspects/ Objectives and Targets/ Environmental Management Program}

INDOT Snow and Ice Liquids

\begin{tabular}{|c|c|}
\hline \multicolumn{2}{|c|}{$\begin{array}{l}\text { Objective: Construct secondary containment for } 100 \% \text { of all snow and ice liquid tanks of } \\
1,350 \text { gallons or more no later than } 2008 \text {. }\end{array}$} \\
\hline Target \#1 & December $31^{\text {st }}, 2008$ \\
\hline Action Items & Construct secondary containment where needed. \\
\hline Operational Controls & $\begin{array}{l}\text { Secondary Containment Plan (reference Greenfield District } \\
\text { Plan) }\end{array}$ \\
\hline Responsible Person(s) & $\begin{array}{l}\text { Facilities Environmental Engineer/Facilities and Equipment } \\
\text { Division }\end{array}$ \\
\hline Schedule & In progress and/or as needed \\
\hline Budget & District Specific \\
\hline Comments & None \\
\hline \multicolumn{2}{|l|}{ Target \#2 } \\
\hline \multicolumn{2}{|l|}{ Action Items } \\
\hline \multicolumn{2}{|l|}{ Operational Controls } \\
\hline \multicolumn{2}{|l|}{ Responsible Person(s) } \\
\hline \multicolumn{2}{|l|}{ Schedule } \\
\hline \multicolumn{2}{|l|}{ Budget } \\
\hline \multicolumn{2}{|l|}{ Comments } \\
\hline \multicolumn{2}{|l|}{ Target \#3 } \\
\hline \multicolumn{2}{|l|}{ Action Items } \\
\hline \multicolumn{2}{|l|}{ Operational Controls } \\
\hline \multicolumn{2}{|l|}{ Responsible Person(s) } \\
\hline \multicolumn{2}{|l|}{ Schedule } \\
\hline \multicolumn{2}{|l|}{ Budget } \\
\hline Comments & \\
\hline
\end{tabular}




\section{R-13: Significant Environmental Aspects/ Objectives and Targets/ Environmental Management Program}

INDOT Shop and Hazardous Waste

\begin{tabular}{|c|c|}
\hline \multicolumn{2}{|c|}{$\begin{array}{l}\text { Objective: Develop a procedure to guide INDOT employees in the proper handling, } \\
\text { packaging and labeling of the department's shop and hazardous waste streams. }\end{array}$} \\
\hline Target \#1 & December 31, 2007 \\
\hline Action Items & $\begin{array}{l}\text { Develop and adopt the shop/hazardous waste procedure } \\
\text { identifying waste applicable to the INDOT recycling/disposal } \\
\text { QPA with applicable vendor. }\end{array}$ \\
\hline Operational Controls & Shop/Hazardous Waste Procedure \\
\hline Responsible Person(s) & $\begin{array}{l}\text { Facilities Environmental Scientist/Facilities and Equipment } \\
\text { Division }\end{array}$ \\
\hline Schedule & Currently under development \\
\hline Budget & Not Applicable \\
\hline \multicolumn{2}{|l|}{ Comments } \\
\hline \multicolumn{2}{|l|}{ Target \#2 } \\
\hline \multicolumn{2}{|l|}{ Action Items } \\
\hline \multicolumn{2}{|l|}{ Operational Controls } \\
\hline \multicolumn{2}{|l|}{ Responsible Person(s) } \\
\hline \multicolumn{2}{|l|}{ Schedule } \\
\hline \multicolumn{2}{|l|}{ Budget } \\
\hline \multicolumn{2}{|l|}{ Comments } \\
\hline \multicolumn{2}{|l|}{ Target \#3 } \\
\hline \multicolumn{2}{|l|}{ Action Items } \\
\hline \multicolumn{2}{|l|}{ Operational Controls } \\
\hline \multicolumn{2}{|l|}{ Responsible Person(s) } \\
\hline \multicolumn{2}{|l|}{ Schedule } \\
\hline \multicolumn{2}{|l|}{ Budget } \\
\hline Comments & \\
\hline
\end{tabular}




\title{
R-13: Significant Environmental Aspects/ Objectives and Targets/ Environmental Management Program
}

\author{
INDOT Universal Waste
}

\begin{tabular}{|c|c|}
\hline \multicolumn{2}{|c|}{$\begin{array}{l}\text { Objective: Develop a procedure to guide INDOT employees in the proper handling, } \\
\text { packaging and labeling of the department's universal waste streams. }\end{array}$} \\
\hline Target \#1 & December 31, 2007 \\
\hline Action Items & $\begin{array}{l}\text { Develop and adopt the universal waste procedure identifying } \\
\text { waste applicable to the INDOT recycling/disposal QPA with } \\
\text { applicable vendor. }\end{array}$ \\
\hline Operational Controls & Universal Waste Procedure \\
\hline Responsible Person(s) & $\begin{array}{l}\text { Facilities Environmental Scientist/Facilities and Equipment } \\
\text { Division }\end{array}$ \\
\hline Schedule & Currently under development \\
\hline Budget & Not Applicable \\
\hline \multicolumn{2}{|l|}{ Comments } \\
\hline \multicolumn{2}{|l|}{ Target \#2 } \\
\hline \multicolumn{2}{|l|}{ Action Items } \\
\hline \multicolumn{2}{|l|}{ Operational Controls } \\
\hline \multicolumn{2}{|l|}{ Responsible Person(s) } \\
\hline \multicolumn{2}{|l|}{ Schedule } \\
\hline \multicolumn{2}{|l|}{ Budget } \\
\hline \multicolumn{2}{|l|}{ Comments } \\
\hline \multicolumn{2}{|l|}{ Target \#3 } \\
\hline \multicolumn{2}{|l|}{ Action Items } \\
\hline \multicolumn{2}{|l|}{ Operational Controls } \\
\hline \multicolumn{2}{|l|}{ Responsible Person(s) } \\
\hline \multicolumn{2}{|l|}{ Schedule } \\
\hline \multicolumn{2}{|l|}{ Budget } \\
\hline Comments & \\
\hline
\end{tabular}


Appendix D: Structure and Responsibilities 


\section{R-01: Persons Responsible for EMS Development}

\begin{tabular}{|c|c|}
\hline Roles & Individual Responsible \\
\hline $\begin{array}{l}\text { "Management representative" having } \\
\text { responsibility for implementing the EMS }\end{array}$ & EMS Champion and EMS Team \\
\hline $\begin{array}{l}\text { Identifying and determining applicability of } \\
\text { legal and other requirements }\end{array}$ & Facilities Environmental Engineer \\
\hline Competency-based training & Reference EMS Scope Document \\
\hline Operational controls & Reference EMS Scope Document \\
\hline Emergency preparedness and response & $\begin{array}{l}\text { Facilities Environmental Engineer of the } \\
\text { Facilities and Equipment Division } \\
\text { Environmental Services Section of the } \\
\text { Production Management and } \\
\text { Environmental Division }\end{array}$ \\
\hline $\begin{array}{l}\text { Monitoring and measurement of "key } \\
\text { characteristics" of operations and activities } \\
\text { that can have significant environmental } \\
\text { impacts (i.e., the "significant environmental } \\
\text { aspects") }\end{array}$ & $\begin{array}{l}\text { EMS Auditors and Office of Facilities } \\
\text { Management } \\
\text { District Management Analyst under the } \\
\text { Highway Operations Director (non } \\
\text { compliance) } \\
\text { District Facilities/Environmental Manager } \\
\begin{array}{l}\text { Environmental Services Section of the } \\
\text { Production Management and } \\
\text { Environmental Division }\end{array}\end{array}$ \\
\hline $\begin{array}{l}\text { Periodic evaluations of environmental } \\
\text { compliance }\end{array}$ & $\begin{array}{l}\text { EMS Auditors and Office of Facilities } \\
\text { Management }\end{array}$ \\
\hline $\begin{array}{l}\text { Handling and investigating nonconformance } \\
\text { with the EMS }\end{array}$ & $\begin{array}{l}\text { EMS Auditors and Office of Facilities } \\
\text { Management } \\
\text { District Management Analyst under the } \\
\text { Highway Operations Director (non } \\
\text { compliance) } \\
\text { District Facilities/Environmental Manager } \\
\begin{array}{l}\text { Environmental Services Section of the } \\
\text { Production Management and } \\
\text { Environmental Division }\end{array}\end{array}$ \\
\hline
\end{tabular}




\begin{tabular}{|l|l|}
\hline Records Management & $\begin{array}{l}\text { EMS Auditors and Office of Facilities } \\
\text { Management } \\
\text { District Management Analyst under the } \\
\text { Highway Operations Director (non } \\
\text { compliance) } \\
\text { District Facilities/Environmental Manager } \\
\text { Environmental Services Section of the } \\
\text { Production Management and } \\
\text { Environmental Division }\end{array}$ \\
\hline Internal EMS audits & $\begin{array}{l}\text { EMS Auditors and Office of Facilities } \\
\text { Management }\end{array}$ \\
\hline
\end{tabular}


Appendix E: Environmental Training Plan 


\section{R-14: EMS Training Plan \\ INDOT’s Environmental Management System}

\section{Scope:}

The environmental activities of INDOT employees as well as the environmental activities of the department's contractor's.

\section{Significant Aspects: General}

1. INDOT Wastewater Treatment Plants (reference INDOT/IDEM agreed order)

2. INDOT Facility Underground Storage Tanks (reference INDOT/IDEM agreed order)

3. Removal of Underground Storage Tanks (reference INDOT/IDEM agreed order) at INDOT construction sites as they are discovered.

4. INDOT Salt Storage Areas

5. INDOT Snow and Ice Liquids

6. INDOT Shop and Hazardous Waste

7. INDOT Universal Waste

Significant Aspects: Targeted Employees

1. Wastewater Treatment Plant:

Employees:

Water Plant System Operator

Facility and Environmental Manager

Facilities Environmental Engineer

Reference: INDOT WWT Plant SOP

IDEM Agreed Order

NPDES Permits
Training/License:

Wastewater License, Continuing Ed. And OJT

Continuing Education

Continuing Ed. but not licensed 


\section{Facility Underground Storage Tanks:}

\section{Employees:}

Facility and Environmental Manager

Facilities Engineer

INDOT Contractors

\section{Training/License:}

24-Hour First Responder Training

IDEM specific Continuing Education (LUST, RISC)

License for Decommissioning and Removal

Reference: IDEM Agreed Order

IDEM Guidelines

Environmental Services Section Spill Response Guidelines (Angie Kattman)

\section{Construction Underground Storage Tanks:}

\section{Employees:}

Environmental Services Section

INDOT Contractors

\section{Training/License:}

24-Hour First Responder Training

Environmental Services Section required training (Angie Kattman)

License for Decommissioning and Removal

Reference: IDEM Agreed Order

IDEM Guidelines

Environmental Services Section Spill Response Guidelines (Angie Kattman)

\section{Salt Storage Area:}

Employees:

INDOT Personnel

\section{Training/License:}

INDOT Snow and Ice Training

Reference: Salt Building Loading SOP

Facility Loading Diagram (Route)

Snow \& Ice Procedural Manual

SOP Development: Salt Building Loading SOP (Howard Geck)

Salt Loading by Vendor (Howard Geck)

Unloading Salt Bed after storm event (Don Arnold)

Salt Brine Loading/Transfer (Don Arnold)

Salt Bed Racks (Gary Williams)

Lubricating Chains (Audit Reports, Dick Shelton, Otis Carter) 


\section{INDOT Snow and Ice Liquids}

\section{Employees:}

INDOT Personnel
Training/License:

INDOT Snow and Ice Training

Reference: Secondary Containment Formula (Greenfield District)

6. INDOT Shop/Hazardous Waste Procedure

Employees:

INDOT Personnel
Training/License:

On the Job Training Central Office/District NEO Presentation

Reference: INDOT Shop/Hazardous Waste Procedure

\section{INDOT Universal Waste Procedure}

\section{Employees:}

INDOT Personnel

Reference: $\quad$ Universal Waste Procedure
Training/License:

On the Job Training Central Office/District NEO Presentation 
Appendix F - Communications Plan 


\section{R-03: Communication Work Plan}

\begin{tabular}{|c|c|c|c|c|c|}
\hline Target Audience & $\begin{array}{c}\text { What to } \\
\text { Communicate }\end{array}$ & $\begin{array}{c}\text { Mode of } \\
\text { Communication }\end{array}$ & When & Budget & $\begin{array}{c}\text { Who Is } \\
\text { Responsible? }\end{array}$ \\
\hline $\begin{array}{l}\text { New INDOT } \\
\text { Employees }\end{array}$ & $\begin{array}{c}\text { EMS } \\
\text { Environmental } \\
\text { Policy and EMS } \\
\text { Program }\end{array}$ & $\begin{array}{c}\text { Copy of Signed } \\
\text { Policy } \\
\text { Verbal } \\
\text { Presentation } \\
\end{array}$ & $\begin{array}{l}\text { Handed out at } \\
\text { New Employee } \\
\text { Orientation } \\
\text { Presentations }\end{array}$ & $\begin{array}{c}\text { Not } \\
\text { Applicable }\end{array}$ & $\begin{array}{l}\text { EMS Champion or } \\
\text { designee and District } \\
\text { Representative }\end{array}$ \\
\hline $\begin{array}{l}\text { Existing INDOT } \\
\text { Employees }\end{array}$ & $\begin{array}{c}\text { EMS } \\
\text { Environmental } \\
\text { Policy and EMS } \\
\text { Program } \\
\end{array}$ & $\begin{array}{l}\text { Intranet link to } \\
\text { Policy or } \\
\text { printed/signed } \\
\text { copy of policy } \\
\end{array}$ & $\begin{array}{l}\text { Implementation } \\
\text { phase of EMS }\end{array}$ & $\begin{array}{c}\text { Not } \\
\text { Applicable }\end{array}$ & $\begin{array}{l}\text { EMS Champion or } \\
\text { designee and District } \\
\text { Representative }\end{array}$ \\
\hline $\begin{array}{l}\text { WWTP Operators, } \\
\text { Facility/ Environmental } \\
\text { Manager and Facilities } \\
\text { Environmental Engineer }\end{array}$ & $\begin{array}{c}\text { WWTP } \\
\text { Significant } \\
\text { Aspect, Target } \\
\text { and Objective }\end{array}$ & $\begin{array}{l}\text { EMS Program } \\
\text { pertaining to } \\
\text { Significant } \\
\text { Aspect (R-13) } \\
\text { and Verbal } \\
\text { Communication } \\
\end{array}$ & $\begin{array}{l}\text { Implementation } \\
\text { phase of EMS }\end{array}$ & $\begin{array}{c}\text { Not } \\
\text { Applicable }\end{array}$ & $\begin{array}{c}\text { EMS Champion or } \\
\text { designee } \\
\text { and } \\
\text { Facilities/Environmental } \\
\text { Managers }\end{array}$ \\
\hline $\begin{array}{l}\text { Facility and } \\
\text { Environmental Manager } \\
\text { and Facilities Engineer }\end{array}$ & $\begin{array}{l}\text { Facility UST } \\
\text { Significant } \\
\text { Aspect, Target } \\
\text { and Objective }\end{array}$ & $\begin{array}{l}\text { EMS Program } \\
\text { pertaining to } \\
\text { Significant } \\
\text { Aspect (R-13) } \\
\text { and Verbal } \\
\text { Communication } \\
\end{array}$ & $\begin{array}{l}\text { Implementation } \\
\text { phase of EMS }\end{array}$ & $\begin{array}{c}\text { Not } \\
\text { Applicable }\end{array}$ & $\begin{array}{c}\text { EMS Champion or } \\
\text { designee } \\
\text { and } \\
\text { Facilities/Environmental } \\
\text { Managers }\end{array}$ \\
\hline $\begin{array}{l}\text { INDOT Environmental } \\
\text { Services Section }\end{array}$ & $\begin{array}{l}\text { Construction } \\
\text { UST Significant } \\
\text { Aspect, Target } \\
\text { and Objective }\end{array}$ & $\begin{array}{l}\text { EMS Program } \\
\text { pertaining to } \\
\text { Significant } \\
\text { Aspect (R-13) } \\
\text { and Verbal } \\
\text { Communication } \\
\end{array}$ & $\begin{array}{l}\text { Implementation } \\
\text { phase of EMS }\end{array}$ & $\begin{array}{c}\text { Not } \\
\text { Applicable }\end{array}$ & $\begin{array}{l}\text { EMS Champion or } \\
\text { designee }\end{array}$ \\
\hline $\begin{array}{c}\text { INDOT CDL } \\
\text { Licensed Personnel }\end{array}$ & $\begin{array}{c}\text { Salt Storage } \\
\text { Area Significant } \\
\text { Aspect, } \\
\text { Objective and } \\
\text { Target }\end{array}$ & $\begin{array}{l}\text { EMS Program } \\
\text { pertaining to } \\
\text { Significant } \\
\text { Aspect (R-13) } \\
\text { and Verbal } \\
\text { Communication } \\
\end{array}$ & $\begin{array}{l}\text { District Snow } \\
\text { and } \\
\text { Ice Training }\end{array}$ & $\begin{array}{c}\text { Not } \\
\text { Applicable }\end{array}$ & $\begin{array}{c}\text { INDOT District } \\
\text { Personnel (Annually) }\end{array}$ \\
\hline $\begin{array}{c}\text { INDOT } \\
\text { Facilities/Environmental } \\
\text { Manager } \\
\text { and } \\
\text { Facilities Environmental } \\
\text { Engineer }\end{array}$ & $\begin{array}{l}\text { Snow and Ice } \\
\text { Liquid } \\
\text { Secondary } \\
\text { Containment } \\
\text { Significant } \\
\text { Aspect, } \\
\text { Objective and } \\
\text { Target } \\
\end{array}$ & $\begin{array}{l}\text { EMS Program } \\
\text { pertaining to } \\
\text { Significant } \\
\text { Aspect (R-13) } \\
\text { and Verbal } \\
\text { Communication }\end{array}$ & $\begin{array}{l}\text { Implementation } \\
\text { phase of EMS }\end{array}$ & $\begin{array}{c}\text { Not } \\
\text { Applicable }\end{array}$ & $\begin{array}{l}\text { EMS Champion or } \\
\text { designee }\end{array}$ \\
\hline $\begin{array}{c}\text { INDOT Shop } \\
\text { and } \\
\text { Maintenance Personnel }\end{array}$ & $\begin{array}{c}\text { INDOT } \\
\text { Shop/Hazardous } \\
\text { Waste } \\
\text { Procedure } \\
\text { Significant } \\
\text { Aspect, } \\
\text { Objective and } \\
\text { Target }\end{array}$ & $\begin{array}{l}\text { EMS Program } \\
\text { pertaining to } \\
\text { Significant } \\
\text { Aspect (R-13) } \\
\text { and Verbal } \\
\text { Communication }\end{array}$ & $\begin{array}{l}\text { Implementation } \\
\text { phase of EMS }\end{array}$ & $\begin{array}{c}\text { Not } \\
\text { Applicable }\end{array}$ & $\begin{array}{l}\text { EMS Champion or } \\
\text { designee }\end{array}$ \\
\hline
\end{tabular}




\begin{tabular}{|c|c|c|c|c|c|}
\hline INDOT Personnel & $\begin{array}{c}\text { INDOT } \\
\text { Universal } \\
\text { Waste } \\
\text { and }\end{array}$ & $\begin{array}{c}\text { EMS Program } \\
\text { pertaining to } \\
\text { Significant } \\
\text { Aspect (R-13) } \\
\text { and Verbal } \\
\text { Significant } \\
\text { Aspect }\end{array}$ & $\begin{array}{c}\text { Implementation } \\
\text { phase of EMS }\end{array}$ & $\begin{array}{c}\text { Not } \\
\text { Applicable }\end{array}$ & $\begin{array}{c}\text { EMS Champion or } \\
\text { designee }\end{array}$ \\
\hline $\begin{array}{c}\text { INDOT Contracts and } \\
\text { Legal Division }\end{array}$ & $\begin{array}{c}\text { EMS } \\
\text { Environmental } \\
\text { Policy } \\
\text { and }\end{array}$ & $\begin{array}{c}\text { EMS } \\
\text { Environmental } \\
\text { Policy } \\
\text { and } \\
\text { INDOT } \\
\text { INDOT Contractors }\end{array}$ & $\begin{array}{c}\text { Contract } \\
\text { Contract } \\
\text { (Add policy to } \\
\text { Boilerplate } \\
\text { contract) }\end{array}$ & $\begin{array}{c}\text { Not } \\
\text { Applicable }\end{array}$ & $\begin{array}{c}\text { Contracts and } \\
\text { Construction Division }\end{array}$ \\
& & Program & & \\
\hline
\end{tabular}

Date Completed:

Contact Person: 
R-07: External Communications Log

\begin{tabular}{|c|c|c|c|c|c|c|c|}
\hline $\begin{array}{l}\text { Communication } \\
\text { From }\end{array}$ & Subject & $\begin{array}{c}\text { Date } \\
\text { Received }\end{array}$ & $\begin{array}{c}\text { Response } \\
\text { Needed } \\
(\mathrm{Y} / \mathrm{N})\end{array}$ & $\begin{array}{l}\text { Who } \\
\text { Will } \\
\text { Respond }\end{array}$ & $\begin{array}{c}\text { Form of } \\
\text { Response }\end{array}$ & $\begin{array}{l}\text { Response } \\
\text { Date }\end{array}$ & $\begin{array}{c}\text { Follow } \\
\text { Up } \\
\text { Needed } \\
(\mathrm{Y} / \mathrm{N})\end{array}$ \\
\hline & & & & & & & \\
\hline & & & & & & & \\
\hline & & & & & & & \\
\hline & & & & & & & \\
\hline & & & & & & & \\
\hline & & & & & & & \\
\hline & & & & & & & \\
\hline & & & & & & & \\
\hline & & & & & & & \\
\hline & & & & & & & \\
\hline & & & & & & & \\
\hline & & & & & & & \\
\hline & & & & & & & \\
\hline & & & & & & & \\
\hline & & & & & & & \\
\hline & & & & & & & \\
\hline & & & & & & & \\
\hline & & & & & & & \\
\hline & & & & & & & \\
\hline & & & & & & & \\
\hline & & & & & & & \\
\hline & & & & & & & \\
\hline & & & & & & & \\
\hline & & & & & & & \\
\hline & & & & & & & \\
\hline & & & & & & & \\
\hline
\end{tabular}

There is no existing SOP for external communications according to Lyle Sadler 